\title{
BIBLIOGRAFIA
}

Observaciones: La presente Bibliografia trata de cubrir todo el territorio hispánico en lo que se refiere a Lingüistica (español europeo y americano, judeoespañol, portugués peninsular y extrapeninsular, catalan, vasco); en lo que se refiete a Literatura, cubre sólo el campo peninsular, o sea que excluye la información sobre la América española y el Brasil.

Las reseñas se consignan a continuación del libro (o articulo) reseñado. Cuando éste se ha descrito ya en una entrega anterior de la Bibliografia, se pone entre paréntesis el número de la ficha correspondiente. También se hacen referencias a ediciones anteriores de una obra, a tomos anteriores de una obra en curso de publicacion, etc. En todos estos casos, la cifra que precede al numero de referencia indica el volumen de la NRFH en que figura la ficha en cuestion. Asi, el "num. 14-39695" corresponde a la ficha 39695, la cual está en el volumen 14 de la NRFH. Cuando no hay cifra inicial, ha de entenderse que el numero remite a una ficha incluida en el presente fasciculo.

\section{SECCIÓN GENERAL}

\section{OBRAS BIBLIOGRÁFICAS $Y$ DE CONSULTA}

19-1. "Bibliografia". - NRFH, 18 (196566) , 598-680.-V. num. 18-4191.

19-2. "Bibliografia". - RFE, 48 (1965), 469-491.-V. núm. 18-4192.

19-3. "Bibliografia hispanoamericana".RHM, 32 (1966) , 124-152.-V. núm. 184193.

19-4. ERnst, Julletre (ed.) L'année philologique. T. 33: Bibliographie de l'année 1962 et complément d'années antérieures.-Les Belles Lettres, Paris, 1964. $\mathrm{xxv}+634 \mathrm{pp}$-..V. nưm. 18-4.195.

19-5. "Bibliographie" [Edad Media]. CCM, 9 (1966), 279.349, 4.35-508, 603. 653.-V. núm. 18-4L96.

[9-6. "Registo bibliográlico" [Portugal y Brasil]. $-B I B, 6$ (1965), 7-I30, 10451169.-V. num. 18-4198.

19-7. The year's work in modern language studies. T. 26: 1964. Ed. by Graham Orton.-The Modern Humanities Research Association, Cambridge, 1965. $\mathrm{xii}+848$ pp. $\| F S, 20$ (1966), 327. 328 (Ewerc); $R P h, 20$ (1966-67), 148 149 (Malkiel) ; BHS, 44 (1967), 122 . 129 (Tate); $H, 49$ (I966), 893-894 (Woodbridge) .

19-8. LA DU, R. R.-.American doctoral degrees granted in the field of modern languages in 1963-1964". - MLJ, 48 (1964), 442-449.-V. núm. 18-4201.

19-9. Huler, C.-- "Dissertations in the Hispanic languages and literatures, 1964".-H, 48 (1965) , 284-294.-V. núm. 18-4202.

19-10. Rodriguez-Moñino, ANTonio-His. toria de una infamia bibliográfica. La de San Antonio de 1823. Realidad y leyenda de lo sucedido con los libros y papeles de don Bartolomé José Gallardo. Estudio bibliográfico._Castalia, Valencia, 1965. $248 \mathrm{pp}$. (La lupa y el escalpelo). \|HR, 36 (1968), 181-183 (Adams); $M L N, 82$ (1967), 655-657 (Avalle Arce) ; $B H i, 69$ (1967), $28 \mathrm{~L} \cdot 283$ (Devoto); Hum, 19 (1967), 105-106 (Hornedo); BHS, 44 (1967), 68.69 (Wilson).

19-11. SILVA, InNocêncio F. DA-Diccionario bibliographico portuguez. T. 6.Imprensa Nacional, Lisboa, 1962. 418 pp. V. núm. 18-20.

19-I2. Stanton, R. G., \& A. I. Dust"A defense of Innocencio [Francisco da Silva]"--PBSA, 61 (1967), 241-249.

19-13. El Sinodal de Aguilafuente, Sego. via (?) (Juan Parix), 1472 (?). Ed. facsi. mil--Joyas Bibliográficas, Madrid, 1965 . 2 ts. (Col. Primeros incunables). $\| B H S$, 44 (1967), 215-216 (Norton); $B H i, 69$ (1967) , 263-265 (Rumeau). 
19-14. Peгxoto, J.— "Um novo incunábulo português"._Ocid, 69 (1965), 42-43. [Tralado de confissão, 1489 ].

19-15. Ol.iveira, A. DE- "A livraria de um teólogo do século xvi".-BBUC, 27 (1966) , 541-588.

19-16. Penney, Clara Louise-Printed books (1468-1700) in the Hispanic Society of America.-The Hispanic Sociely of America, New York, 1965. xlii + 614 pp.-V. núm. 12-32367. || H1, 49 (1966) , 893 (Bleznick) ; HAHIR, 47 (1967), 537 (Gibson); HR, 35 (1967), 181-183 (Grecr1) ; BHi, 68 (1966), 410 . 412 (Scris); $M L N, 82$ (1967), 647-648 (Wilson); PBSA, 60 (1966), 261 (Woodbridge) ; TLS, Feb. 3, 1966 (X).

19-17. Martinez, Marcos G.-Catálogo de Biblias de la Biblioteca Universilaria. Dirección de E. González.-Ia Laguna, 1964. 54 pp. || Sef, 25 (1965), 82 (Cantera) .

19-18. Salvá y Mailén, Pedro-Catálogo de la biblioteca de Salvá (Valencia, J872).-Porter, Barcclona, 1963. 2 ts.: xxxii + 706, $900 \mathrm{pp}$. [Reproducción facsimilar]. || Q1A, 5 (1966-67), 115 (Bertini) ; $H R, 34$ (1966), 82 (Reichenberger) ; H, 48 (1965), 384 (Rotluberg).

19-19. Urquijo y Olano, Juan Ramón de, y Jesús Ugalde Fernández-Biblioteca de la Sociedad Bilbaina. Catálogo de la Sección Vascongada lle autores, comple. mentado con el de revislas y periódicos $y$ un indice diccionario.-Ia Editorial Vizcaína, Bilbao, 1965-66. 2 ts.: xi + 726, 727 pp., ilustr.

19-20. González Echegaray, C.- "Catálogo de la exposición del bicentenario de la Sociedad de Amigos del Pafs, celebrada en la Biblioteca de la Diputación dc Vizcaya".-BSV, 21 (1965), 73-87.

19-21. Zamarrieco, Томás-Enciclopedia de orientación bibliográfica. Dirigida por...-Juan Flors, Barcelona, 196465. 4 ts.: lviii $+829, x l v+793, \times x \times v i$ $+751, \times x \times v+682$ pp. $\|$ AHSI, 34 (1965) , 258-261 (Batllori); Hor, 1965, núm. 17, 86.8 (Campaña); $C D, 178$ (1965) , 362-364 (Estal); RAM, 41 (1965) , 83 (Guy) ; RyF, 171 (1965), 189. 193 (Iturrioz); Hum, 17 (1965), 388 (Martino) ; BDGA, 1965, núm. 82, 7475 (N. F. V.) ; Arb, 59 (1964), 411-413 (Pérez-Prendes y Muñoz de Arraco); Ins, 1966, núm. 231 (Sánchez); PBSA, 60 (1966), 244 (Tliompson).
19-22. Pehrsson, HJalmar, \& Hanna W'u. F (eds.) - The European bibliography.A. W. Sijthoff, Leiden, 1965.

19-23. NorTon, F. J.-Printing in Spain, 1501-1520. With a note on the early editions of the Celestina.-University Press, Cambridge, 1966. xiv + 277 pp. $\| \mathrm{Li}$ brary, 22 (1967), 364-365 (Adains); $B 1 B, 7$ (1966) , 466-470 (Leite de Faria) ; $B H S, 44$ (1967), 291-293 (Wilson) ; PBSA, 60 (1966), 408.409 (X).

19-24. Martinez, Gloria_La imprenta $y$ el papel en Cuenca durante el siglo xvi. -Escuela dcl Magisterio, Cuenca, 1965. 26 pp.

19-25. Peeters-Fontarnas, Jean - Bibliographie des impressions espagnoles des Pays-Bas méridionaux.-Centre National de l'Arclićologie et de l'Histoire du Livre, Nicuwkoop, 1965. 2 ts.: 873 pp. || $R N, 19$ (1966), 144-145 (Avalle-Arce); $Z R P h, 81$ (1965) , 592-593 (Ba]dinger); $B H R, 28$ (1966), 222-223 (Bonnant); $R y F, 173$ (1966) , 546 (E. J.) ; BHS, 44 (1967) , 232-233 (Gibbs) ; LR, 20 (1966), 356-357 (Groult) ; BIB, 7 (1966), 259 296 (Lcite de Faria); StuL, 1966, 351356 (Leite de Faria); Ocid, 69 (1965), 166-167 (Peixoto); $M 1 . N, 81$ (1966), 249-250 (Rivers); PBSA, 59 (1965) , 459 (Thompson); TG, 80 (1967), 95-98 (Vermaseren) ; Library, 22 (1967), 158161 (Wilson).

19-26. Peetrers Fontainas, J. F.- "Les im. pressions espagnoles des Pays-Bas".Le Livre el l'Eslampe, 1965, 3-17, 28-42. 19-27. Libros hispánicos impresos en los Paises Bajos en los siglos xvi-xviii._II Congreso Intermacional de Hispanistas, Nimega, 1965. 42 pp. || LR, 21 (1967), 194 (Groult).

19-28. Bonnant, G.-"Nouvelle note sur des imprimés genevois en langue espagnole dus aux presses de Jcan Crespin (1557-1560)".-BHR, 27 (1965), 318-231. -V. núm. 17-3314.

19-29. UNGERER, G.-."The printing of Spanish books in Elizabethan England", -Library, 20 (1965), 177-229.

19-30. Silva Dias, J. S. DA-“O primeiro rol cle livros proibidos"'-_Bs, 39 (1963), 231-237.

19-31. García Morai.es, J.- "El libro español en las tipografías de Europa, en el momento de la creación de la Biblioteca de El Escorial"._- RABA, 71 (1963), 425-443.

19-32. López Serrano, M. - "Bibliogra- 
fla escurialense. Complemento (19631966) "._. RABM, 71 (1963), 485-495.

19-33. Villalpando Martínez, M.-“Calálogo de la II Exposición de obras impresas sobre Segovia y su provincia"._ESeg, 17 (I965), núms. 50/51.

19-34. Coelho Loff, Maria Isabel N.-Impressores, edilores e livreiros do séc. xvii em Lisboa.-Coimbra, 1965.

19-35. Vizcaya Cárpenter, Antonio-Tipografia canaria. Descripción bibliográfica de las obras editadas. en las Islas Canarias desde la introducción de la imprenta hasta el año 1900.-Instituto de Estudios Canarios, Santa Cruz de Tenerife, 1964. xcii + 731 pp. $\|$ MCan, I965, núms. 93/96, 244-246 (Alzola); BHi, 67 (1965), 403-404. (Ricard); RLit, 29 (I966), 233-234. (Rozas).

19-36. Lrma, A.- “Contribuiçăo para o estudo de $O$ livro romántico em Portugal's.-ABP, 9 (1963), núms. 33/36.

19-97. BrAgA, J. M.—“Primórdios da imprensa em Macau".-Boletim Eclesiástico da Diocese de Macau, 62 (1964), 967-998; 63 (1965), 50-83, 169-195, 251. 270.

19-38. Castro, M._-"Estudio bibliográfico de las Constituciones franciscanas, generales y provinciales". - $A I A, 24$ (1964), 24I-304; 25 (1965), 299-340.

19-39. Collell Costa, Alberto-Escrilores dominicos del principado de Cataluña. Pról. de P. Voltes._Casa Provincial de Caridad, Barcelona, 1965. 904 pp., ilustr. || $B D G A$, 1966, núll. 88, 67-68 (Mateu Ibars).

19-40. Polgár, L.-Bilsliographia de historia Societatis Iesı".-AHSI, 34 (1965), 363-43I.—V. núm. 18-54.

19-41. Navarro, Alberto-Esludos bio-bibliográficos. T. 3.-Férin, Lisboa, 1965. 216 pp., ilustr._. V. múm. 17-21. || Ocid, 70 (1966), 168-169 (Peixoto).

19-42. Instrucciones para la redacción del "Catalogo alfabélico de autores y obras anónimas". 3" ed.-Dirección General de Archivos y Bibliotecas, Madrid, 1964. $\mathrm{xv}+264$ pp. $\| A I A, 26$ (1966), 286 (Castro) .

19-43. Agulló Y Cobo, Mercedes-Madrid en sus diarios. T. 2: 1845-1859. Ordenación y clasificación por...--Inst. de Estudios Madrileños, Madrid, 1965. 454 pp.-V. núm. 18-66. \| $R y F, 172$ (1965), 279 (Jorge) ; Ins, 1965, núm. 227 (Marra López) .

19-44. Casaricro, J. E.-“"Visión periodís. tica de Asturias, ayer y hoy".-BIEA, 1965, núm. 54, 183-204; núm. 55, 4.I-68.

19-45. Pérez Feito, A.- "Periódicos publicados en Mieres".-BIEA, 1965̆, núm. 56, 81-84.

19-46. Rodriguez DoReste, J.-_Las revistas de arte en Canarias"._MCan, 26 (1965) , 47-103.

19-47. Tencarrinha, Joste-História da imprensa periodica portuguesa.-Portugália, Lisboa, 1965. 349 pp. (História, 3). I| BEP, 27 (I966), 290.292 (Bourdon); Ocid, 71 (1966), 150 (Pcixoto)

19-48. "Artes e Letras (1872-1875)".$B I B, 6$ (1955), 165-185. [İndice].

19-49. Brotéria. Indices 1925-1962.-Broteria, Lisboa, 1965. 628 pp. \| Ocid, 70 (1966), I66-168 (Peixoto) .

19-50. Teixeira, ManueL-A imprensa periódica portuguesa no Extremo-Oriente. -Notícias de Macau, Macau, 1965. 39 pp. $\|$ Ocid, 7I (1966), 149-150 (Peixoto) .

19-51. Costa Garcez - "Subsídios para uma bibliografia geral de Lisboa".-. Rev. Municipal, Lisboa, 1965, núms. 104.5, 107-130; 11úms. 106/7, 99-110._ r. núm. 18-4221.

19-52. Enciclopedia universal ilustrada europeo-americana. Suplemento anual $1936-39,1940.41,1942-44,1945-48$. Es. pasa-Calpe, Madrid, 1966. 1377, 1473, 1248, 1548 pp., ilustr.

19-53. Focus. Enciclopedia internacional. T. 1.- Argos, Barcelona, 1965. 1590 pp. 19-54. Enciclopedia internacional Focus. T. 1: $A$-C.-Livr. Sá da Costa, Lisboa, 1964-1965. xii + 750 pp. $\|$ Bro, 78 (1964), 489-491 (Oliveira).

19-55. Gran enciclopedia del mundo. T. 21: Apéndice 1967.-Durvan, Bilbao, 1967. Ilustr.-V. núın. 18-67.

19-56. Enciclopedia luso-brasileira de cultura. T. 2: Amo-Aus._Verbo, Lisboa, 1964. 1878 pp._. V. núm. 18-4235.

19-57. Enciclopedia universal Herder. Ga ed.-Herder, Barcelona, 1965. 1164 pp., ilustr.-V. núm, 16-45823.

19-58. BuchibRGER, Michaed_Lexikon für Theologie und Kirche. 2. Aufl. Bd. 10: Teufel-Zypern.-Herder, Freiburg/Br., 1965-67. 1448 cols.-V. núm. 18.423I.

V. tambièn núms. 126-131, 174-7, 290-1, $400,440,470,478,537,904-08,1455-6$, $1584-5,1627,1643,1661,2235-7,2373-$ 5, 2898, 2901-4, 2984, 3025, 3028, 3092, รโ18, 3158, 3ร13-6, 3758. 
Archivos, manuscritos, textos, critica textual, paleografia, ciencias auxiliares

19-59. Kristeller, Payl Oskar - Iatin manuscript books before 1600: A list of the printed calalogues and unpublished inventories of extant collections. 3d. ed.-Fordham Univ. Press, New York, 1965. xxvi + 284 pp.- V. núm. 16.45826 .

19.60. Inventario general de manuscritos de la Biblioteca Nacional. Publ. por J. I.ópez de Toro y R. Paz. T. 7: Mss. 2375-247\%.-Dirección General de Archivos y Bibliotecas, Madrid, 1963. xi +618 pp.-V. núm. 18-1111. $\| A I A$, 26 (1966), 100 (Castro).

19-61. Soler García, Josffina-El cartulario de Tavèrnoles.-Soc. Castellonense (le Cultura, Castellón de la Plana, 1964. 344 pp., mapas. (Libros raros y curiosos, 14).-V. nưm. 18-167. || ZRPh, 82 (1966) , 236.238 (Colón); AHDE. 32 (1962), 635-639 (Font Rius); $A S T, 36$ (1963), 404 (Vives).

19-62. Mundó, A- "La datación de los códices litúrgicos visigóticos toledanos". $H S, 18$ (1965), 1-26.

19-63. JANni, J., y J M. Marquts_"Facsímiles de manuscritos litúrgicos visigóticos toledanos en los legajos de Burricl".-HS, 18 (1965), 27-31.

19-64. WitTlin, C. ].--"Les manuscrits clits exlel papa Lunas dans deux inventaires de la bibliothèque de Gaspar Johan Sánchez Munyoz à Teruel". $\ldots E R, 11$ (1962), 11-31.

19-65. García Alvarez, M. R.-"Los libros en la documentación gallega de la alta Edad Media".-CuEG, 20 (1965), 292-329.

19-66. García Alvarez, R.-."Más documentos gallegos inéditos del período asturiano".-BIEA, 1965, núın. 55, 3-40.

19.67. Machado Santos, Mariana AMÉLA_Catdlogo de música manuscrita da Biblioteca da Ajuda. T. 7: Apéndire.-Biblioteca da Ajuda, Lisboa, 1964. 192 pp.—V. núm. 18-111.

19-68. Garay Aunós, M.-“"Manuscritos espafioles de la Biblioteca del Trinity College, de Dublin"._Bibl, 12 (1965), núms. $61 / 62$.

19-69. Voltrs Bov, Pedro-Documentos de tema español existentes en el archiro de Estado de Viena...Ayuntaniien10, Barcelona, 1964-65. 2 ts.: 695 pP. (Documentos y estudios, 14).
19-70. Agullar Piñal, Francisco-Catilogo de documentos sevillanos que se conservan en el Museo Británico.Ayuntamiento, Sevilla, 1965. $35 \mathrm{pp}$.

19-71. FernANdez Pomar, J. M._.'Libros y manuscritos procedentes de Plasencia"._HS, 18 (1965), 33-102.

19-72. Pr.coni, A_ "Nanoscritti portoghesí della Biblioteca Federiciana di Fano"._-BIB, 6 (1965), 156.162.

19-73. BEaljouan, G.-Manuscrits scientifiques médiévatux de Salamanque $(\mathrm{N}$. 18-113). || $R T, 31$ (1964), 142-143 (Cappuyns) ; BEC, 122 (1964), 299-301 (Coste Messelière), -V. núm, 18-4243.

19-74. LeMARRE, JOSEPH_Le "Bréviaire de Ripoll", Paris, B. N. lat. 742. Etude sur sa composition et ses textes inédits.Abadfa de Montserrat, 1965. xiii + 232 pp. (Scripta et documenta, 14). \|CCM, 10 (1967), 469.471 (Eizenhöfer).

19.75. Olivar, Alejandro (ed.)-Sacramentarium rivipullense.-C.S.I.C., Madrid-Barcelona, 1964. 301 pp. (Monum. Hispaniae sacra). || StMo, 7 (1965), 231 232 (Janini); ATG, 27 (1964), 466 (Ramos).

19.76. SERDA PRAT, L._. "Fragmento dc sacramentario del Museo Episcopal de Viclı"._HS, 17 (1964), 231-232.

19-77. JANini, J. “Los fragmentos de sacramentarios existentes en Vich".-HS, 18 (1965), 385-409.

19-78. Pinel., J. M._-"Fragmentos de cóclices del antiguo rito hispánico".- $H S$, 17 (1964), 195-229.

19-79. Gatffier, B. DE-“Un abrégé hispanique du martyrologe ljiéronymien". - $A B, 82$ (1964), 5-35.

19-80. Gros, M. S.— “Las órdenes sagradas del Pontifical ms. 104 (cv) de la Bib. cap. de Vich",_HS, 17 (1964), 99-103.

19-81. Tobella, A. M., i A. Mundó_-"Documents del primer segle de la congregacio claustral tarraconense (12121317)"-AMon, 10 (1964), 399-454.

19-82. Fort I Cogul, ElfFmiA-Noticies históriques de Santes Creus. T. 1: Codex 459 de l'Arxiu Históric Nacional de Madrid, T. 2: Manuscrit Baluze de la Biblioteca Nacional de Paris.-Arxiu Bibliograffic, Santes Creus, 1964. 48, $36 \mathrm{pp}$.

19-83. Manzanares de Cirre, M._."Dos inanuscritos aljamiados inćclitos". $M P h, 62$ (1964-65) , 130-136.

19-84. Pinedo, P.- "Una glosa del ms. Ripoll 78".-AFIDE, 31 (1961), 459. 463.

19-85. Batliori, M._."Entorn de la bi- 
bliofilia d'Alfons II de Nàpols".—Studi... in onore di Tammaro de Marinis (Verona, 1964), 43-48.

19-86. LóPEz DE Toro, J.- "Humanistica escurialensia".-BAH, 154 (1964), 159 . 187.

19-87. Dunlop, D. N.—"The Arabic manuscripts of the Academia das Ciências de Lisboa".-Aclas del Primer Congreso de Estudios Arabes e Islámicos (Madrid, 1964), 285-291.

19-88. Camón Aznar, J.- “El arte de la miniatura española del siglo $x^{\prime \prime}$-Goya, 1964, núm. 58, 266-287.

19-89. Werckmeister, O. K._-“Die Bilder der drei Propheten in der Biblia His. palense". - Madrider Mitteilungen, 4 (1963), 141-188.

19-90. Вонigas, P._-"Les manuscrits à miniatures de la Biblioteca Central de Barcelone (Biblioteca de Catalunya)".-Librarium, 7 (1964), 39- 58.

19-91. SÁNchez BELDA, Luis (ed.) - Bibliografia de archivos españoles $y$ de archivistica.-Dirección General de Archivos y Bibliotecas, Madrid, 1963. 340 pp. $\| A I A, 26$ (1966), 105-106 (Castro); $M A, 71$ (1965), 366 (GautierDalché) .

19-92. Matilla Tascón, Antonio-Guiainventario de los archivos de Zamora $y$ su provincia.-Dir. Gral. de Archivos y Bibliotecas, Madrid; Diputación y Ayuntamiento, Zamora, 1964. xv + 479 pp.

19-93. Ajo G. de Rapartegos, Cíndido MaRĹA_Inventario general de los archivos de la diocesis de Avila. 1: Diocesano, catedral, parroquiales, monásticos, conventuales, seminaristico. Pergaminos. Códices. Legajos.-Ávila, 1962. 604 pp.

19-94. GoñI Gaztambide, J._-Catálogo del archivo de la Catedral de Pamplona. T. 1: 829-1500._Diputación Foral, Pamplona. 1965. 560 pp. $\| A E M, 2$ (1965), 659-660 (Crespo) ; $B D G A, 1965$, núm. 83, 59 (Crespo).

19-95. ANDREu VALS, G. "Archivos de la provincia de Castellón inventariados por don Luis Revest Corzo en 1925".$B S C C, 40$ (I964), 249-287.

19-96. Livros de linhagens. Indice onomástico._Horus, Lisboa, I964. 148 pp.V. núm. 17-76. $\| N, 45$ (I965), 76 (Dc Jong) .

19-97. "Inventarios de la sección histórica notarial. Notaría de Montclús".-Archivo Histórico y Museo Fidel Fita, 3 (196I), 179-186; 4 (1962), 56.68, 109 . $112,146 \cdot 155$.
19-98. Rubio Garcia, L.- "Los documentos del Pilar (siglo XII)".-VII Congre. so de hisloria de la Corona de Aragón, 2 (Barcelona, 1964), 32 I-328.

19-99. Bordonau, M.- "La librería y los libros de coro del Real Monasterio de San Lorenzo del Escorial"_-RABM, 71 (1963), 243-273.

19-100. Prieto Cantero, A.-“Inventario razonado de los documentos referentes al monasterio de EI Escorial existentes en la sección de Casa y Sitios Reales del Archivo General de Simancas".-RABM, 71 (1963), 7-127.

19-101. Fernández Martín, P._-“"fndice de los manuscricos de Floranes en la Acadenila de la Historia, por Menéndez Pelayo".-BBMP, 41 (1965), 115-210.

19-102. Mansill.A, D.-La documentación pontificia de Honorio III (1216-1227). Instituto Español de Historia Eclesiáslica, Roma, 1965. xl + 545 pp. $\| C D$, 178 (1965), 713-7l4 (del Estal); $A I A$, 26 (1966), 111-112 (Uribe).

19-103. El Fuero viejo de Castilla, sacado y comprobado con el ejemplar de la misma obra que existe en la Real Biblioteca de esta corte, y con otros miss. (Madrid, 1871). Publicación con notas históricas y legales por I. Jordán de Asso y M. de Manuel Rodriguez.-Lex Nova, Valladolid, 1964. 143 pp.

19-104. Maldonado Y Fernández det Torco, J.-_Un manuscrito del Fuero viejo".-AHDE, 32 (1962), 471-481.

19-105. El Fuero de Baeza, ed. J. M. ''. Roudil (N. 18.160)) . \| ZRPh, 82 (1966) , 238-241 (Colón); TG, 32 (19G4), I09.112 (Gibert); $H R, 33$ (I965), 330 332 (Hadlich).

19-106. El Fuero de Estella, ed. G. Holmér (N. 18-161). $R F, 78$ (1966), 636-637 (Langc); $M A e, 34$ (1965), 58. 60 (Procter); CCM, 9 (1966), 415416 (Roudil) .

19-107. García Gallo, A-“Los fueros de Medinaceli".-AHDE, 31 (1961), 9-16.

19-108. SAEnz Barrio, O. A.-"El fuero de Ocón".-Ber, 17 (I962), 209-21j.

19-109. Caruana Gómez de Barreda, J."La auténtica fecha del Fuero de Teruel".-AHDE, 31 (1961), 115-119.

19-110. MUT RemolA, E._Aspecto jurídico-administrativo de la Carta puebla de Lérida".-Ilerda, 19/20 (196162) , I4-26.

19-111. LoncÁs, P._-“Carta puebla de Quicena"__EMP, 5, 397-400. 
19-112. CANELLAS, ÁNGEL_Colección diplomática de San Andrés de Fanlo (958. 1270)._-Inst. Fernando el Católico, Zaragoza, 1964. 176 pp. (Fuentes histo. ricas aragonesas). \| $A 1 A, 26$ (1966), 279-280 (Barrado).

19-113. Floranes Robles, R.-"Prólogo al becerro de las Behetrías".- $B A H, 154$ (1964), 191-299.

19-114. Goñ I GazTambide, J._-Catálogo del becerro antiguo y del becerro menor de Leyre". $-P V, 24$ (1963), 149. 213.

19-115. Caruana Gómez de Barreda, J"Una relación inéclita de jueces de Teruel"_-CJZ, 14/15 (1963), 227-280.

19-116. Martínez DíEz, G._."Un nuevo cóclice del Liber iudiciorum del siglo xII".-AHDE, 31 (1961), 651-694.

19-117. Brown, T. J-- "Latin paleography since Traube".-Transactions of the Cambridge Bibliograph. Society, 3 (1963) , 361-381.

19-118. Förster, H.-Abriss der lateinischen Paläographie (N. 18-4275). II Scrip, 19 (1965), 138-139 (Bieler); Lat, 24 (1965) , 763 (Cambier); StM, 6 (1965) , 291-296 (Petrucci).

19-119. Morterero y S1Món, ConradoApuntes de iniciación a la paleografia española de los siglos xii a xvii.-Hidalguía, Madrid, 1963. 85 pp.

19-120. Marichal, R._L'écriture latine et la civilisation occidentale du fer au xvie siècle".-[En] L'écrilure et la psychologie des peuples (Paris, 1963), 199 247.

19-121. BOwERs, Fredson - Bibliography and textual crilicism.-Clarendon Press, Oxford; Oxford Univ. Press, New York, 1964. xii + 207 pp. (The Lyell lectu. res, 1959). I| Library, 20 (1965), 326327 (Donaldson); PBSA, 59 (1965), 202-204 (Evans); Era, 18 (1966), 731734 (Schulze).

19-122. Timpanaro, S.-La genesi del melodo del Lachmann (N. 17-3391). I $A F C, 8$ (1964), 241-248 (Buca); DLZ, 87 (1966), 392-394 (Hering) —V. núm. $18-4278$.

19-123. Dondalne, A.-“Abréviations latines et signes recommandés pour l'apparat critique des éditions de textes mediévaux".-Bull, de la Société de la Philosophie Médiévale, 2 (1960), 142149.

19-124. Maluquer DE Motes, J_- "Dos grafitos ibéricos con nombres latinos".Zeph, 14 (1963), 108-110.
19-125. Ruiz, A- "Las inscripciones de los Finojosas del monasterio de Santo Domingo de Silos",__Celt, 12 (1962), 147. 151.

V. también núms. 950, 954-5, 1775, 2372.

\section{HISTORIA}

19-126. Bibliographie internationale des sciences historiques. T. 30: 1961. Publiée par M. François et N. Tolu.-Colin, Paris, 1964. 468 pp.-V. núm. 184284.

19-127. White, Donald A.-Medieval his. tory: A source book.-Dorsey Press, Homewood, Ill., 1965. 575 pp. (Dorsey series in European hislory).

19-128. Van Caenegem, R, C., \& F. L. GANSHOF-Kurze Quellehunde des westeuropiischen Miltelalters: Eine typologische, hilorische und bibliographische Einführung.-Vandenhoeck \& Ruprecht, Göttingen, 1964. xiv + $365 \mathrm{pp}$. II Sp, 41 (1966), 188-189 (Boyce); $D t A, 20$ (1964), 589 (Grundmann); $D L Z, 86$ (1965) , 327-329 (Sproemberg) .

19-129. L.EHMANN, P._Erforschung des Mitlelalters (N. 17-967). || Zeitschr. der Savigny Stiflung, 47 (1961), 421-422 (Bader) ; Scrip, 17 (1963), 185-187 (Bieler); $B T h, 9$ (1962-65) , 350 (Cappuyns); $Z K, 73$ (1962), 160-161 (Elze); Era, 15 (1963), 433-435 (Joris); $D L Z, 82$ (1961), 313-316 (Langosch); StM, 4 (1963) , 239-249 (Leonardi); $A H R, 68$ (1962-63) , 499-500 (Lyon); Gn, 35 (1963) , 735-736 (Norberg); RHE, 57 (1962), 228-230; 58 (1963), 655 (Silvestre); ThLZ, 88 (1962), 45-51 (Sprömberg); $B E C, 119$ (1961), 306-307 (Tessier); $M / O G, 69$ (1961), 122-125; 70 (1962) , 407-410 (Unterkircher) ; $A L M A$, 32 (1962), 126-127 (Van de Woestijne); EHR, 77 (1962), 130-131 (WallaceHadrill); Zeistschr. für Biblioth. und Bibliogr., 9 (1962), 343-346 (Zimmermann).

19-130. Haberken, E., \& J. F. WallachHilfswörlerbuch für Historiker. Mitlelalter und Neuzeit. 2. Aufl.-Francke, Bern, 1964. 678 pp.

19-131. Davis, R. H. C.-Medieval European history. $A$ selected bibliography._Routledge-Kegan Paul, London, 1963. 47 pp.

19-132. Morriten, R.-“Il medioevo nella storiografia deł]'età moderna"-[En] Nuove questioni di storia medioevale (Milano, 1964), 1-36. 
19-133. LE GOFF, Jaceurs-La civilisation de l'Occident médiéval.-Arthaud, Paris, 1964. 696 pp., ilustr. $\| R H E, 60$ (1965), 502-506 (Genicot); $S p, 42$ (1967), 175-177 (Little); Bull. Monum., 123 (1965), 255-256 (Salet) .

19-134. KNOWLES, DAvID_The evolution of medieval thought.-Helicon Press, Baltimore, 1962. 356 pp. \| RSPh, 48 (1964), 287-288 (Bataillon); $A H R, 69$ (I963.64), 420-422 (Kuttner) ; JRH, 3 (I964), 194-195 (Lacey); EHR, 79 (1964), 577.578 (Leff); History, 48 (1963), 200 (Olfler).

19-135. Gênicot, L.-Les lignes de faîle du moyen age (N. 17-3404). 70 (1962), 120-121 (Classen); Ann. de l'Est, 12 (1961), I63-164 (Fédou); RHR, 163 (1963), 103-104 (Jolivet); $R B P H, 41$ (1963), 888- 890 (Lyon); GGA, 216 (1964), I-6 (Sproemberg).V. nưm. 18-210.

19-136. Lacroix, Paul-Military and religious life in the Middle Ages and the Renaissance._Ungar, New York, 1964. $\mathbf{x x}+504$ pp.

19-137. Ferguson, Wallace K.-Renaissance studies.-Univ. of Western Ontario, London, 1963. 170 pp. (Univ. of Westem Ontario studies in the humanities, 2). $\| J M H, 37$ (1965), 75-76. (Cochrane) ; Canadian Hist. Rev., 45 (1964), 344-345 (Davis); History, 49 (1964). 346 (Hay), UTQ, 33 (1964), 414-415 (MacLure); Clurch Hislory, 33 (1964), 497-498 (Spitz).

19-138. LuckI, EMIL-History of the Renaissance. T. 1: Economy and society. T. 2: The Church and religion. T. 8: Education, learning and thought. Univ. of Utah Press, Salt Lake City, 1963-64. $\mathrm{x}+171,155,197 \mathrm{pp} . \| S p$, 40 (1965) , 736 (Becker) ; $R N, 17$ (1964), 334-336 (Bullough); Western Human. Rev., 18 (I964), 28I-282 (Ferguson). 19-139. Secret, F.-Les kabbalistes chréliens de la Renaissance.-Dunod, $\mathrm{Pa}$ ris, 1964. xii + 372 pp., ilustr. (Sigina, 5). I| AHSI, 34 (1965), 262-263 (Batllori); Sef, 24 (1964), 156-159 (Cantera); $R H R, 168$ (1965), 222-224 (Or* cibal) .

19-140. Grfen, Vivian Hubert H.-Renaissance and Reformation: a survey of European history between 1450-1660. 2nd ed.- Edward Arnold, London, 1964. 462 pp. || CHR, 52 (1966), 406-407 (Bartmanu) .

19-I41. Bibliographie de la Réforme, 1450-
1648. Ouvrages parus de 1940 à 1955. T. 3: Italie, Espagne, Portugal. 3c éd.Lciden, 1964-65_-V. núm. 17-122.

19-142. Elton, Geoffrey R.-Reformation Europe, 1517-1559. - Meridian Books, New York, 1964; Collins, London, 1963. 349 pp. || JEH, 15 (I964), 130I31 (Dugmore); Canadian Hist. Rev., 45 (1964), 165-166 (Estes); Manchester Guard. Whly., Jan. 9, 1964, 11 (Hurstfield); History, 49 (1964), 220-221 (Koenigsberger); NYR, Dec. 29, 1966 (Stone); The Journal of Bible and Religion, 33 (1965), 79-80 (X).

19-143. LoRTz, JosepH-Historia de la Reforma. Versión española de Lucio García Ortega, supervisión de J. AguirreTaurus, Madrid, 1964. 2 ts.: 475,345 pp. 19-144. MAZZEo, JosEPH A.-Renaissance and seventeenth century studies-Columbia Univ. Press, New York; Routledge \& Kegan Paul, London, 1964. xi + 211 pp. I| $R R, 56$ (1965), 193 (Clubb) ; Italian Quart., 10 (1966), 97-101 (Mi ner); $R E S, 17$ (1966), 88-90 (Smith); $R N, 18$ (1965), 229-230 (Whitfield) . 19-145. VALJAvEc, Fritz-Historia de la Ilusiración en Occidente. - Madrid, 1964. $366 \mathrm{pp}$.

\section{$E s p a \tilde{n} a$}

19-146. Menéndez Pidal, Ramón (ed.) Historia de España. T. 5: España musulmana hasta la caida del Califato de Córdoba (711-1031). Instituciones y vida social e inlelectual, por E. LÉv PROVENçal. Arte califal, por L. Torres Balbás. 2: ed.-Espasa-Calpe, Madrid, I965. xxiv +838 pp., ilustr.-V. núm. 1232426.

19-147. Menéndez Pidal, Ramón (ed.) Historia de España. T. 15: Los Trastámaras de Castilla y Aragón on el siglo $x v$, por LUIS SUAREZ FERNÁNDEz, Ángel Canellas López y Jaime Vicens VIVEs. — Espasa-CaIpe, Madrid, 1964. clxiv + 862 pp., ilustr.

19-148. Descola, JeAN-Historia de Espar̃a. Trad. C. Bergés.-Juventud, Barcelona, 1964. 446 pp. || $M L R, 61$ (1966), 334-335 (Highfield); $B H S, 43$ (1966), 75 (Lomax) .

19-149. Castro, Amt́rico-Los españoles: cómo llegaron a serlo._Taurus, Madrid, 1965. 297 pp. (Ser y tiempo).

19-150. CAstro, AMÉrICO-Réalité de l'Es. pagne. Histoire et valeurs. Trad. M. Campserveux.-Klincksieck, Paris, 1963. 
$\mathrm{xxiii}+715 \mathrm{pp} . \| L R, 19$ (1965), 251 259 (Borgers) ; JS, 27 (1963), 1173-1174 (Camhy); BHi, 66 (1964), 207-212 (Mas); $R F, 79$ (1967), 445-451 (Schalk).

19-151. UGarTe, Francisco_España y stu civilización. 2nd ed.-_Odyssey Press, New York, 1965. xiv $+368 \mathrm{pp}-\mathrm{V}$. núm. 11-24404. || $H, 49$ (1966), 186 187 (Flynn)

19-152. Laín Entralco, Pedro-Introducción a la cullura española.Santiago, 1963. 39 pp. [Separata de Atenea, núm. 397|. || $B H i, 66$ (1964), 469-470 (Terrasse)

19-153. Menéndez Pelayo, MarcelinoHistoria de los heterodoxos españoles. 2a ed.-C.S.1.C., Santander, 1965. 8 ts.: 4182 pp. (Obras completas, 35-42) .-V. núm. 12-34049.

19-154. Maravall, Jost Antonio-El concepto de España en la Edad Media. 2a ed.-Inst. de Estudios Políticos, Madrid, 1964. 523 pp._-V. núm. 10-21962.

19.155. Sánchez Albornoz, Claudio-Estudios sobre las instituciones medievales españolas.-Universidad Nacional Autónoma, Instituto de lnvestigaciones Históricas, México, 1965. $828 \mathrm{pp}$. \| $R I M$, 27 (1967), 479-481 (Carreras); UMx, 22 (196̆-66), núm. 8 (R. de Magis) .

19-156. Lomax, DereK W.-La Orden de Santiago (1170-1275)._C.S.I.C., Madrid, 1965. xxvi + 306 pp., ilustr. (Estudios, 38). $\| A I A, 26$ (1966), 489-491 (Pa20s).

19-157. Simonet, Francisco Javier-Historia de los mozárabes de España. (Madrid, 1897-1903). A reprint.-Oriental Press, Ansterdam, 1965. Iviii + 976 pp.

19-158. MАкKI, M. A.-“"Ensayo sobre las aportaciones orientales en la España musulmana y su influencia en la formación de la cultura hispano-árabe".RIEI, 9/10 (1961-62), 65-231; $11 / 12$ $(1963-64), 7-140$.

19-159. Marcos Rodrícufz, FlorencioExtractos de los libros de claustros de la Universidad de Salamanca. Siglo xv (1464-1481)._Universidad, Salamanca, 1964. 355 pp. (AcS, Hist. de la Universidad, 6:3) .

19-160. Sala Balust, LuIs-Constituciones, estatutos $y$ ceremonias de los antiguos Colegios seculares de la Universidad de Salamanca. Ts. 1-3.C.C.I.C., Madrid, 1962-64. 402. 256, 362 pp.V. núm. 11-27155. || $H R, 33$ (1965), 157.160 (Morón); CD, 177 (1964), 151 (T. S.).
19-161. ElliotT, John H.-Imperial Spain, 1469-1716.-Arnold, E. \& Co., London, 1963. 411 pp., mapas. || $H A H R, 45$ (1965), 301-302 (Addy); HT, 14 (1964), 72-73 (Boxer); All, 4 (1966), 569. 572 (Cuenca); BHS, 41 (1964), 25425 6 (Lomax); $A H R, 70$ (1964), 133-134 (Spivakovsky); NSN, 10 Jan, 1964 (Thomas) .

19-162. Avalie-Arce, J. B._"Los herejes de Durango".-HRM, 1, 39-55.

19-163. Batllori, Miquel, e Ricardo GarcÍA-VILIOSILADA_Il pensiero della $R i$ nascenza in Spagna e Portogallo.Marzorati, Milano, 1964. 379 pp. (Grande antologia filosofica, 6). \| Sef, 25 (1965), 127-128 (Cantera); BHS, 43 (1966), 143-144 (Jones) .

19-164. Defourneaux, Marct.lin_La vie quotidienne en Espagne au siecle d'or.Hachette, Paris, 1965. 270 pp. \| CuH, 65 (1966), 174-175 (Amorós); $R H$, 235 (1966), 260-261 (Lapeyre); Revue d'Hist. Économ. et Sociale, 44 (1966), 132-133 (Mauro); Livres de France, 1965, nưm. 7, 32-33 (Rio).

19-165 Gu1lléN, C.—'Un padrón de con. versos sevillanos (1510)" - $B H i, \quad 65$ (1963), 49-98. I| Sef, 25 (1965), 145146 (Cantera).

19-166. Turbervlle, A. S.--La Inquisición española. Trad. J. Malagón y $\mathbf{H}$. Pereña. 5a ed.-Fondo de Cultura Económica, México, 1965. 154 pp. (Breviarios, 2) .--V. núm. 10-21978.

10-167. Redondo, A.- "Luther et l'Espa. gne de 1520 à 1533 ".-MCV, 1 (1965), 109-165.

19-168. TellecheA Jdigoras, J. I.-El obispo ideal en el siglo de la Reforma.Inst. Español de Hist. Eclesiástica, Roma, 1963. 260 pp. $\| A I A, 24$ (1964), 279 (Meseguer); $C D, 177$ (1964), 372 (Villegas) .

19-169. Petrie, Charles Alexander-Philipp $I I$ of Spain.-Evre, London, 1963. 319 pp. || $H A H R, 45$ (1965), 117-118 (Gold) ; $A H R, 69$ (1966) , 756-757 (Toomie) .

19-170. Petrie, Charles-Felipe 11. Trad. J. Tobío. - Edit. Nacional, Madrid, 1964. 322 pp., lánıs. (Mundo científico). $\| H, 49$ (1966), 886-887 (Greenfield) .

19-171. Petrue, Chardes-Philipp 1. . von Spanien. Aus dem Englisch yon U. Gmelin. - Kohlhammer, Stuttgart, 1965. 299 pp.

19.172. Golmard, JacQues (ed.)-L'Es- 
pagne au temps de Philippe II.-Haclette, Paris, 1965. 293 pp.

19.173. Madrid en el siglo xvi. T. I: Mis. celanea conmemoratiza del II' centenario del establecimiento de la capitali. dad (1561-1961).-Inst. de Estudios Madrileños, Madrid, 1962. viii $+374 \mathrm{pp}$. || $A I A, 26$ (1966), 100-102 (Castro).

19-174. Simón Díaz, José (ed.) -Fuentes para la historia de Madrid y su provincia. T. 1: Textos impresos en los siglos xui y xuii._Inst. de Estudios Ma. drileños, Madrid, 1964. xi +461 pp. || RLit, 25 (1964), 226-227 (Prades).

19-175. VÁLGOMA, D. DE LA-“Honras fúnebres regias en ticmpo de Felipe II".El Escorial, 1563-1963 (Madrid, 1963), 1, 359-398.

19-176. SÁNCHEZ, R. - "Bibliografía periodística sobre el IV Centenario del monasterio de El Escorial".- $R A B M$, 71 (1963), 463-478.

19-177. ANDrés, GrEgorio DE-Documentos para la historia del monasterio de San Lorenzo el Real de El Escorial.-Madrid, 1964. 470 pp. $\| E m, 33$ (I965), I48-15I (Pomar).

19-178. Loomir, ALBERT J.-The Spanish Elizabethans. - Fordham Univ. Press, New York, 1963. xii + 282 pp. If $B H i$, 66 (1964), 229.231 (Poirier); $A H R$, 69 (1966), 736-737 (Rabb); $A H S I, 34$ (1965), 145.148 (Scaduto).

19-179. Hamilton, Bernice - Political thought in sixteenth-century Spain: a study of the political ideas of Vitoria, De Soto, Suirez, and Molina.-Oxford Univ. Press, London, 1963. vii + 201 pp. || $A H R, 69$ (1966), 1050-1051 (Colie); EHR, 80 (1965), $829-830$ (Gough) ; BHS, 42 (1965), 56-57 (Koenigsberger) ; Heythrop Journ., 5 (1964), 342-343 (Levi); JMH, 37 (1965), 7677 (Malefakis); Rev. of Politics, 27 (1965), 547-549 (Norling); BHi, 67 (1965) , 201-202 (Pérez); TLS, Jan. I6, $1964(\mathrm{X})$.

19-180. Salomon, Nö́l-La campagne de Nouvelle-Castille à la fin du xuie siècle d'après les "Relaciones topográficas". — S.E.V.P.E.N., Paris, 1964. 379 pp. \| $\mathrm{CuH}, 68$ (1966), 232-237 (Gil Novales); $H M, 25$ (1965), 587-601 (Moxo).

19-181. Flliot, J. H. The revolt of the Catalans. $A$ study in the decline of Spain (1598-1610)._Cambridge Univ. Press, 1963. xvi + 624 pp. $\| A H R, 69$ (1964) , 442.443 (Bishko); HT, 13 (1963), 647 (Boxer) ; JMH, 36 (I964), 56-57
(Fagg) ; Canadian Hist. Rev., 46 (1965), 180 (Herr) ; ROcc, 9 (1965), 207-227 (Herr); Econ. Hist. Rev., 16 (1964). 572-574 (Kamen); $B H S, 41$ (1964), 5355 (Koenigsberger); $R N, 17$ (1964), 244-246 (Loomic); Pol. Sci. Quart., 80 (1965), 656-658 (Ranum); Asom, 20 (1964), núm. 1, 64-67 (Salazar Chapela) ; $C C L, 1964$, núm. 84, 96-97 (Salazar Cliapela); NSN, 23 Aug. 1963, 228 (Stone); HAHR, 44 (1964), 391-393 (TePaske); $H, 47$ (1964), 664 (Thomas) .

19-182. Domínguez Ortiz, Antonio-La sociedad española en el siglo xuii. T. 1.-C.S.I.C., Madrid, 1963. xi + 375 pp. (Monografias historico-sociales, 7). $\checkmark$. núin. 12-30719. || $H M, 1965$, núm. 97, 133-134 (Buitrón) ; BHi, 68 (1966), 104-115 (Chaunu); RH, 234 (1965), 468-471 (Defourneaux) ; $\mathrm{CuH}, 62$ (1965), 591-601 (Gómez Marín) ; $A H, 41$ (1964), 390-393 (Herrera) ; $A I A, 28$ (1968), 219 220 (Meseguer)

19-183. Herr, Richard-España y la revolucion del siglo xviii. Trad. E. Fernández Mel.-Aguilar, Madrid, 1964. 440 pp. (Cultura e historia).-V. núm. 16-41994. || ROcc, 8 (1965), 240-246 (Elorza); RIM, 26 (1966), 530-533 (Ezquerra); RLC, 40 (1966), 641-645 (Pageaux) .

19-184. Palacio Atard, Vicente-Los es. pañoles de la Ilustración.-Guadarrama, Madrid, I964. 333 pp. \|NT, 23 (1965) , 390-s992 (Cuenca); Arb, 59 (1964), 399-402 (Fernández Alvarez); $E L, 1965$, núm. 309 (Miró) ; CuH, 65 (1966)，163-169 (Romero Márquez).

19-185. Sarrailh, JEAN-L'Espagne éclairée de la seconde moitié du xviiie siè. cle. Réimpression.-Klincksicck, Paris, 1965. 792 pp.-V. núm. 12-29310. | $B A b r, 39$ (1965), 426 (Aldridge).

19-186. AldeA, Q.- "La Ilustración en España".-MisCo, 43 (1965), 329-341. 19-187. Marías, Julí́n_La España posi. ble en tiempo de Carlos III._.Soc. de Estudios y Publicacioncs, Madrid, I963. 233 pp. || ROcc, 4 (1964), 123.128 (Carpintero Capell) ; Ins, 1965, núm. 226 (Herr) ; Ins, 1963, núm. 205 (Martínez de Pisón); Sur, 1966, núm. 300 (Olivera); Ins, 1964, núm. 208 (de Torre) .

19-188. Tuñón dE LARA._L La España del siglo xix (N. 17-3447). \| BISD, 1964, núm. 31, 284-285 (Díaz); BHi, 67 (I965), 1.56-159 (Lasa). 
19-189. Sobrequés V'ILAR, S,_."Le retard de l'Espagne et du Porugal au xixe sic̀cle".-IH, 26 (196-1) , 13-16.

19-190. SálNz Rodríguez, P.-Evolución de las ideas sobre la decadencia española $y$ otros estudios de critica lite. raria (N. 18-2428). \|RLit, 23 (1963), 269.270 (Marcos) ; Hf, 1964, núm, 22, 77.78 (Schraibman).

19-191. Izquierdo Hernandez, ManuelAntecedentes y comienzos del reinado de Fernando VII._Cultura Hispánica, Ma. drid, 1963. 794 pp. II Ins, 1963, núm. 205 (Campos); CuH, 66 (1966), 189193 (Echánove Guzmán); RyF, 172 (1965), 385-386 (Jorge); Arb, 57 (1964), 215-217 (Santaló).

19-192. Campo Alange, Condesa de_La mujer en España. (Cien años de su historia).-Aguilar, Madrid, 1963. 385 pp. $\|$ CuFI, 64 (1965), 131-145 (Alvarez Villar) ; $H, 49$ (1966), 350 (Bosch); RHM, 32 (1966), 122 (Bosch).

19-193. CACHO VIU, V.LLa Institución Libre de Enseñanza, t. 1 (N. 18-330). $R I M, 25$ (1965), 261-262 (Ezquerra); AESC, 19 (1964), 768-774 (Morazé).

19-194. Eguiagaray, Francisco-Historia contemporánea de España.-Hueber, Mïnchen; Aula, Madrid, 1964. 197 pp. 19-195. Díaz Plaja, Fernando_El siglo xx. Dictadura, Repriblica (1923-1936).Inst. de Estudios Políticos, Madrid, 1965. 920 pp. (La historia de España en sus documentos).-V. núm. 17-3451.

19-196. SEDWICK, FRANK-The tragedy of Manuel Araña and the fate of the Span. ish republic. Foreword by $\mathrm{S}$. de Madariaga.-The Ohio State Univ. Press, Columbus, 1964. xvii + 295 pp., ilustr. || BHS, 42 (1965) , 265-266 (Hennessy); HAHR, 45 (1965), 153-154 (Jackson); $M L J, 49$ (1965), 451 (Villa Fernández).

19-197. García DurÁn, JuAN (comp.) Bibliografia de la guerra civil española 1936-1939....Inst. de Historia de la Guerra Civil Española, Montevideo, 1964. 559 pp. || PBSA, 59 (1965), 458 (Wood. bridge) .

19-198. SÁNchez, José M.-Reform and reaction. The politico-religious back. ground of the Spanish civil war,_Univ. of North Carolina Press, Chapel Hill; Oxford Univ. Press, London, 1964. $\mathrm{xii}+241 \mathrm{pp}$. $\| R y F, 171$ (1965) 550 . 551 (Echánove); BHIS, 42 (1965), 200. 202 (Lomax).

19-199. Ayala, Francisco-España a la fecha.-Sur, Bs. Aires, 1965. $128 \mathrm{pp}$.
Portugal

19-200. SERRÃo, JoEL-Dicionário de historia de Portugal. T. 2: Ean-Maz.-Iniciativas Editoriais, Lisboa, 1963-1965. 988 pp.-V. núm. 17-160. || $C u N, 24$ (1964), 123-124 (Macchi).

19-201. FARIA, AMÉRICo-Portuguesas na história. Biografias.-Edit. Organizações, Lisboa, 1965. 328 pp.

19-202. Siqueira Coutinho, JoAquim dEAn outline of the history of Portu. guese culture.-Saint Anthony's Press, Bronx, N. Y., 1964. 65 pp. \|H, 48 (1965), 378-379 (Moser).

19-203. Rossi, GIUSEPPE CARLO-Nozioni generali di cultura portoghese. 2 a ed.Ed. dell'Ateneo, Roma, 1965. 76 pp. 19-204. Serrão, Joel-Temas de cultura portuguesa. T. 2.-Portugália, Lisboa, 1965. 243 pp. (Problemas, 8) .-V. núm. 16.47516. || RLit, 29 (1966), 231-233 (Ares Montes); BEP, 27 (1966), 288 . 290 (Bourdon).

19-205. CoRTESÃo, JAIME-O humanismo universalista do. portugueses.-Portugália, Lisboa, 1965. 324 pp. (Obras completas).

19-206. Ollyejra Marques, A. H. DEGuia do estudante de história medieval portuguesa.-Cosmos, Lisboa, 1964. 324 pp. $\| B H S, 43$ (1966), 305 (Lomax); RHE, 60 (1965), 1010 (Matoso).

19-207. Oliveira Marques, A. H. DE-Ensaios de história medieval portuguesa.Portugália, Lisboa, 1965. 308 pp. \| $\mathrm{CuN}, 25$ (1965), 146-147 (Macchi); Ocid, 70 (1966), 170-171 (Pinharanda Gomes) .

19-208. Oliveira Marques, A. H. DE- $A$ sociedade medieval portuguesa. Aspeclos da vida quotidiana.-Sá da Costa, Lisboa, 1964. xx + 301 pp., ilustr. II Economia e Storia, 12 (1965), 146-147 (Fanfani); CuN, 25 (1965), 146 (Macchi); Vierteljahrssch. für Soz.- und Wirlschaflgeschichte, 52 (1965), 93-94 (Pohl) .

19-209. BORBA, H._-'Os reis de Portugal $\mathrm{e}$ as suas relações com as artes, as letras e as ciências".-Atlântida, 9 (1965), 114 127, 175-188, 262-277, 10 (1966), 81. 98, 253-281; 335-350.-V. núm. 18-349. 19-210. Brandão, M.-“A Escola pública de Alcobaça, um embuste da historiografia alcobacense".-BAu, 18/19 (1965) , 5-20.

19-211. Nunes Costa, M. A.-Documentos para a história da Univ. de Coimbra 
(N. $17-3477)$. ||$B E P, 25$ (1964), 288289 (Bourdon).

19-212. Borges Coelho, Antónlo-A rezolução de 1383._Portugália, Lisboa, 1966. 190 рр.

19-213. Domingues, Mario-O Cardeal $D$. Henrique. O homem e o monarca. Evocação histórica.-Romano Torres, Lisboa, 1964. $410 \mathrm{pp}$.

19-214. Domingues, MÁrjo-D. Sebastião. o hoinem e a sua época. Evocação histórica.-Romano Torres, Lisboa, 1964. 460 pp.

19-215. Brooks, Mary Elizabeth-A king for Portugal. The Madrigal conspiracy, 1594-1595.-The Univ. of Wisconsin Press, Madison, 1964. 192 pp.-V. núm. 16-47963. || BHi, 69 (1967), 267-269 (Cantel) ; HM, 1965, 456-458 (Castel) ; $L B R, 2$ (1965), núm. 2, 110-112 (McClary); $M L J, 49$ (1965), 342-343 (Roberts) .

19-216. Saraiva, antónio José-A Inquisição portuguesa. 3a ed., rev.-EuropaAmérica, Lisboa, 1965. 130 pp. (Saber, 31). -V. núm. 11-27173.

19-2 17. Domingues, MARro-D. João IIT. O homem e a sua época. Evocação his.tórica.-Romano Torres, Lisboa, 1964. 400 pp.

19-218. França, JosÉ Augusto-Une ville des lumières: la Lisbonne de Pombal. Svepen, Paris, 1965. 259 pp., ilustr.V. núm. 18-370. \|Bro, 82 (1966), 859 . 860 (Maurício); $B E P, 26$ (1965), 237. 241 (Tapié).

19.219. Chantal, Suzanne-A vida quotidiana em Portugal ao tempo do terramoto. Trad. de Álvaro Simões.-Livros do Brasil, Lisboa, [1965?] $302 \mathrm{pp}$. || Ocid, 70 (1966), 121-122 (A.C.).

19-220. SA, VIctor DE-Perspectivas do século xix. Ensaios.-Portugália, Lisboa, [964. 292 pp. || BEP, 24 (1965), 289292 (Silbert).

19-221. Nogueira, César-Notas para a história do socialismo em Portugal (1871-1910).-Portugália, Lisboa, I964. 344 pp. (Movimentos ideológicos, 3) . II $B E P, 27$ (I966), 298-300 (Bourdon).

19-222. Pattes, Riciand - Le Portugal dans le monde._Les Sept Couleurs, Paris, 1964. $224 \mathrm{pp}$.

\section{HISPANISMO Y VIAJES DE ENTRANJEROS}

19-223. Actas del Primer Congreso Internacional de Hispanistas. Ed. by Frank
Pierce and Cyril A. Jones.-Dolphin, Oxford, 1964. 495 pp. $\| B H S, 43$ (1966), 211-214 (Clavería); $M L R, 62$ (1967). I44-146 (Joncs); HR, 34 (I966), 261265 (Place); RFE, 49 (I966), 349362 (Rull); $H, 49$ (1966), 539.534 (Sánchez) ; LR, 20 (1966) , 264-268 (Vermeylen).

19-224. GUEREÑA, J. L.-"Hispanismo en Francia".-Norte, 1965, núm. 6.

19-225. BEYniE, J.- "Quelques notes sur l'enseigniement de l'espagnol dans les Iycées tcclıiques".-I.NL, 1965, núm. 1 102-106.

19-226. Pagearn, R.-."J.-J. Achille Bettrand".- $-R L C, 39$ (1965), 629-638.-.V. núm. 16-45975.

19-227. Rossi, G. C.-_"Información de Italia".-BFE, 1964, núm. 13, 18-19.

19-228. Rossi, G. C.- "La lengua española en Italia: ayer, hoy y mañana".PFE, 1, 371-381.

19-229. Mancini, G.-"Problemas de enseñanza y estudio del castellano en Italia".-PFE, 2, 3939-344.

19-230. GIBERT, R.-"Fincke y Vinckc, una generación de hispanistas". - $A t l, 2$ (1964), 418-424.

19-291. Albareda, J. M.-"Joliannes Vinckc, continuador de Heinrich Fincke".$H J V, I, 1-5$.

19-232. JURETSCHKE, H._-"Richard Konetzke, historiador y testigo del mundo hispánico en la Alemania moderna".$H M, 25$ (1965), núm. 98.

19-233. PoÝ́n Díaz, D.-“La lengua española en Suiza. Consideraciones sobre el futuro".-PFE, 1, 367-369.

19-234. Pavlíkové, S. - "Información de Checoslovaquia".-BFE, 1964, núm, 13, 15-17.

19-235. Bous, F.-“O português nas enciclopédias checas".- $R P, 30$ (1965), 428-429.

19-236. Iordan, Iorgu, y Paul alexandru Georgescu-Los esludios hispánicos en Rumania.-Soc. Ruinana de Lingüística Románica, Bucarest, 1964. 30 pp. || RLit, 27 (1965), 209-210 (Rozas).

19-237. Tudorica, O.-."Algunos estudios hispánicos en Rumania"...EAC, 1965 , núm. 5 ; $R R L, 10$ (1965), 409-413.

19-238. Petkanov, I.-_"Trabajos dedicados a la lingüfstica y a la literatura española en Bulgaria, en los años $196 \mathrm{I}$ 1965".-BFE, 1965, núms. 15/17.

19-239. Santacreu, J.- "Un eminente hispanista soviético".-LS, 1965, núm. 12, 175-177. [Fiodor Kelin (1893-1965)]. 
19-240. Bernstein, H._"The Yankec and the Hispanist".-PFE, 1, 383-391.

19-241. DURÁ, M.-"Nota sobre el hispanismo en Estados Unidos".-Norte, 1965, núm. 6.

19-242. London, G. H.- "La enser̂anza del español en los Estados Unidos".$P F E$, 2, 373-381.

19-243. Gullón, R.-_Literatura espafiola en Estados Unidos"._Ins, 1964, núm. 215.

19-244. FUNKE, Francls J.-.Spanish literalure in the secondary schools in the Southeast: Theory and practice.[Tesis, Florida State Univ.; resumen en $D A, 25$ (1964-65) , 5277].

19-245. "Brazilian and Portuguese studies in progress in the United States and Canada",_LBR, 2 (1965), núm. 2, 97103.

19-246. Asrrcom, B. B.- "Charles Philip Wagner (1876-1964)",-HR, 33 (1965), 165-167.

19-247. McSpadden, George E.-"Henry Grattan Doyle (1889-1964)",_- $H, 48$ (1965) , 207-208.

19-248. Bar-LEwaw, I.-_"Los estudios de español en el Canadá".-Norte, 1965, núm. 6.

19-249. García Morrjón, J.-“Creación y desarrollo del hispanismo en Brasil".-PFE, 1, 345-359.

19-250. Navarro Morales, E., y L. SobriNo PôRTo-"Una experiencia de la enseñanza del español en el Brasil".$P F E, 2,329-332$.

19-251. Mattoso Câmara JR., J-“ “O espanhol no Brasil e a conexão entre o português e o espanhol na América do Norte". $P F E, 1,337-343$.

19-252. CunHA, C.-“O ensino superior de língua e literatura espanhola no Brasil. O espanhol no ensino superior".-PFE, 2, 315-328.

19-253. HARA, M.- "Actividad hispanista en el Japón".-BFE, 1964, núm. 12, 9-15.

19-254. HarA, M.-"Actualidad y orientación para la cnseñanza de español en Japón"-PFE, 2, 357-372.

19-255. Thompson, R, W._."Presencia del español en Hong Kong",_PFE, 1, 403. 404.

19-256. STARKIE, WALTER-Pilgrims of St. James._University of California Press, Berkeley, 1965.

19-257. BOTtINEAU, Yves-Les chemins de Saint-Jacques. - Arthaud, Paris-Grenoble, 1964. || Revue de la Haute Auver- gne, 39 (1964), 132-134 (Bouyssou) ; 1H1, 9 (1964) , 181-182 (Clou]as); $L N L, 1965$, núm. 1, 109-111 (Cloulas); Bull. Monum., 122 (1964), 315-316 (Salet).

19-258. Pelerins et chemins de Saint-Jacques en France et en Europe du $x^{e}$ siecle $\dot{a}$ nos jours.-Archives Nationales, Paris, 1965. xi + 124 pp., ilustr.

19-259. Ducrot, JANINE_Vers Compostelle. Grandes routes et petits chemins touristigues.-Nouv. Ed. Latines, Paris, 1962. $192 \mathrm{pp}$.

19.260. Lachrra, J. M._.'Espiritualidad del culto y de la peregrinación a Santiago antes de la primera cruzada".[En] Pellegrinaggi e culto dei santi en Europa fino alla prima crociata (Todi, 1963) , 115-144.

19-261. Monteverde, J. L.—'Algunas no. tas sueltas sobre la antigua vía de Santiago a su paso por la provincia de Burgos"._BIFG, 162 (1964), 129-135.

19-262. PAMPLONA, G. DE_"El camino de peregrinación jacobea Bayona-Urdax-Velate-Pamplona". $-P V, 25$ (1964), 213-223.

19-263. URRUTIBÉHETY, C.-_"SuT la toute de Compostelle: le passage des gaves et le chemin de Charlemagne"-Bull. de la Société de Borda, 88 (1964), 1939.

19-264. Marḱs, F.-"Cluny y la ruta de los peregrinos a Santiago".-Ensayo, 13 (1961), 25-38.

19-265. Subiás, G. J_- "Los caminos del arte de peregrinación". - Ensayo, 13 (1961), 39-43.

19-266. AlcoleA, S.-_Vitalidad artística del Camino de Santiago en el siglo xvi". $-P V, 1964$, núms. 96/97, 201 202.

19-267. Storrs, Constance $\mathrm{M}$-Jacobean pilgrims from England from the early 12 th century to the late 15 th century.[Tesis, Univ. de Londres, 1964].

19-268. D'Aurora, Conde_Caminho portugués para Santiago de Compostela.Cruz, Braga, 1965. $264 \mathrm{pp}$.

19.269. Fairman, Patricia Shaw-España vista por los ingleses del siglo xvii._. [Tesis, Univ. de Madrid; resumen en $R U M, 13$ (1964), 611-614].

19-270. Secret, F__-"Le voyage d'un érudit allemand en France et en Espagne au xvire siecle",-RLC, 39 (1965), 619.629 .

19-271. Antolne, MicheI_Henry Desmarest (1661-1741). Biographie critique.Picard, Paris, 1965. 216 pp. (Vie musi- 
cale en France sous les rois Bourbons, 10). \| $B H i, 68$ (1966), 166-167 (Bourligueux) .

19-272. Daupiás d'Alcochete, N._“A propósito das Recordaçoens de Jácome Ratton".-Ocid, 68 (1965), 181-189.

19-273. DAupiḱs D'Alcochete, N-“Lettres de Jacques Ratton à António de Araújo de Azevedo, Comte da Barca. Texte et présentation".-BEP, 25 (1964), 137256.

19-274. AMAN, J.- "Une description de Lisbonne à l'occasion de la visite d'une escadre française en juin $1755^{\prime \prime}-B E P$, 26 (1965), 111-143. [Sigue un frag. mento del Journal del Chevalier des Courtils, pp. 145-164, y notas de A. Bourdon, pp. 165-180].

19-275. Elorza, A.- "Notas de viaje en torno al País Vasco (1789-1840) ".- $B S V$, 21 (1965), 9-19. [Jovellanos y algunos extranjeros].

19-276. Marbot, JeAN-Baptiste - Memorias. Campañas de Napoleón en la Peninsula ibérica. Trad. J. Ramos.-Castalia, Valencia, 1965. 27 I pp., ilustr. (Col. Viajes por España). || fns, 1966, núm. 239 (Campos).

19-277. Olivar-Bertrand, R.-“'Notas sobre la visión norteamericana de España de 1860 a $1870^{\prime \prime}$._ROcc, 8 (1965), 5071.

19-278. Gautier, ThÉophile-Voyage en Espagne._Paris, 1964. 424 pp. (Littérature, 7).

19-279. Brey Mariño, María_Viajes a España del pintor Henri Regnault (18681870). España en la vida y en la obra de un artista francés. 2a ed., anm.Castalia, Valencia, 1964. 165 pp. +26 láms._V. nưm. 5-5985. || PSA, 38 (1965), 221-222 (Viñuelas).

19-280. SaINT-PAULIEN-Ho visto vivere la Spagna._La Navicella, Roma, 1965. 210 pp.-V. núm. 13-36220.

19-281. Causse, Michìle, Bernadette ENgelman, et Nicole Marion-lbérie, péninsule de légende.-Hachette, Paris, 1964. $192 \mathrm{pp}$.

19-282, Dedet, Christian_Lla fuite en Espagne.-Les Editions du Seuil, Paris, 1965. 125 pp. || BAbr, 40 (1966), $43 \mathrm{I}$ (Cooper) .

19-283. Brenan, Gerald - The face of Spain._Harmondsworth, London, I965. 269 pp.

19-284. StarkiE, WALkER-Aventuras de ¿ın irlandés en España. Trad. A. Espina._Espasa.Calpc, Madrid, 1965. 231 pp. (A ustral, 1362). \|RyF, 175 (1967), 104-105 (Iturrioz).

19-285. DELANO, LUCI.E KATHRYN-Spain, reality and legend.-Winthrop College, Rock Hill, 1964. 145 pp.

19-286. KazAntzakis, Nikos - Spain. Transl. by Amy Mims. - Simon \& Schuster, New York, 1963. 254 pp. $H, 48$ (1965), 150-151 (Demetrius); $H A H R, 45$ (1965), 157-158 (Jackson).

19-287. Cleugh, James - Furia española (1936-1939). La guerra de España vista por un inglés.-Juventud, Barcelona, 1964. $224 \mathrm{pp}$.

19-288. Dony, PaUL-Reisen in Portugal. Entdecleungen am Rand Europas. Übers. von Lotte Minkus. - Schnell-Steiner, München-Zürich, 1965. 180 pp., ilustr. 19-289. Rowe, VIVIAN-The road to Lisbon.-Eyre \& Spottiswoode, London, 1962. 207 pp., ilustr.

V. también núms. 1441, 1495, 1726-7, 1990, 2334, 3682 .

\section{LINGƯISTICA}

\section{OBRAS GENERALES}

19-290. Bibliographie linguistique de l'an. née 1962 et complément des annés précédentes. - Spectrum, Utrecht, 1965. $\mathrm{xIv}+425$ pp.-V. núm. 18.4358. || ZRPh, 82 (1966), 664-665 (Engler).

19-291. Rice, Frank A., \& AlLENE GuSS (eds.) -Information sources in linguistics.: A bibliographical handbook.-Center for Applied Linguistics, Washington, D. C., 1965. viii +42 pp.

19-292. Proceedings of the Ninth Interna. tional Congress of Linguists, Cambridge, Mass., August 27-31, 1962. Ed. by Horace G. Lunt._-Mouton, The Hague, 1964. xxii + 1174 pp. (Janua linguarum, Series maior, 12). $\| I J A L, 31$ (I965), 259-263 (Bright) .

19-293. Jakobson, R.- "Results of the Congress".-PNCL, 1135-1142.

19-294. Estructuralismo e historia. MisceLanea homenaje a André Martinet. Ed. D. Catalán. T. 3.-Universidad, La Laguna, 1962. 231 pp. (Bibl. filológica). V. núm. 13-36226. || RPh, 21 (1967-68), 353-254 (Lehmann).

19-295. BoRsT, A.-Der Turmbau von Babel, Bd. 3-4 (N. 17-35I5). \|CCM, 10 (I967), 485-486 (d'Alverny); JEH, I5 (1964), 103-I05 (Liebeschütz); MIOG, 72 (1964), 158-159 (Zöllner) -V. nưm. $18-428$. 
19-296. Me]liet, A., et M. Comen (eds.) Les langues du monde.-Société de Linguistique de Paris, 1965. xlii +1296 pp., 21 mapas. [Reprod. fotográfica de la ed. de 1952].-V. núm. 13-34329. 19-297. Muller, Sierfried H. - The world's living languages: basic facts of their structures, hinship, location and number of speakers_-Ungar, New York, 1964. || IJAL, 31 (1965), 264-265 (Gleason) .

19-298. WAlford, AlBert JoHN-A guide to foreign language grammars and dictionaries._Library Association, London, 1964. $132 \mathrm{pp}$.

19-299. BASTIAN, O. - Die europäischen Sprachen.-Francke, Bern, 1964. 120 pp. (Sammlung Dalp). \| ASNS, 203 (1966), 77-78 (Tschizewskij).

19-300. Malmberc, B.-"Barreras lingüísticas en el munclo de hoy" (N. 18429). I B/CC, 20 (1965), 396-398 (Figueroa Lorza).

19-301. I.Ázaro Carreter, F.-Diccionario de términos filológicos, $2^{\mathbf{a}}$ ed. (N. 17-35̃17). || BILE, 1964/65, núm. 7, 145.146 (Chiareno) ; $H, 47$ (1964), 447 (Fish) ; PhP, 8 (1965), 101.102 (Halasová); $V R, 24$ (1965), 302-306 (Heinimann).

\section{Teoría tel lenguaje}

19-302. Сномкку, N.- "De quelques constantes de la théorie linguistique".Diog, 1965, núm. 51, 14-21.

19-303. Krenn, H.-"Zur Frage der Autonomie und ter Funktion in der Sprachwissenschaft"._ZRPh, 81 (1965), 492-506.

19-304. Traraux linguistiques de Prague. J. (L'école de Prague d'aujourd'hui).-Acad. Tcliécoslovaque des Sciences, Prague, 1964. $300 \mathrm{pp}$. || PhP, 8, (1965), 423-425 (Jindra \& Povejsil).

19-305. WEINRICH, H. - "Harmonisierung der Einzelgrammatiken oder allgemeine Sprachwissenschaft?" (N. 17-35ว5) . II $R F E, 48$ (1965), 220-221 (Llorente).

19-306. I, АMB, S. M.- "Epilegomena to a theory of language".-RPh, 19 (196ว. 66) , 531-573. [Prolegomena to a theory of language, de 11 jelmslev].

19-307. ARHMANova, O. S., et al.-Exact methods in linguistic research. $\mathrm{Tr}$. by D. G. Hays \& D. V. Mohr.-Univ, of California Press, Berkeley \& Los Angeles, 1963. 184 pp. || IJAL, 33 (1967), 84-91 (Abernathy); RPh, 19
(1965-66) , 594-596 (Newman); Word, 20 (1964), 440.445 (Sobelman); $A L$, 17 (1965), 172-173 (Thorne).

19-308. Garvin, Paul L.-On linguistic method. Selected papers.-Mouton, The Hague, 1964. 158 pp. || $R P h, 20$ (196667), 91-92 (Togeby) .

19-309. Leroy, MAUrjce-Les grands collrants de la linguistique moderne.Univ. Libre de Bruxelles, BruxellesParis, 1963. 198 pp. (Travaux de la Faculté de Philosophie et Lettres, 24). II ZRPh, 81 (1965), 593-594 (Baldinger); Em, 32 (1964), 339-340 (Bassols); RLiR, 28 (1964), 465-466 (Bourguignon); $E t C, 32$ (1964), 205 (Descaintes); Slovo, 26 (1965) , 290-291 (Duchácek); $A L, \quad 16$ (1964), 163-165 (Diverres); RevPh, 38 (1964) , 329-330 (Ernout); RRL, 11 (1966), 507-509 (Graur); $M L R, 60$ (1965), 107 (Laidlaw); $B J R$, 9 (1964) , 32-33 (Matter); BSLP, 59 (1964), núm. 2, 19-22 (Perrot); $A$ GIt, 50 (1965), 198-200 (Segre).

19-310. I.eroy, Maurice_Profilo storico della linguistica moderna.-Laterza, $\mathrm{Ba}$ ri, 1965. 226 pp. (Bibl. di cultura moderma, 617).

19-311. Bolelli, Tristano-Per una storia della ricerca linguistica.-Morano, Napoli, 1965. 597 pp.

19-312. Graur, Alexandru, \& L. Wald Scurta istorie a lingvisticii. 2a ed.-Ed. Stiintifica, Bucuresti, 1965. 184 pp. $L b R$, 1亏 (1966), 313-314 (Stirbu).

19-313. Ivic, MILKA_Trends in linguistics. Transl. by Muriel Heppell.-Mouton, The Hague, 1965. 260 pp. (Janua linguarum, Series minor, 42). I| $R R L$, 11 (1966), 509-510 (Vincenz); SCL, 17 (1966), 598-599 (Vincenz).

19-314. MohrmanN, C., F. Norman, \& AlF SOMMERFELT (cds.) - Trends in modern linguistics._Spectrum, UtrechtAntwerp, 1963. 118 pp. \|IJAL, 32 (1966) , 198-201 (Flill); Lan, 41 (1965), 308-312 (Householder) ; REA, 66 (1964), 392-393 (Lejeune); ASNS, 200 (1965). 287 (Pilch); RPh, 19 (1965-66), 353. 360 (Uhlenbeck).

19-315. Sebeok, Thomas (ed.)-Current trends in linguistics. T. 1: Soviet and European linguistics. - Mouton, The Hague, 1963. xii +606 pp. \|Lan, 41 (1965), 115-126 (Kucera); Language Learning, Ann Arbor, 14 (1964), 6567 (Larudee); The Linguistic Reporter, 1964, núm. 4 (X) ; ArO, 33 (1965), 113115 (Zgusta). 
19-316. MalmberG, BertiL_New trends in linguistics; an orientation. Tr. by $\mathrm{E}$. Carney.-Stockholm-Lund-Copenhaguen, 1964. 236 pp. (Bibliotheca linguistica, 1) -V. núm. 18-454.

19-317. I.enneberG, ERIC H. (ed.) -New directions in the study of language. M. I. T. Press, Cambridge, Mass., 1964. 194. pp.

19-318. PaIva Bolf́,o, M. DE_-“Algumas tendencias e perspectivas da lingulstica moderna".-RPF, If (1964-1965), 279 346. || ZRPh, 82 (1966), 673 (Höfler); ELi, 1966, núm. 1, 4I-42 (Mattoso Câmara) : $H, 50$ (1967), 188 (Moser) .

19-319. СномsкY, NOAM-Current issues in linguistic theory.-Mouton, The $\mathrm{Ha}$ gue, 1964. 119 pp. (Janua linguarum). II $P R, 32$ (1965), 457-461 (Ohmann).

19-320. REICHLING, A.-Verzamelde studies over hedendaagse problemen der talwentenschap. [3: ed. rev. y aum.]_Zwolle, 1965. \| AGIt, 51 (1966), 80-83 (Francescato).

19-321. Degtereva, T. A.-Puti razuitiia souremennai linguistiki $[E l$ desarrollo de la lingüistica contemporánea].-Mysl, Moskva, 1964. 211 pp. \|BICC, 20 (1965), 631-696 (Montes).

19-322. WAterman, J. T.-Perspectives in lingtistics (N. 18-4.374). $\|$ QIS, 50 (I964), 82 (Hultzén); AION-L, 7 (1966), 218-226 (Romeo); $A L B, 16$ 1966), 167-171 (Szépe).

19-923. MOHRMANN, C., et al. (eds.) Trends in European and American linguistics, 1930-1960 (N. 17-219). $A S o c, 1962,525-526$ (Cohen); $A G I t$, 48 (1963), 66-74 (Ramat); RPh, 19 (I965-66), 353-360 (Uhlenbeck).

19-324. PAPp, F._ "Mathematische und strukturelle Methoden in der sowjetischen Sprachwissenschaft".. $A L B, 14$ (1964), 119-137.

19-325. POTTER, SIMEON-Modem linguistics,-Norton, New York, I964. 192 pp. (Norton library, N223) ...V. núm. 1334350. || Lan, 41 (1965), 88-91 (Waterman).

19-326. Fries, Cilarles C. - Linguistics: the study of language.-Holt, Rinehart \& Winston, New York, 1964. ix + 292 pp. $\| M L J, 49$ (1965), 376377 (Pei) .

19-327. KRATE, Hans-Lingüistica indoeuropea. Trad. cle Justo Vicuña Suberviola. 2a ed.C.S.I.C., Madrid, 1964. 165 pp. (Manuales y anejos de $E m$, 9) .-V. nưn. 9.17086.
19-328. Theban, L._-“Tratados românicos de introdução à linguística".- $R R L$, 10 (1965), 425.434.

19-329. Graur, Alexandru (ed.) -Intro. ducere în lingvistica.-Ed. Stiintifica, Bucuresti, 1965. 383 pp.-V. núm. 1646025.

19-330. PEI, MARIO-Invitation to linguistics: $A$ basic introduction to the science of language.-Doubleday, Garden City, N. Y., 1965. 266 pp. || $H, 48$ (1965), 955.956 (Barrutia); $M L J, 49$ (1965) , 464-465 (Closs); It, 43 (1966), 89-90 (Orwe11); $M L R, 61$ (1966), 656657 (Potter).

19-331. HALL, ROBERT A., JR.-Introductory linguistics.-Chilton, PhiladelphiaNew York, 1964. xiii + 508 pp. (Chilion books). \|RRL, 11 (1966), 101 . 102 (Borodina); RPh, 22 (1968-69), 174-181 (Egerod) ; $M L J, 49$ (1965) , 378383 (Pei); H, 48 (1965), 638-639 (Sa. porta); $I l, 43$ (1966), 201-202 (TWeb. ber) .

19-332. Ornstrin, JACOB, \& William $W^{7}$. GAGE-The $A B C$ 's of languages and linguistic. - Clilton Books, Philadelphia-New York, 1964. xiii + 205 pp. || IJAL, 32 (1966), 288-290 (Campbell); $M L J, 49$ (1965), 376 (Pei); Lan, 43 (1967), $551-553$ (Percival) .

19-393. Rosett1, A.-Linguistica. - Mouton, The Hague, 1965. 268 pp. (Janua linguarum, Series maior, 16). || LiS, I (1966), 419 (Heilmann); SCL, 17 (1966), 700-703 (Saramandu).

19-334. Otтo, ERnst_Stand und Aufgabe der allgemeinen Sprachwissenschaft. 2. durchges. $u$. erw. Aufl.-De Gruyter, Berlin, I965.—V. núm. 9-17061.

19-335. Saussure, Ferdinand DE - Curso de lingüistica general. $5^{\pi}$ ed.-Losada, Buenos Aires, 1965. 4.50 pp., ilustr. (Filosofia y teoria del lenguaje).-V. núm. 16-46019.

19-336. Robins, R. H.-General linguistics: $A n$ introductary surrey. - Longmans, London, 1964. xxii + $390 \mathrm{pp}$. 19-337. BALly, Cifari.es-Linguistique genérale et linguistique française. 4.e éd.l rancke, Borne, I9G: 440 pp.-V. nún. 6.7210. || I'R, 26 (1967), 382 (Hilty); Krat, 10 (1965), 97-98 (Redard).

19.338. Jenkins, F. M._- "Bally's masterpiece in critical retrospect"- $R P h, 19$ (1965-66), 58-68. [Linguistica generale $e$ linguistica francese, ed. C. Segre]. 19-339. MarTINET, ANDRE-Elements of general linguistics. Tr. hy Elisabeth 
Palmer._Univ. Press, Chicago; Faber \& Faber, London, 1964. 205 pp.-V. núm. 17-3560. || $A L B, 15$ (1965), 415417 (Austerlitz); Lan, 41 (1965), 493504 (Hall) ; BHS, 44 (1967), 144 (Hodcroft); $A U M L A, 1964$, núm. 22, 341 (Hollyman); $M L J, 49$ (1965), 377-378 (Pei); $M L R, 60$ (1965), 233-234 (Ullmann) .

19-340. MARTINet, ANDRÉ-Elementos de lingülstica general. Trad. J. Calonge-Gredos, Madrid, 1965. 274 pp. (BRH).Ү. núm. 17-3560. ||$B d F S, 1967$, núm. 19, 299-312 (Carrillo Herrera); $C D$, 179 (1966), 348 (Díez del Rfo).

19-341. MARTINET, ANDRt-Elementos de linguistica geral. Trad, e adapt. para o lector português e brasileiro por Jorge Morais Barbosa.-Sá da Costa, Lisboa, 1964. xii + 224 pp.-V. núm. 17-3560. || ELi, 2 (1967), 80-90 (Azevedo Filho).

19-342. Mattoso Câmara, J., JR.-Principios de lingülstica geral, como introdução aos estudos superiores da lingua portuguêsa. 4! ed., rev. e aum.-Livr. Acadêninica, Rio de Janeiro, 1964. 393 pp. (Biblioteca brasileira de filologia).V. núm. 16-46023.

19-343. Jakobson, Roman_Essais de linguistique générale. Trad. et préf. par Nicolas Ruwet.-Les Editions de Minuit, Paris, 1963. 260 pp. (Arguments, 14). I| $R P h, 18$ (1964-65), 376-377 (Hoijer); Rev. de Etnografie si Folclor, Bucuresti, 1] (1966), 186-192 (Niculescu); Prencves, 1964, núm. 158, 76-82 (Patri). 19-344. Hoenigswald, H. M.-Language change and linguistic reconstruction ( $N$. 16.46058) . || IJAL, 28 (1962), 69-79 Householder); ELi, 1966, núm. 2, 80-81 (Rodrigues) ; IF, 68 (1963) , 176179 (Schmidt) ...V. núm. 17.3537.

19-345. VALIN, RocH_La méthode comparative en linguistique historique et en psychomécanique du langage. - Les Presses de l'Université Laval, Québec, 1964. 57 pp. I| Lan, 42 (1966), 106108 (Contreras); $\mathrm{BHi}, 68$ (1966), 174176 (Chevalier); IJAL, 32 (1966), 410412 (Langdon); $R R L, 11$ (1966), 408. 410 (Lupas) ; SCL, 17 (1966), 602-603 (Lupas) .

19-346. LF.MMANN, W. P._-Historical linguistics (N. 18-465). || Nyelviudományi Közlemények, Budapest, 65 (1963), 241 (Fodor); ArO, 31 (1963), 684-685 (Zgusta) .

19-347. MARTINeT, ANDRÉ-La linguistique synchronique. Etudes et recherches. P.U.F., Paris, 1965. 248 pp. (Le linguiste, 1). || PhP, 9 (1966), 444-446 (Duchácek); $R P h, 20$ (1966-67) , 543-549 (García); MLR, 62 (1967), 328 (Rothwell); JJAL, 33 (1967), 178-183 (Shane) .

19-348. SOMMERFFIT, A.-Diachronic and synchronic aspects of language (N. 18467). || BSLP, 59 (1964), núm. 2, 24. 25 (Benveniste); $R P h, 21$ (1967-68), 67.75 (Lehmann); Sbornik Praci Filosofické Fakulty Brnenské Univ., Rady Jazykovedna, 13 (1964), 235.236 (Vachek); ArO, 32 (1964), 183-184 (Zgusta).

19-349. MALMBerc, BerTIL_Structural linguistics and human communication. An introduction into the mechanism of language and the methodology of linguistics. - Springer, Berlin-GöttingenHeidelberg; Academic Press, New York, 1963. 210 pp. || SCL, 15 (1964), 773775 (Avram); $M L J, 50$ (1966), 56-57 (Frink); IJAL, 32 (1966), 205-206 (Gomes de Matos) FPh, 16 (1964), 315-316 (Winkel).

19-350. JАковSоN, R. (ed.) -Structure of language and its mathematical aspects (N. 17-3535). \|IJAL, 29 (1963), 174178 (Garvin); Scripta Mathematica, New York, 26 (1963), 271 (Kattsof).V. núm. 18-488.

19-351. MARTINET, A.- "Structural variation in language".-PNCL, 521-529.

19-352. Lotman, J. M._"Sur la délimitation linguistique et littéraire de la notion de structure"._Ling, 1964, núm. 6, 59-72.

19-353. VASJLIU, E._"Contribution à la théorie du signe linguistique".-Cahiers de Linguistique Théorique et Appliquée, Bucarest, I (1962), 245-253. \| $A L B, 15$ (1965) , 418-419 (Szépe).

19-354. Dixon, RoberT M. W. What is language? $A$ new approach to linguistic description. - Longmans, London, 1965. xviii + 216 pp. (Long. mans. linguistics library). II Lan, 43 (1967), 742-751 (Langendoen); $E L i$, 1966, núm. 2, 63-66 (Lemle).

19-355. Katz, Jerrold J., \& PaUl PostalAn integrated theory of linguistic description. - M.I.T. Press, Cambridge, Mass., 1964. xi $+178 \mathrm{pp} . \| R R L$, 11 (1966), 289-293 (Golopentia-Eretescu); $P R, 32$ (1965), 457-461 (Ohmann).

19-356. Hammer, JoHn H., \& Frank A. 
RICE $A$ bibliography of contrastive linguistics._Center for Applied Linguistics, Washington, 1965. $41 \mathrm{pp}$.

19-357. Siertsema, B.-A study of glossemalics. Critical sumtey of ils funda. mental concepts. 2nd. ed.-.M. Nijlioff, Den Haag, 1965. xvi +288 pp.- V. nưm. 1 I-245I8.

19-358. Dingwall, William ORR-Transformational generative grammar: $A$ bibliography.-Center for Applied Linguistics, Washington, 1965. ix +82 pp. II $P h P, 9$ (1966), 435-436 (Pocheptsov).

19-359. BACH, EMMON-An introduction to transformational grammars.-Holt, Rinehart \& Winston, New York, 1964. || $I J A L, 31$ (1965), 265-270 (Hale); Lan, 41 (1965), 632-640 (Montgomery); Lingua, 13 (1965), 291-304 (Peng) .

19-360. LEPSCHY, G. C..."La grammatica trasformazionale. Nota introduttiva e bibliografia".-_Studi e Saggi Linguistici, 4 (1964), 87.114.

19-361. Dubois, J._-"Grammaire transformationnelle et morphologie".-FrM, 33 (1965), 81-96, 178-187.

19-362. Hankamer, Paul-Die Sprache. Ihr Begriff und ihre Deutung in 16. und 17. Jahrhundert. Ein Beitrag zu1 Frage der literarhistorischen Gliederung des Zeitraums.-Olms, Hildesheim, 1965. [Reprod. de la ed. de Bonn, 1927].

19-363. BLOOMFLED, LEONARD-Lenguaje. Probl. y bibliografía complementaria por A. Escobar.-Universidad Nacional de San Marcos, Lina, 1964. xxii + 684 pp. || $L L, 1964$, núms. 72/73, 336-338 (Ramírez); $E L i, 1966$, núm. 2, 74-75 (Rodrigues) .

19-364. Bloomfield, L.-"Language history", from "Language" (1933 edition). Ed. by H. Hoijer-Holt, Rinehart \& Winston, New York, 1965; pp. 28I512. || $R P h, 20(1966-67), 149$ (Malkicl) .

19-365. JESPERSEN, OTTO — Language: its nature, development, and origin.-WW. W. Norton, New York, 1964. 448 pp. (Language library)._V. núm. 12-32512.

19-366. Martinet, A.-A functional view of language (N. 18-4390). \|QJS, 50 (1964), 83.84. (Hultzén); BSLP, 59 (1964), núm. 2, 29 (Pottier); $I F, 69$ (1964), 47.49 (Rosenkranz); $A r O, 32$ (1964), 180.183 (Zgusta).

19-367. MARTINeT, ANDRÉLLa considera. zione funzionale del linguaggio. Trad. di G. Madonia.-II Mulino, Bologna, 1965. 228 pp.-V. núm. 18-4390.
19-368. Prieto, Luis I-¿Qué es la lingüistica funcional?-Univ. de la República, Montevideo, 1965. (Cuademos del Instituto Lingüistico Latinoamericano, 1) .

19-369. Gulllalme, Gustave_Langage $e t$ science $d u$ langage.-Les Presses de l'Université Laval, Québec; Nizet, Paris, 1965. || Etudes Anglaises, 18 (1965), 139-144 (Hirtle); $V R, 24$ (1965), 342. 344 (Wunderli)

19-370. Porzig, WaLter-El mundo maravilloso del lenguaje. Problemas, metodos y resultados de la lingülstica mo derna. Trad. A. Moralejo.-Gredos, Madrid, 1964. 508 pp. (BRH).-V. núm. 14-38129.

19-371. PEI, MARIO_Language for every. body: What it is and how to master it.-The Devin-Adair Co., New York, 1965. 362 pp.-V. núm. 11-27252. $M L J, 50$ (1966), 301-302 (Contreras); ibid., 452-454 (Gaeng) .

19-372. BuRcess, ANTHony - Language made plain.-English Universities Press, London, 1964. 186 pp. \| $M L R, 60$ (1965), 84-85 (Close).

19-373. Forster, HaNs A.-Wörter erzählen die Geschichte der Menschheit: eine Begegnung mit der Welt der Sprache.-Orell Füssli, Zürich, 1964.

19-374. PEL, Mario-Voices of man: the meaning and function of language.Allen \& Unwin, London; Harper \& Row, New York, 1964. xv + 138 pp. $R P h, 17$ (1963-64), 460-461 (Egerod); $M L R, 60$ (1965), 586 (Huddleston \& Sinclair).

19-375. PEI, MARIO-The story of langua. ge. Rev. ed.-Lippincott, New York, 1965. 491 pp.-V. núm. 5-6445. $\| M L J$, 53 (1969), 4l-43 (Fought); $M L R, 61$ (1966), 656-657 (Potter).

19-376. Girdansky, MichasL-The adventure of language.-Prentice-Hall, Englewood Cliffs, N. J., 1963. xvi + 349 pp. $\| H, 48$ (1965), 950-951 (Klein); $M L J, 47$ (1963), 392-393 (Pei).

19-377. Budacov, R. A.-Problemy razvitiia iazika [Los problemas de la evolución del lenguaje]._Izd. Nauka, Moskva, 1965. 71 pp. \| BICC, 21 (1966), 377-379 (Montes)

19-378. Potter, Simeon-El lenguaje en el mundo moderno.-Fabril Ed., Buenos Aires, 1964. 223 pp. (Libros del mira. sol)._-V. núm. 16-42097. || $C U, 1966$, núm. 93, 187-188 (B.R.G.).

19.379. UllmanN, StePHEN - Language 
and style. Collected papers,_-Blackwell, Oxford, 1964. 270 pp. || ZRPh, 82 (1966), 597-600 (Baldinger); Lan, 42 (1966) , 632.639 (Householder); IJAL, 31 (1965), 183-186 (Levin); $R R, 59$ (1968), 73 (Louria); $M L R, 60$ (1965), 83.84 (Potter); ASNS, 202 (1965), 370372 (Salmon); FS, 20 (1966), 107-109 (Sayce); $P h P, 9$ (1966), $319-320$ (Trnka).

19-380. HJeger, K._" $\mathrm{Zu}$ den Methoden und Möglichkeiten einer quantitati. ven Linguistik"._-ZRPh, 80 (1964), 327 341. $R F E, 49$ (1966), 392-393 (Llorente).

19-381. Halliday, M. A. K., Angus McIntosh, \& Peter Strevens-The linguistic sciences and language teaching.Longmans, Green \& Co., London, 1964. $\mathrm{xix}+322$ pp. $\| M L R, 62$ (1967), 106-107 (Brown); PhP, 9 (1966), 323330 (Kuncovii); RPh, 23 (1969-70), 130-1.31 (Lehmann).

19-382. POLITZER, ROBERT L.-Foreign language learning: a linguistic introduction. Prel. ed.-Prentice-Hall, Englewood Cliffs, N. J., 1965. 155 pp. $M L J, 50$ (1966), 235-236 (Gaeng); $H$, 49 (1966), 564-565 (Murguía).

19-383. LADO, ROBHRT-Language teaching, a scientific approach.-McGrawHill, New York, 1964. 239 pp. \|IJAL, 31 (1965), 170.178 (Brière); $H, 47$ (1964), 670-671 (Irving); $M L J, 48$ (1964), 176 (Kirch).

19-384. ZiERER, ERNESTO_-Instrucción pro. gramada. Su aplicación en la enseñanza y el aprendizaje de idiomas extranjeros._Univ. Nacional, Trujillo, 1964. 28 pp. || $B R P h, 1966$, núm. 1, 184. 188 (Klare).

19-385. FODOR, JERRY A., \& JERROLD J. KATZ (eds.) -The structure of lan. guage: Readings in the philosophy of language. - Prentice Hall, Englewood Cliffs, N. J., 1964. 612 pp.

19-386. Dixon, ROBERT M. W.-Linguislic science and logic.-Mouton, The Hague, 1963. 108 pp. (Janua lingua. rum, Series minor, 28) . I| $A L, 15$ (1963), 216 (Haas); Fla, 1 (1965), 75 (Kraak); Lingua, 12 (1963), 431 (Lyons); $J L$, 1 (1965), 66 (Matthews); Lan, 42 (1966), 84.93 (Postal).

19-387. Titone, Renzo-La psicolinguislica oggi._Pas Verlag, Zurigo. 1964. 313 pp. ||$B I C C, 21$ (1966), 379-400 (Páez Patiño); AGIt, 50 (1965), 83-85 (Raffler Engel).
19-388. Prieto, L. J.-Principes de noologie. Fondements de la thérie fonctionnelle du signifié. Préf. d'A. Martinet.Mouton, 's-Gravenhage, 1964. $130 \mathrm{pp}$. $\| A O, 15$ (1965), 410-416 (Neira).

19-389. Hertzler, Joyce O.-A sociology of language.-Random House, New York, 1965. xii + 559 pp.

19-390. Jespersen, OTto - Umanilà, nazione $e$ individuo dal punto di vista lin. guistico._Feltrinelli, Milano, 1965, 164 pp. (I falti e le idee. Saggi e biografie, 139).

19-391. TERRACINI, B._Lingua libera $e$ libertà linguistica (N. 18-4369). II Par, 15 (1964), 94-100 (Corti); RPh, 21 $(1967-68), 318-325$ (Uitti).

19-392. Crystal, David-Linguistics, language and religion.-Hawthorn Books, New York, 1965. 189 pp.

19-393. Carroll, John B.-Language and thought. - Prentice-Hall, Englewood Cliffs, N. J., 1964. x + 118 pp. (Foundation of modern psychology series). $I J A L, 32$ (1966), 285-288 (Anisfeld); $M L J, 49$ (1965), 384-386 (Fodor).

19-394. Vygotsky, LEV S.-Pensamiento $y$ lenguaje.Lautaro, Buenos Aires, 1964. 181 pp.-V. núm. 18-497. || BdFS, 1966, núm. 18, 303-306 (Carrillo); BICC, 20 (1965), 287-392 (Montes).

19-395. WhORF, BENJAMIN LEE-Sprache, Denken, Wirklichkeit. Beiträge zur Metalinguistik und Sprachphilosophie. Reinbek, 1963. 157 pp._-V. núm. 12. 30774. \| Deutsche Rundschau, 1964 , núm. 1, 80.82 (Höck); GGA, 217 (1965), 148.152 (Priesemann).

19-396. Henle, Paul (ed.) -Language, thought, culture.-Univ. of Michigan Press, Ann Arbor, 1965. 273 pp. (Ann Arbor paperbacks, AA97) .-V. núm. 16-42108.

19-397. HyMes, DELL (ed.)_L_Language in culture and society: $A$ reader in linguistics and anthropology.-Harper \& Row, New York, 1964.

19-398. Levin, SAMUel R. - Linguistic structures in poetry.-Mouton, The Hague, 1962. $64 \mathrm{pp.} \mathrm{(Janua} \mathrm{lingtuarum,}$ Series minor, 23). II Lan, 42 (1966), 639-649 (Hendricks).

\section{Estudios lingüísticos generales}

19-399. Proceedings of the Fifth International Congress of Phonetic Sciences, held at the University of Münster 1622 August 1964. Ed. by Eberhard Zwir- 
ner and Wolfgang Bethge.-S. Karger, Basel-New York, 1965. xxviii +631 pp., ilustr. || PhP, 10 (1967), 51-55 (Krámsky) .

19-400. BeLASCO, S., et al_"Phonetics".$A S, 40$ (1965), 218-223. [Bibliografia].

19-401. Malmberg, Bertil-La fonetica. Trad. G. G. Bès._Eudeba, Buenos Aires, 1964. 127 pp., ilustr. (Cuadernos, 107) .-V. núm. 13-34379. \|BICC, 20 (1965), 151. (Simbaqueba).

19-402. Tagliavini, C.-Elementi di fonetica generale, Ristampa riveduta.Pàtron, Bologna, 1964. 164 pp.-V. núm. 18-506.

19-403. BELARDI, W,_-Elementi di fonetica generale.-Roma, 1964. 133 pp., ilustr.

19-404. Gili Gaya, SamueL-Elementos de fonética general. $5^{\mathrm{a}}$ ed. corregida y ampliada._Gredos, Madrid, 1966. 198 pp., ilustr. (BRH, Manuales, 2) $=-V$. núm. 16-46072.

19-405. VANVIK, A.-Kort innforing $i$ fo. netikk.-Univforlaget, Oslo, 1965.

19-406. STRAKA, Georces-Album phonétique.-I.es Presses de l'Université Laval, Québec; Klincksieck, Paris, 1965. 188 pp., ilustr. || $\nabla R, 26$ (1967), 165166 (Hilty) ; $R P h, 22$ (1968-69), 3639 (Lehiste); RLiR, 29 (I965), $197-$ 198 (Simon).

19-407. HADDING-Koch, Kerstn, \& LENNART PETERSSON_Instrumentell fonelik: En handledning.-Gleerup, Lund, 1965.

19-408. Delattre, Pierre_Comparing the phonetic features of English, French, German and Spanish.-Julius Groos Verl., Heidelberg; Harrap, London, 1966. 118 pp. $\| F S, 21$ (1967), 281282 (Barnett); $M L J, 51$ (1967), 430. 431 (Valdman); RPh, 21 (1967-68), 227-228 (Zimmer) .

19-409. Delattre, P. - "Comparing the vocalic features of English, German, Spanish and French".-IRAL, 2 (1964), núms. 2, 3 .

19.410. Belard, W., e N. Minissi_Dizionario di fonologia (N. 18-514). \| $R P h$, 18 (1964-65), 377-378 (Pottier).

19-411. Chomsky, N., \& M. Halde-“'Some controversial questions in phonological theory".--JL, 1 (1965), 97-138.

19-412. Pilch, HerberT _-Phonemtheorie. I. Teil._S. Karger, Basel-New York, 1964. xiv + 153 pp. (Bibliotheca phonetica, 1). II ZRPh, 80 (1964), 365372 (Heger); $A L B, 16$ (1966) , 400-402 (Hutterer); $P h P, 8$ (1965), 425-428 Krámsky).
19-413. MoLL, H._"The relation between phonetics and phonemics as one of the aspects of the 4 th International Congress of Phonetic Sciences, Helsinki, 1961"._Ling, 1963, núm. 1, 60-74; 1964 , nưm. 7, 55-62.

19-414. Martinet, A.-La fonología como fonética funcional. Trad. J. L. Prieto.Inst, Lingüístico Latinoamericano, Montevideo, 1965. 59 pp. (Cuadernos, 2). [En mimeografo].

19-415. WeINRICH, H.- "Lois phonétiques et lois phonologiques".-CLR(10), 877 886. II CuN, 25 (1965), 156 (Menichetti)

19-416. Bonfante, Giuliano, e Maria LuiSA Porzio GERNIA_Cenni di fonética $e$ di fonemàtica, con particolare riguardo all'italiano.-_Giappichelli, Torino, 1964. 94 pp. || ZRPh, 81 (1965), 419. 4.22 (Mangold); RLiR, 29 (1965), 378380 (Plomteux) .

19-417. Buchanan, Cynthia D.- $A$ progranmed introduction to linguistics: Phonetics and phonemics.-Heatl, Boston; Harrap, London, 1964. xi + 137 pp. $\| M L J, 49$ (1965), 133-135 (Abrahans); QJS, 50 (1964), 81 (Hultzén) ; $M L R, 61$ (1966), 97 (Sinclair).

19-418. ЈавовsоN, R.-Selected writings. 1: Phonological studies (N. 18-519). I $B S L P, 59$ (1964), nưm. 2, 23-24 (Benveniste) ; Slovo, Praha, 25 (1964), 288291 (Vachek).-V. núm. 18-4400.

19-419. Straka, G.- "La division des sons du langage en voyelles et consonnes peut-elle etre justifiee?" (N. 17-3584). || $R P h, 19$ (1964-65) , 74-76 (Delattre); $R F E, 46$ (1969), 501-504 (Quilis) ; VR, 26 (1967), 119-120 (Wunderli).

19-420. StrakA, G.—“A propos de la ques tion des semi-voyelles".-ZPh, 17 (1964), $301-323$.

19-421. RosetTI, A._"Sur le problème des semi-voyelles".-RFE, 48 (1965), 181183.

I9-422. FintoFt, K.-“"Some remarks on word accents".-Plion, 13 (1965), 201 226.

19-423. ARtemov, V. A. - ["El entonema"].-Phon, 12 (1965), 129-133. [En ruso].

19-424. Bolinger, D. L... "Around the edge of language: intonation".-Harvard Educational Rev., I964, 282-296.

19-4.25. KoCH, WALTER_Zur Theorie des Lautwandels-Münster, 1963. 324 pp. [Tesis]. || $R P h, 18(1964-65), 325.328$ (Togeby) . 
19-426. HocketT, C. F.- "Sound change"_-Lan, 41 (1965), 185.204.

19-427. Guiraud, Pierre_La gramálira._Eudeba, Buenos Aires, 1964. 119 pp._-V. núm. 13-36269.

19-428. Rodríguez Adrados, F.-"Gramaticalización y desgramaticalización"$H A M, 3,5-41$.

19-429. Montes, J. J_- "Sobre la división de la gramática en morfología y sintaxis".-BICC, 18 (1963), 678-685.

19-430. Heger, K.- "Personale Deixis und grammatische Person". - ZRPh, 81 (1965), 76-97.

19-431. Сномкку, NoAM-Aspects of the theory of synlax,-M. I, T. Press, Cambriclge, 1965. x + 251 pp. $\| M L J, 51$ 110-111 (Contreras); $P R, 32$ (1965), 457-461 (Ohmann); $M L R, 63$ (1968), 132-133 (Peter).

19-432. Postal, Paul-Constituent structure: $A$ study of contemporary models of syntactic description.-Indiana Univ., Bloomington, 1964. 122 pp. (IJAL, 30). 19-433. HARTMANN, PETER-Synlax und Bedeutung. 1. Teil: Die syntaktische Bedeutungsmatrix._Assen, 1964. 272 pp. II Lan, 44 (1968), 603-604 (Bach); PhP, 11 (1968), 117-119 (Duchácek).

19-434. Сномккч, N.-Syntaclic structures (N. 13-36276). Il Language Learning, 12 (1962), 308 (Boyd \& King); $A A, \quad 61 \quad$ (1959), 160-162 (Burling); ASoc, 1962, 528-530 (Cohen)._V. núm. 17-3597.

19-435. CHOMSRY, NOAM-Syntactic structures. 4tll ed.-Mouton, The Hague, 1964. 118 pp.-V. núm. 13-36276.

19-436. HiL.Ty, G.-“Tempus, Aspekt, Modus"._VR, 24 (1965), 269-301.

19-137. BRöndaL, Vusco - Teoria delle preposizioni. Trad. di L. Beccaria.Silva, Milano, 1967.-V. núin. 6-6837. (I LiS, 3 (1968), 102-103 (Scalise).

19-438. KLUM, ARNE-Verbe et adverbeAlmqvist \& Wiksell, Uppsala, 1961. 313 pp. If NRFH, 17 (1963-64), 376377 (Lope Blanch); $R J, 16$ (1965), 200-207 (Heger); $V R, 24$ (1965), 349350 (Hilty); $A L, 15$ (1963), 247-250 (Reid) .

19-439. Hallic, R., \& W. yon WartburcBegriffssystem als Grundlnge für die Lexikographie. Versuch einer Ord. nungsschemas. 2. neu bearb. und erw. Auflage.-Akademie-Verlag, Berlin, 1963. 315 pp.-V. núm. 9-16066. \| LiS, 1 (1966), 121 (Rosiello).

19-440. Conpon, J. C._."A bibliography of general senantics".-Etc., 21 (1964), $73-100 ; 22$ (1965), 59-86.

10-441. Hayden, Donald E., \& E. Paul Alworth (eds.) _Classics in seman. tics._-Philosophical Library, New York, 1965. $\mathrm{x}+382$ pp. $\| M L J, 50$ (1966), 224-225 (R. Levin).

19-442. BREAI, MicheL_Semantics: Studies in the science of meaning. $\mathrm{Tr}$. by Mrs. H. Cust, introd. by J. Whatmough.-Dover, New York, 1964. Ixxviii +341 pp. || RLiR, 30 (1966), 223. 224 (Bourguignon); $M L R, 62$ (1967), 102-103 (Van Buren).

19-443. Ullmann, S.-Semanlics. An introduction to the science of meaning (N. 18-561). || ZRPh, 82 (1966), 675 (Baldinger); Leuvense Bijd., 51 (1962), 116-118 (Kruyskamp); IF, 68 (1963), 183-185 (Schmidt); ArO, 32 (1964), 179-180 (Zgusta) .

19-444. ULLMANN, S.-Introducción a la semántica francesa. Trad. y anot. por E. de Bustos Tovar,-C.S.I.C., Madrid, 1965. xvi + 483 pp. (RFE, publicacio. nes, 15) -V. núm. 8-10370. || ZRPh, 82 (1966), 675-676 (Baldinger).

19-445. Guiraud, Pierre-La semántica. Trad. J. A. Hasler, 2a ed.-F.C.E., México, 1965. 118 pp. (Breviarios),V. núm, 16-42179.

19-446. LEPSCHY, G. C._.'"Problems of semantics".-ling, 1965, no 15, 40-65.

19-447. ULLMANN, S. - "Synchronie et diachronie en sémantique". $-C L R(10)$, 55.70. \| CuN, 25 (1965), 150-151 (Menichetti) .

19-448. STTRN, GUSTAF - Meaning and change of meaning.-Indiana Univ. Press, Bloomington, 1964. xiii +456 pp.

19-449. Hecer, K. - “Die methodologischen Voraussetzungen von Onomasiologie und begrifflicher Gliederung"ZRPh, 80 (1964), 486-516. \|RFE, 49 (1966), 397-398 (Llorente).

19-450. Heger, K-“'Les bases méthodiologiques de l'onomasiologie et du classement par concepts".-TLL, 1965, núm. 1, 7-32. || VR, 26 (1967), 282-284 (Wunderli).

19-451. Dubois, J, L. Irugaray et P. MARCIE_- "La transformation négative et l'organisation des classes lexicales'.$C L x, 1965$, núm. 7, 3-32.

19-452. GIRARd, PiERRE-Les mots étrangers.-P.U.F., Paris, 1965. 127 pp. (Que snis-je?, 1166). ||$F S, 20$ (1966), 109 110 (Barnett). 
19.453. Gaill ne' Paratesi, Nora Semantica dell'eufemismo.-Giappichelli, Torino, 1965. 195 pp. (Publ. della Fac. di Lett. e Filos.). $\| A L B, 15$ (1965) , 428-431 (Fogarasi); RPh, 20 (1966-67), 354-357 (Hall); VR, 26 (1967), 140-143 (Huber); $A L, 17$ (1965), 44-48 (Lepschy) ; Em, 34 (1966), 166 . 167 (Monescillo) ; ASNS, 203 (1966), 364.-365 (Rohles) .

19-454. Plomteux, H.-_Tabou, pudeur et euphémisıne. Notes marginales a propos de la Semantica dell'eufemismo de Nora Galli de' Paratesi"._-Orbis, 14 (1965), 23-36.

19-455. Weinrich, H._-"Semântica da metáfora moderna"._Krit, 64 (1964), 261 282.

19-456. REY, A.-"Les dictionnaires: forme et contenu"._- $C L x, 1965$, núm. 7, $65-102$.

19.457. CoHEN, M._-"Le fait dictionnaire".-PNCL, 497-503.

19-458. Muller, C._'Dispersion et usage. A propos des dictionnaires de fréquence",-CLLx, 1965, núm. 7, 33-42.

19-459. Muleer, C._-Calcul des probabilités et calcul d'un vocabulaire" $-T L L$, 1964, núm. 1, 235-244.

19-460. Pottier, B.-“La définition sémantique dans les dictionnaires". $-T L L$, 1965, nưm. 1, 33-39. \|VR, 26 (1967). 284-285 (Wunderli) .

19-461. BaLdinger, K._ “La pesadilla de los etimólogos".-RFE, 48 (1965) , 95104.

19-462. Buck, Carl Darling-A dictionary of selected synonyms in the principal Indo-European languages. $A$ contribu. lion to the hislory of ideas.-The Univ. of Chicago Press, Clicago, 1965. xvii + $15 \mathrm{I} 5 \mathrm{pp}$.-V. núm. 5-6464.

19-463. Europäische Schlüsselwärter. Bd. 2: Kurz-Monographien, I. Hörter im geistigen und sozialen Raum.-Hucber, Miinclien, 1964. xvi +449 pp.-V. nưm. 18-575. || BHS, 44 (I967), 231 (Gifford); $Z R P h, 81$ (1965), 159-I64 (Höfler) ; VR, 23 (1964), I52.I54 (Holmér) ; $M L R, 60$ (1965), 292-293 (Keller) ; Hum, 16 (1964), 223 (Martino).

19-464. Tagliavin, Carlo_Sloria di parole pagane $e$ cristiane attraverso $i$ tempi._Morcelliana, Brescia, 1963. xx + 642 pp. || $V R, 24$ (1965), 178-180 (Aebischer); RLiR, 28 (1964), 455 (Gardette); It, 43 (1966), 202-203 (Hall) ; BICC, 20 (1965), 636-638 (Pá. ramo Pomareda); $A G I t, 51$ (1966), 83-
85 (Pisani) ; ZRPh, 81 (1965), I65-168 (Rohlfs) .

19.465. Tilander, G.-Nouveaux mélanges d'étymologie cynégétique (N. 173609) . II MAe, 33 (1964), 155-157 (Evans); HZ, I96 (1963), 163-165 (Röıtger) .

19-466. GUILBERT, LouIs-La formation $d u$ vocabulaire de l'aviation. - Larousse, Paris, 1965. 712 pp. $\| L i S, 2$ (1967), 247-248 (Arcaini).

19-467. Peytard, J-- Motivation et préfixation: remarques sur les mots construits avec I'élément téle"".-CLx, 1964, nưm. 4, 37.44.

19-468. Gipper, H._-Purpur. Weg und Leistung eines umstrittenen Farbworts",-Gl, 42 (1964), 39-69.

19-469. Wandruszka, M.-_Poésie et sonorités und das Problem der phonetischen Motivation".- $R J, 16$ (1965), 34 48. [Voces onomatopéyicas].

19-470. Bibliographia onomastica, 196I.On, 11 (1964-65), 1-168. [España, pp. 56-60; Portugal, 113-114; Amérique latine, 160-16I].-V. núm. 18-4415.

19-471. Georgncas, D. J-"The eighth International Congress of Onomastic Sciences".-Names, 12 (1964), 52-57. V. núm. 17-3612.

19-472. PoIrier, JEAN_Toponymie. Méthode d'enquéte._Les Presses de l'Université Laval, Québec, 1965. 167 pp. II Names, 14 (1966), 239-240 (Stoudemire).

19-473. Rostaing, Charles_Les noms de lieux. Nouv, éd., rev.-P.U.F., Paris, 1965. (Que sais-je?).-V. núm. 14-38212.

19.474. Rohles, G. "Antroponimia e toponomastica. Aspetti di geografia toponomastica"._ $\operatorname{CCO}(7), 3,479-488 . \longrightarrow \mathrm{r}$ '. nưm. 17-295.

19-475. Rohlfs, G._-"I Faraglioni, Els Faraiones, Les Farillons".-BALM, 196364, nưms. 5/6, 19-24.

19-476. Sмгтн, E. C._-"Bibliography of personal names".-Names, I3 (I965), 263-267.-V. núm. 18-4417.

19-477. EgGer, C.-Lexicon nominum virorum et mulierum. 2a ed.-Studium, Roma, 1964. xii + 263 pp.-V. núm. 13-36297. || Latinitas, 12 (1964), 240 (Bruno) .

19-478. Sörensen, Holger STEeN - The meaning of proper names._Gad. Copenhagen, 1963. 117 pp. \| Lan, 40 (I964), 410.412 (Bloomfield); $M L R$, 59 (1964), 437-438 (Potter); $J P h, 61$ (1964), $450-457$ (Shwayder); Names, 
14 (1966), 240 (Stoudemire); N, 49 (1965), 187.188 (Van Ek).

19-479. Afbischer, P._."A travers l'anthroponymie du haut moyen Age".$\mathrm{CCO}(7), 3,5-26$.

19-480. Eis, G.-"Rufnamen der Tiere",$N, 48$ (1964), 122-146.

19-481. Communications et rapports du Premier Congrès International de Dialectologie Générale (Louvain-Bruxelles, 1960). Publiés par A. J. Van Windekens. Parties 1-4.-Univ. Catholique, Louvain, 1964-65. || BICC, 20 (1965), 381.387 (Figueroa Lorza); ZRPh, 83 (1967) , 631-641 (Wolf) .

19-482. Companys, E_-"A propos des questionnaires dialectologiques".-_CDG (1), 1, 37-45. || ZRPh, 83 (1967), 632633 (Wolf).

19-483. Trancescato. G.-"Struttura linguistica e dialetto". $-C L R(10), 3,1011$. 1017.

19-484. Francescato, G._-"Structural comparison, diasystems, and clialectologie" [sic].ZZRPh, 81 (1965) , 484.491.

19-485. HeiluanN, L.-"Per una dielettologia strutturale". $-C D G(1), 1,94$ 103.

19-486. ScrHÜRR, F._-"Dialectologie et phonologie. Expériences d'un enquêteur".CDG(I), 3, 111-123. || ZRPh, 83 (1967), 638 (Wolf).

19-487. Fourquet, J. - "Le dialectologue devant la notion de loi phonétique".CDG(1), 3, 33-38.

19-488. Morais Barbosa, J. DE-_'De l'intérêt de la phonétique expérimentale pour la dialectologie".._CDG(1), 3, 15-24.

19-489. Kolaric, R_-"Dialekte als historische Zeugnisse"._.CDG(1), 2, 105 109.

19-490. Sa porta, S.-."Ordered rules, dialect differences, and historical processes".-Lan, 41 (1965), 218-224.

19-491. Malkiez, Y. - "Some diachronic implications of fluid spech communities".- $A A, 66$ (1964), núm. 6, 177 186.

19-492. McDavid, R. I., JR,-"The dialectology of an urban society".-CDG(I), $1,68-80$.

19.493. Maxovsk1J, M. M.-."Interaction of areal slang variants and thcir correlation with standard language".Ling, 1964, núm. 7, 42-54.

19-494. Guxhmans, M.-."Langue littéraire et dialecte",_C $C D \mathrm{G}(1), 1,286-295$. 19-495. Hutterer, Cinus_La geografía lingüística y la dialectologia.-Instituto Lingüfstico Latinoamericano, Montevideo, 1965.48 pp. (Cundernos, 10). [En mimedgrafo].

19-496. Ayasenov, R. I. (ed.) --Voprosy teorii lingvisticheskoj geografii._Akad. Nauk, Moskva, 1962. 250 pp. \|IJAL, 32 (1966), 201-204 (Ivic).

19-497. GU1TER, H.-"Géographie linguistique et biogéographie". - $R L R, 76$ (1964), 1-37. || BICC, 2] (1966), 226 227 (Zuluaga Ospina).

19-498. Hall, ROBERT A., JR.-Pidgin and Creole languages._Cornell Univ. Press, Ithaca, N. Y., 1966. xv + 188 pp. II Orbis, 15 (1966), 319.325 (Bosteels); $R P h, 23$ (1969-70), 104-110 (Kaufman); $M L J, 51$ (1967), 317-318 (Keiler); $N$, 52 (1968), 110-111 (Siertsema); Lan, 43 (1967), 817-824 (Taylor).

19-499. Whiniom, K.- "The origin of the European-based Creoles and Pidgins".Orbis, 14 (1965), 509-527.

\section{LATIN}

19-500. Herrero Llorf.NTE, Víctor JoséIntroducción al estuclio de la filologia latina.-Gredos, Madrid, 1965. $388 \mathrm{pp}$. (Bibl. universitaria Gredos, I) \| HuNL, 8 (1967), 712-715 (Ayala).

19-501. LeumanN, M.-“Lateinische Lautund Formenlehre 1955-1962", $-G l, 42$ (1964) , 69-120.—V. núm. 14-38229.

19-502. Allen, W. SydNEY_-Vox latina: a guide to the pronunciation of classial Latin.-Univ. Press, Cambridge, 1965. xi + 112 pp. || Lan, 42 (196i), 664-669 (Wyatt).

19-503. Pisani, V.-Grammatica latina sto. rica e comparativa, 3: ed. (N. 11-27319). || Lat, 23 (1964), 143 (Loicq).

19-504. FontÁn, A-"Historia y sistemas de los demostrativos latinos".-Em, 33 (1965), 71-107.

19-505. PERROT, J.-Les dérivés latins en "-men" et "-mentum" (N. 17-362I). II $C R, 14$ (1964), 63-65 (Jones); $R H E$, 59 (1964), 297-299 (Mallet); $A J, 85$ (1964), 206-209 (Poultney).-V. núm. $18-602$.

19-506. Fratnkel, G.-"The decline of Latin as a model for linguistic analy. sis".-PNCL, 730-737.

19.507. Bassols de Climent, MarianoSintaxis latina. Reimpresión.-C.S.I.C., Madrid, 1963. 2 ts.: xviii + 417. xiii + 469 pp. (Enciclopedia clásica, 3).-V. núm. 13-36309. || $A r b, 57$ (1964), 601. 
602 (Bravo Lozano); $R R L$, I1 (1966), 410.414 (Nichita).

19-508. Oudot, J.-Syntaxe latine. Préf. de

J. Collart.-Fac. des Lettres, Strasbourg, 1964. $625 \mathrm{pp}$. (Initiation, méthodes, 14). || MHe, 21 (1964) , 247 (Béranger); Lat, 23 (1964), 864-866 (François); REL, 42 (1964), 655-658 (Ruch); EtC, 32 (1964), 304 (Van Ooteghem).

19-509. Hofmann, J. B., \& A. SzantyrLateinische Syntax und Stilistik. 3. Lief.-Bech, München, 1965. xcvii + pp. 843-935 + pp. 1*89*. || LiS, I (I966), 255-256 (Calboli) .

19-510. DAHLÉN, ERTC-Etudes syntaxiques sur les pronoms réfléchis pléonastiques en latin.-Almqvist \& Wiksell, Stockholm-Göteborg-Uppsala, 1964. 206 pp. (Studia Graeca et Latina Gothoburgensia, 19). $\mid$ Era, 18 (1966), 16-20 (Pachoud) .

19-511. Thesaurus linguae Latinae. VII, 1, 15: interpello-intervulsus.-Teubner, Leipzig, 1964; cols. 2241-2304.-V. núm. 18-606.

19-512. MonteIL, P.-Beau' et 'laid' en latin. Etude de vocabulaire-Klincksieck, Paris, 1964. 374 pp. (Etudes ct commentaires, 54). || Em, 33 (1965), 404-405 (Ecliave-Sustaeta).

19-513. MikкoLA, ErNo_-Die Abstrahtion im Lateinischen. Eine semantisch-morphologische Untersuchung. I. Teil.Annales Acad. Scientiarum Fennicae, Helsinki, 1964. 232 pp. $\| R P F$, I3 (1964-65), 403-405 (Rocha Pereira).

\section{Latín vulgar y medieval}

19-514. Camargo, M. A. De-"Quelques réflexions sur l'état actuel des études du latin vulgaire".-BJR, 1964, núm. 10, 14-22.

19-515. ILIESCU, M.-"Lucrari recente de latina vulgara". $S C L, 16$ (1965), 549 . 554 .

19-516. VÄ̈NÄNEN, VE1кKо-Introduction au latin vulgaire. - Centre de Philologic, Strasbourg, 1963; C. Klincksieck, Paris, 1964. 229 pp. I| RJ, 16 (1965), I82185 (Dlaz y Diaz) ; $N, 50$ (1966), 156 (EngeIs) ; RRL, 9 (1964), 559-564 (Iliescu); SCL, 16 (1965) , 549-554 (Iliescu); Ro, 86 (1965), 268-270 (Lecoy); SiN, 36 (1964)， 382-387 (Löfstedt); $R E L$, 42 (1964), 529 (Marouzeau); Lat, 23 (1964), 867-870 (Nuclielmans) ; $R F, 77$ (1965) , 386-399 (Reichenkron) ; RBPH, 42 (1964), 1106-1107 (Rocher); Gn, 36
(1964) , 724-725 (Sofer) ; REA, G6 (1964), 461.462 (Thomas).

19-517. HaAdsma, R. A., et J. Nuchel. MANS-Précis de latin vulgaire (N. 184435) - || RPh, 19 (1965-66) , 82-84 (Corbett); $N, 49$ (1965), 353 (Engels); BHS, 44 (1967) , 231 (Gifford) ; SCL, 16 (1965) , 549-554 (Iliescu) ; Ro, 86 (1965), 140 (Lecoy) ; RRo, 3 (1968), 90-93 (OIsen) ; $R F, 77$ (1965) , 382-386 (Reichenkron); $Z R P h, 82$ (1.966), 359-365 (Rothe) .

19-518. VÄ̈NV̈̈NEN, V. - "Considérations sur l'unité du latin vulgaire"-_ $C D G(1)$, $3, \quad 267-272$.

19-519. Uddholm, ALF-Marculfi formularum libri duo. [Ed., trad. francesa y notas].-Eranos Förlag, Uppsala, 1962. 363 pp. || $R P h, 18$ (1964-65) , 335-337 (Sandmann).

19-520. DíAz Y DíAz, M.-Antologia del latin vulgar (N. 18-615). \| RFL, 7 (1963) , 287-289 (Teres Casta).-V. nủm. $18-4440$.

19-521. Kolr, H. G.-_"Zur Stellung des Verbs im spätantiken und frühmittelalterlichen Latein".-MJ, 2 (1965), 241 . 272.

19-522. LUCK, GEORG-Über einige Interjehtionen der lateinischen Umgangssprache.-Winter, Heidelberg, 1964. 88 pp. || $Z R P h, 82$ (1966), 202-205 (Beckmann) ; RF, 77 (1965), 153-156 (Prinmer).

19-523. Mohrmann, Christune Etudes sur le latin des chrdtiens. T. 3: Latin chrétien et liturgique.-Ed. di Storia c Letteratura, Roma, 1965. 458 pp.--V. núm. 17-3632.

19-524. MaGuire, Martin R. P.-Introduction to medieval Latin studies: $A$ syllabus and bibliographical guide.-Ca. tholic Univ. of America Press, Wash. ington, 1964. || $S p, 40$ (1965), 525-526 (Holmes) .

19.525. LANGosch, KARL-Laleinisches Mittelalter. Einleitung in Sprache und Literatur. - Wissenschaftliche Buchgeselischaft, Darmstadt, 1963. 96 pp. II Sp, 39 (1964) , 545-547 (Colker) ; CCM, 7 (I964), 194-195 (Hélin); Lat, 23 (1964), 893 (Huygens); Zeitschrift für Rechtsgeschichte, 81 (1964), 501 (Lange) ; $N, 50$ (1966) , 156-I57 (Minis).

19-526. WALTHER, HANS-Proverbia sententiaeque latinitatis medii aevi. Lateinische Sprichwörter und Sentenzen des Mittelalters in alphabetischer Anordnung. 2.-Yandenhoeck-Ruprecht, Göt- 
lingen, 1964. 1030 pp. (Carmina medii aevi posterioris latina, 2/2) ..V. núm. 18-4446.

19-527. PrINZ, O., et al.-Miltellateinisches Wörterbuch, Lief. 5-6 (N. 18-628). || Germanistik, 1 (1960), 15-16 (Brunhölal) ; Studi Clasice, Bucuresti, 7 (1965), 477.478 (Ceausescu); CC, 113 (1961), 564-567 (Ferrua); Helm, 15 (1964), 292 (Jiménez Delgado) ; $D L Z, 82$ (1961), $19-25$ (Plezia); Zeszjty Nauk. KatolUniu'. Lubelshiego, 8 (1965), 80-82 (Stiawecka) .

19-528. LАтнАM, R. E.-Revised medieval Latin word-list from British and Irish sources,_-Oxford University Press, London, 1965. xxiii + $524 \mathrm{pp}$. $\| M L R$, 62 (1967), 716-717 (Reynolds).

19-529. Plezia, M-Lexicon mediae et infimae latinitatis Polonorum. T. 2, fasc. 8: Consuetudo-conventor._-Polska Akad. Nauk, Wrocláw-Warszawa, 1965. 142 pp.-_V. núm. 18-4452.

19-530. Hubschmo, J._"Mlat. rocca 'Fels' aus lat. "rupica?" (N. 17-3645) . $\mid R F E$, 48 (1965), 218-219 (Llorente).

19-531. LöFstedT, B. - "Zur Lexikographie der mittellateinischen Urkunden Spaniens".-Sep. de $A L M A, 29$ (1959); 89 pp. || ZRPh, 79 (1963), 641-642 (Ba]dinger) .

15-532. LANGE, Wolf-Dieter - Philologischen Studien zur Latinität westhisponi. scher Privaturkunden des 9.-12. Jahrhunderts. [Tesis, Univ. de Colonia, 1965].

19-533. Casado Fuente, Genadio-Estudios sobre el latin medieval español. El abad Samsón.-Fac. de Filosolía y Letras, Madrid, 1965. 34 pp. [Extracto de tesis].

19-534. PEREIRA, M._-'O latim de alguns documentos da Sé de Coimbra (1086. 1210) ".-RPH, 6 (1955), 349-382.

19-535. Glossarium mediae latinitatis Cataloniae. Fasc. 3: bene-captiuus_C.S.I.C., Barcelona, 1963; cols. 257-384_-V. núm. 17-3643. || $A F A, 14 / 15$ (1963-64), 369370 (Alvar); $A S T, 36$ (1963), 393 (Vives).

19-536. Bastardas Parera, J.-_"Mots fantasmes en el llat 1 medieval de Catalunya". $-E R, 8$ (1961), I-8.

\section{LINGนYSTICA ROMÁNICA}

19-537. BAHNER, W.-Kurze Bibliographie für das Studium der romanischen Sprachwissenschaft (N. 18-632). || SCL, 16 (1965), 431-433 (Sanclru).
19-538. BoNi, M._-“Il Xe Congrès international de linguistique et philologie romanes"-Conv, 30 (1962), 507-508.

19-539. Actes du Xe Congrès Internatio. nal de Linguistique et Philologie Romanes, Strasbourg, 1962. Publiés par G. Straka_Klincksieck, Paris, 1965. 3 ts.: $x x i i i$ + $1405 \mathrm{pp},-\mathrm{V}$. núm. 18 636. || $V R, 26$ (1967), 154-155 (Hilty); CuN, 25 (1965), 149-159 (Menichetti); $A O, 15$ (1965), 380-409 (Neira); FS, 20 (1966), 435-436 (Ullmann).

19-540. [Conferencia coordinada para el estudio comparativo y tipologico de las lenguas romances. Resumenes de los in. formes y las comunicaciones, junio 23 . 27].-Academia de Ciencias, Instituto de Lingǘstica, Leningrado, 1964. 98 pp. [En ruso]. $\| R P h, 19$ (1965-66), 606-613 (Vihman).

19-541. Mélanges de linguistique romane et de philologie médiévale offerts d $M$. Maurice Delbouille. Publiés par J. Renson et M. Tyssens,-Duculot, Gembloux, 1964. 2 ts.: 713,769 pp. || ZRPh, 83 (1967), 644-656 (Baldinger); $M A$, 72 (1966), 181-182 (Bossuat); $M L R, 61$ (1966) , 128-129 (Diverres); $N, 48$ (1964), 341-344 (Engels); FS, 19 (1965), 175 176 (Ewerl); ZRPh, 83 (1967), 656659 (Mölk); $M P h, 63$ (1965-66), 380-381 Pei); $l^{\prime} R, 25$ (1966), 289-296 (Stefenelli) .

19-542. Weltoffene Romanistik. Festschrift Aluin Kuhn zum 60. Geburtstag. Hrsg. von G. Plangg und E. Tiefenthaler.-Innsbruck, 1963,329 pp. ||$R J, 16$ (1965), 169-177 (Kröll) ; ZRPh, 82 (1966), 624.637 (Rothe); VR, 26 (1967), 110. 117 (Scluorta).

19-543. RugGier, RugGero M.-Romanlicismo e filologia romanza ieri e oggi. Prolusione dell'Anno Accademico 1963. 64. - Istituto Universitario pereggiato di Magistero Maria SS. Assunta, Roma, 1963. $32 \mathrm{pp}$.

19-544. Gossen, C. T__ “Les études de linguistique romane en Autriche depuis 1945".-_CDG(1), 4, 134-143.

19-545. Niculescu, A. - "Travaux roumains de linguistique romane".- $R R L$, 10 (1965) . 21-30.

19-546. HoNsA, V._"Romance linguistic studies at major universities in the United States"._CDG(1), 4, 157-161. 19-547. Charbonneau, R._."Rapport sur la linguistique romane au Canada".CDG(1), 4, 85-89.

19-548. IORDAN, I._"Probleme generale ale 
lingvisticii romanice".-SCL, 17 (1965), $3 \cdot 12$.

19.549. Hall, Robert A., JR.-Idealism iq Romance linguistics. - Cornell Univ. Press, Ithaca, N. Y., 1969. I09 pp. II AGIt, 49 (1964), 173-176 (Beccaria); $L N, 25$ (1964), 26 (Devoto); $A L, 17$ (1965) , 40-42 (Fox) ; ZRPh, 80 (1964), 363-364 (Heger) ; RR, 56 (1965), 50-52 (Pei) ; FS, 19 (1965) , 93-94 (Reid) ; RJ, 18 (1967), 123-124 (Stempel); IJAL, 30 (1964), 440-441 (Togeby); $I t_{3} 42$ (1965), 310-311 (Weingartner).

19-550. Posner, R.-“Positivism in historical linguistics".- $R P h, 20$ (1966.67), 321-331. [Sobre R. A. Hall, Idealism in Romance linguistics].

19-551. SEeL, OTTO_Römertum und Latinität.-Ernst Klett Verlag, Stuttgart, 1964. 618 pp. || $2 R P h, 82$ (1966), 194197 (Löfstedt).

19-552. ROHR, RUPPRECHT_Einführung in das Studium der Romanistik. - E. Schmidt, Bielefeld, 1964. 186 pp. || VR, 26 (1967), 383-384 (Colón).

19-559. IORDAN, IORGU, \& MARIA MANOLIU-Introducere in lingvistica romanica.-Ed. Didactica si Pedagogica, Bucuresti, 1965. 296 pp. || Cronica, Iasi, 1966, núm. 8 (Giosu); SCL, 17 (1966), 593-596 . (Goga); RRL, 12 (1967), 61-63 (Mihaescu) .

19-554. Auerbach, ERICH - Introduzione alla filologia romanza.-Einaudi, Torino, 1963. 309 pp. (Piccola bibl. Einau. di, 29).-V. núm. 18-651. \| HuNL, 7 (1966) , 529 (Guerra Castellanos) ; StM, 4 (1963), 377-378 (Stussi).

19-555. Tagliavini, Carlo. - Le origini delle lingue neolatine. Introduzione alla filologia romanza. 4? ed.-Pàtron, Bologna, 1964. xxxiv + 602 pp.-V. núm. 16-46254. $\mid A p L, 1965$, núm. 29 (Segre) ; BILE, 1964/65, núm. 7, 116-122 (Siccardo) .

19-556. Reichenkron, GüNter - Historische latein-altromanische Grammatik. Bd. 1: Einleitung: Das sogenannte Vulgärlatein und das Wesen der Romanisierung.-Otto Harrassowitz, Wiesbaden, 1965. xiv + 408 pp. $\| N$, 51 (1967), 74 (Engels); $R R L, 12$ (1967), 165-167 (Mihaescu); Lan, 43 (1967), 969-974 (Pulgram); RF, 78 (1966), 423.426 (Schürr), RJ, 18 (1967), 125-126 (Väänänen) .

19-557. Avalle, D'Arco Silvio-Protosto. ria delle lingue romanze.-Giappichelli, Torino, 1965. 498 pp.
19-558. JABERG, KARI_Sprachwissenschaftliche Eorschungen und Erlebnise. Neue Folge. Hgs. von S. Heinimann-Francke, Bern, 1965. 330 pp. (RHe, 75). II ZRPh, 82 (1966), 601-605 (Baldinger); RLiR, 29 (1965) , 364-365 (Gardecte); ASNS, 202 (1965), 447-452 (Meier); Orbis, 16 (1967) , 580-583 (Plomteux); $R F, 78$ (1966) , 420-423 (Schürr) ; AGIt, 50 (1965), 190-192 (Terracini); SCL, 17 (1966), 369-365 (Vintila); Era, 17 (1965) , 603-607 (Yarrill) .

19-559. Hubschmid, J.-Thesaurus. praeromanicus, Fasc. 1 (N. 18-4477) . $\| R L i R$, 31 (1967), 213-220 (Alessio); $Z R P h$, 83 (1967), 599-602 (Bambeck); LiS, 1 (1966), 124 (Heilmann); $R P h, 20$ (I966-67), 531-537 (Szemerényi) .

19-560. Maniet, A.- "Le substrat celtique dans les langues romanes. Les problèmes et la méthode".- $T L L, 1$ (1963), 195-200. || RPh, 19 (1965-66), 81 (Delattre).

19-561. Malisied, Y.-Diachronic hypercharacterization in Romance (N. 14. 40044). \|IF, 69 (1964), 81.84 (Stimm).V. núm. 16-46266.

19-562. LüDTKE, H.-"Le vie di comùnicazione dell'impero romano e la formazione dei dialetti romanzi".-CLR (10), 2, 1103-1109. || CuN, 25 (1965), 157-158 (Menichetti).

19-563. Coseriu, E.-." "Critique de la glottochronologie appliquée aux langucs romanes".-CLR(10), 87-96. \|CuN, 25 (1965), 15 I (Menichetti) .

19-564. VILDÉ LoT, I.- “Académie des Sciences de l'U.R.S.S. Conférence de liaison pour l'etude comparative et ty. pologique des langues romanes".RLiR, 29 (1965) , 384-387.

19-565. TudoricA, O.-_"Quelques parallèles phraséologiques roumano-cspagnols".--BSR, 2 (1965), 21. [Resumen].

19-566. Baldinger, K., et al._Les anciens textes romans non littéraires: leur ap. port à la connaissance de la langue au moyen age. (Colloque de Strasbourg).Klincksicck, Paris, 1963. 320 pp.

19-567. IORDAN, IORGU (cd.).-Crestomatie romanica. 'T. 2: Ss. xvii-xviii.—Academia Repulslicii Populare Romîne, Bucuresti, 1965. 1211 pp.-V. núm. 18 . 4482. I| Steaua, 10 (1965), 111-112 (Antonescu) .

19-568. POtTIER, BenNARD-Textes médiévaux français et romans, des gloses la. tines a la fin $d u$ xue sičcle.-Klincksieck, Paris, 1965. 197 pp. (Bibliothdque fran- 
çaise el romane, D-1). $\mid Z R P h, 80$ (1964), 526-527 (Baldinger); CCM, 10 (1967), 490-491 (Cantel); $R P h, 19$ (1965. 66), 139-140 (Nichols Jr.); $V R, 25$ (1966), 341 (Rychner); $R J, 16$ (1965), 207-209 (Tavani) .

19-569. Wunderli, P._._Die ältesen romanischen Texte unter dem Gesichtswinkel von Protokoll und Vorlesen".$V R, 24$ (1965) , 44-63.

19-570. Sabatin], F._"Esigenze di realismo e dislocazione morfologica in testi preromanzi".-RCCM, 7 (1965), 972. 998.

19-571. LÜDTKE, H._-"Die lateinische Endungen $-u m /-i m /-u n t$ und ihre romanische Ergebnisse".-HAR, 487-499.

19-572. DARDEL, R. DE-Recherches sur de genre roman des substantifs. de la troisième déclinaison.-Droz, Genève, 1965. 107 pp. (Publications romanes et françaises, 85). || ZRPh, 84 (1968), 128130 (Glasser); $R R L, 11$ (1966), 295300 (Iliescu) ; RF, 78 (1966), 148-152 (Woln).

19-573. HALL, R. R., JR._-"The eneuter in Romance: A pseudo-problem".Word, 21 (1965) , 421-427.

19-574. HASSEIROTH, B.-Etudes sur la formation diminutive dans les langues romanes (N. 13-3635l). \|RPh, 19 (1965-66) , 287-310 (Craddock); $B z N$, 2 (1967), 199-200 (Keller)._i'. núm. 16.46278 .

15.575. Levy, A. K.- "Contrastive development in Hispano-Romance of borrowed Gallo-Romance suffixes". - $R P h, 18$ (1964-65) , 399.429.

19-576. Manoliu, M.- "Innovations dans la structure du groupe nominal roman"._RRL, 10 (1965), 299-307.

19-577. KoEN]c, F_-"The affective and expressive values of verb-complement compounds in Romance".-Essays... A. H. Schulz (Columbus, 1964), 81-99.

19-578. HeinimanN, S. 'Die Lehre vom Artikel in den romanischen Sprachen von der mittelalterlichen Grammatik zur modernen Sprachwissenschaft". VR, 24 (1965) , 23-43.

19.579. Manol.IU, M.-"Asupra pronumelor semiindependente romanice". $H A R, 523-527$.

19-580. HOWEY, GERD-Das "ego"-"hic""nunc"- System der subjektiven Orien. lierung, dargestellt am Gebrauch der Demonslrativa in der romanischen Spra. chen, im Deutschen und Englischen.[Tesis, Univ. de Tübingen, 1965'].
19-581. MEIER, H.-"Futuro y futuridad".- $R F E, 48$ (1965), 61.77.

19-582. Mattoso CÂmara, J.-"Une catégorie verbale: le futur du passé".$P N C L$, p. 63. [Sobre cantaria].

19-583. ЈАСК. W.-Sludien zu den Zeitadverb-Reihen "gestern-vorgestern-torvorgestern"... in den romanischen Sprachen (N. 16-42387). || ZRPh, 80 (1964), 142-147 (Glasser); $R F, 77$ (1965), 130.131 (Gossen) ; $R P h, 19$ (1965-66) , 613-615 (Lloyd); $V R, 25$ (1966), 168-170 (Nj. culescu); $R J, 17$ (1966), 180-181 (Rohr).

19-584. Pottier, B.-Systématique des éléments de relation (N. 18-666). $\|$ FrM, 32 (1964), 217-225 (Arrivé); ASNS, 202 (1965), 393-396 (Christmann); $B H S, 43$ (1966), 214.216 (Hodcroft); Word, 20 (1964), 270-278 (Kock) ; $N$, 48 (1964), 259-261 (Kukenheim); $R J$, 16 (1965), 187-190 (Rothe); RF, 76 (1964), 218.225 (Sandmann).

19-585. Herman, József-La formation du systeme roman des conjonctions de subordination.-Akademie-Verlag, Berlin, 1963. 274 pp. || ZRPh, 82 (1966), 205209 (Beckmann); RLiR, 30 (1966), 227-228 (Bourguignon); ASNS, 200 (1963) , 306-310 (Meier) .

19-586. RAMSDEN, H.-Weak-pronoun position in the early Romance languages.University Press, Manchester, 1963. viii +195 pp. (Publications of the Faculty of Arts, 14). \|ZRPh, 82 (1966), 209213 (Beckmann); RLiR, 27 (1963), 495-496 (Bourguignon); VR, 24 (1965), 136-138 (Burger); ASNS, 202 (1965), 304-309 (Lawton); $R J, 15$ (1964), 209 210 (Meier); Lan, 40 (1964), 275282 (Montgomery); $R F, 77$ (1965), 156-157 (Müller); $B H S, 41$ (1964), 249-250 (Pottier); $M L R, 62$ (1967), $720-721$ (Spence); $R P h, 18$ (1964-65), 459-461 (Togeby); StN, 36 (1964), 160 . 165 (Ulleland).

19-587. BeckmanN, Gustav Adolf-Die Nachfolgekonstruktionen des instrumentalen Ablativs im Spätlatein und im Französischen.-M. Niemeyer, Tübingen, 1963, vi + 291 pp. (Beih.z. ZRPh, 106).-V. núm. 17-319. \| $R P h, 20$ (1966-67), 540-542 (Szemerényi).

19-588. Sabrsula, J.-"Contribution aux problèmes de méthode de la recherche dans le domaine de l'aspect verbal (langues romanes)".-CI.R(10), 157.173.

19-589. DuchÁcER, O., \& R. OSTRA-"Étude comparative d'un champ concep[uc]",-Eludes Romanes de Brno, 1 
(1965), 107-169. ['Belleza' en español. francés, italiano y rumano]. $\| R R L$, 11 (I966), 420-421 (Sandru).

19-590. OsrRA, R.-.Étude comparative des champs conceptuels dans les langues romanes".-Etudes Romanes de Brno, 2 (1966) , 23-33. ['Belleza' y 'trabajo']. || $Z R P h, 82$ (1966), 647-648 (Baldinger).

19-591. Vinos, B. E.-Prestito, espansio. ne $e$ migrazione dei termini tecnici nelle lingue romanze e non romanze. Problemi, melodo e risullati.-Olschki, Firenze, 1965. 423 pp. (Bibl. dell'Archivum Romanicum). || BALM, 7 (1965), 115-116 (Cortelazzo); RLiR, 30 (1966). 218-219 (Pellegrini); ASNS, 203 (1966), 203-204 (Rohlfs).

19-592. Pellegrini, G. B. - "L'elemento arabo nelle lingue neolatine, con particolare riguardo all'Italia".-[En] $\mathrm{L}^{\prime} O \mathrm{C}^{-}$ cidente $e$ l'islam nell'alto medioevo (Spoleto, 1965) , 2, 697-744, 833-843. 19-599. MeIER, H. - "I ateinisch-Romanisches 3"..-RJ, 16 (I965), 243-256. [Sobre buscar, emboscada, res, remolino, etc.].-V. núm. 16-46294.

19-594. Petkanov, I.-“Altri elementi slavi nelle lingue romanze (fino al sec. xvI)". - Annuaire de l'Universite de Sofia, Faculté philologique, 59 (1965), 431499. || Orbis, 15 (1966) , 575.581 (Plomteux).

19-595. Roth, WOLfGANG-Beiträge zur Formenbildung von lat. "esse" im Romanischen.-Romanisches Seminar der Universität, Bonn, 1965. $345 \mathrm{pp}-\mathrm{V}$. núm. 18-680. || $R J, 17$ (1966), 178-180 (Niederehe); Lan, 44 (1968), 120-129 (Politzer).

19-596. Escudero, G., \& D. Copceag-"Les verbes qui signifient 'être' en espagnol et en roumain".-BSR, 2 (1965), 17-18. [Resumen].

19-597. WANDRUSZKA, M.- "Stare in der romanischen Sprachen". - $Z R P h, 81$ (1965) , 423-440.

19-598. GLASSER, RichaRD_ "Sich finden" in den romanischen Sprachen.-V. KIostermann, Frankfurt/M., 1964. 304 pp. (Analecla romanica, 15). \|ASNS, 203 (1966), $311-313$ (Sandmann) .

19-599. Hempel, W._-"Zur Geschichte von spivitus, mens und ingenium in den romanischen Sprachen".- $-R J$, Io (1965), 21.33.

19-600. ReNson, JEAN-Les dénominalions du visage en français et dans les autres langues romanes. Étude sémantique et
onomasiologique.-Les Belles Lettres, Paris, 1962. 2 ts.: 423,738 pp. (Bibliotheque de la Faculté de Philosophie et Lettres de l'Université de Liège, 162). II StL, 20 (1966), 57-64 (Andersson); $M L R, 69$ (1968), 700-70I (Diverres); $N, 49$ (1965) , 265-266 (Engels) ; FS, 19 (1965), 325.327 (Ewert); RLiR, 28 (1964)， 455-456 (Gardette); VR, 25 (1966), 302-303 (Gossen); $R P h, 21$ (1967-68) , 391.335 (Guiraud) ; $R P F, 13$ (1964-65) , 518-525 (Kröll) ; ASNS, 202 (1965), 222-225 (Meier).

19-601. Doblin, Helga B.-Designations of stringed instruments in Romance languages. - [Tesis, Harvard Univ., 1965].

19-602. ILIEscu, M.-“"Haustiernamen in den romanischen Sprachen",- $R L i, 7$ (1962), 101-120._. V. núm. 17-410.

19-603. HARRIS, M. R.-"The semantic prehistory of the Romance progeny of Latin auunculus-amita"-RNo, 7 (I965), 95-100.

19-604. HaAns, O.-"Danser und baller. Der Tanz als Gottes Lob und Dank".Orbis, 13 (1964), 598-603.

19-605. WOLL, D.-“Zur Diskussion über lat. gallicus, aequalicare und varicare im Romanischen"-_RJ, 16 (1965), 257273.

19-606. Bork, HANs DleTER - Die Familie von lat. "quatere" im Romanischen.[Tesis, Univ. de Bonn, 1964].

19-607. MFIER, H._-"Frz. regretter, span.port. gritar".-ASNS, 202 (1965), 266269.

19-608. BALDINGER, K.-“"Die Reseda im Spielfeld der Linguistik".-FHH, 41-46. 19-609. LüDTKE, H., und G. ColóN-“"Die Et ymologie von fr. son 'Kleie' ".- $V R$, 23 (1964), 69-84. [Cat. segó, etc.].

19.610. Rohl.s, G.- "Aspects et problèmes de geographie linguistique romane".-CLR(10), I3-32. \|CuN, 25 (1965) , 150 (Menichetti) .

19-611. GRAD, A.- "Importance de quelques toponymes slovènes pour la géographie linguistique romane".- $C L R$ (10), 1177-1184.

19-612. KAHANE, R., et al.-.The lingua franca in the Levant (N. 14-40095). || Byzantinoslavica, 24 (1963), 127-130 (Dujcev) ._V. núm. 18-704.

19-619. KRÜGER, F.-El mobiliario popular en los paises románicos (N. 18. 4505). II $Z R P h, 82$ (1966), 200-202 (Karlinger) ; $B R P h, 1966$, núm. 1, 180184 (Klare). 


\section{LINGÜISTICA HISPANICA}

19-614. Enciclopedia lingüistica hispánica (ELH), t. 1 (N. 16-42447). \|HuT, 11 (1963), 240-241 (Camarero); Ro, 83 (1962), 134 (Pottier)..V. núm. 18. 708.

19-615. El Simposio de Carlagena (agosto de 1963). Informes y comninicaciones.Inst. Caro y Cuervo, Bogotá, 1965. lix + 377 pp. || ZRPh, 82 (1966), 623-624 (Baldinger) .

19-616. RosARIo, R. DEL_“"Enseñanza e investigación lingüística en el Caribe hispánico"_-SCIC, 3-11.

19-617. Dubsкy, J.—“Apuntes sobre la lingüística en Cuba".- $P h P, 7$ (1964), 194-196.

19-618, Romero Castillo, M...'“Ense. ñanza de lenguas e investigación lingïfstica en] México y América central"._SCIC, 15-34.

19-619. PAtiÑo Roselli, C._-'La Jingüística y la enseñanza de los idiomas modernos en Colombia y Venezuela". SCIC, 35-68.

19-620. Escobar, A._- Informe sobre [lingüística y enseñanza de lenguas en] el Perú". $-S C I C, 69-81$.

19-621. Rabanales, A.-_Pasado y presente de la investigación lingüística $y$ filológica en Chile".-BdFS, 16 (1964), 121-143.

19-622. Carrillo Herrera, G.-"[Lingüística y ensefianza de lenguas en] Chile".-_SCIC, 163-181.

19-623. SUÁREZ, J. A.-“Informe general sobre el estado actual de la lingüística y de la enseñanza de lenguas modernas en Argentina, Paraguay y Uruguay".SCIC, 119-162.

19-624. Paiva BolÉo, M. DE-"O estudo das relações mútuas do português $e$ do espanhol na Europa e na América, e influência destas línguas em territórios da Africa e da Asia"._Liçốes de linguistica portuguesa, 2a parte (Coim. bra, 1965), 61 pp.

19-625. Cruset, J.- "Menéndez Pirlal. un romanista universal".-[ [En su libro] Personajes definitivos (Barcelona, 1964). || SLS, 473-478 (Romano Colangeli).

19-626. Alonso, D.- "Menéndez Pidal y Ja lingüística histórica”. — EL, 1965, nưms. $322 / 3$.

19-627. Aguado, L.-_"Genio y figura de un Menéndez, alumno privilegiado de otro Menéndez".-EL, 1965, núms. $322 /$ 3.
19-628. BAQUERo, G._-"España en don Ramón [Menéndez Pidal]"._EL, 1965, núms. $322 / 3$.

19-629. Giménez Caballero, E.- "Menéndez Pidal y la caudillarquia". $-E L$, 1965, núms. $322 / 3$.

19-630. Cortés, N.-"Entrevista con Menéndez Pidal".-IAL, 1964, núm. 186.

19-631. GARcía BLANCO, M.-"Investidura del Excmo. señor don Ramón Menéndez Pidal como doctor honoris causa do la Universidad de Salamanca".$F H, 2$ (1964), 635-614.

19-632. CAstejón, F._.'Don Ramón y los penalistas".-FH, 2 (1964), 579-588.

19-633. Estudios dedicados a Menéndez Pidal, ts. 6-7 (NN. 13-36374, 17-428). || $A I A, 25$ (1965), 466-467 (Meseguer).

19-634. Mariutti de Sánchez Rivero, A."Carteggio Ramón Menéndez Pida]Joaquim de Araujo, Ramón Menéndez Pidal-Emilio Teza"__SLS, 253-316.

19-635. Rosenblat, A._- Amado Alonso". -[En su libro] La primera vision de América (Caracas, 1965), 271-285.. V. núm. 8-10498.

19-636. Studia philologica. Homenaje ofre. cido a Dámaso Alonso por sus amigos y discipulos con ocasión de su 60. aniversario. -Gredos, Madrid, 1960 65. 3 ts.: $530,622,640$ pp. $\| P h P, 6$ (1963) , 329-331; 8 (1965), 98-100 (Hodousek); $Z R P h, 78$ (1962), 578-606; 80 (1964), 582-595 (Kröll); PhP, 5 (1962), 184-186 (Kejzlarová y Pavlfková) .

19.637. Quilus, A.-_'Bertil Malmberg".$B F E$, 1964, núm. 12, 3-8.

19-638. Quilis, A. — "Manuel Alvar". $B F E$, 1964, nứm. 13, 3-14.

\section{LENGUAS PENINSULARES}

\section{Catalán y valenciano}

19-639. MOLl, F. DE B._"Bernhard Schädel $\mathbf{i}$ els inicis de la lingüística catalana".--Homenaige a Jaume Vicens $i$ Vives (Barcelona, 1965), 1, 95-114.

19-640. ARAMON I SERRA, R.-"L'Institut d'Études Catalanes et son activité linguistique". $C D G(1), 4,7-20$.

19-6A1. Vilar, Sـ_Cataluña, nación de España. Sobre la lengua y la literatura catalanas".—CuA, 1965, núm. 5, 202220.

19-642. GuAnst, Domènec-Pompeu Fabra.-Alcides, Barcelona, 1964. 80 pp. (Biografies populars, 14). 
19-643. Griera. A.-"Influence de lhomonumie sur l'évolution des langues et dialectes'._-CLR(10), 1073-1084. [Ejem. plos catalanes].

19-644. Corominas, J.-“Sur les homélies d'Organyà'._-BHi, 66 (I964), 4554.

19-615. Griera, Antoni_Gramatica histórica catalana.-Inst. Internacional de Cultura Románica, Barcelona, 1965. $168 \mathrm{pp}$.

19-646. Di PIErRo, R. J.-“Los fonemas del catalán".-RFE, 48 (1965), 153158.

19-647. Badía Margarit, A. M._-Función significativa y diferencial de la vocal neutra en el catalán de Barcelona".$R F E, 48$ (1965), 79-93.

19-648. Gulsoy, J._- "Cat. dins y el problema de $\bar{\imath}>i$ ". RPh, i8 (196465) , $36-41$.

19-649. Badía Margarit, Antonio M.Gramática catalana_Gredos, Madrid, 1964. 2 ts.: 1020 pp. $\| R J, 16$ (1965), 367 (Haensch) ; $H, 48$ (1965) , 951-952 (Roca-Pons) .

19-650. GuITER, H.-"Quelques participes passés anormaux dans le catalan du Roussillon".-CLR(10), 399-416.

19-651. Bohigas, P._ "La fixation grammaticale du catalan littéraire moderne".-LHC, 255-256.

19-652. Gulsoy, JosepH-El "Diccionario valenciano-castellano" de Manuel Joaquin Sanelo. Ed., est, de fuentes y lexicología.CC.S.I.C., Castellón de la Plana, 1964. 549 pp. || $R P h, 21$ (196768), $105-110$ (Alpera); H, 51 (1968), 218-219 (Canfield); ZRPh, 82 (1966), 426-429 (Colón) ; RLiR, 29 (1965) , 366 (Gardette) ; BHS, 43 (I966) , 232-235 (Pacheco); HR, 34 (1966), 342-343 (Roca-Pons) .

19-653. Diccionari català-castellà, castellàcatalà.-Editorial Mateu, Madrid, $196 \check{.}$ 683 p.

19-654. Moll, Francesc dE B.-Vocabulari mallorquí-castella, amb inclusid de les paraules tipiques de Menorca $i$ Eivissa._Moll, Palma de Mallorca, 1965. $\mathrm{xv}+327 \mathrm{pp}$.

19-655. Conominas, J. -- “Llegint el Voca. bulari meteorologic català".-Miscellà. nia Fonserè (Barcelona, 1961), 141-155.

19-656. Peset Llorca, Victente-Terminologia psiquiátrica usada en los etados de la Corona de Aragon en la baja Edad Media.-Madrid, 1955. [Jaume Roig, B. Metge, San Vicente Ferrer,
Ausias March]. \|ACCV, 22 (1961), 130 (N. P.).

19-657. Gulsoy, J.- "The descendants of old Catalan and Provençal $a b$ 'with'",RLiR, 29 (1965), 38-59.

19-658. Brosman, P. W._- "French and Catalan glapir".-RNo, 6 (1964), 8285.

19-659. GrierA, ANTONI-La vinya, la verema, el vi._Instituto Internacional de Cultura Románica, Barcelona, 1965. $120 \mathrm{pp}$.

19-660. Nomenclator de pobles $i$ poblats de Catalunya. 2: ed.-Delos, Barce. lona, 1964. xvi + 594 pp., 42 mapas. 19-661. Mascaró Pasarius, José Corpus de toponimia de Mallorca. Relación al. fabética de los topónimos registrados en el Mapa general de Mallorca. T. 1: Abeiar-Cutrt. T. 2: Dalt Mar-Palma.Miramar, Palma de Mallorca, 1962-64. xxxii + 1016 pp. ||$R D T P, 21$ (1965), 439 (Llompart).

19-662. Guiter, H._-"Les suffixes de localisation dans la toponymie des Pyrénées orientales",_-_CCO(7), 2, I09-117.

19-663. Grifra, A.- "Les paroisses de la diocese de Lleyda".- $C C O(8), 201-212$; $B D E, \quad 40$ (1964), 5-23.

19-664. Badía I Margarit, A. M.--"Els ternies de la Roca del Valles a la llum de l'acta de consagració de la seva església parroquial, de l'any 932".-_Miscellània A. M. Albareda (Montserrat, 1962), 275-295.

19-665. Guiter, H._"Quelques curieuses modifications de désignations toponymiques dans les documents carolingiens des Prrénées orientales".- RLiR, 28 (1964) , 22-28.

19-666. Catald I Roca, P.-"Noms de l loc i de sant de la diòcesis de Tarragona".-BDE, 40 (1964), 25-108.

19-667. Griera, A.-"Nombres personales, germánicos en su mayorfa, del siglo $\mathrm{x}$ y XI procedentes del Pirineo catalán".- $C C O(7), 3,161-175$.

19-668. SÁnchez AdelL, J._ “Cognoms castellonenses de 1588 i 1769".-BSCC, 41 (1965) , 305-320.

19-669. Mariner Bigorra, S._-_Les cognomina de Barcino à la lumière d'une inscription de Caracalla récemment dé. couverte".-Akte des IV. intern. Kongresses für gr. und lat. Epigraphik (Wien, 1964), 234-238.

19-670. Fi.EXAS, B.-“Surnoms à Artà (Majorque) ".-AFLA, 1966, núm. 41, 17I. 189. 
19-671. MOLL, F. DE B.-Els llinatges catalans (N. 16-46381). || ZRPh, 81 (1965), 208-210 (Colón) -V. núm. 17-445.

19-672, Cinc mil refranys catalans $i$ frases fetes populars. Recull folklòric.-Ed. Millá, Barcelona, 1965. 230 pp. (Bibl. "Vell $i$ nou", 3).

19-673. Companys, M._."Atlas linguistic del domini català".-Actes du Ile Congrés International des Langues et Littératures du Midi cle la France (Aix, 1961), $145-152$.

19-674. GrierA, A.-"Dialectologie catalane"__CDG(1), 2, 69-84.

19-675. Griera, A._Atlas lingülstic de $\mathrm{Ca}$ talunya. Ts. 1, 2 y 3. Reed._La Poligráfica, Barcelona, 1965.

19-676. Griera, A.- "El qüestionari de Benasc de l'Atla lingüistic de Cata. lunya".-FAK, 346-350.-V. núm. 173721.

19-677. Moll, F. DE B._La nostra llengua a Menorca, avui"._-SO, 6 (1964), núm. 11.

19-678. Colón, G._"Autour de l'atlas linguistique d'Andorre" (N. 17-3747). II RFE, 48 (1965), 203-204 (Llorente).

$\checkmark$. también núms. 535-6, 954, 975, 1762-3, 1793.

\section{Gallego y portugués}

19-679. I Colóquio Internacional de Estudos Luso-Brasileiros. Programa geral (N. 18-743) . || RPF, 13 (1964-65) , 417418 (Moura Santos).

19-680. "No $V$ Colóquio Internacional de Estudos Luso-Brasileiros. Resumo das comunicações sobre temas de língua portuguesa".- $R P, 29$ (1964), 54-62.

19-681. Actas do $V$ Colóquio Internacional de estudos luso-brasileiros.-Univessidade, Coimbra, 1965. 2 ts.: 545, 591 pp. $\| B E P, 26$ (1965), 276-282 (Bourdon); H, 49 (1966), 153 (Head).

19-682. Hoge, HENRY W.-The status of Portuguese language study and Portuguese teaching resources.-Univ. of Wisc. I.ang.-Area Center for Latin An. erica, Milwaukee, 1965. II PhP, 10 (1967), 123 (Hampl).

19-683. Matroso CîmaRA, J-Dicionário de filologia e gramática referente à lingua portuguesa. 2: ed_-J. Ozon, RioSão Paulo, 1964. || $H, 49$ (1966), 181 182 (Gomes de Matos).

19-684. Rosado Fernandes, R. M.-"Achegas para a bibliografia de António José Viale, Epifânio Dias, José Maria Ro- drigues e José Joaquiın Nunes",- $R F L$, 8 (1964), 179-206.

19-685. LeITE DE VASCONCELOS_Carlas $a$ António Tomaz Pires. Folclore, filologia, etnografia e arqueologia (1882-1913). Pról. e notas de Eurico Gama.-Faculdade de Letras, Lisboa, 1964. 327 pp.

19-686. Ribeiro, J.—“A posição de Clóvis Monteiro na filologia brasileira".HCM, 107-120.

19-687. Miscélánea filológica em honra d̀ memória do Professor Clovis Monteiro. Ed. Leodegário A. de Azevedo Filho.Editôra do Professor, Rio de Janeiro, 1965. xxi + 186 pp. $\| R P h, 22$ (1968. 69), 116.117 (Hall) .

19-688. Herculano de Carvaljo, José G.Estudos linguisticos. T. 1.-Verbo, Lisboa, 1964. 222 pp. (Presenças, 3). \|RJ, 18 (1967), 359 (Carstens); HR, 35 (1967) , 301-307 (Head) ; RP, 30 (1965), $171-175$ (Machado); RLiR, 29 (1965), 200-201 (Plomteux).

19-689. Almeida TORres, ARTUR DE-Estudos de filologia.-J. Ozon, Rio de Janeiro-São Paulo, 1964. 192 pp. \| $R P$, 29 (1964) , 539-541 (Machado); $R R L, 11$ (1966), 417-418 (Micusan).

19-690. Herculano de Carvalho, J. G.Lições de linguística, $3^{\mathrm{a}}$ ed. (N. 184379) . I| RPh, 19 (1965-66), 536 (Hall) . 19-691. Ella, Sílvio_Ensaios de filologia.-Livr. Académica, Rio de Janeiro, 1963. 319 pp. $\| R P, 30$ (1965), 77-84 (Azevedo Filho); PhP, 10 (1967), 126 128 (Hampl).

19-692. MeNdes DE AlmeidA, J.-"Unidade linguística do português na diversidade de etnias".-Uliramar, Lisboa, 6 (1965), nums. 1/2.

19-693. Williams, EDwiN B.-From Latin to Portuguese, 2nd ed. (N. 18-758) . II MLJ, 50 (1966), 118-119 (Stavrou).

19-694. SAID Ali, MaNuel-Gramática histórica porluguesa. 3a ed., melh. e aum.São Paulo, 1964.

19-695. JuCÁ FILHo, CÂNDIDo_Curso de português. Gramática histórica. 6* ed.J. Ozon, Rio de Janeiro, 1965. $248 \mathrm{pp}$. 19-696. Steiger, A.—“Aspectos da vida e linguagem árabes no Portugal medievo"._-BAu, $18 / 19$ (1965), 322-325.

19-697. Pinhiaranda Gomes, J.- "A autonomia filosofica da língua portu. guesa antes do século xvir1".-RP, 30 (1965), 462-476.

19-698. Morais Barbosa, Jorge-Elude de phonologie portugaise._Centro de Es. tudos Políticos e Sociais da Junta de 
Investigações do Ultramar, Lisboa, 1965. 244 pp. (Estudos de ciencias políticas e sociais, 77).

19-699. FERNÁNDEZ, OSCAR_Living portuguese. 1: Conversation manual. 2: Portuguese - English, English - Portuguese common usage dictionary.-Crown, New York, 1965. 127, 113 pp., 4 discos. || $M L J$, 51 (1967), 60-6I (Daniel).

19-700. BARRUtia, RICHARD, et al.-Modern portuguese. Trial ed.-Univ, of $\mathrm{Te}$ xas, Austin, 1966, 2 ts.: 370, 354 pp. I) $M L J, 5 \mathrm{l}$ (1967), 506-508 (Batchelor); $H, 50$ (1967), 129-130 (Ellison).

19-701. Moura Santos, M. J. DE-“Remarques sur deux systèmes vocaliques anciens du portugais du Nord" (N. 184569). || $R P h, 19$ (I965-66), 525 (Dembowski).

19-702. Head, Brian Franklin-A comparison of the segmental phomology of Lisbon and Rio de Janeiro--[Tesis, Univ, of Texas; resunien cn $D A, 25$ (1964-65), 5268-5269].

19-703. Paiva Boléo, Manuel de (ed.) Anteprojecto de unificação e simplificação da nomenclatura gramatical portuguesa._Faculdade de Letras, Coimbra, 1965. 54 pp. $\| H, 49$ (1966), 154 (Head) .

19-704. Pestana, Manuel Inácio-Didáclica da lingıı portuguesa.-Atlântida, Coimbra, 1965. $239 \mathrm{pP}$.

19-705. Almeida Tôrres, Artur de-Modema gramática expositiva da lingua portuguésa. 17: ed., rev. e anıpl.-Fundo de Cultura, Rio de Janeiro, 1965. 283 pp.-V. núm. 17-462. || RRL, 11 (1966), 418-419 (Micusan).

19-706. Mata Machado Filho, Aires DAPortugués fora das gramáticas.-Siderosiana, Belo Horizonte, 1964. 239 pp.

19-707. Cunea, Celso_manual de português. 2a ed.-Livr. São José, Rio de Janeiro, 1965. 541 pp.-V. núm. 17-3792.

19.708. Willis, R. CLrve-An essential course in modern Portuguese.-Harrap, London, 1965. 529 pp. $\|$ BHS, 43 (1966), 293.294 (Atkinson); MLJ, 51 (1967), 186-188 (Gomes de Matos); $M L R, 63$ (1968), 276-277 (RussellWood).

19-709. Piper, A. C.-“Modern Portugue.

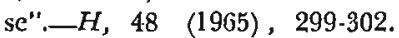

19.710. HAMPEJS, ZDENEK, \& JAROSLAV HoLвfк -- Cesko-portugalskd honverzace.-Státni Pedagogické Nakladatelství, Praha, 1964. 401 pp.

19-711. Crespo Fabião, Luts-Portugees op
reis._.Van Goor Zonen, Den Haag, 1964. 76 pp.

19-712. FARIAS DE LACERDA, Eulício-Sintaxe de português contemporáneo.Pongetti, Rio de Janeiro, 1965.

19-713. BEchara, Evanildo-Lições de português pela análise sintálica. 3: ed., rev. e aum.-Fondo de Cultura, Rio de Janeiro, 1964. 353 pp. (Domine o seu idioma).-V. núm. $17-477$.

19-714. Quintela, F._"Le probleme du nombre. Portugais".-BFS, 43 (1965), 489-491.

19-715. MorAIs, C. B. DE- "O comparativo c o superlativo en português".-Alfa, 1965, núms. 7/8, 89-120.

19-716. Eastlack, Charles Leonard-The morphology of the verb in Portuguese.[Tesis, Univ, of Texas; resumen en $D A$, 25 (1964-6ว) , 2973].

19-717. Gomes, L.— "Topologia pronomi nal'.- $R P, 30$ (1965), $451-454$.

19-7I8. Ribeiro, Jonquim-Estética da lin. gua portuguesa. Rev, de Petrónio Mota.-J. Ozon, Rio de Janeiro, 1964. 536 pp. (Obras completas, I).

19-719. RoDrtgues LAPA, M.-Estilistica da lingua portuguésa. 4: ed., rev. e aum.Livraria Acadêmica, Rio de Janeiro, 1965._V. núm. 16-46461.

19-720. Roche, J.- "Suggestions pour une étude quantitative de la stylistique por. tugaise"_Carav, 1965, núm. 4, 95-133.

19.721. Teixeira DE Agullar, I._- "Formas em que vulgarmente se erra".- $B M P$, 15 (1964), 7-11, 52-56, 73-76, 83.-V. nủm. 14-40142.

19-722. AlmeidA, José DE-Alguns problemas de nossa lingua. "Que", "quem", "qual", ctc.—Oblisco, São Paulo, 1964. $67 \mathrm{pp}$.

19-723. Andrade Cania, Fernando ("Dr. Canhão") -Brevidrio de Ferdenha. 16: parte: Tomar. 17! parte: Não. $18^{\mathrm{n}}$. parte: Dar. 19. parte: Tirar. 20: parte: Estar. 21: parte: Aquilo.-João Francisco Lopes, Lisboa, 1964-1965. 148, 126 , $170,124,136,154$ pp._V. núm. 18-4595. 19-724. MENDES DE ALMEIDA, J.-."Agostinho Barbosa, o segundo lexicógrafo português da língua latina".- $-R d G$, 75 (1965), 31-40.

19-725. Émorine, J-“Quelques normes pour établir un index du vocabulaire portugais",_Carav, 1965, núm. 4, 83-94.

19-726. Carbonell Pico, M. A. T.-“Ano. tações ao Dicionário etimológico da lingua portuguesa de José Pedro Machado". $-R P, 30$ (1965), 37-4.2, 56.61, 
108-110, 152-154, 203-205.—V. núm. 18. 4599.

19-727. Silveira Bueno, Francisco daGrande dicionário elimológico prosódico da lingua portuguésa: vocábulos, expressões da lingua geral e cientifica, sinonimos, contribuições do tupi-guarani. Ts. 1 y 2.-Saraiva, São Paulo, 1964. 2017 pp. || PhP, 10 (1967), 125126 (Hampl).

19-728. FONTINHA, RODRIGO-NONo dicionário etimológico da lingua porluguesa.-D. Barreira, Porto, 1965. 2000 pp.

19-729. Ruiz y Ruiz, Lina AnTONIA-A tentative Portuguese dictionary of dated first occurrences in certain documents between 1351-1450.-[Tesis, Univ. of Pennsylvania; resumen en $D A, 25$ (196465), 5285].

19-730. V'irerbo, frei JosQUim de SANTA ROSA DE-Elucidário das palavras, termos e frnses que em Portugal antigamente se usaram. Ed. crítica, baseada nos inss. originais, por Mário Fiúza. T. 1: A.-Civilização, Porto, 1964. 700 pp. II CuN, 24 (1964), 124 (Macchi); $R P F, 12$ (1962.63), 670-671 (Paiva Boléo) .

19-731. Dicionario da origem e da evolu. ऽño das palnuras. Apêndice, citações historicas. 3" cd.-Científica, Rio de Janeiro, 1963, $260 \mathrm{pp}$. (Bibl. de conhecimentos básicos).

19-732. Caldas Aulete, F. J.-Dicionário contemporaneo da lingua portuguesa. Breve estudo sôbre a origem e evoluçåo da língư portugzuêsa por Antenor Nascentes. 2a ed., rev., atual, e aum. por Hamilcar de Garcia.-Delta, Rio de Janeiro, 1964. 5 ts.-V. núm. 17-3820.

19-733. NASCENTES, ANTENoR - Dicionário geral da lingua portuguêsa. T. 2: D-1.Imprensa Nacional, Rio de Janeiro, 1964. 599 pp.-V. núm. 17-3819.

19-734. Dicionário geral luso-brasileiro da lingua portuguesa. Direcção técnica e coordinaçăo de Afonso Zúquete. T. 1: $A-A p e$,-Ed, Enciclopédia, Lisboa, 196264. 956 pp. || ASNS, 202 (1965) , 69-71 (Woll) .

19-735. Machado, José Pedro-Dicionário da lingua portuguesa. T. 4: L-N.Sociedade da Língua Portuguesa, Lisboa, 1964. 992 pp.-V. núm. 18-4601.

19-736. Almeida Costa, J., \& A. Sampaio E Melo_Dicionário da lingua porluguesa. 5: ed., muito corr. e aum-Porto Ed., Porto, [1965:]. 1556 pp.-V. núm. 18814.
19-737. Machado, Josê Pedro-Dicionário do estudante. Nomes comuns, onomástico, histórico e geográfico, vocabulário camoneano. 2: etl.-Confluência, Lisboa, 1964. 754 pp.

19-738. Pinheiro, Eduardo-Dicionário da lingua portuguesa.-Figueirinhas, Porto, [1965?]. $1446 \mathrm{pp}$-V. núm. 17-3823.

19-739. Torrinha, Francisco-Dicionário de portugues. Nova ed.-Domingos Barreira, Porto, 1964. $1368 \mathrm{pp}$.

19-740. Silya, Fernando J, da, Francisco TORRINHA e Rodrico Fontinha Suplemento aos Dicionários de português, dos nesmos autores.-Domingos Barreira, Porto, 1964. $52 \mathrm{pp}$.

19-741. Lello popular. Novo dicionário ilustrado da lingua portuguesa._Lello, Porto, 1964. $1442 \mathrm{pp}-\mathrm{V}$. núm. 13. 34560 .

19-742. Braz dA SIlya, A. M.-Giria ma. rinheira. Como falam os homens do mar.-Autor, Rio de Janeiro, 1964. $111 \mathrm{pp}$.

19-743. Glossário da segurança social.-Federaçăo de Caixas de Previdência, Lisboa, 1964. 122 pp. [Portugnés, italiano, francés e inglés]. [ $Y$ también: 2a ed., Liboa, 1967. 132 pp.].

19-744. Pessoa de Barros, Frederico, e Isidro Álvares Alonso (eds.).-Dicionário espanhol-portugués. - Mestre Jou, São Paulo, 1965. 2 ts.

19-745. Diclionnaire Europa - Larousse. Français-portugais, portugais-français.Larousse, Paris, 1965. $398 \mathrm{pp}$.

19-746. Dicionário francès - portugues.-m Porto Editora, Porto, 1964. 622 pp. (Dicionários académicos, 1 ).

19-747. Houniss, ANTônio, \& CATHerine B. AVERY-The new Appleton dictionary of the English and Portuguese langua. ges. - Appleton-Century-Crofts, New York, 1964. xx + 636, xx $+665 \mathrm{pp}$. $\| H, 49$ (1966) , 361-363 (Carter); LBR, Summer 1966 (Gomes de Matos); $H$, 48 (1965), 171-172 (Moser); $M L J, 49$ (1965), 452-453 (Sharpe); HR, 34 (1966), 346-349 (Stavrol1).

19-748. AliAndro, Hygino__Compact dic. tionary. T. 1: English-Portuguese; t. 2: Portuguese-English. - David McKay, New York, 1964. 649, 496 pp._-V. núm. 17-508.

19-749. FerndNDEz, OSCAR-Common usa. ge dictionary, Portuguese-English, English-Portuguese. - Crown Publishers, New York, 1965. 113 pp. (The living language courses). 
19-750. Lamb, N. J-_Collins Portuguese Gem dictionary._Collins, London-Glasgow, 1964. 768 pp. $\|$ BHS, 49 (1966), 144-145 (Willis) .

19-75I. Peixoto dA Fonseca, F. V.- "Vocábulos franceses de origem portuguesa exótica. Africanos e orientais".- $R P$, 29 (1964), 11-12, I84-187, 433-436, 557. $563 ; 30$ (1965), 134-138, 448-450, 477479.-V. núm. 18-849.

19-752. Martins, Manuel J.-Dicionário de inglés-português.-D. Barreira, Porto, 1965 . $1130 \mathrm{pp}$-V. núm. 18-839.

19-753. Teixeira de Olivelra, Maria MaNUELA_Dicionário moderno portugués. inglês. Rev. por C. M. Bowker, M. P. Bowker e G. Gusmão de Morais.-Porto Editora, Porto, [1965?]. 1304 pp.

19-754. Rocha E Silva, J. N.-Seleção de adjetivos, sinónimos-antônimos, idéias correlatas $e$ opostas: português $e$ inglês._Rio-São Paulo, 1965.

19-755. Araújo, Avelino-Technical dictionary: English-Portuguese and Portuguese-English.-Freitas Bastos, Rio de Janeiro, 1964.

19-756. Meister, Werner, \& Esaú Pereira LAus (eds.) — Portugiesich-deutsches Wörterbuch._VEB Verl. Enzyklopädie, Leipzig, 1965.

19-757. Melo, A. H. DE, antónio Ngan e Luís Hó - Dicionário chinés-portuguếs._Governo da Prov., Macau, 1964.

19-758. Dicionário portuguếs-cinyanja pelos missionarios da Companhia de Jesus.-Junta de Investigações do Ultramar, Lisboa, 1964. 266 pp.-V. núm. 18-844.

19-759. Silva MaIA, ANTónio da-Dicionário rudimentar português-kimbudo.Missões, Cocujães, 1964. 146 pp.

19-760. Prereira, Sílvio Batista-Vocabulário da Carta de Pero Vaz de Caminha.-Inst. Nac, do Livro, Rio de Janeiro, 1964. xx + 179 pp. (Dicionário da língua portuguésa. Textos e zocabulários, 3) .

19-7Gl. ZaMARIN, L. M.-_"Deceptive cognates in Portuguese".- $H, 48$ (I965), 887-889.

19-762. Mata Machado Filho, Aires daAventuras de $u \mathrm{~m}$ caçador de palavras.Livr. Acadêmica, Rio de Janeìro, 1965. $145 \mathrm{pp}$.

19-763. Delgado, M. J.-“Acerca da obra Influencia arábica no vocabulário portugués, de José Pedro Machado".$R P, 30$ (1965) , 62-76.

19-764. A. S. — "Vocabulário ultramari-
no".-Infantaria, 32 (1965), 135-144, 228-245, 337-349.—V. núm. 18-4635.

19-765. KRöLL, H_.Aditamentos às Designações para embriaguêz".—RPF, I3 (I964-1965), 27-63.

19-766. Pedro, A.-“"Termos e expressões usados nos palcos portugueses".-Autores, 5 (1963), nưm. 20.

19-767. JABERG, $\mathrm{K}$._"Géographie linguistique et expressivisme phonétique. Les noms de la balançoire en portugais".[En sus] Sprachwissenschaftliche For. schungen und Erlebnisse (1965), 63-90.

19-768. Simões CapĀo, A. T.-"Nomes populares do chapin e da codorniz".Lab, 1965, núm. 237; 21 pp.

19-769. Piel, J. M.-_"Zur Herkunft von gal.-port. enguizar, enguiçar "verhexen'".-MMD, 1, 463-467.

19-770. Pif.L, J. M.—."Nótula etimológica: paixão 'estaca'"-RPF, I3 (1964. 1965) , 347-348.

19-771. BAL, W. - "Portugais pombeiro 'commerçant ambulant du sertão'".AION-R, 7 (1965), 123-161.

19-772. Cortez Pinto, A-_Nota filológica sobre a palavra tranglo-manga".$B M P$, 15 (1964), 77-83.

19-779. Mattoso CÁmaRA, J.—“A locução a olhos vistos". $H C M, 103-105$.

19-774. VAz LEÃo, A. - "Ao Iusco-fusco"._RP, 30 (I965) , 355-364.-V. núm. 17-532.

19.775. Contês Pinro, A.-“Dar à dica 'cometer inconfidência comprometendo alguém', 'denunciar um segredo', 'delatar" ". $-R P, 29$ (1964), 295-297.

19-776. SEABra E Melo-"Toponimia"..$B C B D, 11$ (1962), 247-251.

19-777. "Santiago na toponimia portuguesa".-RP, 30 (1965), 286-292.

19-778. Carvalho Costa, A. DE-"Lendas, historietas, etimologias populares e outras etimologias respeitantes às cidades, vilas, aldeias e lugares de Portugal continental"._BCL, 1965, núms. $63 / 64,221-351 .-V$. núm. 16-45763.

19-779. Pinto Loureiro, JosÉ-Toponimia de Coimbra._Câmara Municipal, Coimbra, 1964. 2 ts.: xxxiv + 426, 434 pp.

19-780. MarçaL, H.- Nomenclatura onomástica dos arruamentos intramuros da cidade do Porto"._Trip, 5 (1965) , 209 213.

19-781. Correia, J. Diogo-Topontmia do concelho de Cascais._Camara Municipal, Cascais, 1964. 56 pp.

19-782. Portugal, F. F.-“índice topo- 
nímico do Concelho de Nisa".- $R P$, 29 (1964), 497-519.

19-783. Ramos De Oliveira, M.-_"Celorico da Beira. Toponimia".-BA, 24 (1965), 147-159.

19-784. Cinha, A. R._.'Os tecidos na toponímia". $-D B, 3$ (1965), 503-5]8.

19.785. Brarsa DA Cruz, M.-“"Anas de Chaves [São Tomé]".-BSGL, 82 (1964), 97.101 .

19-786. Fıúza, M.-“"Acerca do topónimo Averomar".-Povon de Varzim, 4 (1965), 19-24, 230-232.

19-787. CUNHA SERRA, P.-“Topónimos do distrito de Aveiro".-ADA, 32 (1966), 36.44; 33 (1967), 39-56_-V. núm. 17549.

19-788. Mourinho, A.-_Algumas considerações sobre o nome e a terra medieval de Bragança".- $B G A B$, agosto, 1964, 15.16 .

19-789. Silva Pinto, S. DA_-"O problema de Portucale. Novas teorias, novas conclusões".-RdG, 74 (1964), 281-289.

19-790. MaCHAs, J-“"Nos tempos que já lá vão... A etimologia de Sarnaclas".$E C B, 1964$, núm. 1], 77-88.

19-791. Correia, J. D.-"Origem do apelido Castelo Branco". - ECB, 1965, núms. 102/4.

19-792. Garcia, J. M._-"Torre das Águias em Almofala. Riba-Cóa". - $B A, 24$ (1965), 223-233.

19-793. MACHADO, J. P.-"Xant laqob (para a história de um topónimo)".$R P, 30$ (1965) , 344-349.

19-794. Rocha Carneiro, J. DE B.-"Da denominação das pessoas pelo Noroeste português".- $R P, 29$ (1964), 555 556.

19-795. Magai.hães Júnior, RaIMUNDoDicionário de provérbios e curiosidades. Adágios comparados, frases feilas. 2: crl.-Cultrix. São Paulo, 1964. 351 pp.-V. núm. 16.465]9.

19.796. Pires de Lima, F. DE C._-"Adagiário português. Contribuição para o seu estudo sistemático".-ACE, 3, 411445.

19-797. Rebelo, J. M.-_"Um quadro da vida alto-duriense. Subsidios para uma paremiologia teológica". $-B G A B, 1965$, núm. 14/]6, 31-39.

19-798. CÂmara Cascudo, L. Da-_"Macaco velho não mete a mão em combuca".-REt, 3 (1964), 291.294; 4 (1965) , 33-34.

19-799. Chaves, L._-"Velerismos. Come diceba... Comme dit... Como diz ou como disse..."-REt, 7 (1966) $67-85$.

19-800. Hercul "Os estuclos dialectológicos em Portugal nos últimos vinte anos" (N. 16. 46532). || $Z R P h, 81$ (1965), 593 (Baldinger)

19-801. Morais-Barbosa, J.-"Língua, dialecto, falar local",-Estudos Politicos e Sociais, 3 (1965), 727-739.

19-802. Drifrado, M. J.- "O calão fino $e$ a giria plebeia".- $R P, 30$ (1965), 155 170.

19-803. Castilho, A.-"Vocabulário regional".-BCBD, 14 (1965), 217-220, 251 . $253,312-317,344-347,374-377$.-V. núm. $17-562$.

19-804. C.Ama. Eurico - Ao rabisco...Rev, de Portugal, Lisboa, 1965. $44 \mathrm{pp}$. 19-805. Carvalio Moniz, M.-"O abegão".-Ethnos, 4 (1965), 145-152.

19-806. MAchado Guerreiro, A._."Afilha. dos e compadres no Baixo Alentejo. Colos".-REt, 5 (1965), 419-429.

19-807. Carvalho Costa, Alexandre deNótulas etnográficas $e$ linguisticas alentejanas apresentadas em expressões po. pulares. - Junta Distrital, Portalegre, 1964. $290 \mathrm{pp} .-\mathrm{V}$. núm. 13-34590.

19-808. DFlgado, M. J.-"Alguns curiosos vocábulos $e$ outras expressões da linguagem popular alentejana e algarvia".- $R P, 30$ (1965) , 480-492.

19-809. SOUSA, ARLINDo DE-Vocabulário de Entre Douro e Vouga. 1. Artes de pesca maritima.-Rev. de Portugal. Lisboa, 1965. $56 \mathrm{pp}$.

19-810. Moura Santos, M. J. de-"Os falares fronteiriços de Trás-os-Montes".$R P F, 13$ (1964-1965) , 65-261,-V. núm. $18-898$.

19-81]. Alves lina, M. - "Matosinhos. Contribuição para o estudo da linguagem, etnografia e folclore do concelho".-RPF, 12 (1962-63) , 395-508.-V. núm. 17-3904. \| $B A L M, 7$ (1965), [16-1]7 (Cortelazzo); ZRPh, 82 (1966), 437-440 (Giese) ; $H, 47$ (1964) 859 (Moser) ; VR, 24 (1965) , 168-172 (Niederer); RDTP, 22 (1966), 22]-222 (Pérez Vidal) .

19-812. Ribeiro, Margaridi-Estudos sobre a Aldeia da Glória (Salvaterra de Magos). Notas sobre a linguagem.-Rev. de Portugal, Lisboa, 1965. $78 \mathrm{pp}$.

19-813. Cautria, A.-"Nótulas sobre a linguagem popular de Vila Nova de Fozcoa". $\rightarrow B C B D, 14$ (1965), 70-72, 188 . 190 . 
19-814. Movrão, I._- "Nóculas sobre a linguagenı popular de Vila Nova de Foscoa"._BCBD, 14 (1965) , 232-233.

19-815. Carvalho Costa, A. DE-“Entretimentos etnográficos e filológicos". $B B P M$, 1965, núm. 12, 57-101. [Giros populares; topónimos].

19.816. Lopes Alves, JoAna-A $A$ linguagem dos pescadores da Ericeira.-Junta Distrital de Lisboa, 1965. xi +258 pp. $\| B H S, 44$ (1967), 297 (Atkinson); $R F, 78$ (1966), 441.443 (Kröll); RDTP, 22 (1966), 227-228 (Manrique): $I R, 28$ (1969), 195-198 (Mctzeltin).

19-817. Fragoso, Augusto Porrírio-O ca. lão mindérico. Santaréin, 1964. $28 \mathrm{pp}$.

19-818. Pestana, S.- "O falar da Ilha da Madeira".- $R P, 29$ (1961), 298-301; 30 (1965) , 119-122.

19-819. Alonso Montero, J.-_"El Evangelio de San Mateo. Estudio lingüistico de la traducción gallega de José Sánchez de Santamaífa (1861)",$B C M L, 7$ (I963), núms. $59 / 60$.

19-820. Pensado, J. L._-_Algunas observaciones lingüísticas sobre el doctor Jerónimo Soriano" (N. 17-4I6I) . || ZRPh, 80 (1964), 624-625 (Höfler).

19-821. Alonso, D., y V. García YERRA_-"El gallega-leonés de Ancares y su interés para la dialectología portuguesa" (N. 17-569) . || RPF, 13 (1964G5), 413-417 (Moura Santos).

19-822. Olano Silva, V. DE-"Vocabulario gallego. (Addenda) "..-BCML, 7 (1963) , 129-130.-V. núin. 17-570.

19-823. Otero Alvarez, A. — "Hipótesis ctimológicas referentes al gallego-portugués'.-CuEG, 20 (1965), 12-30, 330 349.—V. núm. 18-909.

19-824. Pensado Tomé, Jost́ Luis Estudios etimologicos galaico-portugueses. Universidad, Salamanca, 1965. 94 pp. (AcS, Filosofia y letras, 51).

19-825. Blischmann, SigriD_Beiträge zum ctymologischen Wörterbuch des Gali. zischen.-Romanisches Seminar der Universität, Bonn, 1965. 314 pp. (Romanistische Versuche und Vorarbeiten, 15). || VR, 26 (1967), 376-378 (Colón); $R E, 78$ (1966), 499-441 (Kröll); $R L i R$, 31 (1967), 232-233 (Moura Santos) ; ASNS, 203 (1966), 309-31l (Piel) .

19.826. Crespo Pozo, Jost S.-Contribución a un vocabulario castellano-ga. llego. Pról. de V. García de Diego.Revista "Estudios", Madrid, 1963. 672 pp. $[=E M, 19$ (1963), 399.1059]. ॥ FM, 21 (1965), 319 (X).
19-827. Alvarez Álvarez, Domngo-Jergas de Galicia. La de los tejeros, canteros, albañiles $y$ paragüeros.-Tomiño, Pontevedra, 1965. 205 pp., ilustr. $R D T P, 22$ (1966), 232-233 (Ramón y Fernández Oxea).

19-828. Lis Quibên, V_- "La jerga de los canteros de Galicia".-APCE, 3, 113 . 142.

19-829. Refraneiro do viño-Castrelos, Vigo, 1958 (O moucho, 3). I| RDTP, 24 (1968), 210 (Ramón y Fernández Oxea). 19-830. RAMón Y Fernández Oxea, J."A muller no refraneiro galego". $-A C E$. 3, $481-508$.

19-831. Nascentes, A.-"Études philologiques au Brésil"._PhP, 7 (1964), 191 . 194.

19.832. Rodrigues, A. DALL'I._-'Relatório sôbre a lingüística e o ensino de línguas no Brasil".-SCIC, 106-118.

19-833. Rónai, P.- "La vie du Brésil dans le miroir de sa langue"._Carav, 1965, núm. 5, 31-44.

19-834. ScHADEN, E-'A aculturação no plano lingülstico".-Rev. de Antropologia, Săo Paulo, 19 (1965) , 185-192. V. nưm. 10-18610.

19-835. Paiva BolÉo, M. DE-"Linguistique et peuplement. A propos de l'émi gration açoréenne au Brésil" —BSLP, 59 (1964), xxxvi-xxxviii.

19-836. Stecagno Picchio, L.-"Crisi del linguaggio e avanguardie letterarie in Brasile".-Par, 1965, núm. 190, 85-109.

19-837. Dokrig, JohanN-ANTon - Mundo luso-brasileiro. Einführung in die portugiesisch-brasilianische Sprache._-Orell Füssli, Zürich, 1964.

19-838. Angeleas-Bauer, Sylvia - Brasilianisch. - Polyglott-Verlag, Köln-Marienburg, 1964. 32 pp. (Polyglott-Sprachführer, 118 ) .

19-839. Volf, E. - " $\mathrm{La}$ formación de las particularidades lingüísticas nacionales en el Brasil".-En: Las naciones de Latinoamérica, Instituto de Etnografia, Moscú, 1964].

19-840. Bastide, R.-“Le Brésil à la recherche d'une langue".-MF, 354 (1965), 541-548.

19-84.1. Cunha, Celso-Uma política do idioma.-Livr. São José, Rio de Janeiro, 1964. 52 pp.

19-842. Silveira Bueno, F. DA-"Influências italianas no português do Brasil".Orbis, 13 (1964), 240-252.

19-843. "Anteprojecto de simplificaçăo c unificaçăo na nomenclatura grama- 
tical brasileira".- $R P, 29$ (1964), 269 294; 30 (1965), 239-259.

19-844. "Nomenclatura gramatical brasileira".-BMP, 15 (1964), 34-51.

19-845. "Nomenclatura gramatical brasileira"._RP, 29 (1964), 65-80.

19-846. Castilho, A. T. de, \& E. del CarRATORE. - "Considerações sôbre a nomenclatura gramatical brasileira e suas relações com a terminologia latina".Estudos, Marília, 1965, núm. 1, 1-54.

19-847. OliveIRA, José Luis DE-Interpretação da "Nomenclatura gramatical brasileira".-Biblioteca do Exército, Rio de Janeiro, 1965. (Col. General Benicio, 39).

19-848. Gama Kury, Adriano da-Pequena gramática para a explicação da nova nomenclatura gramatical. 9a ed., rev.$\Delta$ gir, Rio de Janeiro, 1964.-V. nim. 18.781.

19-849. NASCENTES, ANTENOR-O idioma nacional. 4: ed., de acôrdo com a nomenclatura gramatical brasileira.Livr. Acadêmica, Rio de Janeiro, 1964. 289 pp._. V. núm. 16-46443.

19-850. WilluMs, EDWIN B.-First Brazilian grammar. A course in beginner's Portuguese. - Appleton-Century-Crofts New York, 1964, 194 pp. \| PhP, 7 (1964), 206 (Hampejs).

19-851. Hoge, Henry W., \& Peter J. LunARdinı_Oral Brazilian Portugnese.Univ. of Wisconsin Press, Milwaukee, 1964. $424 \mathrm{pp}$.

19-852. VAN DEN BesselaAR, J. J.-Hel Portugess van Brazilië. Deel 1: Spraak. leer, oefeningen en lectuur. Deel 2: Foneliek, overzicht van het werhwoord en woordenlijsten._L. C. G. Malmberg, 's-Hertogenbosch, 1964. || Ocid, 68 (1965) , 214-215; RP, 30 (1965), 176177 (Houwens Post); RP, 29 (1964), 565-566 ([Machado]).

19.853. DANTÈs Nascimento, EdmundoOs cem êrros mais correntes da lingua tortuguésa falala no Brasil e sua cor. recio sob a forma prictica. 3a ed.Ed. Brasil, São Paulo, 1964. 196 pp.V. núm. 18-928.

19-854. Silveira Bueno, Francisco daEstilistica brasileira. O estilo e a sua técnica._Saraiva, São Paulo, 1964. 225 pp.

19-855. Silveira Bueno, Franctsco dATratado de semântica brasileira. 4: ed., rev.-Saraiva, Săo Paulo, 1965.-V. núm. 16-46568.

19-856. Ffrnandes, Francisco, \& F. Mar-
Ques GUIMARÃEs_Dicionário brasileiro contemporâneo ilustrado. 2: ed,--O Globo, Pôrto Alegre; Melhoramentos, São Paulo, 1965. xlviii + 1143 pp.-V. núm. 17.582 .

19-857. Buarque de Holanda, Aurelio, e José BAPTISTA DE Luz (eds.) - Pequeno dicionário brasileiro da lingua portuguêsa. 11: ed., aum,_-Civilização Brasileira, Rio de Janeiro, 1964.-V. núm. 18-815.

19-858. PIEL, J. M._"Sobre alguns aspectos da renovação e inovação lexicais no português do Brasil".-RPF, 13 $(1964-65), 1-25$.

19.859. Cruz dE Andrade, N. M.-."A propos du vocabulaire brésilien"._CDG (1), 3, 196-209.

19-860. MATtoso CÂmaRA, J -_"A propos d'un vulgarisme du portugais du Brésil". - HAR, 543-545.

19-861. Vocabulário sul-riograndense._o Globo, Pôrto Alegre, 1965. xi + 489 pp.

19.862. LIND, Ivan_De Porlugal ao Brasil. Um pequeno estudo de toponimia brasi. leira._Casa Portuguesa, Lisboa; Instituto Ibero Americano, Gotemburgo, 1963. $92 \mathrm{pp}$. || $R P h, 19(1965-66), 527-$ 529 (Jensen).

19-863. Machado, J. P._"O nome Brasil".-RP, 30 (1965), 191-202.

19-864. Mederros, W.-"Contribuição à dialectologia brasileira"._-_HCM, 175182.

19-865. Rossi, Nelson-Atlas prévio dos falares baianos.-Inst. Nacional do Livro, Rio de Janeiro, 1964.

19.866. Vilas-BoAs DA Mota, ATICO_Mutirão. Inquérito lingülstico-etnográfico-folclórico. T. 1: Questionário.Universidade Federal, Goiás, Brasil, 1964. 49 pp. || ZRPh, 81 (1965), 603 (Baldinger), RDTP, 22 (1966), 216217 (Pérez Vidal); RLiR, 29 (1965), 198-199 (Plomteux).

19.867. RogADO QUiNTINo, F. R.-"O problema da origem dos termos Guiné e Guinéus".-Boletion Cultural da Guiné Porluguesa, 1965, núnı. 78, 117. 145.

19-868. BRAdShaw, A. T. voN S.-"Vestiges of Portuguese in the languages of Sierra Leone". Sierra Leone Lang. Rev., 1965, núm. 4, 5-37.

19.869. VALkhoFf, M.-Africa do Sul e Portugal. Algumas reflexões sobre os dialecios crioulos.-Tipografia das Missõrs Católicas, Sĩo Tonné. 1961. 
V. también nưms. 534, 624, 958-60, 967, $1049,1070,1114,1160,1175,1249$, 1279, 1294, 1856, 1912, 1932.

$V a s c o$

19-870. MichelenA, L._-_La actividad lingüistica en el campo vasco".-CDG(I), 4, 224-232.

19-871. Aquesolo, L. DE- "Dos notas autobiográficas de Resurrección María de Azkue, comentadas".-BSV, 21 (1965), 35-63.

19-872. LAsA, J. I._-"Iturriaga, adelantado de las artes pedagógicas sobre el vascuence".-_BSV, 21 (1965), I85-196. 19-873. LAFITte, P._"La obra de Luis Michelena Elissalt".-BSV, 2L (1965), 315-339.

19-874. Bosch Gimpera, P._."Arqueología Y lingüística en el problema de los origenes vascos"._-Homenaje a J. M. de Barandiarán (Bilbao, 1964), t. 1.

19-875. Echaide, L. M._-"Sobre Ios orlgenes de los vascos y las fuentes de su idioma, el vascuence o euskera".- $B S V$, 2 I (I965), 297-313.

19-876. UGALDE, M._“¿Está relacionado el euskera con las lenguas africanas?"$B I A E V, 16$ (1965), núm. 63.

19-877. Michelena, L. - "Vasco-romanica"-RFE, 48 (1965), 105-119.

19-878. Griera, A.- "El vasco, lengua ro mánica".-HAR, 325-396.

19-879. PIEL, J. M._-"Erwiderung".- $R F$, 76 (1964), 426-429. [Sobre E. Gainillscheg, "Romanen und Basken", nưm. 17-3966].

19-880. Villasante, L.-"Texto de dos impresos sumamente raros de Juan Antonio de Moguel".-BSV, 20 (1964), 61.73 .

19-88I. Bozas-Urrutia, R.-“La Gramá. tica vasca de Harriet y sus aprobaciones".-BSV, 21. (1965), 421-426.

19.882. ANJEL, JUAN-A puntes para clase de rascuence. Segundo curso.-Euskal-argital-penak, Bilbao, 1966, 43 pp.

19-883. Michelena, L. - "Sobre la formación de dos compuestos vascos". $B S V, 21$ (1965), 100-101.

19-884. LAFON, R.-_L'adjectif épithète et les déterminants en basque".-BSLP, 59 (1964), 82-104.

19-885. López MENDIZÁbaL, ISAAC-Diccionario vasco-español. 4! ed., mejorada y aum.-Auñamendi, San Sebastián, I965. $450 \mathrm{pp}$.-V. nưm. 14-38398. || $B S V, 21$ (1965), 115.116 (Michelena).
I9-886. Estornes Lasa, Bernardo y J. IGnacio GolkoEtXea Olaondo-Diccionario Auñamendi español-vasco. T. 1 : A-Apar. T. 2: Aparcar-Bearin. T. 3: Bear-Cale.-Auñamendi, San Sebastián, 1965. xxiii + 224, 185, 169 pp. (Col. Auñamendi, 44). \| BSV, 21 (1965), 436-437 (Michelena).

19-887. Múcica Berraondo, Plácido-Diccionario castellano-vasco._El Mensajero del Corazón de Jesús, Bilbao, 1965. 1897 pp. I| $B S V, 21$ (1965), 431.433 (Michelena); $B A C o l, 16$ (1966) , 194-197 (X) .

19-888. Iztegi erdera-euskera (castellanovasco). - Ekin, Buenos Aires, 1964. (Bibl. de cultura vasca). $\| B S V, 21$ (I965), 439-440 (Michelena).

19-889. IZAGIRRE-K, A. K. - "Iztegirako gaiak". - BSV, 21 (1965), 197-211. [Léxico].

19-890. GÁRATE, J.- "Los euskarianos tras los cetáceos".-BSV, $2 \mathrm{I}$ (I965), 177 184. [Con un vocabulario].

19-891. ZuMALDE, I._-"Más palabras vascas de Ios siglos xvI y xvI". $-B S V$, 2 I (1965) , 65-68.-V. núm. 18-4705.

19-892. URQuiJo, JuLIO DE - Refranero vasco. Los refranes y sentencias de 1596. T. 1-Auñamendi, San Sebastiản, 1964. (Col. Auñamendi, 40). ॥ $B S V, 21$ (1965), 117-120 (Michelena). 19-893. Michelena, L._-“A propósito de uno de los refranes de 1596" -BSV, 21 (I965), 93-95.

19-894. Michelena, L.- "El atlas lingüístico vasco".-_PFE, $1,427-442$.

19-895. Holmer, Nils M._El idioma vas. co hablado. Un estudio de dialectologia euskérica.-Diputación de Guipúz. coa, San Sebastián, 1964. (Publicaciones del Seminario Julio de Urquijo). $\| B S V, 21$ (I965), 111-113 (Michlelena).

19-896. Michelena, L.- "A propósito del salacenco amastarrika"'-BSV, 20 (1964), 307-311.

19-897. Manso de ZúÑiga, G.-“El zuendoko".-BSV, 21 (1965), 29-39.

19-898. ONDARra, F._"Voces vascas de Bacaicoa"._BSV, 21 (1965), 387-412.

19-899. Irigaray, A._-"Esbozo bio-bibliográfico de literatura éuscara profana (disl siglo $x v$ al $x x$ )".- $-P V, 26$ (1965). núms. $98 / 9$.

19-900. Estornes Lasa, Bernardo (ed.) Fantasia y realidad. Antología literaria vasca.-Auñamendi, San Sebastián, 1964. 203 pp. (Col. Auñamendi, 33). 
19-901. LABAyEN, ANTonio María_Teatro éuskaro. - Auriamendi, San Sebastián, 1965. 2 ts.: 151, 190 pp., ilustr. (Col. Auñamendi, 42-43). II Seg, 2 (1967), 400-401 (Esquer Torres); BSV, 22 (1966), 290-292 (I. Z.) .

19-902. Axular, PEDRo DE-Gero. (Después). Introd., ed. y trad. de L. Villasante.-Juan Flors, Barcelona, 1964. (Espirituales españoles). \|RyF, 172 (1965) , 134 (Meseguer) ; BSV, 20 (1964), 477.478 (Michelena).

19-903. Bozas-Urrutia, R.-."Juan I, de Iztueta y el Prólogo de su Guipuzcoaco dantzac".-BSV, 21 (1965), 349-375.

V. también núms. 19, 20,957, 961, 1218-9, 2343.

\section{ESPAÑOL}

19-904. Serís, Homero-Bibliografía de la lingiüstica española._.Inst. Caro y Cuervo, Bogotá, I964. lix + 981 pp. (Publicaciones del Instituto Caro y Cuervo, 19). || PhP, 10 (1967) . 125 (Hamplová); $R J, 16$ (1965), 363-366 (Körner); $A b s$, 30 (1966), 354-355 (Peñalosa); QIA, 5 (1966-67), 107-108 (T. M.) ; $P B S A, 59$ (1965), 457-458 (Woodbridge); $R P h, 20$ (1966-67), 107-112 (Woodbridge) .

19-905. "Medio siglo de la Revista de Filologia Española".—RFE, 47 (1964), $5-6$.

19-906. Pollin, Alice M., \& RAQUei, KersTEN_Guia para la consulta de la "Re. rista de Filología Española" (1914. 1960).-New York Univ. Press, New York, 1964. 835 pp. || $Z R P h, 80$ (1964), 622-623 (Baldinger); $M P h, 64$ (196667), I84-186 (Haley); $M L J, 50$ (1966), 41-42 (Jackson); H1R, 35 (1967), 179. 180 (Lloyd); RPF, 13 (1965), 412 413 (Paiva Boléo); BHS, 43 (1966), 74 (Ribbans); $H, 49$ (1966), 167 (Woodbridge) ; $P B S A, 59$ (1965) , 348349 (Woodbridge) .

19-907. "Colaboradores te la Revista de Filologia Española".-RFE, 47 (1964). 131-214.

19-908. Boletín de la Academia Argentina de Letras. Indice general (tomos 1-29, 1933-1964).-BAAL, 30 (1965), 129 194.

19-909. RICARD, R._-“La langue espagnole vue par un écrivain portugais".- $-V L$, 1964, núm. 147, 343-347. [Ramalho Ortigão].

19-910. Grass, R.-“America's first lin- guists: their objectives and methods".$H, 48$ (1965), 57-66.

19-911. ZAMORA Elizondo, H.--"El aporte lingüistico de Andrés Bello".-BACos, 9 (1964-65), núms. 14/15.—V. núm. 18-988.

19-912. Oroz, R.- "Bello, fílólogo".-A, 1965, núm. 410, 134-151.

19-913. GonzAlez, A. D.-“"Andrés Bello y la unidad del idioma y de la cultura en España y América"... $R N a, 10$ (1965), 294-297.

19-914. Sánchez Carrillo, A.-“"Las leyes y el valor de las palabras". $-R N C$, 1965, núm. 172, 74-75. [Teorías de $A$. Bello].

19-915. Cuervo, Rufino Jos£, y Emilio TezA_Epistolario. Ed., introd. y notas de Ana Hauser y J. Páramo Pomare. da.-Instituto Caro y Cuervo, Bogotá, 1965. lix + 454 pp. (Archivo epistolar colombiano, 1). \|NA, gen. 1966, 116 118 (Rossi); QIA, 5 (1966-67), 115. 118 (T. M.) ; BICC, 20 (1965), 189. 192 (X).

19-916. LAPESA, R...-'Don Julio Casares (1877-1964)"-BRAE, 44 (1964), 213. 221; $R N a, 1965,42-47$.

19-917. PavlíkovA, S._'Sedmdesátiny Rodolfo Oroze"._-PhP, 8 (1965), 413-414.

19-918. POTTIER, BERNARD - Introduction $\dot{a}$ l'étude de la philologie hispanique. Ts. 1 [3e éd.] et 2 [4e éd.].-Paris, 1964. 122, 156 pp.-V. núm. 16-46346.

19-919. Toscano, Humberto - Hablemos del lenguaje. Ed. por César García Pons.-Joshua B. Powers, New York, 1965. xxi + 457 pp. $\| B I C C, 22$ (1967), 101-102 (Florez).

19-920. Gómez Mayorga, Mauricio-Genio y figura de nuestro idioma._Enigma, México, 1965. 62 pp. (La honda del espiritu).

19-921. Ayala, JuAn ANTonio_Imagen de la lengua española: introducción histórica.-Univ. de Nuevo León, Monterrey, 1963. $135 \mathrm{pp}$. || BHS, 42 (1965), 131 (Hodcroft).

19-922. Isaza Calderón, Baltasar - Co rrecciones de lenguaje._Eds. S. M., Madrid, 1965. 153 pp. $\|$ BICC, 21 (I966), 200-201 (Montes).

19-923. Guitarte, G. L.-."Bosquejo histórico de la filología hispanoamericana".-_SCIC, 230-244.

19-924. FlóreZ, L.-"Presente y futuro de la lengua española. Breve informe sobre el Congreso de Filología Hispánica celebrado en Madrid, 5-12 de 
junio de 1963".-SCIC, 355-359. || PhP, 9 (1966), 335.336 (Dubsky).

19-925. Presente y futuro de la lengua española. Actas de la Asamblea de Filologia del $I$. Congreso de Instituciones Hispánicas. - Cultura Hispánica, Madrid, I964. 2 ts.: 540, 460 pp. II BICC, I9 (1964), 333-342 (Montes); IJAL, 32 (1966), 301-303 (Otero).

19-926. Beinhauer, Werner-El español coloquial. Trad. Fernando Huarte Morton.-Gredos, Madrid, I963. 448 pp. (BRH).-V. núm. 14-38432. || BdFS, 18 (1966), 299-301 (Arancibia Manhey); Ins, 1964, núm. 211 (del Campo); MLR, 64 (1969); 194-196 (Keightley); $R R L, 11$ (1966), 511-515 (Sadeanu); $S C L, 18$ (1967), 101-105 (Sadeanu). 19-927. MORREALE, M._-"El español coloquial: a propósito de la reciente traducción del libro de $W$. Beinhauer".-SLS, 115-134.

19-928. Beinhauer, W.-"Dos tendencias antagónicas en el lenguaje coloquial" $E A c$, 1965, núin. 6 .

19-929. YNdurdin, F.-."Sobre el lenguaje coloquial".-EAC, I964, núm. 3 .

19-930. YNduráis, F._."Más sobre el lenguaje coloquial".-EAC, 1965, núm. 6.

19-931. Beinhaule, W.-"Gracia, ingenio y pocsía del piropo". $-R U B A, 1960$, núm. 1, 35-53. || $L R, 19$ (1965), 6364 (Groult).

19-932. Alonso, D.-"Para evitar la di. versificación de nuestra lengua".- $A \cdot b$, 55 (1969), 7-19; PFE, 2, 259-268.

19-933. Discursos leidos en las recepciones priblicas de la Real Academia Española. Serie tercera. T. I-Atlas, Madrid, 1964. $375 \mathrm{pp}$.

19-934. Alronso, L. “'I.a Comisión Permanente de la Asociación de Academias de la Lengua Española".-CA(4), 43-48.

19-935. PEREira Rodríguez, J.-"Creación de centros interacadémicos de informa. ción idiomática".-CA(4), 57-60.

17-936. ZAMORA Vicente, A.-"Sobre Ia nivelación artística del idiona". $-P F E$, $2,39-49$.

17-937. Terry, E. D.-"The first two language academies in Spanish America".KFLQ 13 (1966), 112-120.

17-938. Echeverri MejíA, O._. "La Academia Colombiana de la Lengua, baluarte del idioma espafiol".-PFE, 2, 103-108.

17-939. "Cuarto Congreso de Academias de la Lengua Española".-BRAE, 44 (1964), 557-560; BAAL, 29 (1961), 439-
448; BICC, 19 (1964), 610-612; CI, 1965, núm. I, 174-179.

19-940. AgüEro, A.-"El IV Congreso de Academias de la Lengua". $-B A C o$, 9 (1964-65), núms. 14/15.

19-941. FLórez, L.-“'Información sobre el IV Congreso de Academias de la Lengua Española".-BACol, 15 (1965), 18.25.

19-942. Conclusiones del Cuarto Congreso de Academias de la Lengua Española. Informe de la Comisión de Enseñanza y Moralidad del Idioma.-Buenos Aires, 1965. 54 pp.

19-943. Bibliographies of books in foreign languages. T. 2: Spanish, Grade 1, through Junior College._Foreign Ianguage Bibliographic Committee, Dade County (1lorida), 1964. 58 pp. $\| H$, 49 (1966), 557-558 (Puig Walsh).

19-944. Heupel, C.-“Spanisch als Schulsprache".-NS, 1963, 430-439.

19-945. Restrepo, F.-"La enseñanza del castellano y de la ortografia"._SCIC, $344-349$.

19-946. GILI GAyA, SAmuel_-_ortografia práctica. 6? ed.-Bibliograf, Barcelona, 1965. I00 pp._.V. num. 9-13849.

19-947. GILI GAYA, SAMUEL-Imitación $y$ creacion en el habla infantil.-Madrid, 1961. 46 pl. || $R P h, 19$ (1965-66) , 131 (Pottier) .

19-948. Rosinblat, ANGEL-Las Nuevas normas ortográficas y prosódicas de la Academia Española.-Oficina de Edu. cación Iberoamericana, Madrid, 1965. 55 pp.-Y. núm. 10-20217.

\section{Textos lingüísticos}

19-949. Fotrtch, T.-An anthology of Old Spanish (N. 18-1013). || BHS, 43 (1966), 57-59 (Hodcroft); Orbis, 16 (1967), 273-274 (Moll) .

19-950. Galmés de Fuentes, A.-."Interés en el orden lingüistico de la literatura española aljamiado-morisca".-CLR(10), 527.546 .

19-951. Lónez Estrada, F.-“Fuentes literarias"'-ELH, 2, 379-392.

19.952. SÁEZ, E.-"Fuentes históricas".ELH, 2, 393-446.

19-953. Tilander, G. - "Fuentes jurídicas".-ELH, 2, 447-460.

19-954. Cantera Burgos, F.-“"Textos de polémica antijudaica y judeo-catalanoaragoneses en un manuscrito de Burgo de Osma".-RFE, 49 (1965), 135144. 
19-955. BALDwiN, S. W., JR.-"Two Old Spanish versions of the Epistle to the Romans".-Mediaeval studies in honor of $U$. T. Holmes, Jr. (Chapel Hill, 1965), 29-42.

19-956. MALkIEL, Y._-Nuggets of linguistic information in critical editions of Siglo de Oro texts".-RPh, 18 (196465), 137-142.

V. también núms. $83,566.9,1176,1251$.

\section{Historia de la lengua}

19-957. MichelenA, L.-Lenguas y pro. tolenguas (N. 18-4740). $\| A U C h, 123$ (1965), 274-276 (Ferreccio Podesta); CuS, 1966, núm. 5, 96-97 (Fontanella).

19-958. BALDINGER, KURT-La formación de los dominios lingïisticos en la Peninsula ibérica. Trad. E. Lledó y $M$. Macau,_Gredos, Madrid, 1963. 398 pp., ilustr. (BRH).-V. núm. 14-40230. Alfa, 1964, núms. 5/6, 147-154 (Caslilho); $R U N P, 1966-67,451-543$ (Díaz V'élez) ; $Z R P h, 83$ (1967), 198-206 (Kuen); $B S V, 20$ (1964), 191.195 (Michelena); Ins, 1964, núm. 211 (Moya Trelles); H, 48 (1965), 380-381 (Spaulding).

19-959. Corominas, J._.'Schmoll's study on Pre-Roman Hispanic languages" (N. 17-628). || RFE, 48 (1965), 204-206 (Llorente) .

19-960. Tovar, Antonio-LLo que sabemos de la lucha de lenguas en la Peninsula ibérica._-Editorial Gregorio dcl Toro, Madrid, 1968. $96 \mathrm{pp}$.

19.961. Garvens, F._"El sustrato éuskaro en España",-CLR(10), 1247-1252.

19-962. IORDAN, Iorgu-Istoria limbii spaniole. (Curs universitar). - Bucuresti, 1963. 190 pp. || SCL, 16 (1965), 423424 (Tudorica).

19-963. d'Arrico Bona, MileddA C.-Storia della lingua. Cenni di storia della lingua e grammalica storica spagnola.Giappichelli, Torino, 1965. viii +167 pp.

19-964. IORDAN, I._“"E] español, tárea lingüística arcaica?”- RFE, 48 (19665), 177 179.

19-965. Fradejas SÁnchez, L.-"Orígenes líricos del español".-Anales, Univ. Central de Quito, 13 (1964), 169-195.

10-966. VÀrvaro, Alberto - Filologia spagnola medioevale. T. 1: Linguistica. T. 2: Letteratura. T. 3: AntologiaLiguori, Napoli, 1965. 3 ts.: 157, 186, $301 \mathrm{pp}$.

19-967. BLAylock, W. C.-Studies in pos- sible Osco-Umbrian influence on Hispano-Romance phonology. - [Tesis, Univ. of California, Berkeley; resumen en $D A, 25 \quad(1964-65), 1899]$.

19-968. PatTison, D. G.-“Quomodo aqua vertit".-BHS, 42 (1965), 251-252. [Expresión usada en documentos españoles de los siglos IX-XI].

19-969. Hons 1 , V._._La extensión de la influencia francesa sobre la estructura del castellano medieval". - $A E M, 2$ (1965), 497-504.

19-970. BeitrÁN Guerrero, L._"La lengua del Rey Sabio".-BANHV, 47 (1964), 34-47.

19-971. Douglass, Ralph Thomas-The evolution of Spanish orthography from 1475 to 1726.-[Tesis, Univ. of Pennsylvania; resumen en $D A, 25$ (1964. $65), 4143.4144]$.

19-972. ZUCKER, GEORGF KENNETH-Linguistic theory of the Siglo de Oro: $A n$ evaluation.-[Tesis, Univ. of Iowa; resumen en $D A, 25 \quad(1964-65), 6611$. $6612]$.

19-973. Garcí Salinero, Fernando_Contribución al estudio del vocabulario español de arquitectura $e$ ingeniería de los siglos xvi y xvii._Facultad de Filosofía y Letras, Madrid, 1965. 36 pp. [Extracto de tesis].-V. núm. 18-4848.

19-974. Restrepo, F._-"Evolución semántica en el castellano de Gonzalo Jiménez de Quesada"-_IDA, 3, 69-129; $A F, 2-3$ (1963-64), 137-194; BACol, 14 (1964), 265-324.

19-975. Llompart, G._."La Real Cédula de 1768 sobre la difusión del castellano y su repercusión en la Diócesis de Mallorca"._BSAL, 33 (1965), 357 379.

19-976. WIS, M- "Uैber den ältesten Ein. fluss des Spanischen auf die deutsche Sprache".-NM, 66 (1965), 619-634. 19-977. DOPpagne, A._-L'apport de l'espagnol an français littéraire, de Barrès à nos jours".-CLR(10), 471-482.

19-978. Beccarla, G. L._"Brio e disinvoltura: due spagnolismi nell'italiano del 500 e 600 come esempio di parole-testimonio e mots-cle letteraric".-Letture Ilaliane, 1965, 432-442.

19-979. Migldorini, B._-A proposito dell'italiano taccagno".-RFE, 48 (1965), 159-163.

V. también núms. 531-3, 556-7, 562-3, 624, $626,921,950,993-4,1004,1031-2,1038-9$, $1045,1176,1188-96,1245-6,1268,1981$, $2251,2533$. 


\section{Fonética}

19-980. Quilis, Antonio.-Fonética y fonologia del español._C.S.I.C., Madrid, 1963. 104 pp. (Cuadernos bibliográficos, 10). $\| B H S, 42$ (1965), 213-214 (Ackinson); $H, 47$ (1964), 661 (Cárdenas); RDTP, 21 (1965) , 195-196 (E. R. P.); Sef, 25 (1965), 213 (Hassán); PhP, 8 (1965), 445 (Pavlíková).

19.981. Canellada, María Josefa-Antologia de textos fonéticos. Pról. de $T$. Navarro._Gredos, Madrid, 1965. 254 pp. (BRH, Textos, 2). || RRL, 11 (1966), 510-51 I (Sandru).

19-982. Navarro, TOMAs_-Manual de pronunciación española. 12: ed.-C.S.I.C., Madrid, 1965. 328 pp. (RFE, publicaciones, 3) .- $T$. núm. 16-46682.

19-983. Thomov, Thomas S.-Ispánska fonétika.-Sofia, 1965. 169 pp. \| PhP, 9 (1966), 220 (Hamplová); RLiR, 30 (1966), 220-221 (Petkanov).

19-984. MalmberG, B. - Spansk fonetih (18-1042). II StN, 36 (I964), 413-418 (Schottländer) .

19-985. Quilis, Antonio, y Josepit A. FerNÁNDEZ Curso de fonética y fonologia españolas para estudiantes angloamericanos. - C.S.I.C., Madrid, 1964. xxvii + 202 pp., ilustr. (Collectanea phonetica, 2) . || H, 49 (1966), 364-365 (Cárdenas) .

19-986. Rodríguez-Castellano, Juan \& Lorenzo-Ejercicios de pronunciación española. Spanish phonological patterns. Scribner's, New York, I955. xi + 110 pp. || BHS, 48 (I966), 302 (Dut. ton); $M L J, 50$ (1966), 303 (LaPrade); H, 49 (1966), 178-179 (Phillips).

19-987. MERINo, JosÉ-La pronunciación del estañol para extranjeros._Editorial Alhambra, Madrid, I965. 116 pp. ilustr.

19-988. Stockwell, Robert P., \& J. Do. NALD BOWEN - The sounds of English and Spanis.h._Univ. of Chicago Press, Chicago, 1965. xi + 168 pp. (Conlrastive siruclure series). $\| R P h, 21$ (196768), 186.200 (Bolinger); $H, 50$ (1967), 199-200 (Saporta).

19-989. LAPESA, R._"Medios para poner cn cjecución el acuerdo número $\mathrm{xx}$ del Congreso de México sobre enseñanza y práctica en escuclas y colegios de la fonética normal del castellano literario"._-TCA, 428-432.

19-990. Catai.Ás, D._-"Nuevos enfoques de la fonologia española"'- $R P h, 18$
(1964-65), 178-191. [Alarcos, Fonologla española, 3* ed.].

19.991. Alarcos Llorach, Emilio-Fonologia española. 4: ed., rev. y aum.Gredos, Madrid, 1965. 290 pp. (BRH).V. núm. 17-646.

19-992. Bits, G. G.- "Examen del concepto de rehilamiento". - BICC, 19 (1964), 18-42. || IJAL, 32 (1966), 169 (Lastra) .

19-993. AlleN, J. H. D., JR.-“Tense/lax in Castilian Spanish".-Word, 20 (1964), 295-321.

19-994. BLaylock, C.-“'The monophthongization of Latin ae in Spanish".$R P h, 18$ (1964-65), 16-26.

19-995. Blaylock, C. - "Hispanic melaphony".- $R P h$, I8 (1964-65), 253-271. II $B I C C, 21$ (1966), 413.414 (Montes).

19-996. Alarcos Llorach, E._-Efectos de la yod sobre la vocal tónica en espanol"._CLR(10), 94.5-950.

19-997. Daniflson, J. D.-"Teaching Spanish /ay/ and /aw/".-H, 47 (I964), 805-806.

19-998. CopceAG, D.-“'Rasgos estructurales ronı́nicos en los diptongos rumanos $e a, o a^{\prime \prime} .-R L i, 9$ (1964), 253-260. [Comparación con el español].

19-999. Quilis, A.- "Datos fisiológico-acústicos para el estudio de las oclusivas españolas y de sus correspondientes alófonos fricativos".-Hom, 1 (1964), 3342. || $R P h, 21(1967-68), 85-86$ (Butler) .

19-1000. SöLL, L._ "Der Zusammenfall von $b$ and $v$ und die Variationen der stimm. haften Verschlusslaute in Ibcroromanisclien"._.BRPh, 3 (1964), núm. 1, 80 . 98.

19-1001. Galmés de Fuentes, A.—“Resultados de - LL- y - LY=, -C'L- en Ios dialectos mozárabes".-RLiR, 29 (1965), 60-97.

19-1002. Anderson, James MAXnell-A structural account of the evolution of intervocalic consonant clusters in Spanish. - [Tesis, Univ. of Washington; resumen en $D A, 25$ (1964-65), 1204].

19-1003. MalmberG, B.- "Obtativo y sujuntivo. A propósito de dos gralĺas".RFE, 48 (1965) , 185-187.

19-1004. MaLkiEL, Y._-Initial points ver. sus initial segments of linguistic trajectories".-PNCL, 402-406. [Sobre tenia, lenié].

19-1005. Matluck, J. H. - "Entonación hispánica".-ALM, 5 (1965) , 5-32.

$\checkmark$. también núms. $399-426,469,486-8$. 
$967,971,1187,1291,1322,1336-7,1346$, $1375,1396,1405-7,2371,3599$.

\section{Gramática}

Morfologia y sintaxis

19-1006. Potrier, B.—“Terminologf́a gramatical".-PFE, 2 393-396.

19-1007. Gili GAYA, S.- "Unificación de la terminología gramatical". - $C A(4)$, 197-]99.

19-1008. LÁzaro Carreter, F._-"Problemas de terminología lingüística".- $P F E$, 2 , 383-392.

19-1009. López VArGas, B.- "Dos épocas de la gramática"._-CI, 1965, núm. 3, 125-131.

19-1010. García, C.-Contribución a la historia de los conceplos gramaticales. La aportación del Brocense (N. 17. 4013). IRPh, 18 (1964-65), 332-834 (Carvalho); $R J, 14$ (1963), 347-349 (Heinimann) ; RDTP, 22 (1966), 215 (Pérez Vidal).

19-1011. Rabanales, A.-“La gramática de la Academia y el estado actual de los estudios gramaticales".-BdFS, 17 (1965), 261-280.

19-1012. BattistessA, A. J.-"Andrés Be!lo, su Gramática y las gramáticas argentinas"._CI, 1965, núm, 3, 141-148.

19-1013. Rosenblat, Ángel - El pensamiento gramatical de Bello: homenaje a don Andrés Bello en el centenario de su muerte.-Ministerio de Educación, Caracas, 1965. 46 pp.-V. núm. 17-657. || $R F E, 49$ (1966), 387-388 (López); Stylo, 1967, núm. 5, 199-201 (Mora Alarcón); $B H i, 69$ (1967), 287 (Redondo) .

19-1014. Isaza Calderón, B.-“Bello y la teoría gramatical".-BRAE, 45 (1965), 345-365.

19-1015. Seco, Manuel-Diccionario de dudas y dificultades de la lengua española. Pról. de S. Fernández Ramírez. 2a ed., aum.-Aguilar, Madrid, 1964. $\mathrm{xx}+516$ pp.-V. núm. 17-4090. PhP, 8 (1965), 102-103 (Shkultéty).

19-1016. Gili Gaya, Samuel_Nuestra lengua materna. Observaciones gramaticales $y$ léxicas._-Instituto de Cultura Puertorriqueña, San Juan de Puerto Rico, 1965. 140 pp.

19-1017. Carballo Picazo, Alfredo-Español conversacional. Ejercicios de gra. matica. 3a ed.-C.S.1.C., Madrid, 1965. 166 pp. (Cursos para extranjeros)_-_V. núm. $18-4777$.
19-1018. Carballo Picazo, Alfredo-Español conversacional. Ejercicios de vo. cabulario. 3a ed. -- C.S.I.C., Madrid, 1965. xxvi + 318 pp.-V. núm. 1646711.

19-1019. Villamana Peco, Elena-La len. gua española enseñada a los extran. jeros. 4a ed.-Librería General, Zaragoza, 1964. 254 pp.-V. núm. 10-17220. 19-1020. Seco, RAFAEL-Manual de gramática española. $7^{\text {a }}$ ed.-Aguilar, Madrid, 1965. xxiv + 324 pp.-V. núm. 17.4041 .

19-1021. AdAMs, Nicholson B., \& HerSCHELL J. FREY-Spanish for today.Holt, Rinehart \& Winston, New York, 1964. $316+\mathrm{xxix}+16 \mathrm{pp}$. $\| H, 49$ (1966), 182 (Carter); $M L J, 49$ (1965), 389-390 (Schwartz).

19-1022. Bull, William E._Spanish for teachers. Applied linguistics.-The Ro. nald Press, New York, 1965. 306 pp. |l $H, 49$ (1966) , 177-178 (McCullough); MLJ, 50 (1966), 295-296 (Turner).

19-1023. Politzer, Robert L., \& C. N. StAuBACH-Teaching Spanish. Revised ed.-Blaisdell, New York-Toronto-London, 1965. $\mathrm{x}+200$ pp... V. núm. 17-667. || $M L J, 52$ (1968), $312-315$ (Agard) ; H, 49 (1966), 553-554 (Tsuzaki).

19-1024. Halm, Wolfcanc, \& José Moli. Marqués - Modernes Spanisch. Ein Lehr-, Ubungs- und Nachschlagebuch für Anfünger. - Hueber, München, 1965. $163 \mathrm{pp}$.

19-1025. SAUER-REISS Spanische Sprachlehre. 24. Aufl.Julius Groos, Heidelberg, 1964. viii $+302,48$ pp.

19-1026. Willers, HermaNN_Spanisch.— Polyglott-Verlag, Köln, 1965. 32 pp. (Polyglott Schnellkurs, 404).

19-1027. Ambruzz1, Lucio_Lengua española. Nuova ed.-S.E.I., Torino, 1964. 386 pp.—V. núm. 16-42829.

19-1028. Iordan, I., \& C. DuhaneanuCurs de gramatica a limbii spaniole. Ed. Didactica si Pedagogica, Bucuresti, 1963. 364 pp.

19-1029. Escudero, Greciorio, \& DUMITrIU CopceaG_Gramatica limbii spaniole, cu exercitii. - Ed. Stiintifica, Bucuresti, 1965. 319 pp. \|L LbR, 15 (1966), 107 . 110 (Sandru) .

19-1030. Fernandez Ramírez, S.—Morfología"._CA(4), 184-191.

19-1031. Badía Marcarit, A.-“La syntaxe historique de l'espagnol",_CDG(1), 3, 192-195. 
19-1032. Badík Margarit, A. M._"Tres notas de sintaxis medieval aragonesa".$F A K, 325-332$.

19-1033. Montes, J. J._-Dos observaciones sintácticas".-BICC, 20 (1965), 138I39.

19-1034. Coste, J, et A. Redondo-Syniaxe de l'espagnol moderne (enseignement supérieur)._Centre de Documentation Universitaire, Paris, 1965. 608 pp. Ins, 1966, núm. 234 (Corrales Egea); $L N L, 1966$, núm. 177, 108-1 I1 (Pottier).

19-1035. Roca PoNs, J.- "El problema de las partes de la oración'...EAc, 1965, núm. 5.

19-1036. Pottier, B.-"Le problème du nombre. Espagnol. (Notes complémentaires) ".-BFS, 43 (I965) , 487-488.

19-1037. Monce, F.- "Los diminutivos en español"._CLR(10), 137-148.

19.1038. Gonzalez Ollé, Fernando_Los sufijos diminutivos en castellano medie. val (N. 18-4792). \|HR, 35 (1967), 183-184 (Blaylock); $R P h, 19$ (1965-66), $310-322$ (Craddock); PhP, 9 (1966), 220 . 222 (Hamplová); RDTP, 22 (1966) , 215.216 (Pérez Vidal).

19-1039. GonzALEz OLLE, F._.'Primeros testimonios de algunos sufijos diminutivos en castellano y nuevos datos para su historia". $C L R(10), 2$, 547-552.

19-1040. NÁÑez, E__¿đUn nuevo sufijo -lito?"-FM, 4 (1965), núms. 19/20.

19-1041. Surrun, A. V.-“Idiomy smestoimenijami la, las $\mathrm{v}$ ispanskom jazyke".-IAN, 24 (1965) , 405-412 ["La de malas", "las de Caín"].

19-1042. YNdurásn, F.- "Sobre un tipo de composición nominal, verbo + nombre".-PFE, 2, 297-302. [Matasellos, etc.].

19-1043. Dubsky, J. — "Intercambio de componentes en las formas descompuestas españolas".-BHi, 67 (1965), 343. 352.

19-1044. Conway, M. Ann Charlotte - Order classes of adjectives in Spanish.-[Tesis, Univ. of Texas; resumen en $D A, 25$ (1964-65), 6607-6608].

19-1045. Paufler, Hans-Dleter-Zu Problemen der Stellung des attributiven Adjehtivs im Altspanischen. - [Tesis, Humboldt-Universität, Berlin, 1964].

19-1046. Solé, Carlos Antonio-Los adjetivos terminados en -al, -ar, -ero, -ico, y -oso en español-[Tesis, Georgetown Univ., 1965].

19-1047. Colón, J.-"Los adjetivos terminados en -al"'_Horizontes, México, 1965, núm. 42.
19-1048. AlFonso, L.... "Los ordinales compuestos".-C CA(4), '173-178.

19-1049. LamíQuiz IbÁÑ̃z, VIDAL_El demostrativo en español, francés, italia. no y portugués.-[Tesis, Univ. de Madrid, 1965; resumen en $R U M, 14$ (1965) , $216]$.

19-1050. "Lalsmo, leismo y loísmo".-TCA, 524-528.

19-105I. Mag Hale, C. F._.'Leísmo y loísmo".-TCA, 469-49I.

19-1052. FerNANdez RAMírtz, S.—“Un proceso lingülstico en marcha".-PFE, 2, 277-285. [Leismo, loísmo y laismo, preposición $a$, pasiva con $s e]$.

19-1053. Montes, J. J.-_Le por les: ¿un caso de economía morfológica?" $-B I C C$, 20 (1965), 622-625.

19-1054. Kenny, M.-.Poise and counterpoise in the presentation of the Spanish self".-AnL, 7 (1965), nún. 4, $79-91$.

19-1055. Lorenzo, E.-“Un nuevo planteamiento del estudio del verbo es. panfol"._-PFE, 1, 471-478.

19-1056. Camps Sarro, F.-La conjugación del verbo español. Lista alfabé. tica de los verbos. irregulares.-Herder, Barcelona, 1965. 52 pp.

19-1057. HEGER, KLAuS-Die Bezeichnung temporal-deiktischer Begriffshategorien im französischen und spanischen Konjugationssystem. - Niemeyer, Tübingen, 1963. viii +244 pp. (Reihefte zur ZRPh, 104). \|IF, 70 (1965). 3557-358 (Engler); $V R, 24$ (1965), 269-301 (Hilty); $A L$, 17 (1965) , 63-66 (Reid) ; Em, 34 (1966), 204 (Sánchez Redondo); $R J, 15$ (1964), 210-216 (Sandmann) ; $R F, 77$ (1965). 144-152 (Schauwecker); $\lambda S, 1964$, núm. 2, 79-8-1 (Soll) .

19-1058. MrNdeloff, IH. - "The passive voice in La Celestina (with a partial reappraisal of Criado de Val's Indice verbal)".- $R P h, 18$ (1964-65), 41-46.

19-I059. Mendelorf, H._."A note on the affirmative commands in old Spanish".PhQ, 44 (1965), 110-113.

19-1060. WILSON, R. E.-"Polite ways to give onders".-FI, 48 (1965), 117-118.

19-1061. Farley, R. A.-"Sequence of tenses: a useful principle?"- $H, 48$ (1965), 549-553.

19-1062. Douvier, Elisabeth-El concepto de verbo auxiliar.-[Diplóme d'études supérieures, Universidad de Estrasburgo, 1964].

19-1063. Navas RuIz, RICARDo-"Ser" y "estar". Estudio sobre el sistema atri- 
butivo del español.-Universidad, Salamanca, 1963.214 pp. (AcS, 17, núm. 3). $\| R L S P, 5$ (1964), 303-305 (Dias Martins); $B H S, 43$ (1966), 217-221 (González Muela); HR, 34 (1966), 343346 (Roca-Pons).

19.1064. VermeyLen, A... “L'emploi de ser et de estar: question de sémantique ou de syntaxe?"-BHi, 67 (1965) , 129-134.

19-1065. Roca Pons, J._-"Le sujet et le prédicat dans la langue espagnole". RLiR, 29 (1965) , 249-255.

19-1066. Badía Margarit, A. M._'El gerundio de posterioridad".. $P F E, 2,287$ 295.

19-1067. Gerrard, Allen Georre- $A$ study of the usage of the Spanish locative adverbs "aqul" and "ach'".-[Tesis, Univ. of Michigan; resumen en $D A, 25$ (1964. 65) , 462-463].

19-1068. GamillschfG, E._"Uber Präposition und Adverb im Spanischen".FHR, 120-139.

19-1069. Skultitty, JozeF_-"Algunos aspectos metodológicos del estudio de las preposiciones". $-P h P, 7$ (1964), 85-87.

19-1070. SIlva Borba, F. DA "Empregos ibéricos da preposição de".-Alfa, 1965, núms. 7/8, 173-198.

19-1071. PEUSER, GüNTER-Die Präposition "de" im modernen Spanischen. Ihre Leistung als Ligament und Semantem.[Tesis, Univ. de Friburgo de Brisgovia, 1965$]$.

19-1072. JACKSON, R., \& D. BOLINGER“Trabajar para'.-H, 48 (1965), 884. 886.

19-1073. Shenton, C. G.—Bajo and debajo de".-H, 47 (1964), 362-366.

19-1074. BREND, RutH MARGARET-A tagmemic analysis of Mexican Spanish clauses.-[Tesis, Univ. of Michigan; resumen en $D A, 25(1964-65), 2972]$.

19-1075. YEPES, J. M.-_Los neologismos de constucución como elemento que atenta contra la unidad del castellano"...TCA, 536-541.

19-1076. Alonso, Martín__Ciencia del lenguaje y arte del estilo. 6a ed.-Aguilar, Madrid, 1964. xxxii + $1638 \mathrm{pp} . \mathrm{V}$. núm. 16-46648.

V. también núms. 427-438, 565, 575-588, 3640-1.

\section{Lexicografía y semántica}

19-1077. DeGoroc, R.-."Trends in Spanish vocabulary". $-H, 48$ (1965), 645667.
19-1078. Salas S., A. "Sobre el estudio del vocabulario".-Stylo, 1965, núm. $1,31-40$.

19-1079. Duchíces, O., у E. SpJtzovA"Diferentes tipos de relaciones semánticas y problemas de los campos lingüísticos".-AO, 15 (1965), 59-72. [En francés y en español].

19-1080. Colón, G.--El Diccionario critico etimológico de la lengua castella. $n a$ de Corominas" (N. 17-4081). $\| R F E$, 48 (1965), 216-217 (Llorente).

19-1081. ZAMORA, ANTONIO-Diccionario de sinónimos. $3^{\text {a }}$ ed.-Claridad, Buenos Aires, 1964. 326 pp.—V. núm, 16-46795.

19-1082. SAINZ DE ROBLEs, F. C.-Ensayo de un diccionario español de sinónimos $y$ antónimos. 6: ed.-Aguilar, Madrid, 1965. 1152 pp.-V. núm. 14-40307.

19-1083. Cruz Aufrere, José, y RenÉ OrTUGTE-Antónimos castellanos. - Don Bosco, Cochabamba, Bolivia, 1965. 209 pp.

19-1084. Cheyne, G. J. G.-A classified Spanish vocabulary.G. G. Harrap, London, 1964. 23 pp. \|BHS, 44 (1967), 142-143 (Raventós).

19-1085. Juilland, Al.phonse, \& E. ChangRODR1GUEZ - Frequency dictionary of Spanish words.-Mouton, The Hague, 1964. ]xxviii + 500 pp. $\| H, 49$ (1966), 367-370 (Cárdenas); Lan, 42 (1966), 817-821 (Contreras); HR, 35 (1967), 270-272 (Lloyd) ; $Z R P h, 81$ (1965), 476483 (Muller).

19-1086. Duden español. Diccionario por la imagen. 2: ed., corr.-Harrap, London; Juventud, Barcelona, 1963. 792 pp. || MLR, 60 (1965) , 133-134 (Stopp) . 19-1087. Diccionario enciclopédico abrevia. do Espasa. Apéndice A-Z.-Espasa-Calpe, Madrid, 1965. 1575 pp., ilustr.V. núm. 18.1138.

19-1088. Diccionario hispánico universal. 10: ed.-W. M. Jackson, México, 1964. 2 ts.: 3000 pp., ilustr._V. núm. 16-46788. 19-1089. Pequeño Larousse ilustrado. Por M. de Toro y Gisbert. Ref. y aum. por R. Garcia Pelayo__Larousse, Paris, 1964. 1664 pp.—V. núm. 18-1139. I| $B A C o l, 15$ (1965), 406-407 (Restrepo). 19-1090. Apéndice al "Diccionario enciclopédico UTEHA".-UTEHA, México, 1964. 2 ts.: 2439 pp., ilustr.-V. núm. 11-24349.

19-1091. Vox. Diccionario enciclopédico ilustrado. Reimpresión actualizada.Biblograf, Barcelona, 1965. 3 ts.: 3000 pp., ilustr._V. núm. 17-704. 
19-1092. Gerrard, A. Bryson, \& José DE Heras_Beyond the dictionary in Span. ish: a handbook of colloquial usage.Funk \& Wagnalls, New York, 1964. 160 pp.-.V. núm. 14-40308. $\| M L J_{3} 5 \mathrm{I}$ (1967), 231 (Bounds); $H, 48$ (1965), 402-403 (Fish).

19-1093. Blanco García, Vicente-Diccionario ilustrado latino-español, español-latino. $7^{\text {a }}$ ed.-Aguilar, Madrid, 1968. 665 pp.-V. núm. 17-4130.

19-1094. BilkenRoth, GEORG - Sechssprachiges Wörterbuch für Gebirgsdruckfragen: Deutsch, Englisch, Französisch, Russisch, Tschechisch und Spanisch. Bearb. v. H. Schmidt.-Akademie-Verl. Berlin, 1965.

19-1095. Corbière, A., et D. LautterDictionnaire espagnol-français.-Bouret, Paris, 1965.

19-1096. Ambruzzi, Lucio-Nuovo dizionario spagnolo-italiano e italiano-spagnolo. 6? ed.-Torino, 1963. 2 ts.-V. núm. 16-42910. || RRo, 3 (1968), 187 (Hoybye) .

19-1097. Fucilla, Joseph G.-Fucilla Spanish dictionary. (Español-inglés, inglés. español). Ed. rev.-Follet, Chicago, I964. 332 pp.

19.1098. Gillhofr, G. A.-Black's Spanish dictionary.-A. \& C. Black, London, 1964. xii $+126 \mathrm{I}$ pp. $\|$ BHS, 42 (I965), 182-I83 (Hall).

19-1099. Guerra da Cal, Ernesto (ed.) The new Applecon dictionary: EnglishSpanish, Spanish-English. Rev, and abridged._Doubleday, Garden City, N. Y., 1964. xiv + 306, xii + 243 pp.V. nưm. 10-16236. || $M L I, 51$ (1967), $30 \mathrm{I}$ (Arnold); $H, 47$ (1964), 892-893 (Stavrou) .

19.1100. Diccionario inglés-español, español-inglés. Pról. de Carlos F. MaciHale.Bibliograf, Barcelona, 1964. 1450 pp. (Vox).

19-1101. Revilla, Armando - Deutsch. Spanisch auf Baustellen. 2. Aufl.-Neuınann, Hannover-Klcefeld, 1964.

19.1102. Filipovici, Nicolae, \& Raúl SERRANo PÉREZ-Diclionar spaniol-romîn. —Ed. Stiintifica, Bucuresti, 1964. xcvi + 1010 pp. If SCL, I6 (1965), 565566 (Tudorica).

19-1103. NeIKov, T.-Diccionario españolbulgaro._Ciencia y Arte, Sofia, 1964. viii + $948 \mathrm{pp}$.

19-1104. Martínez Calvo, Lorenzo-Diccionario ruso-español.-R. Sopena, Barcelona, 1965. 1952 pp.
19-1105. Ducach, JUAN-Nuevo diccionario castellano-hebreo, Mil-lon Sefaradi. Ibri. Redactado y compilado por..., corregido y rev. por M. Konstantynowsky. T. 1: $A-K$-Editora Massadah, Tel Aviv, 1964. 731 pp. \|Sef, 25 (1965), 99-101 (Millás).

19-1106. Dyk, ANNe, \& Betti Stoudt-Vo. cabulario mixteco de San Miguel el Grande.-Inst. Lingüístico de Verano, México, 1965. 192 pp. (Vocabularios indigenas, 12). || IJAL, 33 (1967), 257 258 (Kaufman).

19-1107. Schoenhals, Alvin, \& Louise C. Schoenhals_Vocabulario mixe de Totontepec: mixe-castellano, castellanomixe.-Inst. Lingüistico de Verano, México, 1965. 353 pp. (Vocabularios indigenas, I4) .

19-I108. Slocum, Marianna C., \& Florencia L. GERDEL-Vocabulario tzeltal de Bachajón: castellano-tzeltal, tzeltal-castellano.-Inst. Lingüístico de Verano, México, 1965. 2I5 pp. (Vocabularios indigenas, 13).

19.I109. Delgaty, C. C. - Vocabulario tzotzil de San Andrés, Chiapas_-Inst. Lingüístico de Verano, México, 1964. 81 pp. (Vocabularios indigenas, 10).

19-1110. Ortiz Mayans, Antonio-Diccionario español-guarani. 9? ed.-Autor, Buenos Aires, 1965. $356 \mathrm{pp} \_$-V. núm. 17.744 .

19-1111. Serrano Laktaw, Pedro-Diccionario hispano-tagálog y tagálog-hispano. Reprod. facsimil de la ed. de Manila (1889-1914) .Cultura Hispánica, Madrid, I965. 3 ts.: 2069 pp.

I8-1 I I2. Paluzie-Borreel, J-Diccionario esperanto-español y españolesperanto. Selección de 25,000 voces con los términos usuales y cientificos.-Sopena, Barcelona, 1967. 381 pp.

19-1113. Elsevier's dictionary of acronaulics in six languages: English-Anerican, French, Spanish, Italian, Portugiese and German. Comp. and arrang. ed by A. F. Dorian and J. Osenton.Elsevier, Amsterdam-New York, 1964. $842 \mathrm{pp}$.

18-1114. Elsevier's lexicon of archive terminology: French, English, German, Spanish, Italian, Dutch. Compiled and arranged on a systematic basis by a committee of the International Council on Archives.-Elscvicr, Amsterdam. Nicw York, 1964. 83 pp.

19-1115. Elsevier's lexicon of pressurized packaging (aerosols). Comp. and arrang. 
ed by A. Herzka._-Elsevier, Amsterdam, 1964. $170 \mathrm{pp}$.

19-1116. MostNy, G.-_Diccionario antropológico poligloto"._Vle Congrès International des Sciences Anthrop. et Ethnol., Paris, 1963, t. 2, 203-209.

19-1117. Carnelutti, D.-Diccionario técnico del automóvil. Ed. en español, francés, italiano, inglés y alemán.Gili, Barcelona, 1965. 580 pp.

19-1118. Plass, Carlos Diccionatio técnico-gráfico del automóvil. - Blume, Barcelona, 1965. 208 pp., ilustr.

19-1119. Frías SUCRE, A.-Diccionario comercial español-inglés, inglés-español. 2a ed. - Editorial Juventud, Barcelona, 1965. $300 \mathrm{pp}$.

19-1120. Reyes Orozco, Carlos-Diccionario de comercio y economía, ingles. español.-Centro Anglo-Mexicano del Libro, México, 1965.

19-1121. Budic, Domingo Varentín-Diccionario del comercio exterior.-Ergon, Buenos Aires, 1965. 224 pp.

19-1122. SELL, LEwIS L.-Diccionario para especialistas, español-inglés.—Banca y Comercio, México, 1965. $650 \mathrm{pp}$.

19-1123. Daoud, D.- "Lenguaje profesio. nal de los bancarios".- $B A T F, 1955$, núms. 61-66, 122-123.

19-1124. Pina, RAfael DE-Diccionario de derecho-_Porrúa, México, 1965. 329 pp.

19-1125. RoBB, Louis A.-Diccionario de términos legales. Español-inglés, inglés. español.-Limusa-Wiley, México, 1965. $228 \mathrm{pp}$.

19-1126. Diccionario demográfico plurilingïe. Volumen español. Reed.--Naciones Unidas, New York, 1965.

19-1127. Junco, A._"El léxico en los deportes".-CA(4), 349-351.

19-1128. Léxico de economia. Preparado por el Inst. de Estudios Políticos de América Latina. Trad. de J. Verde Aldea.-Estela, Barcelona, 1964. 100 pp.

19-1129. RIERA, Víctor_Vocabulario eco. nómico.-Centro de Estudios y Documentación Sociales, México, 1964. 106 pp.

19-1130. Heller, Wolfgang-Diccionario de economia politica. Trad. F. Estapé.Labor, Barcelona, 1965. 470 pp. \|CuA, 1967, núm. 4, 244-245 (de la Selva).

19-1131. Elsevier's electrotechnical dictionary in six languages: English/American, French, Spanish, Italian, Dutch and German. Comp. by W. E. Clason.Elsevier, Amsterdam-New York, 1965. $730 \mathrm{pp}$.
19-1132. "Equivalencias en electrotecnia".-BACol, 15 (1965), 48-53.

19-1133. BERNER, G, A.-Illustrated professional dictionary of horology.-Swiss Watcl 1 Chamber of Commerce, LaChaux-de-Fonds, Suisse, 1965. [Francés-inglés-alemán-español].

19-1134. Elsevier's zuood dictionary in seven languages. T. 1: Commercial and botanical nomenclature of world-timbers._Elsevier, Amsterdam-New York, 1964. 479 pp.

19-1135. García Rodríguez, MarianoDiccionario malemático español-inglés, inglés-español._Hobbs Dorman, New York, 1965. 78 pp.

19-1136. VERA, FRANCISCO_Lexicón Kapelusx: Matemática_Kapelusz, Buenos Aires, 1964. 744 pp.

19-1137. VALERO RIVAs, J-Enciclopedia Salvat de ciencias médicas. $2^{\mathrm{a}}$ ed.-. Salvat, Barcelona, 1965. 5 ts.: 5184 pp., ilustr.

19-1138. RuIz TORREs, Francisco-Diccio. nario inglés-español, español-inglés, de medicina. $3^{\text {a }}$ ed.-Alhambra, Madrid, 1965. 714 pp.-V. núm. 16-46827.

19-1139. Mommsen, H.-Diccionario inédico Labor para la familia. Trads. J. Massot Gimeno y J. Vilhur Pedrals. 2a ed.-Labor, Barcelona, 1965. xii + 816 pp., ilustr,—V. núm. 17-4126.

19-I140. HEILER, TON」-Diccionario técnico ilustrado de herramientas de corle para el trabajo de metales. Españolalemán-inglés-francés-italiano._G. Gili, Barcelona, 1965. 474 pp.

19-1141. Elsevier's dictionary of rolling mill terminology in four languages. Comp. and arranged by G. F. Herscu.Elsevier, Ansterdam, 1965. 346 pp. 19-1142. Léxico siderúrgico español-inglés, inglés-español. Preparado por la Comisión de Terminología Siderúrgica.-Compañía de Acero del Pacífico, Huachipato, 1965. $144 \mathrm{pp}$.

19-1143. Schramm, HERBERT Friedrich WILHELM - Bürofach-Begriffe in vier Sprachen: Deutsch, Englisch, Franzö. sisch, Spanisch. — Burghagen, Hamburg, 1964.

19-1144. García HOz, Víctor-Diccionario de pedagogia._Labor, Barcelona, 1964. 847 pp. || CuA, 1967, núm. 4, 242. 245 (de la Selva).

19-1145. Elsevier's oilfield dictionary in five languages. Ed. and arranged by J. Moltzer,-Elsevier, Amsterdam, 1965. $162 \mathrm{pp}$. 
19-1146. LAPEsA, R.-"Términos de la industria del petróleo".-BACol, 15 ([965), 389-391.

19-1147. HAENSCH, GüNTHER-Diccionario de relaciones internacionales $y$ de po. litica. Sistemático y alfabético. Alemán, inglés, francés, español-Hueber, München, 1965. xv + 638 pp.

19-1148. Elsevier's dictionary of industrial chemistry in six languages: English/ American, French, Spanish, Italian, Dutch and German. Comp. by A. F. Dorian, - Elsevier, Amsterdam, New York, 1964. 2 ts.

19-1149. KöNrG, FRANz_Diccionario de las religiones. Trad. de Eduardo Valentí.-Herder, Barcelona, 1965. 816 pp. (Biblioteca Herder).

19-1150. Viroux, Alain_Léxico de sociologia._Estela, Barcelona, 1964. 75 pp.

19-1151. Enciclopedia Salvat de la cien. cia y de la tecnologia._-Salvat, Barcelona, 1964. 3 ts., ilustr.

19-1152. Gili Gaya, S.-"El lenguaje de la ciencia y de la técnica".._PFE, 2, 269. 276.

19-1153. Palacios, J.- "Los neologismos en la ciencia y en la técnica".- $B R A E$, 44 (1964), 421-424.

19-1154. Terminologia usual en la ciencia y técnica de la telecomunicación. 3: impresión.-Madrid, 1965. 382 pp. [Español, francés, inglés].

19-1155. Alfonso, L._-EI estudio de las expresiones técnicas y científicas"._CA (4), 276-284.

19-1156. Echeverri MejiA, O.-["Vocabularios técnicos']. $E A C, 1964$, núm. 3; 1965 , núms. 4, 5, 6; 1966 , núms. $7,8$. [Aviación, medicina, petróleo, etc.].

19-1157. Chambers, Wili.ram-Diccionanio tecnológico español, inglés, francés, alemán. Trad. de Carlos Botet. $2^{a}$ ed.Omega, Barcelona, 1964. 2 ts.-V. núm. 9-1\$871.

19-1158. Vocabulario técnico. Inglés-espanol. English-Spanish. Nueva ed., rev. y ampliada. - Espasa-Calpe, Madrid, 1964. $176 \mathrm{pp}$.

19-1159. Obermüller, D. Rodolfo, y Carlos Witthaus-Diccionario teologico-eclesiástico._Vox Evangelii, Buenos Aires, 1965. (Bibl. de estudios teoldgicos).

19-1160. Elsevier's lexicon of international and national units: English-American, German, Spanish, French, Italian, Japanese, Dutch, Portuguese, Polish, Swedish, Russian. Comp. and arranged by
W. E. Clason,-Elsevier, AnsterdamNew York, 1964. 75 pp.

19-1161. LApesa, R.- “Los diccionarios de la Academia".-BAAL, 30 (1965) , 39 45; $B A C o l, 15$ (1965), 284-287; CA(4), 228-231.—V. núm. 18-4813.

19-1162. Huacuja, D._-"Urgencia de incluir en el Diccionario de la Real Academia Española algunos nombres gentilicios, étnicos o nacionales".-CA(4), 354362.

19-1163. Trjeira, G. B., \& M. Mejía DuTARY - "Revisión de algunas definiciones zoológicas y botánicas en el Diccionario académico"__CA(4), 341-345.

19-1164. LloRÉNs, W.-"Observaciones crfticas a algunos americanismos que figuran en los diccionarios de la Real Academia Espantola"._-CA(4), 247-256.

19-1165. LloRÉNS, W._"PuertorTiqueñismos y americanisinos que faltan en el Diccionario de la Real Academia Española". - $C A(4), 256-270 ; B A A C, 3$ (1967), $42 \mathrm{l} \cdot 454$.

19-1166. Ceballos, L.- "Dos notas para el Diccionario académico"._BRAE, 47 (1967) , 383-390.

19-1167. Casares, Julio-Novedades en el Diccionario académico. 2: ed.-Aguilar, Madrid, 1965. 200 pp. (Col. lite. raria)._. $\mathrm{V}$, núm. 18-4886.

19-1168. "Enmiendas y adiciones a los diccionarios de la Academia aprobadas por la corporación".-BRAE, 45 (1965), 41-64., 477-491.-V. nưm. 18-4887.

19-1169. MINEA, SANDA-Sa vorbim spaniola. Exercitii lexicale.—Ed. Stiintifica, Bucuresti, 1965. 206 pp.

19-1170. SANDRU, T.—Despre fizionomia lexicala a spaniolei contemporanea".$S C L, 16$ (1965) , 835-842. [Y trad. española en $R R L, 10$ (1965), 40I-408].

19-1171. Rosenblat, A.- "Afectación y naturalidad [en el léxico español]".-[En su libro] La primera uisión de A mérica (Caracas, 1965), 203-218.

19-1172. Moony, R.-“Problems of teaching journalism in Spanish".-H, 48 (1965), 302-304. [Aspectos Iéxicos].

19-1173. García Pérez, Manued-Tratado elemental de etimologia greco-latinocastellana y latina._Jus, México, 1965. 352 pp.

19-1174. Hasler, JunN A.-Etimos griegos, latinos y nahuas.-Univ. Veracruzana, Jalapa, México, 1965. 155 pp.

19-1175. DozY, Reinhart A. P., et W. H. ENGELMANN-Glossaire des mots espagnols et portugais dérivés de larabe. 
2e éd. (Leyde, 1869). A reprint.Oriental Press, Amsterdam, 1965. xii + 428 pp.

19-1176. MARTínez Ruiz, J._._Léxico de origen árabe en documentos granadinos del siglo xvi".- RFE, 48 (1965), 121-133.

19-1177. Isaza Calderón, B.- "Diccionatio de anglicismos".-CA(4), 273-276.

19-1178. Alfaro, Ricardo J.-Diccionario de anglicismos. 2: ed.-Gredos, Madrid, 1964. 480 pp.—V. núm. 6-6851. I $B I C C, 20$ (1965), 150-151 (Flórez); $H$, 48 (1965) , 609-610 (Levy) ; BACol, 15 (1965), 402-406 (Restrepo).

19-1179. Peral.es, A. M.-_"The audiolingual approach and the Spanishspeaking student".- $H, 48$ (1965), 99102. [El problema de los "pochismos" o anglicismos].

19-1180. García de Diego, Vicente-Etimologias españolas.-Aguilar, Madrid, 1964. 728 pp. (Col. Cullura e historia).

19-1181. García de Diego, V.-"El len. guaje natural".- $R F E, 48$ (1965), 145151.

19-1182. García dE Diego, V.-'Etimologías naturales".-RDTP, 20 (1964), 3-39; 21 (1965), 3-39.-V. núm. 18 . 4894.

19.1183. Follex, T.-Dictionary of Spanihs idioms and colloquialisms.-Blac. kie, London, 1965. 68 pp. || $B H S, 44$ (1967), 143-144 (Smith).

19-1184. LAvin, James Duncan-A study of Spanish firearms.-[Tesis, Florida State Lniversity, 1964].

19-1185. Tilander, G._"Chasse des taureaux en Espagne"._VR, 23 (1964), 117-129. [Y trad. portuguesa en $R P$, 30 (1965), 94-107].

19-1186. WeBber, E. J._."A lexical note on afortunado 'unfortunate' ".- $H R$, 33 (1965), 347-359.

19-1187. Navarro, T.__Geografía peninsular de la palabra aguja”._RPh, 17 (1963-64), 285-300. || BICC, 20 (1965), 176 (Montes).

19-1188. Montgonery, T._"A datum for the listory of Castilian alguien and nadie".-HR, 33 (1965), 52-57.

19-1189. Montcomery, T.- "Auer $y$ en la Biblia Escurialense",_-_BHi, 67 (1965), 339-341.

19-1190. Corominas, J.-"Sur un mot de l'Archiprêtre de Hita et l'origine de l'espagnol badulaque"._- $M M D, 1,113$. 120.

19-1191. Harris, M. R.-"Bufo, 'owl' or 'toad' in the Libro de los gatos?', - $H R$, 33 (1965), 147.151.

19-1192. SALAS, A._El campo semántico de burla en el español literario".. $B d F S, 17$ (1965), 363-406.

19-1193. Hubschmid, J._."Aspan., agaliz. busto 'Weideland' und spätlat, bustar 'Ochsenstall' ",_ZRPh, 80 (1964), 102. 119. $\| R F, 49$ (1966), 394-395 (Llorente).

19-1194. Piel, J. M. - "Bemerkugen zu hisp.-mlt. bustum"._ZRPh, 82 (1966), 355-358.

19-1195. Ferreccio PodestA, M.- "Cenllos".-ALM, 4 (1964), 257-259.

19-1196. Roudil, J.- "Note brève sur cenllo, cenllos."-AEM, 2 (1965), 505 507.

19-1197. Isaza Calderón, B.-"Las expre. siones concejo y consejo municipal". CA(4), 345-348.

[9-1198. Bertini, G. M._"Hadeduro" SLS, 323-334.

19-1199. MAcDonaLd, G. J.-.'Hamihala, a hapax in the Auto de los Reyes $\mathrm{Ma}$. gos".-RPh, 18 (1964-65), 35-36.

19-1200. MAI.KIEL, Y., \& M. R. LIDA DE MALKIF_-"The Jew and the Indian: traces of a confusion in the Hispanic tradition".-For Max Weinreich (The Hague, 1944), pp. 203-208. [Sobre judio/indio].

19-1201. Colós, G._- "En torno al espafol meaja".-FAK, 333-338.

19-1202. Weiner, J-_"Sobre el origen de las palabras moscovia y moscovita".$H, 47$ (1964), 135-136.

19-1203. GONZÁLEZ LóPEZ, L_-El mote, contribución preciadísima al idioma castellano".-BIEG, 9 (1963), núm. 35.

19-1204. Casullo, F. H._."Disquisiciones sobre la palabra poncho. Americana o española?"-BAAL, 29 (1964), 85-100.

19-1205. Griffin, D. A.-."El castellano ralea ¿arabismo desconocido?"- $B R A E$, 44 (1964), 107-111.

19-1206. Wilson, R. E.- "The real real".$H, 47$ (1964), 129.132.

19-1207. Geiger, W. E., \& P. SMith-"The etymology of Hispanic sosegar".-PhQ, 43 (1964), 112-122.

19-1208. Oltver Asín, J._"Una y mil veces".-AlAn, 29 (1964), 179-197. [Origen árabe de la expresión].

19-1209. Seibel, Ernst August-Einige Aspekte der Komik in spanischen "modismos".-[Tesis, Univ. de Colonia, 1964].

19-1210. MeLendo, A.- "De las locuciones en español"._L $L L, 1965$, núm. 2, 1-31. 
V. también núms. 301, 439-69, 531, 589. $609,826,855-8,973-4 \quad 1015-6,1018$, $1225,1268,1323-8,1347-52,1359,1364-6$, $1391,1418,1444,2517,2979,3034,4054$.

\section{Toponimia y antroponimia}

19-1211. Bartina, S._"España 'isla de emporios" "-Sef, 25 (1965), 72-77.

19-1212. García Blanco, M.- "Nombres de Iugar en España y en América".PFE, 1, 44.9-460.

19-1213. Tovar, A._-Les Celtes en Bétique"._ECel, 10 (1962), 355-373.

19-1214. Tovar, A.-"Baedro (y no Baebro) en Plinio y epigrafía de la región de los Pedroches".-Zeph, 13 (1962) , 105-106.

19-1215. Menéndez Pidal, R.-“Onomástica inspirada en el culto mariánico".CI, 1965, núm. 1, 9-17. \| BICC, 21 (I966), 403-404 (Zuluaga Ospina).

19-1216. Uría Ríu, J, y C. BOBEs-_La toponimia de busto en el N.O. peninsular"._. $A O, 24$ (1964), 74-102.

19-1217. Rubio, F.—“Toponimia menor del Valle Gordo (León) "-_RDTP, 20 (1964) , 77-89._V. núm. 17-840. $B I C C, 21$ (1966), 228-229 (Suárez Pineda) .

19-1218. Sevillano, V.-“Topónimos zamoranos de aspecto vasco".-BSV, 21 (1965), 69-72.

19-1219. Esparza, E. J.— "De toponimia navarra".-PV, 25 (1964), núms. 94/ 95; 26 (1965), núms. 98/99.

19-1220. SÁENz Ridruejo, F._."Formas medievales de topónimos sorianos".Celt, 13 (1963), 217-230.

19-1221. Llorente Maldonado dE GueVARA, A.- "La toponimia árabe, mozárabe y morisca de la provincia de Salamanca"_-MEAH, 12/13 (1963-64), 89.112.

19-1222. Bosch VILA, J.-"Notas de toponimia para la liistoria de Guadalest y su valle".-MEAH, 12/13 (196364) , $47-74$.

19-1223. PIEL, J. M._“"Compostela".$R F, 77$ (1965), 121-125.

19-1224. Martínez Cabello, G.-"Conjeturas acerca de la nomenclatura de El Franco".-BIEA, 1965, núm. 54, 151.156.

19-1225. Pensado, J. L.- "Hidrotopónimo de origen lustral: Lavacolla".ASNS, 202 (1965), 182-186. [Y la etimologia de colla].

19-1226. PIEL, J. M.-"Pancorvo, Pande. rreices, Pamporquero und andere mit lat. pandus zusammengesetzte spanische Ortsnamen". - Namenforschung: Festschr. für Adolf Bach (Heidelberg, 1965), 264-260.

19-1227. GonzÁlez, J. M. - "Amanum portus, Flaviobriga y Bilbao".-AO, 15 (1965), 157-167.

19-1228. Floriano Cumbreño, antonioOrigen, fundación y nombre de Oviedo".-SCA, 176-190.

19.1229. Rodríguez Adrados, $F$._. “Solia, Contosolia y el nombre del Zújar".$R F E, 48$ (1965), 171-176.

19-1230. Farkas, Z. J.-“The challenge of the name America".-Names, 13 (I965), $1 \mathrm{I}-18$.

19-I231. BAR-LEWAW, I._."América Iatina, Iberoamérica, Hispanoamérica?"Norte, I965, núm. 2.

19-1232. RichthofEN, E. von-Tse Spanish toponyms of the British coast, with sideglances at those in the States of Washington, Oregon, and Alaska. Ukrainian Free Academy of Sciences, Winnipeg, 1963. 22 pp. (Onomastica). I| Names, 19 (1965), 66-67 (Zyla) .

19-1293. ARrom, JOSÉ JUAN-Historia $y$ sentido del nombre de Cuba.Academia Cubana de la Lengua, La Habana, 1964. 23 pp.

19-1234. BARNES, WILL C._Arizona place names. 2nd. ed. N. (17.4203). \| RPh, 19 (1965-66), 599-600 (Shipley).

19-1235. Hankey, Clyde T.-A Colorado world geography. - University Press, Alabama, $1960 . \mathrm{x}+82$ pp., mapas. (Publ. of the Amer. Dial. Soc., 34). $R P h, 18$ (1964-65), 524 (Malkiel).

19-1296. ANAya Monroy, FernandoLa toponimia indigena en la historia y la cultura de Tlaxcala.-Instituto de Investigaciones Históricas, Universidad Nacional Autónoma, México, 1965. $187 \mathrm{pp}$.

19-1237. SÁnchez Dextre, Nello Marcos-Proceso etimológico de la palabra "Callao"._Lima, I964. 32 pp.

19-1238. Vidal de Battini, B. E.-“Toponimia.-[En] La Argentina: suma de geografía (Buenos Aires, 196I), t. 8, pp. 275-386.

19-1239. NúÑEZ, BENJAMf́N_Términos topográficos en la Argentina colonial (1516-1810). - Instituto Pan-Americano de Geograffa e Historia, Rio de Janeiro, 1965. $35 \mathrm{I}$ pp._V. núm. 12-31004. 19.1240. Rosenblat, ANGEL $-E l$ nombre de la Argentina._Eudeba, Buenos Ai- 
res, 1964. 88 pp., ilustr. (Biblioteca de América).

19-1241. ARcE, J.- "República Argentina o Nación Argentina". — BAAL, 29 (1964), 421-431.

19-1242. VlDAl de Battini, B. E.-"Nomenclatura geográfica popular".-[En] La Argentina: suma de geografía (Buenos Aires, 1961), t. 8, pp. 387-448.

19-1243. KoeEssler-ILG, B. - "Etimología de algunos topónimos según informantes araucanos".-Tradiciones Araucanas, La Plata, 1 (1962), 271-282.-V. núm. 18.1264.

19-1244. FidALgo, ANDRÉs-Breves toponimia y vocabulario jujeños.-La Rosa Blindada, Buenos Aires, 1965. $58 \mathrm{pp}$.

19-1245. UNTERMANN, JÜRGEN-Elementos de un atlas antroponimico de la His. pania antigua.-C.S.1.C., Madrid, 1965. 199 pp., ilustr. (Biblioteca praehistorica hispana, 7). $\| B z N, 2$ (1967), 287.290 (Tovar).

19-1246. Albertos, M. L.-"Nuevos antropónimos hispánicos". - $E m, 32$ (1964), 209-252; 33 (1965), 109-143.

19-1247. Alyarez, Grace de Jesús-Topónimos en apellidos hispanos: un estudio onomástico. - [Tesis, Univ. of Southern Calif.; resumen en $D A, 25$ (1964-65) , 2503-2504].

19-1248. MúcicA, Jost A.-Los apellidos de Iberia. (Su origen y evolucion).-Sendo, Bilbao, 1965. 304 pp.

19-1249. Ferro Couselo, J.-“'Onomástica caballeresca en Galicia y en Portugal".- $A C E, 3,229-230$.

19-1250. JANNer, H.-"Reflejos onomásticos de las relaciones hispano-germanas".--CCO(7), 3, 389-399.

19-1251. Alvar, M.-"Onomástica, repoblación, historia. (Los Establimentz de Jaca del siglo XIII)".- $C C O(7), 3,27$. 52.

19-1252. Meo Zilio, G._-“Appunti di onomastica rioplatense. (Comportamenti grafici e fonetici dei cognomi italiani nel Plata)",- $C C O(7), 3,227-239$.

V. también núms. $470-80,660-70,1330$, 1400-1.

\section{Paremiología}

19-1253. Di Filippo, Luis-Antología humoristica del refranero._Cajica, Buenos Aires, 1965. || USF, 1965, núm. 64, 374 (A. F. L.)

19-1254. KRAUSS, WERNER-Die Welt im spanischen Sprichwort. Spanisch und
deutsch._Ph. Reclam, Leipzig, 1965.V. núm. 14-38505.

19-1255. CASTAÑón, L-_-"Segundo apéndice al refranero asturiano"- $-B I E A$, 1965, núm. 54, 73-102.-V. núm, 181275.

19-1256. ARMAyor GonzÁlez, O. - "Del refranero de Caso".-BIEA, 1965, núm. $56,47-54$.

19.1257. Feijóo, SAmuel (ed.) —Sabiduria guajira.-Ed. Universitaria, La Habana, 1965. 359 pp. ["Refranes", pp. $17-47]$.

19-1258. VILLAFUerTE, C. - "Refranes y coplas del vino"-C $C B A, 12,1965$, núm. $45,44-46$.

V. también núms. 526, 672, 829-30, 392-3, $1352,1387,1417,1477,1754-5,2525$.

\section{Dialectología}

19-1259. Quilis, A._"Situación actual de la geografía lingiística en el dominio hispánico".-EAc, 1964, núm. 3. || BICC, 22 (1967), 292-293 (Zuluaga Ospina) .

19-1260. Toscano, H. - "Encuestas".EAC, 1965, núm. 5, 28-32.

19-1261. ALYAR, M.-Textos hispánicos dialectales (N. 16-46949). $\|$ LFr, 17 (1964), 168 (Rey García); HuT, 11 (1963), 244-248 (Rona); RFRG, 6 (1962), 173-175 (Sala).-V. núm. 181282.

19-1262. Pérez, R.-“El calo".-H, 48 (1965) , 119-120.

19-1263. Galmés de Fuentes, A-_El dialecto y la lengua general".-PFE, 2, 127-133.

19-1264. GriffiN, D.-"Rotacismo y aspiración: una nota sobre cronologla dialectal".-BdFS, 17 (1965), 407-411.

V. también núms. 481-499.

\section{Peninsular}

19-1265. Alvar, M--"Los atlas lingüísticos de España".-PFE, 1, 417-426.

19-1266. SALA, M. - "Atlase lingvistice spaniole".-SCL, 15 (1964), 375-383. [Y trad. francesa en $R R L, 9$ (1964), 213-221].

19-1267. WeIDHASE, RoseL-Studien zur Wortbildung mittelst Suffixen in der Mundarten Spaniens,-[Tesis, Univ. de Tübingen, 1964].

19-1268. Simonet, Francisco Jayier Glosario de voces ibéricas y latinas usadas entre los mozárabes. Precedido 
de un estudio sobre el dialecto hispano-mozárabe (Madrid, 1888). A reprint. - Oriental Press, Amsterdam, 1965. coxxxvi +628 pp.

19-1269. MYERs, O. T.-"Senor in Saya. gués" - $-M L N, 80$ (1965), 271-273.

19-1270. Rico-Avello, Carlos-El bable y la medicina._C.S.I.C., Oviedo, 1964. 230 pp., ilustr.

19-1271. FERNÁNDEX, J. A.El habla de Sisterna (N. 16-46962). I| BIEA, 1965 . núm. 54, 218-223 (A. P.) ; $M L R, 62$ (1967), 732-739 (Hodcroft); $R P h, 19$ (1965-66), 48.58 (May); Lingua, 12 (1963), 226 (Van Praag) _-V. núm. $17-834$.

19-1272. Álvartz Fernandez-Cañedo, Jesús_El habla y la cultura topular de Cabrales.-C.S.I.C., Madrid, 1963. xxxviii + $246 \mathrm{pp}$. (RFE, anejo 76). $Z R P h, 80$ (1964), 563-564 (Baldinger); $A r b, 60$ (1965) , 141-142 (Larrea); $R J$, 16 (1965), 370-374 (Simon).

19-1279. Menéndez Garcia, Manuel-El Cuarto de los Valles (un habla del Occidente asturiano)_C.C.S.I.C., Oviedo, 1963, 2 ts.: 256, 424 pp.

19-1274. Cobas, M. G. - El habla de Luarca. (Vocabulario dialectológico).-Luarca, 1964.

19-1275. KRÜGER, F-"Aportes a la fonética dialectal de Sanabria y de sus zonas colindantes". - RFE, 48 (1965), 251.282.

19-1276. Nuevo Zarracina, D. G.-."Filandones y esfoyazas. El filandón".$B I E A, 18$ (1964), 63-88. [Terminología y folklore].

19-1277. Salvador, G. - "Encuesta en Andiñuela".- $A O, 15$ (1965), 190-255.

19-1278. MENÉNDEZ PIDAL, R.-El dialecto leonés (N. 17-4256). $\| P h P, 7$ (1964), 442 (Halasová); RPF, 13 (1964-65), 419-421 (Moura Santos).

19-1279. García de LA Torre, J. M.Castille et Galice. Interaction linguistique.-Drukkerij Jacob van Campen, Amsterdam, 1965. $24 \mathrm{pp}$.

19-1280. Llorente Maldonado de GuevarA, A.- "Algunas caracteristicas lin. güísticas de La Rioja en el marco de las hablas del valle del Ebro y de las comarcas vecinas de Castilla y Vasconia".-RFE, 48 (1965), 321-350.

19-1281. Buesa Oliver, T,-"Noticia sobre el Atlas lingüístico y etnográfico de Aragón".-ALM, 4 (1964) , 57-69. 19-1282. Alvar, ManUEL-Proyecto de un Atlas lingülstico y etnográfico de
A ragón-Inst. Fernando el Católico, Zaragoza, $1969.87 \mathrm{pp}$. (AFA, anejo 8). || $R P h, 18$ (1964-65), 379.880 (Hall). 19-1283. Alvar, M.-"Proyecto de un Atlas lingïistico y etnogrdfico de Aragón".-AFA, 14/15 (1963-64), 7-82.

19-1284. Alvar, MaNUEL-Atlas lingüistico y etnográfico de Aragón. Cuestionario.-C.S.I.C., Madrid, I969. 146 pp. II ZRPh, 80 (1964), 642-643 (Baldinger) : $A L M, 4$ (1964), 331.332 (Lope Blancl); $B I C C, 20$ (1965), 376-377 (Montes) .

19-1285. Alvar, M.-_"Las encuestas del Atlas lingǘstico y etnográfico de Aragón".-AFA, 14./15 (1963.64), 247-249.

19-1286. ROLDÁN PÉREZ, ANTON1O-La cultura de la viña en la región del Condado. Contribución léxica a la geografla lingüistica dialectal. - [Tesis, Univ. de Madrid, 1965; resumen en RUM, 14 (1965) , 228-229].

19-1287. GonzÁlez Ollé, Fernando-El habla de la Bureba. Introducción al castellano actual de Burgos._C.S.I.C., Madrid, 1964. 258 pp. (RFE, anejo 78) - || HR, 36 (1968), 152-154 (Craddock); $Z R P h, 82$ (1966), 495-437 (Giese); $M L R, 63$ (1968), 275-276 (Leslie) ; ASNS, 203 (1966), 292-234 (Meier); $R R L, 12$ (1967), 265-269 (Sandru); $R J, 17$ (1966), 343-346 (Simon); RF, 80 (1968), 171-172 (Wolf) .

19-1288. Manrique, G. - "Vocabulario popular de la provincia de Soria".RDTP, 21 (1965) , 380-412.

19-1289. Vela, F._"Modos de hablar [en el Madrid de hoy]". - ROcc, 6 (1964), 347-855.

19-1290. Flórez, L.- "Algunos modos de decir en el espafiol de Madrid".$B A C o l, 15$ (1965) , 279-283.

19-1291. Qurls, A.-"Description phonétique du parler madrilène actuel".Phon, 12 (1965), 19-24.

19-1292. LAPESA, R.-"EI andaluz y el espaniol de América".-PFE, 2, 173-182.

19-1293. Salvador, G.-_La fonética andaluza y su propagación social y geográfica".-_PFE, 2, 183-188.

19-1294. Alvar, M.- "Portuguesismos en andaluz".-FAK, 309-324.-V. núm. 16 43093 .

19-1295. Rold AN, A.- "Léxico de la bodega jerezana".-Hom, 2 (1965) , 69-89.

19-1296. Salvador, G._-"Estudio del campo semántico 'arar' en Andalucía".$A O, 15$ (1965), 73-111.

19-1297. Alvar, Manuel-Atlas lingüis- 
tico y etnogrdfico de Andalucia. T. 3: La casa y la alimentación.-Facultad de Letras, Granada, 1965. 227 láms., 684 fotografias, planos, etc.-V. núm. 17-4272 || RDTP, 21 (1965), 429-438 (Caro Baroja); RLiR, 29 (1965) , 186 (Gardette) .

V. también núms. 610, 673-6, 821, 827-8, $894-5,1001,1032,1187,1980,3599$.

\section{Extrapeninsular}

19-1298. Castillio Barril, M.-"El cspafiol en la Guinea ecuatorial".-EAc, 1964, núm. 3.

19-1299. CAtal $\hat{N}$, D.-“El español en Canarias".-PFE, 1, 239-280.

19-1300. Alyar, M.-“"Cuestionarios de láminas. (El $A L M$ y las investigaciones en Gran Canaria)".-BALM, 7 (1965), 33-43.

19-1301. Alvar, Manuel-Atlas lingüistico y etnográfico de las Islas Canarias. Cuestionario. - C.S.I.C., La Laguna, 1964. xxii + $109 \mathrm{pp}$.

19-1302. Alvar, M.- "Una nota de ictionimia: el Scarus Cretensis".-RFE, 48 (1965), 165-170. [Sus nombres en las Canarias].

19-1303. Gufrra Navarro, FranciscoContribución al léxico popular de Gran Canaria. Pról. de J. Pérez Virlal.-Peña Pancho Guerra, Madrid, 1965. $808 \mathrm{pp}$.

19-1304. Alvar, M.--"Notas sobre el español hablado en la isla de La Graciosa (Canarias Orientales) ". - $R F E$, 48 (1965), 293-319.

19-1305. Alasov, A., y V. G. Dímz-"El concepto de American Spanish en la práctica pedagógica de los Estados Unidos".-CuH, 64 (1965), 94-102.

19-1306. BeLuini, GIUSEPPE - Lo spagnolo d'America. - La Goliardica, Milano, 1962. 83 pp. $\| \quad P h P, 8$ (1965), 105 (Pavliková) .

19-1307. Zamora Vicente, A.- "Algunos aspectos generales del español americano"._CLR(10), 1327-1350.

19.1 308. Rosenblat, A - "Lengua y cultura de Hispanoamérica" (N. 17-4287). || $R F E, 48$ (1965) , 432-433 (Lopez) V. núm. 18-1312.

19-1309. Rosenbiat, A.-“Lengua y cultura de Hispanoamérica. Tendencias actuales".- [En su libro] La primera visión de América (Caracas, 1965), pp. 131-165.-V. núm. 17-4287.

19-1810. Rosenblat, ANGel_El castella. no de España y el castellano de América. Unidad y diferenciación. 2: ed.Univ. Central de Venezuela, Caracas, 1965. 61 pp. (Cuadernos del Instituto de Filología Andrés Bello)._. V. núm. 18-1313.

19-1311. Rona, J. P.-“"Relación entre la investigación dialectológica y la enseñanza de la lengua materna"._-SCIC, 333-343.-V. núm. 18-4976.

19-1312. Berro García, A.-"La encuesta idiomática hispanoamericana y los atlas lingüfsticos de América".- $R N a$, 1965, núms. 233/4, 65-68.

19-1313. RonA, J. P._-"El problema de la división del espafíol americano en zonas dialectales",-PFE, 1, 215-226.

19-1314. Herrero Mayor, Avelino-Contribución al estudio del español americano. - Ministerio de Educación y Justicia, Buenos Aires, 1965. $150 \mathrm{pp}$. I| $R N a, 11$ (1966), 320-321 (Garet Mas) ; $B A C o l, 16$ (1966), 197-198 (X).

19-1315. BORGES, JORGE LUIs-The Spanish language in South America: a literary problem.-The Hispanic and Luso-Brazilian Councils, London, 1964. $36 \mathrm{pp}$. (Diamante, 15). \| BHS, 42 (1965), 281-282 (Franco) .

19-1316. Ribeiro, J.-História da romanização da América (N. 16-46347). || ZRPh, 81 (1965), 406-408 (Salmonski).

19-1317. Guitarte, G. L.- "Cuevvo, Henrfquez. Ureña y la polémica sobre el andalucismo de América" (N. 16-43105). \| RFRG, 7 (1963) , 196-197 (Sala).V. núm. 18-1321.

19-1318. Ymer1, F. S-_El yeísmo, el seseo, el uso del vocablo vos y vicios en las formas verbales que se usan con ese pronombre". $-C A(4)$, 154-156.

19-1319. Herrero MAYor, A.-"Presente y futuro de la lengua española en América".-PFE, 2, 109-125.

19-1320. Balmori, C. H._-"Habla mujeril y varonil en lenguas diferenciadas de Suramérica".-BFS, 43 (1965), 711-722. [= TILAS, 5 (1965), 111-122].

19-1321. Tovar, A.-'Español y lenguas indigenas. Algunos ejemplos"..-PFE, 2, 245-257.

19-1322. MaLmberG, B._-"Tradición hispánica e influencia indigena en la fonética hispanoamericana". - PFE, 2 , 227-243.

19-1323. Buesa Oliver, TOMÁ_-Indoamericanismos léxicos en español.C.S.I.C., Madrid, 1965. 96 pp. (Monografias de ciencia moderna, 73/79). 
|l BdFS, 18, (1966) . 309-313 (Garcia) : BICC, 21 (1966), 199-200 (Montes).

19-1324. Casullo, Fernando Hugo-Voces indigenas en el idioma español. Compañfa Argentina de Editores, Bue. nos Aires, 1964. $116 \mathrm{pp}$.

19-1325. Morínigo, M. A._-"La penetración de Ios indigenismos americanos en el espafiol"...PFE, 2, 217-226.

19-1326. Bfrro García, A.-“Realización de una encuesta idiomática para redactar el gran Diccionario hispanoamericano de la lengua". $-T C A, 450$ 454.

19-1327. KanY, C. E.-Semantica hispanoamericana (N. 18-1329). || BLLE, 1964/65, núm. 7, 151-154 (Chiareno).

19-1328. BALDINGER, K. "Designaciones de la 'cabeza' en la América española".-ALM, 4 (1964), 25-56.

19-1329. Meo ZiLIo, G.-."Settanta italianismi gastronomici nello spagnolo d'America"...LN, 26 (1965), 48-54.

19-1390. Mezzera, Baltasar Luis - El primer mundo antillano. 2: ed., rev.Corvadonga, Montevideo, 1964. $31 \mathrm{pp}$. [Toponimia, y en las pp. 25-30 un "Vocabulario indiano"].

19-1331. Rosario, R. DEL_"Estado actual del español en Puerto Rico".-PFE, I, $153-160$.

19-1392. HULL, ADRLAN LouIs-The linguistic accommodation of a cultural in. novation as illustrated by the game of baseball in the Spanish language of Puerto Rico.-[Tesis, Columbia Univ.; resumen en $D A, 25$ (1964-65), 7256].

19-1333. Dillard, J. L._-“'Spanglish store names in San Juan, Puerto Rico".Names, 12 (1964), 98-102.

19-1334. Ciappi Azcorra, Ángel L.-225 expresiones Diccionario puertorriqueño-cubano.-[¿Rfo Piedras? ¿1965?], 12 pp. mimeogr.

19-1335. Alzor.A, C. T._"Habla popular cubana".-RDTP, 21 (1965), 358-369._ V. núm. 17-861.

19-1336. Isbasescu, C.—“Algunas peculiaridades fonéticas del español hablado cn Cuba".-RRL, 10 (1965), 571-594. [Resumen en francés: BSR, 2 (1965), 15-16].

19-1337. López Morales, H.-"Neutralizaciones fonológicas en el consonantismo final del español de Cuba".$A L M, 5$ (1965) , 183-190.

19-1398. López Morales, H. - "Nuevos datos sobre el voseo en Cuba". $E A C$, 1965, núms. 4 y 5.
19-1339. Arciniera, R.-“EI castellano en Norte-América".-Pren, 1965, núm. 14. 19-1340. Sturtevant, W. C.-.'SpanishIndian relations in southeastern North America".-Ethnohistory, 9 (1962), 41 94. || IJAL, 31 (I965), 247-248 (Bright). 19-1341. McClendon, Juliette Jane C.Spanish speaking children of Big Spring: An educational challenge. [Tesis, Univ. of Texas; resumen en $D A, 25$ (1964-65), 5282-5283].

19-1342. ColtharP, LuRLINE HughesThe influence of English on the language of the "Tirilones"._-_Tesis, Univ. of Texas; resumen en $D A, 25$ (1964. 65) , 2973].

19-1343. SAwYer, J. O.-“The implications of Spanish / $\mathrm{r} /$ and / $\mathrm{rT} /$ in Wappo history"...RPh, 18 (1964-65), 165 177.

19-1344. Lope Blanch, J. M._-'Estado actual del español en México".-PFE, 1, 79-9I.

19-1345. Wonder, J. P._"The bilingual Mexican-American as a potential teacher of Spanish". $-H, 48$ (1965), 97. 99.

19-1346. Canellada de Zamora, M. J., y A. ZAMORA VICENTE-"Vocales caducas en el español mexicano" (N. 16-43119). || BICC, 18 (1963), 699-701 (Flórez).

19-1347. Santamarfa, F, J-Diccionario de mejicanismos (N. 16-43117). $M P h, 63$ (1965-66), 182-184 (Corominas); $R P h, 18$ (1964-65), 479-485 (Hernández) .-V. nứm. I6-46989.

19-1948. Lope Blanch, J. M.-“Influencia de las lenguas indigenas en el Iéxico del español hablado en México".$A L M, 5$ (1965), 33-46.

19.1349. VelAzquez Andrade, ManuelDiccionario nuevo México de la lengua española. - Libro-Mex, México, 1964. 1964. 630 pp. [Contiene mexicanismios].

19-1350. LOPE Blanch, JUAN M.-Vocabulario mexicano relativo a la muerte.-Universidad Nacional Autónoma de México, 1963. 185 pp. \| $H, 49$ (1966), 173 (Bar-Lewaw); $A b s, 29$ (1965), 225-227 (Peñalosa); $V U, 17$ enero 1965 (Villaseñor) .

19-1351. Lope Blanch, J. M.-"El lenguaje mexicano de la muerte"._UMx, I8 (1963-64), núm. 3.

19-1352. Peñalosa, JoAquín AntonioVocabulario y refranero religioso de México.-Jus, México, 1965. 176 pp. 
|| Abs, 30 (1966), 116.118 (Montejano Aguiñaga).

19-1353. VAN W'JK, H. L. A.-"Los gentilicios hondureños".-HIEH, 593-603.

19-1354. VAN WiJk, Hl. L. A.-."Los hipocorísticos hondureños". - $R J, 15$ (1964), 302.312.

19-1355. Alvarado, Florencio - Caló hondureño.-Tegucigalpa, 1952.

19-1356. AGüERo, A. - "El español de Costa Rica y su atlas lingüístico". PFE, 1, 135-152.

19-1357. Agürro Chavfs, A.-“Gentilicios consagrados por el uso en Costa Rica". — BACos, 9 (1964-65), núms. $14 / 15$.

19-1358. Blas Tejeiro, G.-El habla del panameño._Panamá, 1964. $171 \mathrm{pp}$.

19-1359. Isaza Calderón, Baltasar-Diccionario de panameñismos._Lib. Stella, Panamá, 1964. $417 \mathrm{pp}$.

19-1360. Monres, J. J.--"Bibliografía de los estudios sobre el español de Colombia".-BICC, 20 (1965), 425-465.

19-1361. Flórez, L-"Principios y método del Atlas lingüistico-etnográfico de Colombia":-HAR, 245-250. - V. núm. 18.5005.

19.1362. EcheverRI Mejía, Oscar Nuestro idioma al dia.-Espiral, Bogotá, 1965. || BACol, 15 (1965), 234239 (Pabón Núñez).

19.1363. LOZANO, ANTHONY GIRARD-A study of spoken styles in Colombian Spanish.-[Tesis, Univ. of Texas; resumen en $D A, 25$ (1964-65), 2973-2974].

19-1364. AlARIo DI FILIPPO, M.-Lexicón cle colombianismos. - Ed. Bolívar, Cartagena, 1964. 391 pp. || HAHR, 45 (1965), 658 (Beyer); EAC, 1965, núm. 5, 6-11 (Pabón Núñez).

19-1365. GonzÁlez, Euclides Jalme Contrilución al vocabulario de colom. bianismos. - Imp. del Departamento, Cúcuta, 1964. 204 pp. \| ALM, 6 (1966. 67), 241-243 (Lope Blanch).

19-1366. ECHEVERRI MEJiA, O.-“Anglicismos, galicismos y barbarismos de frecuente uso en Colombia"._-PFE, 2, 91-101.

19.1367. Montoya, W.- "Algo sobre folclor".-UdA, 41 (1964), 303-325, 627635. [Colombianismos].

19-1368. Nieto Caballero, A..."Un nue. vo vocabulario".-BACol, 15 (1965), $34-37$.

19-1369. MonTes, J. J.--AAlgunas yoces relacionadas con los animales doméslicos", $-B I C C, 20$ (1965) , l-47.
19-1370. Mendoza Varela, E.-"Materiales para un vocabulario del periodismo en Colombia". - BACol, 15 (1965) , 54-59.

19-1371. Figueroa, J.-“"Onomástica de vehículos".-BICC, 20 (1965), 357-370.

19-1372. Bateman, A. D.-"Pesos y medidas en Colombia". - BACol, 15 (1965) , 216-224.

19-1373. Forero, M. J.- "Algunos gentilicios de Colonnbia". - BACol, 15 (1965), 229-233.

19-1374. Gonzélez de la Calle, Pedro Urbano-Contribución al estudio del bogotano. Otientaciones metodológicas para la investigación del castellano en América.- lnst. Caro y Cuervo, Bogotá, 1963. xx + 343 pp. $\| H, 47$ (1964), 655-656 (Canfield); $R P h, 18$ (1964-65), I29-130 (Canfield); RHM, 30 (1964), 325 (Fernández de la Vega) ; $B A b r, 38$ (1964), 417 (Parker); $A I A, 25$ (1965) , 355-356 (Pazos); SCL, 16 (1965), 568-571 (Sadeanu); Lingua, 12 (1963), 226-228 (Van Praag); RIB, 15 (1965), 170-173 (Zamora Elizondo). 19-1375. Flórez, L.-"El español hablado en Santander: notas de pronunciación"- $A L M, 4$ (1964), 71-94.

19-1376. FlóRez, LU1s-El español hablado en Santander.-Instituto Caro y Cuervo, Bogotá, I965. 383 pp., 96 fotografias, 172 mapas. (Publicaciones del Inst. Caro y Cuervo, 21).

19.1377. Mora Naranjo, A.- “El castellano en Antioquia"._-UPB, 27 (1965), 159-175.

19-1378. Holzapfel, Tamara O. - The Antioquian dialect of Tomds Carras. quilla.-[Tesis, Univ, of Iowa; resu. men en $D A, 25$ (1964-65), 5269-5270].

19-1379. Rodríguez de Montes, M. I"Léxico de la alimentación popular en algunas regiones de Colombia".$B I C C, 19$ (1964), 43-98. \|IJIAL, 32 (1966), 173.174 (Lastra).

19-1380. Figueroa Lorza, J-"Léxico de la caña de azúcar en Palmira y La Cumbre".-BICC, 18 (1963), 553-621. || IJAL, 32 (1966), 172 (Lastra).

19-1381. Gómez, AURA-Lenguaje coloquial venezolano.-[Tesis, Univ, de Madrid, 1965; resumen en RUM, 14 (1965), 206-207].

19-1382. Toscano, HI.-"El espafiol hablado en Ecuador".-PFE, 1, 111-125. 19-1383. Toscano, H.-"La lengua española y su enseñanza en el Ecuador".-SCIC, 92-96. 
19-1384. Toscano, H._-El mar y el habla ecuatoriana"-CI, 1965, núm. 2, 83-99.

19-1385. Carvalho Neto, paulo deDiccionario del folklore ecuatoriano.Casa de la Cultura Ecuatoriana, Quito, 1964. 488 pp., ilustr. $\| R J, 16$ (1965), 368-369 (Giese); CuH, 70 (1967), 641.642 (de Hoyos Sancho); RDTP, 29 (1967), 402-403 (Manrique) .

19-1386. Toscano, H. - "Achachay y ayayay".-CA(4), 284-291.

19-1387. Guevara, D. - "Cien refranes ecuatorianos aplicados a la guerra, la paz y la diplomacia". - Humanitas, Quito, 2 (1965), 9-23.

19-1388. ORR, Carolyn, \& Betsy WrisLEY_l:ocabulario quichua del oriente del Ecuador.-Inst. Lingülstico de Verano, Quito, 1965. 152 pp. (Vocabularios indigenas, 11).

19-1389. González Pastor, P. L.-"El habla vallejiana y la norma gramati. cal".-Rev. de la Univ. de Arequipa, nưm. 50 (1962-63), 155-167.

19-1390. BurNs, D.-_La lingǘstica y los problemas de la lengua en Bolivia".SCIC, 82.91.

19-1391. Fernández Naranjo, Nicolds, y Dora Gómez de Fernandez-Diccionario de bolivianismos.-Univ. Mayor de San Andrés, La Paz, 1964. 251 pp.

19-1392. VARAs ReYes, Víctor-El castellano popular en Tarija. - Talleres Gráficos Bolivianos, Cochabamba, Bolivia, 1965. $251 \mathrm{pp}$.

19-1393. Sanabria Fernandez, HernanDo-El habla popular de Vallegrande (Departamento de Santa Cruz].-Santa Cruz de Ia Sierra, Bolivia, 1965. 198 pp.

19-1394. Costas Arguedas, Jose FelireDiccionario del folklore boliviano. T. I: A-H.-Universidad Mayor de San Fran. cisco Xavier de Chuquisaca, Bolivia, 1967. $354 \mathrm{pp}$.

19-1395. Oroz, R.-“EI español de Chile".-PFE, 1, 93.109.

19-1396. Rabanales, A.- "Hiato y antihiato en el español vulgar de Chile".$C D G(1)$, 3, 81-103.—V. núm. 16-47014.

19-1397. Naranjo Villegas, A- "Chilenismos de uso corriente". $-B I C C, 20$ (1965) , 607-6Il.

19-1398. Riveru, H.-"Glosario de la novela chilena Chicago Chico, de Armando Méndez Carrasco y otros autores".-BdFS, 17 (1965), 281-361.
19-1399. MazzLnGHi, J. A._"El idioma en el Código civil chileno".-_CI, 1965, núm. 3, 117-125.

19-1400. Strune, L-“-Toponimia atacameña. Extremo norte de Chile y sur de Perí".-Publ. Museo y Sociedad Arqueológica de La Serena, 1962, núm. 12, 25-32.

19-1401. WAGNER, C.-CContribución al estudio de la toponimia de Chiloé".EFil, 1964, núm. 1, 283-302.

19-1402. Borello, R. A.-"Actitud del argentino medio frente a la lengua".PFE, 1, 193-198.

19-1403. Cardevila, A.—"Desazones idiomáticas argentinas". - CI, 1 (1965), núm. 2, 21-38.

19-1404. Vidal DE Battini, B. E.-“EI español en la Argentina".-PFE, 1, 183-192.

19-1405. Honsa, V. - "The phonemic system of Argentinian Spanish"- $-H$, 48 (1965) 275-283.

19-1406. Gandolfo A.-"Phonetics and allophonic variants of $/ r /$ and $/ 2 /$ in Spanish as spoken by porteños and correntinos".-PNCL, 575.577.

19-1407. Gandolfo, A.-“'Spanish $l l, y$ and $r r$ in Buenos Aires and Corrientes".-PNCL, 212-215.

19-1408. VIDAL DE Battini, B. E.-"Zonas de leísmo en el español de la Argentina".- $C D G(1), 2,160-169$.

19-1409. Weber de KURLat, F_-"Vocabulario para la designación de grupos étnicos en el castellano de la Argentina. Significados, estilística". - CDG(1), 3, 273-294.—V. núm. 17-899.

19-1410. SÁnchez Viamonte, C.-_"Semántica y constitución argentina"- $-R U N C$, 6 (1965), 47-56.

19-1411. Giuria, Carlos Alberto-Indagación del porteño a través de su lenguaje._Peña Lillo, Buenos Aires, 1965. 98 pp. (La siringa, 33) .

19-1412. Borges, JORGE LuIs y José E. CLemente-El lenguaje de Buenos Aires._Emecé, Buenos Aires, 1965. 102 pp.-V. núm. 18-1393. || HuNL, 6 (1965). 560-563 (Rangel Guerra).

19-1413. Gobello, José, \& Eduakdo StilMAN_Diálogos de Villoldo. - Buenos Aires, 1964. 154 pp. ["Notas lexicográ. ficas", pp. 75-154].

19-1414. BRAvo, D. A.-"El sustrato Iingüústico de Santiago del Estero".HuT, 1962, núm. 15, 77-87.

19-1415. Narbi, R. L. J.- "El quichua de Catamarca y La Rioja".-Cuadernos 
del Inst. Nac. de Antropol, Buenos Aires, 3 (1962), 189-285.

19-14]6. Terrera, Gulliermo AlfredoAntiguo vocabulario ibero-indigena $y$ su vigencia actual.-Patria Vieja, Buenos Aires, 1964. $85+$ (14) pp.

19-1417. Madueño, Raúl R.-Vocabulario $y$ refranero de cazadores._-Ergon, Buenos Aires, 1964. 142 pp.

19-1418. Lexique argentin-français._Centre de Littérature et Philologie Ibéro. Américaines, Paris, 1963. 86 pp. PhP, 7 (1964), 206 (Hampejs).

19-1419. Meo ZiLio, G._.'Algunos italianismos en el espafiol popular del Rio de la Plata".-Diólogo, 6-7 (196465); $16 \mathrm{pp}$.

19.1420. MEo Zizıo, G._-'Italianismos generales en el español rioplatense". $B I C C, 20$ (1965), 68-119.

19-1421. Meo ZiLio, G__'Italianismos me. ridionales en el español rioplatense" $B d F S, 17$ (1965) , 225-235.

19-1422. Meo Zilio, G._."Notas de español americano: el elemento jergal italiano en el rioplatense popular".-SLS, 411.428.

19-1423. JAMES, H., \& J. Ricci_"The influence of locally spoken Italian clialects on River Plata Spanish" Forum Italicum, 1 (1967), 48-59.

19-1424. Malanca DE RodrfGutz Rojas, ALICIA-Aportes al estudio de la cultura popular de Punilla (prov. de Córdoba, Argentina). La vivienda rural._-Universidad Nacional de Cuyo, Mendoza, 1965. 177 pp., ilustr. (AIL, t. 9) .

19.1425. ZAMORA VICENTE, A.-.Tres expresiones argentinas"-EMP, 5, 141-147.

19-1426. Rosenblat, A._.'Orjgen e his. toria del che argentino" (N. 18-1407). || IJAL, 32 (1966), 174-175 (Lastra); $B I C C, 20$ (1965) , 650 (Montes).

19-1427. MALmBERG, B.-"A propos du che argentin. Note sur la dite étymologie phonétique".-StL, 18 (1964), 47-54.

19-1428. BALmori, C. H._-Apuntes para el étimo de charango",-PFE, 1, 309 213.

19.1429. Rangel Guerra, A.-"El lunfar. do".-VU, 24 de enero, 1965.

19-1430. Grayson, J. D...'Lunfardo, Argentina's unknown tongue". $H, 47$ (1964) , 66-68.

19-1431. VALIE, E. R. DEI_" "Dialecto o germanía?"-EAc, 1965, núm, 5 .

19-1432. Casullo, Fernando Huga-diccionario de voces lunfardas y vulgares.Freeland, Buenos Aires, 1964. $230 \mathrm{pp}$.
19.1433. CAMmarota, Federica Vocabu. lario familiar y del lunfardo. $2^{2}$ ed.Peña Lillo, Buenos Aires, 1964. 62 pp.V. núm. 18-1412.

19-1434. Meo Zilio, G.-"El cocoliche rioplatense".-BdFS, 16 (1964), 61-119.

19-1435. Soler CAÑAs, LuIs-Origenes de la literatura lunfarda. Pról. de J. Gobello._Siglo Veinte, Buenos Aires, 1965. $268 \mathrm{pp}$.

19-1436. Gandolfi Herrero, Arístides_La poesía dialectal porteña y Versos rantes.-Buenos Aires, 1961. $75 \mathrm{pp}$.

19-1437. Coluccio, Fúlux - Diccionario folklórico argentino,-L. Laserre, Buenos Aires, 1964. 2 ts.: 790 pp. (Col. de estudios folklóricos)_-V. núm. 6-7708. || RDTP, 21 (1965) , 203-204 (Castil]o de Lucas).

19-1438. Mieres, C., et al._"Diccionario uruguayo documentado". - $R \mathrm{Na}, 10$ (1965), 113-129, 243-289, 361-427.

19-1439. Rosell, Avenir-Petiso. Didlogo lexicológico. - Montevideo, 1963. 143 pp._V. núm. 18-5038.

19-1440. RONA, JOSE PEDRO-El dialecto "fronterizo" del Norte del Uruguay.Fac, de Humanidades y Ciencias, Montevideo, 1965. $45 \mathrm{pp} .-\mathrm{V}$. núm. 181415. II SCL, 20 (1969), 117-I18 (Av. ram); PhP, 10 (1967), 122-123 (Hampl).

19-1441. Fuentes Álvarez, D._-"La lengua española en el Río Grande del Sur (Brasil)"._PFE, 1, 361-366.

19-1442. KAHLE, G._'Das Guaranf als paraguaysche Volkssprache".-Kölner Ethnolog. Mitteilungen, 4 (1965), 105-117.

19-1443. Morínico, M. A.-“Influencia del espafiol en el léxico guaranf".-Fil, 8 (1962), 213-220. || IJAL, 32 (1966). 172-173 (Lastra) ; BICC, 20 (1965) , 649 (Montes) .

19-1444. Gonzh́lez, G., C. R. Centurión y R. Nielia_-"Guaranismos en el diccionario de la Academia".-TCA, 492. 499; $C A(4), 315-322$.

19-1445. GASPARI, In DE_-"Presente y futuro de la lengua española en el Paraguay".-PFE, 1, 127.133.

19-1446. RuBIN, JOAN-National bilingualism in Paraguay.-[Tesis, Yale Univ; resumen en $D A, 25$ (1964-65), 751].V. nitm. 17-4341.

19-1447. Cortés DE FERNÁNDEZ LUMBA, LELILIA_Un bosquejo histórico de la Academia Filipina.-[Tesis, Univ. de Madrid, 1965; resumen en $R U M, 14$ (1965), 199-200].

19-1448. Verdín Díaz, G,_"Problemas del 
castellano en Filipinas".-PFE, 1, 297. 302.-V. núm. 18-1421.

19-1449. La lengua española en Filipinas. Datos acerca de un problema.-Oficina de Educación Iberoamericana, Madrid, 1965. $114 \mathrm{pp}$.

19-1450. GalláN Mayot, Nattvidad-Un estudio de los diferentes dialectos en el desarrollo de la enseñanza del español en Filipinas.-[Tesis, Univ., de Madrid; resumen en $R U M$, I4 (1965), 276-279].

19-1451. Lopez, C.-_Contributions to a comparative Philippine syntax".-Lingua, 15 (1965), 3-16.

19-1452. Lopez, C._“The Spanish overlay in Tagalog".-Lingua, 14 (1965), 467. 504.

19-1453. Villa Pangantban, J.-“'Influencia hispanomexicana en el idioma tagalo".-HMx, 14 (1964-65), 261-271.

19-1454. Rómulo, C. P.-“La Universidad de Filipinas y el lenguaje español". - $B A C o l, 15$ (1965), 288-296; $B A H O, 10$ (1965), nưın. 2.

$V$. también nưms. 923, 936, 1074, 1164-5, I204, 1236-44, 1252, 1292.

\section{Judeoespañol}

19-1455. Gaov, Mosise David (Moché Catane) -A bibliography of the Judeo. Spanish (Ladino) press.-Ben Zvi Institute, The Hebrew University, Jerusalem, 1965. 144 pp. \|Sef, 26 (1960), 229-235 (Hassán).

19-I456. BEsso, HENRY V.-Ladino books in the Library of Congress. $A$ bibliography.-Hispanic Foundation, Washington, D. C., 1963. 43 pp. \| Sef, 24 (1964), I63-164 (Cantera); $H R, 34$ (1966), 191 (Lloyd) .

19-1457. OtERo SEco, A.-“Don Ramón Menéndez Pidal, los sefarditas de Israel y chuetas de Mallorca". - $C U$, 1964-65, núm. 87, 11-16.

I9-1458. Cantera Ortiz de Urbina, Jesús-Los. sefardies, 2a ed.-Publs. Españolas, Madrid, 1965. $31 \mathrm{pp} .-V$. núm. 14-38519.

19-1459. Alcazy, LEúN — Sephardis. Lowe \& Drydone, London, 1958. $63 \mathrm{pp}$.

19-1460. KLEIN, B.- "The decline of a Sephardic cammunity in Transilvania"._HMJB, 349-358. || Sef, 26 (1966), 156-157 (Lacave y Hassán).

19-1461. Nehama, J._-"Salonique au xvine siècle. Instruction et culture juives".-. HMJB, 397-347. \| Sef, 26 (1966), 156 (Lacave y Hassán).
19-1462. Gonzalo Maeso, D._"Granada en la historia del judaísmo español"... OYS, 7 (I964), Ixxxv-xcvi.

19-1463. Crews, C.-"Corrigenda in A A Judeo-Spanish medical MS. (ca. 14001450) " - $-V R, 24$ (1965), 132-133.-V. nứm. 18-5051.

19.1464. Sala, M.-"La disparition des langucs et la polysémie". - RLi, 7 (1962) , 289-294.

19.1465. Molho, I. R.-"Al torno del fogarero".-BACol, 15 (1965), $38-40$. 19-1466. Doppacne, A.-"Notes sur le judéo-espagnol parlé à Bruxelles".Sef, 25 (I965), 466-467. [Resumen].

19-1467. HassAN, I. M._-"De los restos dejados por el judeoespañol en el español de judios del norte de Africa".Sef, 25 (1965), 467-469. [Resumen de una comunicación].

19-1468. Révâ, I. S.-"Formation et évo. lution des parlers judéo-espagnols des Balkans",-CLR(10), 3, 1351-1371; OYS, 7 (1964), 41-48.-V. núm. 17-4371.

19-I469. SAlA, M._- "La organización de una enorma española en el judeoespañol'. - $C H(2), 543-550 ; A L M, 5$ (1965) , 175-182.

19-I470. Stankiewicz, E._Balkan and Slavic elements in the Judeo-Spanish of Yugoslavia".-For Max Weinreich (The Hague, 1964), 229-236.

19-147I. Molio, M. "Penetración de extranjerismos en el español de Oriente".-PFE, 1, 325-334.

19-1472. SALA, M._Considérations sur la valeur de la partie initiale des mots" [judeo-español de Bucarest] (N. 17-4372). || $A L B, 15$ (1965), 422-423 (Szépe) .

19-1473. Sala, M.- "La inanière dont une langue romane contribue à la disparition d'une autre (a propos du judéo-espagnol de Bucarest)". — $C L R$ (10), I373-1376.

19-1474. Alvar, M.-"Un edescubrimiento. del judeo-español".- $-H M J B$, 363366.

19-1475. Kolonomos J-_'Observations sur les différences entre les parlers judéo-espagnols de Vitola (Monastir) et Skopje (Ưsküib, Macédonie) ".-Sef, 25 (1965), 469-470. [Resumen].

19-I476. SALA, M._-"Elementos balcáni$\cos$ en el judeoespañol". - Sef, 25 (1965), 470-47I. [Resumen].

19.I477. Elnecave, D._"Folklore de los sefardies de Turquia".-Sef, 28 (1963), 12I-139, 325-334; 24 (1964), I2I-136; 
25 (1965), 189-212. [Romances, cantares, refranes y locuciones].

19-1478. MOLHo, I. R.-."Israel en correlación a la cultura hispánica"PFE, 1, 303-306; OYS, 7 (1964), xxxxiv.

19-1479. Bar-Lewaw, I._"Aspectos del judeo-español de las comunidades sefardíes de Atlanta (Georgia) y Montgomery (Alabama)".-Sef, 25 (1965), 465-466. [Resumen].

17-1480. MERrilL, G.-"The role of Sephardic Jews in the British Caribbean area during the 17 th century".-Caribbean Studies, 4 (1966), 3, 32-49.

19-1481. Molmo, I. R.-'En margin de la investigación y la literatura"._OYS, 7 (1964), 98.104.

19.1482. Quilus, A.-“Canciones religiosas de Pascua y romanzas judeoespañolas"._Hom, 2 (1965), 39-68. || Sef, 25 (1965), 365 (Cantera).

19-1483. Martínzz Ruiz, J.-“Poesía sefardí de carácter tradicional (Alcazarquivir) "-AO, 13 (1963), 79-215. || Sef, 24 (1964), 388-389 (Cantera); RDTP, 22 (1966), 436-437 (Pérez Vidal) .

19-1484. Alvar, M._- "El paralelismo en los cantares de boda judeo-españoles".ALM, 4 (1964), 109-159.

19-1485. ARMISTEAD, S. G., \& J. H. SilVERMAN_-"A Judeo-Spanish kompla and its Greek counterpart".-WF, 23 (1964), 262-264.

19-1486. Noy, Dov (ed.)___Setenta y un cuentos populares narrados por judios marroquies.-Dep. de Publ. de la Agencia Judía, Jerusalem, 1965. 216 pp.

19-1487. Rubiato, M. T.“"El repertotorio musical de un sefardi'”-_Sef, 25 (1965), 453-463.

V. también núms. 2882-4.

\section{LITERATURA ESTUDIOS GENERALES}

19-1488. Hungerland, H.- "Selective current bibliography for aesthetics and related fields"'-JAAC, 23 (1964-65), 531-554.-V. núm. 18-1453.

19-1489. Starobinski, J.-_Les directions nouvelles de la recherche critique".Preuves, 1965, nủm. 172, 23-32.

19-1490. EscarPIT, ROBERT-Rapport sur le dictionnaire international des termes littéraires.-Faculté des Lettres, Bordeaux, 1964.
19-1491. PreminfFr, Alex (cd.)-Enclclopedia of poetry and poetics-Princeton University Press, Princeton, 1965. xxiv + $\$ 06$ pp. $\| B A b r, 40$ (1966), 97 (Marks) ; $M L J, 50$ (1966), 226-227 (Slayton); $1 t, 43$ (1966), 76-79 (Starr). 19-1492. Moderne encyclopedie der wereldliteratunr. T. 1,-Brand en De Boer, Hilversum, 1964.

19-1493. Downs, ROBERT B. - Famous books, ancient and medieval: outlines of 108 great works that have shaped modern civilization.-Barnes \& Noble, New York, 1964. xx +329 pp. (Everyday handbooks, 297).

19-1494. Die romanischen Literaturen des 19./20. Jahrhunderts, Band 2, 1. Teil, Heft 5.9 (N. 18-5059) . || RJ, 15 (1961), 262-265 (von Jan).

19-1495. LevY, K. L._-"Ulrich Leo (1890. 1964)".-HR, 33 (1965), 63-65.

19-1496. Wort und Text. Festschrift für Fritz Schalk. Hrsg. yon H. Meier und H. Sckommodau. - V. Klostermann, Frankfurt, 1963. xi+531 pp. \| ZRPh, 80 (1964) , 566-575 (Hatzfeld); $R F, 77$ (1965) , 227-231 (Lausberg); $R J, 17$ (1966), 170-171 (Müller-Bochat) ; $R P h$, 18 (1964-65), 329-332 (Polt); LR, 19 (1965) , 152-154 (Pouilliart); ASNS, 202 (1965), 218-222 (Scheel).

\section{Teoría y crítica literaria}

19-1497. PUPPo, Mario_Il metodo e la critica di Benedetto Croce. - Mursia, Milano, 1964. 189 pp. \|BAbr, 39 (1965), 334 (Berget) .

19-1498. Morales, A. L.- "Teoría literaria y literatura en Alfonso Reyes". RevIb, 31 (1965), 89-94.

19-1499. REYES, ALFONSO_La experiencia literaria. Tres puntos de exegética. Páginas adicionales.-Fondo de Cultura Económica, México, 1962. (Obras completas, 14). || CuH, 57 (1964), 159-161 (Chávarri); CuA, 1963, núm. 2, 243. 245 (de la Selva).

19-1500. VIVAS, ELISEO_The artistic transaction and Essays on theory of literature.-Ohio State Univ. Press, Columbus, 1963. || CL, 17 (1965), 173-177 (Bertocci) .

19-1501. Díaz Plaja, Guillermo — LOS métodos literarios. - Ciordia, Buenos Aires, 1965. 260 pp.-V. núm. 13-36656. 19-1502. Wilson, EDMuND — Raizes da criação literária. Trad. de E. A. Cunha.-Rio de Janeiro, 1965. 232 pp. 
19-1503. LuKÁcs, Grong-Ensaios sóbre literatura. Coordenação e pref. de Leandro Konder.-Civilizaçăo, Rio de Janeiro, 1965. $235 \mathrm{pp}$.

19-1504. Dragomirescu, MigueL-Intro. ducción a la ciencia de la literatura.A. Peña Lillo, Buenos Aires, 1964. 159 pp. || Davar, 1965, núm. 105, 140-142 (Koremblit).

19-1505. PEYRE, HENRI-Literature and sincerity.-Yale University Press, New Haven, 1969. xii +362 pp. (Yale Romanic studies, 9). || $M L R, 60$ (1965), 417. 418 (Crow); $B A b r, 37$ (1963), 449 (Fleischmann) ; $M L N, 78$ (1963), 544546 (Grover); RLC, 40 (1966) , 328-329 (Jeune) ; RF, 76 (I964), 241-244 (Ott).

19.I506. KAYSER, WOLFGANG-Das sprachliche Kunstwerk. Eine Einführung in die Literaturwissenschaft. 10. Aufl. Francke, Bern-München, 1964. 454 pp.V. núm. 13-34785.

19-1507. Correa Calderón, E., y FernanDo LAzARo-Cómo se comenta un texto literario.-Anaya, Salamanca, 1965. 199 pp. (Manuales Anaya).

19-1508. HatzFeld, H.-"Points de repere dans l'évolution de la stylistique romane, 1886-1962".-MMD, 325-340. I| $R P F, 13$ (1964-65) , 490-491 (Aguiar e Silva) ; BJR, 1964, núm. 10, 65-66 (Beauchemin);

19-1509. HatzFeld, H. A. - "Questions disputables de la stylistique".-_CDG(1), $1,6-18$.

19-1510. RIFFAtERRE, M.-“'The stylistic function".-PNCL, 316-322.

19-1511. Mattoso CÂmara, J.- "Para uma estilistica estrutural".-HRO, 291-299.

19-I512. LAUSBERG, H._Elemente der literarischen Rhetorik, 2 Aufl. (N. 181480) . || Gn, 37 (1965), 415-418 (Fuhrmann); Lat, 23 (1964), 145.146 (Portalupi); $2 R P h, 83$ (1967), 89-90 (Sand. mann).

19-1513. Grane, R. S.-The languages of criticism and the structure of poetry.Univ. Press, Toronto, 1964. (Canadian Univ. paperbachs, 22) ..V. nưm. 10 . 20410.

19-1514. PFEIFFer, Johannes-Die dichterische Wirklichleit. Versuche über Wesen und Wahrheit der Dichtung.Meiner, Hamburg, 1965. 170 pp. \| $O L$, 20 (1965), 807-913 (Dehn).

19-1515. MeIER, Hugo - Die Metapher. Versuch einer zusammenfassenden Betrachtung ihrer linguistischen Merkmale._P. G. Keller, Winterthur, 1963. $\mathrm{x}+246$ pp. || $R P h, 22(1968-69), 70-72$ (Dembowski); ZRPh, 82 (1966), 187 194 (Lieb) ; ASNS, 203 (1966), 204-207 (Söll) ; VR, 24 (1965), 306-309 (Weinrich).

19-1516. Fletcher, Angus-Allegoty. The theory of a symbolic mode.-Cornell Univ. Press, New York; Oxford Univ. Press, London, 1964. xxi +418 pp. \| LiS, 2 (1967) , 396-397 (Basile) ; $M L R$, 62 (1967), 298-299 (Fraser); $R P h, 20$ $(1966-67), 557-563$ (Matthews) .

19-1517. Piehler, Paul Herman TyneGATE_Landscape and dialogue: $A$ study of allegorical tradition in medieval literature.-[Tesis, Columbia Univ.; resumen en $D A, 26$ (1965), 1634-1635]. 19-1518. KAYSER, WOLFGANG JOHANNESLa grotesco; su configuración en pintura y literatura. Trad. Ilse M. de Brugger.-Nova, Buenos Aires, 1964. 233 pp., ilustr.—V. núm. 13-36788. || CdS, 1966. nưm. 5, 86-89 (Cvitanovic); USF, 1964, núın. 6I, 389 (Zaffaroni).

19-1519. FüGEN, Hans Norbert - Die Hauptrichtungen der Literatursoziologie und Methoden. Ein Beitrag zur literar. soziologischen Theorie.-Bouvier, Bonn, 1964.

19-1520. Nisin, ARTHur-La literatura $y$ el lector.-Nova, Buenos Aires, 1964.V. núm. 17-4394. || CuH, 64 (1965), 407-411 (García).

19-1521. Fayolle, Roger-La critique littéraire._A. Colin, Paris, 1964. 430 pp. (Coll. U). IIS, 20 (1966), 106-107 (Cruickshank); $M L J, 52$ (1968), 515516 (Oxenhandler) .

19-1522. KaplaN, Charles (cd.) - Criticism: twenty major statements.-Chand. ler, San Francisco, 1964. viii + 482 pp.

19-1523. Scotr, W.-Five approaches of literary criticism (N. 17-4417). || $M L R$, 60 (1965), 236-297 (Klingopulos).

19-1524. WELLEK, RENE-Concepts of criticism. -Yale University Press, New $\mathrm{Ha}$ ven, 1963. $\mathrm{xv}+403$ pp. \| $M L J, 48$ (1964), 252-253 (Aldridge); $C L, 17$ (1965), 161-163 (Brown); JAAC, 22 (1963-64) , 353-354 (Marks); $M L R, 59$ (1964), 252-253 (Moore); RLit, 28 (1965) , 249-252 (Pérez Gállego); $R P h$, 17 (1963-64), 689-695 (Scaglione); $S R$, 72 (1964), 321-326 (Spears).

19-1525. SHuMAKER, WAYNE-Elements of critical theory. - Univ. of California Press, Berkeley and Los Angeles, 1964.V. núm. 8-12594.

19-1526. FRYe, NORThOP_Analyse der Li- 
teraturkritik,-Kohlhammer, Stuttgart, 1964. 359 pp.

19-1527. Richards, I. A.-I fondamenti della critica letleraria._Einaudi, Torino, 1961. xxxiii + 238 pp. \| Riv, di Es. tetica, 7 (1962), 289-292 (Eco).

19-1528. Starobinski, J.-"Remarques sur le structuralisme". - FHF, 275-278. [Aplicado a la critica literaria].

19-1529. EdGLeY, R.- "The object of literary criticism".-ECr, 14 (1964), 221 . 236. [Réplica por F. W. Bateson, pp. 436-437].

19.1530. EMBLER, W.-'The language of criticism".-Etc., 22 (1965), 261-277. 19-1531. Gutiérrez Girardot, R.-“"Ptoblemas de la crítica literaria".-CuH, 62 (1965), 307-324.

19-1532. WELLEK, RENÉ-A history of modern criticism: 1750-1950. T. 3: The age of transition. T, 4: The later nineteenth century.-Yale University Press, New Haven, 1965. xvi +389 , vi + 671 pp.-.V. núm. 12-32910. $\mid$ BAbr, 40 (1966), 338 (Pritchard).

19-1533. DElla VolPe, G.-Crilica del gusto. 2a ed.-Feltrinelli, Milano, 1964. 299 pp. || LiS, 1 (1966), 120-121 (Rosiello) .

\section{LITERATURA GENERAL Y COMPARADA}

19-1534. Medium Aevum Romanicum. Festschrift für Hans Rheinfelder. Hrsg. von $H$. Bihler und A. Noyer-Weidner.-Hueber, München, 1963. xx + 411 pp. || RJ, 15 (1964), 204-209 (Beckmann); Em, 33 (1965), 420-422 (Bravo Lozano); $Z R P h, 82$ (1966), 637-643 (Christmann) ; VR, 25 (1966), 297-299 (Ineichen); $R F, 77$ (1965), 232-237 (Lausberg); Hum, 15 (1963), 305 (Матtino); ZFSL, 75 (1965), 75-90 (Mü1ler) : FS, 18 (1964), 248-249 (Rickard) .

19-1535. Prado Coelmo, J. do-"O IV Congresso da Associação Internacional de Literatura Comparada". $-B A L, 36$ (1964) , 470-482.

19-1536. BATAILlon, M.- "La renaissance de la philologie à Chapel Hill".-Helikon, 10 (1964), 49.55.-V. núm. 16. 47143.

19-1537. Roddier, H.-“Principes d'une histoire comparée des littératures européennes. Première partie: Qu'est-ce qu'une littérature?".-RLC, 39 (1965), $178-225$.

19-1538. МсСовміск, J. (ed.) -A syllabus of comparative literature. - Scarecrow Press, New York, 1964. 113 pp. $\| M L J$, 49 (1965), 336 (Aldridge).

19-1539. VAJDA, G. M.-"Acta comparationis litterarum universarum",-YCL, 14 (1965), 37.45.

19-1540. VAN Bever, P._"Réflexions sur le comparatisme". - $R L V, 31$ (1965), $613 \cdot 623$.

19-1541. Cioranescu, Alejandro-_Principios de literatura comparada.-Univ. de La Laguna, Tenerife, 1964. 135 pp. II RPh, 19 (1965-66) , 136-137 (Campbell); Conv, 33 (1965) , 550-551 (Carile); RFE, 48 (1965) , 195-198 (Rull); SF, 9 (1965), 319-321 (Trousson).

19-1542. WELLIK, R,-“Comparative literature today".-CL, 17 (1965) , 325-337. [Siguen (pp. 338-345) algunos resúmenes de comunicaciones presentadas por varios especialistas en Harvard, abril de 1965].

19-1543. Einsiedel, WolfGang von (ed.) Die Literaturen der Welt in ihren mündlichen und schriftlichen Vuberlieferung. - Kindler-Verlag, Zürich, 1964. $\mathrm{xix}+1402 \mathrm{pp}$.

19-1544. Muschg, Walter-Historia trd. gica de la literatura. Trad. de Joaquín Gutiérrez Heras.-F.C.E., México, 1965. 720 pp. (Col. Lengua y estudios litera. rios).-.V. núm. 9-17385. || UMx, 22 (1965-66), nưm. 7 (Cantú) ; CuA, 1966, núm. 2, 268-270 (de la Selva); CuA, 1965, nưm. 6, 265-268 (Venegas).

19-1545. HAuser, ARNold-Historia social de la literatura y el arte. 3a ed.-Gua. darrama, Madrid, 1964. 2 ts.: 1070 pp.V. núm. 13-34848.

19-1546. WEIDLÉ, WLADIMIR-Arti e lette$r e$ in Europa. Unità nella diversiti. Trad. di L. Dal Fabro, prol. di C. Bo.Ferro, Milano, 1965. 372 pp.

19-1547. Krauss, WERnER-Zur Dichtungsgeschichte der romanischen Völker.Reclam, Leipzig, 1965. 372 pp. II Weimarer Beiträge, 12 (1966), 144.146 (Rencon \& Barck).

19-1548. Curtius, ERnst Robert-Euto. päische Literatur und lateinisches Mittelalter. 5. Aufl.-Francke, Bern, 1965. 608 pp.-V. núm. 18-1552.

19-1549. Laugesen, ANker Tellgard-Middelalder-litteraturen, en orientering.Gyldenhal, Copenhague, 1966. $440 \mathrm{pp}$. II RRo, 3 (1968), 72-77 (Bukdahl).

19-1550. Jackson, W. T. H.-Medieval literature: $a$ history and a guide. $A$ sur. vey of the poetry, prose and drama of 
Western Europe from 622 to 1500.Macmillan, New York; Collier-Macmillan, London, 1965. 287 pp. (Collier books, 05229).

19-1551. Battaglia, Salvatore - La coscienza letteraria del medioevo.-Liguori, Napoli, 1965.748 pp. (Coll. di testi $e$ di critica, 2) .

19-1552. VISCARDI, A.-"Le origini romanze e la tradizione letieraria mediolatina".-MMD, 2, 687-704.

19-1559. BEZzoLA, RETO R.-Les origines et la formation de la littérature courtoise en Occident (500-1200). 3e partie: Le société courtoise: littérature de cour et littérature courtoise.-Honore Champion, Paris, 1969.2 ts.: 633 pp. (Bibliotheque de l'École des Hautes Études, 320) - -V. núm. 17-4449. || $S p, 40$ (1965), 123-125 (Holmes) ; $R R, 56$ (1965), 284286 (Jackson) ; CCM, 7 (1964) , 187-189 (Micha) : RPh, I9 (1965-66), 103-107 (Payen).

19-1554. LAzar, Moshé-Amout courtois et "fin anors" dans la littérature du xiie siècle.-Faculté des Lettres, Strasbourg, 1964. 185 pp. (Bibliothèque francaise et romane). || VR, 25 (1966), 172174 (Ineichen); LR, 21 (1967), 168173 (Jodogne); ZRPh, 83 (1967), 428430 (Mölk) ; $R P h, 21$ (1967-68), 113 116 (Newsiead) ; CuN, 27 (1967), 173 181 (Pasero) ; RJ, 18 (1967) , 160-162 (Tavani) .

19-1555. Pollman, Leo- "Trobar clus", Bibelexegese und hispano-arabische Literatur.-Aschendorff, Münster Westfale11, 1965. 94 pp. (Forschungen zur romanischen Philologie, 16).

19-1556. BrzzolA, R. R.-"Das Erbe der antiken Kultur im Mittelalter".-[En:] Das Erbe der Antike (Zürich-Stuttgart, 1963), $51-68$.

19-1557. BOLGAR, R. R.-The classical heritage and its beneficiaries: from the Carolingian age to the end of the Renaissance.-Harper \& Row, New York, 1964. viii +591 pp.-V. núm. 10-22886.

19-1558. L'humanisme médiéval dans les littératures romanes du xiie au xive siècle. Colloque de Strasbourg--Klincksicck, Paris, 1964. 264 pp. |l $V R, 25$ (1966) , 300-302 (Buck) ; RPh, 20 (196667), 122-126 (Friedman); CCM, 9 (1966), 297-239 (Miclia); $M A, 72$ (1966), 129-137 (Payen) ; FS, 20 (1966), $51-52$ (Rickard) ; $R R, 59$ (1968), 44-45 (Ryding) : RJ, 18 (1967), 157-160 (Tavani) .
19-1559. Bezold, Friedrich VoN - Das Fortleben der antiken Götter im mittelalterlichen Humanismus. - Zeller, Aalen, 1962. 113 pp.

19-1560. Spanneut, M.-"Sénéque au moyen âge".-RT, 31 (1964), 32-42.

19-1561. Reynolds, L. D.-The medieval tradition of Seneca's "Letters".-OXxford Univ. Press, New York, 1965. (Oxford classical and philos. monographs).

19-1562. Courcelr.e, P.-Les "Confessions" de saint Augustin dans la tradition littéraire (N. 18-1566) . URHE, 60 (1965), 109-116 (Fontaine); JThS, 15 (1964), 413-416 (Frend); RHLF, 65 (1965). (1965), 347-349 (Orcibal); RFN, 57 (1965), 191-196 (Pizzolato); Rev. Êt. Augustiniennes, 10 (1964), $21-34$ (Testard) .

19-1569. MarX, JEAN_Las literaturas célticas._Eudeba, Buenos Aires, 1964. 128 pp. (Cuademos de Eudeba).-V. núm. 16-43357.

19-1564. SPOERrI, TheopHILDante und die europäische Literatur.-Kohlhammer, Stuttgart, 1963. 208 pp. || It, 42 (1965) , 198-201 (Hatzfeld); ZRPh, 80 (1964), 208-212 (Rüegg).

19-1565. Aurrbach, ERICH-Literary language and its public in late Latin antiquity and in the Middle Ages. Transl. by R. Mannheim.-Routledge \& Kegan Paul, London; Bollinger, New York, 1965. 405 pp.-V. núm. 17-4437.

19-1566. Flin, John_Le Roman de Renart dans la littérature française et dans les littératures étrangères au moyen âge.-P.U.F., Paris, 1964. xii + 732 pp. (Univ. of Toronto Publications). - V. núm. 16-43958. \| $M L N, 80$ (1965), 430-432 (Frank); MLJ, 49 (1965), 329-830 (Friedman); $R P h, 21$ (1967-68), 124-129 (Giacchetti); Spiegel der Letteren, 8 (1964-65), 202-209 (Keyser) ; RF, 77 (1965) , 218-220 (KröIner); $C C M, 8$ (1965), 418-421 (Niedzielski); $R R, 58$ (1967), 211.212 (Peckham); MLR, 61 (1966) , 704-706 (Ross); StM, 7 (1966) , 434-436 (Ruggieri) ; FS, 20 (1966) , 47-48 (Varcy); $N, 49$ (1965), 178 (Zumthor).

19-1567. Lewis, C. S. - The discarded image: an introduction to medieval and Renaissance literature. - Cambridge Univ. Press, London-New York, 1964. $\mathrm{x}+232$ pp. || Sp, 40 (1965), 354-356 (Bloomfield) ; ECr, 15 (1965), 207-211 (Burrow); NQ, 11 (1964), 350-351 (Davies); Isis, (1965), 99.100 (Grant); 
Spectator, June 5 1964, 760 (Holloway); Neo-Latin News, 11 (1965), 23-24 (P. W. B.) ; Seventeenth Century News, 22 (1964), núms. 3/4, 46-47 (Patrick); English, 15 (1965), 143-144 (Peschmann); Etudes Anglaises, 18 (1965), 67-68 (Poirier) ; $R P h, 22$ (1968-69) , 327329 (Scaglione); Thought, 40 (1965), 291-293 (Taylor); Cath. Rev, 51 (1965), 87-88 (X) ; Dalhousie Rev., 45 (1965), $225-227$ (X).

19-1568. LACROIX, PAUL-Science and literature in the Middle Ages and the Renaissance.-Ungar, New York, 1964. 552 pp.

19-1569. AlLEN, DON CAMERON-Doubt's boundless sea. Skepticism and faith in the Renaissance.-Johns Hopkins Press, Baltimore, 1964. $\mathrm{xi}+272 \mathrm{pp} . \| R N, 17$ (1964), 211-213 (Colie); FS, 19 (1965), 402.403 (Hall) ; RLC, 39 (1965), 641. 642 (Klein); Études Anglaises, 18 (1965), 68-69 (Legouis); Seventeenth Century News, 23 (1965), 13-14 (Mulder); CLS, 2 (1965), 95-97 (Tetel); CHR, 51 (1965), 89-90 (Valone); Ital. Studies, 20 (1965), 112-118 (Whitfield).

19-1570. GRANT, W. LEONARD Neo-Latin literature and the pastoral._Univ. of North Carolina Press, Chapel Hill, 1965. x + 434 pp. \| $M L R, 62$ (1967), 126-127 (Binns); Seventeenth Cent. News, 23 (1965), 62-63 (Blackford); $M S$, 11 (1967), 56-58 (Clough); CLS, 4 (1967), 207-209 (Greenwood); Phoenix, 19 (1965), 336-338 (MacLure); FMLS, 3 (1967), 67-75 (McFarlane); $M L J, 49$ (1965), 515-516 (Palmer); $R P h, 23$ (1969-70), 244-246 (Scaglione); $R N, 19$ (1966), 16.18 (Smith); $M P h, 64$ (1966-67) , 254-256 (Williams).

19-1571. ARTZ, F. B.-From the Renaissance to Romanticism (N. 18-1580). SAQ, 63 (1964), 247 (Cherpack); History, 49 (1964), 131-132 (Gombrich); $R R, 58$ (1967), 48-49 (Katz); $A H R$, 69 (1964), 715-716 (Nelson); $M L R$, 61 (1966), 108.109 (Praz); RPh, 17 (1963-64), 797-799 (Scaglione); RES, 15 (1964), 447.448 (Thomas).

19-1572. Auerbach, ERICH-Mimesis. Dargestellte Wirklichkeit in der abendländischen Literatur. 3 Aufl. - Francke, Bern-München, 1964. 525 pp.-V. núm. 14.40532 .

19-1573. Pogcioli, Renato_-The spirit of the letter: Essays in European literatures.-Harvard Univ. Press, Cambridge, 1965. || $S R L$, Dec. 25, 1965 (Cle- ments) : $M L R, 63$ (1968), 140-141 (Seznec) ; YR, 55 (1966), 429-432 (Wellek) .

19-1574. Weinrich, Harald-Tempus. Besprochene und erzählte Welt.-Kohlhammer, Stuttgart, 1964. 358 pp. (Sprache und Literatur, 16). [Autores españoles estudiados: Echegaray, Unamuno y Cela]. || Era, 19 (1967), 167-168 (Berendsohn); VR, 24 (1965), 269-301 (Hilty); $R J, 17$ (1966), 171-178 (Sand. mann); $R P h, 19$ (1965-66), 596-599 (Togeby) .

19-1575. Flücel, HEINZ - Konturen des Tragischen. Exemplarische Gestalten der Weltliteratur. - Evangelisches Verlagswerk, Stuttgart, 1965. [Don Quijote, Fausto, Hamlet, etc.].

19-1576. KRAuss, WERNER - Perspektiven und Probleme.-Luchterhand, Neuwied. Berlin, 1965. 397 pp. [Hay un ensayo sobre literatura comparada y otro so. bre Cervantes]. || ASNS, 203 (1966), 478-482 (Schalk).

19-1577. KRANZ, G.-Christliche Literatur der Gegenwart (N. 17-990). $R y F$, 170 (1964), 527 (Blajot); $M L N, 82$ (1967), 631-633 (Frances).-V. núm. $17-4457$.

19.1578. MULLER, HERBERT J.-Science and criticism: the humanistic tradition in contemporary thought. - Yale Univ. Press, New Haven-London, 1964. xvii + 303 pp.

\section{Períodos literarios}

19-1579. EGGEBRECHT, AXEL-Epochen der Welt literatur._Bertelsmann, Güterslol, 1964.

19-1580. SchMIdT, AlbERT-MARIE - xive, xue siècles, les sources de l'humanis. me.-Seghers, Paris, 1964. 256 pp. ( $P a-$ noramas illustrés, 1 ).

19-1581. ChASTEL, ANDRÉ y ROBERT KLEIN -El liumanismo. - Salvat, Barcelona, 1964. 340 pp., 130 láms.

19-1582. Ruiz I C.ALONJA, J.-"Anotacions sobre l'humanisme".—ER, 11 (1962), 1.10 .

19-1583. WEISS, ROBERT-The spread of Italian humanism.-Hutchinson, London; Hillary House, New York, 1964. 144 pp. $\| R P h, 20(1966-67), 147$ (Costa); $S p, 41$ (1966), 191-192 (Gilbert); $F S, 19$ (1965) , 285-286 (Roaf) .

19-1584. "Bibliographie des articles relatifs da l'histoire de l'humanisme et de la Renaissance, 1964".-BHR, 27 (1.965), 761-810.—V. núm. 18-5104. 
19.1585. Wells, W. (ed.) - "Literature of the Renaissance in $1964^{\prime \prime} .-S P h, 62$ (1965) , 215-491-V. núm. 18-5105.

19-1586. Hay, Denys (ed.) - The Renaissance debate.-Holt, Rinehart \& Winston, New York, 1965. 115 pp.

19-1587. Bush, Douglas-Prefaces to Re. naissance literature. - Harvard Univ. Press, Cambridge, Mass. [Y también: W. W. Norton, New York], 1965. xiii + 110 pp. I| Seventeenth Cent. News, 28 (1965), 32 (Daves); $M L R, 61$ (1966), 662-663 (Hill); Concordia Theol. Month. ly, 36 (1965), 453 (Meyer): TLS, August 19,1965 (X).

19-1588. Checksfield, M. M.-Portraits of Renaissance life and thought.-Longmans, London; Barnes \& Noble, New York, 1964. ix +244 pp. [Incluye a Cervantes]. || RN, 19 (1966), 62 (Artz); TLS, Nov. 19, 1964 (X).

19-1589. Antunes, M.-“A Companhia de Jesus e o seu humanismo".-Bro, 81 (1965) , 28-40.

19-1590. TAPIÉ, Victor-LUCEeN-El barroco.--Eudeba, Buenos Aires, 1964. 151 pp. (Lectores, 38) - -V. núm. 18-1609.

19-1591. AlEWYN, Richard-L'univers $d u$ Baroque.-Gonthier, Utrecht, 1964. 167 pp. (Bibl. Médiations). \| CdS, 1967, núms. 6/7, 203-205 (Cvitanovic) .

19-1592. HAuser, ARNOLD - Mannerism. The crisis of the Renaissance and the origin of modern art. Transl. in collaboration with the author by Eric Mosbacler.-Knopf, New York, 1965. 2 ts.: $\mathrm{xx}+425$ pp., 322 láms. $\| C L, 18$ (1966), 284-286 (Burgess).

19-I593. Manierismo, barocco, rococó: Concetti $e$ termini. Convegno internazionale, Roma 21-24 aprile 1960. Relazioni e discussioni. - Academia Nazionale dei Lincei, Roma, 1962. 419 pp.

19-1594. Carr, C. T.-"Two words in art history: 1. Baroque; 2. Rococo".FMLS, 1 (1965) , 175-190, 266-281.

19-1595. PEYRE, HENRI-Qu'est-ce que le classicisme?-Nizet, Paris, 1965. 313 pp. || FS, 20 (1966) , 184-186 (Moore).

19-1596. WELLER, R.-."The term and concept of "classicisms in literary history".-[En:] E. R. Wasserman (ed.), Aspects of the eighteenth century (BaItimore, 1965), 105-128. [Texto alemán en Schweiz. Mon., 1965, 154-173].

19-1597. Mandel, Frani E. (ed.) -The Enlightenment. - Prentice Hall, Englewood Cliffs, N. J., 1965. 184 pp. I| $M L J, 50$ (1966), 239 (Aldridge).
19-1598. Ottino della Chiesa, A.-_Neoclassico e romantico in Europa".- V Veltro, 9 (1965), 23-32.

19-I599. STONE, EDWARD (ed.) - What was naturalism? Materials for an answer.Appleton-Century-Crofts, New York, 1965. 204 pp.

19-1600. Barilli, ReNATO-_La barriera del naturalismo. - Mursia, Milano, 1964. $30 \mathrm{~L}$ pp. I| $K N, 12$ (1965), 420-422 (Heinstein) .

19-1601. Torre, GuIllermo DE-Historia de las literaturas de vanguardia.-Guadarrama, Madrid, 1965. $976 \mathrm{pp}$. Asom, 1967, núm. 3, 32-38 (Adell): fns, 1966, núm. 231 (Cano) ; RHM, 33 (1967) , 190-132 (Cirre) ; PSA, 42 (1966), 89-96 (Cozarinsky): ROcc, 14 (1966), 378-383 (Doreste); Eidos, 1965, núm. 23, 136-137 (Gómez) ; BHi, 69 (1967), 520-524 (Laffranque); $R L M o, 7$ (1968), 149-150 (Ruiz Díaz); CuH, 66 (1966), 420-432 (Scuderi); Sur, 1966, nứm. 300, 106-109 (Zuleta).

19-1602. Billeskov Jansen, F. J. (ed.) Tvaersnit: Europaeish modernisme efter krigen.-Borgen, Copenhague, 1965.

19-1603. Bonet, Carmelo M.-Escuelas literarias. $\mathbf{3}$ ? ed.-Columba, Buenos Aires, $1965.63 \mathrm{pp}$. (Esquemas, 6) -V. nưm. 10-19018.

\section{Géneros literarios}

19-1604. Dízz-TaboAdA, J. M.-“Notas sobre un planteamiento moderno de la teoría de los géneros literarios".-_Hom, 2 (1965), 11-20.

19-1605. MINOT, STEPHEN-Three genres: The writing of fiction, poetry, and drama. - Prentice-Hall, Englewood Cliffs, 1965. $1 \mathbf{x}+308 \mathrm{pp}$.

19-1606. EörSI, I. - "György Lukács and the theory of lyric poetry". - The New Hungarian Quart., Budapest, G (1965), núm. 18, 39-46.

19-1607. Zumthor, Paul_Langue et techniques poétiques à l'époque romane xic - xiiie siecles).-Klincksieck, Paris, 1963. $223 \mathrm{pp}$. (Études littéraires, 4). II FS, 19 (1965) , 284-285 (Barnett); RLiR, 27 (1963), 499-500 (Bourguignon); $R P h, 18$ (1964-65), 226-231 (Dembowski) ; $N, 49$ (1965), 226-268 (Guiette); $R F, 79$ (1967) , 650-653 (Nolting-Hauff); $R R, 56$ (1965) , 56-57 (Pei) ; $D L Z, 86$ (1965), 207-209 (Pollmann); RJ, 17 (1966), 187-189 (Rohr); VR, 24 (1965), 138-143 (Rychner); StM, 6 (1965), 455- 
456 (Stussi); $Z R P h, 82$ (1966), 366-370 (Ziltener).

19-1608. DRAPER, J. W.-."The origin of rhyme. A supplement". - RLC, 39 (1965) , 452-453.-V. núm. 12-32951.

19-1609. Zuмтнов, P._-"Le vers comme unité d'expression dans la poésie romane archaïque"._CLR(10), 763-774.

19-1610. MONTEVERDI, A-_-"Problèmes de versification romane".-CLR(10), 33-54. \|CuN, 25 (1965), 150 (Menichetti).

19-1611. PER, H._-"La versification à accents fixes dans la prosodie romane".-CLR(10), 775-782.

19-1612. Chatman, Seymour-A theory of meter.-Mouton, The Hague, 1965. 229 pp. Il LiS, 1 (1966), 254-255 (Cremante) ; $B A b r, 40$ (1966), 343 (Hendricks).

19-1613. Burgess, R. M.-"The sonnet, a cosmopolitan literary form in the Renaissance".-CLC(4), 169-184.

19-1614. Maldonado de Guevara, F.- "E1 soneto, forma perenne". — RIEs, 28 (1965), 79-94.

19-1615. Richmond, H. M.-The school of love.-Princeton Univ. Press, Princeton, 1964. [La lírica amorosa].

19-1616. MCLAughlin, Richard, \& Howard E. SLACK_Music of the mind: 1000 years of European poetry._-Groset \& Dunlap, New York, 1963. 297 pp.

19-1617. FRIEDRCH, Hugo-Die Struktur der modernen Lyrik. 7. Aufl.-_Rowohlt, Hamburg, 1964.-V. núm. 17-4503.

19-1618. WelleK, A.-"Die Struktur der modernen Lyrik. Betrachtungen zu dem Buch von Hugo Friedrich und zu Grundsatzfragen einer Literaturästhetik und systematischen Literaturwissenschaft".-_StG, 16 (1963) , 36-46.

19-1619. VIGLiz, CIAUDE-Révolte et louanges. Essais de poésie moderne.-José Corti, Paris, 1962. 219 pp. [Hay un ensayo sobre Guillén]. || $C L, 17$ (1965), 372-375 (Brée).

19-1620. WhitMan, Cedric H. - Homer and the heroic tradition.-Norton, New York, 1965. $\mathrm{xv}+314$ pp.-V. núm. 16 . 47246.

19-1621. Bowra, C. M.-Heldendichtung. Eine vergleichende Phänomenologie der heroischen Poesie aller Völker und Zeiten. Ubers. von H. G. Schürmann.Metzler, Stuttgart, 1964. $656 \mathrm{pp}-\mathrm{V}$. núm. 8-12656. || $W W, 16$ (1966), 278 281 (Rosenfeld); $N, 50$ (1966), 173175 (Van der Lee); EtG, 21 (1966), 101-102 (Zink).
19-1622. DE VRIEs, J.-Heldenlied und Heldensage (N. 17-4505). \|I IF, 68 (1963), 254 (Fromm); \$p, 39 (1964). 136.137 (Jackson); Germanistik, 4 (1963), 41-42 (Lemmer); German Life o Let. ters, 17 (1963-64) 54-56 (Norman).V. núm. 18-1638.

19-1623. DF VRuss, J-Heroic song and heroic legend (N. 18-1639) . $\mid$ AUMLA, 1964, núm. 21, 98-99 (Thornton) .

19-1624. VISCARDI, A.- "Letteratura epico-storica di corte e poesia cortese". ZRPh, 81 (1965), 454-475.

19-1625. FRIEDEMANN, KÄTE - Die Rolle des Erzählers in der Epik.-Wissenschaftliche Buchgesellschaft, Darmstadt, 1965. [Reprod. de la ed. de 1910].

19-1626. DuRLing, Robert M.-The figure of the poet in Renaissance epic.Harvard Univ. Press, Cambridge, Mass., 1965. 280 pp. || ZRPh, 84 (1968), 138 140 (Buck); RES, 18 (1967), 455-456 (Buxton); $R R, 59$ (1968), 49-51 (Carrington); UTQ 36 (1967), 206-208 (Corrigan); CLS, 4 (1967), 331 -334 (Lievsay); RQ 20 (1967), 357-360 (Mirollo); Italian Studies, 22 (1967), 133-134 (Moores); Belf, 22 (1967), 113-116 (Petrini).

19-1627. "Bibliographie" [sobre teatro]$B H T, 17$ (1965) , 216-265, 324-377, 435489._V. núm. 18-5140.

19-1628. ANDERson, M. J. (ed.) - Classical drama and its influence:essays presented to $H$. D. F. Kitto.-Barnes \& Noble, New York, 1965. 377 pp. \| Hermathena, 1966, 93-94 (Hinds); QJS, 52 (1966), 395-396 (Reardon).

19-1629. Nicoll, A.-Historia del teatro mundial, desde Esquilo a Anouilh. Trad. J. Mar-Ruiz-Werner. - Aguilar, Ma. drid, 1964. xxiv + 939 pp. + 40 láms. (Bibl. de cullura e historia). II Seg, 1 (1965), 423-424 (Esquer Torres); USF, 1965, núm. 64, 371-372 (Storni).

19-1630. KinderManN, H. - Theaterge. schichte Europas, Bd. 4 (N. 17-1046). |l $W W, 11$ (1961), 57-59 (Frenzel); EtG, 20 (1965), 104-105 (Girard); GRev, 39 (1964), 145-147 (Hunningher).

19-1631. Hillard, G.-"Theater in Geschichte und Gegenwart"-_Merkur, 18 (1964), 583-587. [Sobre las obras de Kindermann y Melchinger-Rischbieter]. 19-1632. Maccowan, K., y W. MeLnitzLas edades de oro del teatro. Trad. C. Villegas y J. Prieto.-F.C.E., México, 1964. 344 pp. (Col. popular, 54) v. núm. 17-1049. \|CuH, 62 (1965), 
445-446 (Chávarti); Seg, 1 (1965), 424425 (Esquer Torres); CuA, 1964, núm. 6, 281-282 (de la Selva); Rev. del Pacifico, Valparatso, 4 (1967), I54-156 (Weinstein)

19-1633. Díaz Plaja, Guilffrmo-Esque. ma de historia del teatro.-Instituto del Teatro, Barcelona, 1964. 79 pp., ilustr.

19-1634. DownER, ALAN S. (ed.)-Great world theater. With introd. and glossary.-Harper \& Row, New York, 1964.

19-1635. HESS, RAINER-Das romanische geistliche Schauspiel als profane und religiöse Komödie (15. und 16. Jahr. hundert)._Fink, Munchen, 1965. 198 pp. (Freiburger Schriften zur Romanischen Philologie, 4). \| ZFSL, 76 (1966), 381-983 (Engler); $R P h, 21$ (1967-68), 139-140 (Friedman); $R F, 78$ (1966) , 582-586 (Nerlich) ; $N, 50$ (1966), 465 (Oostendorp) ; FS, 21 (1967), 58.60 (Warne) .

19-1636. SLETsJöE, L__"Quelques réflexions sur la naissance du théâtre religieux".-CLR(10), 2, 667-675.

19-1637. Everding, A._-Die Darstellung des Hciligen auf der Bühne".-Festschrift Romano Guardini (Würzburg, 1965) , 392-409.

19-1698. JACQUOT, JEAN, et al. (eds.) Le lieu théâtral à la Renaissance. Royaumont, $22-27$ mars 1963 _C.N.R.S., Paris, 1964. || $M L R, 62$ (1967), 509-510 (Bradbrook); $R P h, 20$ (1966-67), 985386 (Clubb) ; EtG, 21 (1966), 288-289 (Gravier); RHT, 17 (1965), 426-428 (Konigson) ; $R R, 57$ (1966) , 123-128 (Panizza Lorch).

19-1639. Herrick, MARvin T.-Italian tragedy in the Renaissance.-University of Illinois Press, Urbana, 1965. $315 \mathrm{pp}$. || $R N, 19$ (1966) , 23-26 (Aguzzi-Barbagli); SQ, 17 (1966), 89-90 (Clubb); $M S, 9$ (1965) , $178-180$ (Grant); $M L N, 82$ (1967) , 114-116 (Howe) ; Era, 17 (1965), 532-533 (Junker); CMLR, 22 (1965), 77-78 (Mollica) ; RLMo, 7 (1968), 182184 (Nallim); QJS, 51 (1965), 471 (Pritchard) ; Amer. N. \& Q., 4 (1965), 1415 (Rachow); Italian Quarterly, 10 (1966) , 89-92 (Speroni); TLS, Oct. 14, 1965 (X).

19-1640. Jacquot, JEAN, et Marcel Oddon (eds.) -Les tragédies de Sénèque et le thétre de la Renaissance. Préf. de R. Lebègue. - C.N.R.S., Paris, 1964. xli + 320 pp. $\|$ ASNS, 202 (1965), 452.455 (Bürger); RHLF, 65 (1965),
695-696 (Morel); RHT, 18 (1966), 240-242 (Van Tieghem); CL, 18 (1966), 85-86 (Wassermann).

19-1641. Herrick, Marvin T. - Comic theory in the sixteenth century.-Univ. of Illinois Press, Urbana, 1964. 248 pp.--V. núm. 9-15021. || $H L J, 49$ (1965), 457-458 (Houppert); $B H R, 28$ (1966). 202-208 (Stäble).

19-1642. Brahmer, M.-_La comédie polyglotte (xvie-xvire siècles)". — CLR (10), 373-384.

19-1643. Carlson, M. - "Modern drama: A selected bibliography of bibliographies"'-MD, 8 (1965), 112-118.

19-1644. JAuss, H, R. (ed.) - Nachahmung und Illusion: Kolloquium Giessen, Juni, 1963. Vorlagen und Ver. handlungen. - Eidos, München, 1964. 252 pp. [Estudios sobre Ia novela]. II $M P h, 64$ (1966-67), 173-175 (Frank); RF, 78 (1966) , 177-189 (Nerlich); Era, 18 (1966), 739-743 (Yarrill) .

19-1645. Casais Monteiro, Adolfo-O romance. Teoria e critica.-J. Olympio, Rio de Janeiro, 1964. xvi + $417 \mathrm{pp}$. || $B A b r, 40$ (1966), 242 (Barrow).

19-1646. GoldmanN, Lucien-Pour une sociologie du roman.-Gallimard, Paris, 1964. 229 pp. (Bibliotheque des idées). || Aut Aut, 1966, núm. 92, 86-88 (Caruso) ; $A E S C, 20$ (1965), 490-502 (Chatclet); $M L N, 80$ (1965), 382-388 (Grover); Riv. di Estetica, II (1966), 452455 (Romano).

19-1647. GIRARD, R.-Mensonge romantique et vérité romanesque (N. 17-4408), II AESC, 20 (1965), 465-475 (Cohen); ibid., 476.489 (Crouzet); Crit, 1962, núm. 176, 19.31 (Deguy).

19-1648. GIRARD, RENéDeceit, desire, and the novel. Self and other in literary structure. Trad. Y. Freccero.-Johns Hopkins Press, Baltimore, 1965. $318 \mathrm{pp}$. [Cervantes y otros].-V. núm. 17-4408. II $H R, 36$ (1968), 189-194 (Uitti).

19-1649. HARDY, JOHN EDWARD-Man in the modern novel._-Univ. of Washington Press, Seattle, 1964. 228 pp. \| Thought, 41 (1966), 134-136 (Reilly). 19-1650. SCHULte-KeMmLNGHAUSEN, KARL \& GEORG HüLleN (eds.)-Märchen der europäischen Völker. Bde. 4-5.-Aschen. dorff, München, 1963-64. 222, 236 pp.V. núm. 17-4539. || EtG, 2I (1966), 468-469 (Fink) .

19-1651. EBEL, UDA-Das altromanische Mirakel. Ursprung und Geschichte einer literarischen Gattung.-Heidelberg, 1965. 
144 pp. (Studia romanica, 8) - -V. núm. 18-5157. || $R P h, 20$ (1966-67), 387.388 (Koenig); $R F, 78$ (1966), 154-158 (Rothe).

19-1652. BIELLA, A.-“"Considerazioni sull'origine e sulla diffusione della pastorella".-CuN, 25 (1965), 236-267.

19-1653. Rotermund, ERwiN-Gegengesänge. Lyrische Parodien vom Mittelalter bis zur Gegenwart.-Eidos, München, 1964. 277 pp. || Germanistik, 5 (1964), 445 (Reichert).

19.1654. Lehmann, P.-Die Parodie im Mittelalter (N. 18-5158). \| $R B, 75$ (1965), 189-190 (Misonne); RHE, 60 (1965), 519-524 (Silvestre).

19-1655. Hempel, W._-"Parodie, Travestie und Pastiche. Zur Geschichte von Wort und Sache"._GRM, 15 (1965), 150-176.

19-1656. LiMA, Sílvio - Ensaio sobre a essência do ensaio. 2a ed.-A. Amado, Coimbra, 1965. 206 pp. (Studium, 41).

19-1657. Hamburger, M. - "Essay über den Essay".-Akzente, 12 (1965), 290292.

19-1658. NuEz, A. DE LA-"Antiguos y nuevos métodos de penetración del ensayo". $-A F, 4$ (1965), 7-94.

\section{Temas literarios generales}

19-1659. Trousson, RAYMond-_Un problème de littérature comparée: les études de thèmes. Essai de méthodologie.Minard, Paris, 1965. 111 pp. (Siluations, 7). $\| L R, 21$ (1967), 91 (Pouilliart). 19-1660. FRENZEL, E.-Sloffe der Weltlileratur (N. 18-1683). II German Life and Letters, 17 (1963-64), 119-120 (Forster); Leuvense Bijd., 53 (1964), 172 (Jacob) ; $Z V, 61$ (1965), 274-275 (Röh. rich) .

19-1661. "Bibliographie [arthurienne] pour 1964".--BBSIA, 17 (1965), 7.84。V. núm. 18-5161.

19-1662. Loомis, R. S.-The development of Arthurian romance (N. 18-5112). II RES, 16 (1965) , 58-59 (Davies); $J E G P h, 63$ (1964), 762-763 (Lumiansky); $M A e, 34$ (1965), 84.85 (Pickford) .

19-1663. MARX, JEAN-Nouvelles recherches sur la littéralure arthurienne. Origines el développement de la légende du Graal._Klincksieck, Paris; Verlag Moritz Diesterweg, Frankfurt-Berlin-Bonn, 1965. 323 pp. (Bibliothèque française et romane). || CCM, 10 (1967), 471-477
(Gallais) ; $M A, 72$ (I966) , 149.15I (Ménard) ; Ro, 86 (1965) , 546-550 (Payen); StM, 7 (1966), 447-448 (Ruggieri).

19-1664. LOOMIS, ROGER SHERMAN-The Grail. From Cellic mith to Christian symbol_-Univ. of Wales Press, Cardiff; Columbia Univ. Press, New York. London, 1963. xi +287 pp. $\| R R$, 56 (1965) , 57-59 (Ackerman); Sp, 40 (1965) , 152-155 (Adolf); StN, 38 (1966), 146-148 (Almqvist); Germanistik, 5 (1964) , 48-49 (Closs); $L R, 20$ (1966), 357.360 (Jodogne) ; Ogam, 15 (1963), 264 (Le Roux); JEGPh, 63 (1964), 763 (Lumiansky); Thought, 39 (1964), 121 122 (Melton); CCM, 9 (1966), 421. 424 (Payen).

19-1665. ADOLF, H.-Visio pacis: Holy city and Grail (N. 17-1065). IN NQ, 9 (1962), 74 (Dronke); Germanistik, 2 (1961), 531-532 (Eggers) ; $R R, 55$ (1964), 113.114 (Fowler); CCM, 9 (1966), 229230 (Gallais) ; FS, 20 (1966), 171 (Lyons) - -V. núm. 18-1690.

19-1666. Weston, Jessix L-The quest of the Holy Grail._Bames \& Noblc, New York, 1964. $\mathrm{x}+162$ pp. [1: ed., London, 1913].

19-1667. Peri PFLAUM, H.-Der Religions. disput der Barlaam-Legende (N. 1647289). II ZRPh, 81 (1965), 525-527 (Bogdanow); ReSR, 49 (1961), 283284 (Dumeige); $A L M A, 32$ (1962), 122 (Hélin); DtA, 17 (1961), 622.623 (Ploss); Muséon, 73 (1960), 440-441 (Quecke).-V. núm. 17-4550.

19-1668. D'AlVERnY, M. T.-“Les Muses et les sphères célestes".-Studies... B. L. Ullman (Roma, 1964), 2, 7-19. 19-1669. TROUSSON, RAYMOND-Le thème de Prométhée dans la littérature européenne.-Droz, Genève, 1964. 2 ts. II $B A b r, 40$ (1966), 47-48 (Mermier): $B B F, 9$ (1964), 399 (Peyraube); $M L R$, 63 (1968), 661-662 (Pollard); FS, 19 (1965), 51-53 (Seznec); SF, 1966, núm. 28, 113-114 (Wais).

19-1670. Ross, D. J. A.-Alexander historiatus. A guide to medieval illustrated Alexander literature.-The Warburg Institute, London, 1963. 128 pp. II FS, 19 (1965) , 400-401 (Foster) ; CCM, 8 (1965), 218-220 (La Du); Lat, 23 (1964) , 410 (Liénard) ; $M L R, 60$ (1965), 421-422 (MacDonald); $S p, 40$ (1965), 368 (Magoun); REL, 42 (1964), 644645 (Martin); PBSA, 59 (1965), 217 (Thompson) .

19-1671. Nardicchia, Marjo_Inès de Cas- 
tro in opere teatrali dell'occidente romanzo.-[Tesis, Univ. de Nápoles, 1965]. 149 pp.

19-1672. Buck, A-_Democritus ridens et Heraclitus flens".-FFS, 187-186.

19-1673. GöllneR, C.-_Der Türke in der dramatischen Literatur des 16. Jahr. hunderts".-_Revue des Etudes Sud-Est Européennes, 3 (1965), 131-153. [Cervantes y Lope de Vega, entre otros]. II EtG, 22 (1967), 616-617 (Ravicovitch).

19-1674. Grécorre, R.-"Le mépris du monde dans la littérature latine médiévale'.-RAM, 41 (1965), 251-287.

19-1675. WALKER, D. P.-The decline of hell: seventeenth-century discussions of eternal torment.-Univ, Press, Chicago, 1964. 272 pp. $\| M P h, 63$ (1965-66) , $70-72$ (Fixler) ; $F S, 19$ (1965) , 405-406 (Fletcher) ; $C H R, 52$ (1966), 262-263 (Keller).

19-1676. Grimm, JüngEN_Die literarische Darstellung der Pest in der Antike und in der Romania.-W. Fink, München, 1965. 243 pp. (Freiburger Schriften zur romanischen Philologie, 6). \| ZRPh, 83 (1967), 418.421 (Glasser); FS, 21 (1967) , 237-238 (Legge); $R R, 58$ (1967), 315.316 (O'Brady); $N, 50$ (1966), 465 (Oostendorp) .

19-1677. Bresse, AlFred-The development of the feeling for nature in the Middle Ages and modern times.Franklin, New York, s. a. 376 pp. [Reimpr. de la ed. de 1905].

19-1678. TAYLER, EDWARD WILLIAM-Nature and art in Renaissance literature.Columbia, Univ. Press, New York-London, 1964. ix +225 pp. $\| R N, 18$ (1965), 338-340 (Feninger); $M L R, 61$ (1966), 271-272 (Hill); RES, 18 (1967), 317.318 (Jones); JEGPh, 65 (1966), 172-174 (Manley); $M L J, 49$ (1965), 397-398 (Merrill); CL, 18 (1966), 8790 (Paolucci) ; BAbr, 39 (1965), 347 (Pritchard) ; Thought, 41 (1966), 283284 (Robinson); Era, 20 (I968), 171. 174 (Schulze); $M L Q, 26$ (1965), 47I473 (Wallace); St $N, 38$ (1966), I56158 (Williamson).

19.1679. WilhelM, James J.-The cruelest month: Spring, nature, and love in classical and mediaeval lyrics.-Yale University Press, New Haven, 1965. II CJ, 61 (1965), 156.157 (Lind): Virginia Quart. Rev., 42 (1966), núm. 1, 21 (X) ; $N, 51$ (1967), 188.189 (Zum. thor).

19-1680. Hatto, Arthur T. - Eos: $A n$ inquiry in the theme of lovers' meetings and partings at dawn in poetry.Mouton, The Hague, 1965. 854 pp. I $C L, 18$ (1966) , 264-266 (Romig); $M L R$, 62 (1967), 300-301 (Sayce).

19-1681. Krutch, Joseph Woon (ed.) The world of animals. A treasury of lore, legend, and literature by great writers and naturalists from the $5 t h$ century B.C. to the present.SimonSchuster, New York, 1961. 508 pp., ilustr. || Science, 196 (1962), 504 (Milne) .

19-1682. BihleR, H._'Zur Gestalt mittelalterlicher lateinischer, französischer und spanischer Fassungen der Fabel vom Fuchs und vom Raben".-FHR, $21-48$.

19-1683. Jones, R. O._-"Renaissance butterfly, mannerist flea: tradition and change in Renaissance poetry" $-M L N$, 80 (1965), 166-184.

19-1684. Asensto, J._- “La alondra, arque. tipo Iiterario".-EM, 21 (1965), 123130.

19-1685. Garcí Templado, J.-_El poético tema de la cebolla".-ROcc, 10 (1965) , 235-242.

19-1680. Anderson, George K.-The legend of the Wandering Jew.-Brown Univ. Press, Providence, R. I., 1965. $M L R, 63$ (1968), 138-139 (Butter).

19-1687. Les utopies à la Renaissance Colloque International (avril 1961).-Presses Universitaires de Belgique, Bruxelles; Presses Universitaires de France, Paris, 1963. 228 pp. || $C d S, 1967$, núms. 6/7, 184 (Ciocchini); $\mathrm{CuH}, 61$ (1965), 624-632 (Elorza); Moreana, 1966, núm. 10, 4753 (Jasques) ; $R N, 18$ (1965), 223-225 (Patrick); Era, 17 (1965), 75-77 (de Tervarent) .

\section{Relaciones literarias}

Influencias extranjeras

19-1688. Catal $\hat{N}$, D._La Biblia en la literacura medieval española".- $-H R, 33$ (1965), 310-318.

19-1689. Demetrius, JAMES KLEON-Greek scholarship in Spain and Latin America. Introd. by L. Nicolau d'Olwer.-Argonaut, Chicago, 1965, 144 pp. $\| H R$, 35 (1967), 972-978 (Beardsley); Atl, 4 ([966), 351-353 (Fernández Galiano); $B F E$, 1966, núms. 20/21, 74-76 (Gangutia) ; BBudé, 14 (1967), 259 (J. M.) ; $B A b r, 40$ (1966), 453 (Rexi- 
ne); Helm, 17 (1966), 154-156 (Rodríguez); PBSA, 60 (1966), 263 (Thompson); $H I, 50$ (1967), 196 (Woodbridge); $H A H R, 46$ (1966), 348 (X).

19.1690. Robledo Garcia, M. N.-El mundo clásico en el pensamiento español contemporáneo: Unamuno, Antonio Ma. chado, Baroja y Pérez de Ayala.-[Tesis, Univ, de Madrid; resumen en $R U M$, 14 (1965), 255-256].

19-1691. Rubió i Balacuer, J.-“Sobre Sallusti a la cancellería catalana (segle xIv-xv) ".-SpF, 21 (1963) .

19-1692. Serrano Poncela, S__. "Séneca entre españoles".-CuA, 1964, núm. 3, 97-112; HIAC, 383-396.

19-1693. IsAR, H. E.-"La question du prétendu sénéquisme espagno]".-[En] J. JACQuot (ed.), Les tragédies de Sénèque et le thétre de la Renaissance (Paris, 1964) ...V. núm. 13-37056.

19-1694. PENNA, M.-"Traducciones cas. tcllanas antiguas de la Divina Comeclia".-RUM, 14 (1965), 81-110.

19-1695. ARce FernÁndeZ, J-_"La lengua de Dante en la Divina Comedia y en sus traductores españoles", $-R U M, 14$ (1965) , 9-48.

19-1696. ARCE, J.-_La bibliografla hispánica sobre Dante y España entre dos centenarios (1921-1965)",-_[En el volu111en] Dante nel mondo (Firenze, 1965), 407.431 .

19-1697. Castro, S._- Dante in Portogallo (1922-1964) "-[En el volumen] Dante nel mondo (Firenze, 1965), 365-367.

19-1698. Simón DíAz, J-_Los traductores españoles de Malvezzi"._- RLit, 28 (1965) , 87-93.

19.1699. Calabró, G._"Beccaria e la Spagna".-Atti del Convegno su Beccaria (Torino, 1965), 101-120.

19-1700. Defourneaux, M.-L'Inquisition espagnole et les livres français au xviiie siecle (N. 18-4313). II QIA, 5 (196667), 95.97 (Cruz); HR, 34 (1966), $351-356$ (Sebo]d) .

19-1701. Booy, J. DE-“'A propos de l'Encyclopedie en Espagne” (N. 17-4576). \| RFE, 48 (1965), 463-464 (López Jiménez) .

19-1702. Carboneli, J.- "Dues traduccions rosselloneses setcentistes de la Zä̈ra de Voltaire".-ER, 11 (1962), 161-170.

19-1703. RIBER, A.-"Mireille en cata. lan".-Rev. de Langue et Litt. Provençales, Avignon, 1960, núm. 1, 191. 193.

19-1704. ARAMON I SERRA, R, "El ressò de l'oda I troubaire catalan a Cata. lunya"_-ER, 11 (1962), 187-247.

19-1705. Orcibal, J.-"Les traductions du Spieghel de H. Herp en italjen, portugais et espagnol".-Dr. L. ReypensAlbum (Antwerpen, 1964), pp. 257. 268. || LR, 19 (1965), 138 (Groult); Bs, 40 (1964), 427-429 (Silva Dias).

19-1706. López Estrada, F.- "La primera versión española de la Utopla de Moro, por Jerónimo Antonio de Medinilla (Cordoba, 1637)".-HAC, 291-309.

19-1707. Schwarz, E.-"The reception of German culture in Spain".-YCL, 14 (1965), 16-36.

19-1708. MöNNIG, RICHARD_Traducciones del alemán. Español.-Vandenhoeck \& Ruprecht, Göttingen, 1964. 137 pp.

19.1709. Koch, HerRerT_Schiller y Espnĩa.-Editora Nacional, Madrid, 1965. || BACol, 16 (1966), 282 (X).

19-1710. Cano, J. L.-"Gessner en España" (N. 17-1108). \|RFE, 48 (1965), 454-455 (López Jiménez).

19-1711. Balashov, N. I._"Rukopisi ispaniskij dram o Rusi i gumanisticeskaja tradicija literatury Ispanii xvil v."$I A N, 23$ (1964), 18-35.

19-1712. InIESTRA ONECA, A..." Sobre al. gunas traducciones españolas de nove. las"._RLit, 27 (1965), 79.84.

V. tambiên núms. $167,969,1860,1926$, $1998,2047,2093,2429,2500,2531,2641$, $2924-5,2990,3292,3306,3443,3677$, $3874-5,3886,3950,4020,4024$.

\section{Influencias hispánicas}

19-1719. WUNDERLI, PETER-Études stur le "Liure de lEschiele Mahomet". Prolégoménes à une nouvelle édition de la version française d'une traduction alphonsine.-P. G. Keller, Winterthur, 1965. ix + 154 pp.-V. núm. 18-1739. || $R J, 17$ (1966), 192.194 (Mettrmann). 19-1714. Pelosi, Silvio-Dante e la cultura islamica: analogie tra la "Commedia" $e$ il "Libro della scala", con un'introduzione in lingua araba..-Christen, Tripoli, 1965. $39 \mathrm{pp}$.

19-1715. Cruz HernANdez, M- "La raiz común de la religiosidad del mundo de la profecia, y la posibilidad de las relaciones entre la escatología islámica y la Divina Comedia"_-RUM, 14 (1965), 49-80.

19-1716. Croce, A.-'Notizie su La Spagna nella vita italiana".__SLS, 373-378. 19-1717. Meregall, F.-"Giuseppe Baret- 
ti e la letteratura spagnola".__Studi Bruno Revel (Firenze, 1965), 415-422. 19-1718. Ricisthofen, E. von-“Le subs. trat hispano-portugais de la légende de Loherinc et de l'Arthur d'Algarve".$A E M, 2$ (1965), 525-530.

19-1719. Chamoux, A. L.-“Quelques jalons pour l'étude des influences espagtioles sur les écrivains français".-IL, 17 (1965), 220-225.

19-1720. KoENIG, W._"Un type universel de la littérature française: Ie Cid".NS, 1965, núm. 8.

19.1721. Herreras, D._-Fuentes españolas de La escuela de los maridos".$R y C, 10$ (I965) , 257-272.

19-1722. Guinard, P. J.- "Une fausse lettre espagnole de Voltaire" (N. 1647352). \|RFE, 48 (I965) , 460-467 (Lo. pez Jiménez).

19-1723. PEYre, JOSEPI_LLos lanceros de Jerez._Bruguera, Barcelona, 1964. 350 pp.

19-1724. RANDALL, DALE, B. J.-The golden tepestry: a critical survey of non. chivalric Spanish fiction in English translation (1543-1657). - Duke Univ. Press, Durham, 1963. vii + 262 pp.V. núın. 13-\$6840. || Era, 17 (1965), 28-30 (Brunner); HR, 33 (1965), 399$40 \mathrm{I}$ (Knowles); HAHR, 44 (1964), 390-391 (Leonard); $B H i, 68$ (1966), 408-410 (Pelorson); $C L, 16$ (1964), 179.181 (Pierson); $H, 47$ (1964), 868. 869 (Rothberg) ; WHR, 18 (1964), 285 286 (Sacks); $R N, 17$ (1964), 240-241 (Singleton) ; $M L R, 59$ (1964), 452-453 (Wilson) .

19-1725. Remarque, Erich Marta-Uma noite em Lisboa.-Europa-América, Lisboa, 1964. 362 pp.-V. núm. 18-5219.

19-1726. CoY, J. J.- "La España de Kazantzakis".-PE, 1964, núns. $97 / 98$.

19-1727. Demetrius, J. K.-“Nikos Kazantzakis in Spain".-HMJB, 215-225.-V. núm. 16-43578.

19-I728. Molho, M.—“La producción literaria castellana en Oriente en el siglo xv1". $\angle M J B, 333-336$.

19-1729. Strzalkowa, M.-Studia polskohiszpanskie (N. 17-4605). $\|$ BHS, 42 (1965), 268-269 (Smieja).

19-1730. Alekseev, M. P.-Ocherki istorii Ispano-Russkij literaturnyj otnoshenii $x v i-x i x$ vv.-[Universidad], Leningrad, 1964. || $R L C, 38$ (1964), 477-4.79 (Corbet) ; $B A b r, 39$ (1965), $\$ 59-360$ (Ferrer); $H, 49$ (1966), 348-349 (Ferrer); $B H i, 69$ (1967), 139-14.8 (Gacon); LS,
1965, 11úm. 3, 180-183 (Plavskin); $H$, 48 (1965), 370-371 (Schanzer); $R L C, 39$ (1965), 454-463 (Zviguilisky).

19-1731. FoRD, H. D. $-A$ poet's war. British poets and the Spanish civil war.Philadelphia, 1965. 328 pp.

V. también núms. 278-9, 286, 976-8, 1671 , 1791-2, 1858, 2033-5, 2358-9, 2556-8, $2560,2589,2880,2907,3012-3,3015$, $3045-6,3087,3120-1,3297-8,3308,3381$, $3383-7,3402-3,3612-3,3842-3,4023,4026$.

\section{LATINLSTAS Y HUMANISTAS}

19-1732. BRANCA, V.-"Ermolao Barbaro e la sua presentazione alla corte arago. nese".-Studies B. L. Ullman (Roma, 1964), 2, 385-411.

19-1733. Matos, L. DE - "L'humanisme portugais et ses relations avec l'Europe".-BEP, 26 (1965) , 45-65.

19-1734. Gomes DA Silva, N. J. E.-Humanismo $e$ direito em Portugal no século xvi.-[Tesis, Univ. de Lisboa, 1964]. $400 \mathrm{pp}$.

19-1735. Frèchas, Claude-Henri-Le théa tre neo-latin au Portugal, 1550-1745. Bertrand, Lisboa, 1964. xiv +583 pp. II $K F, 78$ (1966), 618-619 (Hess); $B E P$, 26 (1965), 250-253 (Le Gentil); Bro, 80 (1965) , $261-263$ (Martins) ; RHT, 18 (1966), 236-238 (Massa); AHSI, 36 (1967), 194-200 (Scaduto); CuN, 24 (1964), 289-294 (Stegagno Picchio).

19-1736. Frèches. C. H._Quelques aspects du drame néo-latin au Portugal".-_Co, I965, núm. 36.

19-1797. Fréches, C. H.“'Le téatre néoIatin au Portugal. La Tragicomédie de dom Manuel".-APK, 5 (1965), 106148. I| AHSI, 36 (1967), 194-200 (Sca. duto).

19-1738. Gil Fernindez, J.--Nebrija en el Colegio de los españoles de Bolonia'.-Em, 33 (1965), 347.349.

19-1739. FeIst Hmsch, E_-"The discoveries and the Ilumanists" _-[En] J. Parker (ed.), Merchants and scholars (Minneapolis, 1965), 35-46. [Sobre Góis].

19-1740. Hornik, M. P._-"Profiles of conversos".- $H A C, 7-20$. [En particular, Luis Vives].

19-1741. Pinta Llorente, Miguel de LA, y José María de Palacio y PalacioProcesos inquisitoriales contra la familia judia de Juan Luis Vives.-Introd. y transcripción paleográfica de... T. 1: Proceso contra Blanquina March, madre del humanista...C.C.I.C., Madrid-Barce. 
lona, 1964. 107 pp., láms. II Sef, 24 (1964), 380-382 (Cantera); RBPH, 44 (1966), 1413-1414 (Crahay); Aleōn, 20 (1966) , 353-366 (González Gallego); $B H I S, 44$ (1967) , 75-76 (Kamen) ; $R H$, 235 (1966) , 260 (Lapeyre); AlA , 27 (1967), 479-480 (Meseguer Fernández) ; $B H i, 67$ (1965) , 378-379 (Pérez); RLit, 25 (1964), 229 (Rozas).

19-1742. Millas Valiucrosa, J. M.-"La ascendencia judaica de Juan Luis Vives y la ortodoxia de su obra apologética".-Sef, 25 (1965), 59-65.

19-1743. SANCHEZ Gamborino, F, M, "Concordia y equidad en el pensamiento jurídico de Vives".-Rev. General de Legisl. y Jurisprud., 51 (1965), 535542.

19-1744. Serrano Serrano, J. M.-'Doctrina de Juan Luis Vives sobre la propiedad y el trabajo y su repercusión en las instituciones sociales contemporáneas"._Salm, 12 (1965), 57-107.

19-1745. Manzari, B. - "Le prospettive dell'educazione secondo $L$. Vives e G. G. Rousseau",-Rassegna di Scienze Filosofiche, 18 (1965), 27-54.

19-1746. Momigliano, A.-"Enrique Caiado e la falsificazione di C.I.L. II, 30".Ath, 42 (1964) , 3-11.

19-1747. SECRET, F.-"Un humaniste oublié. Joannes Vaccaeus Castellanus de Murcie, parisien d'adoption":-RLC, 39 (1965), 66-74 [Juan Vaca de Castro].

19-1748. Meneses, D. PEDRo DE-Oraçẫo proferida no Estudo Geral de Lisboa. Oratio habita... in scholis Ulyxbonae. Trad. Miguel Pinto de Meneses. Introd. de A. Moreira de Sá.-Instituto de Alta Cultura, Lisboa, 1964, 124 pp.

19-1749. Prado Coello, J. DO-“O humanismo de Matias Aires: entre o cepticismo e a confiança".-Rev. Bra. sileira de Filosofia, 15 (1965), 3.7.-V. núm. 17-4613.

19-1750. Braz Tetxeira, A.-"Matias Aires".-_Rev. Brasileira de Filosofia, 14 (1964), 597-599.

19-1751. Holanda, Francisco de-Dialoghi romani. - Rizzoli, Milano, 1965. $160 \mathrm{pp}$.

Laguna: v. núm. 3301.

19-1752. ANDRÉs, GREGoRIo dE-El maestro Baltasar de Céspedes, humanista salmantino, $y$ su "Discurso de las letras humanas". Estudio biografico y edición critica._La Ciudad de Dios, El Escorial, 1965. 262 pp.-V. núm. 13. 34993. || Helm, 18 (1967), 164-165 (Mar- cos) ; RLit, 27 (1965)，225-227 (Rozas) .

19-1753. RockA, M.-["Temas lituanos en la obra de Pedro Ruiz, y papel cultural de este escritor en Lituania"].Lietuvos T.S.R. Bokslu Akad. Darbai, Lit., 8 (1965), 130-152. [En lituano].

19-1754. Castillo de Lucas, A.-" Refranes de mesa, salud y buena crianza de Lo. renzo Palmireno"... Teruel, 1965, núm. 33.

19-1755. Palmirfono, Lorenzo - Refranes de mesa, salud y buena crianza. Facsímil de este refranero (ed. de 1573), estudio sobre el autor, ordenación y glosa de los refranes por A. Castillo de Lucas.-Teruel, 1965. 52 pp., 13 facsímiles.

19.1756. Pereira, A.-"Un prior de San Marcos: D. Benito Arias Montano":$E L, 1965$, núms. 324/5.

19-1757. Theunissen, P._."Arias Montano et la Polyglotte d'Anvers".- $L R, 19$ (1965), 231-246.

19-1758. OzAeta, J. M.-"El tratado inédito De fide quae revelanda erat, de Arias Montano, según dos manuscritos de El Escorial"._-CD, 178 (1965), 433463.

19-1759. MoReaU, J.- "Francisco Sanches, pré-cartesiano".-Esp, 1965, núms. 8/9, 99-104.

19-1760. SANZ, C.-“Formación humanistica de don Manuel Martí, deán de Alicante".-Actas del 11 Congreso espa. ñol de estudios clás. (Madrid, 1964), 651.654 .

V. también nưms. 86, 2273.

\section{IITERATURAS PENINSULARES}

\section{Catalana}

19-1761. RIQUer, MARTIN DE-Historia de la literatura catalana.-Ariel, Barcelona, 1964. 2 ts: 707,741 pp. || RLit, 27 (1965), 211-217 (Juliá Martínez); ZRPh, 81 (1965), 208 (Köhler); CuN, 24 (1964), 122 (Tavani); H, 49 (1966), 351-352 (Thomas).

19-1762. SANSONE, GIUSEPPE E-Studi di filologia catalana.-Adriatica Ed., Bari, 1963. 293 pp. (Bibl. di filologia romanza, 7). \| CCM, 7 (1964), 195-197 (Bohigas): RFE, 49 (1966), 385-387 (Cerdả Massó) ; ZRPh, 82 (1966), 615622 (Colón); AION-R, 7 (1965), 113 . 114 (Fernández Murga); $L R, 21$ (1967), $91-92$ (Groult) ; $R P h, 18$ (1964-65) , 506- 
509 (Gulsoy) ; Conv, 94 (1966), 639. 644 (Molas) ; H, 48 (1965), 191 (Thomas); BICC, 20 (1965), 156-165 (Valderrama Andrade) .

19-1763. RIBA, CARLES_Llengua $i$ literatura. A cura de Joaquim Molas.-Edicions 62, Barcelona, 1965. 97 pp. (Antologia catalana).

19-1764. Castellet, Josep M.--Poesia, realisme, historia.-Edit. A. C., Barcelona, 1965. 92 pp. \|CuH, 69 (1967), 191 . 193 (Revuelta).

19-I765. Cap d'any 1964.-Moll, Palma de Mallorca, 1964. 147 pp., ilustr._V. núm. 18-I794. || $B A b r, 39$ (1965), 112119 (de Boer).

19-1766. Berrini, G. M.-“Entorn de la pietat afectiva a la Catalunya medieval"._ER, 10 (1962), I55-171.

19-1767. ROMEU Figueras, J-"Sobre la poesía tradicional y popular gallegaportuguesa en la catalana".- $A C E, 2$, 329--336.

19-1768. Soberanas I Lleo, A. J.-“Una versió desconeguda d'Augats, seyós qui credets Dèu lo Payre"._ER, 10 (1962), 147-I54.

19-1769. Triadú, JoAN-Nova antologia de la poesia catalana, 1900-1964. (De Maragall als nostres dies). - Selecta, Barcelona, 1965. 350 pp. (Bibl. Selecta, 368) - -V. núm. 12-33097.

19-1770. Massot I Muntaner, J.-“Aportació a l'estudi del romancer balear" (N. 18-1802) . \|RDTP, 22 (1966) , 234-235 (Pérez Vidal).

19.1771. Massor I Muntaner, J-_"Notes sobre la supervivencia del teatre catalá antic".-ER, 11 (1962), 49-101. RDTP, 23 (1967) , 394-395 (Manrique). 19-1772. Romeu I Figueras, J.-“Els textos draniàtics sobre el davallament de la creu a Catalunya, $i$ el fragment inèdit d'Ulldecona'.-ER, Il (1962), 103-132.

19-1773. BoHIGAs, P._"Un nou fragment del Lançalot català"._ER, 10 (1962), 179-187.

19-1774. Vincke, J.-"Das Echo des Ave Maria und des Salve Regina in dem Brief des Templers Ramon Saguàrdia an die Königin Blanca von Katalonien-Aragon".-ER, 10 (1962) , 173-177.

19-1775. VIvEs, J.- "Un Ilegendari hagiogràfic català (Ms. Ripoll 113) ",$E R, 10$ (1962), 255-271.

19-1776. Field, William Hugh- $A$ critical edition of part of the works of Raimón Vidal de Basalú, with linguis. tic and literary commentary-[Tesis, Univ. of Chicago, 1965].

19-1777. LewENT, K._."Thoughts on Lo Sopni que fetz en Cerveri".-ER, 10 (1962) , 1-15.

19-1778. Platzeck, E. W.-Raimund Lull. -Eds. Franciscanae, Roma; L. Schwann, Düsseldorf, 1962-1964. 2 ts.: xxiv + 470 , xi +340 pp. II Collectanea Franciscana, 35 (1965), 209-211 (Anthonis); Freiburger Zeitschrift für Philos. und Theol., 12 (1965), 539-541 (Hufnagel); $B H i, 68$ (1966), 402 (Llinarès); BHS, 45 (1968), 71-72 (Pring-Mill).

19-1779. [Llull, Ramon]-Das Leben des seligen Raimund Lull. Die "Vita coëtanea" und ausgewählte Texte zum Leben Lulls aus seinen Werken und Zeitdokumenten. Úbertr. und eingel. von Erhard-W. Platzeck. - Patmos-Verlag, Düsseldorf, 1964. 180 pp. \|BHi, 68 (1966) , 404 (Llinarès) .

19-1780. Sugranyes de Franch, R.-“Ramon Lull i l'Islam"...ER, 10 (1962), $17-31$.

19-1781. Platzeck, E. W_- "Von der lullschen zur cusanischen Denkform".Mitteilungen und Forschungsbeiträge der Cusanus-Gesellschaft, Mains, 4 (1964), 145-163.

19-1782. Colomer, E_- "Nicolau de $\mathrm{Cu}$ sa e Raimundo Lulio" (N. 16-49633). || $R F L, 8$ (1964), 293-294 (Gama Caeiro) .

19-1783. RABADE Romeo, S.- "La metafísica del siglo xiv".-ELu, 8 (1964), 1732.

19-1784. Вонigas, P.-["Las cronologias Iulianas y el significado personal de algunas obras de Ramón Llull'].ELu, 9 (1965) , I67-180.

19-1785. BAUZA, M.-["Reimpresión de la ed. de Maguncia de las obras de Ramón Llull"]._ELu, 9 (1965), 251254.

19-1786. SaIz BARBFRA, J_"Libro del amigo y del amado".-RE, 24 (1965), 273285.

19-1787. Guilleumas de Rubió, R.-"Notes sobre la tradició manuscrita $\mathrm{i}$ impresa del Llibre d'amic e amat'.—ER, 10 (1962), 73-83.

19-1788. Pring-Mill, R. D. F._"Entornde la unitat del Libre d'amich e amat". -ER, 10 (1962), 33-61.

19.1789. DolG, M.-“Ocells i arbres en el Llibre d'amic e amat".-ER, 10 (1962), 69-71.

19-1790. Lluil, RAMoN_Llibie de les 
bèsties. A cura de Pere Bohigas_-Edicions 62, Barcelona, 1965. 71 pp. (Antologia catalana, 1) \& $\| B H i, 67$ (1965), 377 Llinarès) .

19-1791. Lulle, Raymond_Le "Livre des bétes". Versión français du xve siècle, avec trad. en français moderne, introd. et notes par Armand Llinarès.-Klincksieck, Paris, 1965. 200 pp. (Bibliotheque française et romane). \|V VR, 26 (1967), 162-164 (Colón); Sp, 41 (1966), 346-347 (McCulloch); BHS, 45 (1968), 156-157 (Pring-Mill); RLit, 30 (1966). 144.145 (Rull); ZRPh, 82 (1966), 421 426 (Sansone); FS, 20 (1966), 173. 174 (Watkins); $R P h, 22$ (1968-69), 9599 (Willard).

19-1792. LluLl, RAMoN_Il Livre des bestes. Traduzione francese anonima de] $\mathrm{XY}$ secolo. Testo inedito a cura di Giuseppe E. Sansone-Quaderni di Marsia, Roma, 1964. 82 pp. || BHi, 67 (1965), 377-378 (Llinarès).

19.1793. Badia I Margarit, A. M.-"Notes per a una caracterització lingüìstica dels manuscrits del Libre de contemplació. Contribució a l'estudi de la llengua de Ramon Llull". $-E R, 10$ (1962), 99-129.

19-1794. VERNET, J.-“'Observacions sobre el llibre Oracions de Ramon".-ER, 10 (1962), 85-89.

19-1795. Stegmüllex, F. -.. "Eine neue Handschrift der Taula general von Ramon Llull", -ER, 10 (1962), 91-97.

V. también nưm. 1898.

19-1796. AINAud, J.-_.Jaume Sarroca i Jaume I"-_ER, 10 (1962), 131-136. [Sarroca, colaborador de la Crónica de Jaume I].

19-1797. Soldevila, F.- "La crónica de Marsili $e^{\text {lna }}$ influï en la darrera redacció de la Crónica de Jaume I?"$E R, 10$ (1962) , 137-146.

19-1798. Colon, G,-“Un passatge obscur del Llibre de fortuna $e$ prodència de Bernat Metge"._ER, 10 (1962), 209216.

19-1799. EpAlzA, M. DE-"Nuevas aportaciones a la biografía de fray Anselmo Turmeda (Abdallah al-Tarchumân) "-AST, 38 (1965), 87-158.

19-1800. Marfany, Joan-Lluis - Ideari d'Anselm Turmeda._Eds. 62, Barcelona, 1965. 72 pp.

19-1801. Coll I ALENTORN, M.-"El rei Martí, historiador"_-ER, 10 (1962), 217-226.

19-1802. Via, Franceso de la-Obres. In- trod., text i notes per Arseni Pacheco. T. 1: Procés de la Senyora de Valor contra en Bertran Tudela.-Pro Libris, Barcelona, 1963. 180 pp. (Biblioteca catalana d'obres antigues). I| $R P h, 18$ (1964-65), 509.511 (Friedman); HR, 34 (1966), 79-81 (Gulsoy); BHS, 42 (1965), 52-53 (Keightley).

Roís de Corella: y. núm. 1807.

19.1803. NICOLAU D'OlwER, L.-“"Tirant lo Blanc: examen de algunas cuestio. nes" (N. 16-47438). || LR, 19 (1965), 64-65 (Groult).

19-1804. Brummer, R.- "Die Episode von König Artus im Tirant lo Blanch".-ER, 10 (1962), 283-290.

19-1805. Pierce, F.-"The role of sex in the Tirant lo Blanch"'-ER, 10 (1962), 291-300.

19-1806. TATE, R. B.-“Joanot Martorell in England"- $-E R, 10$ (1962), 277-281. 19-1807. Colón, G.-."Premiers échos de l'Ordre de la Jarretière"._ZZRPh, 81 (1965), 441-453. [En el Tirant lo Blanc y en el Triunfo de les dones].

19-1808. Molas, J. - "L'obra lírica de Lluis Icart". $-E R, 10$ (1962), 227-254. 19-1809. RiQuer, M. DE-_"Francesc Carrós Pardo de la Casta"._ER, 10 (1962), 301-305.

19-1810. Sanchis i Guarner, M.-"Sobre la data de les regles de purisme idiomàtic de Bernat Fenollar". $E R, 10$ (1962), 307-310.

19-1811. Batzle I Prats, Ll.-"La Passió de fro Antoni de Sant Jeroni $i$ la processió dels Dolors de Mieres".-ER, 11 (1962), 133-144.

19-1812. MOLAs, IsmRE-Illeari de Francesc Pi i Margall._-Edicions 62, Barcelona, 1965. 120 pp. (Antologia catalana).

19-1813. Valentí i Fiol, E.-"L'adaptació catalana de l'hexàmetre en Maragall $i$ en les traduccions de l'Odissea de Carles Riba"._ER, 11 (1962), 249264.

19-1814. CoмAs, A.-"Maragall i La ben plantada".-ER, 11 (1962), 265-273.

19-1815. Maragall I Noble, Jordi (ed.) La gloria y la fama de Joan Maragall. Notas biográficas y sel. de...-Cruz del Sur, Madrid, 1965. 215 pp. (Renuevos de Cruz y Raya).

19-1816. Capdevila, Josep Maria_Eugeni d'Ors. Etapa barcelonina (1906-1920). Barcino, Barcelona, 1965. 82 pp. (Publicacions de "La Revista").

V. también núms. 1814, 3582, 3690-3701. 
19.1817. Terry, A.-_Un nu i uns ulls. Comentari a uns poemes de Carles Riba'"_ER, 11 (1962), 283-303.

19.1818. Riba, Carles-Poems. Transl. by J. L. Gili_-Dolphin, Oxford, 1964. 71 pp. I| $B A b r, 40$ (1966), 128 (de Boer); RHM 32 (1966), 99-101 (PorquerasMayo) ; $B H S, 42$ (1965), 69 (Ribbans); CCL, 1965, núm. 93, 84 (Salazar Chapela) ; $M L R, 62$ (1967), 738-739 (Terry); $H, 48$ (1965), 618 (Thomas).

V. también nưm. 1813 .

19-1819. Foix, J. V._Catalans de 1918. Pròleg de J. Coromines.-Eds. 62, Barcelona, 1965. 93 pp. (Antologia catalana).

19-1820. Forx, J. V.-Escenificació de cinc poemas. - Ed. Rocas, Barcelona, 1965. $181 \mathrm{pp}$.

19-1821. Cots I Moner, J.- “La preocupació religiosa en l'obra de Pere Quart".-QVC, 1965, núm. 29, 29-44.

19-1822. PERE QUART-Vacaciones pagadas. Poemas. Pról. de Sergio Beser. Trad. de José Batllo. Versión bilingüe. -EI Bardo, Barcelona, 1966. 133 pp. ' II Ins, 1966, núm. 235 (Marco) ; $\mathrm{CuH}$, 66 (1966), 450-452 (Soto Vergès).

19-1823. Gaziel_-Paris, 1914. Diari d'un estudiant. Pról. de M. de Ios Santos Oliver.-Aedos, Barcelona, 1964. 300 pp. (Biblioteca biográfica Aedos).

19-1824. GAzIEL Tots els camins duen a Roma. História d'un desti, 1893-1914. 3: ed._Aedos, Barcelona, 1964. 494 pp. + 30 láms. (Biblioteca biográfica catalana, 15).

19-1825. GAZLEL_Castilla adentro._E.D. H.A.S.A., Barcelona, 1963. || Ins, 1964, nưms. 212/3 (Marra-López)

19-1826. GAZIEL-Portugal lejano.-E.D.H. A.S.A., Barcelona, 1964. \|l Ins, 1965, núm. 220 (Marra López).

19-1897. Espriu, SAlvador - Narracions. Pról. de F. Vallverdú._Edicions 62, Barcelona 1965. 74 pp. (Antologia catalana).

19-1828. Espriu, SAlvador-La pell de brau. Trad. al castellano de José Agustín Goytisolo.-Ruedo Ibérico, Paris, 1963. x1 + 159 pp.-V. núm. 18-1863. || $B A b r, 43$ (1969), 584 (de Boer); $B H S$, 43 (1966), 235-236 (Terry).

V. también núm. 2314.

19-1829. Bori i Fontesta, ANTONI - El trobador catala. Llibre de poesies $i$ proses originales. - Millá, Barcelona, 1964. 186 pp. (Bibl. "Vell y nou", 2).

19-1830. Lloria, MatildE_Altissim reg- ne. - Diputación Provincial, Valencia, 1965. II Ins, 1966, nủm. 239 (Ifach) .

V. también núm. 1704.

\section{Gallega y portuguesa}

19-1831. Espírto SANTo, L. DO_-"Da critica literária portuguesa"...-Esp, 196465, núms. $4 / 5$.

19-1832. Quadros, A.-_"Da literatura portuguesa"_Esp, 1964.65, núms. 4/5, 57 71 .

19-1833. Barreiros, ANTONIO José-Histo. ria da literatura portuguesa. T. 1.Livr. Pax, Braga, 1965. 340 pp.

19-1834. MoIsÉs, Massaud-A literatura portuguésa. 3a ed., ref. e aum.-Cultrix, São Paulo, 1965. 410 pp.-V. núm. 18-1872. || Alfa, 1965, núms. 7/8, 233 235 (Décio).

19-1835. Rossi, Giusepre Carlo-Geschich. te der portugiesischen Literatur. Ubers. von Erika Rossi_-Niemeyer, Tübingen, 1964. xii + 426 pp., ilustr. $\| H R$, 36 (1968), 294-299 (Glaser) ; $D L Z, 81$ (1967) , 898-900 (Koch); Bücherei und Bildung, 19 (1967) , 744 (Riethmüller); $R I, 16$ (1965) , 374-384 (Rühl) ; $A H S I$, 35 (1966), 258-259 (Schurhammer); $N$, 52 (1968), 93 (Teensma).

19-1836. Saraiva, António José, \& Óscar LOPES_História da literatura portuguesa. $4^{\text {. }}$ ed., corr.-Porto Ed., Porto, [1965?]. 1106 pp.-V. núm. 17-4704.

19-1837. Chorão de Carvalho, José-Os grandes escritores portugueses. 2a ed.Ministério da Educação Nacional, Lisboa, 1965. 220 pp. (Col. educativa).V. núm. 13-36917.

19-1838. Rodrigues LApA, M.-Miscelánea de lingua e literatura portiuguêsa medieval.-Inst. Nacional do Livro, Rio de Janeiro, 1965. 304 pp. (Bibl. cientifica brasileira, Col. de filologia, 7). II CuN, 27 (1967), 203 (Macchi).

19-1839. Sins, Segismundo-Da Idade Média e outras idades._-Conselho Estadual de Cultura, Comissão de Literatura, São Paulo, 1964. 177 pp. || RLit, 29 (I966) , 234-235 (Ares Montes); Alfa, 1966, núm. 9 (Novaes Coelho).

19-1840. Ciddde, Hernîni-A literatura portuguesa e a expansão ultramarina. 2:-ed., refund. e ampl.-A. Amado, Coinbra, 1963-64. 2 ts.: 366, 428 pp.V. núm. 2-781. || BEP, 27 (1966), 283. 285 (Cantel); Co, 1965, núm. 34 (Caratão Soromenho); Dialoghi, 13 (1965) , 528-530 (Rossi). 
19-1841. Cardooso, M.-."The idea of history in the portuguese chronicles of the age of discovery"._CHR, 49 (1963), 1-19.

19-1842. QuAdros, A.-“A diáspora portuguesa".—Esp, 1965, núms. 8/9, 57-73.

19-1843. BARchiesi, R.-"Italia e Portogallo nel Settecento".-Atti del Quarto Congresso dell'Associazione Intermazionale per gli Studi di Lingua e Lettera. tura Italiana (1965), $14 \mathrm{pp}$.

19-1844. Moser, G. M.-."The campaign of Seara Nova and its impact on Portuguese literature", $L L B R, 2$ (1965), núm. 2, 15-42.

19-1845. Costa Dias, Augusto-A crise da consciência pequeno-burguesa. T. 1: O nacionalismo literário da geração de 90. 2" ed., rev.-Portugália, Lisboa, [1965]. 324 pp.-V. núm. 17-4782. || $B E P, 27$ (1966), 300-302 (Bourdon).

19-1846. BEAU, AlbiN Eduard-Estudos. T. 2: Goethe, Herculano, Burckhardt, Antero de Quental, Vianna da Motta, Vossler, Croce, Hofmannsthal, Rilke, Gundolf, Fernando Pessoa, Heidegger.— Universidade, Coimbra, 1964. 542 pp. (Acta Univ. Conimbr.).-V. núm. 16. 43689. || RJ, 17 (1966), 383-385 (Woll).

19-1847. CANDIDO, ANTôNIo-Literatura $e$ sociedade. Estudos de teoria e história literária.-Companhia Editôra Nacional, São Paulo, 1965. 229 pp. (Col, Ensaio, 3).

19-1848. Melo, Alírio DE-Panorama de critica $e$ de historia.-Gráfica do Douro, Aveiro, 1965. [Sobre Fialho, João de Deus, etc.].

19-1849. Coimbra Martins, António-Luzes. - Iniciativas Editoriais, Lisboa, 1965. 22 pp.

19-1850. Prado Cofl.ho, Jacinto do (ed.)o Rio de Janeiro na literatura portuguesa. Antologia._Secretariado Nacional de Informação, Lisboa, 1965. 359 pp. \| BEP, 26 (1965), 256 (Frèches).

19-1851. TARracha Ferreira, Ema, e BEATR1Z PAULA SILVA-Textos literários, século xvi.-Aster, Lisboa, 1965. 637 pp. (Livros de estudo).-.V. núm. 17-4763.

19-1852. Bettencourt Coelfo, José Aucusto_Selecta de textos da época gongórica e arcádica.-Porto Editora, Porto, 1965. 488 pp. (Col. liceal).

19-1853. Atrinson, Dorothy M.-Selections of nineteenth century Portuguese prose.-Harrap, London, 1965. $106 \mathrm{pp}$. || $M L J, 51$ (1967), 52-53 (Fernández); BHS, 43 (1966), 145 (Lamb).
19.1854. CôrTEs-Rodrigues, A._Os $A$ ço res.-Bertrand, Lisboa [1965?]. 230 pp. (Antologia da terra portuguesa, 4).

19-1855. AMORIM DE CARvalHo Tratado de versificação portıguesa. (Teoria moderna de versificação). 2a ed.-Portugália, Lisboa, 1965. $170 \mathrm{pp}$.

19-1856. Cunha, Celso_Lingua e verso. Ensaios._Livr. S. José, Rio de Janeiro, 1965. $95 \mathrm{pp}$.

19-1857. Casais Monteiro, Adolfo- $A p a$ lavra essencial: estudos sóbre a poesia._Ed. Nacional-Ed. da Univ., São Paulo, 1965.

19-1858. CAMPBELl, RoY-Collected poems. [Portuguese poems: Mindinho, Pero Meogo, Airas Nunes, Gil Vicente, Camões, Bocage, Antero de Quental, Fernando Pessoa, Joaquim Paço d'Arcos, Francisco Bugalho, José Régio, Manuel Bandeira].-The Bodley Head, London, 1960. $144 \mathrm{pp}$.

19-1859. Negrelli, Leo (ed.) -Il sonetto portoghese, dalle origini ai nostri gior. ni.-Il Fauno, Firenze, 1964. 334 pp. || EIP, 1965, núm. 25, 271-273 (Bur. gada).

19-1860. Costa Ramalho, A. DA-"Três odas de Horácio em alguns quinhentistas portugueses". - Inst, 127 (1965), 15-30. [Ferreira, Camões, Sá de Miranda].

19-1861. Ficueiredo, F. DE -Variações sobre o espírito épico".-RLSP, 5 (1964), 11.51._. V. núm. 10-20664. \| $H, 49$ (1966), 539 (Sayers).

19-1862. SENA, J. DE-“Maneirismo e barroquismo na poesia portuguêsa dos séculos XVI e XVII".-LBR, 2 (1965), ním. 2, 29-53.

19-1863. Prado Coelho, Jacinto do (ed.)Poetas do romantismo.-Livr. Clássica, Lisboa, 1965. 2 ts.: 94, 86 pp.

19-1864. SimбEs, J. G._"A grande crise do Orpheu".-Cronos, 1965, num. 1. 19-1865. GalHoz, M. A.-"No cinquentenário de Orpheu"._Pal, 1965, núm. 24, 34-39.

19-1866. MAtos Reis, A.-"A moderna poesia portuguesa faz 50 anos. Desde o Orpheu ao experimentalismo". - Cenáculo, 4 (1965) , 346-353.

19-1867. Ross1, G. Cr--"Lírica moderna portoghese".-NA, 1965, 413-418.

19.1868. Prado Coflho, J. do-"Quelques thèmes caractéristiques de la poésie portugaise moderne". — $B E P, 26$ (1965), $11-43$.

19-1869. LiND, G. R.-"Sôbre poesia ale- 
mã e portuguésa do após-guerra"Humboldt, 1965, núm. 11.

19-1870. BLANG DE Portugal, J-_-"Notas sobre a moderna poesia experimental portuguesa".-Rumo, 1965, núm. 101, 57-70.

19-1871. Alonso, R-“"Panorama de la actual poesia portuguesa".-Espiral, Bogotá, 1965, núm. 97, 32-44.

19-1872. Pinheiro Pimentel, L. M."Subsidios para uma biobliografia dos modernos poetas cabo-verdianos". $-A B P$, 9 (1963), 8-32.

19-1873. Quadros, A.-“"Teatro português, teatro universal".-Esp, 1965, núms. 6/7, 3-16.

19-1874. Cunha LEÃo, F. DA-“'O portugués e a dramaturgia. Trés momentos do teatro nacional".-Esp, 1965, núms. $6 / 7,89-97$.

19-1875. Braz Teixeira, A.-"Possibilidade e realidade do teatro portugués". Esp, 1965, núms. 6/7, 49-53.

19-1876. ALMEIDA, F. DE- “Um documento do teatro português"._Vértice, 25 (1965) , 141-149.

19-1877. Lopes Dias, J.-“O teatro popular na Beira Baixa da Idade Média à actualidade"... $A P C E, 3$, 191232.

19-1878. Frìches, C. H._-“Le thêatre aristocratique et l'ćvolution du goût au Portugal d'après la Gazeta de Lisboa de 1715 aे 1739" $-B E P, 26$ (1965), 95-110.

19-1879. Azinhal Abelho-"Teatro popular português".-Esp, 1965, núms. 6/7, 62-69.

19-1880. Aguiar e Silva, Vítor Manuel $\mathrm{DE}-O$ teatro de actualidade no romantismo português (1849-1875).-Coimbra Editora, Coimbra, 1965. $76 \mathrm{pp}$.

19-1881. Teles, L.-“O ambiente do teatro em Portugal no século $\mathrm{xx}^{\prime \prime}$.—Esp, 1965, núms. 6/7, 131-134.

19-1882. LisBoA, E.-"'Três décadas e meia de artistas dramáticos italianos em Portugal (1892-1927)".-EIP, 1965, núm. 25, $169-216$.

19-1883. Vitorino, O., e Azinhal AbeLHO-"Teatro d'arte de Lisboa: o problema do teatro português"-_Esp, 1965, núms. $6 / 7,127-130$.

19-1884. Novelas históricas portuguesas. De D. Alfonso Henriques à batalha de Aljubarrota. Antologia.-Estúdios Cor, Lisboa, 1965. 314 pp. (Cor de bolso, 14) .

19-1885. Andrade, Joño de (ed.) -Os me- lhores cantos portiugueses, $3^{\mathrm{a}}$ série, 2: ed.-Portugália, Lisboa, 1965. 488 pp. (Antologias universais)_-V. núm. 16 45758.

19-1886. Pоме́s, M.-"Nouvelles et romans portugais"-_RDM, 1965, 619622.

19-1887. CASTRO, A. DE-“O novo romance".-Rumo, 1965, 386.390.

19-1888. Rossi, G. C.-“'Letteratura portoghese contemporanea: la prosa narrativa femminile". $-N A$, aprile 1965 , 562.567.

19.1889. Mighael, Maurice \& PamelaPortuguese fairy tales. $\mathrm{F}$. Muller, London, 1965. 185 pp.

19-1890. Gentr Marques-Lendas de Portugal. T. 3.-Universus, Porto, 1965. $440 \mathrm{pp}$.

19-1891. Ś́rgio, ANTónio-Prosa doutrinal de autores portugueses. 2a ed.-Portugália, Lisboa, 1965. $476 \mathrm{pp}$. (Antologias universais.)

19-1892. CRABbÉ ROGHA, ANDRÉE-A epistolografia em Portugal-Livr. Almedina, Coimbra, 1965. 444 pp.

19-1893. ANDRADE, A. A. DE-“"Antologia do pensamento político português. Século xvi, Perlodo joanino".-Estudos Politicos e Sociais, 3 (1965), 537-658, 867. 995.

19-1894. Pinharanda Gomes-"Notas so. bre a moralística aristocrática portuguesa".-Itinerário, 1965, núm. 2.

19-1895. PINA, L. DE-“"A mágia nos livros médicos portugueses do século xvin".$A P C E, 2,9-42$.

19-1896. Alfonso el Sabio-General estoria. Versión gallega del siglo $\mathrm{xIv}, \mathrm{ms}$. O. I. 1 del Escorial. Ed., introd. Iingüistica, notas $\mathrm{Y}$ vocabulario de $R$. Martínez López.-Fac. de Filosoffa y Letras de la Univ., Oviedo, 1963. Ixi + 375 pp. (Publ. de Archivum). \|CuN, 24 (1964), 119-120 (Tavani).

19-1897. LINDLEY CinTRA, L. F.-Crónica geral de Espanha de 1344: a lenda do Rei Rodrigo. Introd., notas e glossário de...-Verbo, Lisboa, 1964. 94 pp.

19-1898. Millás Vallicros apologética luliana en la obra Livro da corte enperial". $-B A u, 18 / 19$ (1965), 385.387.

19-1899. Martuns, M.-“A legenda dos santos mártires Veríssimo, Máxima e Júlia, do cód. CV/1-23 d. da Biblioteca de Evora".-RPH, 6 (1965) , 45-93. 19-1900. Pensado, J. L. (ed.) -Miragres de Santiago (N. 14-38808). \|AIA, 25 
(1965), 130-132 (Castro); RPh, 20 (1966-67), 366-372 (McCartney).-V. núms. 17-4760.

19-1901. Tilander, GunNar-Livro que fez Enrique Emperador d'Alemanha e Livro que fez o mui nobre rei d'Ancos. Dois tratados portugueses inéditos de falcoaria, publicados com Phisica avium por...-E. G. Johanssons Boktryckeri, Karlshamn, 1966, 88 pp. (Cynegetica, 15) .

19-1902. Tilander, G.-"Livro que fez Enrique emperador d'Alemanha. Tratado do muito nobre rei d'Ancos". $N M$, 66 (1965), 607-618.

19-1903. Rossi, Nflson (ed.) -Livro das aves. Ed. preparada por Jacira Andrade Mota el al. Apresentação de A. G. Cunha.-Instituto Nacional do Livro, Rio de Janeiro, 1965. viii $+121 \mathrm{pp}$. (Diciondrio da lingua portuguesa, Textos e vocábulos, 4).

19-1904. Pisan, Christine DF-Buch von den drei Tugenden in portuguiesischer Ubersetzung. Ausgabe u. Einführung von D. Carstens-Grokenberger.-Aschendorff, Münster/Westfalen, 1961. 159 pp. (Portuguiesische Forschungen der Görresgesellschaft). \|RPF, 13 (196465) , 362-364 (Loureiro) ; $R P h, 18$ (196465), 133-134 (Maler); $R R, 55$ (1964), 119-120 (McPheeters); RJ, 15 (1964), 376.378 (Moser); $R F, 77$ (1965), 169 171 (Woll) -V. núm. 18-1925.

19-1905. Teixeira, P. M.-_O primeiro tradutor da Bíblia em português foi um ministro protestante". - Boletim Eclesidstico da Diocese de Macau, 63 (1965), 514-518.

V. también núms. 1671, 1733-7, 2463.

\section{A utores antiguos}

19-1906. Crespo, F._.'Temas de poesia lirica e trovadoresca".-ECB, 1965, núm. 15, 86-91. [Cancioneiras].

19-1907. Rossi, G. C._-'La filologia italiana e tedesca del Novecento e l'antica lirica portoghese". Atti del II Convegno Internazionale di Studi Italo-Tedeschi (Merano, 1965), 355-362.

19-1908. CREsPO, F._-_"Temas trovadorescos e populares".-Oocid, 68 (1965), 61-65.

19-1909. FERnÁNdez Pousa, R.-“Un pueblo que canta. Juglares y cancioneros".$E L, 1965$, núms. 320/1.

19-1910. Rodricues LAPA, MaNueL_Cantigas d'escdrneo $e$ de mal dizer dos cancioneiros medievais galego-portugueses.
Ed. crítica.-Atlantida, Coimbra; Galaxia, Vigo, 1965. 764 pp. (Col. filologica). $B A b r, 40$ (1966), 119-120 (Adler); $A I O N-R, 8$ (1966), 327-336 (Reali); $H, 49$ (1966), 346 (Rodriguez Puértolas).

19-1911. Alfonso EL SABIo-Cantigas de Santa Maria. Salomón, Cantar de los cantares. JORGE MANRIQUe, Coplas que hizo por la muerte de su padre D. Rodrigo. Trad. y pról. de A. Espina.Edics. E. M., Madrid, 1965. 137 pp. (Col. de bolsillo Edime).

19-1912. MetrmanN, W. - "Lexikalisches und etymologisches aus den Cantigas de Santa Marta" (N. 16-47585) . \|RFE, 48 (1965), 436-437 (Lorente).

19-1913. Sousa SoARES, T. DE-“O pensamento político de El-Rei D. Diniz".Inst, 127 (1965), 229-243.

19-1914. KeliermanN, W.-"Drei Dichter der ältesten portugiesischen Lyrik".FHR, 200-222. [João Soares Somesso, Bernal de Bonaval, João Garcia de Guilhade].

19-1915. Azevedo Fil.Ho, L. A.-"Estrutura e ritmo do verso decassllabo no cancioneiro de D. João Garcia de Guilhade".-RP, 30 (1965), 365-384.

19-1916. "Sobre unha cantiga de Рето Annes Solaz"._Grial, 1965, 236-237.

19-1917. ReAli, ERILdE Le "Cantigas" di Juyão Bolseyro. - Istituto Universirario Orientale, Napoli, 1964. 112 pp. (Testi, 3).-V. núm. 18-5447.

19-1918. Lourenço-Poesie e tenzoni. Ed., introd. e note di G. Tavani.-Soc. Tip. Editrice Modenese, Modena, 1964. 162 pp. (Istitulo di Filologia Romanza del'Universitd di Roma. Testi e manuali). || RFE, 48 (1965), 424-426 (Ares Montes); CuN, 24 (1964), 301-302 (Menichetti): $R F, 78$ (1966), 621-622 (Mettmann).

19-1919. TAVANI, GIUSEPPE-Le poesie di Ayras Nunez, Ed. critica, introd, note e glossario. - Ugo-Merendi, Milano, 1964. 179 pp. (Coll. internazionale di filologia romanza, 1), || $M L J, 50$ (1966), 168-170 (Davis); CuN, 24 (1964), 302304 (Menichetti); $R F, 78$ (1966), 620 621 (Mettmann).

19-1920. Askins, Arthur LeE-The Cancionero de Evora: Critical edition and notes,_Univ, of California Press, Berkeley \& Los Angeles, 1965. 159 pp. (UCPMPh, 74) _-V. nuim. 18-5452. II $L B R, 3$ (1966) , 87-90 (Carter); $B H S$, 43 (1966), 129-131 (Cummins); $H, 48$ 
(1965), 604-605 (Moser), $M L N, 81$ (1966), 248-249 (Rivers); $A I O N-R, 8$ (1966), 319-321 (Rossi) .

19-1921. Dias de Carvalho, J-_"Traços medievais na Ifrica brasileira".-HCM, 93-101.

V. también nưm. 1858.

19-1922. Saraiva, ANTónio José-Fernão

Lopes. 2: ed. rev.-Publicações EuropaAmérica, Lisboa, 1965. 140 pp. (Col. Saber, 21).

19-1923. LOPES, FERNÃO_Crónica de D. Fernando. 2* ed.-Livr. Clássica, Lisboa, 1965. (Clássicos portugueses).

19-1924. Martins, D._- "O sistema do universo na Virtuosa bemfeitoria do infante Dom Pedro".-BAu, 16/17 (1964), 292-300.

19-1925. MARTINs, D._“O sistema moral da Virtuosa bemfeitoria" —RPFB, 21 (1965) , 236-254.

19-I926. MARTINs, D.-“O De beneficiis de Séneca e a Virtuosa bemfeitoria do Infante Dom Pedro'. - RPFB, 21 (1965), 255-321.

19-1927. GuidArelli, ANNA Gloria-La "Crónica dos feitos de Guine" di Gomes Eanes de Zurara.-['Tesis, Univ. de Roma, 1965]. 139 pp.

19-1928. Barradas de Carvalho, J.-"As edições e as traduções da Crónica dos feitos de Guine".-RHSP, 30 (1965), $181-190$.

19-1929. Alves, Frenerico--Romance da conquista da Guiné. Adaptação para rapazes da Crónica do descobrimento $e$ conquista da Guine, por Gomes Eanes de Zurara, clássico português do século Xv._-Panorama, Lisboa, 1965. $128 \mathrm{pp}$.

19-1950. EANes de Zurara, Gomes-Cronica da tomada de Ceuta. Introd., sel. e notas de Alfredo Pimenta. 2a cd.Livr. Clássica, Lisboa, 1964, 104 pp. (Clássicos portugueses. Textos escolhidos).

19-193I. Lourinhã, HILARIo DA-Vida do honrado Infante Josaphate filho del rey Avenir. Versão de..., e a identificação por Diogo do Couto (I542. 1616) de Josaphate com o Buda. Introd. e notas por Margarita Corrêa de Lacerda._-Junta de Investigações do Ultraniar, Lisboa, 1963. 209 pp. I| Ocid, 69 (1965), 127-128 (E. P.).

19-1932. МАснаDo, J. P.-“A carta do Dr. Martim Lopes (I500)".-RP, 30 (1965), 19-36.

19-I933. Mendes, J. - "Comemoração de Gil Vicente".-Bro, 8I (1965), III-120.
19-1934. Comemorações do quinto centenário de Gil Vicente._Cfrculo de Cultura Teatral [Ed. Divulgação], Porto, 1965. || Bro, 81 (1965), 713 (A. R.). 19-1935. Saraiva, ANTónio José-Comemorações do quinto centenário de Gil Vicente._Círculo de Cultura Teatral, Lisboa, 1965.

19-1936. Programa das comemorações do $V$ centenário de Gil Vicente.-Ministério de Educação Nacional, Lisboa, 1965. 48 pp.

19-1937. Crdade, H._"No centenário de Gil Vicente. Homenagem de Camões a Mestre Gil".-Co, 1965, núm. 36.

19-1938. Lopes DIAS, J.—“No V centenário de Gil Vicente".-ECB, 1965, núm. $18,9-25$.

19-1939. SENA, J. DE-"Sobre Gil Vicente. A propósito de um centenário hipotético".-TM, 8 (1965), I136-1140.

19-1940. Exposição Vicentina da Biblioteca Geral da Universidade de Coimbra. Catálogo.-Comissão Nacional do V. Centenário de Gil Vicente, Lisboa, 1965. 22 pp.

19-1941. Exposição Vicentina da Biblioteca Puiblica de Evora. Catálogo.-Comistálogo._Comissão Nacional do V. Centenário de Gil Vicente, Lisboa, 1965. 54 pp.

19-1942. Exposição Vicentina da Biblioteca Pública de Evora. Catálogo. Conisão Nacional do V. Centenário de Gil Vicente, Lisboa, 1965. 36 pp.

19-1943. Exposição Vicentina da Biblioteca Municipal de Santarém. Catálogo.Comissão Nacional do V. Centenário de Gil Vicente, Lisboa, I965. 24 pp. 19-1944. ["Gil Vicente"]._o Estado de São Paulo, 4 dic. I965. [Número especial].

19-I945. Rodrigues LAPA, M._"Ainda, e sempre, o nosso Mestre Gil".-Vértice, 25 (I965), 699-7I4.

19-1946. Martins, M.-“Gil Vicente". Bro, 81 (1965) , 13-28.

19-1947. "Gil Vicente".-Livros de Portugal, Lisboa, 1965, núm. 80, 6-18.

19-1948. Rebelo, I. F._. "Actualidade de Gil Vicente". $S N, 44$ (1965), 208.

19-1949. "Actualidade de Gil Vicente. Debate gravado". $-T M, 1965,1147-1181$.

19-1950. MalpiQUe, C.-_"Gil Vicente num relámpago".-GV, I6 (1965), I01-105, $145-150$.

19-195I. Ventura, F.-'Gil Vicente: poeta de Portugal". Sulco, I (1965), 530566. 
19-1952. Martins Fernandes, M. - "Gil Vicente en el torbellino del siglo Xv1".$P N, 1965$, nứm. 13, 9-12.

19-1953. CidAJE, H._"Gil Vicente: a épo$\mathrm{ca}$, o homem e o poeta". $-R d G, 75$ (1965) , 174-191.

19-1954. Castro, A. DE-"Os principaís fac. tores econômicos que plasmaram a sociedade da época de Gil Vicente".Vértice, 25 (1965), 677-698.

19-1955. Aviz de Brito, L. F._'Contribu. to dos notários e guardasmores para a identificação de Mestre Gil Vicente".GV, 16 (1965) , 69-73.

19-1956. Santos Rego, D. DOS_"Gil Vicente, lavrador da Beira?" $-B C B D, 14$ (1965) , 98-102, 183-185, 196-202.

19-1957. SÃo Payo, Marquês de_"No V centenário de Gil Vicente. Subsídios para a árvore genealogica da sua descendência". $-A T, 6$ (1965), 115-136.

19-1958. Pf.stana, S.- "Estudos gilvicentinos"._Ocid, 69 (1965), 205-218,-V. núm. 18-5472.

19-1959. Sten, H.-“Uma opinião dinamarquesa sobre Gil Vicente" -Ocid, 69 (1965), 15-16.

19-1960. SousA, ARlindo DE-Pequena introdução às obras de Gil Vicente. Tex. to segundo a ed. princeps de 1562. Ed. escolar._Progresso, Porto, 1965. 290 pp.

19-1961. Costa Ramalho, A. DA-"Algumas observações sobre o latim de Gil Vicente".-HuC, $17 / 18$ (1965-66), 198-210.

19-1962. Oliveira, Z. DE-“Deus e o homem em Gil Vicente".-Lumen, 29 (1965), 441-446, 522-529.

19.1963. Pimenta, A.-"O conceito do diabo na Bíblia e em Gil Vicente".Ocid, 69 (1965), 231-247.

19.1964. Martins, M.—OO tempo e a morte em Gil Vicente"._Bro, 81 (1965), 186-203.

19-1965. Alburquerque, L. DE-"Gil Vicente e a astrologia". — Vértice, 25 (1965), 817-823.

19-1966. Cury, J.-“Gil Vicente e a teoria do livre-arbitrio"_-Ocid, 69 (1965), 158-163.

19-1967. Hess, R.-“Die Naturauffassung Gil Vicentes".-APK, 5 (1965), 1-64.

19-1968. SoAres, M. M.- "Gil Vicente e o folclore". $-B C L, \quad 1965,353-360$.

19-1969. LOPES, O.-“O sem-sentido em Gil Vicente",_SN, 44 (1965), 275-278.

19-1970. LÁFER, CELSO_O judeu em Gil Vicente.CConselho Estadual de Cultura, São Paulo, 1963. I15 pp. \|H,
48 (1965), 177 (Johnson); Bro, 80 (1965), 546-547 (Maia); Alfa, 1963, núm. 4, 222-225 (Novaes Coelho).

19-197I. D'Alge, C._-'Universalidade do teatro vicentino"._Clã, Fortaleza (Brasil), 17 (1965), 115-131.

19-1972. Brasil, REIS-Gil Vicente $e$ a evolução do teatro.-Minerva, Lisboa, 1965. $72 \mathrm{pp}$.

19-1973. Rebelo, L. F.-"As duas faces do teatro vicentino".-Esp, 1965, núms. $6 / 7,79-81$.

19-1974. Saraiva, António José_Gil Vicente $e$ o fim do teatro medieval.Publicacões Europa-América, Lisboa, 1965. I| Rumo, 1966, núm. 110, 314315 (Aguiar) ; Bro, 82 (1966), 676683 (Mendes) ; H, 49 (1966), 886 (Moser) .

19-1975. BrasiL, REIS-Gil Vicente $e$ o teatro moderno. (Tentativa de esquematização da obra vicentina).-Miner. va, Lisboa, 1965. $244 \mathrm{pp}$.

19-1976. SLETSJÖE, LEIF_-O elemento cénico em Gil Vicente.-Instituto IberoAmericano, Gotemburgo, 1965. 158 pp. || $M L N, 83$ (1968), 351-352 (Hart); Ocid, 71 (1966), 292 (Pinharanda Gomes); StN, 38 (1966), 853-355 (Sten).

19-1977. Pforo, A.-CComo seriam postas em cena as peças de Gil Vicente?"-Co, 1965, núm. 36.

19-1978. DENIZ-JACINTO_-'O actor numa encenação de Gil Vicente"._._Vértice, 25 (1965) , 799-805.

19-1979. Lopes, O.- 'Estructura do cómico vicentino. Um aspecto: os parvos"._Vértice, 25 (1965), 807-816.

19-1980. Stegagno Picchio, L.-"Considerazioni sui testi saiaghesi di Gil Vicente".-SLSP, 231-241.

19-1981. SLETSJöE, L. — "Los posesivos nuesso y vuesso en el espańol de Gil Vicente".-RJ, 16 (1965), 274-289.

19-1982. Vicen'IE, GuL_Obras. Autos, farsas, comédias, tragicomédias, obra várias. Contribuições para o conhecimento das obras de Gil Vicente.-Lello \& Irmão, Porto, 1965. $1468 \mathrm{pp}$. || Bro, 81 (1965), 711 (A. R.).

19-1983. Vicente, Gil-Auto da alma. Ed. de A. Nunes de Almeida.-Aviz, Lisboa, 1965. $91 \mathrm{pp}$.

19-1984. Gomes, A. F.-"Características do Auto da alma e fé de Gil Vicen. te".-Ocid, 69 (1965), 17-21.

19-1985. Machado, J. P._._ A fala da Moura das Cortes de Jupiter de Gil Vicente",-Ocid, 69 (1965), 17-21. 
19-1986. PEDro, A.-“Acerca do que ninguém leu, ou não quis ler, na Farsa dos fisicos de Gil Vicente".-TM, 3 (1965), 1141-1146.

19-1987. MOSER, G. M. “A volta do marido"-Vértice, 25 (1965), 795-798. [Gil Vicente, Auto de India].

19-1988. VICENTt, Giz-Comédia de Rubena. Introd., testo e note a cura di Giuseppe Tavani.-Edizioni dell'Ateneo, Roma, 1965. 169 pp. \| $M L N, 82$ (1967) , 645-64 (Hart) ; CuN, 26 (1960), 309 (Menichetti).

19-1989. VICENTE, GIL-Quem tem farelos? Pref. e notas de Ernesto de Campos de Andrada._Lisboa, 1965. (Textos literários. Autores da lingua portuguesa).

19-1990. Montenecro, A.-_"Doutor Guido Battelli, insigne lusófilo",_-Ocid, 69 (1965) , 22-28. [Con un fragmento de la traducción italiana del Triunfo do inverno, de Gil Vicente].

19-1991. LEMos, E. DE-"A propósito de Gil Vicente, poeta lírico".-Pan, 1965, núm. $19 / 14$.

19-1992. Vicente, GiL_Liricas. Pref., bibliografia, notas e glossário de J. de Almeida Lucas. 2! ed.-Livr. Clássica, Lisbod, I965. $110 \mathrm{pp}$.

19-1993. VICENTE, GIL-Poesia. Ed. de Thomas R. Hart.-Anaya, Salamanca, 1965. 68 pp. (Biblioteca Anaya, 57). || StN, 38 (1966), 136-139 (Sletsjöe).

I9-1994. SANCHEZ, A.-."Os pocmas castelhanos de Gil Vicente".-Vértice, 25 (1965), 727-794.

V. también núms. 1858, 2090.

19.1995. Auto de Dom Luis e dos turcos. Testo anonimo del sec. xvi, con introd. c note di Giuliano Macchi.-Edizioni dell'Ateneo, Roma, I965. 143 pp. II CuN, 26 (1966) , 309-310 (Menichetti).

Sá de Miranda: v. núm. 1860.

19-1996. "Bernardim Ribeiro". - $L P$, 1965, núm. 82, 6-10.

19-1997. RideIro, BernARDIM - Eclogas. Jano $c$ Franco. Comentários de Arlindo de Sousa, 2a ed., rev. por A. Freire Mauricio. - Progresso, Lisboa, 1964. 94 pp. (Col. Estudante, 14) - -V. núm. 17-1920.

19-1998. Ricciardelli, M.-"Relazione tra Menina e moşa di B. Ribeiro e l'Arcadia di J. Sannazaro".-It, 42 (1965), 371-379.

19-1999. Tayares, C. N.-"Garcia de Orta e os Colóquios".-Naturalia, 9 (1964), 11-25.
19-2000. Correia, M.-“Garcia d'Orta c a anatomia. A citação de Vesálio".$B A L, 37$ (1965), 160-173.

B. dos Mártires: v. núm. 3762.

19-2001. Falcão, CrIstóvão-Crisfal. Texto fixado e anotado por F. da Costa Mar. ques.-Aclântida, Coimbra, 1964. 92 pp. (Col. literária, 13).

19-2002. Trovas de Crisfal. Reprod. facs. da $1^{a}$ ed. Estudo, variantes e notas por G. G. de Oliveira Santos.-Livr. Portugal, Lisboa, 1965. $262 \mathrm{pp.}$

19-2003. Bechara, E.- “Notas à margem do Crisfal o de $O$ bobo"._HCM, 87-91. 19-2004. DE JoNG, M.-"Samuel Usque. Nótulas bibliográficas". - Ocid, 71 (1966) , 129-130.

19-2005. UsQUe, SAMUEL $A$ consolation for the tribulations of Israel. Third dialogue. English transl. with notes and introd. by Gershon J. Gelbart. _Gershon J. Gelbart Memorial Fund, New York, 1964. xi +458 pp. || Sef, 24 (1964), 378-379 (Lacave).

19-2006. Usque, SAMUEL_Consolation for the tribulations of Israel (Consolaşam as tribulaçoens de Israel). Tr., with an introd., by Martin A. Cohen.-Jewish Publ. Soc. of America, Philadelphia, 1965. (Judaica, Texts and translations).

19-2007. Glaser, E.-"Convertentur ad vesperam. On a rare Spanish translation of an inquisitorial sermon by frei João de Ceita". $-H A C$, 137-174.

19-2008. Alves DAs Neves, J--"Camōes e o Brasil, no tricentenário do poeta".Co, 1965, núm. 35.

19-2009. SpInA, S.-'O primitivo acervo camoniano da Biblioteca Nacional"',$R C a, 2$ (1965), 153-156.

19-2010. MENDEs, J.-"Presença de Ca. mões: Revista Camoniana".-Bro, 80 (1965) , 371-375.

19-2011. Simōes CᄉिÃo, A.-“Actualidade em Camões".-LLab, 32 (1963), núm. 222.

19-2012. Cunha E Freitas, E. A. DA"Um poeta quinhentista amigo de $\mathrm{Ca}$ mões. Inédito camoneano?". $-A A P H$, 15 (1965), 205-240.

19-2019. Ferdinanny, M. DE-“El dilema de Camões"._CuH, 61 (1965), 514541.

19-2014. CAmóEs, Luís DE-Os Lustadas. Ed. de Ramiro de Aguiar-Aviz, Lisboa, 1965. $571 \mathrm{pp}$.

19-2015. CAMôEs, Luís DE_-Os Lustadas. Comentário e est. critico por Reis Bra- 
sil. Vol. 3, t. 2.-Divulgação, Porto, 1964. 350 pp.—V. núm. 18-5514.

19-2016. CAMóEs, Luís DE-Os Lusiadas. Con ulma introd., análise dos cantos e dicionário dos termos mitológicos, históricos e geográficos por $\mathrm{H}$. Guedes de Oliveira._Civilização, Porto, 1965. 428 pp.-V. núm. 18-5515.

19-2017. CAMōEs, Luís DE-Os Lusiadas. Ano das Comemorações HenriquinasMinistério da Marinha, Lisboa, 1960. $468 \mathrm{pp}$.

19-2018. CАMð̄E, Luís DE_Os Lusiadas contados às crianças e lembrados ao povo. Adapt. por Joâo de Barros. 11: ed._Sá da Costa, Lisboa, 1965. 215 pp. (Os grandes livros da humanidade).V. núm. 17-1338.

19-2019. CамóEs, Luís DE_Lusiadi. Trad. di Mercedes La Valle.-Guanda, Parma, 1965. 428 pp. \|EIP, 1965, núm. $25,269-270$ (Burgada) .

19-2020. [CAMōEs, Luís DE]-A chave dos "Lusiadas". Pról., paráfrase e notas de José Agostinho. 10a ed.-Figueirinhas, Porto, [1965?]. 614 pp.

19-2021. Gallut, ANNE_Le Morgado de Mateus, éditeur des "Lusiadas"-[Tesis, Toulouse, 1965]. $479+108 \mathrm{pp}$.

19-2022. Gallut, A.- "Documents inédits sur Ic Morgado de Mateus et son édition des Lusiadas"_-BEP, 26 (1965), 181-222.

19-2023. Galiut, A.-"A propos de l'édition des Lusiadas du Morgado de Mateus. Documents inédits"_CIEL(5), 3, $547-562$.

19-2024. LÁrER, C._"O problema dos valores n'Os Lusiadas".-RCa, 2 (1965), 72-108.

19-2025. PAIVA, L.- "O comportamento de Gama em Os Lisiadas"__RCa, 2 (1965), 55.71.

19-2026. SENA, J. DE_“A estrutura de $O s$ Lusiadas, II".-RdL, 7 (1964), núm. 26, 63-83.-V. núm. 17-1343.

19.2027. SpINA, S._-_Castelhano ou lusitano?"-RCa, 2 (1965), 109-115. [Os Lusiadas, III, 19].

19-2028. Moraes Sarmento, H. P. DE"O achamento da Ilha dos Amores".Inst, 127 (1965), 59-73.

19-2029. Torrance, R. M.- “Se fantásticas são, se verdadeiras; the gods of the Lusiads on the Isle of Love" $M L N, 80$ (1965) , 210-234.

19-2030. JANSEN, R.-"Die historischen Grundlagen zu Os Lusiadas, VIII, 18". $-A P K, 5$ (1965), 228-247.
19-2031. Avelino, Leonidas Q.-The adjective and the verb in "The Lusiads" of Camões: a critical analysis and interpretation, preceded by a survey of Camonean criticism.-[Tesis, Harvard Univ., 1965].

19-2032. P1PER, A. C._-Direct discourse in the Lusiadas".-LBR, 2 (1965), núm. 1, 57-65.

19-2033. Palma Cafiano, J. A.-_Der portugiesische Dichter Lufs de Camões und die älteren deutschen Romantiker".-Moderne Sprachen, Wien, 1965, 2./4. Heft, 13-17.

19-2034. Letzrinc, $M$._"The influence of Camoens in English literature" $-R C a$, 1 (1964), 158-180; 2 (1965), 27-54,V. núm. 18-5525.

19-2035. HAMPL, Z."Camões em tcheco".-RCa, 2 (1965), 151-152.

19.2036. SENA, J. DE-"As emendas da edicão de 1598 das Rimas de Camōes".$R C a, 2$ (1965) , 13-26.

19-2037. Otrevaere, J. — "Dix-sept sonnets de Camões".-Synth, 1965, 428 . 454. [Introd., trad. y notas].

19-2038. Ribeiro dA Cunha, M. H. "O neoplatonismo amoroso na Ode VI [de Camões]". $-R C a, 2$ (1965), 116128.

19-2039. Vieira NAtTvidade, J.-“A flota da lirica de Camóes. Excertos de um estudo inédito".-Livro de homenagem do professor Fernando Fonseca (Lisboa, 1965), 20I-210.

V. también núms. 737, 1858, 1860, 1937. 19-2040. Rocha Pereira, M. H. DA "Dois epigramas de António Ferreira"...Inst, 127 (1965), 183-186.

19-2041. Rorg, A._'Sur une édition disparue et retrouvée de la Castro d'Antó. nio Ferreira".-BEP, 26 (1965), 89-94.

V. también nưm. 1860 .

Diogo Bernardes: v. núm. 2117.

19-2042. Garcia, C. A.-"Um exemplo de literatura ecológica. Duarte Lopes e a Relação do Reino do Congo"Ultramar, 5 (1964), 123-134.

19-2043. Vieira de Mello, A-“O Padre Vieira na Itália"_Leitura, 1965, núms. $100 / 1$.

19-2044. Boxer, C. R.A great LusoBrazilian figure: $P$. António Vieira (N. 13-35097). II BHi, 67 (1965), 203.204 (Cantel); HIAHR, 45 (1965), 162-163 (Tambs) .

19-2045. Cantel, R..."La place de la femme dans la pensée de Vieira"... Carav, 1965, núm. 4, 23-34. 
19-2046. RüHL, K.__Biblischer Originaltext und Bibelversion in den Predigten Vieiras"_APK, 5 (1965), 201-227.

19-2047. Durão, P._"Séneca nos semnõcs de Vieira"._-RPFB, 21 (1965), 322-327.

19-2048. Bukmeier, F._. "António Vieira: Predigt auf den heiligsten Namen $\mathrm{Ma}$ riens. (Text mit Anmerkungen)", $A P K, \quad 5 \quad$ (1965) , 149-200.

19-2049. Martins, Heitor-Manuel de Galhegos: um poeta do barroco português. Com uma peça inédita.-Belo Horizonte, 1962. [En mimeógrafo].

19-2050. Martins, Heitor-Manuel de Galhegos. Um poeta entre a Monarquia Dual e a Restauração.-Cisial (Anadia. Portugal), 1964. 189 pp. || RLit, 26 (1964), 213 (Blanco Carril); $H R, 36$ (1968) 194-198 (Glaser) ; $N$, 50 (1966), 167-168 (de Jong); $B H i, 67$ (1965), 391.392 (Ricard); Seg, I (1965), 449. 452 (Rozas) ; BHS, 43 (1966) , 145-146 (Willis) .

19-2051. Gras, D.- "La Fiammetta et les Lettres portugaises [Mariana Alcoforado]".- $R L C, 39$ (1965), 546-574.

19-2052. ProschwITZ, G. voN_"Les lettres portugaises devant la critique".Moderna Sprak, 59 (1965), núm. 1.

19-2053. Mirandola, G.-"Robert Chasles e le Lettres portugaises".-SF, 9 (1965), 271-275.

19.2054. Mirandola, G.-“Ancora sulle Lettres portugaises e sul problema della lorn genesi'.-SF, 9 (1965), 94-96.

19-2055. LeINER, W._-"Vers une nouvelle interprétation des Lettres portugaises: Marianne entre son amour et son amant".-RF, 77 (1965), 64-74.

19-2056. JANNINI, P. A.- "Les Lettres portugaises in Italia".-EIP, 1965, núm. 24, 37-43.

\section{A utores modernos}

19-2057. SilverRA, P. DA_“"Algumas achegas para a bibliografia de Domingos Maximiano Torres, entre os Árcades Alfeno Cintio".-SN, 44 (1965), 278$279,283$.

19-2058. Cidade, H. - "Bocage"__Co, 1965, núm. 95.

19-2059. Claro, Rogtrio-Homenagem a Bocage. II centenário. Antologia. Sel., pref. e notas de...-Junta Distrital, Setúbal, 1965. 304 pp.

19-2060. Simöes Müller, A.-“Eternidade de Bocage".-Rev. Municipal, Lisboa, 1965, núms. I06/7, 58-70.
19-2061. Correia, Romeu-Bocage.-Ulisseia, Lisboa, 1965. 164 pp. (Vária).

19-2062. MourÃo FERREIRA, D.-"O dra. ma de Bocage"._Pan, 1965, nưm. 14, 15-18.

19-2063. Caratão Soromenho, P.-“Biografia lisboeta de Bocage".-_olisipo, 28 (1965), 184-186.

19-2064. Lancastre Bobone, M. DE-"O retrato de Bocage pintado do natural"'-BAPE, 10 (1965), 277.224.

19-2065. Pereira Forjaz, A.-"Bocage e as Academias".-BAL, 37 (1965), 202216.

19-2066. Prado Coelho, J. do-“Bocage. A vocação do obscuro".-TM, 3 (1965), 1182-1194.

19-2067. Mendes, J.—Bocage o pré-romântico"._Bro, 81 (1965), 500-508.

19-2068. GedeÃo, A.—“O sentimento cien. tífico de Bocage"._Ocid, 69 (1965), I77-192.

19-2069. Costa Dias, A.-"Enterrar os mortos e cuidar dos vivos. A propósito de uma peça sobre Bocage".--SN, 1965, 209.

19-2070. Amaral, Eloy do-Bocage. Notas de...-Ulisseia, Lisboa, 1965.

V. también núm. 1858.

19-2071. Diegues Júnion, M._."Um precursor do folclore: Almeida Garrett". $R B F, 5$ (1965), 143-148.

19-2072. PIRES DE LIMA, F. DE C.-"O Romanceiro de Almeida Garrett".-REt, 5 (1965), 113-127.

19-2073. Silveira, P. DA-“Um documento respeitante à ida de Garrett para a Ilha Terceira em [809"._V tice, 25 (I965), 235-236.

19-2074. Almeina GaRRetT-Filipa de Vilhena._Civilização, Porto, 1965, $180 \mathrm{pp}$. (Aulores portugueses).-V. núm. 17 4914.

19-2075. AlMEDA GARRETT-Frei Luis de Sousa. Texto rev., introd., notas e glosres Martins, Porto, 1965.-V. núm. 9. 16526.

19-2076. Almeida GarretT-Frei Luis de Sousa. Texto rev., introd., notas e glossário de Mário Fiúza.-Porto Ed., Porto, [I965?]. $172 \mathrm{pp} .-\mathrm{V}$. núm. 18-2077.

19-2077. Botrel, J. F._."La représentation de Frei Luis de Sousa".-Etudes luso-brésiliennes (Rennes, 1966).

19-2078. AlMEIDA GARRETT_Viagens na minha terra. - Livraria Figueirinhas, Porto, [1965?]. 282 pp.-.V. núm. 17. 1409.

19-2079. Ar.meIDA GARRETT-Obra politi- 
ca. Introd. de Augusto da Costa Dias.Portugália, Lisboa, 1965.

19.2080. "António Feliciano de Castilho". $-L P, 1965$, núm. 70.

19-2081. Tavares, J.-“Castilho e Bulhåo Pato perante a memória de José Estêvão",- $A D A, 1965,163-177$.

V. también núm. 2180 .

Estêvão: v. núm. 2081.

19-2082. Machado Santos, M. A.-"Alexandre Herculano e a Biblioteca da Ajuda".-_Inst, 127 (1965), 99-174. II Ocid, 70 (1966), 163-166 (Peixoto).

19.2083. TRINDADE, MANUEL-O padre em Herculano. - Verbo, Lisboa, [1965?]. 264 pp. (Presenças, 4).

19-2084. Herculano, AleXandre-Eurico o presbitero. Ed, dirigida por V. Nemé. sio. Notas e apéndices de $M$. H. Lucas. 2! ed.-Difusão Europeia do $\mathrm{Li}$ vro, São Paulo, 1965. 261 pp._V. núm. 18-2088.

V. también núms. 1846, 2003.

19-2085. Gracias, Bernardino - Camilo [Castelo Branco] suicida. Ensaio biobibliográfico.-Tip. da E.N.P., Lisboa, 1965. 190 pp.

19-2086. MENEZES, MARIo dE-Camilo en Ribeira de Pena._Coimbra, 1965. 108 pp.

19-2087. RICARD, R_- "Une notation médicale de Camilo".-REl, 4 (1965), 35 37.

19-2088. Bastos, C._-"Rapsódia camiliana".-Trip, 1965, núm. 1.

19-2089. Malpique, C-_-'Camilo bibliófilo".-Trip, 10 (1965), 306-310.

19-2090. ARREU, J. DE- "Camilo Castelo Branco: notas em livros". - $R P, 30$ (1965) , 418-427. [Notas en unas Obras cle Gil Vicente].

19-2091. LOUREIRO, F. DE-"Diário I. Como escrevia Camilo". - BAPE, 10 (1965), 232-236.

19-2092. MAIA, J.-_Camilo Castelo Branco, crítico literário".-Bro, 81 (1965), 644-648.

19-2093. Girodon, J. - "L'numoire aux amants. Camilo et l'Heptaméron".$B E P, 26$ (1965) , 223-234.

19-2094. Castelo Branco, Camilo-Amor de perdição. Memórias duma familia. Ed revista por A. C. Pires de Lima.Porto Ed., Porto, [1965?]. $246 \mathrm{pp}-\mathrm{V}$. núm. 17-4931.

19-2095. Castelo Branco, Camilo-amor de perdição $e$ outras novelas. Introd. de F. Mendonça. Boa Leitura, São Palllo, 1965 .
19-2096. Oliveira Ramos, L. A. DE-"Uma figura de Camilo no Amor de perdição.-StGP, 10 (1963), 174-181.

19-2097. Correia, Romeu-Amor de per. dição. Glosa dramática em três partes do romance de Camilo Castelo Branco.-Porto, [1966]. 132 pp.

19-2098. Castelo Branco, Camilo - $A$ caveira da mártir. 4! ed.-Domingos Barreira, Porto, [1965?]. $434 \mathrm{pp},-\mathrm{V}$. núm. 18-2101.

19-2099. Castelo Branco, Camilo-Es. trelas propicias. 6 a ed, conforme a 2:, última revista pelo autor. Fixação do texto e nota prel. de M. A. Zaluar Nunes.-A. M. Pereira, Lisboa, 1965. $240 \mathrm{pp}$.

19-2100. Castelo Branco, Camilo-ia novela de un hombre tico.—Dédalo, Madrid, 1965. $48 \mathrm{pp}$. (Novelas y cuentos).

19-2101. Castelo Branco, Camilo_-Onde está a felicidade? Fixação do texto e nota prel. por A. Cabral. 11: ed.-António Maria Pereira, Lisboa, 1965. 392 pp.

19-2102. Castelo Branco, Camilo - o regicida. Romance histórico. $7^{\mathrm{a}} \mathrm{ed}$. revista pela 1: ed. Nota prel. de N. Rodrigues Alves.-A. M. Pereira, Lisboa, 1965. $268 \mathrm{pp}$.

Bulhão Pato: v. núm. 2081.

Joño de Deus: v. núm. 1848.

19-2103. RODRIGUES CAVALHEIRo-"Rama. tho Ortigão e os primeiros passos da República".-Sulco, 1965, 18-33, 147. 169.

19-2104. RamalHo ORTIGÃo-_Folhas sol. tas. (1865-1915).-Livr. Clássica, Lisboa, 1965. 346 pp. (Obras completas).V. núm. $12 \cdot 33163$.

V. también núm. 909.

19-2105. BrAGA, G.-"Júlio Dinis"-Trip, 5 (1965), 359-362.

19-2106. Dinis, JúLIo-Uma familia inglesa. Cenas da vida do Porto.-Saraiva, São Paulo, 1965. 2 ts.

19-2107. Denis, Júl10-Uma familia inglesa. Cenas da vida do Porto.-Civilização, Porto, 1965. $368 \mathrm{pp} .-\mathrm{V}$. núm. 18-2113.

19-2108. Dinis, Júlio__Os fidalgos da Ca. sa Mourisca. Crónica da aldeia. Nova cd. conforme a la, actualizada na gra. fia.-Civilização, Porto, 1965. 406 pp.V. núm. 18-2111.

19-2109. Dinis, Júlio-A morgadinha dos Canaviais. Crónica da aldeia. Noya ed. conforme a la, actualizada na grafia.- 
Civilização, Porto, 196ว. 424 pp.-V. núm. 18-5614.

19-2110. Dinis, Júlio_-As pupilas do senhor reitor. Crónica da aldeia. Nova ed. conforme a $I^{\mathrm{a}}$, actualizada na grafia.Civilização, Porto, 1965. 280 pp.-V. núm. 18-5615.

19-2111. Dinis, Júlio_-Poesias,_Civilização, Porto, 1965. 268 pp.-V. núm. 174945 .

19-2112. Galvão de Carvalho, R.-“Antero de Quental e o ultimatum inglês de 1890".-Sulco, 1 (1965), 504-513.

19-2113. Malpique, C.-“"Umas quantas notas a esmo sobre Antero"._L Lab, $\$ 7$ (1963), núms. 221, 222.

19-2114. Galvão dE Carvalho, R.-“O génio poético de Antero".—Bro, 81 (1965) , 173-180.

19-2115. Novaes Coelho, N.-“O mundo poćtico anteriano"..Alfa, 1965, núms. $7 / 8,61-74$.

19-2116. Galvão de Carvalho, R.—“Antero, o maior de todos".-BAPE, 10 (1965), 158-166.

19-2117. MENDES, J._."Exercício escolar sobre dois sonetos".-Bro, 80 (1965), 225-228. [De Quental y de Bernardes].

19-2118. Atrinson, D. M._"As imagens nas Odes modernas, de Antero de Quental"._Ocid, 69 (1965), 145-155.

19-2119. Galvão dE Carvalho, R.-“A Serenata, de Antero"._Ocid, 69 (1965), 156-157.

V. también núms. 1846, 1858.

19-2120. HampeJs, Z.-“José Maria Eca de Queiroz".-Kulturne Politicky $K a$ lendár, 1965, 131-33.

19-2121. BARBosa, V.—“Eça de Queirós, poveiro"._-Póvoa de Varzim, 4 (1965), 5-18.

19-2122. Couto, Alberto_E_Eça de Queiroz e Oliveira de Azeméis.-[Lisboa?], 1965. 20 pp.

19-2123. Cochorel, F._."Eça de Queirós e Penaliel".-Penafidel, 1965, núm. 3. 13-17.

19-2124. Andrews, N. H., JR.--"The artist and the servant problem: Example, Eça de Queirós".-LBR, 2 (1965), núm. 1, 43-55.

19-2125. CésAR, G._-"Diante da nova critica: Eça de Queirós"._-Co, 1965, núm. $33,53-55$.

19-2126. César, G。“"Eça de Queirós diante da nova crítica" $-B G P L$, agosto $1966,41-48$.

19-2127. Zaluar Nunes, M. A.-"O sonho na ficção queirosiana e em precedentes obras portuguesas"._Pal, 1965, núm. $23,30-55$.

19-2128. LyRA, HEITOR_o Brasil na vida de Eça de Queiroz._Livros do Brasil, Lisboa, 1965. 548 pp. || $P h P, 9$ (1966), 448-449 (Hampl).

19-2129. MAchado da Rosa, AlbertoEça discipulo de Machado? Formação de Eça de Queirds: 1875-1880. Ed. rev. c act.-Presença, Lisboa, 1965. 408 pp. (Divulgação e ensaio, 15) .-.V. núm. 185626. || Bro, 82 (1966), 418 (Maia).

19-2130. Castilho, G. DE_-"Eça de Queirós e António Nobre"._Co, 1965, núm. 32, $41-43$.

19-2131. EÇA dE QueIroz, José María — Obras completas. Trad. de J. Gómez de la Serna.-Aguilar, Madrid, 1965. 3 ts.: cciv + 1230, 1450, 1092 pp. (Obras eter. nas).-V. núm. 18-2139.

19-2132. EÇA DE Querrós-Páginas de... Ed. por Ester de Lemos._Verbo, Lisboa, 1965. 104 pp. (Textos clássicos).

19-2133. EÇA DE QUEIRoz Uma campanha alegre de "As Farpas".__Lello \& Irmão, Porto, 1965. 2 ts.: 230, 232 pp. 19-2134. EÇA DE QuErRoz-The Maias. Transl. by Patricia McGowan Pinheiro and Ann Stevens_-The Bodley Head, London, 1965. 633 pp. \| BHS, 44 (1967), 227-238 (Lamb).

19-2135. Oliveira Martins, A. A. DE"No $70^{\circ}$ aniversário da sua morte. OHiveira Martins, moralizador e renovador da polftica nacional". - $B A P E, 10$ (1965) , 46-54.

19-213G. ERcolani, Paola-Joaquim $\mathrm{Pe}$ dro de Oliveira Martins come biografo.-[Tesis, Univ. de Roma, 1965]. 190 pp.

19-2137. Oliveira Martins, Joaquim PEDRO DE-História da República romana.-Guimarães Ed., Lisboa, 1965, 2 ts.: $468,446 \mathrm{pp}$.

19-2138. LoyoLA, M. DE_ “El cavador".Manantial, 1963, núm. 14. [Guerra Junqueiro].

19-2139. Guerra Junquetro-Horas de luta. Pról. de Mayer Garção._Lello \& Irmão, Porto, 1965. 246 pp.

19-2140. MARTINS JANFiro, A.- "Um intérprete português do Japão: Wenceslau de Moraes".-Boletim Eclesiástico da Diocese de Macau, 63 (1965), 443459.

19-2141. Martins, V. A.—“O sDai Nippon e a cidade de Cobe consagram Venceslau de Morais"._Pan, 1965, núm. 14, 19-22. 
Fialho de Almeida: v. núm. 1848.

19-2142. Osório DE Ollvelra, J.-"JJaime de Magalhães Lima".-Co, 1964, núm. 27, 47-48.

19-2143. Sousa Machado, A. DE-"A propósito de duas poesias inéditas de $\mathbf{A n}$ tónio Feijo"._BAPE, 10 (1965), 153157.

19-2144. MIRANdA dE ANdRAdE-"O Cancioneiro chinés de António Feijó".Ocid, 69 (1965), 89-102.

19-2145. Silveira, P.- "Um esquecido prefácio do esquecido Raul Brandão" SN, 45 (1965), 358.

19-2146. Castilio, A. T. DE-“'Recursos da linguagem impressionista em Raul Brandão"._Alfa, 1965, núms. 7/8, 19 38.

19-2147. Cruz, D. I._"Notas sobre o teatro de Raul Brandão"...Esp, 1965, núms. 6/7, 98-101.

A. Nobre: v. núm. 2130.

\section{Autores contemporaneos}

19-2148. Dantas, Júlio-Revoada de musas. As mulheres na vida dos homens célebres._Portugália, Lisboa, 1965. 218 pp.

19-2149. Dantas, Júlio_Serões da provîncia._Civilizaçăo, Porto, 1965. 2 ts.: 264, $264 \mathrm{pp}$.

19-2150. Espiney Patrício, E. DE-"O poeta António Patrício"._Co, 1965, núm. 35 .

19-2151. Mag,alfiäes-Vilhena, V.-António Sérgio: o idealismo crítico $e$ a crise da ideologia burguesa.-Seara Nova, Lisboa, 1965.-.V. núm. 17-1485. || $B E P$, 26 (1965), 253-256 (Boisvert).

19-2152. Lopes, O._-"O mundo pícaro de Aquilino Ribeiro"_Vértice, 25 (1965), 885-896.

19-2153. Ribeiro, AQuilino - A aldeia. Terra, gente e bichos,-Bertrand, Lisboa [1965?]. 362 pp.

19-2154. RIBEIRo, AQUILINO-Wenn die Wölfe heulen. Ubertr. von Peter Eck.S. Fischer, Frankfurt/M., 1965, 316 pp. [Trad. de Quando os lobos uivam].

19-2155. SÁFADY, N._AA poesia de Fernando Pessoa".-RUMG, 1965, núm. $15,89.101$.

19-2156. Décio, J.-"Aspectos da poesia de Fernando Pessoa". - Al/a, 1965, núms. $7 / 8,199-206$.

19-2157. SOIFER, M.-“Sonho e criação na poesia de Fernando Pessoa".- $L P a, 14$ (1965), 62-76.
19-2158. Hess, R.-“As metáforas cénicas na obra de Fernando Pessoa".Ocid, 68 (1965), 10-24.

19-2159. BENE, ORIeTTA DEL - Alberto Caeiro, uno "pseudonimo" di Fernando Pessoa.-[Tesis. Univ. de Roma, 1965]. $121 \mathrm{pp}$.

19-2160. Pessoa, Fernando-Dichtungen. Nachwort und Ubertragung von Georg Rudolf Lind.-S, Fischer, FrankfurtMain, 1965. 232 pp.

19-2161. Pessoa, FERNANDO-Quadras ao gosto popular-Atica, Lisboa, 1965. 128 pp. (Poesia).

19-2162. Pessoa, Fernando-O banqueiro anarquista e outros conto de racioci: nio. Antologia. Organização e pref. por Fernando Luso Soares.-Lux, Lisboa, 1964. 160 pp. (Col. antológica). $\| B A b r$, 40 (1966), 243 (Listopad).

V. también núms. 1846, 1858, 2324.

19-2163. Figueiredo, FIDELINo DE Símbo. los e mitos.-Publs. Europa-América, Lisboa, 1964. 186 pp. (Estudos $e$ documentos, 29). $\|$ Co, 1964, núm. 31 (Cidade) ; $B A b r, 40$ (1966), 123 (Chambers); $H, 48$ (1965), 170 (Moser).

19-2164. Houwens Post, H._"Mário de Sa-Carneiro, premier poète surréaliste portugais (1890-1916)".-N, 49 (1965). 301-306.

19-2165. SA Carneiro, Mário DE-[Antologia]. Sel e estudo de C. Berardinelli. 2: ed-Agir, Rio de Janeiro, 1965. 83 pp. (Nossos clássicos, 22).

19-2166. Cidade Moura, H._"Um semiinédito de Mário de Sá-Carneiro".Co, 1965, núm. 36.

19-2167. Pinharanda Gomes-'Um d'Orpheu: Raul Leal. Ensaio biobibliográfico".-BAPE, 10 (1965), 248-257.

19-2168. Forjaz Tricueiros, L._ "Mário Beirão, poeta da terra e do homem".$B A L, 37$ (1965), 143.150.

19-2169. AmenL, J._"Mário Beirão, poeta místico".-BAL, 37 (1965), 151-158.

19-2170. Cortez Pinjo, A.—“Mário Beirão ou a alma em êxtase".-Co, 1965, núm. 34, 49-51.

19-2171. Cruz, D. 1.-"Almada Negreiros: estética e dramaturgia". _ Esp, 1965, núms. $6 / 7,118-122$.

19-2172. AlmadA Necreiros, Jost DEOrpheu (1915-1965). - Ática, Lisboa, [1965?]. 28 pp. (Obras completas).

19-2173. Vasconcelos, J. C. DE-"Cinquenta anos de vida literária de Ferreira de Orpseu (1915-1965). - Ática, Lisboa, 19-2174. FERREIRA dE CASTRO-Eternidade. 
11: ed.-Guimarães, Lisboa, 1965. 328 pp.-V. núm. 17-1530.

19-2175. Campos de Figueiredo_Eminio libertada".-ACo, 19-20 (1964), 179.197.

19-2176. Campos de Figueiredo.-“"Sonnets et chansons".-Inst, 126 (1965), 107. 170.

19-2177. Miranda Mrendes-“Um escritor português"'-Co, 1965, nưm. 32. [Osório de Oliveira].

19-2178. Osório de Oliyeira, José-Pala. vras ao vento.-Sociedade de Expansão Cultural, Lisboa, 1965. 278 pp. (Grandes cronistas portugueses contempordneos).

19-2179. SaCramento, M.-“Tema para um colóquio sobre José Régio"._-Vértice, 24 (1964) , 256-258.

19-2180. Rodrigues Miguéis, J.- "Um novo Castilho?-SN, 44 (I965), 372-\$76. [Sobre José Régio].

19-2181. Braz Teixeira, A.- "Sobre o teatro religioso de José Régio".-Esp, 1965, núms. 6/7, 123-125.

19-2182. RÉgio, Joste-Davam grandes passeios aos domingos...-Inquérito, Lisboa, 1964. 116 pp. (Antologia dos amigos do livro, 6).

19-2 I83. RÉcIo, José-Jacob e o anjo. 3n. ed.-Portugália, Lisboa, 1964. 190 pp. (Obras completas, 2). Il Ocid, 70 (1966), 174 (A. C.) .

19-2184. RégIo, JosÉ-Poemas de Deus e do diabo. 6. ed.-Portugália, Lisboa, 1965. 160 pp. (Obras completas).-V. núm. 16-47791.

19-2185. RÉgio, José-Poesia de ontem e de hoje. 2: ed.-Direç̧ão Geral do Ensino Primário, Lisboa, 1965. 116 pp. (Col. edicativa).

V. también núm. 1858 .

19-2186. Rodrigues Miguéis, Jost__E proibido apontar. Reflexões de um burguês. T. 1. - Estúdios Cor, Lisboa, 1964. 212 pp. || Alfa, 1965, núms. 7/8, 245-248 (Décio).

19-2187. Rodrigues Miguérs, José-Páscoa feliz. 3: ed.-Estúdios Cor, Lisboa, [1965?]. 176 pp. (Latilude, 30).-V. núm. 14-38876. || Alfa, 1966, núm. 10, 187 189 (Décio).

19-2188. Monteiro, Domingos_Contos do Nalal._Soc. de Expansão Cultural, Lisboa, 1964. 124 pp. || Ocid, 69 (1965), 126 (A. C.).

Bugalho: v. núm. 1858.

19-2189. VIOLANTE, M._-"A memória de Carlos Queiroz"._StGP, 10 (I963), 93113.
19-2190. Ctsar, G._-Miguel Torga, o ibérida".—Co, 1966, núm. 41.

19-2191. Torga, Miguel-Poemas ibéri. cos,_Coimbra, 1965. 80 pp.

19-2192. TORGA, MigueL_Vindima. 3․ ed. rev._Coimbra, 1965. 272 pp.-V. núm. I I-26428.

19-2193. TORGA, Migued_Weinlese. Ubers. von Erika Farny._.Scherz, Bern, 1965. 328 pp.

19-2194. Pimenta, A.-“O problema da justiça em $O$ braço da justiça, peça do segundo ciclo de teatro de Joaquim Paço d'Arcos"._ocid, 68 (1965), 305. 312. I| Ocid, 7I (1966), 118-119 (F. S.) .

19-2195. PAÇo D'Arcos, JoAQUIM-O caminho da culpa. $5^{\circ}$ ed.-Guimarães, Lisboa, 1965. 324 pp.

19-2196. Paço d'Arcos, Joaquim - Cela 27.-Guimarães, Lisboa, 1965. 198 pp. II Ocid, 70 (1966), 173 (F. S.) ; $B A b r$, 40 (1966), 370 (Listopad).

19-2197. Cruz, Duarte Ivo-O teatro de Joaquim Paço d'Arcos. Ensaio interpretativo e critico._Livr. Cruz, Braga, 1965. 76 pp. || Ocid, 71 (1966), I17118 (F. S.) .

19-2198. PAÇO D'ARCOS, JoAquim-Teatro. Primeiro ciclo. - Guimarães, Lisboa, 1965. $402 \mathrm{pp}$.

V. también nưm. 1858.

19-2199. DÉcio, J.—“O sentido ensalstico do romance de Vergílio Ferreira". Alfa, 1965, núms. 7/8, 39-59.

19-2200. Sacramento, M.-“Crítica literária" [sobre Virgilio Ferreira] $-\mathrm{S} N$, 44 (1965) , 284-286.

19-2201. Ferreira, Vercílo Alegria breve._Portugália, Lisboa, 1965. $276 \mathrm{pp}$.

19-2202. Castro Soromenho-Giro di boa. Trad. di L. Pellisari-Bompiani, Milano, 1965. $244 \mathrm{pp}$.

19-2203. Castro Soromenho-Noite de an. gústia. 4ㄹ. ed.-Ulisseia, Lisboa, 1965. 156 pp. (Atlántida, 13).

19-2204. Lromilové, P._-'Tri postavy soucasne portugalské prózy". — $P h P, 8$ (1965) , 71-80. [Fernando Namora, Antunes da Silva, Jorge Reis].

19-2205. Namora, Fernando - Casa da malta._Publs. Europa-América, Lisboa, 1965. $236 \mathrm{pp}$.

19-2206. Namora, Fernando-Deuses e demónios da medicina. T, 2.-Arcádia, Lisboa, 1964. 408 pp.

19-2207. NAMORA, FERNANDO-Domingo $d$ tarde._Publs. Europa-América, Lisboa, [1965?]. 242 pp.-V. núm. 18-2315. || Bro, 82 (1966), 840-842 (Vasconcelos). 
19-2208. NAMORA, FERNANDO-Fogo na noite escura._Publs. Europa-América, Lisboa, [1965?]. 450 pp.

19-2209. Pina de Morais, GraçA-O medo. Raquel._Lux, Lisboa, [1965?]. $162 \mathrm{pp}$.

19-2210. Pina de Morais, Graça, Urbano Tayares Rodrigues e Manuel MenDES-As trés virtudes teológicas.-Minotauro, Lisboa, 1964. (Col. Antologia).

19-2211. Andrade, EuGÉNIO DE-Ostinato rigore._Guimarães, Lisboa, 1964. 48 pp. (Poesia $e$ verdade). $\| B A b r, 39$ (1965), 492 (Listopad).

Tavares Rodrigues: v. núm. 2210.

19-2212. Suassuna, ARIANo-Aulo de la compadecida. En dos partes. Escrito en portugués brasileño. Adaptación de José María Pemán.-_Alfil, Madrid, 1965. 81 pp. (Col. Teatro).

19-2213. Suassuna, Ariano-Auto de la compadecida._Yorick, Barcelona, núms. $5 / 6$ (1965).

19-2214. Suassuna, Arinno - The rogue's trial. Transl. by D. F. Ratcliff._Univ. of California Press, Berkeley, 1963.

\section{A utores gallegos}

19-2215. PONCE DE LEÓN, L. "Notas previas para un mapa literario de $\mathrm{Ga}$ licia".-EL, 1965, núms. 320/1, 322/3, $324 / 5$.

19-2216. Braz TejXeirA, A.-“Breve apresentação da literatura galega".-Esp, 1 (1964-65), 72-80.

19-2217. Alvarez BlAzQuez, J. M.-"Lite. ratura popular gallega en torno a Pardo de Cela"__CuEG, 20 (1965), 350378.

19-2218. LORENZANA, S. "A xeneración "Nóss na cultura galega".-Grial, 1965, 75-86.

19-2219. SuÁrez-Llanos, C. G. - "Notas para unha visión actual do problema da literatura galega"._-Grial, 1965, 189 198.

19-2220. VAREla JÁcome, B._-"Albores de la moderna poesía galaica".-EL, 1965, núms. $320 / 1$.

19-2221. González Portocarrero, E. "Poetas gallegos del siglo $\mathrm{xx}$ " $-E L$, 1965, núms. 320/1.

19-2222. Carballo Calero, R-Eduardo Pondal._Galaxia, Vigo, 1965, 33 pp. 19-2223. Gamallo Fierros, D.- "Rosalía de Castro"_EL, 1965, núms. 320/1.

19-2224. Prado Ronrígutz, J._-"Rosalía de Castro en $\mathrm{mi}$ recuerdo"._Horizontes, México, 1965, núm. 42.
19-2225. VAreiA, J. L.-"Huellas del pasar de Rosalía".-EL, 1965, núms. 320/1.

19-2226. Esquer TORRES, R. - "Resonancias: Bécquer y otros románticos en Rosalía de Castro".-Hom, 2 (1965), $21 \cdot 37$.

19-2227. NAYA PÉREZ, J--"Raices folklóricas en la obra de Rosalía de Castro",-APCE, 3, 71.76.

19-2228. Carballo Calero, R.-'Un verso de Rosalía: «Donde estraña me alomeans"_CuEG, 20 (1965), 124-126.

19-2229. Fernandez Pereiro, N. G. B. DE"Dialecto y tradición en un poema gallego de Curros Enríquez".-CDG(1), $1, \quad 279-285$.

19-2230. VARELA JÁcome, B._-"La versificación de Ramón Cabanillas".-CuEG, 20 (1965), 90-108.

19-2231. Otero Pedrayo, R.-“Una interpretación literaria gallega del Conde de Ourém". $-B A u, 18 / 19$ (1965), 114-121.

19-2232. CASTELAO, ALFONSO R.-Escolma posible. Sel. y pról, de Mariano Dóne. ga._Galaxia, Vigo, 1964. || BAbr, 39 (1965) 486 (de Boer); Ins, 1965, núm. 220 (Portela).

19-2233. Fernández TeIXeiro, M. M."Vida e poesia de Xosé Crecente Vega"._Bs, 40 (1964), 261-317.

19-2234. Torres, Xohana-A outra banda do fberr._Galaxia, Vigo, 1965. 96 pp. $\| B A b r, 40$ (1966) 367 (de Boer).

\section{LITERATURA ESPANOLA}

19-2235. Simón Díaz, J.-Manual de bibliografía de la literatura española (N. 18-5799) . || AHSI, 34 (1965), 281-283 (Batllori); $R y F, 171$ (1965), 210 (Hornedo); $R I B, 16$ (1966), 58-60 (Lau. renti); HR, 33 (1965), 395-399 (Mc Cready) ; BHS, 42 (1965), 278 (Pierce); Atl, 3 (1965) , 433-438 (Rozas); $H$, 48 (1965), 610 (Woodbridge).

19-2236. Simón Díaz, Jost_Bibliografía de la literatura hispánica. T. 3, vol. 2: Siglo xv. 2" ed._-C.S.I.C., Madrid, 1965. 626 pp.-V. núm. 9-14083.

19-2237. Simón Díaz, J. (ed.) _-'Información bibliográfica [sobre literatura española]".-RLit, 25 (1964), 269-338; 27 (1965), 273-321.-V. núm. 18-2373. 19-2238. Diccionario de literatura española. Dirigido por Germán Bleiberg y Julián Marías. 3? ed.-Rev. de Occidente, Madrid, 1964. xvi + 1056 pp.- 
V. nứnd. 12-31311. || $B A b r, 39$ (1965), 444 (Meyer); Diál, 1965, núm. 6, 4344 (Xirau).

19-2239. Sainz de Robles, Federico CarLos-Ensayo de un diccionario de la literatura. 3\% ed. - Aguilar, Madrid, 1965. 2 ts.: 1220, 1294 pp.-V. núm. $12-31050$.

19-2240. "Apuntes para un censo de es. critores nacidos en Galicia".-EL, 1965, núms. $322 / 3$, $324 / 5$.

19-224.1. Rozas, J. M. (ed.) -El Liceo Artistico y Literario Español, núm. 1.. Hom, 2 (1965), 93-144.

19-2242. PaniaguA, D.-Revistas cultura * les contempordneas, I (N. 18-5807). U fns, 1965, núm. 222 (X).

19-2243. SÁnchez Castañer, F._"Aportaciones a la biografía de Nicolás Antonio".-RFE, 48 (1965), 1-37.

19-2244. Pérez Y Gómez, ANTonio-Segundo centenario del nacimiento de don Diego Clemencin Viñas, 1765. 1834.-Academia Alfonso X el Sabio, Murcia, 1965. $14 \mathrm{pp}$.

19-2245. Florit, R_ "Ángel del Río: Bi. bliografia".-RHM, 31 (1965), 455.459.

19-2246. DifGo, G._'Ángel del Río en Soria".-RHM, 31 (1965), 120-123.

19-2247. Andrews, J. R., S. G. Armistead, \& J. H. Silverman_ "María Rosa Lida de Malkiel (1910-1962)"'_IH, 47 (1964), 408.409.

19-2248. Barrenechea, A. M._María Ro. sa Lida de Malkiel".-Davar, 1965, núm. 107, 105-110.

19.2249. Homenaje a Maria Rosa Lida de Malkiel._Fac. de Filosoffa y Letras de la Universidad, Buenos Aires, 1962 [1964]. 420 pp. (Filologia, 8). I| ZRPh, 81 (1965), 573 (Baldinger); AION-R, 7 (1965), $261-264$ (Cirillo).

19-2250. Studies in honor of Mair J. Benardete. (Essays in Hispanic and Sephardic culture).-Las Américas, New York, 1965. 501 pp. \|RFE, 49 (1966), 362-364 (Alvar) ; Sef, 26 (1966), 153. 158 (Lacave y Iassán); RHM, 33 (1967), 144 (Mades); Ins, 1967, núm. 244 (Marra López).

V. también núıns. 951,956 .

\section{Historia y critica literaria}

19-2251. Fogarasi, M._-"Pensieri sulla sto. ria della lingua letteraria italiana $e$ spagnola".-Annales Universitalis Scien. tiarum Budapestinensis de Rolando Eö. tuös nominatae, 6 (1965), 55-64.
19-2252. Ticknor, George - History of Spanish literalure. A reprint of the 6th American edition (1891) - Stechert-Hafner, New York, 1965. 3 ts.

19-2253. Estrella Gutiérrez, Fermín_L Literatura española. 12a ed.-Kapelusz, Buenos Aires, 1965. 622 pp., ilustr.V. núm. 13-\$77051.

19-2254. CAMP, JEAN-La literatura española. Trad. A. A. de Alba-Diana, México, 1965. 197 pp.-V. núm. 11 . 28089.

19-2255. TORRI, Julio-La literatura es pañola. 4a ed.-Fondo de Cultura Económica, México, 1965. 438 pp. (Breviarios, 56) .--V. núm. 9-16564.

19-2256. Castro Calvo, José M.-Historia de la literatura española.-Crédito Editorial Sánchez, Barcelona, 1965. 2 ts.: 395, 413 pp., ilustr.

19-2257. Chandler, R. E., \& K. Schwartz$A$ new history of Spanish literature (N. 17-5154). \|CuH, 65 (1966), 185187 (Ruiz-Fornells) _-V. núm. 18-5819. 19-2258. SamonA, Carmelo - Profilo di storia della letteratura spagnola.-V. Vecchi, Roma, 1965. 182 pp.-V. núm. 17-5152.

19.2259. VAlbuena PRAt, AngeL_Literatura española en sus relaciones con la universal.S.A.E.T.A., Madrid, 1965, $528 \mathrm{pp}$.

19-2260. Díaz Plaja, Guillermo-Historia de la literatura española encuadrada en la universal, a través de la critica $y$ de los textos. 8: ed-Ciordia, Bue. nos Aires, 1965. 626 pp., ilustr.-V? núm. 13-37050.

19-2261. SMYTH, PhILIP-An outline of Spanish and Spanish-American literature with reading references. - The Thrift Press, Ithaca, N. Y., 1965. 70 pp. || $H, 49$ (1966), 911-912 (Stone).

19-2262. Rulz Morales, J. M.-“Relaciones culturales entre Espafía y el mundo árabe".-RIEI, 7-8 (1959-1960), 1-40.

19-2263. AL-Makkari_Analectes sur l'his. toire et la littérature des arabes d'Espagne. Publiés par Reinliart Dozy [et al.] (Leyde, 1855-1861). A reprint.Oriental Press, Amsterdam, 1965. 2 ts.: cxlvi + 943, lxiii + 933 pp.

19-2264. Dozy, ReinhaRT A. P.-Recherches sur l'histoire et la littérature de l'Espagne pendant le moyen age. 3? éd. (Levde, 188I). A reprint.-Oriental Press, Amsterdam, 1965. 2 ts.: 1090 pp. 19-2265. GreEN, OtIs H.-Spain and the western tradition. The Castilian mind. 
in literature from "El Cid" to Calderón.-Univ, of Wisconsin Press, Madison-Milwaukee, 1963-66. 4 ts.: 329, 365, 507,345 pp. II YCL, 16 (1967), 96-98 (Cantarino); RR, 59 (1968), 57-60 (Carrasco Urgoiti); Ins, 1964, núm. 210 (Ciplijauskaite); $M L J, 51$ (1967), 361 (Crow); $B A b r, 38$ (1964), 427; 39 (1965), 453-454; 41 (1967), 87-88, 463 (Chambers); $M L R, 61$ (1966), 145-146; 62 (1967), 737-738 (Davies); $H, 50$ (1967), 1012-1018 (Durán); CuH, 67 (1966), $768-773$ (Ferrán); MPh, 63 (1965. 66 ), 348-350 (Glaser); $s p, 40$ (1965), 348-351; 41 (1966), 743.746 (Keller); $R N, 17$ (1964), 246-248 (MacCurdy); BICC, 20 (1965), 392-395; 21 (1966), 212-215; 22 (1967), 103-106 (Montes); RLit, 27 (1965), 199-204 (Morón Arroyo); $H R, 33$ (1965) , 66-68; 35 (1967), 93-99; 36 (1968) , 59-63 (Parker); BHS, 42 (1965) , 46-48; 44 (1967), 73.74 (Pierce) ; ROcc, 9 (1965) , 126-131; 23 (1968), 385-392 (Rico); BHS, 45 (1968), 133 . 134 (Riley); $M L N, 80$ (1966), 235244; 81 (1966), 246-248; 83 (1968), $31-316$ (Rivers); $R P h, 19$ (1965-66), 360-363, 646 (Russell) ; HAHR, 46 (1966), 451-452 (Schwartz); MLQ 28 (1967) , 490-491 (Stone); RQ 20 (1967), 246-247 (Valbuena-Briones).

19-2266. Catalín, D.-"La historiografia en verso y en prosa de Alfonso XI a la luz de nuevos textos"-_BAfI, 155 (1964), 79-130; 156 (1965), 55-87.

19-2267. CRIADo dE VAL, MaNUEL-De la Edad Media al Siglo de Oro._Madrid, 1965. 154 pp. (Claves de España). II $A, 1966$, núm. 411, 279-282 (Muñoz G.) .

19-2268. RIQUER, MARTíN DE-Vida caballeresca en la España del siglo xv.-Real Academia Española, Madrid, 1965. 143 pp. [Discurso acaclémico; contestación de D. Alonso].

19-2269. Riquer, M. DE-“Caballeros andantes españoles".-ROcc, 9 (1965), 20-32.

19-2270. LiDa DE Malkiel, M. R.-Two Spanish masterpieces (N. 17-5170). II RJ, 17 (1966), 351-355 (Bihler); Era, 18 (1966), 357.358 (Rheinfelder).-V. núm. 18-5836.

19-2271. VERY, F. G.-The Spanish Corpus Christi procession (N. 18-2416). || Hf, 1966, núm. 26, 55.59 (Bergman); BHi, 67 (1965), 214-215 (Flecniakoska) ; H, 47 (1964), 196 (Johnson); $R R, 55$ (1964), 313-314 (Kline); RDTP,
22 (1966), 225.226 (Pérez Vidal) ; $H R$, 35 (1967), 278-281 (Varey); $R P h, 19$ (1965-66), 127-129 (Weber de Kurlat). 19-2272. Eguiagaray, F.-Los intelectua. les de Carlos V.-Maclrid, 1965. 172 pp. || HIS, 19 (1966), 217-219 (Cuenca).

19-2273. SHEPARD, S.--"La teoría del buen gusto entre los humanistas".-RFE, 48 (1965), 407-421.

19-2274. Arrazola Echeverrí, M. A.El Renacimiento en Guipuzcoa.-[Tesis, Univ. de Madrid, 1965; resumen en RUM, 14 (1965), 242-243].

19-2275. Porqueras Mayo, Alberto-El prólogo en el Renacimiento español. C.S.I.C., Madrid, 1965. xii + 244 pp. (RLit, anejo 24). \| $R F, 78$ (1966), 175-177 (Cano Ballesta); $R J, 17$ (1966), 355-357 (Caravaca) ; BHS, 44 (1967), 127-128 (Davies); RLit, 29 (1966) , 240 (Esquer Torres); H, 50 (1967), 183184 (Laurenti); $A L M, 5$ (1965), 236238 (Lope Blanch).

19-2276. RuIz JURADo, M.-"Espiritualidad seglar en nuestra edad de oro".Man, 37 (1965), 77-86.

19-2277. Moreyra, Carlos Alaerto-Esoterismo religioso alel Siglo de Oro español._Córdoba (Argentina), 1965. 72 pp. [Góngora, Gracián, Cervantes y otros].

19-2278. Terracini, Lore - Tradizione illustre e lingua letteraria nella Spagna del Rinascimento_-Tip. P.U.G., Roma, 1964. 170 pp.-V. núm. 18-5837. || $F M$, 1965-66, núms. 21/22, 157.159 (Chiclana Carclona); $R P h, 22$ (1968-69), 247250 (Weber de Kurlat).

19-2279. SCHuster, E. J.-'Schizophrenia and the flight from reality in Golden Age Spanish literature".-KFLQ, 13 (1966), 103-111.

19-2280. Escobar Prieto, Eugenio-hijos ilustres de la villa de Brozas. Pról., notas y sección adicional por Miguel Muñoz de San Pedro. 2a ed.-Ed. Extremadura, Cáceres, 1961. xxviii +218 pp., ilustr.

19-2281. SHEPARD, S.-El Pinciano y las teorias literarins del Siglo de Oro (N. 18-2420) . \| H, 48 (1965), 937 (Bosch); ASNS, 201 (1964), 393-394 (Newels); MLR, 62 (1967), 146-149 (Pring-Mill) ; $H R, 34$ (1966), 373-376 (Trueblood).

19-2282. YUdin, FLORENCE LILLIAN_Gente identity in the Golden Age: the postcervantine "novela corta" and the "comedia".-[Tesis, Univ, de Illinois; re- 
sumen en $D A, 25 \quad(1964-65), 1223$. 1224].

19-2283. KING, WILI.ARn F-Prosa novelistica y academias literarias en el siglo xuii._-Silverio Aguirre Torre, Madrid, 1969. 248 pp. (BRAE, anejo 10) V. núm. 12-29966. || $B H S, 42$ (1965), 127. 128 (Dunn); $H R, 34$ (1966), 174-176 (Hafter) ; BAbr, 39 (1965) , 195 (Silverman) .

19-2284. Carrasco Urcoiti, M. S._-"Notas sobre el vejamen de Academia en la segunda mitad del siglo XvII".-_RHM, 31 (1965), 97-111.

19-2285. Bataillon, Marcel-Daria lección de clásicos españoles. Trad. de José Pérez Riesco-Gredos, Madrid, 1964. 443 pp. (BRH). || CuH, 61 (1965), 620-624 (Amorós); Ins, 1965, núm. 220 (Ares Montes) ; BHi, 69 (1967), 276-277 (Devoto); $R y F, 173$ (1966) , 657 (Hornedo) ; $M L R, 62$ (1967) , 540-541 (Jones); Bro, 85 (1967), 306 (Maurício); $R P h, 20 \quad(1966-67), \quad 142-146$ (Morby); RLit, 28 (1965), 265-268 (Morales) : $R L M a, 1965$, núm. 4, 164166 (Nallim); RAM, 41 (I965), 210211 (Ricard) ; $H, 49$ (1966), 344 (Stamm); BICC, 21 (1966), \$62-377 (Valderrama Andrade); $L R, 20$ (1966), 172-176 (Vermeylen); BHS, 43 (1966), 131-132 (Wilson).

19-2286. LEón PAGANo, JosÉ-Evocaciones. Ensayos.-Academia Argentina de Letras, Buenos Aires, 1964. $\$ 22$ pp. [Cervantes y otros]. || $C I, 1965$, núm. 2, 155-158 (Battistessa).

19-2287. Rodríguez Chicharro, César-Estudios literarios.-Universidad Veracruzana, México, 1969. 167 pp. \| PH, 11 (1967) , 860-862 (Jiménez); RHM, 30 (1964), 317-318 (Jiméncz).

19-2288. HATZFeld, H._Estudios sobre el Barroco._Gredos, Madrid, 1964. 487 pp. (BRH). || RPF, 13 (1964-65), 493498 (Aguiar e Silva); Atl, 3 (1966), 426-427 (Benitez Claros); $R y F, \quad 173$ (1966), 656 (Hornedo); MLR, 61 (1966) , 336-338 (Jones) ; $H, 48$ (1965), 177-178 (Roaten) ; BHS, 42 (1965) , 196198 (Terry) ; RLMo, 1967, núm. 6, 129 . 131 (Torres); CL, 19 (1967), 279. 283 (Wardropper); CdS, 1966, núm. 5. 101-105 (Zamudio).

19-2289. García Morejón, Julro-Coordenadas do barróco.-Faculdade de Filosofia, Ciências c Letras da USP, São Paulo, 1965.

19-2290. Carili.4, E.-"La literatura ba- rroca como contención y alarde". $-A L M$, 5 (1965), 93.105.

19-2291. Carilla, E.-“Lo barroco como aproximación o fusión de las artes". HRO, 93-109.

19-2292. Battistessa, Ángel J.-El poeta en su poema.-Ed. Nova, Buenos Aires, 1965. $\$ 85 \mathrm{pp}$. [Incluye estudios sobre Góngora y sobre la Dorotea]. II $R L M o$, 1965, núm. 4, 161.164 (Nallim) .

19-2293. Rocamora, Penro-De Góngota a Unamuno.-C.S.I.C., Madrid, 1965. $180 \mathrm{pp}$. [Góngora, Lope, Quevedo, Unamuno].

19-2294. Martín Ortegi, alejundro-pe. dro Vergel, alguacil de la Casa y Corte de su Majestad.-Madrid, 1965. $156 \mathrm{pp}$. [Sus relaciones con Lope, Salas, Barbadillo y Villamediana]. || $R$ Lit, 28 (1965), 272-273 (Rozas).

19-2295. Collard-Wery, ANDrée M.-"Cultismo", "conceptismo" and related critical categories.-[Tesis, Harvard Univ., 1965].

19-2296. GONZÁLEZ LóPEZ, EMILIO-Historia de la literatura española. La edad moderna (siglos xviii y xix).--Las Américas, Madrid-New York, 1965.857 pp.V. núm. 18-2394. II Ins, 1967, núms. 248/9 (Cano); RHM, 32 (1966), 120121 (Jiménez) ; CuA, 1966, núm. 4, 246-252 (Ripoll) .

19-2297. Di Pinro, Marro-Studi sulla cultura spagnola nel Settecento.-Edizioni Scientifiche Italiane, Napoli, 1964. 208 pp. (L'Acropoli, 10). || MLJ, 52 (1968), $11 \%$ (Aldridge); QIA, 5 (196667) . $54-55$ (Bertini); BHS, 49 (1966), 64-65 (McClelland); $B H i, 67$ (1965), $394-395$ (Ricard) ; RLit, 26 (1964) , 216 219 (Rull) .

19-2298. MonTIEL, I._-“El duende crítico de Madrid», en el siglo xviri".-AIEM, 1 (1966) , 279-295.

19-2299. Morales Lezcano, V.-"La Ilustración en Canarias". - $A E A t l, 11$ (1965) , 103-127.

19-2300. Gaos, V.-_"Sobre romanticismo español". $-E L, 1965$, núm. 326.

19-2301. Lozano Guirao, P.-“-Vida y obra de Javicr de Burgos".-_RLit, 28 (1965), 39-64.

19-2302. JURETschise, Hans-Los afrancesados en la guerra de Independencia (N. 18-326) . || $H R, 34$ (1966), 176-180 (Sebold); RyF, 169 (1964), 556 (Yturrioz) .

19-2303. Helman, Eorth-Trasmundo de 
Goja.-Revista de Occidente, Madrid, 1963. 264 pp., 88 ilustr. \| CuH, 58 (1964), 452-453 (Bravo-Villasante); Ins, 1964, núm. 209 (Cano); CuA, 1965, nứm. 1, 193-198 (Durán); BHi, 67 (1965), 397-398 (Pariset).

19-2304. Aguilar Piñal, Franicisco-Don Manuel Maria del Mármol y la restauración de la Real Academia Sevillana de Buenas Letras en 1820.-Academia Sevillana, Sevilla, 1965. 48 pp. [Discurso académico; contestación de F. López Estrada]. || RLit, 27 (1965), 239 (Rull) .

19-2305. ZuletA, E. DE_-"El escritor espafol en el último tercio del siglo xix".RLMo, 1965, núm. 4, 103-115.

19-2306. BARJA, CESAR-Libros $y$ autores contempordneos. A reprint.-Las Américas, New York, 1964. vii + $493 \mathrm{pp}$. |l $B A b r, 40$ (1966), 67 (Klibbe); $R L M o$, 1965, núm. 4, 168 (Zuleta).

19-2307. FERRERAS, J. 1.-“La generación del 98. (34 notas para un libro del mismo título)".-LNL, 1965, núm. 2, 54-66.

19-2308. Montero Padilla, J-_Segovia de escritores",_ESeg, 17 (1965), 329346.

19-2309. Quintanilia, M._._'Segovia y la generación del 98".-ESeg, 17 (1965), 125-131.

19-2310. Ferreres, RAFAEL - Los limites del modernismo y del 98.--Taurus, Madrid, 1964, 186 pp. (Persiles, 27) -V. núm. 11-28126. || EL, 1965, núm. 311 (Bonilla) ; Ins, 1965, núm. 227 (Cano) ; $A U C h, \quad 1966$, núm, 137, 196-200

19-2311. Díaz-PlajA, G.-"El modernismo, cuestión disputada".- $-H, 48$ (1965), 407-412.

19-2312. Lozano, C._-"Parodia y sátira en el modernismo"._C $u A$, 1965, núm. 4, 180-200. [Revistas españolas, 1897$1909]$.

19-2313. Balseiro, José A.-Cqatro individualistas de España. (Blasco Ibáñez, Unamino, Valle-Inclón y Baro. ja).-Eliseo Torres, New York, 1964.

19-2314. URMENETA, F. DE__"Sobre estética teatral y novelistica"._-RTEs, 23 (1965), 299-303. [Benavente, Moraleda; Espriu, Sinera; Unamuno, Niebla; Coloma, Boy].

19-2315. Garagorri, Paulino-Del pasado al porvenir. - EDHASA, Barcelona, 1965. (Col. El puente). [Ensayos sobre Unamuno, Giner, Marañón y Ortega]. |) ROcc, 14 (1966), 122-128 (Luzu- riaga) ; Ins, 1965, núms. 228/9 (Mainer) .

19-2316. Navas Ruiz, Ricardo-Pressupostos críticos.-Conselho Estadual de Cultura, São Paulo, 1965. 108 pp. 19-2317. Díaz-Piaja, Guillermo-Ensayos elegidos._Revista de Occidente, Madrid, 1965. 572 pp. $\| H, 49$ (1966), 889-890 (Villegas) .

19-2318. LAzaro Carreter, Fernando, y E. Correa Calderón - Literatura española contemporánea, - Anaya, Salamanca, 1965. $348 \mathrm{pp}$.

19-2319. Torrente Ballester, G.-Panorama de la literatura española contemporánea. 3: ed.Guadarrama, Madrid, 1965.736 pp__-V. núm. 16-47928.

19-2320. NifDERMAYER, Franz_Spanische Literatur des 20. Jahrhunderts: Eine kritische Darstellung. - A. Francke, Bern, 1964. 117 pp. || $R F, 78$ (1966), 505-507 (Domínguez); RHM, 32 (1966), 120 (Roberts); NT, 23 (1965) , 527. 528 (X).

19-2321. Urbanski, E. S._"El revisionismo en la valoración de las letras y cultura contemporánea de España".$H, 48$ (1965), 816-825.

19-2322. GranJEL, L. S.—“'Cincuentenario de una revista: España”.-Ins, 1965, núm. 219.

19-2323. Nuez Caballero, S. DE LA_"Una revista de vanguardia en Canarias, La Rosa de los Vientos (1927-1928)".AEAll, 11 (1965), 193-230.

19-2324. Paz, Octavio_Cuadrivio.-Joaquin Mortiz, México, 1965. 203 pp. [Incluye estudios sobre Pessoa y Cernuda]. || PSA, 41 (1966), 108-110 (Viñuelas); $E_{c o}, 12$ (1966), 585-588 (Charry Lara); $R N C, 1967$, núm. 180, 138 (López Ruiz).

19-2325. VILAR, SERGIO-Manifiesto sobre arte y libertad. Encuesta entre los intelectuales y artistas españoles. — Las Americas, New York, 1963. || Ins, 1964, núm. 210 (Marra-López); $P S A, 40$ (1966), 307-311 (Vilanova).

19-2326. "Generación del 36".-Ins, 1965, núms. 224/5. [Encuesta. Respuestas de M. Fernández Almagro, Delibes, Celaya, Aleixandre, Aranguren, Pemán, Caballero Bonald, Max Aub, Garciasol, Gerardo Diego, G. Dlaz-Plaja, Bousoño, L. de Luis y otros].

19-2327. Gullón, R.- "La generación española de 1963". _ Ins, 1965, núms. $224 / 5$.

19-2328. TORRE, G. DE "La generación 
de $1936 . .$, por segunda vez".-Ins, 1965, núms. 224/5.

19-2329. Villamar, Pablo-la generación literaria del 63 y el generacionis. mo.-Madrid, 1964. 94 pp. (Conferen. cias y ensayos).

19-2330. Corrales EgeA, J.—“¿Crisis de la nueva Iiteratura?".-_nis, 1965, núm. 223.

V. también nưms. 43, 190, 899, 966, 1547-50, 1555, 3678, 3974.

\section{Colecciones de textos}

19-2331. Vilanova, antonio (ed.) - Antologia literaria de autores españoles.Teide, Barcelona, 1961. 798 pp. || BHS, 43 (1966) , 238-239 (Ribbans).

19-2332. RIBes, Francisco (ed.) -Páginas literarias. Antologla de la prosa en lengua castellana._.Santillana, Madrid, 1965. 184 pp., ilustr.

19-2339. BaLlew, HaL L. (ed.) Senderos literarios españoles. - Macmillan, New York, 1965. 304 pp. \| $H, 49$ (1966) , 562-563 (Lott) ; $M L J, 49$ (1965), 509.510 (Moore).

19-2334. Aubrun, Charles V., et Robert LARRIEU_Lo hispánico. (Littératures et civilisations hispaniques). - Delagrave, Paris, 1965. 302 pp., ilustr. \|LNL, 1965, núm. 3, 110-112 (Bourligueux); fns, 1965, núms. 228/9 (Guy).

19-2335. Patt, Beatrice P., \& Martin Nozick (eds.) - Spanish literature: 1700-1900.-Dodd, Mead \& Co., New York, 1965. ix + 469 pp.

19-2336. Aubrun, Charles V. (ed.)-An. thologie espagnole (depuis 1849). Versions pour la licence de lettres modernes. - Institut d'Etudes Hispaniques, Paris, 1965. 132 pp. (Les langues vivantes à l'Université, 9).

19-2337. Andrian, Gustave W. (ed.)Modern Spanish prose and poetry. An introductory reader.-Macmillan, New York, 1964. 216 pp. || $M L J, 50$ (1966), 447-448 (Nemes); $H, 47$ (1964), 886 887 (Schevill) .

19-2338. Alpert, M. (ed.) -Modern Spanish texts. - Harrap, London, 1965. 48 pp.

19-2339. ENTRAmbasaguas, Joaquín DEProsa española moderna y contemporanea. Textos para ejercicios de lectura y comentario gramatical. 8: ed.C. S. I. C., Madrid, 1965. 904 pp.V. núm, 17-1705.

19.2340. Escolar, Hipólito, y José Gar-
cí-MazÁs (eds.) - Primera antologia sonora de autores españoles contemporaneos.-Chilton Books, Philadelphia, 1965. xii + 285 pp. $\| M L J, 52$ (1968), 166-167 (Allen).

19-2341. Gullón, Ricardo, y Grorge SCHADE Literatura española contemporánea. - Scribner's, New York, 1965. xxxii + 702 pp. Ins, 1966, núm. 230 (Cano) ; $M L J, 52$ (1968), 237-238 (Carter) ; $H, 49$ (1966), 360-361 (Fabian); $B H S, 43$ (1966), 238-239 (Ribbans).

19-2342. DurAN, Manuel, \& Federico ALvAREZ (eds.) -Voces españolas de hoy.Harcourt, Brace \& World, New York, 1965. 320 pp. || H, 49 (1966), 191-192 (Seay).

19-2343. BAÑEZ, JEsús (ed.) -El humorismo vasco a través de la historia (siglo xvi hasta nuestros dias). Trozos escogidos de 25 distintos autores $y$ una breve nota bibliográfica de cada uno de ellos.-Gómez, Pamplona, 1965. 325 pp. (Col. Ipar).

V. también núms, 900, 966.

\section{Temas literarios}

19-2344. Rubio, F.-“Un texto castellano occidental de la leyenda de Alejandro Magno"._CD, 178 (1965), 311-336.

19-2345. P'́rez, J.-"La mort du chevalier d'Olmedo. La légende et l'histoire".-HJS, 2, 243-251.

19-2346. Castro, Américo_Le drame de l'honneur dans la vie et dans la littérature espagnoles du xvie siècle. Trad. de Yvette Billod, avant-propos de $\mathrm{M}$. Bataillon.-C. Klincksieck, Paris, 1965. 159 pp. (Témoins de l'Espagne). LMo, 59 (1965). 858-860 (Larrieu).

19-2347. JONES, C. A.—“'Spanish honour as historical phenomenon, convention and artistic motive".-HR, 33 (1965), 32-39. [Resumen en LHC, 313-314].

19-2348. OOSTENDORP, H. T.-El conflicto entre el honor y el amor en la literatura española hasta el siglo xvii (N. 18-2498). || BHi, 67 (1965), 392-393 (Heugas) .

19-2349. BOREL, JEAN-PAUL - Quelques aspects du songe dans la litterature espagnole.-Les Éditions de la Baconnière, Boudry-Neucliatel (Suisse), 1965. 75 pp. || KN, 14 (1967), 320-321 (Piekarec) ; $B H i, 69$ (1967), 302 (Ricard). 19-2350. Singer, Armand $\mathrm{E}$-The Don Juan theme, version and ariticism: 
A bibliography. Rev. ed.-West Virginia University, Morgantown, 1965. 370 pp._V. núm. 10-20766. || BHi, 69 (1967), 545-546 (Nougué); $H, 50$ (1967). 602-603 (Eschweitzer); HR, 36 (1968), 167-169 (Weinstein).

19-2351. Espina, A.-“Don Juan no era una cocotte"-[En su libro] El genio cómico y otros ensayos (Madrid, 1965).

19-2352. Cortés AHumadA, E.-"El donjuanismo como conocimiento". $-B C B$, 8 (1965), 1008.1014.

19-2353. BAUEr, A. F.-_Teología y religión en Don Juan". - Stylo, 1965, ním. 1, 91-97.

19-2354. Grunwald, H. A.-“The disappearance of Don Juan". [En:] The light of the past (New York, 1965), 232-241._V. núm. 17-5229.

19-2355. LE GaLL, A. - "Psychanalyse caractérologique de Don Juan". - $L a$ Caractérologie, Paris, 6 (1964), 85-94.

19-2356. LOREN, S.-_Don Juan, la salvación y el valor. A cuenta de un desconocido Tenorio del xvi1".-EL, 1965, núm. 314.

19-2357. MANDEL, O.-The theatre of Don Juan (N. 18-5919) . || Prairie Schooner, 39 (1965), 176-185 (Cutler et al.); Seg, 2 (1966), 387-388 (Ruiz Fornells).

19-2358. WEINSTEIN, L.-The metamorphoses of Don Juan (N. 16-44114). II $M L N, 80$ (1965), 390-395 (Kamber). -V. núm. 17-5225.

19-2359. VARAs, F. P._Apunte sobre la fortuna de Don Juan en Alemania". $F M, 4$ (1965), 223-245.

19-2360. Perzold, L.- - Don Juan in der volkstumlichen Uberlieferung". - Lao. graphia, 22 (1965), 354-363.

19-2361. Alfaro, M.- "Tres heroínas nefastas de la literatura espafiola".CuA , 1965, 3, 246-254. [Doña Perfecta, la tía Tula, Bernarda Alba].

19-2362. Sáez Piñuela, María José (ed.) - La moda femenina en la literatura [española].—Taurus, Madrid, 1965. 210 pp., ilustr.-V. núm. 17-149.

19-2363. GRANELL, E. F.- "La mujer voladora".-RHM, 31 (1965), 192-206.

19-2364. Maravall, J. A.-"La cortesía como saber en la Edad Media".-CuH, 62 (1965), 528-538.

19-2365. SEDWICK, FRANK-A history of the "useless precaution" plot in Spanish and French literature.—Univ. of North Carolina Press, Chapel Hill, 1965. || $S A B, 1967$, núm. 21, 17-18 (Allen); BHS, 44 (1967), 145 (Heath- cote); $R R, 58$ (1967), 96 (Pollin); $H, 49$ (1966), 348 (Singer).

19-2366. MILANI, V. I.-"The origins of the Spanish braggart in Strozzi's Commedia erudita".-It, 42 (1965) , 224-230.

19-2367. GREEN, O. H.- "La dignidad real en la literatura del Siglo de Oro: notículas de un estudioso".-RFE, 48 (1965) , 231-250.

19-2368. PÉREZ, AQuILNo-El uso del co. lor y la iluminación en las obras de algunos autores del nıodernismo y de la generación del 98.-[Tesis, Univ. de Madrid, 1965; resumen en $R U M$, 14 (1965), 220-221].

19-2369. Fernández Murga, F.-"Pompeya en la literatura española".-AION-R, 7 (1965), 5-52 || PEsp, 1965, núm. 152 (Umbral) .

19-2370. JASON, H. M.--"The Negro in Spanish literature to the end of the Siglo de Oro"-Atenea (Mayagüez), 1965, núms. 3/4, 13-21; CLAJ, 9 (1965), 121-131.

19-2371. Navarro, T.-“El sentimiento literario de la voz".- $R H M, 31$ (1965), 345-356.

V. también núms. 1659-60, 1668-87, 23813, 2398, 2448, 2459, 2922, 3059, 3621-2.

\section{POESIA}

19-2372. RODRfGUez-MOÑ1No, ANTONIO, y María Brey Mariño (eds.) —Catd́logo de los manuscritos poéticos castellanos (siglos xv, xvi $y$ xvii) existentes en la biblioteca de The Hispanic Society of America. - The Hispanic Society of America, New York, 1965-66. 3 ts. 632, 608, 620 pp., ilustr. || Amer, 23 (196667) , 443-445 (Chávez); PBSA, 61 (1967), 281-284 (Stone) ; BHS, 44 (1967), 288 291 (Whinnom).

19-2373. Simón Díaz, J-Impresos del xvi: Poesia (N. 18-5935). \|BHS, 42 (1965), 279 (Wilson).

19-2374. Aguilar Piñal, Francisco-Impresos del siglo xui: Poesia. (Adiciones). C.S.I.C., Madrid, 1965. I6 pp. (Cuadernos bibliográficos, 12a). - V. núm. 18-5935.

19-2375. SIMÓN DIAZ, J.-."Primer índice de publicaciones poéticas del siglo xvil".-RLit, 27 (1965), 143-196.

19-2376. Díez Echarri, Emiliano-La poesía española vista por Menéndez Pela. yo. 2a ed.-Edit. Nacional, Madrid, 1965. 318 pp.-V. núm. 11-26480. 
19-2377. Zardoya, C.-“Angel del Rlo y la poesía española"...RHM, 31 (1965), 439-450.

19-2378. Argumosa, Miguel ÁNGel DEBreve historia de la poesía española... Autor, Madrid, 1965. 172 pp.

19-2979. Francisco Iglesias, Jull deHistoria de la poesia lírica eucarlstica española y sus temas, desde el siglo xiii al xix.-Instituto Nacional de Ensefianza Media, Toledo, 1965. $45 \mathrm{pp}$.

19-2380. Michalski, ANDRé S.-Description in medieval Spanish poetry.-[Tesis, Princeton Univ; resumen en $D A, 25$ (1964-65), 5933].

19-2381. Orozco DíAz, E.-“Sobre el sen. timiento de la naturaleza en la poesla cspañola medieval".-RIEs, 23 (1965) , 3-34.

19-2382. Aguirre, J. M.-“Ensayo pata un estudio del tema amoroso en la primitiva lifica castellana"._UnivZ, 42 (1965), núms. $1 / 2$.

19-2383. LuCAS, JoAQufN B. DE-El tema mariano en la poesia castellana de la Edad Media.-[Tesis, Univ. de Madrid, 1964; resumen en RUM, 14 (1965), 197-198].

19-2384. GybBon-Monypenny, G. B. "The Spanish mester de clerecia and its intented public: Concerning the validity as evidence of passages of direct address to the audience".-Medieval miscellany presented to Eugène Vinaver (Manchester, 1965), 230-244.

19-2385. Frore, S._"La tenson en Espagne et en Babylonie: évolution ou polygé. nèse?"-CLC(4), 982.992.

19-2386. Unieto Arteta, A._-“"¿Versos del siglo xv?'"-Arg, 11 (1960), 293-234.

19-2387. ARGumosa, Miguel Ángel DEHistoria de la poesia montañesa.-Ma. drid, 1964. 87 pp. || RLit, 27 (1965), 221 (Diez Taboada); $E L, 1965$, núm. 315 (Larrea); PEsp, 1965, núm. 146 (Umbral) .

19-2388. Rodrfguez MoÑno, ANtonio-Construcción critica y realidad en la poesia española de los siglos xvi y xuii. Pról. de Marcel Bataillon.-Castalia, Madrid, 1965. 57 pp.-V. núm. 18-5944. Ins, 1966, núm. 232 (Cano); REE, 22 (I966), 172-I74 (F. C.) ; HR, 36 (1968), I60-I62 (Wilson) .

19-2389. Bu.EcUA, J. M.-“Imprenta y poesia en la Edad de Oro".-Fiesta del Libro de 1964 (Barcelona, 1965), pp. 55-67.

19-2390. Alonso, AMADO_Materia y for.

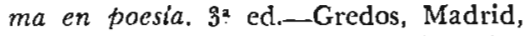
1965. 402 pp. (BRH).-V. núm. 1644132.

19-2391. Alonso, DAMASO_Saggio di metodi $e$ limiti stilistici. A cura di Giorgio Cerboni Baiardi._Il Mulino, Bologna, 1965. $\mathrm{xx}+393 \mathrm{pp}$.

19-2392. Alonso, D. - Sponische Dichtung (N. 17.5324). \|WeW, 21 (1966), 240 (Konrad); ZRPh, 82 (1966), 250. 253 (Landsberg).

19-2393. Alonso, D.-"Petrarquismo hecho geometria. (La metaforia de los 'daños de Amor', la correlación poética y Do. menico Veniero)".-FFF, 1-22.

19-2394. Entrambasaguas, J. DE_"El Rea" Sitio de Aranjuez en cuatro poetas de la Edad de Oro".-Reales Sitios, 1965, núm. 4, 37-47.

19-2395. Benito RuANo, E.-"Jomada y sátira sevillanas de la marquesa de Denia (1599)" $-A O, 15$ (1965), 142 156.

19-2396. Mentendez PIDal, R.-"La poesía como ciencia, en el barroco. (Apuntes varios)"-RCCM, 7 (1965), 1-5.

19-2397. Nerlich, Michael - Untersuchurgen zur Theorie des klassizistischen Epos in Spanien (1700-1850).-Droz, Ge. neve; Minard, Paris, 1964. $299 \mathrm{pp}$. (Kölner Romanistische Arbeiten, 27) -V. núm. 18-5961. || $R F, 78$ (1966), 501 504 (Almazán); HR, 95 (1967), 284 288 (Bihler); $A S N S, 203$ (1966), 159160 (Briesemeister); LR, 21 (1967), $181-183$ (Groult) ; $D L Z, 88$ (1967), 510 511 (Krauss); Era, 18 (1966), 669671 (Myers); $R L C, 40$ (I966) , 151-156 (Pageard); MLQ, 27 (1966), 356-358 (Sobejano) .

19-2398. Tudisco, A._."América en la poesía española del siglo xvirl".- $R H M$, 31 (1965), 431-438.

19-2399. Diego, G_- "La poesla de Andrés Bello".-BRAE, 4.5 (I965), 291 313 [En relación con la de Jovellanos, Arriaza y Cienfuegos].

19-2400. Cernuda, Luis_Paesia y literatura. T. 2,-Seix Barral, Barcelona, 1964. 274 pp. (Biblioteca breve, 205).V. núm. 16-4.8016. $\|$ Eco, 13 (1966), 555.557 (Charry Lara); $H, 49$ (1966), 538 (Gariano) ; fns, 1965, núms. 228/9 (Mainer); CuH, 63 (1965), 409-413 (Murciano) ; BAbr, 40 (1966), 191 (Sarmiento); $B H S, 43$ (1966), 59.60 (Terry) .

19-2401. Molina Campos, E.-"Cernuda, crítico literario"._fns, 1964, núm. 208. 
19-2402. Pachieco, J, E. "Cernuda ante la poesía española. (Intento de aclaración".-RML, 1964, núms. 1/2, 71-78.

19-2403. Young, Howard $T$. The victorious expression. A study of four contemporary Spanish poets, - Univ, of Wisconsin Press, Madison, 1964. xii + 223 pp. [Unamuno, Machado, J. R. Jiménez, G. Lorca]. || $B A b r, 39$ (1965), 349 (Angeles) ; $M L J, 50$ (1966), 455 (Gicovate) ; Asom, 1965, núm. 4, 76-80 (González); Ins, 1964, núm. 215 (Gu$116 \mathrm{n}) ; H, 49$ (1966), 890 (Johnson); $H R, 35$ (1967) ; 193-195 (Morón Arroyo); $B H S, 43$ (1966), 292-293 (Ribbans).

19-2404. DíEz CANEdo, ENRIQUE__Estudios de poesía española contemporánea.Joaquín Mortiz, México, 1965. $235 \mathrm{pp}$. || $U M x, 20$ (1965-66), núm. 6 (Ríns); $R L M o, 1967$, núm. 6, 126-127 (Zuleta).

19-2405. SiebenManN, Gustav-Die mo. derne Lyrik in Spanien. Ein Beitrag zu ihrer Stilgeschichte.-Kohlhammer, Stuttgart, 1965. 318 pp. (Sprache und Literatur, 22). $\| H f, 1967$, núm. 29, 65 (Bosch); Era, 18 (1966), 95-100 (Owen); ASNS, 203 (1966), 317-320 (Sobejano); Ins, 1967, núm. 251 (Valverde).

19-2406. FERNANDEZ VILLAVERDE, A.-"Sobre poesía y surrealismo".-EL, 1965, núm. 310.

19-2407. CaMP, J-_La generación poética de 1925 en España".-BACol, 15 (1965) , 89.105.

19-2408. Caballero Bonald, J. M._"Apostillas a la generación poética del $36^{\prime \prime}$ Ins, 1965, núms. 224/5.

19-2409. Jiménez, José Olivio_Cinco poetas del tiempo: Vicente Aleixandre, Luis Cernuda, José Hierro, Carlos Bousoño, Francisco Brines.-Insula, Ma. drid, 1964. 458 pp. || Ins, 1965, núm. 223 (Cano); RHM, 32 (1966); 96-98 (Florit) ; EL, 1966, núm. 338 (Iglesias Laguna); $P E s p, 1965$, núm. 156 (Murciano); $H, 49$ (1966), 890-891 (Ullman).

19-2410. López ANGLAdA, Luis-Panorama poético español (1939-1964). Historia y antología. - Edit. Nacional, Madrid, 1965. 681 pp. || H, 50 (1967), 185-186 (Gicovate); $E L, 1965$, nứm. 329 (Jiménez Martos); Eidos, 1965, núm. 23, 137-138 (Martínez); PEsp, 1965, núm. 153 (Umbral).

19-2411. BALBín LucAs, RAFAEL DE-Poesia castellana contemporánea. - Rialp, Madrid, 1965. 57 pp. (Col, O crece o muere). ||$N T, 23$ (1965), 203-205 (F. A.) ; PEsp, 1965, núm. 147 (Murciano); RLit, 27 (1965), 263.264 (Rozas).

19-2412. Alonso, Dimaso-Poetas españoles contemporáneos. 3a ed., aum.Gredos, Madrid, 1965, 424 pp. (BRH). V. núm. 13-37249.

19-2413. Jiménez, J. O.- "El tiempo en la poesía española actual",_ins, 1965, núm. 218.

19-2414. Dominco, J.- "El estudio del tiempo en la poesía española contem. poránea".-PSA, 38 (1965), 191-202.

19-2415. Delcado, F._"Poesía social española (1936-1964)".-Hum, 17 (1965) $77-93$.

19-2416. Luis, L. DE_-"La poesía social española".- $C U, 1965$, núm. 88, 28-36.

19-2417. SicARD, A.-"Pósie el protestation".-La Nouvelle Critique, 1965, núm. $165,49-83$.

19-2418. VELA, RUBÉN-Ocho poetas españoles.-Buenos Aires, 1965. 129 pp.

19-2419. MAYER, R. N.-_La poésie en Espagne"._La Tour du Feu, mars 1965.

19-2420. MarRA-López, J. R.-“Una nueva generación poética". — Ins, 1965, núm. 221.

19-2421. MARRA-LópfZ, J. R_-"Jóvenes poetas españoles en Méjico. (Una promoción desconocida)".-ins, 1965, núm. 222.

19-2422. Paniagua, D. (ed.) - Medio siglo de revistas poéticas en España". PEsp, 1964, nums. 140/1; 56 pp. [25 colaboraciones]. || RLit, 25 (1964), 246. 247 (Rozas).

19-2423. Agulló y Cobo, Mercedes La poesia española en 1962 _C.S.I.C., Ma. drid, 1965. 88 pp. (Cuadernos biblio. gráficos, 17) .... V. núm. 18-5977.

$V$. también núms. 1606-7, 1615.9, 1626, $1679.80,2881,3035,3079,3131$.

\section{Métrica}

19-2424. BAEHR, R.-Spanische Verslehre auf historischer Grundlage (N, 182581). II ZRPh, 80 (1964), $187-190$ (Huber); Era, 17 (1965), 147-148 (Myers); GRM, 13 (1963), 338-340 (Sobejano). 19-2425. Alonso, Martín_Métrica y teo. ria literaria.-Cia. Bibliográfica, Ma. drid, 1965. 272 pp.-V. núm. 16-44153. 19-2426. Maldonado DE Guevara, F."Knittelvers 'verso nudoso' ".-_RFE, 48 (1965) , 39-59. [Origen germánico de la métrica castellana]. 
19-2427. Clarke, DoRothy C.-Morphology of fifteenth century Castilian verse.-Duquesne University Press, Pittsburgh, 1964. 233 pp. || LiS, 2 (1967), 118-120 (Cremante); BHS, 42 (1965), 188-189 (Cummins); $R P h, 19$ (196566) , 125-127 (Green) ; $M P h, 63$ (196566) , 376-380 (Kraemer); $H, 47$ (1964), 865 (Marin) ; RFE, 48 (1965), 191-193 (Marfn Molina) ; $S p, 39$ (1964), 508510 (Place); $M L R, 61$ (1966) , 335-336 (Reckert) ; $M L J, 49$ (1965), 189 (Sturcken) ; BAbr, 38 (1964), 467 (Wade) .

19-2428. Tavani, G-Considerazioni sulle origini dell'carte mayors"-CuN, 25 (1965), 15-33.

19-2429. ARCE, J--"The Dantesque tercet in Spanish poetry". - $B A b r, 39$ (1965), 121-127.

19-2430. SDun, W.-_'Sprechtakte und Akzentuierung in Vers und Prosa".- $S p F$, 22 (1965), 258-282.

19-2431. Cascales, Francisco - Florilegio de la versificación. Trad. del latín por A. Sobejano.-Academia Alfonso $\mathbf{X}$ el Sabio, Murcia, 1964. 31 pp. \| RLit, 27 (1965), 235 (Juliá Martínez).

19-2432. Mata Gavidia, J. - "Descubrimientos filológicos".-Cults, 1965, núm. extraordinario, 30-53. [Sobre la obra de Francisco Gavidia; en particular, sus teorfas métricas].

19.2433. Alfaro Arriaga, AlejandroRubén Darlo, precursor de la prosodia castellana autónoma. - Tegucigalpa, 1964. 31 pp.

19-2434. Celaya, G_- "La poesía oral"ROcc, 8 (1965), 208-215.

V. también núms. 1608-14, 2230, 2548, 2596, 3884.

\section{Cancioneros y antologías}

19-2435. Cummins, J. G.- "The survival in the Spanish Cancioneros of the form and themes of Provençal and OId French poetic debates". - BHS, 4.2 (1965), 9-17.

19-2436. Cancionero musical de Palacio (siglos $x v-x v i)$. T. 3-A: Introducción $y$ estudio de los textos. T. 3-B: Ed. critica de los textos. Por José Romeu Figueras.-Instituto Español de Musicologia, Barcelona, 1965. xvii $+610 \mathrm{pp}$. (La música en la Corte de los Reyes Católicos, 4).

19-2437. Bertini, Giovanni Maria (ed.) Poeti spagnoli tradizionalisti del secolo xvi. (Castillejo, Silvestre, D. Hurtado de Mendoza, s. de Horozco)._Quaderni Ibero-Americani, Torino, 1965.

19-2438. Ruano, E. B.-"EI Ms. 64 de la biblioteca de la Universidad de Ovie. do".-BIEA, I965, núm. 54, 47-56.

19-2439. Rodríguez MoÑino, A.- "La Flor" de enamorados, cancionaro bilingüe. Ensayo bibliogtáfico (1562-1954)". -ER, 11 (1962) , 33-47.

19-2440. Rozas, Juan Manuel (ed.) Academia que se celebró en la ciudad de Ciudad Real en 1678.-Inst. de Estudios Manchegos, Ciudad Real, 1965. 70 pp. $\|$ RLit, 27 (1965), 235-236 (Torres Martínez) .

19-2441. Alonso, Dkmaso, y Joste Manuel Blecua-Antologia de la poesta espanola. T. 1: Lirica de tipo tradicional. 2a ed.-Gredos, Madrid, 1964. Ixxxvi + 266 pp. (Antologla hispánica).-V. núm. 12-33281. || ALitt, 8 (1966), 507-508 (Horányi); Bro, 82 (1965), 282-283 (Maia).

19-24.42. Montes de OCA, FranciscoOcho siglos de poesia en lengua española. 2a ed.-Porrúa, México, 1965. 554 pp. (Sepan cuantos, 8).-V. núm. $16-4.8037$.

19-2443. Florit, Eugenio (ed.) - Cien de las mejores poesias españolas. - Las Américas, New York, 1965. \| $H, 50$ (1967), 390-391 (Adrian).

19-2444. TERRY, ARTHUR-An anthology of Spanish poetry 1500-1700. Part. 1: 1500-1580. - Pergamon Press, Oxford, 1965. xxxii +175 pp. $\| R P h, 21$ (1967-68), 608-609 (Giles); BHS, 43 (1966), 287-288 (Jones); $M L N, 82$ (1967) , 269-270 (Rivers); MLR, 64 (1969), I97-198 (Truman) .

19-2445. Florr, EUGENIo (ed.) -Invitation to Spanish poetry._Dover Publ., New York, 1965. 143 pp. \| $H, 49$ (1966) , 558-559 (Jiménez); RyF, 174 (1966), 130 (Nz. Gz.) ; $M L J, 50$ (1966), 171-172 (Resnick).

19-2446. Agostini DE DEL Río, Amelia (ed.) -Poesia hispanica: unos momentos liricos.-Holt, Rinehart \& Winston, New York, 1965. xxii $+230+x x x i v$ pp. \| MLJ, 52 (1968), 128-129 (Nemes); H, 49 (1966), 366-367 (Ruiz-Fornells). 19-2447. Ribis, Francisco-Poesia de España y América. Sel. y pról. de... 2a ed.-Santillana, Madrid, 1965. 88 pp., ilustr-V. núm. 18.6004.

19-2448. Altazor-la caza en la poesía. (Antologia).-Clan, Madrid, 1965. 51 pp. (El mirlo blanco). 
19-2449. Winczakiewicz, Jan - Sonety hiszpanshie.-Oficyna Poetow i Malarzy, London, 1965. $34 \mathrm{pp}$.

19-2450. Esquer Torres, R._Dos álbumes inéditos del romanticismo". $-R L i t$, 28 (1965), 163-227.

19-2451. Cannon, Calvin (ed.) -Modern Spanish poems: Jiménez, Machado, Lorca, Otero. - Macmillan, New York, 1965. 114 pp. $\| M L J, 49$ (1965), 511 (Allen) ; H, 48 (1965), $961-962$ (Young). 19-2452. Patjerson, Helen Wohl (ed.) Antología bilingüe (español-inglés) de la poesia española moderna._Cultura Hispánica, Madrid, 1965. 365 pp. I $B A b r, 40$ (1966), 503 (Debicki); $\mathrm{CuH}$, 64 (1965), 630-633 (Echanove Guzmán) ; PEsp, 1965, núm. 151 (Umbral).

19-2453. FERNANDEZ RETAMAR, ROBERTo (ed.) -Antología de poetas españoles del siglo $x x .-$ La Habana, 1965. 291 pp.

19-2454. Romano Colangeli, Maria (ed.) -Voci femminili della lirica spagnola del '900. — Pàtron, Bologna, 1964. 1211 pp. || Ins, 1966, núm. 233 (Ifach); $\mathrm{CuH}, 67$ (1966), 831-834 (Manrique de Lara); $N A, 495$ (1965), 129-131 (Marzi); EL, 1966, núm. 334 (Murciano); RLit, 28 (1965), 296-297 (Palomo) ; PEsp, 1966, núm. 159 (Umbral) .

19-2455. GaOs, Vicente - Antologia del grupo poético de 1927.-Anaya, Salamanca-Madrid, 1965. 161 pp. (Bibl. Anaya).

19-2456. Mantero, Manuel (ed.) -Poesia española contempordnea, 1939-1965. _Plaza y Janés, Barcelona, 1965. 622 pp. (Selecciones de poesia española). II İns, 1966, núm. 238 (Miró); Hum, 19 (1967), 104-105 (del Río).

19-2457. Beneyto, María (ed.) -Poesía 1947-1964. - Plaza-Janés, Barcelona, 1965. 220 pp. (Selecciones Poesia española).

19-2458. Antologia de la actual poesia onubense.-Huelva, 1965. 80 pp. (Col. Litoral). || RLit, 28 (1965), 303-304 (Marcos Marín).

19-2459. Cano, José Luis (ed.) -El tema de España en la poesia española contemporánea. Antologia.-Rev. de Occidente, Madrid, 1964. 304 pp.-V. núm. 17-1743. || Res, 3 (1966), 128-130 (Delgado); $B A b r$, 39 (1965), 442 (Durán); CuH, 68 (1966) , 748-752 (Gómez Marín); CCL, 1964, núm. 90, 87-89 (Iglesias); PSA, 35 (1964), 191-200 (de Luis); Ins, 1964, núm. 214 (Marra-López) ; CuH,
61 (1965), 380-382 (Quiñones); Sur, 1965, núm. 296, 87-90 (Scuderi); Diál, 1965, núm. 2 (Xirau).

19.2460. Luis, LeOPOLdo dE (ed.) - La poesia española conlemporánea. Anlologia (1939-1964). Poesia social._Alfaguara, Madrid, 1965. 434 pp. || Asom, 1965, núrn. 3, 60-61 (Cano); Ins, 1965, núm. 226 (Cano); RHM, 32 (1966), 105-106 (Jiménez); RLit, 27 (1965), 254-255 (Mantero); CuH, 68 (1966), 245-249 (Miranda Luque); PEsp, 1965, núm. 155 (Umbral).

19-2461. Jiménez MARtos, L. (ed.) - $A n^{-}$ tologia de la poesia española, 1963-64. Aguilar, Madrid, 1965. 319 pp. (Col. lileraria).-V. núm. 18-2618. || $R I B$, 17 (1967), 83-84 (Carpio); PEsp, 1965, núm. 156 (Murciano).

19-2462. Cuatro poetas de hoy: José Luis Hidalgo, Gabriel Celaya, Blas de Otero, José Hierro. Sel. y notas por Mar̉ía de Gracia Ifach.-Taurus, Madrid, 1965. 251 pp. (Ser y tiempo).V. núm. 16-48022.

Autores antiguos

19-2463. Rodrigues IAPA, M._"As jarchas e as orixes da lírica galego-portuguesa"._-Grial, 1965, 92-95.

19-2464. Pascual Buxó, J.-_Las jarchyas. Primitiva lírica hispana".-Rev. de la Univ. del Zulia, 1965, nún. 30, 111. 120.

19-2465. Gricoriev, V. P.-["Notas sobre la antigua lírica de la Península ibérica" (jarchyas) ]. - Vestnik Leningr. Univ., Ist. Jazyka Lit., 20 (1965), 8696. [En ruso; resumen en inglés].

19-2466. García Gómez, Emilio - Las jarchas romances de la serie arabe en su marco. Ed. en caracteres latinos, versión española en calco rítmico y estudio de 43 moaxajas andaluzas.Estudios y Publicaciones, Madrid, 1965. 431 pp. || $H R, 36$ (1968), 154-156 (Solá-Solé) ; CuN, 26 (1966), 305-307 (Tavani) .

19-2467. Stern, Samuel M._Les chansons mozarabes. Les vers finaux ("khar. jas") en espagnol dans les "muu'ashshahs" arabes et hébreux.-Bruno Cassirer, Oxford, 1964. xxviii + 65 pp.V. nim. 9-15262. || ZRPh, 80 (1964), 643 (Baldinger); BHS, 42 (1965), 214 (Dutton); RLit, 27 (1965), 224 (Esquer Torres); $H, 49$ (1966), 344-345 (Irving); $H R, 35$ (1967), 201 (Solá-Solé). 
19-2468. Dutron, B.-_'Some new evidence for the Romance origins of the $m u$ washshahas".-BHS, 42 (1965), 73-81.

19-24.69. RICARD, R.- "Notes sur Berceo". $-L N L, 1965$, nưm. 1, 1-15.

19-2470. Gericke de Etchegorry, A. S. "Notas para Gonzalo de Berceo". Presencia, Paraná, 1963, núm. 1, 25-38. 19-2471. BAICHE, M.-_Retrouver Berceo".-LNL, 1965, núm. 4, 26-29.

19-2472. ARTILEs, JoAquín_Los recursos literarios de Berceo._Gredos, Madrid, 1964. 269 pp. (BRH). $B A b r, 40$ (1966) , 67 (Browne); Ins, 1965, núm. 221 (Cardenal) ; CuH, 65 (1966), 372. 374 (Chamorro) ; BHS, 42 (1965), I84. 186 (Dutton); $H, 49$ (1966), 345-346 (Gicovate) ; Ber, 19 (1964) , 477 (Lope Toledo); ZRPh, 83 (1967), 617.619 (López Molina); $A O, 14$ (1964), 259. 262 (Neira).

19-2473. Dutron, B.- "Gonzalo de Berceo y los cantares de gesta".- $\mathrm{Ber}, 20$ (1965) , 407-415.-V. núm. 17-1780.

19-2474. Berceo, Gonzalo DE-Milagtos de Nuestra Señora, Vida de Sto. Do. mingo de Silos, Vida de San Millán de la Cogolla, Vida de Santa Oria, Martirio de San Lorenzo.-Porrúa, México, 1965. 485 pp. (Sepan cuantos, 35). \|A Abs, 30 (1966), 118-119 (Peñalosa).

19-2475. Berceo, Gonzalo de-Milagros de Nuestra Señora. Texto integro en versión de D. Devoto. 2a ed., corr.Castalia, Valencia, 1965. 226 pp. (Odres nuevos)._V. núm. 14-38969.

19-2476. Berceo, Gonzalo DE-Milagros de Nuestra Señora.-Ed. e presenta. zione di Cesco Vian.-La Goliardica, Milano, 1965. xxix $+92 \mathrm{pp}$.

19-2477. Gariano, C.- "Aspectos estructurales de los Milagros de Berceo".Ber, 1965, núm. 75, 321-346.

19-2478. Gariano, Carmelo-Análisis estilístico de los "Milagros de Nuestra Señora", de Berceo._Gredos, Madrid, 1965. 234 pp. (BRH).-V. núm. 186021. || $B H S, 43$ (1966), 284-285 (Dutton); ZRPh, 84 (1968), 231-234 (Lopez Molina); $M L Q, 28$ (1967) , 102-103 (Montgomery) ; ibid., 512-513 (réplica de Gariano) ; $H R, 36$ (1968), 142-151 (Morreale) ; PEsp, 1966, num. 160 (Murciano); $M L J, 52$ (1968), 52 (Perry); $H, 50$ (1967), 385-386 (Scholberg).

V. también núms. 1651, 2384.

Apolonio: v. núms. 2384, 2482.

19-24.79. WARE, N. J.C"The date of composition of the Libro de Alexandre: a re-examination of stanza 1799".BHS, 42 (1965), 252-255.

19-2480. Nelson, Dana ARthuR-Toward a definitive edition of " $E l$ libro de Alexandre". - [Tesis, Stanford Univ.; resumen en $D A, 25$ (1964-65), 5934$5995]$.

19-2481. Michael, I._-"The description of hell in the Spanish Libro de Alexandre".-Medieval miscellany presented to Eugène Vinaver (Manchester, 1965) , 220-229.

19-2482. DeYermond, A. D._.'Mester es sen peccado"._RF, 77 (1965), 111-116. [EI Alexandre y el Apolonio].

V. también núms. 1670, 2384.

19-2483. AlFonso, J-“Juan Ruiz, carne de choto".-EL, 1965. núm. 339.

19-2484. Mignani, R._-Bibliografia compendiaria sul Libro de buen amor". $C u N, 25$ (1965), 62-90.

19-2485. Ruiz, JuAN, ARcipreste de Hita -Libro de buen amor. Ed. critica por M. Criado de Val y E. W. Naylor.C.S.I.C., Madrid, 1965. xxxi +656 pp. (Cldsicos hispánicos, serie 2, 9) . || Bro, 83 (1966), 700 (Maurício).

19-2486. RuIz, JuAN-Libro de buen amor. Trad. y pról. de A. Espina.-Edit. E. M., Madrid, 1965, 159 pp. (Col. Edime). 19-2487. Ruiz, JunN, Arcipreste de HitaLibro de buen amor. Texto integro en versión de Maŕa Brey Mariño. 5: ed. rev.-Castalia, Madrid, 1966. 275 pp. (Odres nuevos).-V. múm. 18-6032.

19.2488. ZAhAREAS, ANTHONY N. - The art of Iuan Ruiz, Archpriest of Hita.Estudios de Literatura Espafiola, Madrid, 1965. xii +227 pp.-V. núm. 18-2696. || $R F, 78$ (I966), 607-610 (Gilman); $H R, 35$ (I967), 99-106 (Willis).

19-2489. MÁrquez Vilianueva, F.-"EI buen amor'.-ROcc, 9 (1965), 269-291.

19-2490. Zairareas, A. N.-"The stars: worldly love and free will in the Libro de buen amor".-BHS, 42 (I965), 82.93.

19.2491. Zahareas, A.-"Parody of the canonical hours: Juan Ruiz's art of satire".-MPh, 62 (1964-65), 105-109.

19-2492. WALkER, R. M.-“A note on the female portraits in the Libro de buen amor".-RF, 77 (1965), 117-120.

19-2493. Pincus, M. S._.Doría Endrina revisited".- $R$ No, 7 (1965), 71-72.

19-2494. Martín REcuerda, José- ¿Quién quiere una copla del Arcipreste de Hita? Sucedidos imaginarios en dos partes, sobre Juan Ruiz, Arcipreste de Hita, inspirados en el "Libro de buen 
amor".-Alfil, Madrid, 1965. 78 pp. (Obras del teatro español). \| RLit, 28 (1965), 294-295 (Marcos Marín).

V. también núms. 1190, 2270.

19-2495. Klausner, J. H.-"The historical and social milieu of Santob's Prover. bios morales". $-H, 48$ (1965), 783-789.

19-2496. Gimeno Casalduero, J.--"Pero López de Ayala y el cambio poético de Castilla a comienzos del $\mathrm{xv} ",-H R$, 33 (1965), 1-14.

19-2497. Morreale, M.-“Para una antologla de la literatura castellana medieval: la Danza de la Muerte",-Annali del Corso de Lingue e Letterature Stra. niere presso l'Università di Bari, 6, 1963; 70 pp. [Separata]. II Sef, 25 (1965), 126 (Cantera); HR, 34 (1966), 358-360. (Solá-Solé) .

19-2498. SorA-SOLÉ, J. M.-"El rabí y el alfaquí en la Dança general de la muerte".-RPh, 18 (1964-65), 272-283. || Sef, 27 (1967), 139-140 (Millás).

19-2499. VARVARo, AlberTo-Premesse ad un'edizione crilica delle poesie minori di Juan de Mena.-Liguori, Napoli, 1964. 130 pp. || $H R, 36$ (1968), 63-66 (Crosby) ; BHS, 44 (1967), 74-75 (Gallagher); $R P h, 20 \quad(1966-67), 252-254$ (Gimeno Casalduero) ; ZRPh, 83 (1967), 620 (Mettmann); RLil, 27 (1965), 225 (Rozas); VR, 26 (1967) , 378-380 (Salomonski).

19-2500. Pianca, A. H.-"Influencias dantescas en la obra del Marqués de San. tillana".-EM, 21 (1965), 263-272.

19-2501. LAPESA, R.-"Sobre la Corona. ción de mossén Jordi de Sant Jordi. Venus y los elefantes".-ER, 10 (1962), 273-276.

19-2502. SIEBER, H.-"Dramatic symmetry in Gomez Manrique's $L a$ representación del nacimiento de nuestro Señor".HR, 33 (1965), 118-135.

V. también núm. 2895.

19-2503. Benito Ruano, E.-"Algunas rentas de Jorge Manrique". - HM, 25 (1965), 1]3-119.

19-2504. Manrique, Jorge-Poesía. Ed., pról. y notas de J. M. Alda-Tesán.Anaya, Salamanca-Madrid, 1965. 110 pp. (Bibl. Anaya).

19-2505. PÉrez Gómez, A.-"La primera versión impresa de las Coplas de Jorge Manrique, Zaragoza, s. a. (14821483) "-Gutenberg-Jahrb., 40 (1965), 93-95.

19-2506. Lluch MorA, Franctsco-La hue. lla de cuatro poetas del Cancionero en las "Coplas" de Jorge Manrique,Rodadero, Yauco, 1964. $76 \mathrm{pp}$.

19-2507. García Berrio, A.-"Una lectura nueva de las Coplas de Jorge Manrique".-Conv, 33 (1965), 641-643.

19-2508. Rico, F.-“Unas coplas de Jorge Manrique y las fiestas de Valladolid en 1428".-AEM, 2 (1965), 515-524.

V. también núm. 1911.

"Mingo Revulgo": v. núm. 2510.

19-2509. STERN, C.-"Fray Iñigo de Mendoza and medieval dramatic ritual".$H R, 33$ (1965) , 197-245.

19-2510. Rodrf́cuez Puértolas, J.-"Sobre e] autor de las Coplas de Mingo Re. vulgo".-HRM, 2, 131-142. [Propone a fray Ifnigo de Mendoza].

V. también núm. 2895.

Gil Vicente: v. núms. 1993-4.

19-2511. Poullain, G.-"Garcilaso de la Vega",-RLR, $77^{\circ}$ (1965), 79-90.

19-2512. BONET NAVARRO, ANGEI-Invitación al viaje. Garcilaso de la Vega.Aula Nueva de Extensión Cultural, Zaragoza, 1965. $21 \mathrm{pp}$.

19-2513. MACRí, O.-"Recensión textual de la obra de Garcilaso".-HIEH, 305-330.

19-2514. Garcilaso DE LA VEGA-Obras completas. Ed. de Ellas L. Rivers.-Castalia, Valencia, ]964. 242 pp. $\| H f$, 1967, núm. 29, 63-64 (Ebersole); $M L J$, 51 (1967), 108.109 (Gicovate); H, 50 (1967) , 182 (Marin); $B H i, 68$ (1966), 160-161 (Marrast); Hum, 17 (1965), 389 (Martino); PSA, 38 (1965), 109. 110 (Molina); $R J, 19$ (1968), 348-350 (Reichenberger); $M P h, 64$ (1966-67); 337 339 (Rodriguez-Luis) ; $B H S, 43$ (1966), 288-290 (Terry) ; $B A b r, 40$ (1966), 375 (Triwedi); $H R, 35$ (1967), 188-190 (Wilson); ins, 1965, núm. 222 (X); TLS, Sept. 2, 1965 (X).

19-2515. Garcilaso DE LA VEGa-Obras.Miñón, Valladolid, 1965. 224 pp. ( $B i^{-}$ blioteca del bolsillo).

19-2516. GARCILASO DE IA VEGA-Poesias completas. - Huemul, Buenos Aires, 1965. 221 pp. (Clás. Huemul, 43).

19-2517. Dutron, B.- "Garcilaso's sin duelo".-MLN, 80 (1965), 251-258.

19-2518. Oroz, R.-"Andrés Bello, imita. dor de las Bucólicas de Virgilio".BdFS, 17 (1965) , 237-259. [Directamente, y a través de Garcilaso y Figueroa]. 19-2519. DunN, P. N.-"Garcilaso's ode $A$ la Flor de Gnido. A commentary on some Renaissance themes and ideas".$Z R P h, 81$ (1965), 288-309.

19-2520. IventoscH, H.-'Garcilaso's son- 
net $\mathrm{O} / \mathrm{l}$ dulces prendas: a composite of classical and medieval models".AlON-R, 7 (1965), 203-227. \| ZRPh, $81(1965), 582-583$ (Ziltener).

19-2521. MAcRì, O.- "Un testo inedito del son. XXXIII di Garcilaso".-SLS, 245 252.

19-2522. MCCoRMIck, B. A.-“Garcilaso de la Vega y la poesía española contemporánea".-H, 48 (1965), 837-840.

19-2523. Almedd, J. A.-“'Garcilaso a través de los nuevos aspectos del New Criticism".-CuH, 64. (1965), 325-356.

19-2524. Sprvakovsky, E.-"Diego Hurtado de Mendoza and averroism".-JHI, 26 (1965), 307-326.

$\checkmark$. también núm. 2437.

19-2525. Castro Escudero, J.- $A$ bad $y$ ballestero. Nota al refrán glosado de Sebastián de Horozco". - LNL, 1965, núm. 2, 91.93.

V. también núm. 2437.

Castillejo, G. Silvestre: v. nưm. 2437.

Luis de León: v. núms. 3882-6.

19-2526. Dumas, C. - "Réflexions sur quelques points d'histoire dans La Araucana, d'Alonso de Ercilla".-TILAS, 5 (1965) , 135-149.

19-2527. Concha, J.-“'Observaciones acerca de La Araucana".-EFil, 1964, núm. $1,63-79$.

I9-2528. Schaible, C.-"La Araucana, editada por Sanclia".-BACh, 31 (I964), 188-196.

19-2529. ERcilla, Alonso DE-The Historie of Aravcana. Transcribed with in. trod. and notes by Frank Pierce.-University Press, Mancliester, 1964. xxi + 52 pp. ||$B d F S$, IT (1965), 423-425 (Garcla); BHS, 42 (1965), 26I-262 (Sinitli).

San Juan de la Cruz: v. núms. 3862-6.

19-2530. Kossofr, A. D.-"Another Herrera autograph: two variant sonnets".-HR, 33 (1965), 318-325.

19-2531. BERtini, G. M.-“Hernando de Herrera e la ecorrente italianeggiante. del sec. xvI'.-FHH, 79-84.

19-2592. Di BENEDETTO, UbaLdo-Las teorias sobre el lenguaje en la Ilalia del Renaciniento $y$ en Fernando de $\mathrm{He}$ rrera.-[Tesis, Univ. de Madrid; resu. inen en $R U M, 14$ (1965), 196-197].

19-2533. Porqueras-MaYo, A.-“Herrera y Calderón a través de un olvidado escricor del siglo ximn".-RNo, 7 (1965), $36-39$.

Figueroa: v. núm. 2518.

19-2534. OwRE, J. R.-"Apunces sobre La
Florida de Alonso de Escobedo". $A P C H, 401-407$.

Cervantes: v. núms. $3405,3416$.

19-2535. Rodrícuez MoñIno, A.-"El doctor Francisco Garay (tres manuscritos de sus poesias)".-RHM, 31 (1965), 373-384.

Valdivielso: v. núm. 3083.

Lope de Vega: v. núms. 3073-8.

19-2536. PaBón NúÑEz, L.-"Góngora, Velázquez y el Greco"., $-B C B, 7$ (1964), $1563-1572$.

19-2537. LAPESA, R.-"Góngora y Cervantes: coincidencia de temas y contraste de actitudes".- RHM, 31 (1965), 247 269.

19-2538. BodINI, V.-Studi sul barocco di Góngora (N. 18.6096). || IS, 48 (1965), 348 (Tomasso) .

19-2539. Canavaggio, J.-"Góngora et la Comedia nuceva: un témoignage inédit de Francisco del Villar". - $M C V, 1$ (1965) , 245-254.

19.2540. Marasso, ARTuro-Góngota: hermetismo poético y alquimia.-Theoria, Buenos Aires, 1965. 104 pp. (Clás universales).

19-2541. GESKE, RudolPu-Góngoras Warnrede im Zeichen der Hekate.Colloquium-Verlag, Berlin, 1964. 134 pp. (Bibliotheca Ibero Americana). $\| R F$, 78 (1966), 615-616 (Guillessen) ; Mundus, 2 (1960), 110-111 (Niedermayer); LMFA, I (I968), 162 (Niederinayer) ; $B H S, 44$ (1967), 65.66 (Terry).

19-2542. Góncora, Luis DE - Obras en verso del Homero español. Edición de Vicuña. Madrid, 1627. Pról. e índices por Dámaso Alonso.-C.S.I.C., Madrid, 1963. 1xxxii + $338 \mathrm{pp}$. (Clásicos hispanicos, facsiniles, I) . || Map, 1965, núm. 9, 231-232 (Terreccio Podestá) ; HR, 34 (1960), 168-170 (Gates) : RJ, I7 (1966), 363-364 (Pabst) ; Fil, I0 (1964), 234239 (S. de Cortazar); LR, 20 (1966), I78-180 (Vermeylen).

19-2543. Góngora, Luis DE - Letrillas. Texte établi et annoté par Robert Jammes.-Eds. Hispano-Americanas, Paris. 1963. $\mathrm{xxii}+531$ pp. \| $L N L$, 1964, núm. 2, 100-101 (Darmangeat); $H R, 34$ (1966), 170-173 (Wilson).

19-2544. Bershas, H. N.-"La biznaga honrada".-RNo, 7 (1965), 62-67.

19-254.5. Araya, G.-“Shakespeare y Góngora parodian la fábula de Plramo y Tisbe".-EFil, 1964, nưm. 1, 19-40. 19-2546. LAzaro Carreter, F.-“Dificul- 
tades en la Fibula de Plramo y Tisbe" (N. 18-2710) . || ZRPh, 81 (1965), 562. 563 (Giese).

19.2547. SмiтH, C. C.-"An approach to Góngora's Polifemo",-BHS, 42 (1965), 217-238.

19-2548. SMITH, C. C.- "Ricl thyme in Góngora's Polifemo".-BHS, 42 (1965), 106-112.

19-2549. GóncoRA, LUIS DE-The solitudes. A verse translation by Gilbert F. Cunningham.-Edinburgh, 1965. [Ed. privada, de 500 ejemplares].

19-2550. GóngorA, LuIs DE-The solitudes. A text with verse translation by Edward M. Wilson. - Cambridge Univ. Press, Cambridge, 1965. xxi + $130 \mathrm{pp}$. II HR, 36 (1968), 68-70 (Morley); Nation, 203 (1966), 288-289 (Myers); Hum, 19 (1967), 371-372 (del Rio); $B H S, \quad 44$ (1967), 217-218 (Terry); AUMLA, 1967, núm. 27, 128 (Thompson) .

19-2551. Gates, E. J.-Documentos gongorinos (N. 17-5386). || FM, 4 (1965), 283-285 (Ares Montes).-V. núm. 18. 6108.

19-2552. PABST, W._.'Ein aragonesischer Gongorist in Granada: Don Gaspar Buesso de Arnal" (N. 17 5389) . $\mid R F E$, 48 (1965), 437 (Llorente).

19-2553. Espinosa MEDRANo, J.-“Apologético en favor de don Luis de Góngora",-Revista Universitaria, Lima, 5152 (1962-63), 1-81.

19-2554. MarqueríE, A.-"De Don Luis a Don Mendo".-EL, 1965, núm. 333.

19-2555. RubiNs, M. S._-"Inspiraciones y correspondencias".-UMX, 19 (1964-65), núm. 4 [Uina de ellas: Góngora y José Gorostiza]

19-2556. Müller, B.-"Orpheus und der Schwan vom Betis. $\mathrm{Zu}$ Jean Cocteaus Góngora-Rezeption".-ZFSL, 75 (1965), 193-227.

19-2557. RAT, M.-“Traduction ou adaptation?"-VL, 1962, núm. 128, 605-607. [Un poema de Góngora trad. por J. Camp (1947) e imitado por H, Carpentier (ca. 1930) ].

19-2558. PABst, W.-“Góngoras Nachruhm in Deutschland".-FFS, 251-280.

V. también núms. 2277, 2292-3.

19-2559. Carreño, Alberto María-Joyas literarias del siglo xvii encontradas en México. Fr. Miguel de Guevara y el célebre soneto castellano No me mueve mi Dios para quererte. $2^{3}$ ed.-Jus, México, 1965. 279 pp., ilustr.
19-2560. BABLER, O. F.-"Le sonnet $N o$ me mueve $m i$ Dios dans la littérature tchèque" (N. 17-1809). \|RFE, 48 (1965) , 455-456 (López Jiménez).

19-2561 Kouvel, AUdrey L.-Pedro Espinosa: desarrollo de su sintaxis, vocabulario, estructuras formales $e$ imdgenes.[Tesis, Harvard Univ., 1965].

19-2562. Brown, J. M.-"La teorla del arte de Pablo de Céspedes".-RIEs, 23 (1965), 95-]05. [Poema de la pintura].

J. de Salinas: v. núm. 3645.

19-2563. RozAs, JuAN MANuel-La poesia del conde de Villamediana. - [Tesis, Univ, de Madrid, 1965; resumen en RUM, 14 (1965), 2307.

19-2564. RozAs, J. M. $-\dot{E} l$ Conde de $V i$ llamediana (N. 18-6117). \|RFE, 48 (1965), 193.194 (Palavecino) .

V. también núm. 2294.

19-2565. Coste, JEAN-Francisco de Rioja, racionero entero de la santa iglesia de Sevilla.-Imp. Soler, Valencia, 1965. LNL, 1965, núm. 4, 100 (Larrieu).

19-2566. Coste, J.-'Francisco de Rioja, albacea del tesorero Juan de Asiaín Ugalde".-AH, 43 (1965), 139-143.

Quevedo: v. núms. 3891-4.

19-2567. GLASER, E.-"Two notes on the Hispano-Jewish poet don Miguel de Barrios".-REJ, 124 (1965), 201-211.

19-2568. Moокick, Charles James-The poetic style of Miguel de Barrios.[Tesis, Univ. of Southern California; resumen en $D A, 25$ (1964-65), 3578 . $3579]$.

19-2569. Scholderg, K. R,-La poesia religiosa de Miguel de Barrios (N. 18 . 2753) - \| RPh, 21 (1967-68), 243-245 (Bergman); HR, 33 (1965), 337-341 (Glaser); S, 18 (1964), 187-189 (Sarmiento).

19-2570. RtvaH, I. S.-"Les écrivains Manuel de Pina et Miguel de Barrios et la censure de la communauté judéoportugaise d'Amsterdam". - OYS, 8 (1965), lxxiv-xci. \| $B E P, 26$ (1965), 311-312 (Frèches).

19-2571. MARín, Nicol.As-La obra poetica del Conde de Torrepalma.-Oviedo, 1963. (Cuad. de la Cátedra Feijoo, 15).

Autores modernos

19-2572. Aguilar PiÑal, F.-"Trigueros, apologista de España”. - BBMP, 41 (1965), 63-85.

Jovellanos: v. núms. 2399, 2608.

Manuel de S. Jasé: v. núm. 19-2298 
19-2573. Salinas, P. - "La poesía de Meléndez Valdés"._ELHi, 236-272_V. núm. 17-5407.

19-2574. Meléndez Valdés, Juan-Poesia. Sel., pról. y notas por Joaquín Marco Revilla.-Ebro, Zaragoza, 1965. 154 pp. (Clásicos Ebro).

19-2575. MELÉNDEZ VALdÉs, JUAN-Correspondance relative à la réunion des $h b$. pitaux d'Avila. Textes en prose inedits publiés avec une introduction, des notes et appendices par Georges Demerson.Féret \& Fils, Bordeaux, 1964. 198 pp. (Bibliotéque de l'École des Hautes Études Hispaniques, 35) . || CuH, 67 (1966), 776.777 (Amorós); $L N L$, 1966, núm. I, 112-113 (Andioc); $A I A, 26$ (1966), 283-284 (Barrado); $A M, 79$ (1967), 94 (Defourneaux) ; $B H i, 69$ (1967), 238 . 245 (Guinard); $R L C, 40$ (I966), 638 . 641 (Pageard); RLit, 27 (1965), 240. 241 (Rodríguez Cepeda) .

19-2576. Demerson, G.-“Un extremefio: D. Crisıóbal Meléndez Valdés, sobrino del a Restaurador de la poesia." $-A O$, 15 (1965), 112-125.

Moratín: v. nưm. 3176.

19-2577. López ANGLAda, L.-“Cienfuegos, prerromántico".-EL, 1965, núm. 326.

19-2578. Cano, J. L.-“Un prerromántico: Cienfuegos".-CuT, 65 (1966), 462-474.

19-2579. Alcald Galiano, A.-“Afrance. sado patriota". $-E L, 1965$, núm. 326. [Cienfuegos].

V. también nưm. 2399.

Arriaza: v. núm. 2399.

19-2580. CuEvas, J. DE LAS-"Miscelánea sobre el poeta sevillano José María Roldán".-AH, 42 (1965), 79-115.

19.2581. Fernández Larraín, S.-"José María Blanco White y Andrés Bello".$M a p, 4$ (1965) , 288-308.

19-2582. Śnnchez Castañer, F.-“José María Blanco White y Alberto Lista en las Escuelas de Cristo hispalenses",$A H, 42$ (1965), 229.247.

19-2583. ROSALES, L. - "Vida y andanzas del Duque de Rivas".- $B R A E, 45$ (1965), 395-406.

19-2584. VÁlComA, D. DE LA - "Alcalá Galiano y el Duque de Rivas en la Real Academia de la Historia".- $B A H$, 157 (1965), núm. 2.

19-2585. Martínez Ferrol, M.-"Breve idea de Angel Saavedra".-EL, 1965, núm. 326.

19-2586. Jiménez Martos, L.-"El Duque de los romances".-PEsp, 1965, núm. 150 .
19-2587. Mathi.AS, J.-“Rivas, dramaturgo".-EL, 1965, núm. 326.

19-2588. Baquero, A.-"Don Alvaro manifiesto".-EL, 1965, núm. 326.

19-2589. Caravaca, F.- “Plagió Mérimée el Don Alvaro del Duque de Rivas?"$L T, 1965$, núm. 49, 77-135.

19-2590. Castelltort, R.- "Miscelánea en torno al P. Arolas".-ACa, 5 (1964), 360.407.

19-2591. CaravacA, F.-"Romanticismo y románticos españoles". - $L N L, 1965$, núm. 1, 41-64. [Espronceda].-V. núm. 16.48238 .

19.2592. Casalduero, J-Espronceda (N. 17.1866). $\mid R J, 16$ (1965), 391-393 (Garavaca) .

19-2593. Casalduero, J.- "El arte de Espronceda".-Los Sesenta, México, 1964, núm. 1.

19-2594. Gallina, A. M.-"La traiettoria "drammatica di Espronceda: dal neoclassicismo al romanticismo".-AION-R, 7 (I965) , 79.99.

19-2595. EsproncEDA, José DE-El estudiante de Salamanca. Edición, prólogo y notas de Carlos Becciro.-Aguilar, $\mathrm{Ma}$ drid, 1965. 186 pp. (Bibl. de iniciación hispánica).

19-2596. Foster, D. W.-"A note on Espronceda's use of the romance meter in El estudiante de Salamanca". $-R N o$, 7 (1965) , 16-20.

19-2597. EspronceDA, José - El diablo mundo. - Espasa-Calpe, Madrid, 1965. 220 pp. (Clás. cast., 50).-V. núm. 56216.

19-2598. Serrano Castilia, F.-"Más a propósito del comentario de textos: La canción del pirata, de Espronceda, y Traidor, inconfeso y mátir, de Zorrilla".-Rev. de Enseñanza Media, 1965, 754-756.

19-2599. Espresati, Carlos G.-La juventud de Amalia Fenollosa, poetisa romántica.-C.S.I.C., Castellón de la Plana, 1965. 196 pp. (Libros raros y curiosos). $-\mathrm{V}$. núm. 18-6156. \|l RLit, 27 (I965), 240 (Esquer Torres).

19-2600. Gómez, V. M.-"Un desconocido poema de Campoamor: La velada de San Juan".-BBMP, 41 (1965), 107-114. 19-2601. Rodrfguez Batllori, F.-"Sofía Casanova y Ramón de Campoamor".Norte, México, 1963, núm. 193.

Garcia Tassara: v. núm. 3423.

19-2602. Mancini, G.-“Sulla semplicità di Zorrilla".-SLS, 81-97.

19-2603. Zorrilla, José-Poesias.-Espasa- 
Calpe, Madrid, 1965. 284 pp. (Clás. cast., 63) .

19-2604. ZORRILlA, Jost-Leyendas y tradiciones. 3a ed.-Kapelusz, Buenos Aires, 1965, $106 \mathrm{pp}$. (Grandes obras de la lit. universal).-V. núm. 16-48251.

19-2605. AdAms, N. B.-"Don Juan Tenorio: 1877",-RHM, 31 (1965), 5-10.

19-2606. Mansour, George Phillip-The "Don Juan Tenorio", zarzuela of Zorrilla: the progression and modulation of a theme.-[Tesis, Michigan State Univ.; resumen en $D A, 26$ (1965-66), 4666-4667].

V. también núm. 2598.

19-2607. KNOWLTON, JOHN FREDERICK Gaspar Núñez de Arce: his poetry and the critics.-[Tesis, Univ. of Oregon; resumen en $D A, 26 \quad(1965-66), 4662]$.

19-2608. KNowlton, J. F.-"Two epistles: Núñez de Arce and Jovellanos",-RNo, 7 (1965) , 130-133.

19-2609. Guarner, L.- "Vicente W. Querol, poeta horaciano". - BSCC, 4I (1965) , 27-46.

19-2610. QUerol, Vicente W.-Poesias, Introd. y notas de Luis Guarner.-Espasa-Calpe, Madrid, 1964. cv + 203 pp. (Clás, cast., 160),-V. núm. 18-6166. || RLit, 26 (1964), 228 (Esquer Torres); BHS, 43 (1966), 144 (Herrero).

19-2611. Querol, Vicente W.-;Quiero ser empleado! Pieza en un acto. Ed. de L. Guarner.-Seg, 1 (1965), 361-395.

19-2612. A yllón, C.-"Bécquer: su realidad poética".-HuNL, 6 (1965), 201216.

19-2613. Esquer TORres, R.-“Reminiscencias de nuestros clásicos en Bécquer".-BRAE, 45 (1965), 185-201.

19-2614. Hartsook, J. H. "Bécquer and Enrique Gil".- $-H, 48$ (1965), 800-805. 19-2615. SORIA, A.-"Bécquer y Dante. (La vida de la letra)". - CuH, 63 (1965) , 377-382; RLit, 28 (1965), 6773.

19-2616. Solfer, M.-“Bécquer y Baudelaire",-RdL, 1961, núms. 23/24, 83-91.

19-2617. GonZílez-GerTH, M.- "The poetics of Gustavo Adolfo Bécquer". $-M L N$, 80 (1965), 185-201.

19-2618. BÉcQUer, Gustavo AdOLFO-Rimas, Estudio y ed. de J. M. Dfez Taboada.-Eds. Alcalá, Madrid, 1965. 139 pp. (Aula Magna, 2).

19-2619. BÉCQuer, Gustayo ADOLFo-Rimas. Introd. y notas de R. M. Rey. 2a ed.-Huemul, Buenos Aires, 1965. 117 pp. (Clás Huemul).-V. núm. 18-2805.
19-2620. Bécquer, Gustavo Adolfo-Rimas. Pról. de Pedro Rourres Ribas.Zeus, Barcelona, 1965. 235 pp., ilustr. 19-2621. BÉcQUER, GuSTAyo ADOLFo-Ri-

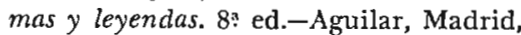
1965. 574 pp. (Crisol, 270).-V. núm. 18-6183.

19-2622. B ́lCQUER, GUSTAYo ADOLFo-Ri. mas y leyendas. - Sopena, Barcelona, 1965. 333 pp. (Bibl. Sopena, 59-1).

19-2623. BÉCQUER, Gustavo AdOLFo-Rimas, leyendas y cartas literarias.-Miñon, Valladolid, 1965. $328 \mathrm{pp}$. (Biblioteca de bolsillo).

19-2624. BÉcQuer, Gustavo Adolfo-Rimas, leyendas y narraciones. 2: ed.Porrúa, México, 1965. 217 pp. (Seban cuantos, 17).-V. núm. 18-2808.

19-2625. BÉcQuer, GustAyo ADOLFO-Rimas, leyendas, teatro, articulos. Pról. de V. de Pedro.-Buenos Aires, 1965. (Col. Marisol).

19-2626. Díez Taboada, Juan MaríLa mujer ideal. Aspectos y fuentes de las "Rimas" de G. A. Bécquer.-C.S.I.C., Madrid, 1965. xi +179 pp. (Anejos de RLit, 25. || Ins, 1966, núm. 231 (Ares Montes); RLit, 29 (1966), 241242 (Esquer Torres).

19-2627. Caravaca, F.-“"El motivo del arpa en la Rima VII (13), de Bécquer".-RJ, 16 (1965), 333-360.

19-2628. Balbín, R. DE-"El poema becqueriano $A$ todos los santos",-RFE, 48 (1965), 383-39I.

19-2629. LAMотHE, Louis G. - Gustavo Adolfo Bécquer y la poesía contemporánea.-Port-au-Prince, 1965. 20 pp. 19-2630. Young, C.-"The cantables of Bécquer's theatre".-RNo, 6 (1965), 126-130.

19-2631. Becquer, GustAvo Adolfo "Textos [sobre estética]". Sel. y notas de E. Pardo Canalfs.-RIEs, 23 (1965), 309-326.

V. también núm. 2226.

19-2632. Cubero Sanz, Manuela-Vida $y$ obra de Augusto Ferrán.-C.S.I.C., Madrid, 1965. 303 pp. (RLit, anejo 23) .v. núm. 18.6187. $\| H R, 35$ (1967), 378-381 (Brown); Ins, 1966, núm. 232 (Cano) ; BHi, 68 (1966), 389-394 (Pageard).

Rosalía: y. núms. 2223-8.

19-2633. Garcís Pardo, J. - "Salvador Rueda, poeta del alma andaluza, Cafés cantantes, cátedra del cante jondo".-Azor, 1963, núm. 12.

19-2634. RequenA, F.-'Salvador Rueda, 
poeta de Andalucia".-PLi, 1965, núm. 15.

Unamuno: v. núms. 2403, 3983-90.

19-2635. Garcia Morales, Justo-Vicente Medina $y$ el otro 98.-Artes Gráficas Soler, Valencia, 1964. 39 pp.-V. núm. 17-1881. || $B D G A, 1966$, núms. 90/91 (Pérez Rioja).

19-2636. Romano Colangeli, Maria La poesia di Gabriel y Galán.-Pàtron, Bologna, 1965. 239 pp.-V. núm. 1648292.

19-2637. Gabriel y GatAN, José MaríaObras completas. Nueva ed.-A. Aguado, Madrid, 1965. 2 is.: 335,367 pp.-V. núm. 14-41006.

19-2638. Gabriel y GaLAN, José MaríaObra inédita y olvidada. Ed., estudio y notas de R. Esquer Torres.-C.S.I.C., Madrid, 1965. 145 pp. || $R P h, 22$ (1968. 69), 127 (Rico) .

19-2659. Marchesr, S._-"Storia ed arte di Spagna nella poesía di Manuel Machado". - Studi... in onore di Bruno Revel (Firenze, 1965), 385-392.

19-2640. García Fernandez, Carlos-[Manuel Machado]. Discurso... Contestación de F. López Estrada.-Academia Sevillana de Buenas Letras, Sevilla, 1964. 50 pp. $A H, 41$ (1964), 382383 (M. J. M.).

19-2641. NEwberRy, W.- "The influence of Pirandello in two plays of Manuel and Antonio Machado".-H, 48 (1965), 255-260.

19-2642. Honenaje a Antonio Machado.$L T, 12$ (1964), 11-533. || CCL, 1965, núm. 92, 84-85 (Garavito).

19-2643. Cardoza Y Aracón, L.-“Antonio Machado".-[En su libro] Perfiles (La Habana, 1964), 23-36.

19-2644. Segre, C.-“Due appunti su Antonio Machado".-SLS, 147-157.

19-2645. Rodríguez, CaRLos-El retralo de Antonio Machado.-Univ. de Los Andes, Mérida, 1965. $95 \mathrm{pp}$. \| $R N C$, 1965, núm. 170, 107 (Magallanes) .

19.2646. Rulz dE Conde, Justina-Antonio Machado y Guiomar.-Insula, Madrid, 1964. 192 pp. $\| f n s, 1965$, núm. 220 (Cano) ; H, 49 (1966), 892 (Cirre); ALitt, 9 (1967), 343 (Horányi); CuH, 64 (1965), 626-630 (Miro).

19-2647. BaLbontín, J. A.-“La filosofia de A. Machado", $-I A L, 1965$, núm. 196.

19-2648. Chaves, J. C._"La ideologfa de Antonio Machado".-Espa, Asunción, I (1963), 18.25.

19-2649. Horfmans, M._-"El Dios de
Antonio Machado".-RFCR, 4 (196465) , 339-345.

19-2650. RoJAs, C. "Machado the moralist". - Emory Univ. Quart., 21 (1965), 32-44.

19-2651. Cobos, Pablo DE A.-Humor $y$ pensamiento de Antonio Machado en La metaflsica poética.-Insula, Madrid, 1964. 174. pp., ilustr. \|f $n s, 1964$, núm. 214 (Albornoz); Asom, 1965, núm. 3, 80-23 (González): ALitt, 9 (1967); 342-343 (Horányi); $B A b r, 39$ (1965), 65 (Klibbe); $B H i, 67$ (1965) , $173-177$ (Laffranque) .

19-2652. HorANYT, M._-La formación de la poética de Antonio Machado".ALitt, 7 (1965), 377-393.

19-2653. AlLEN, J. L. - "Suspension of formal unities as a poetic device in a poem by A. Machado".-RNo, 7 (1965), 144148.

19-2654. IORANYI, M._-Le problème de l'authenticité poétique dans les ouvra. ges sur Machado"'-Filol. Közlöny, Buclapest, 11 (1965), 315.325.

19-2655. Laitenderg, Hugo-Antonio Machado. Sein Versuch einer Selbstinterpretation in seiner apolkriphen Dichter. philosophen.-[Tesis, Univ, de Tübingen, 1965].

19-2656. Gener Cuadrado, E_-Los poetas apócrifos de Antonio Machado".$E L$, 1965, núm. 3II.

19.2657. DoBriaN, W. A.- "Formal and rhetorical consciousness in Antonio Macliado".-H, 48 (1965), 452-455.

19-2658. Piñera, H._"Tempo de Proust en el tiempo de Machado"._LT, 1965, núm. 49, 137-154.

19-2659. VILleGAs, J._-El tema del tiempo en un poema de Antonio Machado".- $H, 48$ (1965) , 442-45l.

19-2660. Rodríguez Forteza, Adela-La naturaleza y Antonio Machado. Contri. bución al estudio de la naturaleza en su poesia._Cordillera, San Juan de Puerto Rico, 1965. $362 \mathrm{pp} .-\mathrm{V}$. núm. 18-6241. || PSA, 43 (1966), 268-272 (Molina) .

19-2661. Rodríglez FortezA, A.-"La naturaleza y su relación con Ios otros grandes temas poéticos de $A$. Machado".-EG, 7 (1965) , 15-38.

19-2662. Guerra Castellanos, E.-"El paisaje en la poesía de Antonio Machado".-HuNL, 6 (1965), 173-187.

19-2663. SHEETs, JANE M.-Landscape in the poetry of R. M. Rilhe and A. Machado.-[Tesis, Indiana Univ., 1965]. 
19-2664. Machado, Antonio Obras. Poesia y prosa. Ed. preparada por Aurora de Albornoz y Guillermo de Torre.Losada, Buenos Aires, 1964. 1068 pp. \| Sur, 1965, núm. 294, 125-127 (Albornoz) ; Ins, 1965, núms. 228/9 (Marrast); CI, 1966, núm. 5, 171-175 (de Miguel); CuA, 1965, núm. 4, 269-271 (de la Selva); Ins, 1965, núm. 222 (X).

19-2665. AlboRNoz, A. DE-_."En torno a Antonio Machado, Obras, poesia y prosa".-IAL, 1965, núm. 196.

19-2666. TORRE, G. DE-"Sobre las Obras: Poesia y prosa, de A. Machado"._Ins, 1965, núm. 227.

19-2667. Machado, Antonio-Poesias. 6a ed.-Losada, Buenos Aires, 1965. 271 pp. (Bibl. contemporinea, 19) - - V. núm. 17-5462.

19-2668. Machado, Antonio-Poeslas completus. 8? $^{\text {? }}$ ed.-Espasa-Calpe, Madrid, 1965. 447 pp.-V. núm. 18-2836.

19-2669. MACHaDo, ANTONIO_Prosas $y$ poesias olvidadas. Recogidas y presentadas por Robert Marrast y Ramón Martinez López.-Centre de Recherches de l'Institut d'Etudes Hispaniques, Paris, 1964. || LNL, 1964, núms. $3 / 4$, 96-97 (Darmangeat); RHM, 30 (1964), 305-306 (Jaimes-Freyre); $B H i$, 67 (1965) , 208-209 (Laffranque); Asom, 1966, núm. 2, 60-61 (Otero Seco).

19-2670. Foster, D. W._-'La tierra de Alvargonzdlez: una contribución machadeana al romance español".-DHR, 4 (1965), 65-77.

19-2671. WARDROPPER, B. W._"The modern Spanish elegy: Antonio Machado's lament for Federico García Lorca". $-S, 19$ (1965), 162-170.

19-2672. Phillips, A. W. "Algo más sobre Antonio Machado y Valle-Inclán".CuH, 62 (1965) , 557-564_V. núm. 18 2843.

19-2673. Gullón, Ricardo - Relaciones entre Anlonio Machado y Juan Ramón Jiménez.-Istituto di Letteratura Spagnola e Ispano-Americano della Università, Pisa, 1964. $89 \mathrm{pp}$. $\| H R, 36$ (1968), 83-84 (Arroyo); $H, 48$ (1965), 387-388 (Palley) ; RLit, 26 (1944), 233234 (Rull).

19-2674, García Nieto, J.- "Actualidad y eterniclad de Antonio Machado". LEsp, 13 (1965) , 450-456.

$V$. también llúms. 1690, 2403, 2451, 2641, 2705.

19-2675. Montero Alonso, Jost́_Vida de Eduardo Marquina._- Edit. Nacional,
Madrid, 1965. 302 pp. (Vida y pensamiento españoles). || Seg, 1 (1965), 464 (Torres).

19-2676. Basave Fernandez del VAlle, A.-"Juan Ramón Jiménez: el andaluz universal"._AyL, 8 (1965), núm. 4, 517.

19-2677. Gullón, R-Conversaciones con Juan Ramón (N. 14-39047). \| $A L M$, 4 (1964), 346-349 (Abreu Gómez).

19-2678. Rodríguez Luis, J-“"Los Jiménez".-Asom, 1965, núm. 4, 37-44. [Zenobia y Juan Ramón].

19-2679. LANDARECH, A. M._"Semblanza de Juan Ramón Jiménez".-ECA, 20 (1965), 111-116.

19-2680. Lundgren, A.- "Jiménez och hans rymd",_Lyrikvännen, Stockholm, 1965, núm. 2.

19-2681. Senabre Sfmpere, R._-“El proceso creador en Juan Ramón Jiménez". PSA, 38 (1965) , 135-146.

19-2682. Gicovate, B.-_Poesla y poética de Juan Ramón Jiménez en sus primeras obras"._ALM, 5 (1965), 191 201.

19-2683. Gicovate, B.-"El yo poético y su significado".-Asom, 1965, núm. 3, 40-47. [J. R. Jiménez y otros poetas]. 19-2684. Martín-Crosa, R.-"Notas de urgencia para una poesía de lo absoluto"_-CuH, 61 (1965), 103-109. [J. R. Jiménez].

19-2685. Espinosa Altamirano, H_"La eternidad azul en Juan Ramón Jiménez"._Boletín Bibliográfico de la Secretaria de Hacienda y Crédito Público, México, 6 (1965), 16-17.

19-2686. PaBlos, BAsillo DE-El tiempo en la poesia de Juan Ramón Jiménez.Gredos, Madrid, 1965. 260 pp. (Campo abierto). $\quad \| H, 49$ (1966), 538-539 (Fox) ; BHi, 69 (1967), 293-294 (Laffranque); $P E s p, 1965$, núm. 151 (Murciano); BHS, 43 (1966), 135-137 (O1son) .

19-2687. Johnson, R.-_Juan Ramón Jiménez, Rabindranath Tagore, and la poesia desnuda".-MLR, 60 (1965), 534-546.

19-2688. Azancot, L.- "Juan Ramón, inédito".-IAL, 1965, núm. 199.

19-2689. Jiménez, JuAN RAMón-Antologia poética. Ed. V. Gaos-_Anaya, Salamanca-Madrid, 1965.

19-2690. Jiménez, JUAN RAMÓN-Libros inéditos de poesía. Ordenación y pról. de F. Garfias.-Aguilar, Madrid, 1964. 500 pp. (Col. literaria). || ins, 1965, núm. 
222 (Cano); PEsp, 1965, núm. 147 (Murciano) .

19-2691. JLMÉNEz, JUAN RAMón-Dios deseado y deseante. Introd., notas y explicación de los poemas por A. Sánchez Barbudo.-Aguilar, Madrid, 1964. 328 pp. (Col. literaria). || Ins, 1965, núm. 222 (Cano); Res, 2 (1965), 95-103 (Jiménez H. Pinzón); PEsp, 1965, nưm. 155 (Murciano).

19-2692. UMBral, F._.'El Dios deseado y deseante de Juan Ramón Jiménez".$P E s p$, 1966, nưm. 164.

19.2693. Jiménez, Juan Ramón-Pastorales. Ed. y pról. de F. Garfias.-Losada, Buenos Aires, 1965. 143 pp. (Bibl. contemporánea, 219) .

19-2694. Jiménez, JuAn Ramón-Poemas májicos y dolientes (1909). Aumentada con apéndice. Ed. Y pról. de Francisco Garfias.-Losada, Buenos Aires, 1965. 121 pp. (Bibl. clásica y contemporánea, 220) .

19-2695. JMMÉnez, JUAN RAMón-Siviglia. A cura di Vicenzo Josia,-Nuova Accademia Editrice, Milano, 1965. || PEsp, 1966, núm. 166 (Murciano).

19-2696. Jornson, R.-“Juan Ramón Jiménez and La viudita". $-N, 49$ (1965), 223-228.

19-2697. Predmore, Michael P. - The prose of Juan Ramón Jiménex.-[Tesis, Univ. of Wisconsin; resumen en $D A$, $25(1964 \cdot 65), 5939]$.

19-2698. JIMÉnez, JUAN RAMón_Platero y yo. A cura di A. M. Gallina.-Pironti, Napoli, 1965. 129 pp. (Coll. di testi romanzi).-V. núm. 16-44419.

19-2699. JIMÉnez, JuAN RAMón_Platero y yo. 2a ed.-Aguilar, Madrid, 1965. I60 pp., ilustr. (El globo de colores).V. núm. 18-2876.

19-2700. JIMÉNEz, JUAN RAMón-Platero y yo. 8a ed.-Aguilar, Madrid, 1965. 354 pp. (Cal. literaria).-V. núm. 18 . 6292.

19-2701. JIMÉNEZ, JUAN RAMón-Platero y jo. 23: ed._Losada, Buenos Aires, 1965. 118 pp. (Lecturas selectas escolares). $V$. núm. 18-6293.

19-2702. Jiménez, JUAN RAMón-Platero y yo. $3:$ ed.-Taurus, Madrid, 1965. 252 pp. (Ser y tiempo).-V. núm. 182874.

19-2703. Brogcini, Nilda Elena-"Platero y yo". Estudio estilistico.-Huemul, Buenos Aires, 1965. 150 pp.

19-2704. JIMÉNEZ, JUAN RAMÓN-Retratos liricos. Con una col. de retratos por
Vázquez Diaz y dibujos inéditos por $\mathrm{J}$. R. J.-Díaz-Casariego, Madrid, 1965. || $P E s p, 1966$, núm. 167 (Murciano).

19-2705. PREDMORE, M. P.-“J. R. Jiménez's second portrait of Antonio Machado".-MLN, 80 (1965), 265-270.

19-2706. Jiménez, Juan Ramón, y R. PasEYro-Le mythe Neruda. - L'Heme, Paris, 1965. || $L N L, 1965$, núm. 4, 97-99 (Darniangeat) .

19-2707. Giner DE Los Ríos, F, — “Don Francisco [Giner de los Ríos] y Juan Ramón" - CuA, 1965, núm. 2, 124-145. [Con seis textos inéditos de Juan $\mathbf{R a -}$ món].

V. cambién núms. 2403, 2451, 2679, 2760.

\section{Autores contempordneos}

19-2708. Venegas, R.-“León Felipe"s-_$V U, 3$ abril, 1966.

19-2709. I.EÓN FELIPE - Antologta rota. Epflogo de G. de Torre. 2: ed.-Losada, Buenos Aires, 1965. 228 pp. (Bibl. clásica $y$ contemporánea)._-V. núm. 1233432 .

19-2710. LEón FELIPE-iOh, este viejo $y$ roto violin!-Tezontle, México, 1965. 215 pp. || RHM, 33 (1967), 332-335 (Arenal de Rodriguez); $C u A, 1966$, núm. 3, 268-272 (de Ia Selva); UMx, 20 (196566), núm. 11 (Souto Alabarce).

19-27I1. GARcía, SOLFDAD_Homenaje a Federico Garcia Lorca. (En el XXX aniversario de su muerte).-B. Costa Amic, México, 1965. 61 pp.

19-2712. DurAn, M. (ed.) LLorca: $A \mathrm{col}$ lection of critical essays (N. 18-2894). || $A L M, 5$ (1965), 238-240 (Ontañón de Lope); Hf, 1965, núm. 24, 55-59 (Zardoya) .

19-27I3. Boneschi, F.-."Federico Garcla Lorca".-Idea, 21 (1965), 112-115.

19-2714. SIK, C. L. _- "Federico García Lorca"._Alföld, Budapest, I956, núm. 5. $77-81$

19-27 I5. WALLIS, P._Lorca"-TLS, Oct. 7, $1965,899$.

19-2716. Marinello, J.- "Du nouveau sur Federico García Lorca"._E, 1965, núms. $437 / 8,133-155$.

19-2717. Santareno, B.-_Federico García Lorca e "o segundo Século de Oiro."..Esp, 2 (1965), 106-114.

19-2718. Guereña, J. L._-Con García Lorca"-C CuH, 6I (1965), 371-372.

19-27I9. Marinello, J.-Garcia Lorca en Cuba._Eds. Especiales, Habana, 1965. || $U H, 29$ (I965), 165.166 (Bueno). 
19-2720. PARK, C._.Auf eine neue Klassik zu"._WWt, 20 (1965), 55-58. [Sobre trece poetas modernos, uno de ellos García Lorca].

19-2721. Ramos GiL, C.- "El eco de la canción añeja en la lírica de Lorca" (N. 18-2909) . || ZRPh, 81 (1965), 563564 (Giese).

19-2722. ScARPA, R. E.-El dramatismo en la poesia de $F$. García Lorca (N. 17-5525) . $\| C I, 1965$, núm. 3, 182-184 (villardo) .

19-2723. Cano Ballesta, J.-_Una veta reveladora en la poeśa de García Lorca. (Los tiempos del verbo y sus matices expresivos)".- $R F, 77$ (1965), 75107. $\|$ Hf, 1967, núm. 30, 70-71 (Bosch).

19-2724. Boscán, L._-La muerte en la poesía de Lorca. (La luna y el jinete. símbolos representativos)". - $A F, 4$ (1965) , 281-295.

19-2725. Frazier, Brenda Diana - La mujer en la obra de Federico Garcia Lorca.-[Tesis, Univ. de Madrid, 1965; resumen en RUM, 14 (1965), 204-205].

19-2726. Serrano Poncela, S.- "Lorca y los unicornios".-_tns, 1965, núm. 221.

19-2727. BEck-Agular, V. F. DE_-"Entomological symbols in the Chapeks and Garcia Lorca",-Literature East and West, 9 (1965) , 96-103.

19-2728. García Lorca, Federico_obras completas. 8: y 9a ed.-Aguilar, Madrid, 1965. lxxx + 2020 pp., ilustr. (Obras eternas)._V. núm. 18-6335. \| $B C B, 9$ (1966), 1585-1586 (Rodríguez).

19-2729. García Lorca, Federico_Obras escogidas. Introd. and notes by E. Florit.-Dell Laurel, New York, 1965.

19-2730. García Lorca, Federico-Antologia poética. 3: ed.-Losada, Buenos Aires, 1965. 254 pp. (Bibl. comtemporánea, 269) _. V. núm. 16-48399.

19-2731. García Lorc $\Lambda$, Federico-[Poestas. Trad. por Cosmas Politis y Nicos Simiriotis].-A. Caravias, Atenas, 1964. $183 \mathrm{pp}$.

19-2732. García Lorca, Federico-Primeras canciones. Canciones. Seis poemas gallegos. $4^{a}$ ed.-Losada, Buenos Aires, 1965. 128 pp. (Bibl. clásica y conlemporánea, 151).-V. núm. 17-1960.

19-2733. GArcia Lorca, Federico-[Llanto por Ignacio Sánchez Mejias. Trad. de Klitos Kyrou].-Thessalonike, 1963. 16 pp.

19-2734. LoRE1S, H. J. - "Waarom de Llanto van Lorca opnieuw vertaald?" De Vlanmse Gids, 49 (1965), 30-41.
19-2735. García Iorca, FEoErico-Poeta en Nueva York (1929-1930). Sel. y estudio por P. L. Avila.-La Goliardica, Milano, 1965. $73 \mathrm{pp}$.

19-2736. García LorCA, FEDERICo-Poeta a Nuova York. Introd. e versioni di Carlo Bo._Guanda, Parma, 1965. 115 pp. (Piccola fenice, 21).

19-2737. Río, A. DEL_-'Poeta en Nueva York: pasados veinticinco años". $-E L E C$, 251-293.

19-2738. MARCILly, C.-Ronde et fable de la solitude $\dot{a}$ New York (N. 18 2927) . || LR, 19 (1965), 99-100 (Borgers) ; BHS, 41 (1964), 202-203 (Morris) .

19.2739. AÑEz, M. E.-."lnterpretación de algunos aspectos de Poeta en Nueva York".-AF, 4 (1965), 297-307.

19-2740. NÉmETH, L. - “García Lorca színpada”. — Nagyvilág, 1957, 899-918. [Reprod. y ampliado en su libro Saj$k$ ódi esték (Budapest, 1961), pp. 238. 283].

19-2741. Alberich, J- "El erotismo femenino en el teatro de García Lorca". —PSA, 39 (1965), 9-36.

19-2742. Carbonell, D. - "Tres dramas existenciales de F. García Lorca".CuH, 64 (1965), 118-130.

19-2743. García Lorca, Federico-Doña Rosita la soltera o El lenguaje de las flores. $6^{\text {a }}$ ed.-LLosada, Buenos Aires, 1965. (Bibl. contemporánea, 113) .-V. núm. 18-2935.

19-2744. RÉMY, P._-"Le chromatisme dans Bodas de sangre". _. RG, 10 (1965), 43-79.

19-2745. García Lorca, Federico-Yerma. $7^{\text {a }}$ ed.-Losada, Buenos Aires, 1965. 101 pp. (Bibl. clásica y contemporánea, 131) -.V. núm. 18-2939.

19-2746. SÁNchiez Díaz, C.-_"Sobre la infecundidad de Yerma".- $A F, 4$ (1965), 247-259.

19-2747. Lotr, R. E.- "Yerma: the tragedy of unjust barrennes".-MD, 8 (1965) , 20-27.

19-2748. García LORCA, Federico - La casa di Bernarda Alba. Trad. V. Bodini.-Einaudi, Torino, 1965. 63 pp.

19-2749. IClesias BARBA, M. D.- "La casa de Bernarda Alba".-MB, 4 (1965), 163-165. [Sobre una representación del drama en Barcelona].

19-2750. BLUEFARB, S.-"Life and death in Garcia Lorca's House of Bernarda Alba".-DS, 4 (1965), 109-120.

19-2751. MonTe, A. DEI_-'11 realismo di 
La casa de Bernarda Alba",_Belf, 20 (1965) , 130-148.

19-2752. Rubia BArcla, J.-_El erealismo mágico, de La casa de Bernarda Alba". -RHM, 31 (1965), 385-398.

19-2753. García Lorca, Federico-“Cinco cartas inéditas" [a Adriano del VaIIe]. Publ. por R. Marrast._fns, 1965, núms. $228 / 9$.

V. también núms. 2361, 2403, 2451, 2671, 4058.

19-2754. "Rafael Alberti, premio Lenin de la paz"._LS, 1965, 7, 136-137.

19-2755. GONZÁlez LANUzA, Eduardo Rafael Alberti__Ediciones Culturales Argentinas, Buenos Aires, 1965. 194 pp. (Clásicos universales).

19-2756. Gullón, R.—Alegrias y sombras de Rafael Alberti. Segundo momento".-Asom, 1965, núın. 1, 27-36; nưm. 2, 22-35.

19-2757. GatTo, A._.'L'inedito stupore del creare".-Europa Letteraria, 1965, núm. 33. [Sobre Alberti].

19-2758. FuENTE, P. DE LA-"Ralael Alberti en Roma". $-S N, 44$ (1965), 180 191.

19-2759. Fuente, P. DE LA-“Rafael en Roma".-Íns, 1965, núm. 222.

19-2760. F[E1Jóo], S-“Rafael Alberti y Juan Ramón Jiménez". - Islas, 1965, nưm. 19, 95-96.

19-2761. Connell, G. W.-"The end of a quest: Alberti's Sermones and $\mathrm{Mo}$ radas and three uncollected poems". $H R, 33$ (1965), 290-309.

19-2762. AlbERTI, RAFAEL - Selected poems. Ed. and transl. by Ben Belitt. Introd. by Luis Monguió,_-University of California Press, Berkeley, 1965, 219 pp. $\| H, 51$ (1968), 367 (Johnson); $B H S, 44$ (1967), 305 (Morris) ; $R N C$, 1966, núm. 176, 87-89 (Tello [y réplica de Belitt]) .

19-2763. AlBerTI, RAFAEL-Abierto a todas horas (1960-1963).-A. Aguado, Madrid, 1964. 112 pp. (Col. Guiomar). I) $I A L, 1965$, núm. 196 (Azanco); $M a p$, 1965, núm. 1, 204-206 (Fernández Molina) .

19-2764. Albert, RAFAer-Qui a dit que nous étions morts? Trad. C. Couffon.Les Editeurs Français Réunis, Paris, 1965. || $L N L, 1965$, núm. 4, 100 (Larrieu) .

V. también núm. 3079.

19-2765. FeAl DeIBE, Carlos-la poesia de Pedro Salinas.-Gredos, Madrid, 1965. 265 pp. (BRH, Estudios y ensa- yos, 83) _._V. núm. 18-2976. ||$B H S, 43$ (1966), 229-231 (Connell); Fil, 10 (1964) , 239-243 (Cowes); CFil, 1 (1967), 125-126 (Genoud) ; ALitt, 8 (1966), 509 (Horányi); $E L, 1966$, núm. 344 (Iglesias); HR, 36 (1968), 72-74 (Jiménez); $L N L, 1966$, nún. 1, 116-117 (Larrieu); Ins, 1966, núm. 231 (Mainer); $H, 50$ (1967), 187 (Palley); $P E s p, 1965$, núm. 151 (Umbral).

19-2766. Ontẫón de Lope, P.-"Tres aspectos de la poesla de Pedro Salinas".-ALM, 5 (1965), 123-140.

19-2767. Palley, J.-"Presagios de Pedro Salinas".- $H, 48$ (1965), 437-441.

19-2768. Helman, E.-"Pedro Salinas y la critica desde dentro".-RHM, 31 (1965) , 222-229.

19-2769. MARICHAL J-“Pedro Salinas: la voz a la confidencia debida".-ROcc, 9 (1965), 154-170.

19-2770. Salinas, PEDro - La voix qui t'est due. Prol. de Mathilde Pomès, trad. de Bernard Sesé.-Centre de Documentation Universitaire, Paris, 1965. 80 pp. ||$B H i, 68$ (1966), 415 (Laffranque) .

19-2771. Cowes, Hugo W.-Relacion yotu y trascendencia en la obra dramatica de Pedro Salinas._Fac. de Filos. y Letras, Universidad, Buenos Aires, 1965. 165 pp. ||$H R, 36$ (1968), 203204 (Debicki); $B H i, 69$ (1967), 295 (Sesé) .

19-2772. JimÉnez Martos, L. — "Jorge Guillén, entre naturaleza e historia".-. LEsp, 1965, núm. 94.

19-2773. DEHENNIN, E.- "Introduction à l'oeuvre poétique de Jorge Guillén".RUB, 17 (1965) , 288-304.

19.2774. Gurllén, Jorce — Selección de poemas._Gredos, Madrid, 1965. 294 pp. (Antologia hispánica, 23) . \|Ins, 1965, núm. 222 (Alfaro); Asom, 1965, núm. 2, 60-62 (Cano); Asom, 1968, núm. 1, 70-72 (Ciplijauskaité) ; PEsp, 1965, núm. I48 (Murciano); $H, 49$ (1966), 892-893 (Palley).

19-2775. BATEs, M._Notes on a translation of Jorge Guillén's Primavera delgada".-FHH, 61-63.

19-2776. Cano, J. L._La poesía ‘comprometidas de Jorge Guillén".-CuD, 1965, núm. 25.

19-2777. Pinna, M.-“J. Guillén... Que van a dar en la mar".-SLS, 443-449. V. también núm. 1619.

19-2778. Johansson, K. A._."Poet i inbordeskrigets Spanien".-_Studiekamra- 
ten, Lund, 47 (1965), 101-102. [Miguel Hernández].

19-2779. Cano Ballesta, J.-La poesia de Miguel Hernández (N. 18-2999) . II HuT, 12 (1964), 218-219 (Fernández); $R L M o, 1966$, núm. 5, 172.173 (Pouget).-V. núm. 18-6400.

19-2780. Valente, J. A-"Miguel Hernández: poesía y realidad".-Ins, 1965, núms. 224/5; Diál, 1965, núm. 6, 27 30.

19-2781. HerndNdez, Miguel - Poemas. Sel. de J. Manresa. Introd. de J. I. Cano._.Plaza y Janés, Barcelona, 1964. $134 \mathrm{pp}$. (Sel. de poesía española). $\| R y F$, 172 (1965), 496 (Castro y Delgado); BHi, 67 (1965), 212 (Laffranque).

19-2782. Hernández, Migufl - Gedichte. Poemas. Aus dem Spanischen von Katja und Erich Arendt. - Kiepenheuer \& Witsch, Köln-Berlin, 1965. 336 pp. [Bilingüe].

19-2783. Homenaje a Emilio Prados. Ed. por Angel Caffarena.-El Guadalhorce, Málaga, 1964. 14 hojas.

19-2784. Prados, Emillo-Úlitimos poemas. Pról, de Carlos Blanco Aguinaga. - El Guadalhorce, Málaga, 1965. 118 pp. I| $A L M, 6$ (1966-67), 254-256 (Fernández Molina); PSA, 41 (1966), 220.222 (Molina).

19-2785. CANo, J. L._._"Un diario íntimo de Emilio Prados"._Diál. 1965, núm. 6, 23-26.

19-2786. Gariano, C._-“Aspectos clásicos de la poesía de Luis Cernuda"... $H$, 48 (1965) , 234-246.

19-2787. NEWMAN, ROBERT KENDALL Luis Cernulda: A neo-romantic's view of the world.-[Tesis, Indiana Univ.; resumen en $D A, 25$ (1964-65), 6632].

19-2788. CeRnUdA, Luis-La realidad $y$ el deseo. 4a ed., aumentada con $L a$ desolación de la quimera.-F.C.E., México, 1965. 384 pp.-V. núm. 16-44565.

19-2789. L.ón, M. T.- "Luis Cernuda, entre la realidad y el deseo".-Unión, La Habana, 4 (1965), núm. 4, 104-108.

19-2790. Lozano, E.-."Una carta de Luis Cernuda".-AH, 42 (1965), 297-298.

V. también núms. 2324, 2400-2, 2409.

19-2791. CarranzA, M. M.- "Hablando con un gran poeta: Vicente Aleixandre"- $B C B, 8$ (1965) , 1539-1545.

19-2792. Gauthier, M._."Vicente Aleixandre, Narcisse écartelé".- $-L N L, 1966$, nún. $1,84-104$.

19-2793. Homenaje a Vicente Aleixandre._Gráf, Parramón, Manresa, 1964.
77 pp. (El bardo, 5). \|EL, 1965, núm. 308 (Jiménez Martos).

19-2794. MarrA, N.-"La poesía de Vicente Aleixandre". - Temas, Montevideo, núm. 4, 26-29.

19-2795. AleixandRe, Vicente - Presencias. Poesias.-_Seix Barral, Barcelona, 1965. 178 pp. (Biblioteca breve, 208). II Ins, 1965, núm. 227 (Alfaya); $H$, 50 (1967), 389-390 (Cannon); Res, 2 (1965) , 285-289 (Loring); $B A b r, 40$ (1966), 450-451 (Sarmiento); CuA, 1966, núm. 5, 255-256 (de la Selva).

19.2796. ALEIXANDRE, VICENTE-Retratos con nombre. - Ifac, Barcelona, 1965. 108 pp. (El bardo). || fns, 1965, núm. 227 (Alfaya); Asom, 1965, núm. 3, 59-60 (Cano); Espiral, Bogotá, 1965, núm. 96 (Garavito); $E L, 1965$, núm. 326 (Jiménez Martos) ; PSA, 39 (1965), 95-102 (de Luis); RLit, 29 (1966), 246.249 (Mantero); PEsp, 1965, núm. 156 (Umbral) .

19-2797. FERRÁn, J.--"Mirada cimal. Vicente Aleixandre y sus Retratos con nombre".-Eco, 11 (1965), 496-506.

V. también núm. 2409.

19-2798. MACrì, O._-"Dámaso Alonso"$A p L, 1965$, núm. 31, 133-134.

19-2799. Gullón, R.-"El otro Dámaso Alonso".-PSA, 36 (1965), 167-196.

19-2800. FUENTES, M. R. - "Nuestro Gerardo Diego".-PE, 1966, núms. $112 /$ 113.

19-2801. Diego, G.-Mi Santander, mi cuna, mi palabra (N. 17-2056). $\| P S A$, 32 (1964), 211-213 (de Luis); $\mathrm{CuH}$, 61 (1965), 427-432 (Miró).

19-2802. Dieco, Gerardo-Poesía amorosa (1918-1961).-Plaza y Janés, Barcelona, 1965. 207 pp. (Selecciones poesia española). || Res, 3 (1966), 37-41 (Borrego Pimentel) ; $B A b r, 40$ (1966), 451 (Sarmiento); PE, 1966, 777-780 (X). 19-2803. Diego, Gerardo - Gedichte. Ubertr. von B. Vesper-Triangel_-Gud. run Ensslin, Stuttgart, 1964. 120 pp., ilustr. || $R J, 16$ (1965), 393-397 (Lind); $N R, 76$ (1965), núm. 4 (Vordtriede).

19-2804. Diego, Gerardo - El jándalo. (Sevilla y Cádiz).-Madrid, 1964. 119 pp. (Palabra y tiempo, 18). $\| A H$, 40 (1964), 221-223 (Garcfa Fernández); $E L, 1965$, nứm. 310 (Jiménez Martos) ; PEsp, 1965, núm. 146 (Manrique de Lara).

19-2805. ALEIXANDRE, V, - "Encuentro con Leopoldo Panero", $-C u H, 63$ (1965), 100-101.—V. núm. 17-5599. 
19-2806. Bapuero, G.-"El caballero Leopoldo Panero".-CuH, 63 (1965), 106 125.

19-2807. Ruiz PeÑA, J-“"Pliego salmantino. Historia de una amistad. (Leopoldo Panero y yo)". - BIFG, 44 (1965) , 623-627; $\mathrm{CuH}, 63$ (1965), $195 \cdot$ 199.

19.2808. Tovar, A.-."Leopoldo Iuchador, Leopoldo balbuciente". - $\mathrm{CuH}, 63$ (1965) , 131-137.

19-2809. Rosales, L-_-"Leopoldo Panero hacia un nuevo humanismo".- $\mathrm{CuH}, 63$ (1965) , 35-79.

19-2810. Gullón, R.-"Leopoldo en su poesia".-CuH, 63 (1965), 157-164.

19-2811. Sото, R.-"Una incursión en los lugares de Panero".-CuH, 63 (1965), 209-218.

19-2812. Maravall, J. A.-"Poesía del alma".-CuH, 63 (1965), 138-149.

19-2813. Souvirón, J. M. - "Acerca de Dios en la poesía de Leopoldo Panero".-CuH, 63 (1965), 169-177.

19-2814. Umbral, F._.'Su poesía amorosa".-CuH, 63 (1965), 202-206.

19-2815. Miro, E.-"El hijo en Panero y en la poesía española contemporánea". $-\mathrm{CuH}, 63$ (1965), 230-256.

19-2816. Chávarri, R.- "La sociedad y su proyecto en la poesía de Leopoldo Panero".-CuH, 68 (1965), 222-226.

19-2817. GIL, I. M.-_El paisaje en la poesía de Leopoldo Panero".-C CuH, 63 (1965), 81-96.

19-2818. Diego, G.-_"La tela delicada de Leopoldo Panero".-CuH, 64 (1965), 467-488.

19-2819. Sánchez-Camargo, M.- "Leopoldo Panero y la pintura española contemporánea".—CuH, 63 (1965), 186 191.

19-2820. Panero, L. - Poesia (N. 183044). $\| A t l, 3$ (1965), 108-I10 (Hierro) ; $H, 47$ (1964), 662 (Ruiz-Fornells)

19-2821. NúÑEZ, A.-Encuentro con Luis Rosales".-Ens, 1965, núms. 224/5.

19-2822. Celaya, Gabriel-Baladas y decires vascos. - Ifac, Barcelona, I965. (CoI. El bardo). \| PSA, 40 (1966), 109-110 (Molina); PEsp, 1965, núm. 156 (Umbral) .

19-2823. Celaya, Gabriel-La lintema sorda._Ifac, Barcelona, 1964. 38 pp. (El bardo, 1). I| PEsp, 1965, núm. 150 (F. V.) ; PSA, 37 (1965), 106-112 (Yrache) .

V. también núm. 2462.
19-2824. Benito DE Lucas, J. - "José Hierro en Berlín".-EL, 1965, núm. 316.

V. Lambién núms. 2409, 2462.

19-2825. Romano Colangeli, Maria-José Luis Hidalgo, poeta della morte.Pátron, Bologna, 1965. 219 pp. - V. núm. 17-5598.

V. también núm. 2462.

19-2826. Miró, E. “"La poesía trascendida de Concha Lagos". - PSA, 39 (1965), 237-251.

19-2827. Crespo, ANGeL-Poesic. A cura di Mario di Pinto._Salvatore Sciascia Editore, Caltanissetta-Roma, 1964. 237 pp. || BHS, 4.3 (1966) , 137-139 (Terry) .

19-2828. CREsPo, ANGEL-Cartas desde un pozo._La Isla de los Ratones, Santander, 1964. (Poetas de hoy). \| CuH, 64 (1965) , 173.177 (Soto Vergés).

19-2829. Crespo, ANGel-No sé cómo decirlo.-Carboneras de Cuenca, 1965. 60 pp. (Col. El toro de barro, 2) .

19-2830. CRESPO, ANGEL-Puerta clavada, 1958.1960.-Caballo de Mar, Montevi. deo, 1961. 43 pp. (La red y el viento).

19-2831. Gennaro, G. DI-“'L'esperienza poetica di José Maria Valverde".-Lett, 20 (1965), 427-446.

19-2832. Paraíso, M. I- “José María Valverde: trayectoria de una vocación asumida".-CuH, 62 (1965), 383-402.

Bousoño: v. núm. 2409.

19-2833. Marra-López, J. R.- "La poesía de José Angel Valente"._fns, 1965, núm. 219.

19-2834. VALINTE, JOSÉ ANGEL-Sobre el lugar del canto (1953-1963).-J Jaime Sa. linas, Barcelona, 1963. 69 pp. $\| R y F$, 173 (1966), 216-217 (Brugarola).

19-2835. García Gutiérrez, J. I.-."Itinerario espiritual en la poesía de Blas de Otero".-Res, 2 (1965), 3-18.

19-2836. Alín, J. M.-."Blas de Otero y la poesía tradicional". $\rightarrow A O, 15$ (1965), 275-289.

19.2837. Cano, J. L.-"El tema de España en Blas de Otero".-Ins, 1965, núm. 221.

19-2838. OTERo, BLAS $\mathrm{DE}$ Que trata de España. Poesías.-Edit. R. M., Barcelona, 1965. 101 pp. || Res, 3 (1966), 123124 (Gutiérrez); $C U, 1966$, núm. 90, 240-242 (Lopetegui); CuA, 1965, núm. 6, 276-277 (de la Selva).

V. también núms. 245I, 2462.

19-2839. Gaos, VICENTE-Concierto en mi y en vosotros.-Universidad de Puerto Rico, Rio Piedras, 1965. || fns, 1966, 
núm. 239 (Cano); EL, 1966, núm. 353 (Jiménez Martos); CuH, 73 (1968), 159-164 (Miró) ; PSA, 43 (1966), 265267 (Molina) ; $I A L, 1966$, núm. $213(\mathrm{X})$. Brines: v. núm. 2409.

\section{Épica}

19-2840. CatalÁN, D.-“Crónicas generales y cantares de gesta" (N. 18-3077). || $L R, 20$ (1966), 288 (Groult); BICC, 22 (1967), 306-307 (Valderrama Andrade)

19-2841. IAPESA, R.-“La lengua de la poesía épica en los cantares de gesta y en el romancero viejo".-ALM, 4 (1964), 5-24.

19-2842. Gómez Pérrz, J.- "Leyendas del ciclo carolingio en España".-RLit, 28 (1965) , 5-18.

19-2843. DEYERMOND, A. D.-"The singer of tales and the medieval Spanish epic"_BHS, 42 (1965), 1.8.

19-2844. Muñoz GoNzález, L. — "Andrés Bello y los orígenes de la epopeya romancesca".- $A, 1965$, núm. 410, 125 . 133. [Sus estudios sobre el Poema del $C i d]$.

19-2845. TEJERA, M. J.-“La investigación [de A. Bello] sobre el Cantnr de mio Cid". $-R N C, 1965$, núm. 172, 69-73.

19-2846. CIISSOLD, STEPHEN_In search of the Cid.-Hodder \& Stoughton, London, 1965. 254 pp., ilustr. \| BHS, 44 (1967) , 54-55 (Smith) .

19-2847. Menéndez Pidal, RaMón-En tor. no al "Poema del Cid". 2" ed.E.D.H.A.S.A., Barcelona, 1965. 222 pp. (El puente)...V. núm. 18-6471.

19-2848. MENÉNdez PDAL, R.-Cantar de mio Cid".-[En] Gran enciclopedia del miındo, t. 4 (Bilbao, 1962); 28 cols. II SLS, 394-395 (Galina).

19-2849. Martínez de Pisón, E.-_Bien e tan mesurado"._Ins, 1965, núms. 224/ 5. [Sobre trabajos de Menéndez Pidal y Laza Palacio].

19-2850. Poema de mio Cid. 7: ed.Aguilar, Madrid, 1965. 467 pp. (Crisol, 96).-V. núm. 18-6474.

19-2851. Poema del Cid. Pról. y notas de Ramón Menéndez Pidal. 11\% ed.-Espasa-Calpe, Madrid, 1966. 299 pp. (Clás. cast., 24) -V. núm. 18-3081.

19-2852. Poema del Cid. Versión de Pedro Salinas. 2: ed.-Losada, Buenos Aires, 1966. 249 pp. (Bibl. contemporánea, 170) - -V. núm. 18-3082.

19-2853. Horrent, J.-."Notes de critique textuelle sur le Cantar de mio Cid".$M M D, 2,275-289$.

19-2854. Huerta, E.-.La primera hoja del Mio Cid".-HAC, 259-265.

19-2855. Poema de mio Cid. Versión de Pedro Salinas. 3a ed.-Rev. de Occidente, Madrid, 1965. 232 pp. (Selecta).V. núm. 18-3082.

19-2856. CALdera, ERMANNo-“L'oratoria nel Poema de mio Cid".-MSI, 1965 , núm. 10, 5-29. || BHi, 70 (1968), 180 (Mercadier) ; RLit, 28 (1965) , 255 (Rodriguez Cepeda).

19-2857. WEBBER, R. H.-“Un aspecto estilístico del Cantar de mio Cid".-AEM, 2 (1965), 485-496.

19-2858. Picciotto, RoberT S.-Dramatic and lyrical unity in the "Cid" and the "Roland".-[Tesis, Indiana Univ., resumen en $D A, 25$ (1964-65), 29662967].

19-2859. Battaglia, S.—'Poesia e realtà nel Poema de mio Cid"._-[En] La coscienza letteraria del Medioevo (Napoli, 1965) , 151-169.

19-2860. Guclielmi, N.- "Cambio y movilidad social en el Cantar de mio Cid".$A H A$, 1963-65, núm. 12, 43-65.

19-2861. SMuth, C. C._-"Did the Cid repay the Jews?--Ro, 86 (1965), 520538.

19-2862. BANDERA-GÓmEz, C.--'El sueño del Cid en el episodio del león".-MLN, 80 (1965) , 245-251.

19-2863. Horrent, J-_'La prise de Castejón" (N. 18-3089). $\| A E M, 1$ (1964), 710 (Argemí de Abadal).

19-2864. Huici Miranda, A.- "Las luchas del Cid Campeador con los Almorávides y el enigma de su hijo, Diego".-Hespéris-Tamuda, 6 (1965).

19-2865. Huici MirandA, A._"El cadí de Valencia Ibn Yahhaf, quemado vivo por el Cid",-RIEI, 11/12 (1963-64), 149167.

19-2866. AGuirre Beliver, JOAQuíN-El juglar del Cid. 2a ed.-Doncel, Madrid, 1965. 144 pp. (La ballena alegre)...V. nưm. 16-48543.

19-2867. Gafaell, María Luisa-El Cid.Noguer, Barcelona, 1965. \|t ins, 1966, núm. 238 (Canito).

19-2868. SHOLOD, BARTON-Charlemagne in Spain: the cultural legacy of "Roncesvalles".-[Tesis, Columbia Univ.; resumen en $D A, 25$ (1964-65), 1219].

19-2869. LACARRA, J. M.-_Roncesvalles y la Chanson de Roland"._EEM, 7 (1962), 762-764. 
19-2870. Armistead, S. G., \& J. H. SilVERMAN- "Sobre unos versos del cantar de gesta de las Mocedades de Rodrigo conservados tradicionalmente en Marruecos".-ALM, 4 (1964), 95-107.

19-2871. Nougué, A._"Bibliografia sobre Fernán González".-BIFG, 44 (1965), 755.763 .

19-2872. Pt́rez de Urbel, J. - “Fernán González: su juventud y su linaje’.HJV, 47-72.

V. también nưms. 1620-5, 1720, 2266, 2473.

\section{Romancero}

19-2873. Menéndez Pidal, Ramón - Romancero tradicional. T. 2: Romanceros de los condes de Castilla y de los in. fantes de Lara._Gredos, Madrid, 1963. vii +298 pp.-V. núın. 13-37350. \| ZRPh, 81 (1965), 205-208 (Rüegg); BHS, 42 (1965), 50-52 (Smith) .

19-2874. MENÉNDEZ PIDAL, RAMón-Flor nueva de romances viejos. 20 ! ed.-Espasa-Calpe, Madrid, 1965. 317 pp._-V. núm. 13-3735I.

19-2875. Smith, C. ColnN (ed.) -Spanish ballads._Pergamon Press, Oxford, 1964. 220 pp. || ZRPh, 82 (1966), 679.680 (Baldinger); $H, \quad 50$ (1967), 206-207 (MacCurdy) ; $M L N, 82$ (1967) , 644-645 (Morley); BHS, 42 (1965), 186-187 (Wilson).

19-2876. Moser, G. M.-"A litherto unknown ballad of the cycle of the Infantes de Lara".-HR, 33 (1965), 383387.

19-2877. Gatdaru, Demetrio - Factores orientales, griegos y egipcios en la ela. boración del tema literario de "Fonte frida".-Sep. de Humanidades, Ia Pla(a. 38 (1961), 139-168.

19-2878. Solf-Solé, J. M.- "En torno al romance de la morilla burlada".- $H R$, 33 (1965) , 136-146.

19-2879. Barceló Verdú, JoAquín-El ro. mancero español y las "embajadas" de Sax. Moros y cristianos._Sax (Alicante), 1965. 117 pp. $\| B H i, 67$ (1965), 408 (Ricard) .

19-2880. Profeti, M. G.- "Berchet e le vecchie romanze spagnuole". - $M S I$, 1965, núm. 10. || RIit, 28 (1965), 256 (Rodriguez Cepeda) .

19-2881. Böhmer, Ursula_Die Romanzc in der spanischen Dichtung der Gegenwart. - Romanisches Seminar der Universität, Bonn, 1965. 269 pp. (Romanistische Versuche und Torarbeiten,
16). || $H R, 36$ (1968), 185-189 (Siebenmann) ; $R F, 79$ (1967), 681-684 (Siebenmann); $R J, 18$ (1967), 386-389 (Sobejano) ; $B H S, 44$ (1967), 235-236 (Terry); LR, 22 (1968), 402 (Vermeylen).

19-2882. Armistean, S. G., \& J. H. SilVERMAN_Diez romances hispánicos en un manuscrito sefardl de la Isla de Rodas (N. 18-6508). \| SLS, 335-340 (Caldera) .

19-2883. Armistead, S. G., y J. H. SilverMAN_- Influencias griegas en el folklo. re sefardi: Ia Balada del puente de Arla".-Davar, 1965, núm. 107, 97-104.

19-2884. Armistead, S. G., y J. H. SilverMAN_-"Christian elements and de-christianization in the Sepluardic romancero". $-H A C, 21-38 . \|$ Sef, 26 (1966), 448-449 (Hassán).

19-2885. REDONDO DE FELDMAN, S-_Romances viejos en la tradición popular cubana".-RHM, 31 (1965), 965-372.

19-2886. Feijóo, Samuer (ed.) -El movimiento de los romances cubanos del siglo xix._Universidad Central de las Villas, [La Habana], 1964. 4.36 pp. $\| H$, 49 (1966), 896 (Sardiña).

V. también núms. 1477, 1482, 1770, 2072 , 2841, 3159, 3302.

\section{TEATRO}

19-2887. Bonnin, H.- "Instituto del Teatro de Barcelona. Un cuarto de siglo"__PA, 1965̆, núm. 70.

19-2888. SASTRE, A.- "Lo nuevo y lo viejo en el teatro español. Planteamientos generales".- $P A, 1964$, núm. 51 .

19-2889. Quinto, J. M. DE-"Lo nuevo y lo viejo en el teatro español. La critica".-PA, 1964, núm. $5 \mathrm{I}$.

19-2890. Muñoz, Matilde - Historia del teatro en España. Puesta al dla con un apéndice de A. Retana. T. 1: El drama y la comedia; t. 2: La opera y el Teatro Real; t. 3: La zarzuela y el género chico-Tesoro, Madrid, 1965. 318, 262, 328 pp.--V. núm. 8-11671.

19-2891. Albrun, Chardes V.-Histoire du theatre espagnal.-P.U.F., Paris, 1965. 128 pp. (Que sais-je?, 1179). \|CuH, 66 (1966), 6I6-618 (Amoros); RHM, 32 (1966), 118 (Jaimes-Freyre); LMo, 59 (1965) , 856.857 (Larrieu); LNL, 1965, núm. 4, 103-106 (Larrieu), Seg, I (1965), 426.428 (Rozas); $A U P, 36$ (1966) , 266267 (X) .

19-2892. Criado de Val, Manuel (ed.) Teatro medieval.-Taurus, Madrid, 1963. 
211 pp. (Col. Temas de España, 18). || Seg, 1 (1965), 176-178 (Roldán).

19-2893. Romev Figueras, J.- "Teatro hispánico del período románico". $-E E B$, 1963, núm. 9, 7.27.

19-2894. ROMEU Figueras, J.- "La canción popular navideña, fuente de un misterio dramático de técnica medieval".-AnM, 19 (1964), 167-184.

19-2895. Ferrairo de Orduña, L.- "La adoración de los pastores".-Fil, 10 (1964), 153-178. [Auto de los Reyes Magos, Gómez Manriquc, Fr. Iñigo de Mendoza, Juan del Enzina, Lucas Fernández].

19-2896. Entrambasacuas, J. DE-"La literatura dramática española en el siglo xv1".--El Escorial, 1563.1963 (Ma. drid, 1963), 1, 603-632.

19-2897. FroldI, RINALDO-Il teatro valenzano e l'origine della commedia ba. rocca._Università di Pisa, 1962. $112 \mathrm{pp}$. $\| H, 47$ (1964), 866-867 (Fucilla) ; RLit, 21 (1962), 181.183 (Juliá Martínez); $A r b, 56$ (1963), 321-322 (Larrea); HR, 32 (1964), 265-268 (Morby).

19-2898. McCreAdy, W. T., \& R. R. Bishop - "A current bibliography of forcign publications dealing with the comedia". $-B C, 1964$, núm. 1, 20-27; núm. 2, 16-19; 1965, núm. 1, 9.11; núm. 2, 3วั-39.-V. núm. 18-3128.

19-2899. WeBber, E. J.-"Hispano-Italian Renaissance drama: notes on opportunities and problems".- $R D, 7$ (1964), 151-158.

19-2900. Reynolds, J. J-LLibro 43: un tomo colecticio del siglo xyII",-_Hf, 1964, núm. 21, 31-40.

19-2901. Moll, J.-"Catálogo de comedias sueltas conservadas en la Biblioteca de la Real Academia Española".BRRAE, 44 (1964), 113-168, 309-360, $541.556 ; 45$ (1965), 203-235; 46 (1966), $125-158$.

19-2902. MCKNIGHT, W'ilLiAM A., \& MABEL BARRETT JONES-A catalogue of "co. medias sueltas" in the Library of the University of North Carolina.-Univ. of Nortl Carolina, Chapel Hill, 1965. 240 pp. $\| M L J, 51$ (1967), 364 (Ashcomb) ; $S A B, 32$ (1967), 23-24 (Hayes) ; $B C, 17$ (1965) , 34-35 (MacCurdy) ; HR, 34 (1966), 383 (McCready); PBSA, 62 (1968) , 160 (Thompson) ; H, 50 (1967), 386 (Whitby).

19-2903. Ashcom, B. B.-A descriptire cnlalogile of the Spanish "comedias suellas" in the Wayne State University
Library and the privale library of Professor B. B. Ashcom.-Wayne State University Libraries, Detroit, Mich., 1965. 103 pp. || MLJ, 51 (1967), 368369 (Castañeda) ; BHS, 43 (1966), 303 (Dixon); Seg, 2 (1966), 203-204 (Rozas).

19-2904. SubirÁ, José-Catálogo de la sección cle música de la Biblioteca Municipal de Madrid. T. 1: Teatro menor, tonadillas y sainetes-Artes Gráficas Municipales, Madrid, 1964. $396 \mathrm{pp}$. \| BHi, 69 (1967), 280-281 (Bourligueux).

19-2905. Aubrun, CH. V.-“Les débuts du drame lyrique en Espagne".-[En:] J. JAcQuor (ed.), Le lieu thétral à la Renaissance (Paris, 1964), 423.444.

19-2906. BENEDEK, M.-"Spanyol és angol reneszánsz színház".-[En su libro] Könyv és szinház (Budapest, 1963), pp. 385.404.

19-2907. BrüggemanN, Werner - Spanisches Theater und deulsche Romantik. Bd. 1.-Aschendorffsche Verlagsbuchlaandlung, Münster, 1964. 275 pp. (Spanische Forschungen der Görresgesellschaft, 2 Reihe, 8 Bd.). || ElG, 21 (1966), 300-301 (Ayrault); Seg, 1 (1965), 428429 (Diez Taboada); $F M$, 1965-66, núms. 21/22, 59.73 (Juretschke); $R y F$, 173 (1966), 327 (Ilorca); BHS, 42 (1965) , 266-268 (Orton) ; Era, 18 (1966), 734-737 (Owen); $C L, 18$ (1966), 7980 (Schwarts).

19-2908. SANCHez Escribano, Federico, y ALrerto PORQUERAS MAYO-Preceptiva dramática española del Renacimiento y el Barroco-Gredos, Madrid, 1965. 258 pp. (BRH). || fns, 1966, nums. 236/7 (Ares Montes) ; H, 50 (1967), 386-387 (Ashcom); HuNL, 1967, núm. 8, 708 . 712 (Ayala); RHM, 32 (1966), 252 (Bleznick); BHi, 68 (1966), 407-408 (Canavaggio); Hf, 1967, núm. 29, 66 (Ebersole) ; $A L M, 6$ (1966-67), 248-251 (Lope Blanch); HR, 36 (1968), 276279 (Riley) ; Seg, 2 (1966), 197-201 (Rozas) ; $M L N, 82$ (1967) , 266-269 (Wardropper).

19-2909. MANcinI, G.-."Qualche considerazioni sulla precettistica teatrale del Siglo de Oro".-MSI, 1965, 27-43. || RLit, 28 (1965) , 254-255 (Rodrfguez Cepeda).

19-2910. Morr, D.-"The classical tradition in Spanish dramatic theory and practice in the seventeenth century".Classical drama and its influence: Es- 
says presented to H. D. F. Kitto (New York, 1965) , I93-228.

19-2911. JosÉ PRADEs, JuANA DE-Teoría sobre los personajes de la comedia nue. va, en cinco dramaturgos._C.S.I.C., Madrid, 1963. 337 pp. (RLit, anejo 20) || NT, 2I (I963), 605 (C.R.S.M.); $R F E, 46$ (1963), 480-482 (Díez Taboada): Seg, 1965, núm. 1, 147-149 (Esquer Torres); RLit, 23 (1963), 281283 (Herrero); Ber, 18 (I963), núm. 65, 108 (Lope Toledo) ; RHM, 30 (1964), 145-146 (Porqueras-Mayo); Era, 19 (1967), 279-281 (Pörtl); N, 49 (1965), 181 (Van Praag).

19-2912. Rennert, Hugo A.-The Spanis/ stage in the time of Lope de Vega.Dover, New York, 1965. xv + 403 pp. 19-2913. Díz-PLAJA, G_"Una aportación al estudio de la técnica escénica tradicional". - EMP, 6, 327-337.-V. núm. 13-35475.

19-2914. Roux, L.-“Un exemple d'amenagement de lieu théatral à l'occasion d'une canonisation"._-[En] J. JAcQuoT (ed.), Le lieu théatral d la Renaissance (Paris, 1964), 253-258.

19-2915. Roux, L.-“Quelques aperçus sur la mise en scène de la comedia de san. tos dans la première moitié du xuie siècle".-[En] Le lieu théâtral à la Renaissance (Paris, 1964), 235-252.

19-2916. Shergold, N. D.- "Le dessin de Comba et l'ancien théâtre espagnol".[En] Le lieu theatral à la Renaissance (Paris, 1964), 259-272.

19-2917. SASSONE, H._."El teatro español en los temas y en el tiempo".- $C U, 1964$ 65, nưm. 87, 50-58.

19-2918. Ruple, J. — "Teaching cultural themes using the Spanish theatre". $-H$, 48 (1965), 511.516.

19-2919. Manson, William R.-Attitudes toward authority as expressed in typical Spanish plays of the Golden Age.-[Tesis, Univ. of North Carolina; resumen en $D A, 25 \quad(1964-65), 4703]$.

19-2920. MacCurdy, R. R.-“La tragédie neo-sénéquienne en Espagne au xviLe siècle et le thème du tyran".-[En] J. JACQUot (ed.), Les tragédies de Sénèque et le thèatre de la Renaissance (Paris, 1964), 73-85.

19-2921. FlecniakoskA, J. L.-'L'horreur morale et l'horteur matérielle dans quelques tragédies espagnoles du xvie siècle".-[En] Les tragédies de Sénéque et le theatre de la Renaissance (Paris, 1964), 61-72.
19-2922. Salomon, Nö̈L-Recherches sur le thène paysan dans la "comedia" au temps de Lope de Vega.-Institut d'Etudes Ibériques et Ibero-américaines de l'Université, Bordeaux, 1965. xxxiv + 946 pp._V. núm. 14-41233, || fns, 22 (1967), nưm. 250 (Azaña); CuH, 72 (1967), 226-233 (Gil Novales); $R F E$, 49 (1966), 365-385 (López Estrada); CuA, 1967, nưm. 2, 156-177 (Tuñón de Lara).

19-2923. W'EBER DE KurLat, F._-“Sobre el negro coino tipo cómico en el teatro español del siglo xvI'.- $R P h, 17$ (196364) , $380-391$.

19-2924. Balashov, N. I.-["Problemas renacentistas en comedias españolas del siglo xvil sobre temas eslavos"]._. Slavianshie literatury (Moskva, 1963), 89124. [En ruso].-V. núm. 18-3260. || $B H i$, 69 (1967), 148-152 (Zviguilsky).

19-2925. BALASHOV, N. I.-["Los manuscritos de comedias españolas sobre Rusia y la tradición humanística de la literatura en la España del siglo xvi'].IAN, 23 (1964), 18-85. [El gran duque de Moscovia, de Lope, y el Parecido de Rusia, anónimo]. || BHi, 69 (1967), 153-158 (Zviguilsky).

19-2926. Spanisches Theater. Deutsche Übertragung von Hans Schlegel und Hermann Kurz.-Winkler, München, 1964. 909 pp. [Tirso, Moreto, Guillén de Castro, Coello, Jiménez de Enciso, Cervantes].

19-2927. STARKIE, WALTER-Eight Spanish plays of the Golden Age. Transl., ed. and with an introd. by...-Modern Library, New York, 1964. xlviii +328 pp.

19-2928. AlPERN, HyMAN (ed.) - Three classic Spanish plays: The Sheep Well, Life is a dream, None beneath the king.-Washington Square Press, New York, 1964. $\mathrm{x}+229 \mathrm{pp}$.

19-2929. CaravagGi, G.-"Genesi di una fiesta burlesca anonima del xviro secolo: Las bodas de Orlando".._SLSp, 1 (1964) , 249-265.

19-2930. REcoules, H.-“Entremés farnoso y pintoresco de Los dos cornudos en uno".-BBMP, 40 (1964), núms. 1/4.

19-2931. WADE, G. E._Tour loas and their data on actors and actresses".- $B C$, 1964, nưm. 1, 9.17; núm. 2, 12-15.

19-2932. Hoppe, H. R.-"Spanish actors at Ghent and Brussels, 1594-1681".$B C, 16$ (1964), núm. 1, 17-18._V. núm. 9-17941. 
I9-2933. Ruiz-Iagos de Castro, ManuelControversias en torno a la licitud de las comedias en la ciudad de Jerez de la Frontera (años 1550-1825).-Centro de Estudios Históricos Jerezanos, Jerez de la Frontera, 1964. $106 \mathrm{pp}$.

19-2934. EsQuer TORRES, R.-"Las prohibiciones de comedias y autos sacramentales en el siglo xvir. Clima que rodeó a la Real Orden de 1765"._-_Seg, 1 (1965), 187.226.

19-2935. Flecniakoska, J. L.-La formation de l"auto" religieux en Espagne avant Calderón (N. 18-3158) . \|Atl, 2 (1965) , 215-217 (Benítez Claros); Seg, 1 (1965), 143-147 (Juliá Martínez); BHS, 42 (1965), 192-194 (Parker).

19-2936. VAzQUEz DE PRADA, A.-'Dramatización alegórica de la teología".-Atl, 2 (1964), 243-272.

19-2937. VArey, J. E.-"La mise en scène de l'auto sacramental à Madrid au xve et xvıe sićcles",-[En:] Le lieu théatral à la Renaissance (Paris, 1964), 215255.

19-2938. Shiergold, N. D., \& J. E. VAREY_-"A problem in the staging of autos sacramentales in Madrid, 1647 . 1648",-HR, 32 (1964), 12-35.

19-2939. HEIDENREICH, HELMUT _- Figuren und Komik in den spanischen "Entre" meses" des goldenen Zeitalters.-Universität, München, 1962. $221 \mathrm{pp} .-\mathrm{V}$. núm. 17-5682. || $R$ Lit, 27 (1965), 228229 (Diez Taboada); Seg, 1 (1965), 150152 (Díez Taboada); $B H S, 40$ (1963), 202.203 (Dixon); $R P h, 18$ (1964-65), 520 (Myers).

19-2940. Buendía, Fruicidad (ed.) -Antologia del entremés (siglos xvi y xuii).Aguilar, Madrid, 1965. 1000 pp. (Col. Joy'a).

19-294]. García Pavón, F. (ed.)-Teatro menor del siglo xvii. Antologia.-TTaurus, Madrid, 1964. 211 pp. (Temas de España, 19).

19-2942. GoNzALEZ Ruiz, NicolAs (ed.) Antologia de piezas cortas de tealro.Labor, Barcelona, 1965. 2 ts. xxxii + 1294 pp. || Seg, 2 (1966), 201-203 (Rull). 19-2943. SubIRA, J._-'La ópera castella. nas en los siglos xvi y xviri. (Tema con rariaciones lexicográficas) "-Seg, 1 (1965), 23-42.

19-2944. VELA, F._."El género chico".ROcc, 10 (1965) , 364-369.

19-2945. Jato Macías, M.-“Aportaciones sobre el género chico".-Proceedings of the 15th Pacific Northwest Confer. ence on Foreign Languages (Montana State Univ., 1964), 207-211.

19-2946. Iglesias BARBA, D._."La zarzuela, pieza de museo". $-M B, 8$ (1964), $177-180$.

19-2947. Herrero Garcí, Miguel - Madrid en el teatro.-Inst. de Estudios Madrileños, Madrid, 1963. 450 pp. (Bibl. de estudios madrileños, 7), |1 $B S V, 19$ (1963), 278.279 (Arocena); $R y F, 219$ (1964), 214-215 (Barinaga); RLit, 23 (1963), $261-265$ (Juliá Martínez); Ber, 19 (1964), 94-95 (Lope Toledo) ; $P E, 1963$, núms. 86/87, 123-124 (Rozas) ; Seg, 1 (1965), 149-150 (Rull). 19-2948. Jato Macías, Manufi-Repertorio de los teatros de Madrid, 1900 . 1905.-[Tesis, Northwestern Univ.; re. sumen en $D A, 25$ (1964-65), 480].

19-2949. Herrero Salgado, FÉlix-Carte. lera teatral madrileña. T. 2: 1840-1849.C.S.1.C., Madrid, 1963. 105 pp. (Cuadernos bibliográficos, 9)-V. núm. 17 . 5684. || $H R, 34$ (1966), 68-71 (Adams); $B F E, 4$ (1965) , 33 (Morales); RLit, 23 (1963) , 291-292 (Rozas).

19-2950. Acuilar PIÑAl, F_-"Las representaciones teatrales y demás festejos públicos en la Sevilla del rey José".$A H, 41$ (1964), 251-304.

19-2951. SPARKS, AMY JAMES-The honor code in representative Spanish roman. tic dramas.-[Tesis, Louisiana State Univ; resumen en $D A, 25$ (1964-65), $1220 \cdot 1221]$.

19-2952. LAPrade, JoHN HARRY-GoldenAge authors in 19th-century Spanish plays.-[Tesis, Univ. of North Carolina; resumen en $D A, 24$ (1963-64), 3750]. 289 pp.

19-2953. PEAK, J, HuNTER-Social drama in nineteenth century Spain.-Univ. of North Carolina Press, Chapel Hill, 1964. 168 pp. (Univ. of North Carolina Studies in the Romance Languages and Lileralures, 51) _V. núm. 11-25309. || $H, 50$ (1967), 185 (Jato Macías); $R R$, 58 (1967) , 302-303 (Pollin); Seg, 2 (1966) , 224-226 (Rodriguez Cepeda) ; $M L J, \quad 50 \quad$ (1966), 307-308 (Seay); RHM, 32 (1966); 118-119 (Sobejano). 19-2954. García Pavón, F.-Teatro social en España (N. 18-3173). \| RLit, 25 (1964) , 241-242 (Roldán); Seg, 1 (1965), 171-174 (Roldán).

19-2955. Monleón, J.- -El teatro en la generación del 98"._-Lyra, 1964, núms. $192 / 4$.

19-2956. Paz Vel.́zquez, F..."El teatro 
español en lo que va del siglo"-Eidos, 1963, núm. 19. || Seg, I (1965), 136138 (Dlez Taboada).

19-2957. AuB, M._Algunos aspectos del teatro español, de 1920 a 1930 ".- RHM, 31 (1965), 17-28.

19-2958. PÉREz MiNIK, D.. "Itinerario patético de una generación de dramacurgos españoles [la de 1936]".-fns, 1965, núms. 224/5.

19-2959. Auz Castro, V.- "Panorama du théatre espagnol contemporain"._Le Théâtre dans le Monde, Bruxelles, 12 , núm. 3.

19-2960. САMP, JEAN__"La evolución del teatro español contemporáneo". $-U d A$, 41 (1964), 795-814.

19-2961. Clocchintti, E.- "Espafía y su tea tro con temporáneo".-CuH, 60 (1964), 291-297; Ins, 1964, núm. 206, Supl.

19-2962. Doménech, R.-"Nuestra literatura dramática [actual]".-CuD, 1965, núms. 25, 26.

19-2963. Domt́NECH, R_cEl joven teatro".-CuH, 62 (1965), 564-568.

19-2964. LoRinG, S.- "Conversaciones sobre el teatro español actual"._-Res, 2 (1965) , 362-370.

19-2965. Rodríguez RICHART, T._Entre renovación y tradición. Direcciones principales del teatro espaniol accual".$B B M P, 41$ (1965), $\mathbf{3 8 3 - 4 1 8 . ~}$

19-2966. Ptrez de Olaguer, G.-“La nueva generación teatral española".-_Res, 1 (1964) , 257-268.

19-2967. Hidnaloo López, J._"Arte y realidad en el teatro actual",- $P N, 1965$, núm. 12.

19-2968. Cílla, M.-_"O sentido de denúncia da nova dramaturgia espanhola".$J L A, 3$ (1964), 2, I4.

19-2969, DomÉNEch, R._"La nueva literatura dramática: sentido de su lucha".-PA, 1964, nún. 54.

19-2970. Gordon, José - Teatro experimental esprañol. Antologla e historia.Escelicer, Madrid, 1965. 211 pp. (Col. $21,39)$. || RyC, 10 (1965), 302-303 (López Montenegro); Seg, I (1965). 461-463 (Ruil).

19-2971. Suelto de Sáenz, P.—“El teatro universitario espafiol en los últimos treinta años".-BICC, 19 (1964), 543557.

19-2972. Suárez Radillo, C. M._"Veinlicinco años de teatro español".CultS, 1965, núm. 38, 57-63.

19-2973. Valentini, G.-"Il teinpo e la Spagna"._L'Osservatore Politico-Lette- rario, Milano, 10 (1964), núm. 4, 69. 74. [Teatro].

19-2974. SAinz de Ronles, F. C. (ed.) Teatro español 1950-51. 8? ed.-Aguilar, Madrid, 1964. 490 pp. (Col, literaria).-V. núm. 12-30197.

19-2975. SAiNz dE Robles, F. C. (ed.) Teatro español 1961-62.-Aguilar, Madrid, 1963. 512 pp. (Col. literaria).-V. nưin. 18-9180. || Agora, 1969, núms. 79/ 82, 46 (Fraile).

19-2976. FERRER, O. P.- "Three years of Spanish theater: 1960-63'.-BAbr, 38 (1964), 28-31.

19-2977. Allvaro, Francisco_El espectador y la critica. El teatro en España en 1960,1961, 1962, 1963, 1964.-Autor. Valladolid, 1961-65. 5 ts_-V. núm. 1644840. || $E L, 1965$, núm. 328 (Aragonés).

19-2978. Rozas, J. M.- "El teatro en Madrid en la temporada 1963-64"._Seg, I (1965) , 113-128, 399-419.

V. también núms. 901, 1627-43, 2282, 2539, 3277, 3621 .

\section{$A u t o r e s$ antiguos}

19-2979. FISH, G. T.-"iHe nos venidos... Inamihala!"- $H, 48$ (1965) , 553554. [Auto de los Reyes Magos].

V. también núms. 1199, 2895.

Gómez Manrique: v. núms. 2502, 2895.

Iñigo de Mendoza: v. núms. 2509, 2895. 19-2980. Auto de la luuida de Egipto. Ed. de J. D[jez] T[aboada] y J. M. R[Ozas].-Hom, 1 (1964), 78-89.

19-2981. REDondo, A. Fernando de Rojas et l'Inquisition". $-M C F, 1$ (1965), 345-347.

19-2982. GiLmAN, S.- "Fernando de Rojas as author".- $R F, 76$ (1964), 255 . 299.

19-2983. Ferreccio PodestA, M.—“La formación del texto de La Celestina"... AUCh, 1965, núm. 198, 89-122.

19-2984. HerRIotT, J. HoMER-Towards a critical edition of the "Celestina". $A$ filiation of early editions.-University of Wisconsin Press, Madison-Milwaukee, 1964. 293 pp. || $M L J, 49$ (1965), 387. 388 (Barrick); $H, 49$ (1966), \$46-347 (Fraker) ; N, 50 (1966), 166-167 (Oostendorp) ; $S p, 41$ (1960), 145-146 (Rey); BHS, 49 (1966), 61-62 (Trotcer); $S$, 21 (I967), 358-360 (Webuer).

19-2985. Ferreccio Podestà, M. — "Hacia una edición crílica de La Celestina".$A L M, 5$ (1965) , 47-76. 
19-2986. Hodcroft, F. W.-_"La Celestina: crrores de interpretación en el estudio de su sintaxis".-FM, 1964, núm. 14, $154-156$.

19-2987. LIDA DE Malkiel, M. R.-La originalidad arlistica de "La Celestina" (N. 18-3191) . || $C d S, 1967$, núms. 6/7, 195-198 (Bermejo Hurtado); $B C B, 7$ (1964), 276-277 (Camacho); $R B P H, 44$ (1966), 738-748 (Dehennin); BAbr, 38 (1964), 172 (Hart); ALitt, 7 (1965), 473-479 (Kulin); CL, 16 (1964), 269. 274 (Morby) ; RLMO, 1965, núm. 4, 168-17I (Pauliello de Chocholus); Era, 18 (1966) , 354-357 (Rheinfelder); $N, 48$ (1964), 85-87 (Van Praag).

19-2988. Green, O. H.-"The artistic originality of La Celestina". - HR, 33 (1965) , 15-31.

19-2989. Segre, C. — “L'originalità della Celestina", $A p L, 9$ (1963), 137-144.

19-2990. DEYERMOND, A. D.-The Pelrar. chan sources of "La Celestina" (N. 17-5693). II BHi, 70 (1968), 147-151 (Heugas) ; $R R, 54$ (1963) , 286-288 (McPheeters); RLSP, 5 (1964), 290-294 (Mendonça) ; $R L M o, 1967$, núm. 6, 119. 120 (Nallim) .

19-2991, ReynolDs, J. J.-_" "La moça quc esperaua al ministro (Celestina, aucto III) ".-RNo, 5 (1964), 200-202.

19-2992. MOORE, J. A.- "Ambivalence of will in La Celestina"._H, 47 (1964), 251-255.

19-2993. Russell, P. E.-"Literary tradition and social reality in La Celestina"-BHS, 41 (1964), 230-237.

19-2994. Marayall, José Antonio - El mundo social de "La Celestina"._Gredos, Madrid, 1964. 165 pp. (BRH, Estudios y ensayos, 80). || BAbr, 40 (1966), 68 (Angeles); Ins, 1965, núm. 221 (Ares Montes) ; $H, 50$ (1967), 181-182 (Ayllón); IAL, 1966, núm. 207 (García); ROcc, 11 (1965), 115-127 (Gómez Мarín); $R E P, 1965$, núms. 141/2, 249-253 (González Seara); BHi, 69 (1967), 495 . 502 (Heugas); DLZ, 89 (1968), 602. 603 (Krauss); $E L, 1965$, núm. 318 (Miró); RLit, 26 (1964), 208-209 (Romero); $B H S, 43$ (1966), 125-128 (Russell); $\mathrm{CuH}, 64$ (1965), 159-166 (Trías).

19-2995. Berndt, ERNA Ruth - Amor, muerte y fortuna en "La Celestina".Gredos, Madrid, 1963. 235 pp. (BRH). || $H, 48$ (1965), 382-383 (Ayllón); $H R$, 33 (1965), 401-406 (Barrick), $B C B, 7$ (1964), 1840-1841 (Camacho Guisado); BHS, 42 (1965), 53-54 (Deyermond);
Ins, 1963, núm. 203 (Moya Trelles); CuN, 23 (1963), 295-296 (Scoles).

19-2996. FOSTER, D. W_-"Some attitudes towards love in the Celestina".-H, 48 (1965) , 484-492.

19-2997. Barbera, R. E.-"A harlot, a heroine". $-H, 48$ (1965), 790-799. [L.a Celestina].

19-2998. Toro-Garland, F. -_ "Cclestina, hechicera clásica y tradicional".-CuH, 60 (1964), 431-445.

19-2999. Aruirre, J. M.-Calisto y Melibea, amantes cortesanos. - Almenara, Zaragoza, 1962. 94 pp. (Col. de ensayos, 1). $B H S, 41$ (1964), 67-68 (Deyermond) ; $B H i, 69$ (1967), 493-495 (Heugas).

19-3000. Barbera, R, E.-“Calisto: the paradoxical hero"._H, 47 (1964), 256. 257.

19-3001. CAstro, AmÉrico "La Celestina" como contienda literaria. (Castas y casticismos)._Revista de Occidente, $\mathrm{Ma}$. drid, 1965. 180 pp. || PSA, 38 (1965), 319-326 (Agostini de del Rfo); $E L$, 1965, núm. 314 (Aguado); $B A b r, 40$ (1966), 316 (Ángeles); $B C B, 9$ (1966), 1385-1391 (Cortés) ; EG, 1966, núm. 16, 127.136 (González Torres); CuH, 62 (1965), 601-603 (Miró); RLMo, 6 (1966), 169-170 (Zuleta).

19-3002. Vессн1о, F. _E1 a antifeminismos de Sempronio"._-Proceedings of the 16th Pacific Northwest Conference on Foreign Languages (Seattle, 1965), 115-118.

19-3003. FlightNER, J. A._-"Pleberio".-H, 47 (1964), 79-81.

19-3004. WARdROPPER, B. W._-"Pleberio's lament for Melibea and the medieval elegiac tradition".-MLN, 79 (1964), 140.152 .

19-3005. GreeN, O. H._"Did the aworld * «create, Pleberio?"- $R F, 77$ (1965), 108-110. || Hf, 1967, núm. 30, 71 (Bosch). 19-3006. ROJAs, FERNANDO DE_Tragicomedia de Calixto y Melibea. Libro también llamado "La Celestina". Ed. crítica por M. Criado de Val y G. D. Trotter. 2" ed., corregida_C.S.I.C., Ma(lrid, 1965. xv + 322 pp. (Clásicos his. panicos). -V. núm. 16-41652. || $H R$, 37 (1969), 315-320 (Herriott); RHM, 33 (1967), 149.150 (Mades); ZRPh, 83 (1967), 696 (Mettmann).

19-3007. Rojas, FERnando dE-La Celestina. Ed., introd. y notas de Agustín Millares Carlo y J. I. Mantecón.-Iñprenta Universitaria, México, 1964. 300 
pp. (Nuestros clásicos). \|UMx, 18 (1963-64), núm. 11 (Valdés) .

19-3008. Rojas, FERnando dE-La Celestina.-E.D.A.F., Madrid, 1965. 254 pp. (Biblioteca E.D.A.F.).

19-3009. Rojas, Fernando de-La Celestina.-Edime, Caracas-Madrid, 1964. 159 pp.

19-3010. Rojas, Fernando DE-LLa Celestina o tragicomedia de Calixto y Melibea.-Mateu, Barcelona, 1964. 268 pp. (Todo para muchos, 111).

19-3011. Rojas, Fernando DE-La Celestina.-_Eds. R, La Habana, 1964. (Bibl. básica de lit. estañola).

19-3012. Scolfs, E.-"La prima traduzione italiana della Celestina: repertorio bibliografico".- $S L S p, 209-230$.

19-8013. Martínez LACALle, G.-“A manuscript version of Mabbe's Celestina".$R L C, 39$ (1965) , 78-91.

19-3014. RoJAs, FERNANDO DE-The Spanish bawd: La Celestina. Being the tra. gi-comedy of Calisto and Melibea. Transl. by J. M. Cohen.--Penguin Books, Harmondsworth, 1965. 247 pp. \|MLJ, 50 (1966), 293 (Barrick).

19-3015. Rojas, FERnando DE-Célestine. A critical ed. of the first French transIation (1527) by Gerald J. Brault.Wayne State Univ. Press, Detroit, 1963. 264 pp. || ZRPh, 82 (1966), 241-250 (Baldinger); $R L R, 76$ (1964), $132-$ (Flecniakoska); $R R, 55$ (1964), 120121 (Fraker); $H R, 33$ (1965), 332-334 (Herriatt); NM, 66 (1965), 406-407 (Kramer); $R P h, 18$ (1964-65), 251-252 (Picoche) : CuN, 29 (1963), 296 (Scoles); BHS, 41 (1964), 125-126 (Trotte1); $N, 48$ (1964), 89 (Van Praag).

19-3016. Arugonés, J. E.-_Alejandro Casona, fiel revisor de La Celestina".$E L, 1965$, núm. 329.

19-3017. DomènECH, R._"La Celestina, revisión de Casona".-PA, 1965, núm. 69, 55-56; CuH, 64 (1965), 594-596.

19-3018. Iglesias Barba, M. D.-" $L a C e$ lestina, revisión de Alejandro Casona".$M B, 1965$, núm. 11, 177-178.

19-3019. Segura, F_-"La Celestina adaptada por Casona".-Res, 2 (1965), 960 . 362.

19-3020. Miserocchi, M.-"La Celestina".NA, 495 (1965), 415-416. [Sobre una representación hecha en Venecia].

V. también núms. 29, 1058, 2270, 3279, 3372.

Enzina: v. núm. 2895.

Gil Vicente: v. núms. 1933-94.
19-3021. Bryant, Willlam C.--Lucas Fernandez and the early Spanish drama.[Tesis, Univ, of California (Berkeley); resumen en $D A, 25$ (1964-65), 6616].

19-3022. Lihani, J.- "The question of the authorship of the Coplas attributed to Lucas Fernández".-KFLQ 12 (1965) , 238-245.

V. también núm. 2895.

19-3023. TrotTer, G. D._-."The date of the Comedia Thebayda". $-M L R, 60$ (1965) , 386-390.

19-3024. Abrams, F-“Lope de Rueda: una bibliografla analttica en el cuarto centenario de su muerte".- $-D H R$, 4 (1965), 39-55.

19-3025. Tusón, VIcente-Lope de Rueda: Bibliografia critica.-C.S.I.C., Madrid, 1965. 85 pp. (Cuadernos bibliográficos, 16). II Seg, 1 (1965), 431.432 (Esquer Torres) ; PBSA, 60 (1966) , 247 (Woodbridge) .

Cervantes: v. núms. 2926, 3408-15.

19-3026. PARDO MOROTE, M. L.-“"Conmcmoración del centenario del nacimiento de Lope de Vega".- $-R A B M, 70$ (1962), 417-419.

19-3027. Morales Vallespín, M. I.-_"Medallas que conmemoran a Lope de Vega".- $R A B M, 70$ (1962), 413-416.

19-3028. Parker, Jack H., \& ArThur M. Fox (eds.) - Lope de Vega studies, 1937. 1962: A critical survey and annotated bibliography._-University Press, Toronto, 1964. xi +210 pp. $\| Z R P h, 80$ (1964), 635-636 (Baldinger); Hf, 1966, núm. 27, 46-47 (Dixon) ; $H, 49$ (1966), 159-160 (Morby) ; BICC, 20 (1965) , 155 156 (Osuna); Seg, 1 (1965), 486-437 (Rozas); $H R, 34$ (1966), 370-373 (Shergold) ; $M P h, 63$ (1965.66), 261-262 (Wardropper) ; BHIS, $4 \$$ (1966), 76.77 (Wilson) .

19-3029. Lope de Vega. Estudios reunidos en conimemoración del $I V$ centenario de su nacimiento (N. 18-6524). $\| H, 49$ (1966) , 160 (Ortigoza); $H R, 34$ (1966) , 384-385 (Parker) .

19-3030. HernáNDEZ, J.- "Lope de Vega Carpio (1562-1635)"-_Sembradores de Amistad, Monterrey, 18 (1963), 7-12.

19-3031. Acerete, J. C.- "Desde Parma con Lope". $-P A, 1965$, núm. 65, 24-30. 19-3032. Barceló Jiménez, J.- "La epístola de Cascales a Lope de Vega con motivo de la licitud de las comedias".Seg, 1 (1965), 227-245.

19-3033. Samonì, C.-“'Su un passo dell"Arte nuevo di Lope".-SLS, 13̆̈-146. 
19-3034. Lázaro Carreter, F.-"El Arte nuevo (vs. 64.73) y el término entremés".-ALM, 5 (1965), 77-92.

19-3035. García de Enterría, M. C."Función de la letra para canlar en las comedias de Lope de Vega: comedia engendrada por una canción".- $-B B M P$, 41 (1965), 3-62.—V. núm. 18-3268.

19-3036. WinecoFf, J.- "The role of the escudero in twelve plays of Lope de V'ega".-RNo, 7 (1965), 46-50.

19-3037. Carro Celada, José AntonioSanta Maria de Lope de Vega.-Juan Flors, Barcelona, 1965. xiii + 209 pp.

19-3038. Morrison, ROBERT REID-Sainthood in the theater of Lope de Vega.[Tesis, Univ. de Florida; resumen en $D A, 25$ (1964-65), 481-482].

19-3039. Dessau, A._"Grösse und Niedergang Spaniens im Werk Lope de Vegas"._Wissenschafliche Zeitschrift der Univ. Rostock, 12 (1963), 701-707.

19-3040. FERNÁNDEZ,-SHAw, C._."América en Lope de Vega".-Acentos Lilerarios Americanos, 1964, núm. 5...V. núm. 17. 5756.

19-3041. Rugc, E. "EI padre en el teatro de Lope de Vega".-Hf, 1965, núm. $25,1-16$.

19-3042. TyLER, R. W.-"False accusation of women in plays probably by Lope de Vega"._BC, 17 (1965), 13-15.

19-3043. VAlencia, J. O.-“El complejo de culpa en una comedia de Lope".Norte, 5 (1964), 118-120.

19-3044. VAlbuena PRAT, A.-_"Algunos temas de arte y arqueología en Lope de Vega".-Homenaje... Cayelano de Mergelina (Murcia, 1961-62), 821-835.

19-3045. KRISPYN, E_-'Grillparzer's tragedy Die Jülin von Toledo". $-M L R$, 60 (1965), 405-415. [En relación con Lope de Vega].

19-3046. Drimba, O.- "Lope de Vega si Românii. Consideratii în jurul unei piese privind epoco lui Mihail Viteazul".Studii si Cercetari de Istoria Artei, Bucuresti, 12 (1965), 55-59.

19-3047. Pescador del Hoyo, M. del C. "Escritos autógrafos, atribuidos y falsos, de Lope de Vega en el Archivo Histórico Nacional".- $R A B M, 70$ (1962), 409.412.

19-3048. Moreno Garbayo, J., y C. MoRales Borrero "Obras de lope de Vega en la Biblioteca de Palacio. Inventarios y precisiones".- $R A B M, 70$ (1962) , 339-392.

19-3049. VEGA, LOPE DE-Obras. Ed. y es- tudio prel. de M. Menéndez Pelayo. T. 10: Comedias de vidas de santos-Atlas, Madrid, 1965. 443 pp. $(B A E, 180) . \mathrm{V}$. núm. 18-6591.

19-3050. VEGA, LOPE DE-Obras completas. Ed. de J. de Entrambasaguas. T. 1: Obras no dramáticas. Arcadia. La Dragontea. Isidro. Fiestas de Denia. Romance $a$ las venturosas bodas que se celebraron en la insigne ciudad de Valencia._C.S.I.C., Madrid, 1965. lx +439 pp. || BHi, 69 (1967), 530-531 (Bourligueux) .

19-3051. García Mornles, J.- "Dos anuevas comedias de Lope de Vega".$R A B M, 70$ (1962) , 393-408.

19-3052. ARJONA, J. H._"Two plays attributed to Lope de Vega and Guillén de Castro"._HR, 33 (1965), 387-394.

19-3053. CASE, T.-."The early date of composition of Lope's Las almenas de Toro".- $R$ No, 6 (1965), 156-159.

19.3054. Weber DE KurLat, F._Amar, servir y esperar de Lope de Vega y su fuente".-HAC, 435-445. [El socorro en el peligro, de Castillo Solórzano].

19-3055. VEGA, LOPE DE_La buena guarda. Ed. de Pilar Díez y Giménez Cas. tellanos._Ebro, Zaragoza, 1965. 128 pp. (Clás. Ebro).

19-3056. VEGA, LOPE DE- $I l$ certo per l'incerto. Trad. Antonio Gasparetti_-Rizzoli, Milano, 1965. $94 \mathrm{pp}$.

19-3057. VEGA, LOPE DE La desdichada Estefania. A critical, annotated ed. of the autograph MS. by Hugh W. Kennedy.-[Tesis, Univ. of California, Los Angeles; resumen en $D A, 25$ (1964-65), 3575-3576].

19-3058. VEGA, LOPE DE-La schiava del suo innamorato. Trad. A. Gasparetti.Rizzoli, Milano, 1965. 91 pp. (Bibl, universale Rizzoli, 2271).

19.3059. BARNSTONE, W._Lope de Vega's Don Leonido: a prototype of the traditional Don Juan"._CLS, 2 (1965), 101. 115. [La fianza satisfecha].

19-3060. VEGA, LOPE DE-Fuenteovejuna. Pról. de I. Alvarez Cardón._Culturama, Buenos Aires, 1965. 103 pp.

19-3061. VEGA, LOPE DE-Fuenteovejuna. Peribánez y el Comendador de Oca. ña. Ed. y estudio prel. de F. Garcla Pavón.-Taurus, Madrid, 1965. 296 pp. (Ser y tiempo, Temas de España). [3: ed., 1967].-V. núm. 41238.

19-3062, López Estrada, Francisco "Fuente Ovejuna" en el teatro de Lope $y$ de Monroy $[y$ Silva]. (Consideracion 
critica de ambas obras).-Universidad, Sevilla, 1965. 106 pp. || RLit, 27 (1965), 229-231 (Rodríguez Cepeda); Seg, 2 (1966) , 206-207 (Rodriguez Cepeda).

19-3063. BocsI, J. P._-Laura perseguida, Lucinda perseguida y Nadie se conoces".Seg, 1 (1965), 301-309.

19-3064. VEGA, L, DE-Las paces de los reyes y Judia de Toledo, ed. J. A. Castañeda (N. 18-6622). || $S A B, 33$ (1965), núm. 3. 8-9 (Hayes) ; RF, 77 (1965), 472-579 (Hilty); $A L M, 4$ (1964), 342-343 (Ontañón de Lope). 19-3065. Soons, A.- "Las paces de los reyes".-FC, 53-56.-V. nưm, 18-3313.

19-3066. VEGA, LOPE DE-Peribánez y el comendador de Ocaña. Texte espagnol publié avec une notice, une étude litteraire et des notes par Ch. V. Aubrun et J.-F. Montesinos.-Hachette, Paris, 1965. xlix + 205 pp.

19-3067. VEGA, LOPE DE-Peribañez y el comendador de Ocaña. Noticia lite. raria: Joaquín Artiles. Notas teatra. les: Antonio Ayora.-Dirección General de Enseñanza Media, Madrid, 1965. 126 pp.. ilustr. (Nueva bibl. teatral). || Seg, 2 (1966) , 207 (Rozas) .

19-3068. VEGA, LOPE DE-Peribañez y el comendador de Ocaña. La dama boba. Ed. de A. Zamora Vicente-_EspasaCalpe, Madrid, 1963. lvi + 282 pp. (Clás. cast., 159) . \|BHi, 68 (I966), 406-407 (Bourligueux) ; BHS, 42 (1965), 194-196 (Dixon).

19-3069. VEGA, LaPE DE_-Peribánez $e$ il commendatore di Ocaña. Trad. A. Gasparetti.-Rizzoli, Milano, I965. $95 \mathrm{pp}$.

19.3070. BONET, O._"El perro del horte. lano: una experiencia".-Mascara, Buenos Aircs, 1965, núm. 1.

19-3071. Salomon, N.-“"A propos de la date de El villano en su rincón, come. dia de Lope de Vega".-BHi, 67 (1965), 4.2-62.

19-3072. Monleón, J.- "Crítica teatral de El villano en sic rincón, de Lope".$P A$, 1965, 43-45.

19-3073. VEGA, LOPE DE-Poesias. Sel. y pról. de R. Alberti._Losada, Buenos Aires, 1965. 160 pp. (Bibl. contemporánea, 97) .

19-3074. Erdman, E. George, JR.-Source, sense and siructure: An approach to the sonnets of Lope de Vega.--[Tesis. Johns Hopkins Univ., 1965].

19-3075. Prieto, A.-“Interpretación de un soneto de Lope"._RLit, 28 (1965), $19 \cdot 38$.
19.3076. VEGA, LOPE DE_Cinco canciones. Versión para canto y guitarra de Graciano Tarragó.-Unión Musical Española, Madrid, 1964. 6 hojas.

19-9077. VEGA, LOPE DE_Coloquio pastoril en alabança de la limpia y pura Concepción de la Virgen Nuestra Scñora. (Málaga, Juan Rene, 1615). Reproducción facsímil.-El Guadallıorce, Málaga, 1965. $12 \mathrm{pp}$.

19-3078. VEGA, LOPE DE-La Gatomaquia. Ed. de Pilar Díez y Giménez Castellanos.-Ebro, Zaragoza, 1965. $146 \mathrm{pp}$. (Clás. Ebro).

19-9079. Alberti, RataEL_LLope de Vega y la poesia contemporinea. Conferencia. Seguida de La pajara pinta [acto I]._-Institut d'Etudes Hispaniques, $\mathrm{Pa}$ ris, 1965. 92 pp. (Pages oubliées, pages retroncuées). || Asom, 1966, núm. 2, 60 61 (Otero Seco).

19-3080. Subirá, V. I._-La filigrana del Peregrino".-ABP, 9 (1963), núms. 33/ 36.

19-3081. VEGA, Lope DE-La Dorotea. Ed. de M: P. Aparici_Ebro, Zaragoza, 1965. 154 pp. (Clás. Ebro).

19-3082. VEGA, LOPE DE-Triunfo de la fee en los reynos del Japón. Ed. by J. S. Cummins.-Tamesis Books Ltd., Lon. don, 1965. xlix + 116 pp. $\| A I A, 27$ (1967), 239 (Borges); BHi, 69 (1967), 270-271 (Bourdon); JEH, 17 (1966), 267-268 (Boxer); $B H S, 44$ (1967), 218 220 (Gallagher); $M H, 23$ (1966), 383 (Merino) ; HR, 36 (1968), 300-301 (Parker) ; AHSI, 35 (1966), 253-264 (Scliurhammer) .

V. también núms. 1673, 2292-4, 2345, 2912, 2922, 2925, 2928, 3397-9.

19-3083. Agutrre, J. M.-José de Valdivielso y la poesia religiosa tradicional. Instituto Provincial de Investigaciones y Estudios Toledanos, Toledo, 1965. 222 pp. $\| B H S, 49$ (1966), I32.134 (Smieja).

19-3084. Iglesias BARBA, D.-“Crítica teatral de El hospital de locos de Valdivielso".- $M B, 8$ (1964), 180-183.

Góngora: v. núm. 2554.

19-8085. Wilson, W. E._"Guillén de Castro and the codification of honor".$B C, 19$ (I967), 24-27.

19-3086. Castro, Guillév DE-Las mocedades del Cid. Pról. y notas de I. M. Gil.-Aguilar, Madrid, 1964. 132 pl). (Bibl. de iniciacion hispanica). I' Seg, I (1965), 447-448 (RulI).

19-3087. Bihler, H. - "Zum Stil cincs Monologs in Guillén de Castro's r.as 
mocedades del Cid und Pierre Corneilles Le Cid".-HJ H', 555-578. || RJ, 17 (1966), 376 (Glaser).

19-3088. WEIGER, J. G.-"Los silencios de Las mocedades del Cid".,-Hf, 1965 , núm. 23, 1-7.

V. también núms. 1720, 2926, 3052.

19-3089. Profetr, M. G.-"Note criliche sull'opera di Vélez de Guevara".MSI, 1965, núı. 10, 47-174. || BHi, 70 (1968) , 181 (Mercadier); RLit, 28 (1965) , 252-254 (Rodríguez Cepeda).

19-3090. VÉlez DE Guevara, LuIs.-Virtucles vencen señales. Introd., testo critico e note a cura di M. G. Profeti.Istituto di Lett. Spagnola e IspanoAmericana, Università, Pisa, 1965. 276 pp. (Collana di studi, 9) . || RLit, 28 (1965), 280-283 (Rorlriguez Cepeda); Seg, 2 (1966), 212-214 (R. Cepeda).

V. también núms. 3312,3418 .

19-3091. Alatorre, A." "Para la historia de un problema: la mexicanidad de Ruiz de Alarcón".- $A L M, 4$ (1964), 161202.-V. núm. 11-26631.

19-3092. Poesse, WaLter-Ensajo de una bibliografia de Juan Ruiz de Alarcón y Mendoza._Castalia, Valencia, 1964. $\mathrm{xx}+85 \mathrm{pp}$. (Estudios de Hf).-V. núm. 18-3352. || Recensiones, Maracaibo, 1967, núms. 11/12, 171-174 (Millares Carlo); Seg, 1 (1965), 159 (Rozas); BHS, 41 (1964), 265 (Shergold); PBSA, 60 (1966), 247 (Woodbridge) .

19-3093. Claydon, Ellen E-Juan Ruiz de Alarcón: baroque dramatist.-_[Te. sis, Univ. of Colorado; resumen en $D A$, 28 (1967-68), 2203A-2204A].

19-3094. Brooks, J.- "Stage business in the plays of Juan Ruiz de Alarcón".$B C, 17$ (1965), 3-5.

19-3095. Rulz de ALARcón, JuAN.C Cuatro comedias. 3a ed.-Porrúa, México, 1965. xxxix + 206 pp. (Sepran ctuantos, 10) V. núm. 18-6656.

19-3096. Ruiz de ALARcón, JUAN-La verdad sospechosa. Introd, y notas de E. B. de Meyer, 2a ed.-Huemul, Buenos Aires, 1965.142 pp. (Clás. Huenuul).-V. núm, 17-5824.

19-3097. VosSLER, KARL_Lecciones sobre Tirso de Molina. - Taurus, Madrid, 1965. 147 pp. (Persiles, 28) . \| CuH, 65 (1966), 364-365 (Amorós); RLit, 27 (1965), 232-234 (Diez Taboada); Seg, 2 (1966), 208-21l (Diez Taboada).

19-3098. Guastavino Gallent, G._-"Notas tirsianas, I11".- $-R A B M, 70$ (1962), 121139.-V. núm. 17-2245.
19-3099. Chittenden, Margaret JeAn STAHL-Los nombres de personajes en las comedias de Tirso de Molina..-[Tesis, Univ. of Texas; resumen en $D A$, 25 (1964-65), 7263].

19-3100. Valbufna PRAT, A.-"Sobre la creación de caractercs y la temática de Tirso de Molina".__Seg, 1 (1965), 11-22.

19-3101. Schalk, F. - "Melancholie in Theater von Tirso de Molina".-FHF, 215-238.

19-3102. TIRso de Molins-El burlador de Sevilla y Convitlado cle piedra.-Sopena, Barcelona, 1965. 175 pp. (Bibl. Soprena, 62-1).

19-3103. TIRSO DE MOLINA-El burlador de Sevilla. La prudencia en la mujer. Ed. by Raymond R. MacCurdy,_Dell, New York, 1965. 288 pp. (Laurel language library).

19-3104. WADE, G. E.-."El burlador de Sevilla: the Tenorios and the Ulloas".S, 19 (1965) , 249-258.

19-3105. Groul.t, P.- "Des Jésuites de Bavière aux Arabes cl'Andalousie, ou les sources du Burlador de Sevilla"._LR, 19 (196ว) , 247.250.

19-3106. Sloman, A. E.-"The two versions of El burlador de Sevilla".-BHS, 42 (1965), 18-33.

19-3107. Guastavino Gallent, G.-“"Sobre La elección por la virtud de Tirso".RLit, 27 (1965), 51-63.

19-3108. KENNEDY, R. L.-"Literary and political satire in Tirso's La fingida $A r$. cadia".-[En] The Renaissance reconsidered. $A$ symposium (Northampton, Mass., 1964), 91-110.

19-3109. HARPER, J. P., \& G. E. WADE"Tirso and No es amor como se pinta".-RNo, 6 (1965), 153-155.

19.3110. TiRso DF. MoLiva-La prudencia en la mujer. El burlador de Sevilla. Don Gil de las calans verdes. Introd. de C. Rivas Xerif.-Ateneo, México, 1965. 352 pp.

19-3111. Samona, Carmelo-"La pruden. cin en la mujer" $e$ i problemi del dram. ma storico barocco. Anno accademico 1964-65._E. De Santis, Roma, 1965. 205 pp. [Incluve el texto de la comedia].

19-3112. TIRso DE MoLINA-El vergonzoso en palacio. El condenado por des. confiado. El burlador de Sevilla, La prudencin en la mujer. Ed. por Juana de Ontañón.-Porrúa, México, 1965. 7xxvii +265 p.). (Sepan cunntos, 32). 
19-3I13. Glenn, R. F._-Disguises and masquerades in Tirso's El vergonzoso en palacio".-BC, 17 (1965), 16-22.

19-3114. Nougut, ANDRÉ-L'auvre en prose de Tirso de Molina (N. 18-3374). |l CuH, 65 (1966), 362.364 (Amorós); RLit, 28 (1965), 275-280 (Cañedo).

19-3115. WADE, G. E._-'Tirso's Cigarrales de Toledo: some clarifications and identifications"._HR, 33 (1965), 246-272.

19-31 I6. Rocchi Barrotta, M. C.-“Fuentes de la novela del Cigarral quinto de los Cigarrales de Toledo, del maestro Tirso de Molina".-EM, 21 (1965), 411 $440 ; 22$ (1966), 81-1I5.

V. también núms. 2950-60, 2926.

Jiménez de Enciso: v. núm. 2926.

19-3117. Rivas Xerif, C.-“"Calderón de la Barca". - Libros Selectos, México, 1965, núm. 27.

19-3I18. Martín, A. M.-“Ensayo bibliográfico sobre ediciones, traducciones y cstudios de Calderón de la Barca" (N. I7-2302). || RL, 19 (1965), 73-74 (Groult).

19-3119. WARDROPLER, B. W.-"Menéndez y Pelayo on Calderón"._-CritL, 7 (1965), 363-372.

19-3120. HARDY, SWANA I.-Goethe, Cal. deron und die romantische Theorie des Dramas. - Carl Winter, Heidelherg, 1965. 200 pp. (Heidelberger Forschungen, 10). \| EtG, 22 (1967), 287-288 (Ayrault); Seg, 3 (1967), 417-418 (Dlez Taboada); GRM, 16 (1966) , 437.438 (Franzbach); Ruperto-Carola, 1966 , núin. 40, 462 (Pfaff) ; N, 41 (1967), 308. 309 (Steinmetz).

19-3121. Madariaga, Salvador DE-Shelley and Calderón, and other essays on English and Spanish poetry.-Kennikat Press, Port Washington, N. Y., 1965. xii +198 pp. [Reimpresión de la ed. de 1920].

19-3I22. WARDROPPER, BruCE W._Critical essays on the theatre of Calderon.New York University Press, New York, 1965. xvi + 239 pp. || MLR, 62 (1967) 543 (Dixon); $H, 50$ (I967), 184-185 (Ebersole); QJS, 53 (1967), 303.304 (Leonard); $B H i, 69$ (1967), 533-534 (Marrast); QIA, 5 (1966-67), 109.110 (Molina) ; $H R, 35$ (1967), $392-393$ (Parker) ; $R Q, 20$ (1967), 509-512 (Ricart); Seg, 3 (1967), 414 (Rull); BHS, 44 (1967) 131-134 (Varey) ; TLS, Nov. 11, 1965 (X).

193123. OCHSE, HoRsT_Studien zur Melaphorik Calderóns.-Eidos Verlag, München, 1965. 136 pp. (Freiburger Schrif- ten zur romanischen Philologie).-V. núm. 16-48787. || $R F, 80$ (1968), 606-610 (Glaser) .

19-3124. Valbuena Briones, A.- "El simbolismo en el teatro de Calderón" (N. 17.5835) . || RFE, 48 (1965), 4.38-4.39 (Llorente).

19-3125. Valbuena Briones, Āngel-Perspectiva critica de los dramas de Cal. deron.-Rialp, Madrid, 1965. 425 pp. $E L, 1966$, núm. 341 (Aguado); $R E H$, 1 (1967), 265-266 (Hamilton); $M C$, 74 (1966), 147-148 (Marín); CFil, I (1967) , 115-1 I6 (Nallim); Seg, 2 (1966), 221-222 (Rozas).

19-3126. Ruiz LAcos, M.-“Las alegorfas inanimadas, como técnica escenográfica en el teatro simbólico de CaIderón".$A O, 15$ (1965), 256.274.

19-3127. Hon 1G, E.-"The concept of honor in the dramas of Calderón".NMQ 35 (1965), 105-117.

19-3128. Flasche, H.-"Antiker Mythos in christlicher Umprägung. Andromeda und Perseus bei Calderón".-RJ, 16 (1965) , 290-317.

19-3129. Cerny, V. - "Das unbekannte Weltdrama Calderóns".- $-M K, 11$ (1965), $1-9$.

19-3130. LAcosta, F. C._-Los autos sacramentales de Pedro Calderón cle la Barca".-AH, 42 (I965), 9-26.

19-3131. WiLson, EdWARd M., \& JACK SAC;E-Poestas liricas en las obras dra. máticas de Calderón. Citas y glosas.-. Tainesis Books, London, 1964. $165 \mathrm{pp}$. || Bro, 84 (I967) , 397 (A. B.) ; $H R, 34$ (1966), 173-174 (Gates); $M L R, 63$ (I968), $726-727$ (Jones) ; $B H S, 43$ (I966), 225227 (Moir); $R J, 17$ (1966), 367.369 (Pring-Mill); Seg, 2 (1966), 222.224 (Rull); $M P h, 63 \quad(1965-66), 268-269$ (Valbuena Briones) ; $N, 52$ (1968), 90 (Van Praag); $H, 51$ (I968), 196-197 (Wexler).

19-3132. Calderón de la BArca, PedroObras. (Teatro doctrinal y religioso). Ed., pról. y notas de A. Valbuena Prat.-Vergara, Barcelona, 1965. I033 pp.

19-3133. Calderón de la BARCA-Obras completas. T. 3: Autos sacramentrles. Recop., pról. y notas de A. Valbuena Prat. 2\% ed.-Aguilar, Madrid, $196 \%$. 1915 pp.--V. núm. 8-13038.

19-3134. Calderón dE LA BARca, PEdro-El alcalde de Zalamea._Edit. Nacional, Madrid, 1965. 128 pp. (Obras teatro español). 
19-3135. Calderón de la Barca, PedroEl alcalde de Zalamea. La vida es sue. ño. Introd. de Jorge Campos. 2a ed.Taurus, Madrid, 1965. 238 pp. (Ser y tiempo. Temas de España).-V. núm. 14.41259 .

19-3136. Calderón de la Barca-El alcalde de Zalamea. La vida es sueño. El gran teatro del mundo. Introd. de C. Rivas Xerif.-Ateneo, México, 1965. $264 \mathrm{pp}$. (Obras inmortales).

19-3137. Calderón de la BARca, PedroLa desdicha de la voz. Ed. A. V. Ebersole.-Castalia, Valencia, 1963. xxiv 139 pp. I| $\mathrm{BHi}, 67$ (1965), 203 (Flecniakoska); $H, 48$ (1965), 610-611 (Hilborn); $R P h, 18$ (1964-65), 138 (Ma1kiel); Seg, 1 (1965), 163-164 (Rozas); BHS, 41 (1964), 191-193 (Wilson).

19-3138. Calderón de la Barca, PedroLa estatua de Prometeo. Comedia. Prol. ed. et notes de Charles V. Aubrun.Centre de Recherches de l'Institut d'Études Hispaniques, Paris, 1965. xxxiv 71 pp.—V. núm. 17-5847. \|CuH, 66 (1966), 618-620 (Amorós).

19-3139. Calderón de la Barca, PedroEl gran Duque de Gandia. Publiée d'après le manuscrit de Mladá Vozice avec une introduction, des notes et un glossaire par Václav Cerny.-Éditions de l'Académie Tchécoslovaque de Sciences, Prague, 1963. 208 pp. || IAL, 1964, núm. 183 (Barce) ; CuH, 70 (1967), 419-425 (Domenech) ; $R P h, 18$ (1964-65), 140 141 (Malkiel) ; CI, 1965, núm. 3, 170173 (Olivera Giménez); Seg, 1 (1965), ]65-167 (Rull); Map, 1 (1963) , 296-299 (Varas); TLS, 64 (1965), 330 (X).

19-3140. Juliá Martínez, E__Una comedia de Calderón de la Barca, recuperada".—RLit, 27 (1965), 5-32. [El gran Duque de Gandía].

19-3141. SiebenmanN, G._-_El gran Duque de Gandia: ein nuentdecktes Drama von Calderón"._GRM, 25 (1965) , 262-275.

19-3142. CaIderón de la Barca, PedroDramas de honor: El médico de su honra. El pintor de su deshonra.-EspasaCalpe, Madrid, 1965. 232 pp. (Clás. cast., 142) ._V. núm. I2-30177.

19-8143. Soons, A.- 'El médico de su hon$r a " .-F C, 103-111 .-V$. núm. 16-44753.

19-3144. Rogers, D.- "Tienen los celos pasos de ladrones: silence in Calde. rón's El médico de su honra".-HR, 33 (1965) , 273-289.

19-3145. SPARKs, A.-"Honor in Hartzenbusch's refundición of Calderón's $E l$ médico de su honra".--H, 49 (1966), 410-413.

19-3i46. Calderón de la Barca, PedroLa vida es sueño. Ed. M. H. Lacau. Introd. M. E. Foix. 8 ed.-Kapelusz, Buenos Aires, 1965. $123 \mathrm{pp}$.

19-3147. Calderón de la Barca, PedroLa vida es sueño.Losada, Buenos Aires, 1965. $259 \mathrm{pp}$. (Bibl. contemporánea, $307)$.

19-3148. Calderón de la Barca, Pedro$L a$ vida es sueño y El alcalde de Zalamea. Pról. de G. Díaz-Plaja.-Porrúa, México, 1965. 165 pp. (Sepan cuantos). 19-3149. FLASCHE, H._Baustein III zu einer kritischen und kommentierten Ausgabe Calderóns. (Vers. 538-802 des Auto sacramental La vida es siseño)".$S p F, 22$ (1965), 223-250._V. núms. $18-3392,18-6718$.

19-3150. Joly, M._-A propos d'une leçon erroné de $L a$ vida es sueño". $-L N L$, 1965, núm. 3, 69.

19-3151. Meca Ketterer, A.- "El sentido de lo barroco en La vida es sueño, de Calderón".-PEsp, 1965, núm. 147.

19-3152. Porqueras Mayo, A._-"Más sobre Calderón: "Pues el delito mayor del hombre es haber nacidos".-Scg, ] (1965) , 275-299.

19-3153. LAwson, R. H. - “Grillparzer's fragmentary translation of La vida es sueño".-RNo, 7 (1965), 58-61.

19-3154. ReYNoIds, J. J.-'La vida es sueno in New York".-H, 48 (1965), 499. 501.

19-3155. Ferdinandy, Magdalena dE Sprache und Gebärde. Untersuchungen zur mimischen Interpretation Calderóns und seiner deutschen Überset. zer.-[Tesis, Univ, de Berlín, 1965].

19-3156. Moon, H. K._-“Calderón and Casona",-_H, 48 (1965), 37-42.

V. también núms. 2533, 2928, 2935-8, 4136. 19-3157. Bergman, HanNaH E. - Luis Quiñones de Benavente y sus entremeses. Con un catálogo bibliográfico de los actores citados en sus obras.-Castalia, Madrid, 1965. 571 pp. (Bibl. de erudición y critica, 7).-.V. núm. 9. 17716. $M L N, 82$ (1967), 256-262 (Asensio); Ins, 1966, núms. 236/7 (Cano) ; Hum, 19 (1967) 249-250 (Hornedo) ; RHM, 33 (1967), 147.148 (Laurenti) ; $H, 51$ (1968), 575-576 (Ortigoza); $N V H, 1966$, núm. 3 (R. W.); RLit, 28 (1965) , 269-272 (Rodriguez Cepeda) ; Seg, 2 (1966), 217-221 (Ro- 
driguez Cepeda) ; BHS, 45 (1968) , 59-60 (Shergold) ; $M L R, 63$ (1968), 499-500 (Wilson) .

19-3158. MACCURDY, RAYMOND R.-Francisco de Rojas Zorrilla: Bibliografía critica.-C.S.I.C., Madrid, 1965. 47 pp. (Cuadernos bibliográficos, 18). $\| \mathrm{Hf}$, 1968, núm. 33, 59-62 (Pocsse).

19-3159. MacCuRdy, R. R. _- "Two instances of Rojas Zorrilla's parody of Spanish ballads".-HRM, I, 367-370.

19-3160. Ullman, P. L._"A theme of Del rey abajo, ninguno, and its analogy with limpieza de sangre".-RR, 57 (1966), 25-34.

19-316I. Testas, J._."A propos de la comedia Del rey abajo ninguno". $-L N L$, 1965, nưm. I, 34-40.

V. también núm. 2928.

Coello: v. núm. 2926.

Monroy: v. núm. 3062.

19-3162. PoYAN DíAz, D._-"Sin desdén para el desdén. Notas al margen de un libro sobre el teatro de Moreto".-Seg, 1 (1965), 311-323. [El de E. Caldera].

19-9I63. BAUER, R.-_Les métamorphoses de Diane".-FFS, 294-314. [El desdén con el desdén y su fortuna europea].

19-3164. Moreto, Agustín-El parecido en la Corte. Ed. de J. de José Prades.Anaya, Salamanca, 1965. 114 pp. \|Seg, I (1965), 455-457 (Rozas).

19.3165. Moreto, Agustín_El poder de la amistad. A critical ed. by Dwain Edward Dedrick.-[Tesis, Northwestern Univ.; resumen en $D A, 25$ (1964-65), 3567].

19-3166. Moreto, Agustín-Entremés de Doña Esquina. Ed. y est. de R. de Balbín._Seg, 1 (1965), 95-109.

$\checkmark$. también nưm. 2926.

19-3167. Simón Díaz, J.—Cuatro poemas de Matos Fragoso". -- RLit., 28 (1965) , $97-161$.

19-3168. Rozas, J. M.-“La licitud del teatro y otras cuestiones literarias en Bances Candano, escritor límite".-Seg, I (1965), 247-273.

$A$ utores modernos

19-3169. Mancint, G.-"Per una revisione critica di Garcia de la Huerta". $-S L S p$, 267.274 .

19-3170. García dE LA HUERTA, VicenteRaquel. (Tragedia española en tres jornadas). Ed. y cst. prel. por J. G. Fucilla.-Anaya, Salamanca, 1965. $110 \mathrm{pp}$. 19-3171. EFrross, S. H.C"Lcandro Fer. nández de Moratín in England".- $H$, 48 (1965) , 43-50.

19-3172. FERNÁNDEZ dE MORATÍN, LEANDro-El st de las niñas. Pról, ed. Y notas de J. Montero Padilla.-Anaya, Madrid-Salamanca, 1965. 80 pp. (Bibl. Anaya).

19-3173. Fernández de Moratín, LeanDRo_El si de las niñas y La comedia nueva o $E l$ café. Introd. y notas por José Francisco Gatti. 6! ed.--Troquel, Buenos Aires, 1965. 298 pp. (Clas. Troquel)...V. nưn. 18-3448.

19-3174. Aubrun, C. V._-"El si de las niñas, o más allá de la mecánica de una comcdia".- $R H M, 31$ (I965), 29-35.

19-3175. ANDIOC, R.- "Une zarzucla rctrouvée: El barón, de Moratín".- $M C V$, I (1965), 289-321.

19-3176. ANDIOC, R.-"Broutilles moratiniennes"'_LNL, 1965, núm. I, 28-33. [Cinco poesfas inćditas].

19-3177. Torre Pintuel.es, Elías-Tres estudios en torno a Garcia Villalta. fnsula, Madrid, 1965. 140 pp.

Martínez de la Rosa: v. núm. 390?.

Duque de Rivas: v. núms. 2587-9.

Hartzenbusch: v. núm. 3145 .

Zorrilla: v. núms. 2605-6.

19-3178. López de Ayala, Anelardo-Obras completas. Ts. I y 2: Teatro; t. 9: Teatro, poesias y proyectos de comedias. Ed. Y est. mrel. de José Marfa Castro y Calvo.-Atlas, Madrid, 1965. cxxiii + 179, 365, 390 pp. (BAE). || Seg, 2 (1966), 227-229 (Esquer Torres) .

19-3179. Esquer TORREs, R. _- "Tamayo y Baus y la polftica del siglo xix"... Seg, 1 (1965), 71-91.

19-3 I80. Esquer TORrEs, RAMón-El teatro de Tamayo y Baus.-Inst. Miguel de Cervantes, Madrid, 1965. 296 pp. (Anejos de la RLit, 22).-V. núm. 17-2323. || Seg, I (1965), 459-460 (Dlez Taboada); RFE, 48 (1965), 430.432 (Rull) .

19-3181. Tamayo y Baus, Manuel_La locura de amor. Un drama nuevo. 2. ed.-Espasa-Calpe, Madrid, 1965. 240 pp. (Austral, 545).

Echegaray: v. núm. 1574.

Querol: v. núm. 2611.

Bécquer: v. núm. 2690.

Unamuno: v. núms. 3991-5.

19-3182. Menecazzo CANÉ, M.-_Algo so bre Benavente" - RETe, 1966, núin. I0, $61-65$.

19-9183. Carter, Sistrer Mary RegrnalnThe innage of woman in selected play's 
of Jacinto Renavente $y$ Martinez.-[Tesis, Univ. of St. Louis; resumen en $D A$, 26 (1965-66), 4653-4654].

19-3184. BeNAVENTE, JACINTO-Los intereses creados. Ed. de F. Lázaro Carreter.Anaya, Salamanca, $1965.73 \mathrm{pp}$. (Bibl. Anaya).

19-3185. BenAVENTE, Jacinio--Por ser con todos leal, ser para todos traidor. El tren de los maridos.-Dédalo, Madrid, 1965. 36 pp. (Novelas y cuentos).

V. también núm. 2314.

19-3186. I.eNTZEN, MANFReD-Carlos Arniches. Ein halbes Jahrhundert stanischen Thenters.-[Tesis. Univ, de Colonia, 1965].

19-3187. Ruiz LAgos, M.-“Sobre Arniches: sus arquetipos y su esencia dramática"._Seg, 2 (1962), 279-300.

19-3188. Alvarez Quintero, SFrafín y JOAQuiN-Amores y amorios. Estudio preliminar y notas por Isabel Rius. Ed. dirigida por M. H. Lacau._Kapelusz, Buenos Aires, 1965. 116 pp. (Grandes obras de la literatura universal).

19-3189. Álvarez Quintero, SERAFín y Jolevín_Cinco lobitos.-Dédalo, Ma. drid, $1965.40 \mathrm{pp}$. (Novelas y cuentos). Machado: v. núm. 2641.

19-3190. Ruibal, J.-."Imagen última de Jacinto Grau".- $P A, 1965$, núm. 68 , 56 58.

19-3191. O'ConNor, P. W.-"La madre española en el teatro de Gregorio Mar. tinez Sierra".-DHR, 4 (1965), 17-24.

Muñoz Seca: v. núm. 2554.

García Lorca: v. núms. 2361, 2740-52

19-3192. FrRnANdez Santos, A.-"Alejandro Casona".-PA, 1965, núm. 68, 48-50.

19-3193. Cano, J. L.-“Casona".-Asom, 1965 , núm. 4, 67.68.

19-3194. Palacio, A.-“Alejandro Casona".-BIEA, 1965, núm. 56, 218-219.

19-3195. SANTAló, J. L.- "Alejandro Casona (1903-1965)".-Arb, 62 (1965), $221-228$.

19-3196. "Casona".-Ins, 1965, núm. 227.

19-3197. Castellano, J. R_-"Alejandro Casona ha muerto".- $H, 49$ (1966), 91.

19-3198. GonzÁlez, N.-"Murió Casona, o la sociología sin futuro". $-R y F, 172$ (1965), 299-304.

19-3199. Gascó Contell, E.-"Adiós a Casona".-Libros Selectos, México, 1965, núm. 27.

19-3200. ApAricio Lopfz, T.-"Alejandro Casona, el dramaturgo que nos deja una obra con luz de eternidad".- $R y C, 10$ (1965), 597-604.
19-3201. Díaz, O._-"Un abrazo de amigo y compañero para Alejandro Casona".$B C B, 8$ (1965) , 1516-1520.

19-3202. ArAGonís, J. F..-"Un corazón honrado". $-E L, 1965$, núm. 328. [Casona].

19-3203. Plans, J. J.- "Primer árbol".$E L$, ] 965, núm. 327. [Casona].

19-3204. Plans, Juan José-Alejandro Casona. (Juego biográfico dividido en una raiz y tres árboles).-_Richard Grandio, Oviedo, 1965. 138 pp. ilustr. || EL, I966, núm. 336 (Aragonés); RLit, 29 (1966), 267-269 (Rodríguez Richart).

19-3205. Sainz de Robles, F. C.-."El humor en el teatro de Alejandro Casona"._-Seg, 1 (1965) , 327-342.

19-3206. Gallecos Valdés, L.-_"El mensaje optimista del teatro de Casona".Culls, 1965, núm. 37, 32-42.

19-3207. PORRAs, R.-"Las dos fachadas de A. Casona",-P.V, 1965, núm. 10.

19-3208. Araronts, J. E.-“Casona, mágico y realista".-EI., 1965, núm. 317.

19-3209. RIVAS ANDRÉs, V.-."Actitud social en el teatro de Casona".-Res, 2 (1965) , 343-347.

19-3210. Casona, ALEJandro-Obras com. pletas. Pról. de F. C. Sainz de Robles. 4a ed. Ts. 1-2.-Aguilar, Madrid, 196566. ccxliv $+1112,1466 \mathrm{pp}$. (Bibl. de autores modernos).-_V. núm. 18-6807.

19-3211. Rodrícurz Garavito, A. - "Los árboles mueren de pie, por Alejandro Casona". $-B C B, 8$ (1956), 1393 1394.

19-3212. Cason.1, Alejandro-El caballero de las espuelas cle oro. Retablo jo. vial.-Espasa-Calpe, Madrid, 1965. 207 pp. (Austral, 1358). II Res, 1 (1964), 294-296 (Pérez de Olaguer).

19-3213. Casona, Alejandro-la casa de los siele balcones. Comedia en tres actos.-Alfil-Escelicer, Madrid, 1965. 99 pp. (Teatro). || PE, 1964, nưms. 97/98, 113-115 (Ponce Muñoz).

19-3214. Casona, Alejandro-A dama da madrugadn. - Vozes, Petrópolis, 1965. 120 pp. (Dińlogo da Ribalta, 7).

19-3215. Leichton, C. H.-_"Alejandro Casona and the devil"- $H, 48$ (1965), 29-36.

19-3216. DOMĖNECH, R.-"Prohibido sticidarse en primavera, de Casona"$P A, 1965$, núm. 63, 45-47.

19-3217. Casona, Alejandro - A serein adormecida.-Vozes, Petrópolis, 1965. 88 pp. (Diálogo da Ribalta, 5).

19-3218. CASONA, AIEJANDRO-La tercera 
palabra.-Alfil, Madrid, 1965. 87 pp. (Teatro).

19-3219. Rodríguez Richart, J.- "Sobre Tres diamantes y una mujer, de Alejandro Casona"._Seg, I (1965), 343357.

19-3220. LORCA-PRADA_“Tres poemas de Alejand ro Casona".- $P N, 1965$, núm. 13, 4-8.

V. también núms. 3016-9, 3156.

19-3221. ANTLITZ, H.-_"Enrique Jardiel Poncela und das moderne spanische Theater'. $-M K, 11$ (1965), 55-77.

19-3222. HAMmarstrand, RoberT E.-The comic spirit in the plays of Enrique Jardiel Poncela._[Tesis, Univ. of CaIifornia (Berkeley), 1966].

Alberti: v. núm. 3079.

19-3223. Holt, Marion PerRy - The theatre of José López Rubio.-[Tesis, Univ. of Illinois; resumen en $D A, 25$ (1964. $65), 4[48]$.

19-3224. MCCoRMICK, KATHRYN-Estudio comparativo entre José López Rubio $y$ atras figuras representativas del "tea. tro de evasion"._-[Tesis, Univ. de Madrid; resumen en $R U M, 14$ (1965) , 219. $220]$.

19-3225. Clarke, Barbara P.-La temdtica social en las obras dramáticas de Antonio Buero Vallejo.-[Tesis, Univ. de Madrid, 1965; resumen en $R U M, 14$ (1965), 198-199].

19-3226. Halsey, Martha TaliaferroThe tragedies of Antonio Buero $\mathrm{Va}$. llejo.-[Tesis, Ohio State Univ.; resu-en en $D A, 25$ (1964-65), 5278-5279].

19-3227. Buero Vallejo, Antonio - $E l$ concierto de San Ovidio. Ed. with exercises, notes \& vocabulary by $\mathbf{P} . \mathbf{N}$. Trakas; prol. by J. R. Castellano.Scribner's, New York, 1965. 215 pp. II $B H S, 44$ (1967), 77 (Edwards); $H$, 49 (I966) , 56I-652 (Rivas) ; $M L J, 50$ (1966), 446 (Tucker)

19-3228. Buero VALLEJo, ANTONIO-Historia de uma escada._-Vozes, Petrópolis, 1965. 104 pp. || Lumen, 30 (1966) , 171 (Oliveira); Bro, 83 (1966), 142 (Ve. loso) .

19-3229. KIRSNER, R.-"Historia de una escalera: a play in search of characters"__HRM, 1, 279-282.

19-3230. Buero VAliejo, Antonio-Hoy es fiesta. Ed. by J. E. Lyon.-Harrap, London, 1964. 192 pp.

19-3231. Macrt, O.-"Realismo di [Alfonso] Sastre".-APL, 1965, núm. \$1, $131-133$.
19-9232. SASTRE, ALFONSO-Tres dramas españoles.-Eds. du Globe, Paris, 1965. || $H, 5 \mathrm{I}$ (1968), 369 (De Coster) ; Ins, 1966, núm. 230 (Núñez).

19-3233. Rolf, R._."Historia de una muñeca abandonada, de Alfonso Sastre".$H D, 1965,597-598$.

19-3234. SASTRE, AI.Fonso - El paralelo 38.-Alfaguara, Madrid, I965. $90 \mathrm{pp}$. (La novela popular). \|EL, 1965, núm. 372 (Iglesias Laguna).

19-3235. SASTRE, Alfonso-Anatomia del realismo.-Seix Barral, Barcelona, 1965. 262 pp. \| RyF, 172 (1965), 496-497 (Barinaga); MLR, 63 (1968), $511-512$ (Bayón); $B A b r, 40$ (1966), 917 (Courtines); $H, 50$ (1967), 187-188 (Prjevalinskaya Ferrer) .

19-3236. PÉRez Conas, Patricio-El teatro de Miguel Mihura.-[Tesis, Univ. de Madrid, 1965; resumen en RUM, I4 (1965), 221-222].

19-3237. Baquero, A.-“Mihura, el anarquista de la sonrisa". $-N T, 29$ (1965), 512-516.

19-3238. Cazorla, H._."Simbolismo en el teatro de Carlos Muñix"._H, 48 (1965), 230-233.

\section{PROSA NARRATIVA}

19-3239. Alonso, D._-“La novela española y su contribución a la novela realista moderna"._CI, 1 (1965), 17-43. ||$B I C C$, 21 (I966), 404-406 (Zuluaga Ospina).

19-3240. Gómez PÉrez, J.-“Leyendas carolingias en España".-AF, 2-3 (196364), 7-136; 4 (1965), 121-193. [Con una ed. critica de dos textos: Berta y Mainete].

19-3241. IAPP, DONALD HOMER-Archaisms in four novels of chivalry.-[Tesis, Univ. of Iowa; resumen en $D A, 25$ (1964-65), 5270].

19-3242, Avalle-Arce, J. B.- "Tres comienzos de novela".-PSA, 37 (1965), I8I-2I4. [Amadis, Lazarillo, Quijote]. 19.3243. VArela, J. L.- "Revisión de la novela sentimental",- $R F E, 48$ (1965), 351.382 .

19-3244. Sainz de Robies, Federuco CarLos (ed.) -Antologia de cuentos vie. jos de la vieja España.-Aguilar, Madrid, 1964. I 120 pp.

19-3245. Sacks, Norman P. (ed.) -Cuentos de hoy y de aycr.-The Ronald Press, New York, 1965. 267 pp.-V. núm. 11-28770.

19-3246. Casariego, J. F.-“El mat y la 
aventura en la novela española".-Rev. Musical Chilena, 69 (1963), 849-852. 19-3247. Montesinos, Josí F.-Costumbrismo y novela. Ensayo sobre el descubrimiento de la realidad española. 2: ed. Castalia, Madrid, 1965. 144 pp. (La lupa y el escalpelo)._-V. núm. 17. 5911. $\mid R F, 79$ (1967), 454-456 (Gillessen); $E L, 1966$, núm. 342 (Iglesias Laguna) .

19-3248. Carrasco Urgoiti, M. S._La obra de Montesinos en torno a novelistas españoles del siglo xix".- $R O c c$, 9 (1965), 253-261.

19-3249. Caballero Bonald, J. M.-“El realismo como crítica de la vida española. (Notas sobre historia y novela) ".Norte, 6 (1965), 101-105.

19-3250. EOFF, SHERMAN H._El pensa. miento moderno y la novela española.Seix Barral, Barcelona, 1965. 273 pp. (Bibl, breve, 206).-V. núm. 18-3489. II CuH , 66 (1966), 603-615 (Conte); $L F r, 18$ (1965), 186 (H. H.); $A, 1965$, núm. 410, 282-285 (Mữoz G.); Azor, 1966, núm. 22 (Murciano) ; $P N, 1966$, núm. 15 (Valdivia).

19-3251. SABAU Bergamín, G._.'Más novelas escurialenses".- $N E t, 1965$, núm. $30,29-38$.

19-3252. Marra López, J. R.-“Los novelistas de la promoción de 1936".Ins, 1965, nưms. 224/5.

19-3253. Traberg, EBbE (ed., trad.) -Mo. derne spanske noveller. — Gyldendal, Köbenhavn, 1965.

19-3254. Beichior Pontes, Maria de LourDES_-Do romance espanhol._Sociedade Portuguesa de Escritores, Lisboa, 1964. $19 \mathrm{pp}$.

19-3255. Colford, William E. (transl) Classic tales from modern Spain.-Barron's Educational Series, New York, 1964. ix + 202 pp. $\| M L J, 51$ (1967), 306-307 (Bryant).

19-3256. VILLARREAL, C.-_Dieciséis relatos, Antologia de prosistas granadinos.Hombres y Caminos, Granada, 1965. 203 pp.

19-3257. Notтe, G.-“Il romanzo spagnuolo dal 1939 al 1964".-Nostro Tempo, Napoli, 1965, núm. 6, 6-13.

19-3258. Rojas, Carios (ed.) -De Cela a Caslillo-Navarro: Veinte años de prosa españolo contemporánea.-.PrenticeHall, Englewood Cliffs, N. J., 1965. 224 pp. \| $M L J, 52$ (1968), 32 (Grupp); $H, 49$ (1966), 556-557 (Tatum).

19-3259. Fiecniakoska, J.-L. _ "Le Prix
Nadal a 20 ans... Qu'est-ce que le Prix Nadal?'-LNL, 1965, núm. 2, 32-38. 19-3260. Duncan, B. G.-"Three novelists from Spain"._BAbr, 39 (1965) 165-166. [Ana María Matute, Ignacio Aldecoa, Antonio Ferres].

19-3261. Nougut, ANDRE, et J.-L. FLECNIAKOSKA-Romanciers espagnols d'aujourd'hui._Privat, Toulouse; Didier, Paris, 1964. 226 pp. (Textes espagnols). II fns, 1966, núm. 238 (Guy); LMo, 1965, núm. 2, 123 (Larrieu); $L N L, 1965$, núm. 1, 118-120 (Urrutia) .

19-3262. Olmos García, F.- "Novelas y novelistas españoles de hoy. (Introducción y encuesta) ".- $L N L, 1965$, núms. 3, 34-61.

19-3263. Bosch, R.-."The style of the new Spanish novel".-BAbr, 39 (1965), 10 14.

19-3264. Elizalde, I._-El tema de la emigración en algunas novelas de hoy".$H D, 1965,778.783$.

19-3265. García Viño, M._-"Última Jiora de la novela española".- $-N T, 24$ (1965), $478-497$.

19-3266. Álvarez Fernández, M.-“La nue. va ola en la novela".- $P N, 1965$, núm. 12.

19.3267. Werrir, P.-“La anouvelle vagues espagnole".-TR, 1966, núm. 225. 146-152. [En la novela].

19-3268. MARRA-LóPEz, J. R.-Narrativa española fuera de España (N. 18-3495). || $A L M, 4$ (1964) , 349-356 (Rius) .

19-3269. Bosch, R.-"The Spanish novel in 1964". $-B A b r, 89$ (1965), 139-141. V. también núms. 1644-9, 1724, 2282.

\section{$A u t o r e s \quad a n t i g u o s$}

19-3270. Walker, R. M.-"The unity of E1 libro del cavallero Zifar".-BHS, 42 (1965), 149-159.

19-3271. ScholberG, K. R.-"La comicidad del Caballero Zifar".-HRM, 2, 157-163.

Libros de caballerías: v. núms. 1249, 3241.

19-3272. REALI, E_-"Leonoreta / fin roseta nel problema dell' Amadís de Gaula".-AION-R, 7 (1965), 237-254. || ZRPh, 81 (1965), 583-584 (Ziltener). 19-3273. Amadis de Gaula. Ed. y anotaciones de Edwin B. Place. T. 3.C.S.I.C., Madrid, 1965. xviii + pp. 659954_-V. núm. 17-5939. || H, 49 (1966), 885-886 (Keller) ; HR, 35 (1967), 281 282 (Rey). 
19-3274. Amadigi di Gaula. Introd. c trad. di Antonio Gasparetti.-Einaudi, Torino, 1965. xliv +1433 pp. $\| A p L$, 1966, núm. 33, 120-123 (Macrf) ; IS, 48 (1965), 369 (Rossi).

V. también núm. 3242.

19-3275. Whinnom, K.-_Two San Pedros". - BHS, 42 (1965), 255-258. [Diego de San Pedro].

19-3276. FlightNer, J. A.- "The popularity of the Carcel de amor"._- 4,47 (1964), 475-478.

V. también núm. 3243.

19-3277. Baquero Goyanes, M.-"El entremés y la novela picaresca"._EMP, $6, \quad 215-246$.

19-3278. Paulson, R.- "The fool-knave relation in picaresque satire".-_Rice University Studies, Houston, 51 (1965), 59-81.

19-3279. VAL, JOAQuíN DEL (ed.) -Novela picaresca. $2^{\mathrm{a}}$ ed. - Taurus, Madrid, 1965. 589 pp. (Persiles). [La Celestina, el Lazarillo, el Guzmán, Rinconete $y$ Cortadillo y el Buscón].-V. núm. 16. 48961 .

19-3280. Monte, Alberto Del (ed.)-Narratori picareschi spagnoli del Cinque e Seicento._Vallardi, Milano, 196j. 2 ts.: 819, 624 pp. \| CuH, 70 (I967), 590-594 (Aniorós) ; RR, 59 (1968), 106109 (Aubrun); BICC, 24 (1969), 118120 (de Granda) ; ALilt, 8 (1966) , 336 337 (Horányi); BHS, 44 (1967), 58-59 (Jones) ; Ins, 1969, núm. 266 (Mainer); LHi, 69 (1967) , 272-275 (Nougué) ; Ins, 1966, núm. 239 (Silverman).

19-3281. Lazarillo de Tormes, Vida del Buscón. Estudio prel. de G. Diaz Plaja.-Porrúa, México, 1965. xxxix + 188 pp. (Sepan cuantos, 34). [2a ed., 1966, 3: ed., 1967].

19-3282. BaAder, Hors [ (ed.) Spanisshe Schelmenromane.-Carl. Hanser, München, 1964-65. 2 ts.: 879,635 pp. [Lazavillo, trad. H. Henze; Guzman, trad. R. Specht; Buscon, trad. H. Koch; Marcos de Obregón, trad. R. Specht].

19-3283. Alter, Robert-Rogue's progress: Studies in the picaresque novel.-Harvard Univ. Press, Cambridge, Mass., 1964. $\mathrm{xi}+148$ pp. (Harvard St. in Comparative Lit., 26). [Lazarillo de Tormes, Lesage, Defoe, Smollett, Mann, etc.]-_V. núm. 17-5953. \| RLMo, 7 (1968), 165-166 (Allende); EG, 1966, núm. 14, 100-102 (Fernández Seln); Crit5, 7 (1965), 196-198 (Fussell); $M L Q \quad 27$ (1966), 353-356 (Goldberg);
AUMLA, 1966, núm. 26, 318-320 (O'Brien) ; JEGPh, 64 (1965), 303-305 (Paulson); CEn, 26 (I964), 65 (Randall) ; $B A b r, 39$ (1965), 341 (Silverinan) .

19-3284. RumeAu, A.-"Notes au LazariLo"._LNL, 1965, núm. 1, 16-25.-V. núin. 18-6928.

19-3285. RumeAu, A.-Le "Lazarillo de Tormes". Essai d'interprétation. Essai d'attribution. - Eds. Hispano-Americanas, Paris, 1964. 38 pp. \| H, 49 (1966), 160-16I (Uliman).

19-3286. AGUAdo-ANDreUt, Salvador-Algunas abservaciones sobre "El Lazarillo de Tormes".-Editorial Universitaria, Guatemala, 1965. 243 pp. || Lect, I965, nứm. 3, 94-96 (Sender); $H, 50$ (1967), 182-183 (Villegas) .

19-3287. Defant, A.-"EI Lazarillo de Tormes, (Tema y estructura técnica del hanibre)".-HuT, 12 (1964), 107-123.

19-3288. Deyermond, A. D.-"The corrupted vision: further thoughts on $L a$ zarillo de Tormes".-FMLS, 1 (1965), 246-249.

19-3289. Woonward, L. J.-"Author-reader relationship in the Lazarillo de Tormes".-FMLS, 1 (1965), 42-53.

19-3290. Deyermond, A. D._-“Lazarus and Lazarillo".-Studies in Short Fiction, 2 (1965), $351-357$.

19-3291. Ayala, F.- "Fuente árabe de un cuento popular en el Lazarillo".-BRAE, 45 (1965), 493-495.

19-3292. Molno, J.-"Lazavillo de Torines et les Métamorphoses d'Apulee".BHi, 67 (1965), 322-339.

19-3293. La vida de Lazarillo de Tormes $y$ de sus fortunas $y$ adversidades. Pról. de A. M. Delfino. 2a ed._Estrada, Bue. nos Aires, 1963. I39 pp., ilustr.

19-3294. La vida de Lazarillo de Tormes. Introd., notas y vocab. de J. C. Pellegrini. 3a ed.-Fuemul, Buenos Aires, 1965. 109 pp.-V. núm. 18-6935.

19-3295. La vida de Lazarillo de Tormes. Ed. anotada por E. Terzano de Gatti.Plus Ultra, Buenos Aires, 1965. 110 pp. 19-3296. Het leven van Lazarillo de Tormes, en over zijn wederwaardigheden en tegenslagen.-Wereld-Bibliotheek-Vereninging, Amsterdam, 1965. 111 pp.- V. nún. 10-19256.

19-3297. Guise, R.- "La fortune de $L a$ zarille de Tormès en France au xixe siècle". $-R L C, \quad 39$ (1965), 337-357.

19-3298. LAmbert, M._Filiation des éditions françaises du Lazarille de Tor- 
ines (1560-1820)",--RSH, 1965, 587. 603.

19-3299. Vida de Lazarillo de Tormes. Estudio crítico de la Segunda parte de Juan de Luna por Joseph L. Laurenti.Eds. de Andrea, México, 1965. 119 pp. \| $R F, 79$ (1967), 491-432 (MüllerBochat) .

19-3300. Luna, JuAn de-Lazarillo de Tormes. Segunda parte. Probl. de Juan Alcina Franch.-Juventud, Barcelona, 1965. 208 pp. (Col. Z, 115).

V. también nứms. 3242, 3279, 3281-3.

19-3301. L.OZOYA, MARQUés DE-_."Andrés Laguna y el problema de los conversos segovianos". - $H A C, 311-316$.

19-3302. López Estrada, Francisco (ed.) El Abencerraje. T. 1: Novela; t. 2: Romancero. - Anaya, Salamanca, 1965. (Bibl. Anaya, 64, 68). \|CuH, 66 (1966) , 442-444 (Uceda).

19-3303. López Estrada, Francisco, \& JOHN F. KELLER (eds.)-Antonio de Villegas" "El Abencerraje".-Univ. of North Carolina Press, Chapel Hill; Soler, Valencia, 1964.86 pp. (Univ. of North Carolina Studies in comparative literature, 33). I| H, 49 (1966), 347 (Carrasco Urgoiti); SAQ 32 (1967), núm. 2, 19-20 (Lasley); Hf, 1966, núm. 27, 47.50 (Lihani); $H R, 34$ (1966), 381-382 (Morby) ; BHS, 43 (1966), 7576 (Pierce); SFQ, 30 (1966), 281-283 (Unthank).

19-3304. LóPEZ EsTRADA, F.-_"Tres notas al Abencerraje".-RHM, 31 (1965), 264-272.

19-3305. Guillén, C.--"Individuo y ejemplaridad on el Abencerraje".-HAC, 175-197.

V. también núm. 3311 .

19-3306. RicciardeliI, MICHELE-Notas sobre la "Diana" de Montemayor y la "Arcadia" de Sannazaro.-Inst. de Estudios Superiores, Montevideo, 1965. 20 pp. || BAbr, 40 (1966), 316-317 (Ångeles).

19-3307. Garcia ABAd, A-_-"Sobre la patria de la Diana",-RLit, 27 (1965), 67-77.

19-3308. GonzÁlez-MARina dE JACOBSON, J.- "La fuente literaria de la comedia de Shakespeare The two gentlemen of Verona".-ins, 1965, núm. 220. [La Diana de Montemayor].

19.3309. PaGfard, R.-"Deux épîtres inédites de Mateo Alemán".-BHi, 67 (1965), 334.339.

19-3310. MCGRADY, D.—“Consicleraciones sobre Ozmin y Daraja, de Mateo Alemán"_-RFE, 48 (1965), 283-292.

19-3311. Soons, A.-“Dos momentos de la novela morisca".-FC, 17-19. [El Abencerraje y Ozmin y Daraja].

19-3312. Nikolaeva, I._.'Guzmán de Al. farache y El diablo cojuelo en lengua rusa".-LS, 1965, núm. 7, 187-188.

V. también núms. $3279,3282$.

19.3313. ACKerman, Dorothy P., et al. (eds.) - A catalogue of the Talfourd $P$. Linn collection of Cervantes materials on deposit in the Ohio State University Libraries. -O Ohio State University Press, Columbus, 1963. (The Ohio Siates Univ. Libraries Publications, 1). || HR, 34 (1966), 83-84 (Knowles); $B H S, 42$ (1965) , 68 (Riley); $M L J, 48$ (1964), 387 (Stoudemire).

19-3314. Plaza Escudero, Luis M-Ca tálogo de la colección cervantina. T. 5: 1916-1930_Biblioteca Central, Barcelona, 1964. xix + 365 pp.-V. núm. 10-23810. || BHi, 67 (1965), 408-409 (Canavaggio); $B D G A, 1965$, núm. 82 , 72 (Pérez Rioja); H, 49 (1966), 534535 (Singer).

19-3315. EstradA JAsso, ANDrús-Catálogo abreviado de la colección cervantina "Carlos Prieto" del Instituto Tecnológico $y$ de Estudios Superiores de Monterrey.-Instituto Tecnologico, Monterrey, 1965. $112 \mathrm{pp}$.

19-3316. STRAzZarino, H_-"La biblioteca cervantina de don Arturo E. Xalambri",-PLi, 1965, núm. 14.

19-3317. Motta Salas, Juilin_-Vida del principe de los ingenios, Miguel de Cervantes Saavedra. - Renacimiento, México, $1965.430 \mathrm{pp}$.

19-3318. Entwistle, William J-Cervantes (1547-1616). A reprint.-Oxford Univ. Press, London, 1965. 192 pp.

19-3319. Orutsagasti Galiastegut, ANGEL F.-Cervantes en su tiempo, en su patria y en su obra universal. (Con tesis de unidad de tiempo de las aventuras del Quijote). Pról. de E. Abreu Gómez,-B. Costa-Amic, México, 1965. xxiii + 155 pp.-V. num. 17-5981.

19-3320. Malpique, Cruz_Cervantes, cidadão do mundo._Divulgação, Porto, 1965. 264 pp.

19-3321. Díaz Peñafiel, Julidn_Cervan. tes segin Cide Flamete Benengeli.Eds. Mi Desván, Buenos Aires, 1964. 170 pp. II EstF, 14 (1965) 420 (J. M. P.) ; Aug, 10 (1965), 139 (Legarra); EM, 21 (1965), 491 (Nebreda). 
19-3322. Martín Borro, H.-"El cautivo de Argel".-PLi, 1965, núm. 13. [Cervantes].

19-3323. Penna, M.- "Il lugar del esquife. Appunti cervantini".-Annali della $F a$. coltà di Lettere e Filosofia della Universitì degli Studi di Perugia, 2 (196465), 213-288. \| BHi, 68 (1966), 406 (Canavaggio) .

19-3324. Granados, J_- "Ricordi geogra. fici d'Italia nell'opera cervantina".-SLS, 397-409.-.V. núm. 16-49008.

19-3325. FREDÉN, GuSTAF-Tres ensayos cervantinos._fnsula, Madrid, 1964. 71 pp. $\| B H i, 67$ (1965), 383-384 (Canavaggio) ; $A r b, 61$ (1965), 255-256 (Larrea); $B H S, 42$ (1965), 279-280 (Riley); RHM, 32 (1966), 117 (Sobejano).

19-3326. Jaramillo, J. E. - "Cervantes, maestro del ideal"._Udem, Medellin, Colombia, 9 (1965), 93-98.

19-3327. Descouzrs, P._-“Cervantes sotto una luce nuova: echi d'un passato mal conosciuto".-Conv, 33 (1965), 561-575.

19-3928. Cortés Rodríguez, H.-“Cervantes y la soledad".-Rev. de Educación, Tunja, 1965, núm. 3, 51-65.

19-3329. Olmos García, F.-_Ideas de Cervantes sobre la función de la literatura y la misión del autor".- $L T a$, 1965, núm. 228, 92-105.

19-3330. Trotter, George Douglas_Cervanles and the art of fiction: inaugural lecture of the Chair of Spanish in the University of Exeter, delivered on 8 February 1965._Univ., Exeter, 1965. $22 \mathrm{pp}$.

19-3331. Ayala, F._"Notas sobre la novelfstica cervantina".-RHM, 31 (1965), $36-45$.

19-3932. UndurraGA, A. DE-.-"Cervantes y el cuento"._CCL, 1965, núm. 92, 9192.

19-3933. Freiberg, M-“Opera Iui Cervantes"-Rev. de Istorie si Teorie Literara, Bucarest, 14 (1965), 835-843.

19-3334. Cervantes, Miguel DE - Obras completas. Recopil., est. prel. y notas de A. Valbuena Prat. 13a ed.-Aguilar, Madrid, 1965. 1812 pp. (Obras eternas).-V. núm. 18-3548.

19-3335. Cervantes, Mrguel de - Obras completas. Pról. de G. de Argumosa. Ts. 1 y 2.-Juventud, Barcelona, 1965. 1624 pp. (Clásicos y modemos).

19-3336. Schnemers, A. J.- "Don Quijote 1615-1965".-LTa, 1965, 216-218.

19-3337. Cervantes, Miguel DE-El in genioso hidalgo Don Quijote de la
Mancha._Bruguera, Barcelona, 1966. 955 pp. (Joyas literarias).

19-3338. Cervantes, Miguel de-El ingenioso hidalgo Don Quijote de la Mancha. Ed. de J. García Soriano y J. Garcla Morales. 10ㄹ ed.-Aguilar, Madrid, 1965. 1684 pp. (Joya).-V. núm. 11-28590.

19-3339. Cervantfs, Miguel de-Don Quijote de la Mancha. Pról., génesis y vocabulario de Martin Alonso.-E.D.A. F., Madrid, 1965. 1021 pp.

19-3340. Cervantes, Miguel de-Don Quijote de la Mancha. Con ilustr. de S. Dali._Emecé, Buenos Aires, 1965. 423 pp. (Selección Emecé de obras contemporáneas).-V. núm. 13-35612.

19-3341. Cervantes, Miguel De-Don Quijoté de la Mancha. Versión de J. Ardanuy.-FHER, Bilbao, 1961. 80 pp. ilustr. (Selecciones literarias, 1).

19-3342. Cervantes, Miguel de-Don Quijote de la Mancha. Pról. de Martín de Riquer. - Juventud, Barcelona, 1965. 1096 pp. (Clásicos).-V. núm. 17-6003.

19-3343. Cervantes, Mrguel DE-El ingenioso hidalgo Don Quijote de la Mancha. Pról. de A. Castro. 4: ed.-Porrúa, México, 1965. Ixix + 586 pp. (Sepan cuanlos, 6).-V. núm. 18-7003. [5: ed., 1966; 6* ed., 1966; $7^{\text {a }}$ ed., $1967]$.

19-3344. Cervantes, Miguel De_Don Quijote de la Mancha. Introd. et notes par R. Romeu.-Privat-Didier, Paris, 1965. || $L N L, 1965$, núm. 4, I0I-102 (Lar. rieu) .

19-3345. Cervantes, Miguel DE,-El ingenioso hidalgo Don Quijote de la Mancsa.-U.T.E.H.A., México, 1965. [Ed. para niños].

19-3346. Cervantes, Miguel de-Don Quijote de la Mancha en pocas palabras. Resumen por $M$. de Riquer, ilustr. de Gustavo Doré.-G. Menéndez, México, 1965. 332 pp.

19-3347. Cervantes, Miguel de-Don Quijole en casa de los Duques. Adapta. ción de S. Mena.-Aguilar, Madrid, 1965. 120 pp., ilustr.

19-3348. Cervantes, Miguel DE—Sancho Panza gobernador. Adaptación para niños de M. Toledano. $2^{\mathfrak{a}}$ ed-Juventud, Barcelona, 1965. 48 pp., ilustr. 19-3349. Cervantes, Mrguel de-Don Quixote. Knightly adventures in 17 th century Spain. Ed., abridged and introd. by Lester G. Crocker._Washington Square Press, New York, 1965.

19-3350. Cervantes, Miguel de-Don Qui- 
xole: the remarkable adventures of the waliant knight of the rueful countenance. Retold by Arthur Kilingley.-E. Ward, London, 1965. 243 pp.

19-3351. Cervantes, Mguel de-Dom Quixote de la Mancha. Introd. de Brito Roca. Com um ensaio de $L$. da Câmara Cascudo, "Com Dom Quixote no folclore do Brasil".-Eds. de Ouro, Rio de Janeiro, 1965.

19-3352. Cervantes, Miguel DE-Don Quijote de la Mancha. Trad. de Ion Frunzetti si Edgar Papu. Cu un covint înainte de María Teresa León. Postfata de Ovidiu Drimba.-Editura Pentru Literatura Universala, Bucuresti, 1965. $1351 \mathrm{pp}$.

19.3353. EFRON, ARTHUR-Satire denied: $A$ critical history of English and Amer. ican "Don Quixote" criticism.-[Tesis, Univ, of Washington; resumen en $D A, 25$ (1964-65), 5274-5275].

19-3354. Navarro, Alberto_El Quijote español del siglo xvii.-Rialp, Madrid, 1964. 410 pp. (Bibl. del pensamiento actual). || EL, 1965, núm. 308 (Aguado) ; HR, 36 (1968), 66-68 (AvalleArce); $R H, 235$ (1966), 261-262 (Lapeyre); $N T, 23$ (1965), 275-276 (M. M. F.) .

19-3355. Garciasol, Ramón DE-Claves de España: Cervantes y el "Quijote".Cultura Hispánica, Madrid, 1965. 314 pp. II Ins, 1965, núms. 228/9 (Alfaro); $C U, 1966$, núm. 90, 66-71 (de Luis); $P S A, \quad 39$ (1965), 331-335 (Nin de Cardona); $H, 49$ (1966), 887 (RuizFornells) .

19-3356. Snetrova, Nina Pavlovna-"Don Kixot" Servantesa._Khudozhestvennaja Literatura, Leningrad, 1965. $156 \mathrm{pp}$.

19-3357. Thívenaz-SEINGRY, ROBERT-Du carnctère de Don Quicholle et du génie de Miguel de Cervantes.-.Genève, 1965. $47 \mathrm{pp}$.

19-3358. Palacín Iglesias, Gregordo B.En torno al "Quijote". (Ensayo de interpretación y crítica). 2\% ed-Leira, Madrid, 1965. xv + 216 pp.

19-3359. Gaos, V.- "Alto y sobajado Don Quijote".-EL, 1965, núm. 332.

19-3360. Pestel, MI-_L'étrange psychose de Don Quichotte. Essai sur un idéalisme engagé".-Presse Médicale, 72 (1964), 3407-3412.

19-3361. Coulf́on, H-“L'étrange folie de Don Quichotte. Cervantès et la psychiatrie".Annales Médico-Psychologiques, 122 (1964), 555-566.
19-3362. BEAUMONT, ELIE DE_op weg naar "Don Quichotte", door een labyrinth van drie en een have eeuw literaire kritiek._Boucher, 's-Gravenhage, 1964. 213 pp. || LTa, 1965, núm. 228, 146148 (Van Heusden).

19-3363. RICA, C, DE LA-"El mito de lo histórico y el amor de Don Quijote en San Tiago Dantas"._Rev, de Cul. tura Brasileña, 1965, núm. 15, 440449.

19-3364. Torrente Ballester, G._"Es. bozo de una teoría del personaje literario"._CI, 1965, núm. 3, 67-86. [Sobre todo en el Quijote].

19-3365. Vilar, P._-"Le temps du Quichotte".-Cahiers de la Compagnie Renaud-Barrault, 1965, núm. 51, 84-101.V. núm. 11-28623.

19-3366. García Morales, J.-“Don Quijote, conciencia a caballo".-EL, 1965, nưm. 332.

19-3367. Gianturco, E.-'El ingenioso hidalgo $\mathrm{e}$ il meraviglioso impossibile sogno".-Quaderni degli Amici della Spagna, Napoli, 1965, núm. 3.

19-3368. NeuschäFER, Hans-JöRG - Der Sinn der Parodie im "Don Quijote".Carl Winter, Heidelberg, 1963. 119 pp. (Studia Romanica, 5).-V. núm. 16. 49066. || $D L Z, 87$ (1966), 402-404 (Bahner); $R F, 77$ (1965), $201-204$ (Hempel); $A S N S, 203$ (1966), 240 (Janner); $R J, \quad 16$ (1965), 388-391 (Latorre); ZRPh, 81 (1965), 401-405 (Rüegg).

19-3369. SALEMA, A_“'O relativo e o absoluto do Quixote".-SN, 44 (1965), 308-309.

19-3370. Dantas, SaN TIAgo-Dom Quixote: um apólogo da alma occidental.Tempo Brasileiro, Rio de Janeiro, 1965. 19-3371. ECHEVERRÍA, JosÉ El "Quijote" como figura de la vida humana.-Ed. Universitaria, Santiago de Chile, 1965. 142 pp. || $B A b r, 41$ (1967), $72-73$ (Browne) ; $A$ som, 1967, núm. 3, 62-63 (Gon. zález) ; $A, 1966$, núm. 412, 243-248 (Muñoz G.) : $R I B, 17$ (1967), 440.441 (Núñez); $A r b, 66$ (1967), 332 (Portela Diaz).

19-3372. Ruano, A.-"El ingenioso hidalgo Don Quijote de la Mancha y Celestina".-Aienea, P. R., 1965, núm. 1, $61-70$.

19-3373. Descouzis, P. M. - "Cervantes, catedrático de ecasos de conciencias".H, 48 (1965) , 257-274.

19-3374. Montserrat, Santiago-la conciencia burguesa en el "Quijote". 
Universidad Nacional, Córdoba, 1965. 53 pp. || USF, 1966, núm. 67, 323324 (Rivacoba y Rivacoba).

19-3975. Alcántara San Pelayo, J."Justicia en La Mancha".-Rev. de Derecho Judicial, 1965, núm. 23, 11-20. 19-3376. PÉrez FERNANDEZ, Jost́-Ensayo humano y juridico de "El Quijote". Madrid, 1965. $302 \mathrm{pp}$.

19-3377. Martínez VAI., J. M._._Sanclio Panza en la Academia"-MuH, 1965 , núm. 206.

19-3378. Forero, M. J.- "En casa de Dulcinea del Toboso". $-B C B, 8$ (1965), 1885-1887.

19-3379. NúÑEz, Francisco MaríA-Roci. nante y Rucio.-San José, 1965. $65 \mathrm{pp}$.

19-3380. PAlAcín, G. B.-"Pasajes del Quijote mal interpretados (el final de la primera parte y los epirafios तel mismo)".-HuNL, 6 (1965), 243249.

19-3381. Palacín iglesias, Gregorio B.El "Quijote" en la literatura univer. sal-LLeira, Madrid, 1965. $70 \mathrm{pP}$.

19-3982. VIL ANov'A, A. - "La Moria de Erasnı y el prólogo del Quijote".$H A C, 423-433$.

19-3383. Bodivi, V.-"Manzoni c Cervantes: eScendeva dalla soglia...." Lett, 1965, núms. 76/77, 99-101.

19-3384. Sir.Es, J.- "La influencia de Don Quijote en Hudibras".-FM, 4 (1965), 185-192.

19-3385. Stout, G. D.-_"Some borrowings in Sterne from Rabelais and Cervantes".-English Language Notes, 3 (I965), $111-118$.

19-3386. Frchner, J. U._-"Cervantes und Kleist: ein Kapritel europäischer Novellistik". $-L T a, 1964,711-723$.

19-3387. Fredén, Gustaf-"Don Quijole" en Suecia.-Instituto Iberoamericano, Gotenburgo, 1965. $112 \mathrm{pp}$.

19.9388. Arcintegs, G.-"Don Quijote y la conquista de América".-RHM, 31 (1965), II-16.

19-3389. RojAs Garcidueñas, José-Presencias de Don Quijote en las artes de México.-Instituto Tecnológico, Monterrey, 1965. 131 pp., ilustr.

19-3390. Vento, A. C.-"El Periquillo y el Quijote"-UUNx, 19 (1964-65), núm. 12.

19-3391. GuevarA, Darío-La sabiduria de Sancho en la novela ecuatoriana.Minerva, Quito, 1965. $56 \mathrm{pp}$.

19-3392. Rosenib $A$ T, A.- "Montalvo y los Capltulos que se le olvidaron a Cer-
vantes".-_[En su libro] La primera visión de América (Caracas, 1965), 247270.

19.8393. VAI.JALO, DAnd - La primera aventura de Don Quijote.-Ed. Teatro de Cámara, Hollywood, Cal., 1965. [Teatralización].

19.3394. Cervantes, Miguel DE-Novelas ejemplares. Comentario de S. Fernálldez. 3! ed.-Porrúa, México, 1965. 277 pp. (Sepan cuantos, 9).-V. núm. 187116.

19-3395. Cenvantes, Migued DE-Three exemplary novels in the original Spanish: El licenciado Vidriera, El casamiento engañoso, El coloquio de los perros. Ed., introd. and notes by J. B. AvalleArce_-Dell, New York, 1964. 160 pp. (The Laurel language library). || $H R$, 35 (1967), 113 (Green) ; H, 49 (1966), 560 (Predmore); $B H S, 43$ (1966), 76 (Trotter) .

19-3396. Uribe Ferrer, R.-“Las Novelas ejemplares",-UdA, 42 (1965), 35.41.

19-3397. AvAlle-ARCE, J. B.-"Lope de Vega and Cervantes". - TQ 6 (1963). núm. 1, 190-202. || $L R, 21$ (1967), 94 (Groult).

19-3398. Ayllón, C.-"Sobre Cervantes y Lope: la novella" (N. 18-7123) . $\| R F E$, 48 (1965), 444-445 (Llorente).

19-3399. RothberG, I. P.- "Two similar zeugmas in Cervantes and Lope".-RNo, 7 (1965), $51-53$.

19-3400. Supervía, R.- "Sobre lo que le hizo el pastor a Berganza".-Hf, 1965, núm. 24, 19-24. [Cervantes, El coloquio de los perros.]

19-3401. Thompson, J.- "The structure of Cervantes' Las dos doncellas".-BHS, 40 (1963), 144-150. || LR, 20 (1966), 292 (Groult).

19-3402. HUdDLrstone, E. L.-"The Spanish Gipsy [de Thomas Middleton] and La Gitanilla: An unnoticed borrowing".-NQ 12 (1965), 103-I04.

19-3403. Cros, E.- “A propos de la première traduction italienne de $I a$ gitanilla de Cervantes". - LNL, 1965, núm. 4, 35-38.

19-3404. García Lorca, I.-"El licenciado Vidriera y sus nombres".-RHM, 31 (1965), 159-168.

19.3405. Green, O. H.-"El licenciado Viriera. Its relation to the Viaje del Parnaso and the Examen de ingenios of Huarte".-FHH, 213-220.

19-340G. Cervantes, Miguel DE-Rinconete y Cortadillo. Est. prcl. y notas 
por J. A. Zamudio de Predan.-Kapelusz, Buenos Aires; 1965. 52 pp. (Grandes obras de la literatura universal).

19-3407. Cervantes, Miguel de-La señora Cornelia. Ed. de Carmen Castro.Anaya, Salamanca-Madrid, 1965. 69 pp. (Biblioteca Anaya).

19-3408. Cervantes, Miguel de-El cerco de Numancia. El gallardo español. 3: ed-Espasa-Calpe, Madrid, 1965. 150 pp. (Austral, 774) .

19-3409. Cervantes, Miruel DF-La Numuncia. Pról. de Max Aub-Ecualor $0^{\circ} 0^{\prime} 0^{\prime \prime}$, México, 1965. [48] pp.

19-3410. Rodríguez Moñino, A._-"Reaparición de un manuscrito cervantino (el Trato de Argel y la Numancia)",$A L M, 4$ (1964), 269-275.

19-3411. Cervantes, Miguel DE-Entremeses. Est, y notas de V. Francone.Kapelusz, Buenos Aires, 1965. xl + 88 pp.

19-3412. Noulet, E.-"I,es intermèdes de Cervantès".-Cahiers de la Compagnie M. Renaud-Jean Louis Barrault, 1965, núm. 51, 102-104.

19-3413. Recoules, H._-Dios, el diablo y la Sagrada Escritura en los entremeses de Cervantes"'-BBMP, 41 (1965), 91 . 106.

19-3414. Cervantes, M. DE-La garde zélée. Trad. par E. Noulet et Josep Carner.-Cahiers de la Compagnie M. Renaud-Jean Louis Barrault, 1965, núm. $51,105-127$.

19-3415. MÁrQUEZ, F.-._Tractición y actualidad literaria en La guarda cuidadlosa"._HR, 33 (1965), 152-156.

19-3416. Szymdtowa, Z.- "Liryka Cervantesa".- $K N, 12$ (1965), 119-132.

$\checkmark$. también núms. 1575-6, 1588, 1648, 1673, $2277,2286,2537,2926,3242,3279$.

19-3417. Bataillon, M.-"Style, genre et sens: les Asturiens de La pícara Jusina"._FHH, 47-59.

Espinel: v. núm. 3282.

19-3418. Vélez de Guevara, Luis_El diablo cojuelo.-Marte, Barcelona, 1965. 186 pp. (Pliegos de cordel). || EL, 1966, núm. 338 (Umbral) .

V. también núm. 3312 .

Quevedo: v. núms. 3279, 3281, 3895-6.

Salas Barbadillo: v. núm. 2294.

Tirso de Molina: v. núms. 3114-6

Castillo Solórzano: v. núm. 3054.

19-3419. MarichaL, J._-_"Torres Villarroel: autobiografía burguesa al hispánico mo. clo".-PSA, 36 (1965), 297-306.

19-3420. Di Stefano, G.-“Mito e realtà ncll'autobiografia di Diego de Torres Villarroel".-MSI, 1965, núm. 10, 175202. II BHi, 70 (1968), 181-182 (Mercadier); RLit, 28 (1965), 255 (Rodríguez Cepeda).

\section{$A$ utores modernos}

19-3421. Herrero, Javier-Fernán CabaIlero: Un nuevo planteamiento-Gredos, Madrid, 1963. 346 pp. (BRH). $R F, 77$ (1965) , 206-207 (Ayllón) ; BHS, 43 (1966), 69-70 (Brown); HR, 33 (1965), 414-415 (Hafter); CD, 177 (1964), 168-169 (L. G.) ; H, 48 (1965), 383.384 (Qualia); $B A b r, 38$ (1964), 293 (Regalado); $B H i, 66$ (1964), 193194 (Ricardi) ; $A H, 1964,236-239$ (Tassara y de Sangrán).

19-3422. FERNÁN CABAILERO - Una en otra.-Dédalo, Madrid, 1964. $40 \mathrm{pp}$. (Novelas y cuentos).

19-3423. Herrero, J.-_"Un poema desconocido de Gabriel García Tassara a Fernán Caballero"._BHS, 42 (1965), 117-119.

Estébanez Calderón: v. núm. 3430.

19-3424. Hesse, José (ed.) -El Madrid de Mesonero Romanos.-Taurus, Madrid, 1964. 158 pp. (Temas de España).

19-3425. MEsonero Romanos, RAMónEscenas matritenses. Ed. de E. Correa Calderón. - Anaya, Salamanca-Madrid, 1964. 115 pp. (Bibl. Anaya, 55).

19-3426. Montesinos, J. F.-“"Trueba y su realismo. (Nota a un primitivo)".FFS, 434-448.

19-3427. LEDDA, G.-"Il romanzo storico di Gil y Carrasco".- $M S I, 1964$, núm. 8, 133-146.

19-3428. GIL Y Carrasco, ENrIQUe El señor de Bembibre. [Adaptación]. Aguilar, Madrid, 1966. (El globo de colores).

V. también núm. 2614.

19-3429. Soca, J.-_"Perfil del pueblo de don Juan Valera"-MuH, 1965, núm. 210.

19-3430. Echínove, J. DE_-"Juan Valera en Brasil y en Portugal. (Correspondencia con Serafín Estébanez Calderón) "._- $u$ CuH, 62 (1965), 189-195.

19-3431. Alarcón, Pedro ANTONIO DE-Historietas nacionales. Ed. de L. González Palencia._Anaya, Salamanca, 1965. 82 pp. (Bibl. Anaya).

19-3432. Weiss, GerARD MATTHEw-The novelistic world of Pereda as seen in his themes and characlers.-[Tesis, New 
York Univ.; resumen en $D A, 26$ (1965. 66) , 3355].

19-3433. Pereda, José María de-De tal palo tal astilla. 39 ed.-Espasa-Calpe, Madrid, 1965. 211 pp. (Austral, 487).

19-3434. Pereda, Jost́ María dE-Don Gonzalo González de la Gonzalera. 5a ed.-Espasa-Calpe, Madrid, 1965. 230 pp. (Austral, 58).

19-3435. Pereda, José María de-Pedro Sánchez. 2: ed.-Espasa-Calpe, Madrid, 1965. (Austral, 528) .

19-3436. Pereda, José María dE-Peñas arriba. 4: ed.-Espasa-Calpe, Madrid, 1964. 264 pp. (Austral, 414).

19-3437. Moncr, A.-_"Enigmas de Galdós'.-In.s, 1965, nứm. 222.

19-3438. CorreA, G.-"Presencia de la naturaleza en las novelas de Pérez Galdós".-BICC, 18 (1963), 646-665.

19-3439. BELL, WENDOLYN YvonNE_Galdos' use of nomenclature in characterization.-[Tesis, Univ. of Iowa; resumen en $D A, 25$ (1964-65), 5272].

19-3440. SHOEMAKER, WILLAM H.-Los prólogos de Galdos (N. 18-3620). I MLJ, 48 (1964), 58-59 (Brown); Hf, 1965, núm. 23, 39-41 (Chamberlin); Fil, 10 (1964), 233-234 (Gatti); $H R$, 32 (1964), 187 (Hafter); $M L R, 60$ (1965), 291 (Jones); BHS, 41 (1964) . 56-57 (Round).

19-3441. Ruiz Ramón, Francisco-Tres personajes galdosianos-_Rev, de Occidente, Madrid, 1964. 272 pp. || $H, 48$ (I965), 938-939 (Fedorchek).

19-3442. Pérez Galdós, Benito-La som. bra. Ed. de R. Cardona.-W. W. Norton, New York, 1964. xxviii + $147 \mathrm{pp}$. || $M L J, 49$ (1965), 197 (Adams); $H$, 48 (1965), 202.203 (Chamberlin).

19-3443. Mills, William Donald-La influencia de Tolstoi en tres novelas de Galdos: "Nazarin", "Halma" y "Misericordia".-[Tesis, Univ. de Madrid; resumen en $R U M, 19$ (1964) , 596-597]

19-3444. Pérez Galdós, Benito-Miséricorde. Trad. ct préf. par P. Guenoun.Les Editeurs Francais Reunis, Paris, 1964. || LMo, 1965, núm. 2, 122-123 (Larricu); $L N L, 1965$, núm. 172, 121 122 (Larrieu).

19.3445. Conde Gargollo, Enrique-Galdos, periodista._Madrid, 1964.

19-3446. Shotmaker, W. H.-“Galdós y La Nacion".-_Hf, 1965, núm. 25, 21-50.

19-3447. Ricard, R.- "Cartas a Galdós y cartas de Galdós".-AEAtl, Il (1965), 163-19l.
19-3448. ORTEGA, SolEdAd_Cartas a Galdós. Presentadas por...-Rev. de Occidente, Madrid, 1964. 454 pp. + 10 láms. + 17 facs. \| CuH, $6 \mathrm{I}$ (1965), 406-4I2 (Bravo-Villasante); Ins, 1965, núm. 219 (Cano) ; $H, 49$ (1966), I62 (Chamberlin); CuH, 64 (1965), $372-$ 376 (de Torre).

19-3449. RAs, M._Una carta intima de Galdos".-MuH, 1965, núm. 204.

19-34.50. Schraibman, J.-"An unpublished letter from Galdós to Ricardo Palma", $H R, 32$ (1964), 65-68.

$V$. tambiên núms. 2361, 4017.

19-3451. Coloma, LuIs-Pilatinhos._Eds. Salesianas, Lisboa, 1964. 96 pp. (Col. Ardinha, 15).

V. también núm. 2914.

19-3452. Sobejano, G.- "Clanín y la crisis de la critica satfrica"_- $R H M, 31$ (1965), 399.417.

19.3453. Alas, Leopoldo (Clarín)_Obras. T. 1: La Regenta. Ed., introd., bibliografia y notas de J. M. Martínez Cachero. - Planeta, Barcelona, 1963. lxxxviii + 862 pp. (Clásicos Planeta). \| BHS, 43 (1966), 303-904 (Beser).

19-3454. AI.AS, LeOPOLDO-Guentos escogidos. Ed. by G. G. Brown,-Dolphin, Oxford, I964. 229 pp. || BHS, 44 (1967), 134-135 (Cheyne); $M L R, 63$ (1968), 734735 (Hall); HR, 35 (1967), 202-203 (Kronik) .

19-3455. Bull, William, \& Vernon A. Chamberlon-Clarin: the critic in action.-Oklahoma State University, Norman, Okl., 1963. 64 pp. || $H, 48$ (1965), 178 (Gramberg) ; Hf, 1965, núm. 25. 5762 (Kronik); HR, 34 (1966), 192-193 (Pattison) .

V. tainbién núm. 3976 .

19-3456. Osborne, Robert E. - Emilia Pardo Bazán: su vida y sus obras.De Andrea, México, 1964. 152 pp. (Studium, 42). I| Stylo, 1967, núm. 5. 195-196 (Aguayo Quesada); $M L J, 50$ (1966) , 294-295 (Brown); H, 48 (1965), 6I2-613 (Davis) ; HR, 36 (1968), 70.72 (Hafter) ; BHS, 43 (1966), 134-135 (Herrero) ; RNC, 1966, núms. 174/175, 134-135 (Velázquez) .

19-3457. SÁnchez, PORFrio-Emilia Pardo Bazan: a contrast study beiween the novelist and the short-story writer.['Tesis, Univ. of California, Los Ángeles; resumen en $D A, 25$ (1964-6.5), 19247.

19-3458. Pardo BazAN, Emilia - Obras completas. T. 2, $3^{\mathrm{a}}$ ed.-Aguilar, Ma- 
drid, 1964. 1732 pp. (Obras eternas).—V. núm. 11-28703.

19-3459. Pardo BAZAN, EMILIA-Novelas $y$ cuentos. T. 1, 4a ed.-Aguilar, Madrid, 1964. 1712 pp. (Obras eternas).v. núm. 12-33685.

19-3460. GRANJEI, L. S- "Silverio Lanza en el recuerdio de sus coetáneos".PSA, 34 (1964), 43-53.

19-3461. BARGA, C.- "Del hombre raro de Getafe. Dos cartas y una invita. ción",-PSA, 34 (1964), 9-39.

19-3462. Senabre SEmpere, R.-"Silverio Lanza y el Marqués del Mantillo".PSA, 34 (1964), 97-108.

19-3463. ZORITA, A_-"El anticlericalismo de Silverio Lanza"._PSA, 34 (1964), $75-94$.

19-3464. Granjel, L. S.—"Obras de Juan Bautista Amorós, Silverio Lanza".PSA, 34 (1964), 111-112.

19-3465. DurÁN, M.-."Silverio Lanza y Silvestre Paradox".-PSA, 34 (1964), 57-72.

19-3466. Smith, PaUl ClarencE-Vicente Blasco Ibáñez: $A$ critical survey of the novels from 1894 to 1909.-_[Tesis, Univ. of Califormia; resumen en $D A, 25$ (196465), 5943].

19-3467. BLASCO IBÁ̃̃EZ, VICENTE-La barraca. Ed. by G. J. G. Cheyne.-.Harrap, London, 1964. 263 pp. || BHS, 43 (1966), 78-79 (Brooks).

V. también núm. 2313.

Unamuno: v. núms. 2361, 3996-4008.

19-3468. GUERrERo, OBDULIA_Valle-Inclán o el novecientos.-[Tesis, Univ. de Madrid, 1964; resumen en RUM, 14 (1965), 208-209].

19-3469. NAvAs RuIz, Ricardo_Literatura y compromiso,-lnst. de Cultura Hispánica, São Paulo, 1963. 118 pp. (Ensayos sobre la novela politica hispanoamericana). [Incluye un estudio sobre Tirano Banderas]. || RLSP, 5 (1964), 301-303 (Almeida Prado); Ins, 1966, núm. 238 (Campos); Rev. de Cultura Brasileña, 4 (1965), 128-129 (Chavarri); RLit, 23 (1963), 271-272 (Esquer Torres) ; $B H S, 43$ (1966), 147-148 (Franco) ; RHM, 32 (1966), 119-120 (Tudisco) .

19-3470. RAmírez, M. D. - "América y americanismos en la obra de Vallelnclán".-DHR, 4 (1965), 123-134.

19-3471. VALlE-1NCLAN, RAMÓN DEL_Aguila de blasón. 2: ed.-Espasa-Calpe, Madrid, 1964. 154 pp. (Austral, 667). V. también núms. 2313, 2672.
19-3472. LatchaM, R.--Pío Baroja, intimo"._A, 1965, núm. 408, 161-165.

19-3473. Arвó, S. J.-Pio Baroja y su tiempo (N. 18-7332). $\| A L M, 4$ (1964), 344-346 (Abreu Gómez).

19-3474. BELLINI, GIUSEPPE-Introduzione a Baroja. Appunti dalle lezioni.-La Goliardica, Milano, 1964. 105 pp.

19-3475. Garcia, E.-“Schopenhauer, Hesse y Baroja".-EFil, 1964, núm, 1, 125-135.

19-3476. Nallim, Carlos Ortando - $E l$ problema de la novela en Pio Baroja... Ateneo, México, 1964. 284 pp. \| $H$, 48 (1965), 939-940 (Brown); RLit, 26 (1964) , 237-238 (Romero); RLMo, 1965. núm. 4, 160-161 (Ruiz Díaz); BHS, 42 (1965), 203-204 (Shaw).

19-3477. BARoJA, Pí-[Aurora roja. Trad. rusa por $G$. Stepanov._-Editorial Literaria, Moscú, 1964]. \|LS, 1965, núm. 8, 179-182 (Wasiliewska).

19-3478. Santander, C.-“Camino de perfección, de Pio Baroja".-EFil, 1964, núm. 1, 197-217.

19-3479. BARojA, Píl_Las veleidades de la fortuna. $3^{\mathrm{a}}$ ed.-Espasa-Calpe, Madrid, 1964. 160 pp. (Austral, 228).

19-3480. BAROJA, Pío_Zalacaín el aventurero. 4: ed.Espasa-Calpe, Madrid, 1964. 156 pp. (Austral, 346).

19-3481. Rodríguez Adrados, F_-“El Zalacain de Baroja y el canto VI de la Ilia. da".-ROcc, 8 (1965), 202-208.

19-3482. WAGNER, KLAUS-Die "Memotias" von Pio Baroja.-[Tesis, Univ, de Munich, 1964].

V. también núms. 2313, 3465 .

19-3483. Vidal, RAymond_Gabriel Miró. Le style. Les moyens d'expression.Féret, Bordeaux, 1964. 232 pp. (Bibl. de l'École des Hautes Etudes Hispaniques, 33) . $\| \mathrm{BHi}, 69$ (1967), 257-261 (Laffranque) : BHS, 42 (1965), 206207 (Woodward) .

19-3484. RAMos, VICENTE_El mundo de Gabriel Miró._Gredos, Madrid, 1964. 478 pp. (BRH). \| BAbr, 39 (1965), 326 (Angeles) ; ins, 1964, núm. 214 (Cano); RLit, 25 (1964), 247-254 (Juliá Martínez) .

19-3485. Miró, Gabriel Las cerezas del cementerio. El abuelo del rey. Figuras de la Pasión del Señor. Años y leguas.Vergara, Barcelona, 1965. 816 pp.

19-3486. BEck, MARY-La novela de Ramón Pérez de Ayala. (El problema del intelectualismo).-Tesis, Univ. Nacional Autónoma de México, 1964. 
19-3487. Pérez de Ayala, Ramón-Obtas completas. Pról. de J. García Mercadal. Ts. I y 2,-Aguilar, Madrid, 1964, 1965. Ixxvi + 1308, $1200 \mathrm{pp}$.

19-3488. Soldevlla-Durante, I.--"Ramón Pérez de Ayala. De Sentimental club a La revolución sentimental".-CuH, $6 \mathrm{I}$ (1965), 5-19.

V. también núms. 1690, 4018 .

19-3489. Garriga Rodríguez, Caridad -. Wenceslao Fernández Flórez: vida $y$ obra.-_[Tesis, Univ. de Madrid, 1965; resumen en $R U M, 14$ (1965) , 281].

19-3490. Fernhindez Flórez, WenceslaoObras completas. T. 6. 2a ed.-Aguilar, Madrid, 1964. 976 pp. (Col. Joya).V. núm. 16.45128.

19-3491. Fernández Flórez, WenceslaoObras completas. Ts. 8 y 9.-Aguilar, Madrid, 1964. 1250, 1200 pp. (Col. Joya).-V. nưm. 16-45128.

19-3492. FERNANDEZ FLóREZ, WENCESLAOEl bosque animado._Espasa-Calpe, Madrid, 1965. 219 pp. (Austral, 1356).

19-3493. FernANdez Flórez, WenceslaoEl malvado Carabel._-Espasa-Calpe, Madrid, 1965. 219 pp. (Austral, 1363).

19-3494. Fernindez Flórez, WenceslaoImpresiones de un hombre de buena fe (1914-1936)._Espasa-CaIpe, Madrid, 1964. 2 ts.: 210,254 pp. (Austral, 1342, 1343). ||$R y F, 173$ (1966), 217 (Brugarola).

19-3495. García Lora, J. - - "Fabulación dramática del fabuloso Max Aub".ins, 1965, nưms. 222, 223, 224/5.

19-3496. AUB, MAX_El zopilote y otros cuentos mexicanos.-Edhasa, Barcelona, 1964. 206 pp. || Res, 2 (1965), I08-110 (Hornedo) ; EL, I965, núm. 311 (Iglesias Laguna) ; PSA, 38 (1965) , 106.108 (Molina) ; CCL, 1965, núm. 94. (Scuderi) .

19-3497. VAlencid, A.-_Juan Antonio de Zunzunegui, novelista"._LEsp, 8 (1965), 597-6I2.

19-3498. Carbonell Basset, Delfín-La novelistica de Juan Antonio de Zun. zunegui._[Tesis, Univ. de Madrid; resumen en $R U M, 13$ (1964), 588-589].

19-3499. ELLIS, KEITH-El arte natrativo de Francisco Ayala._Gredos, Madrid, 1964. 260 pp. (BRH).-V. núm. 17-6302. || BHS, 44 (1967), 69-70 (Aguirre); $H R, 36$ (1968), 289-294 (Cardona); $R R, 57$ (1966), 151-152 (Klin); Ins, 1965, núm. 222 (Marra-López); PSA, 38 (1965), 222-223 (Molina) ; $H, 49$ (1966), 891892 (Scliwartz).
19-3500. Ayala, F._-Carta literaria".PSA, 33 (1964), 81-98. [Sobre su propia obra novelística].

19-3501. Ayala, F._"Carta del Atlántico",-UMX, 18 (1963-64), núm. 5.

19-3502. Ayala, Francisco_El as de bastos.-Sur, Buenos Aires, 1963. II9 pp. || $R H M, 32$ (1966), 91-93 (Agostini de del Río) ; PSA, 32 (1964), $947-348$ (Sobejano) .

19-3503. Ayala, Francisco-De este mundo y el otro.-E.D.H.A.S.A., Barcelona, 1963. 154 pp. (El puente). I| Ins, 1965, núm. 219 (Mainer); ROcc, 7 (I964), 252-253 (Scuderi).

19-3504. Ayala, Francisco-Death as a way of life. Transl. by Joan MacLean.Macnillan, New York, 1964. 218 pp.

19-3505. Ayala, Francico-Historia de macacos.-Libros del Mirasol, Buenos Aires, 1964. $145 \mathrm{pp}$.

19-3506. RodRíguez-ALcALA, H._."El cuento $E l$ inquisidor de Francisco Ayala".RHM, 30 (1964), 20-34.

V. también nưm. 199.

19-3507. Tovar, A._-Dos capftulos para un retrato literario de Sender".-CI, 1966, núm. 4, 17-35.

19-3508. SENDER, RAMóN J.-La avenlura equinoccial de Lope de Aguirre.Las Américas, New York, 1964. 362 pp. II $A b r, 40$ (1966), 196 (Allen) ; $B C B$, 9 (1966), 130-I4I (Allen); RHM, 33 (I967), 140 (Cano); fns, 1965, núm. 220 (Mana-López) ; RevIb, 33 (1967), I56-160 (González-Araúzo), EL, 1967, núm. 383 (Sainz de Robles).

19-3509. SENDER, RAMón-Carolus Rex. Carlos II el hechizado. Novela histórica.-Eds. Mexicanos Unidos, México, I963. I72 pp. \|I İs, 1964, nún. 209 (Marra-López) ; Norte, sept.-oct. 1966 (Rivas) .

19-3510. SEnder, R.-La llave (N. 1645150). || RHM, 32 (1966), 106-107 (Schraibman); H, 48 (1965), 180-181 (Schwartz) -V. núm. 17-6308.

19-3511. SENDER, RAMóN_Los tontos de La Concepcion.-Coronado Press, Sandoval (New Mexico), 1963. I25 pp. I BAbr, 39 (1965), 70 (Boscll) ; $H, 48$ (1965) , 614 (Bosch) ; RHM, 30 (1965) , 141 (Bosch) .

19-3512. Gimferrer, P._._En torno a la obra narrativa de Serrano Poncela".fns, 1965, núm. 226 .

19-3513. Serrano Poncela, Segundo-Habitación para hombre solo.-Seix $\mathrm{Ba}$. rral, Barcelona, 1968. 179 pp. $\| B A b r$, 
38 (1964), 416 (Figueira); RHM, 32 (1966), 107 (Schraibman).

19-3514. Arbó, Sebastí́n JuAN_Martín de Caretas en el campo.-Plaza y Janés, Barcelona, 1964. 186 pp. (Libros Plaza).

19-3515. Arbó, Sebastián JuAN-Relatos del Delta-Mateu, Barcelona, 1965. 320 pp. (Col. La pluma). || EL, 1966, núm. 338 (Plans).

19-3516. Castellet, J. M., et al,-Camilo José Cela. Vida y obra. Bibliografiaantologia. - Hispanic Institute, New York, 1962. 180 pp. $\| B I C C, 21$ (1966), 220-221 (Berrfo Toro); H, 48 (1965), 181-182 (Kronik) ; $R R, 57$ (1966), 150151 (Rodrfguez-Alcalá).

19-3517. Foster, DAvid Wulliam-Studies on the contemporary novel as experiment: $A$ technical and siructural examination of the novels of Camilo José Cela.-[Tesis, Univ, of Washington; resumen en $D A, 25$ (1964-65), 5275$5276]$.

19-3518. llie, PaUL_la novelistica de Camilo José Cela.-Gredos, Madrid, 1963. 238 pp. (BRH).-V. núm. 1441462. || BHS, 41 (1964), 199-200 (Alberich) ; RLMo, 1966, núm. 5, 171172 (Chochoulous); $M L N, 82$ (1967), 262-26-1 (Durand); HR, 33 (1965), 185-190 (Predmore); RR, 57 (1966), 148-149 (Rodríguez-Alcalá); $M L R, 62$ (1967), 149-150 (Shaw)

19-3519. KIRSNER, ROBERT - The novels and travels of Camilo Jose Cela.-Univ. of North Carolina Press, Chapel Hill, 1963. 187 pp. ||$B H S, 42$ (1965), 209211 (Alberich); HI, 48 (1965), 615 (Boudreau) ; RHM, 32 (1966), 116 (Dennis) ; HR, 34 (1966), 193-194 (Predmore); $R R, 57$ (1966), 150 (Rodriguez-Alcalí); RLit, 25 (1964), 262-263 (Romero) .

19-3520. Polo García, V.-"Poesía y ritmo en la prosa de Camilo José Cela".AUM, 23 (1964-65), 91-131.

19-3521. Cela, Camilo JoséObra completa. T. 1: Cauteloso tiento por lo que pudiera tronar.-.Destino, Barcelona, 1963. 604 pp. [Contiene $L a \mathrm{fa}$ milia de Pascual Duarte, Pabellon de reposo y Nuevas andanzas y desven. turas de Lazarillo de Tormes]. II Ins, 1963, núm. 196 (Canito); PSA, 31 (1963), 93-103 (Sobejano).

19-3522. Cela, Camilo Jost_La familia de Pascual Duarte_Destino, Barcelona, 1963. 186 pp. (Ancora y delfin).-.V. núm. 13-37696.
19-3523. Cela, Camro Jost.-The family of Pascual Duarte. Transl. by A. Ker. rigan.-Little, Brown \& Co., Boston. Toronto; Weidenfeld \& Nicolson, London, 1964. $\mathrm{xx}+166 \mathrm{pp}$.

19-3524. Cela, Camilo José-The family of Pascial Duarte. Transl. by A. Kerrigan.-Avon Books, New York, 1966. 144 pp.

19-3525. CFin, Camilo José. - Druzina Pascuala Duarteja_-Drzavna Zalozba Slovenije, Ljubljana, 1960. 104 pp.

19-3526. OrteGA, J.- "El sentido temporal en La colmena"._-S, 19 (1965), 123131.

19-3527. Ortega, J. - "Importancia del personaje Martín Marco en La colme. na de Cela".-RNo, 6 (1965), 92-95.

19-3528. KIRSNeR, R.- "La Catira, novela anıérico-hispana".-PSA, 38 (1965), 87-93.

19-3529. Cela, Camilo Jost-Historias de España. Los ciegos, Los tontos. Nucva ed., corr. y aum.-Alfaguara, Madrid, 1965. 99 pp. (A la pata de palo, 1). 19-3530. Cela, Camilo José-Cajón de sastre.-Alfaguara, Madrid, 1965. 341 pp. (Hombres, hechos, ideas).

19-3531. Cela, Camilo Jost́-La familia de héroe, o cliscurso histórico de los ullimos restos. (Ejercicios para una sola mano). Nueva ed., corr. y aum.-Alfaguara, Madrid, 1965. 89 pp., ilustr. (A la pata de palo, 2). i| Asom, 1965. núm. 3, 78-80 (Fernández Molina); $B A b r, 40$ (1966), 318-319 (Foster).

19-3532. Cela, Camllo José-Gavilla de fábulas sin amor. Ilustr. de Picasso.Alfaguara, Madrid, 1965. 172 pp. (Museo secreto). \| $E l, 1966$, núm. 334 (Plans) .

19-3533. Cela, Camilo José_lzas, rabizas y colipoterras. Drama con acompañamiento de cachondeo $y$ dolor de co. razón. Fotograflas de Juan Colón.Lumen, Barcelona, 1964. 86 pp. $H D, 40$ (1964), 802-803 (Roig).

19-3534. Cela, CAMILO Joś́-El solitario y "Los sueños de Quesada" de $R a$. fael Zabaleta.-Papeles de Son Armadans, Palma de Mallorca, 1964. (Col. Principe don Juan Manuel, 3).

19-3535._Urbistondo, V.-."Cela y Rubens: estudio analtico sobre Tobogán de hambrientos".-PSA, 39 (1965), 252278.

19-3536. Cena, Camilo José-El ciudadano Iscariote Reclús.-Alfaguara, Madrid, 1965. (Col. A la paia de palo). $\| A L M$, 
5 (1965), 247-248 (Fernández Molina); $E L, 1966$, nưm. 340 (Iglesias Laguna). 19.3537. Cela, Camilo José-Páginas de geografia errabunda.-Alfaguara, Madrid, 1965. 317 pp., ilustr.

19-3538. Cela, Camilo Jost_-Viaje al Pirineo de Lérida. Nolas de un paseo a pie por el Pallars Sobira, el Valle de Arán y el condado de Ribagorza-Alfaguara, Madrid, 1965. 334 pp., lánıs. \| $H, 49$ (1966), 597 (Flightner); ins, 1965, núm. 220 (Marra-López); Res, 2 (1965) , 269-271 (Micó Buchón); $E L$, 1965, núm. 312 (Trulock).

V. también núm. 1574.

19-3539. Gironella, José María_-Phantoms and fugitives.-Sheed \& Ward, New York, 1964. 177 pp.--V. núm. 17-2718. 19-3540. GironelLA, José MARÍA-El Japon y su duende._Planeta, Barcelona, 1864. 336 pp. (Autores españoles contemporaneos). || NT, 23 (1965), 661-663 (J. E. M.).

19-3541. Gironella, José María-China, ligrima innumerable.-Planeta, Barcelona, 1965. 232 pp., láms. (Autores españoles contemporáneos).

19-3542. NúÑEZ, A.- "Encuentro con Ana Marla Matute".-Ins, 1965, núm. 219.

19-3543. Sexton, Thomas P.-Los temas dominantes en la obra de Ana Maria Malule.-[Tesis, Univ. de Madrid, 1965̆; resumen en $R U M, 14$ (1965), 232-233].

19-3544. Martínez Palacio, J.- "Una trilogía novelística de Ana María Matute".-Ins, 1965, núm. 219.

19-3545. Terterián, I._"Publicación en ruso de la novela de Ana Marla Matute Los hijos muertos".-LS, 1965, núm. 6, 157-158.

19-3546. Matute, ANa Marí-El polizón de "Ulises".-Lumen, Barcelona, 1965. 122 pp. (Grandes autores para niños, 22) .

19-3547. Matute, Ana María-Erste Erinnerung. Ubers. von Doris Deinhard.Deutsche Verlags-Anstalc, Stuttgart, 1965. 251 pp. $\| W e W, 20$ (1965), 237 (Hellmuth) .

19-3548. Matute, ANa María_Los soldados llaran de noche.-Desino, Barcelona, 1964. 227 pp. (Ancora y delfin). II RHM, 30 (1964), 309 (Bosch); Ins, 1964, nún. 214 (Cano) ; RyF, I73 (1966) , 328 (Castro y Delgado) ; LFr, 18 (1964) , I71 (Mauri) ; BAbr, 39 (1965), 197 (McMahon), $P E, 1964$, núms. 97/ 98, 141-142 (Murciano); H, 48 (1965), 942 (Winecoff).
19-9549. Matute, ANA MaRía - Nachts weinen die Soldaten. U'bers. von Doris Deinhard. - Deutsche Verlags-Anstalt, Stuttgart, 1965. 225 pp. || Die Allantis, 1966, febrero, 135-136 (lmhasly) .

19-3550. Matute, ANa Maria-El tiempo.--Mateu, Barcelona, 1963. 283 pp.V. núm. 13-35736.

V. también núm. 3260.

19-3551. WLNECOFF, J. - "Fictionalized autobiography in the novels of Dolores Medio".-KFLQ, 13 (1966), 170. 178.

19-3552. Medro, Dolorfs-Bibiana. (Priinera parte de la crilogía Los que va. mos a pie).-Edit. Bullón, Madrid, 1963. 354 pp. (Generaciones juntas). II fns, 1964, núm. 209 (Alfaro); BAbr, 39 (1965), 69 (Tatuni).

19-3553. Rodríguez Alcalde, L.-“El novelista Miguel Delibes"._LEsp, 1966, núm. 97.

19-3554. Delibes, MigueL_Viejas historias de Castilla la Vieja. Fotograffas de Ramón Masats._Lumen, Barcelona, 1964. II Ins, 1965, núm. 221 (Marra-López); $P E, 9$ (1964), 127-129 (Umbral).

19-3555. Delibes, Miguel_El libro de la caza menor._Destino, Barcelona, 1964. 218 pp. II fns, 1965, núm. 221 (Marra-López), Hum, 16 (1964), 224 (Martino) .

19-3556. Marra-López, J. R.-“Lirismo y esperpento en la obra de Igracio Aldecoa"._ins, 1965, núm. 226.

19-3557. Aldecoa, Ignacio_Los pájaros de Baden-Baden-Cid. Madrid, 1965. 263 pp. || $B A b r, 40$ (1966) , 317-318 (Allen); $E L$, 1965, núms. 324/5 (Bonilla).

V. también núm. 3260 .

19-3558. Paolini, Gilberto - Bartolomé Soler novelista.-A. G. Atenas, Barcelona, 1963. 93 pp. \|Hf, 1966, núm. 27, 5l.54 (Kronik); $H, 48$ (1965), 617 (McMahon).

19-3559. Ruiz y Díaz, I.—"Sánchez Ferlosio: encuentro en el diálogo"'- $P N$, 1966, núm. 15.

19-3560. SAlcado, M. A.-“Fantasía y realidad en Alfanhui".-PSA, 39 (1965), 140-152.

19-3561. ALLEN, N._-"Alfanhuí y su cartilla intacta".-RHM, 30 (1964), 126135.

19-3562. Sánchez Ferlosio, RAfael-El Jarama. 6* ed.-Destino, Barcelona, 1965. 365 pp. (Ancora y delfin, 121).-V. núm. 12-30396.

19-3563. Ortegn, J._"Tiempo y estruc- 
tura en El Jarama".-CuH, 67 (1966), 801-808.

19-3564. Van PraAg Chantraine, J. "Juan Goytisolo".-Synth, 1965, 259. 265.

19-3565. ScHWARTZ, K. - "The United States in the novels of Juan Goytiso$10 "$. $R$ No, 6 (1965), 122-125.

19-3566. Goytisolo, JuAN - [Novelas: Juegos de manos; El circo; La resaca; Ia isla. Trad. rusa._Ed. Progreso, Moscú, 1964]. \|LS, 1965, núm. 1, 185-187 (Terterián).

19-3567. Goytisolo, JuAN - Fiestas. 2a ed.-Destino, Barcelona, 1964. $235 \mathrm{pp}$. (Ancora y delfín, 248).-V. núm, 1439434. || $R y F, 171$ (1965), 110 (Blajot).

19-3568. Goytisolo, JuAN - Fiestas. Introd. y notas de K. Schwartz.-Dell, New York, 1964. 255 pp. (The Laurel language library).

19-3569. Goyt'ISOLO, JuAN_L'isola. Trad. di Maddalena Raimondi Capasso.Einaudi, Torino, 1964. 177 pp. $\| C C$, 116 (1965), 171-172 (De Gennaro).

19-3570. Díaz-PlajA, F.-"Náufragos en dos islas. Un paralelo narrativo: Goytisolo y Golding"._fns, 1965, núm. 227. [Sobre La isla].

19-3571. Goytisolo, JuAN-Pueblo en marcha.-Librerf́a Española, París, 1963. 170 pp. (Col. Club de bolsillo). I LNL, 1966, núm. 1, 117-118 (Larrieu); CuA, 5 (1964), 285-286 (de la Selva).

19-3572. Goytisolo, JUAN_Le terre di Nijar. La Chanca. Trad. Elena Clementelli.-Feltrinelli, Milano, 1965. 284 pp. (I narratori, 66).

19-3573. García Viño, M.-“Castillo Puche y la novela católica".- $-N T, 23$ (1965), 291-306.

19-3574. Castillo Puchr, J. L.-El perro loco._Alfaguara, Madrid, 1965. 93 pp. (La novela popular, 2).

19-3575. Ferres, ANTONIO-Con las manos vacias.-Seix Barral, Barcelona, 1964. 201 pp. $\| H, 49$ (1966), 166 (Bosch); RHM, 30 (1964), 312 (Bosch); RyF, 173 (1966), 216 (Castro y Delgado); Ins, 1965, num. 222 (Marra-López).

19-3576. FERRES, ANTONIO-Tierra de olivos.-Seix Barral, Barcelona, 1964. 212 pp. $H, 48$ (1965), 941-942 (Bosch); RHM, 30 (1964), 312 (Bosch).

19-3577. FERres, ANTONIO_LLos vencidos._ Librairie du G]obe, Paris, 1965. 242 pp. II CuA, 25 (1966), 267-268 (de la Selva).

V. también núm. 3260 .

\section{PROSA VARIA}

19-3578. Gill Gaya, Samuel (ed.)-Historiadores de los siglos xvi y xvii. C.S.I.C., Madrid, 1964. 252 pp. (Biblioteca literaria del esiudiante, 16). || $A I A, 25$ (1965), 353-354 (Borges).

19-3579. Bleznick, Donald W.-El ensayo español del siglo $x v i$ al $x x$.-De Andrea, México, 1964. 144 pp. (Col. Studium, 44) . \|HR, 35 (1967), 184187 (Morón Arroyo) ; $H, 48$ (1965), 938 (Nozick) ; RHM, 32 (1966), 98-99 (Roberts) ; BAbr, 39 (1965), 326 (Sarmiento); USF, 1965, num. 64, 347-348 (Zuleta) .

19-3580. Bellini, Giuseppe (ed.) _Saggisti spagnoli del secolo xviii.-La Goliardica, Milano, 1965. ix + $143 \mathrm{pp}$.

19-3581. BLfZnick, Donald W. (ed.) -El ensayo español del siglo $x x$.-The Ronald Press, New York, 1964. 194 pp. || $M L J, 49$ (1965), 510 (Iglesias); H, 47 (1964), 677 (Schwartz).

19-3582. FERNÁNDEZ DE LA MORA, GoNZALO-Pensamiento español 1964. De Unamuno a d'Ors, - Rialp, Madrid, 1965.-V. núm. 18-7490. || HR, 35 (1967), 200 (Morón Arroyo); EM, 22 (1966), 157-158 (Pikasa).

V. también núms. 179, 952, 2266, 2840 , 3240.

\section{A utores antiguos}

19-3583. Mollat, M._"Notes sur la vie maritime en Galice au xııe siècle d'après l'Historia compostellana". - $A E M, 1$ (1964), 531-540.

19-3584. Crónica latina de los Reyes de Castilla. Ed. crítica e indices por María Desamparados Cabanes Pecourt.Valencia, 1964. J54 pp. (Textos medievales, 11).

19-8585. Crónicas navarras. Ed. crítica e indices por Antonio Ubieto Arteta.Valencia, 1964. 58 pp. (Textos medievales, 14).

19-3586. García Álvarez, M. R.-"Sobre la Crónica de 1ria".-CuEG, 19 (1964), 161-184.

19-3587. London, G. H.-“Unos títulos más de bibliografía allonsina". $B F E$, 1965, núms. 15/17. [Alfonso X el Sabio]. 19-3588. CataléN, D.—"El taller historiográlico alfonsí. Métodos y problemas en el trabajo compilatorio".-_Ro, 84 (1963) , 354-375. || LR, 20 (1966) , 287288 (Groult). 
19-3589. Morreale, M._"La fraseología bíblica en la General estoria. Observaciones para su estudio".-FHH, 269. 278. II Sef, 25 (I965), I25 (Cantera). 19-3590. Calila y Dimna. Selección de $\mathbf{M}$. Trocoms y J. R. Serra._Univ. de Zulia, Maracaibo, 1964. (Trabajos de la Escuela de Letras).

V. también nưms. 970, 1713, I896, 1911-2. Libro de los gatos: v. núm. 1191.

19.359I. Semeiança del mundo, ed. W. E. Bull \& H. F. Williams (N. 16-49432). $\| L R, 19$ (1965), 81.82 (Horrent); RHM, 29 (1963), 319 (Jungemann); Bulletin Codocologique, 2 (1959), 320 (Wiltek).—V. núll. 17-6393.

19-3592. ESQuer ToRres, R._.Dos rasgos escilisticos en don Juan Manuel".RFE, 47 (1964), 429-435.

19-3593. Juan Manuel, Don_El Conde Lucanor. Versión moderna e introd. de A. Bolaño e Isla.-Porrúa, México, 1964. xxiv + 201 pp. (Col. Sepan cuantos, 28).

19-3594. JUAN MANUEL, DON-El conde Lucanor._Troquel, Buenos Aires, 1964. $228 \mathrm{pp}$. (Clásicos Troquel).

19-3595. Montcomery, T. - "Don Juan Manuel's tale of don Illán and its revision by Jorge Luis Borges".-H, 47 (1964), 464-466.

19.3596. Compton, James Donald-A linguistic study of the "Libro del cavallero et del escudero" of Don Juan Manuel in MS. 6376 of the National Library of Madrid, Spain.-[Tesis, Univ. of Wisconsin; resumen en $D A, 25$ (196465), 6620].

19-3597. Di Sterano, G._-Don Juan Manuel nel suo Libro de la caェa". $S L S$, 379-390.

López de Ayala: v. núm. 2496.

19-\$\$598. Fernández de Heredia, JuANLa Grant Crónica de Espanya. Libros 1-2. Ed. by Regina af Geijerstam.-Acta Universitatis Upsaliensis, Uppsala, 1964. $406 \mathrm{pp}$. (Studia Romanica Upsaliensia, 2) . $\| Z R P h, 84$ (I968), $241-244$ (CoIon) : PhP, 9 (196G), 222 (Hamplová); $B H S, 44$ (1967) , 55-56 (Leslie); $H R$, 35 (1967), 277-278 (Place); StN, 36 (1964), 996-406 (Sletsjoe \& Jörnving).

19-3599. Hodcroft, I.-."Notas sobre la Crónica de Morea. (Fonética) "- $-A F A$, 14/15 (1963.64), 83-102. [Juan Fernál1. dez de Heredia].

19-3600. Sánchez de Vercial, C.LLibro de los exenplos por A.B.C. (N. 17-6392). $\| R P h, 20$ (1966-67), I35-142 (Gi- meno Casalduero); SCL, 16 (1965), 435-436 (Sala).-V. núm. 18-3783.

19-360I. Toledo, Alfonso de-Invencionario. Ed. with introductory study and notes by Philip Otto Gericke.-[Tesis. Univ. of California. Berkeley; resumen en $D A, 26$ (1965-6G), 3952].

19-3602. PIERO, R. DEL-"Sobre el autor y fecha del Invencionario" (N. 17-6394). || $L R, 19$ (1965) , 186 (Dewaele); BICC, I9 (1964), 598-599 (Valderrama Andrade) .

19-3603. Lapesa, R._-"Sobre Jualł de Lucena. Escritos suyos mal conocidos o inéditos".-HAC, 275-290.

19-3604. Pardo, M.- Un épisode du Victorial: biographie et élaboration romanesque".-_Ro, 85 (1964), 269-292. [Díez de Games].

19-3605. Balowin, S. WW., JR.-_The role of the moral in La vida del Ysopet con sus fábulas historiadas"...H, 47 (1964), 762-765.

19-3606. Ricard, R.-“Sur le texte des chapitres de Bernáldez relatics aux Canaries".-BHi, 66 (1964), 55-56.

19-3607. TATs, R. B.- "Four notes on Gonzalo Garcia de Santa Maria'.- $R P h$, 17 (1963-64), 362-372.

19-3608. GREY, ERNEST-Guevara acctoss tse centuries.-[Tesis, Harvard, 1965]. 19-3609. Gibes, J-Vida de Fray Antonio de Guevara (N. 17-6397) . \| $A I A, 26$ (1966), 98-100 (Castro); H, 47 (1964), 865-866 (Jones).

19-3610. GILMAN, S.-"The sequel to $E l$ villano del Danubio".-RHM, 31 (1965), 174-184.

19-9611. Jones, J. R.-“'The Academysponsored edition of Guevara's let. ters"._RNo, 5 (1963) , 76-77.

19-3612. BABILAS, L. A.-Antonio de Gue. vara und sein Ubersetzer Cosimo Baroncelli (N. I7-6398) . || RLit, 23 (1969), 286-287 (Diez Taboada); BHS, 42 (1965), 67-68 (Gibbs); BHi, 67 (I965), 37938L (Redondo); RHM, 30 (I964), 32032I (Roberts) ; HR, 34 (I966), 82.83 (Schweitzer) .

19-3613. SANCHEZ Escribano, 1:__."Sobre el posible origen español de la frase il faut cultiver notre jardin, de Candide. (Coll un apéndice de las obras españolas o sobre España en la bilslioteca de Voltaire) "-_Hf, 1964, núln. 22, 15 26 [\{Antonio de Guevara?].

19-3614. PérEz, J.- “Le razonamiento de Villabrágima”.-BHi, 67 (1965), 217-224. [Quizá sea una mentira de Guevara]. 
19-3615. Cota, Sancho - Memorias. Ed., introd. and notes by Hayward Keniston.-Harvard Univ. Press, Cambridge, 1964. 261 pp. (Harvard studies in Romance langunges, 28). $\|$ Sef, 28 (1968), 89-94 (Cantera Burgos); BHS, 44 (1967), 76-77 (Gibbs); BHi, 67 (1965) , 198-199 (Pérez); $R P h, 19$ (196566) , 521-523 (Tate) .

19-3616. REDONDo, A. "A propos de la Crónica del emperador Carlos $V$ de Pedro Girón".-BHi, 67 (1965), 314 321.

19-3617. Girón, PEDro-Crónica del empe. rador Carlos $V$. Ed. de Juan Sánchez Montes, pról. de Peter Rassow.C.S.I.C., Madrid, 1964. Iix + 617 pP., láms. || $A r A, 59$ (1965), 265-266 (Aramburu) ; $A I A, 27$ (1967), 469-471 (Meseguer Fernández) ; $B H S, 43$ (1966), 128129 (Tate).

19-3618. PezzellA, S._"Alfonso de Valdés e la politica religiosa di Carlo V".Studi e Materiali di Storia delle Religioni, Roma, 36 (1965), 211-268.

19-3619. Valdís, Alfonso DE-Diálogo de Mercurio y Carón.-Espasa-Calpe, Madrid, 1965. 248 pp. (Clís. cast., 96) -V. núm. 10-21423.

19-3620. Cionf, Edmondo - Fede e ragione nella storia._Capelli, Bologna, 1963. 391 pp. [Hay un ensayo sobre Juan de Valdés]. \| $R L C, 40$ (1966), 141-142 (Klein).

19.3621. RICART, D._"El concepto de la honra en Juan de Valdés".-RFCR, 4 (1964), 145-164.

19-3622. RICART, D.-"El concepto de la honra en el teatro del Siglo de Oro y las ideas de Juan de Valdés".-_Seg, 1 (1965) , 43-69.

19-3623. VALDÉs, JUAN DE_Diálogo de docLrina christiana. El Salterio. Introd., ed. y notas de Domingo Ricart.Universidad Nacional Autónoma de México, 1964. 372 pp. \| Hf, 1966, núm. 27, 43-45 (Escribano); $R N, 19$ (1966), 36-37 (MacCurdy); $H, 49$ (1966), 534 (Sturcken).

19-3624. RICART, D._-“El texto auténtico de una consideración valdesiana".Hf, 1965, núm, 23, 23-36.

19-3625. ARALAR, J. DE "E1 doctor Martín de Azpilkoeta y la democracia"$B I A E V, 14$ (1963), núm. 53.

19-3626. Azpilcueta, Martín DE-Comentario resolutivo de cambios. Introd. y texto crítico por Alberto Ullastres, José M. Pérez Prendes y Luciano Pe-
reña.-C.S.I.C., Madrid, 1965. cxvii + $167 \mathrm{pp}$. (Corpus Hispanorum de pace, 4). $\|$ Sef, 27 (1967), 147-149 (Cantera Burgos); $C D, 179$ (1966), $371-372$ (Zaragiieta) .

19-3627. l parraguirrF, D. - "La découverte des phénomènes économiques à l'Université de Salamanque au xyıe siècle". - [En] Pédagogues et juristes (Paris, 1963), 87-91. [Azpilcueta y otros].

19-3628. Vermaseren, B. A-"Autour de l'édition de l'Histoire de l'Estat $d v$ Pais Bas, et de la religion d'Espagne, par $F$. de Enzinas dit Dryander (1558)",-BHR, 27 (1965), 463-494.

19-3629. Enzinas, Francisco DE-Les mémorables. Ed. et trad. par Jean de Savignac. - Librairie Encyclopédique, Bruxelles, 1963. 302 pp. || $L R, 19$ (1965), 157-159 (Groult); Church Hist., 33 (1964), 366 (Hohl, Jr.).

19-3630. Gonzalez Moreno, J.“"Don Fadrique Enriquez de Rivera"...AH, 39 (1963) , 201-282.

19-3631. Doussinage, J, M._-“Ignacio de Loyola y Jerónimo de Zurita"_VII Congreso de Historia de la Corona de Aragón, t. 2 (Barcelona, 1964), 4154.

19-3632. Martínez Ferrando, J. M-“Sobre la continuación de los Anales de Zurita".-HM, 23 (1963), 380-400.

19-3633. Pineda, JuAN DE-Diálogos familiares de la agricultura cristiana. Introd. de J. Meseguer Fernández.Atlas, Madrid, 1963-1964. 5 ts.: cxxiii $+385492,451,474,464$ pp. (BAE). $A I A, 24$ (1964), 340-341 (Henares). 19-3634. BlfzNicR, D. W.-'Los conceptos políticos de Furió Ceriol".-REP, 149 (1966) , 25-46.

19-3635. Furió Ceriol, Fadrique - Of councils and counselors. An English reworking [1570], by Thomas Blundeville, of El consejo y eonsejeros del principe [1559]. A facsimile reproduction with an introd. by K. L. Selig.Scholars' Facsimiles \& Reprints, Gainesville, Florida, 1963. xi + $140 \mathrm{pp}$.

Huarte de San Juan: v. núm. 3405.

19-3636. Ludis Y NAvas Brust, J.-_"Las doctrinas de Mariana sobre el derecho del rey a regular la fabricación de la moneda".-Caesaraugusta, 1964, núms. $21 / 22,123-153$.

19-3637. MARIANA, JUAN DE-Historia de España. Ed., estudio y notas de Manucl Ballesteros. 4a ed.-Ebro, Zaragoza, 1964. 
126 pp. (Bibl. clas. Ebro, 3). \|RHE, 59 (1964), 391-392 (Conzemius).

19-3638. LEwY, H.-The political philosophy of Juan de Mariana (N. 172785). II RHE, 59 (1964), 391-392 (Conzemius)

19-3639. Ceverio de Vera, J._Viaje de la Tierra Santa (1596). Ed., introd. y notas por Concepción Martínez Figueroa $y$ Elias Serra Ráfols.-Instituto de Estudios Canarios, La Laguna, 1964. xxiv + 202 pp. | BHi, 68 (1966) , 161-163 (Mas); $A S T, 38$ (1965), 199-200 (Vives).

19-3640. QuIlIs, A., y J. M. RozAS “"La originalidad de Jiménez Patón y su huella en el Arte de la lengua del maestro Correas".-_RFE, 46 (1963), 81-95.

19.9641. JIMÉNez PATón, BARTOLOMÉEpitome de la ortografía latina y cas. tellana. Instituciones de la gramática española. Est. y ed. de A. Quilis y J. M. Rozas.-C. S. I. C., Madrid, 1965. cxxii + 114 pp., láms. (Clásicos hispdnicos, Ediciones históricas, 3). I| RLit, 29 (1966), 238-239 (Esquer Torres).

19-3642. URMENETA, F. DE-'El quehacer político en Saavedra Fajardo".-Rev. del Inst. de Ciencias Sociales, Barcelona, 1965, núm. 6, 229-240.

19-3643. PÉrez GuIlhou, D.-“Saavedra Fajardo y la razón de Estado".Boletin de Estudios Pollticos y Sociales, Mendoza, 1962, núm. 12, 51-64.

19-3644. SaAyedra Fajardo, Diego Locuras de Europa. Introd. y notas de José María Alejandro.-Anaya, Salamanca, 1965. 64 pp. (Bibl. Anaya, 56).

19-3645. Carré, M. D.- "EI poeta oscense Salinas y Gracián". — CJZ, 16/18 (1963-65), 275-293.

19-3646. [Graciá, Baltasar]-The best of Gracian. A new transl. by Thomas G. Corvan-Philosophical Library, New York, 1964. 84 pp.

19-3647. LAcostA, F. C.- "EI conceptismo barroco de Baltasar Gracián en Arte y agudeza de ingenio".- $R R, 55$ (I964) , 85-90.

19-3648. GraGiÁN, BALTASAR-Handorahel und Kunst der Welthlugheit. Aus dessen Werken gezogen von Vincencio Juan de Lastanosa und aus dem spanischen Original treu und sorgfältig übers. von Arthur Schopenhauer. Mit einem Nachwort hrsg. von Arthur Hübscher... Reclam, Stuttgart, 1964. 161 pp. (Reclams Universal-Bibliothek, 22712272) - -V. núm. II -26786.

V. también nưm. 2277.
19-3649. Selic, K.-L.-"Antonio Palomino y la tradición de la literatura em. blemática en España".-APCH, 443 . 446.

19-3650. PÉREz RIoJA, J. A.-“Centenario y actualidad de Feijoo". $-E L, 1965$, núms. $322 / 3$.

19-365I. BAтtistessa, A. J.-“Dos centenarios". $-C I, \quad 1$ (1965), 95-128. [Feijoo y Unamuno].

19-3652. Benito Ruano, E. - "Simposio sobre el P. Feijoo y su siglo"-SiMo, 6 (1964), 398-400.

19-3653. Martínez, G.- "Ciclo de conferencias feijoanas en la real abadía de Samos".-StMo, 6 (1964), 395-398.

19-3654. Armesto, V.-Dos gallegos: Feijoo y Sarmiento._La Coruña, 1964. 161 pp. $\| E L, 1965$, nưms. 320/21 (Aguado) .

19-3655. ARMesto, V._-Entre padres anda el juego"._EL, 1965, núms. 322/3. [Feijoo y Sarmiento].

19-3656. Noval, M. B. G. DE LA-“Cuatro cartas autógrafas del P. Feijoo al P. Martin Sarmiento".-Yermo, 2 (1964), 259-265.

19-3657. Eguiagaray, Francisco-El Padre Feijoo y la filosofia de la cultura de su época.-Inst. de Estudios Políticos, Madrid, 1964. 182 pp. (Col. Pensamiento politico). I| $H M, 47$ (1964), 151-152 (Mercader); RLC, 40 (1966), 304-306 (Pageaux); BHi, 66 (1964), 454-455 (Ricard) .

19-3658. ARdao, A.-La filosofia polémica de Feijoo (N. 18-3802). $\| C y F, 21$ (1965) , 43.44 (Delfino \& Galarraga). 19-3659. PRADO VÁzQuez, José-El mundo clásico en la obra del Padre Feijoo.[Tesis, Univ. de Madrid; resumen en RUM, 13 (1964), 632-634].

19-3660. Feljoo, Benito Jerónimo-["Textos sobre estética"]. Sel. e introd. de J. Vila Selma.-RIEs, 22 (1964), 339. 356.

19-3661, Domínguez Ortiz, A.-"Aspectos de la España de Feijoo",- $H M$, 24 (I964), 552-576.

19-3662. Pérez Bustamante, C.-“La España del P. Feijoo".-BBMP, 40 (1964), $5 \cdot 17$.

19-3663. Crusafont Y Pairó, M.—El enciclopedismo ortodoxo del padre Feijoo y las ciencias naturales". $-B B M P$, 40 (1964), 65-97.

19-3664. Morros SARDA, J.-“La medicina, los médicos y el P. Feijoo".-Medicamenta., 1965, nưm. 411, 27-36. 
19-3665. Rof Carballo, J. - "Medicina crítica y medicina comprensiva en la obra del P. Feijoo".-BBMP, 40 (1964), 37-64.

19-3666. JUNCEDA Avelló, E.-El saber gi. necológico del $P$. Feijoo.-Instituto de Estudios Asturianos, Oviedo, 1964. 82 pp., ilustr. ||$B I E A, 1965$, núnı. 54, 207. 209 (Valero de Cabal)

19-3667. ANDRÉU VALDÉS-SOLÍs, M.-.."Actualidad de Feijoo".-BIEA, 18 (1964), $3 \cdot 6$.

M. Sarmiento: v. núms. 3654-6.

19-3668. GuiNARD, P.J.—"Remarques sur un ouvrage interdit: Lo que no se ha escrito, de Francisco de la Justicia y Cárdenas"_-BHi, 66 (1964), 349-458.

\section{Autores modernos}

19-3669. Miguel López, Raimundo DEEl Filosofo Rancio. Sus ideas politicas y las de su tiempo.-_Seminario Metropolitano, Burgos, 1964. 208 pp. [Francisco Alvarado]. || $R y F, 171$ (1965), 653 (J. A. S.).

19-3670. Marías, J.-_Antonio Alcalá Galiano, 1789-1865".-BRAE, 45 (1965), 407-420.

19-3671. Willuams, M. A.-“'Some state documents concerning Alcalá Galiano's exile in France" (N. 17-2845). $\| B I C C$, 19 (1964), 375 (Valderrama Andrade).

V. también núm. 2584.

19-3672. Marra-López, J. R.-_Castelar, reeditado".—Ins, 1965, núm. 223.

19-3673. CAsTELAR, EMILIO-Discursos $y$ ensayos, Recopilación, pról. y notas de José García Mercadal.-Aguilar, Madrid, 1964. 336 pp. (Ensayistas hispánicos). $\mathrm{CuH}, 62$ (1965), 210-217 (A1. varez Junco).

Giner de los Ríos: v. nưms. 193, 2315, 2707.

19-3674. Díaz de Cerio, F.—“Joaquín Costa y el premio extraordinario del doctorado en filosofía, 1875".-Pens, 21 (1965), 325.337.

19-3675. Cheyne, G. J. G.-“Menéndez Pelayo, Costa and the premio extraordinario del doctorado en filosofia $y$ letras"_-BHS, 42 (1965), 94-105.

19-3676. AGUiRRE PRAdo, LUIS-Joaquin Costa.-Publicaciones Españolas, Madrid, 1965. 29 pp., láms. (Temas españoles, 457).

19-3677. López Calera, N. M._"K. Ch. F. Krauses Rechtsphilosophie in Spanien: Joaquín Costa"..Archiv. für Rechts- und Sozialphilosophie, Berlin, 1964, 387403.

19-3678. PÉrEz DE IA DEHESA, RAFAELEl pensamiento de Costa y su repercusion en la generacion del 98.-[Tesis, Brown Univ.; resumen en $D A, 24$ (1963-64), 3755]. 239 pp.

19-3679. Costa, Jonquín_Ideario. Textos escogidos y ordenaclos por Joaquín García Mercadal.-Aguado, Madrid, 1964. $404 \mathrm{pp}$.

19-3680. PÉrez Embid, F,_"Menéndez Pelayo descle la actualidad".- $-N T, 23$ (1965), 539-554.

19-3681. PÉREZ EMBID, FlorentiNo-Menéndez Pelayo desde la actualidad.Rialp, Madrid, 1965. 34 pp. (O crece o muere). || $A H, 1964$, núms. 126/27, 174.175 (M. J. M.).

19-3682. Meregall1, F.“Menéndez Pelayo, Croce e Farinelli".__SLS, 99114.

19-3683. Serrano Castil.ia, F._"Menéndez Pelayo y Galicia"._Sep, del $B A G, 1964$; $8 \mathrm{pp}$.

V. también núms. 101, 153, 2376, 3119, 3675,3755 .

Unamuno: v. núms. 4009-13.

19-3684. Cano, J. L._._Ganivet y su centenario".-Asom, 1965, núm. 4, 65-67.

19-3685. MARra López, J. R.- "Un centenario lejano:: Angel Ganivet"_-Ins, 1965, núms. 228/9.

19-3686. FERNANDEZ Almagro, M._-"Angel Ganivet (1865-1898)".LLEsp, 8 (1965) , 127-138.

19-3687. Herrero, JAvier-Angel Ganivet: un iluminado.-Gredos, Madrid, 1964. 346 pp. (BRH, Estudios y ensayos, 88). II Stylo, 1967, núm. 5, 196197 (Aguayo Quesada) ; $B C B, 9$ (1966), 2230-2232 (Allen); $M L R, 63$ (1968), 503504 (Franco); CuH, 69 (1967), 381385 (1.izano); BHS, 46 (1969), 66-68 (López-Morillas) ; $B H i, 69$ (1967) , 254 257 (Ricard); EL, 1966, núm. 356 (Ríos Ruiz); H, 50 (1967), 605-606 (Schweitzer).

19-3688. García Mercadal, José-Ideario de Angel Ganivet.-A. Aguado, Madrid, 1964. 272 pp. || H, 49 (1966), 349 (Raggi) .

19-3689. OsBorne, R. E.-"Observations on Ganivet's La conquista del reino de Maya".-HRM, 2, 39-45.

19-3690. Amorós, A.-"Eugenio d'Ors, sin pasión"...Ins, 1967, nủm. 251.

19-3691. Díaz-PlajA, G.-_Diez años sin Xenius".-ins, 1965, núm. 223. 
19-3692. Salvador, T. - "Xenius, once años".-EL, 1965, núm. 329.

19-3693. Loren, S.-“El" Angel y Ios leones"._EL, I965, nưm. 329. [Sobre E. d'Ors].

19-3694. Serra Rafols, E.- "Diálogos con las sombras: Eugenio d'Ors y el Instituto".-Estudios Canarios, 1965, núm. 10, 13-22.

19-3695. "Un s ind i c a I is t a : Eugenio d'Ors".-EL, 1965, núm. 328.

19-3696. Ferr $A N$, J._"Eugenio d'Ors entre Europa y Atlántida"._Atl, 3 (1965), 277-284.

19-3697. Bravo Villasante, C._._La obra queda, y don Eugenio [d'Ors]".-EL, 1965, núm. 329.

19-3698. Bravo Villasante, C.-_"Clásico y barraca". - ELL, 1965, núm. 329. [E. d'Ors].

19-3699. D'Ors, Eugenio_La ciencia de la cultura. Prol. de E. Rojo Pérez.Rialp, Madrid, 1964. 498 pp. (Col. de cuestiones fundamentales).

19-3700. Benítez Claros, R. - "Eugenio d'Ors y La ciencia de la cultura". $C I, 1965$, núm. I, 129-138.

19-3701. SÁnchez Morales, N.-“El filosofo de la cultura".-EL, 1965, núm. 329.

V. también nứms. I814, I816, 3582.

Marañón: v. núm. 2315.

19-3702. Giusti, R. F.-"Homenaje a José Ortega y Gasset".-BAAL, 30 (1965), 348-350.

19-3703. Rodrícuez Hutscar, A.-“Carta abierta a José Antonio Maravall en el decenario de la muerte de Ortega".CuH, 64 (I965) , 33-45.

19-3704. De Tomasso, V._ "A dieci anni dalla morte di Ortega".-Annali della Pubblica Istruzione, 1965. nưms. 4/5.

19-3705. Treves, R.—“Ortega y Gasset"[En su libro] Libertà politica y verità. (Milano, 1962), 63-10I._V. núm. 172872.

19-3706. Balbontín, J. A.- "En torno a José Ortega y Gassct".-IAL, 1965, nủm. 198.

19-3707. Herrero, E.- "En torno a Ortega. (Tesis-antítesis-sintesis) ". $-A C a$, 5 (I964), 299-359.

19-3708. Marías, T.- "Cuando el futuro ha cmpezado y'a".-_tns, 1965, nưm. 227. [Sobre Ortega].

19.3709. Garacorri, P.-"El tema de Ortega".-HuT, 12 (1964), 85.97.

19-3710. RODRÍGUEz HuÉscar, ANTONIOCon Ortega y otros escritos.-Taurus,
Madrid, 1964. 363 pp. (Ensayistas de hoy). II Ins, 1966, núm. 232 (Carpintero) ; $B H i, 69$ (1967), 292-293 (Guy) ; RHM, 30 (1964), 316-317 (Mades).

19-3711. Garagorri, Paulino-Relecciones $y$ disputaciones orteguianas.-Taurus, Madrid, 1965. 113 pp. (Cuadernos Taurus).

19-3712. GuimerA Peraza, M.-“Ortega y las virtudes pequeñas"._C Cris, 18 (1965) , nưn. 365, 17-18.

19-3713. Laurenza, R. J.-_"Ortega desde América".-ROcc, 8 (1965), 350363.

19-37I4. Maravall, J. A.-“Una nueva lectura de Ortega"._-CuD, 1965, núm. 26.

19-3715. ABellAN, J. L.-"El humanismo renacentista de Ortega".-Asom, 1965, núm. 4, 50-59.

19-3716. Walgrave, J. H._."De Newman a Ortega y Gasset".-ROcc, 11 (1965), 133-156.

19-3717. Guy, A.- “L'aristotélisme jugé par Ortega y Gasset".-AFLT, 1 (1965), 123-137.

19-3718. VELA, I'_-"Ortega: una filosofia original pensada y escrita en el mejor cspañol".-LEsp, 8 (I965), 239-252.

19-3719. Walgrave, J. H.-La filosofía de Ortega y Gasset. Trad. por Luis G. Daal.-Rev. de Occidente, Madrid, 1965. 344 pp.-V. nưm. 16-45316. || ROcc, I I (1965) , 93-101 (Carpintero); CuH, 69 (1967) . I32-134 (Romana Garcfa).

19-3720. RuKsER, U._"Grundzïge von Ortegas Philosophie". $-Z P F$, I9 (1965), 668-68'?

19.3721. AbeLLAN, J. L.-"Ortega y cl fracaso de ]a metafísica".-CuA, [965, nưm. 3, 108-119.

19-3722. Lira, Osvaldo-Orlega en su espiritu. I. Metafisica y estética.-Univ. Católica. Santiago de Chile. 1965. $\| A$, I966, núm. 411, 290-297 (Araya); Fin, [966. núm. 55, 53-55 (Egaña) .

19-3723. García Marcos, M._-_La radica. lización del presente en Ortcga".RevFil, 24 (1965), 353-372.

19-3724. Soler Grima, Francisco_Hacia Ortega. I. El mito del origen del hom. bre._Fac. de Filos. y Educacion, Universidad de Chile, Santiago, 1965. 312 pp. II $A, 1966$, núm. 411, 290-297 (Araya) : Map, 5 (1966), 260-263 (González); $A$, 1965, núm. 410, 286-289 (Munita). 19-3725. Sotiello, G. DE-"Dios y 10 religioso en la obra de Ortega y Gasset". $-N G, 12$ (1965), 73-98. 
19-3726. SÁnchez Maurand, ANTonio Errores de Ortega y Gasset.-Murcia, 1964. 76 pp. $\| E M, 21$ (1965), 500501 (Ortúzar).

19-3727. Morales Lezcano, V.-.'Linaje de la sociología de Ortega y Gasset".$I A L, 1965$, núm. 198.

19-3728. Ballestero Pareja, E.-“Ortega y la gente. (Una sociologla sin conciencia)".-RIS, 23 (1965), 23-35.

19-3729. Alluntis, F._-"Social and political ideas of José Ortega y Gasset". The New Scholasticism, 39 (1965) , 467490.

19-3730. Mazlish, C. S._-Ortega y la circunstancia española"._fins, 1965, núm. 227.

19-3731. Marías, J-_"Vocación teórica y vocación polf́tica en Ortega".-RHM, 31 (1965) , 296-302.

19-3732. Hierro SÁnchez-Pescador, JoséEl derecho en Ortega.-Revista de Occidente, Madrid, 1965. 348 pp. (Estudios orteguianos, 1).-.V. núm. 18-7628. || CuH, 73 (1968), 369-403 (Malo); Asom, 1967, núm. 3, 58-62 (Mayda); CoSP, sct.-out. 1966 (Mello Kujawski); $R O c c$, 16 (1967), 371-377 (Nin de Cardona).

19-3733. READ, H.- "High noon and darkest night: some observations on Ortega y Gasset's philosophy of art".$J A A C, 23$ (1964-65) , 43-50.

19-3734. Senabre Sempere, Ricardo-Len. gua y estilo de Ortega y Gasset.-Uni. versidad, Salamanca, 1964. $290 \mathrm{pp}$. (AcS).—V. núm. 18-3841. \| RLit, 26 (1964) , 248-249 (Esquer Torres); BICC, 21 (1966), 358-362 (Luque).

19-3735. Marías, J.- "La función del paisaje en el pensamiento de Ortega".-CI, 1965, núm. 2, 5-21.

19-3736. Ortega Y GASset, JOsE_-"Anotaciones sobre la guerra, en forma de cliario. (Texto inédito)". - CuH, 64 (1965) , 3-11.

19-3737. Basave Fernández del. Valle, A.- "José Ortega y Gasset en sus obras inéditas".-HuNL, 6 (1965), 529-549.

19-3738. ORTECA Y GASSET, JosÉ Obras completas. T. 6. 6? ed.-Revista de Occidente, Madrid, 1965. 576 pp.V. núm. 17-2892.

19-3739. Orteca Y GASset, José_Obras completas. Ts. 8 y 9. $2^{\text {a }}$ ed.-Revista de Occidente, Madrid, 1965. 672, 856 pp.-V. núm. 17-6499.

19-3740. Garacorri, P.-"En torno al Goya de Ortega".-RIEs, 23 (1965), 169. 182.
19-3741. ORTECA Y Gasset, José_Ideas y creencias $y$ otros ensayos de filosofia. 9? ed-Revista de Occidente, Madrid, 1965. 199 pp. (El arguero).-V. núm. $16-45367$

19-3742. Ortega y Gasset, José-Kant, Hegel, Dilthey. 3? ed.-Revista de Occidente, Madrid, 1965. 218 pp. (El arquero)._V. núm. 17-2897.

19-3743. ORTEGa y Gasset, José-Misión de la Universidad. 4a ed.-Rev. de Occidente, Madrid, 1965. 188 pp. (El arquero).-V. núm. 16-49608.

19-3744. Ortega y Gasset, José_Pasado y porvenir para el hombre actual (N. 17-6509) . || CuH, 61 (1965), 412-427 (Garciasol).

19-3745. Ortega y Gasset, José- Qué es filosofia?_Revista de Occidente, Madrid, 1965. 272 pp. (El arquero).-V. núm. 18-3854.

19-3746. ORTEGA Y GAsseT, José_La ribellione delle masse. A cura di $\mathrm{S}$. Battaglia__-Il Mulino, Bologna, 1962.

19-3747. Orteca y Gasset, José Eine Interpretation der Weltgeschichte. - G. Müller, München, 1964. 288 pp. | Philosophischer Literaturanzeiger, 19 (1966), 180-183 (Franke).

19-3748. Ослмғо, V..."A]gunas cartas de Ortega y Gasset"._Sur, 1965, núuss. $296 / 7,1-18$.

V. también núms. 149-50, 3881, 3927.

19-3749. "En los ochenta af́os de Américo Castro"._PSA, 37 (1965), 115-142. [Escriben C. J. Cela, D. Alonso, R. Lapesa, P. Laín Entralgo, S. Gili Gaya, S. Fernández, J. L. Aranguren, J. Caro Baroja, A. Tovar, J. Marías y otros].

V. también núms. 149-50, 3381, 3927.

19-3750. MAiner, J. C._-"Las memorias de Corpus Barga"._-Ins, 1965, núm. 227.

19-3751. BARGA, Corpus-Los pasos contados. Una vida española a caballo en dos siglos (1887-1957). T. 1: Mi familia. El mundo de mi infancin. T. 2: Pue. rilidades burgucsas,-E.D.H.A.S.A., Barcelona, 1963-1965. 245, 276 pp. (El puente). II PSA, 35 (1964), 351-352 (Fernández Molina); Ins, 1964, nim. 208 (Marra-López) ; $C C L, 1964$, núm. 85, 77. 79 (Scuderi) ; ROcc, 7 (1964), 248-249 (Scuderi) ; LL, 1964, núms. 72/73, 356 358 (Tauro).

19-3752. Marquínez Arcote, Germán-En torno a Zubiri.-Studium. Madrid, 1965. 155 pp. (Col. Scientia).

19-3753. Manteiga Pedrares, J.-“La realidad y la esencia. Reflexiones en tor- 
no al pensamiento filosófico de $\mathrm{Xa}$ vier Zubiri"._Grial, 1965, I5l-159.

19-3754. García-SabelL, D._"Laín o el diagnóstico de la realidad"._fns, 1965, nưm. 218.

19-3755. Laín Entralgo, Pedro-Obras. (Menéndez Pelayo; La espera y la esperanza; Ensayos y articulos).__Plenitud, Madrid, 1965. $1250 \mathrm{pp}$.

19-3756. Zambiano, MaríA_España, sueño y verdad.-E.D.H.A.S.A., BarcelonaBuenos Aires, 1965. \| $C u H, 65$ (1966), 556-561 (Gómez Marín); Ins, 1966, núm. 230 (Mainer).

19-3757. Zambrano, Maria_Spagna. Pensiero, poesia e una città._Vallecchi, Firenze, 1964 . $125 \mathrm{pp}$.

\section{LITERATURA RELIGIOSA}

19-3758. Simón Díaz, Jost_Impresos del xvi: Religidn.-C.S.I.C., Madrid, 1964. 64 pp. (Cuadernos bibliograficos, 14). || $A r A, 59$ (1965), 263 (Casado); BHS, 42 (1965), 279 (Wilson).

19-3759. Alarcón, Manuel-La renuncia y el uso de las cosas materiales en los tratados ascéticos "De fuga mundi" de los siglos xii a xiii._Univ. Gre. goriana, Roma, 1961. [Tesis].

19-3760. Ricard, RoBERT-Estudios de literatura religiosa española. Trad. de Manuel Muñoz Cortés._Gredos, Madrid, 1964. 280 pp. (BRH). \|Ins, 1965, núms. 228/9 (Ares Montes); $C D, 178$ (1965), 558-559 (C. M. A.); $R A M, 41$ (1965), 504 (Gensac); LR, 19 (1965), 147-I48 (Groult) ; AHSI, 34 (I965) , 343345 (Iparraguirre); $B H i, 68$ (1966), 163-165 (Krynen); $L N L, 1965$, núm. I, 122-123 (Larrieu) [repetida ibid., núm. 4, 102-103]; Bro, 84 (1967), 132133 (Maia) ; $A I A, 28$ (1968) , 235 (Messeguer); CuH, 62 (1965), 379-383 (Miro) ; RLit, 26 (1964), $201-203$ (Quintana) ; $B I C C, 23$ (1968), 373-388 (Valderiama Andrade).

19-376I. IpARRAGUIRRE, IgNACIO-Estilo espiritual jesuitico (1540-1600).-Mensajero del Corazón de Jesús, Bilbao, 1964. 280 pp. (Espiritualidad ignaciana, 5) . || RAM, 43 (1967), 356-358 (Bottereau); $A H S I, 34$ (1965), 267-269 (De Mielesi).

I9-3762. HuergA, A.-_"Sobre el obispo ideal".-Angelicum, Roma, 41 (1964), 401-420. [Díaz de Luco, Carranza, Bartolomeu dos Mártires, Granada, etc.]. 19-3763. Gasca QueirazzA, G._-"Una Vita di San Francesco d'Assisi in antico castigliano"..SLS, 219-244.

19-3764. Talavera, H. DE-Católica impugnación, ed. F. Márquez y F. M. Hernández (N. 17-2945). \|RPh, 19 (1965-66), 384-391 (Avalle-Arce); $L R$, I9 (1965), 136 (Groult); Gr, 44 (1963), 625-629 (Villoslada) .

19-3765. Huerga, A.-_EI Beato Āvila, imitador de San Pablo"._TE, 9 (1965), 247-291.

19-3766. Granada, Luis DE, y Luis MuÑoz_Vidas del Maestro Juan de Avila. Presentación y ed. por Luis Sala BaIust.-J. Flors, Barcelona, 1964. 618 pp. (Espirituales españoles, 19) . $\| R y F$, 173 (1966), 105-106 (Barjau); Man, 37 (1965), 87 (Granero); VyV, 23 (1965), 171-172 (Meseguer) : $E M, 21$ (1965), 319 (Vázquez).

19-3767. JERECZEK, B.-."Sur deux prologues discutés (Audi, filia 1556 et 1574) ".-BHi, 65 (1963), 5-19.

19-3768. AviLA, JUAN DE-Sentencias espirituales por A.B.C. Sel. de J. M. Escribano y O. Pecharromán,-J. Flors, Barcelona, 1964. $495 \mathrm{pp}$.

19-3769. Sala Balust, L__-"Una biografia recuperada: La vida de Doña Sancha Carrillo, discipula del Maestro Avila, escrita por su hermano don Pedro Fernández de Córdoba".-Ib, núm. 6.

Granada: v. nưms. 3762, 3766.

19-3770. Valtanás, Domingo DE-Apologia sobre ciertas materias morales en que hay opinión. Apologia de la comunión frecuente.-Juan Flors, Barcelona, 1963. $214 \mathrm{pp}$. (Espirituales españoles, 12). RLit, 23 (1963) , 285-286 (Rozas).

19-377I. Tellechea Idígoras, J. I._-Bartolomé Carranza y la restauración católica inglesa (1554-1558) ".-_AnA, 12 (1964), I59-282.

19-3772. TELlechea Idígoras, J. I.- ${ }_{i} U n$ sermón de tolerancia de Bartolomé Carranza? Valladolid, 21 agosto 1558.Seminario Hispano-Americano, Madrid, 1963. 45 pp. [Sep. de Scriptorium Victoriense]. || HZ, 200 (1965), 504 (PohI). V. también núm. 3762 .

19-3773. I PARRAGUIRRE, IgNAcio - Orientaciones bibliográficas sobre San Ignacio de Loyola. 2: ed. renovada y puesta al dia.-Institutum Historicum Societatis Iesu, Roma, 1965. 199 pp. (Subsidia ad historiam S. I., 1).-V. núm. 12-32082. || AHSI, 34 (1965), 267-269 (Colpo); CyF, 2I (1965), 662 (Fiorito). 
19-3774. "Ignatian survey: 1963",-WL, 93 (1964) , 115-139.-V. núm. 18-3892

19.3775. Dalmases, C. DE-Fontes narrativi de S. Ignatio, t. 3 (N. 17-3028). II $A B, 82$ (1964), 278-280 (de Gaiffier); $E E, 39$ (1964), 227-237 (Quera) _. V. núm. 17-6664.

19-3776. KRÄMER-BADON1, RudOLF - Ignatius von Loyola, oder die grössere Ehre Gottes__J. P. Bachem, Köln, 1964. 268 pp. (Moderne Hagiographien). || Tijdschrift $v$. Geest. Ieven, 20 (1964), 678679 (Penning de Vries); GuL, 38 (1965), 399-400 (Wulf) .

19-3777. L[Ecuona], M. DE-."Camino recorrido por 1ñigo de Loyola desde Pamplona, donde fue herido, hasta Azpeitia y su casa solariega de Loyola".$B S V, 20$ (1964), 168-172.

19-3778. LecuonA, M. DE_-_Itinerario de San Ignacio herido" $-B S V, 21$ (1965), 240-243.

19-3779. RAIINER, HUGO_Ignatius von Loyola als Mensch und Theologe.-Herder, Freiburg-Basel-Wien, 1964. $528 \mathrm{pp}$. । Hochland, 58 (1965), 179-182 (Bäumer) ; Bijdragen, 26 (1965), 352-353 (Coppens) ; Credo, 46 (1964), 138-139 (Gerlach) ; AHSI, 33 (1964), 361-362 (Iparraguirre) ; $C H R, 52$ (1967), 599 601 (Iparraguirre); $W W t, 1965$, núm. 20, 140-141 (Kranz); OGE, 38 (1964), 454-455 (L. M.); ThLZ, 91 (1966), 288-290 (Loewenich) ; Zeitschrift für $K a$ thol. Theol., 87 (1965), 101-103 (Meyer); NRTh 87 (1965), 329-330 (Mols); GuL, 39 (1966), 237-238 (Mulde); Salm, 12 (1965), 808 (Nicolau); $A T G, 27$ (1964), 391-392 (Segovia).

19-3780. RaHNER, Huco-Sp. Ignacije Lo. jolski $i$ povijest njegove duhounosti.Zagreb, 1963. 100 pp.

19-3781. Chiarmot, F.-Deux maitres, une spiritualité: 1. de Loyola et $F$. de Sales (N. 18-3901) . \| Streven, 18 (196465) , 826-827 (Chappin); AHSI, 34 (1965), 343 (Iparraguirre).

19-3782. CREIXELL, JUAN__Contra la supuesta insuficiencia especulativa de San Ignacio. Gráficas Marina, Barcelona, 1951. 36 pp. (Vindicia ignaciana, 16).

19-3783. HORNEDO, R. M. DE-“Algunos rasgos comunes entre la contemplación ignaciana y la del Cartujano".Man, 36 (1964), 337-342.

19-3784. LAPJAACE, J.-"Le Christ de Saint Ignace"._VSp, 110 (1964), 535-552.

19-9785. Schneider, B._"Die Kirchlichkeit des heiligen Ignatius yon Loyola".-
Theologisches Jahrb., Leipzig, 1964, 522551.

19-3786. MENDizÁBAL, L.—"El thecho eclesiásticos de la obediencia ignaciana".Man, 36 (1964), 403-420.

19-3787. Palmés dF. Grnover, Carlos-La obediencia religiosa ignaciana.-E. Subirana, Barcelona, 1963. xvi +332 pp.-V. núm. 17-6702. || AHSI, 33 (1964), 125-127 (Iparraguirre); $A T G$, 1966, 395-396 (Olivares) ; Augu, 5 (1965), 206-208 (Santamarta).

19-3788. SCHNEIDER, B.- "Die Geistlichen Ubungen des Ignatius von Loyola".[En] Bücher der Entscheidung (Würzburg, 1964), 78-88.

19-3789. IpARRAgurRe, IGNAZIo-Diretlorio per gli "Esercizi spiriluali" (per un corso di cinque o tre giorni). 20: Guida pratica fondamentale._Ancora, Milano; Cenacolo, Brescia, 1964. 354 pp.

19-3790. IgNAzIO di LoyolA, S.-Esercizi spirituali. Tradotti e annotati da Vincenzo Insolera,_Stella Matutina, Roma, 1964. $187 \mathrm{pp}$.

19-3791. Przywara, ERuch-Deus semper maior. Theologie der Exerzitien. Theologumenon und Philosophumenon der Gesellschaft Jesu. 2. Aufl. - Herold, Wien-München, 1964. 2 ts.: 526, 414 pp. || Era, 18 (1966), 71-73 (Goetchius).

19-3792. Marobin, P. L.-"Identidade de espírito".-EP, 24 (1964), núm. 2, 64-69. [Los Ejercicios].

19-3793. Stanley, D. M..." The liturgical word, the Spiritual exercises, the Jesuit response".-WL, 93 (1964), 345 360.

19-3794. Santiago, J.-_"Three notes on the principle and foundation".-WL, 93 (1964), 193-206.

19-3795. Horatczuk, Mighael — Frontwechsel zum Guten. Die Unterscheidung der Geister.-Verlag Herold, WienMünchen, 1964. $232 \mathrm{pp}$.

19-3796. GonzÁlez-Quevedo, J-_."Explicación idéntica a puntos diferentes en la contemplación para alcanzar amor" Man, 36 (1964), 317-336.

19-3797. BeirnaERT, L.-“De l'incertitude à la totale assurance chez saint $\mathrm{Ig}$ nace"._Chr, 11 (1964), 195-208.

19-3798. Ignatil DE Loyola, SANCti-Epistolae et instructiones, 1524-1555. Reimpr. photomechanica editionis Matritensis. Romae, 1964-66. 8 ts.: 810, 800, 824, $771,820,788,800,789$ pp. (Monumenta Historica S. 1. 22, 26, 28, 29, 31, 33, $34,36)$. 
19-3799. IGNACE DE LOYOLA-Correspondance avec les fernmes de son temps. Ed. Hugo Rahner. Trad. G. Dumeige, Introd. $F$. von Groenendael._-Desclée de Brouwer, Paris, 1964. 2 ts: 378,370 pp., ilustr_W. núm. I1-26909. \| Rev. de l'Univ. d'Ottava, 36 (1966), 203204 (Cloutier); Rev. du Dioc. de Namur, 18 (1964), 302-303 (E. V.); RUL, 19 (1965), 595 (Elv. P.) ; Bull. de Litt. Eccl., 1965, 230-231 (Gensac) ; RHE, 60 (I965), 663-664 (Gilnont); Etudes, 322 (1965), 278-279 (Giuliani); $A H S I, 33$ (1964), 125 (Iparaguirre); $R y F, I 73$ (1966), 106 (Iturrioz); Bro, 80 (1965), 809 (Maurício); Irish Theol. Quart., 32 (1965), 174-175 (McKevitt); RE, 24 (1965), 632-633 (Muñoz Alonso); $R A M, 41$ (1965) , 95-98 (Olphe-Galliard) ; $M i s C o$, 49 (1965), 507-509 (Rey); Teol. Espirit., 8 (1964), 517 (Robles Sierra); $A T G, 27$ (1964), 390-391 (Segovia); $E E, 40$ (1965) , 503-504 (Segura); Sciences Eccl, 17 (1965), 362-364 (StatonJean); Rev. des Communautés Rel., 37 (1965), 130-134 (Thiry); Collationes Brug. et Gandav., 12 (I966), 141-142 (Vanovermeire); Collect. Mechl., 49 (1964), 512-5I3 (Weber).

19-3800. Walz, A.- "La plegaria Alma de Cristo".-Teologia Espiritual, Valencia, 8 (1964), 125-134.

V. también nứm. 3631 .

19-3801. Montguerre, JEAN-Marc — San Francisco Javier por los caminos de Oriente. Trad. por Sandra Trabucco.Juventud, Barcelona, 1964. 174 pp., láms. (Grandes biografias).

19-3802. GnanadickAm, Josery-Ars. Savêriar Saritai._Pentland Press, Palayamkottai, 1964. 296 pp.

19-3803. SGHURHAMMER, JORGE_El primer héroe. San Francisco Javier. Esbozo de su vida. 3a ed. Siglo de las Misiones, Bilbao, 1964. 127 pp. (Héroes del apostolado católico).

19-3804. Schurhammer, Georg - Gesammelte Studien. Hrsg. zum 80. Geburtstag des Verfassers... unter Mitwirkung von Las7ló Szilas. T. 2: Orientalia. T. 3: Xaveriana. T. 4: Varia.-Institutum Historicum S. I., Roma; Centro de Estudios Histớricos Ultramarinos, Lisboa, 1963-65. Ixiii + 815, xx + 703, xxiii + I055 pp. (Bibliotheca Instituti Historici S. I., 21-23). I| Neue Z. f. Missionswiss., 22 (1966), 67-68 (Beckmann) ; AHSI, 35 (1966), 259-262 (Bo- xer) ; Streven, $19(1965.66), 1017$ (Dicrickx) ; RyF, I73 (1966), 657.658 (Echánove); Zcils. für Missionswiss., 50 (1966), 120 (Glazik); NRTh, 88 (1966), 658. 659 (Mols); HS, 18 (1965), 465-466 (Vives) .

19-3805. Ubillos, Guillermo - Vida de San Francisco Javier. $7^{\mathrm{a}}$ ed.-Apostolado de la Prensa, Madrid, 1964. 240 pp.

19-3806. Lourenço, A.— “O gigante do apostolado". _ Boletim Eclesiástico da Arquidiocese de Goa, 23 (1964), 317. 322.

19-9807. Ferreiro Alemparte, J-“Rilke y el Padre Pedro de Ribadeneira".. FM, 4 (1963-64), núm. 13, 29-51.

19-3808. Yeomans, W. - "St. Alphonsus Rodriguez"._Month, 27 (1962), 20 29.

19-3809. Rodrícuez, Alphonsus, St.-A $A$ tobiography. Transl. by W. Yeomans.G. Clapman, London, 1964. 256 pp.V. núnı. 12-33998.

19-3810. Bondo VÁzquez, F._Baltasar Alvarez, S. J., en la historia de la es piritualidad del siglo xv".-MisCo, 41 (1964), 155-257.

19-3811. Boado, Faustino-el V. P. Baltasar Alvarez, S. I. La oración del silencio._Comillas, 1964. 103 pp. [Resumen de tesis, Univ. Gregoriana].

19-9812. Olphe-Galdiarn, M. - "Chronique. Mystique carmélitaine'.-RAM, 39 (1963), 26I-268. [Santa Teresa, San Juan de la Cruz].

19-3813. LAVELLE, LouIs-Four saints.Univ. Press, Notre Dame, 1964. (Notre Dame paperbacks, 33). [San Francisco, Santa Teresa, San Juan de la Cruz, San Francisco de Sales].

19.3814. PARDo, ENRIQUE JORGE-Estudios teresianos-Univ. Pontificia, Comillas, 1964. 422 pp. \| Man, 98 (1966), 90 (Granero); Estudios Josefinos, Vallado. lid, 19 (1965) , 153 (José de Jesús M.); $R y F, 171$ (I965), 651 (Segura).

19-3815. Jiménez Duque, Baldomero-En torno a Santa Teresa. - Institución Gran Duque de Alba, Ávila, 1964. 240 pp. || $A H, 42$ (1965), 307-309 (Antón); Man, 38 (1960), 185 (X).

19-3816. Jiménez DuQue, B.-“Reflexiones crlticas teresianas".-TE, 8 (1964), 107 121.

19-3817. Gutiérrez RuedA, L._"Ensayo de iconografia teresiana".-RE, 23 (1964), 1-143.-V. núm. I7-6586.

19-3818. Salvador de la Virgen deL CarMEN-Teresa de Jesús._-Diputación Fo. 
ral de Alava, Vitoria, 1964. 580 pp. $C T, 118$ (1966), 660 (Hernández); $R y F$, 172 (1965), 388.389 (Jorge); Estudios Josefinos, Valladolid, 19 (1965), 150 (José de Jesús Marfa); $M C, 72$ (1964), 608 (Luis de San José).

19-3819. Jor1t, P.—Sainte Thérèse d'Avila.-Bloud et Gay, Paris, 1964. \| ArA, 59 (1965), 429 (Casado); RyC, 11 (1966) , 155-156 (Castellanos); RyC, 10 (1965), 625-62 (V'aca).

19-3820. FreIre, A.- "Teresa d'Ávila, doutora santa".-Lumen, 29 (1964), 189. 196.

19-3821. EFRÉn DE LA MADRE DE DIOS"Santa Teresa y Felipe II".-El Escorial, 1563-1963 (Madrid, 1963), 1, 417437.

19-3822. TOMAs dE LA CRUZ - "El voto de obediencia de Santa Teresa y sus tres relatos autógrafos". - EC, 15 (1964), 155-176.

19-3823. Las monjas carmelitas hasta Santa Teresa de Jesús. - Carmelus, 10 (1963) ; 312 pp. || BHi, 68 (1966) , 425426 (Ricard); $E C, 15$ (1964), 479-480 (Tomás de la Cruz).

19-9824. Simeón de LA Sagrada familia"Prima instructio novitiarum Carmeli Teresiani; opus hucusque ignotum $\mathrm{M}$. Mariae a S. Ioseph (Salazar) ".-EC, 15 (1964), 130-154.

19-3825. Pérez Carmona, J-_-Burgos en tiempo de Santa Teresa",-Burg, 1964, núm. 5.

19-3826. ErRÉN DE LA MADRE DE DIOS"Posibles influencias josefinas ambientales en Santa Teresa"_Estudios Josefinos, Valladolid, 18 (1964), 243-250.

19-3827. Cifuentes, J. A. — "Influencias franciscanas en la devoción de Santa Teresa de Jesús a San José".-Estudios Josefinos, Valladolid, 18 (1964), 251300.

19-3828. Benito M. de la CRuz “"El josefismo de Santa Teresa"._-Estudios Josefinos, Valladolid, 18 (1964), 325-338.

19-3829. Jiménez Duque, B.-"Mística teresiana"._Arb, 57 (196٪), 165-171.

19-3830. SinNige-BREEd, A. M.-“L'évolution mystique de Thérèse d'Avila exprimée par ses images".-VSp, 70 (1964), 327-344.

19-3831. Santiaco de SAN José-“Esquema teresiano para unos ejercicios espirituales".-RE, 23 (1944), 290-302.

1?-3832. Teodosio dE IA SAgrada Fami1.IA_Santa Teresa, maestra de oración._El Carmen, Vitoriạ, 1964. 51 pp.
\| $M C, 72$ (1964), 61: (Ruiz de la Asunción).

19-3833. JUAN JosÉ dE IA INMACULAdA"Criterio práctico de Santa Teresa de Jesús sobre la oración mistica" - $R E$, 23 (1964), 492-506.

19-3834. Muñoz Alonso, A.-"Concetto del mondo e delle cose in Teresa di Gesù".-Sapicnza, 17 (1964), 378-391. 19-3835. Moreyra, Carlos Alberto-Los criptogramas de Santa Teresa__Córdoba (Argentina), 1964. $40 \mathrm{pp}$.

19-3836. Terfsa de Jesús, SANTA-Obras completas. 9a ed.-Apostolado de la Prensa, Madrid, 1964. 1272 pp._-V. núm. 12-33886.

19-3837. Teresa DE Jesús, SANTA_Obras completas. 3: ed.-Plenitud, Madrid, 1964. xxxii + 127] pp.-V. núm. 1439529.

19-3838. Teresa DE JEsús, SANTA-Libro de su vida. Versión de Tomás de la Cruz.-E1 Monte Carmelo, Burgos, 1964. 509 pp.

19-3839. Teresa de Jesús, SANTA_Vida. Notas del P. Félix Martín.-Madrid, [1964?]. 493 pp. I| Aug, 10 (1965), 280 (Armas).

19-3840. Teresa de Jesús, Santa_Camino de perfección. T. 1: Reproducción en facsimil del autógrafo de Valladolid. T. 2: Introducción, transcripción del texto, léxico.-Tipografia Poliglotta Vaticana, Roma, 1964-1965. 406 láms., 170 $+540 \mathrm{pp}$.

19-3841. Teresa de Jesús, Santa_Camino de perfección. Libro de las fundaciones. 3: ed.-Aguilar, Madrid, 1964. 622 pp. (Crisol, 280) _-V. núm. 1439531 .

19-3842. Braybrookr, N._'Cháteaux, ou la géographie de l'âme: Ste. Thérèse et Kafka".- $R L V, 19$ (1965), 187-195._V. núm. 16-45461.

19-3843. HENRARD, A.- "Une source espagnole au Château de Kafka?" $-R L I$, 31 (1965) , 444-453.

19-3844. Serrano Plaja, A.-_Una noche toledana. Del castillo interior al castillo fugitivo. Santa Teresa, Kafka y el Greco"._PSA, 35 (1964), 263302.

19-3845. TomAs of. IA CRUZ "Una carta autógrafa de Santa Teresa donada a Paulo VI".-EC, 15 (1964), 425-434. 19-3846. RICARD, R._Bossuet et son $P a$ négyrique de sainte Thérèse".-RAM, 40 (1964), 31-44. || $L R, 19$ (1965), 150151 (Groult). 
19-3847. Kerdreux, MICHEL DE-Papa Giovanni e Santa Teresa. Trad. di L. Vigliasindi.-Edizioni Borla, Torino, 1964. $168 \mathrm{pp}$.

19-3848. Otronello, P. P._._Una bibliografia della letteratura comparativa su San Juan de la Cruz".- $R L C, 98$ (1964), 638-652.

19-3849. Ottonello, P. P._Bibliografia degli studi sulla dottrina asceticomistica di S. Giovanni della Croce dal 1926 al 1962".-_Riv. di Ascetica e Mistica, Firenze, 9 (1964), 561-569.

19-3850. AguIRre Prabo, LuIs_San Juan de la Cruz,_Cia. Bibliográfica Espafiola, Madrid, 1964. 212 pp. (Un autor en un libro) [Estudio y antología]. II MC, 72 (1964), 608.609 (Miguel Angel de Santa Teresa).

19-3851. Leroy, O-_Quelques traits de saint Jean de la Croix comme mâ̂tre spirituel"-Carmelus, 1 I (1964), 3-43.

19-3852. Mt́lançon, O.- "Saint Jeall de la Croix: son rôle prépondérant dans Ia theologie ascétique et mystique".RUL, I8 (1964), 80I-812, 914-929.

19-3853. VEGA, ÁNGEL C.-Cumbres misticas: Fray Luis de Leon y San Juan de la Cruz.-Aguilar, Madrid, 1964. 292 pp. (Ensayistas hispánicos). || $R y C, 9$ (1964), 583.597 (Arrilucea): $A r A, 58$ (1964), 289 (Cilleruelo); $C D, 177$ (1964), 376 (Manrique); $M C, 72$ (1964), 604606 (Miguel Angel de Santa Teresa).

19-3854. Giovanna della Croce-Christus in der Mystik des hl. Johannes vom Kreuz.-Heiler, Wien, 1964. 123 pp. \| $M C, 73$ (1965), 494-495 (Díez).

19-3855. ZABALZA DE LA INMACULADA, LAUREANo-El desposorio espiritual según San Juan de la Cruz._El Monte Carmelo, Burgos, 1964. 142 pp. $E C, 16$ (1965) , 529-530 (Eulogio de lid Virgen del Carmen).

19-3856. Té́filo de LA VIRGEN DEL CARMEN-_Estructura de la contemplación infusa sanjuanista".- $R E, 23$ (1964), 347-423.

19-3857. Lucas, Francisco J.-La cruz de San Juan de la Cruz.-EI Mensajero del C. de Jesús, Bilbao, 1964. 157 pp.

19-3858. Rudolf, M.-Der Mensch und die Dinge nach Johannes vom Kreuz.Echter-Verlag, Würzburg, 1964. I84 pp.

19-3859. Chamorro, J.-“El paisaje andaluz en la obra de San Juan de la Cruz".-BIEG, I962, núm. 34, 9-44.

19-3860. Palau de Nemes, G.-“De Zur- barán y San Juan de la Cruz".-Ins, 1964, nứn. 209.

19-3861. Juan de la Cruz, San-Breviario místico. Sel. del P. Simeón de la Sgda. Familia.-El Monte Carmelo, Burgos, 1964. $319 \mathrm{pp}$.

19-3862. [Juan dE la Cruz, SAN]--Die lebendige Flamme. Die Briefe. Die klei. nen Schriften. Ubertr. von Irene Behm. - Johannes Verlag. Einsiedeln, 1964. 204 pp. (Sämtliche Werke, 4).

19-3863. HATzFELd, H.__Los elementos constituyentes de la poesia mística".APCH, 319-325.-V. núm. 17-6646.

19-3864. De Pilato, S.-San Giovanni della Croce $e$ il suo "Cántico espiritual"._Conchiglia, Roma, 1953. 25 pp. (Coll. L'astro, 1).

19-3865. Johannes vom Kreuz-Das Lied der Liebe. C'bertr von Irene Behm. Johannes Verl., Einsiedeln, 1964. (Lectio spiritualis). || Arb, 58 (1964), 226. 227 (Jiménez-Duque) .

19.3866. Krynen, J.-"A propos de Llama, I, 3, y la diferencia que hay entre el hábito y el acto»".-BHi, 66 (I964), $65-67$.

19-3867. Orcibal, J. - "La Montée du Carmel a.t-elle ćté interpolée?"-RHR, 166 (1964), 171-213. || Bs, 40 (1964), 427-429 (Silva Dias).

19-3868. Johannes vom Krevz-Empor den Karmelberg. Ubbertr. von Oda Schneider.-Johannes Verl., Einsiedeln, 1964. xliv + 340 pp. $\| A r b, 60$ (1965), 294-295 (Jiménez Duque).

19-3869. Fortunato de Jesús SacramentaDo_." ¿Son de San Juan de la Cruz los Avisos para despues de profesos de la Instrucción de novicios descalzos?"'$R E, 23$ (1964) , 517-526.

19-3870. HuerGa, A.- "La inautenticidad sanjuanista de los Avisos".-Angelicum, Roma, 41 (I964), 35-50.

19-3871. FenErico dE SAN JUAN DE LA Cruz_"Avisos para profesos: Aclaraciones".-_RE, 23 (1964), 507-516.

V. también núms. 3812.3.

19-3872. Díaz G.-“"Tratado inédito sobre los sentidos de la Sagrada Escritura de Agustín Antolínez".- $-C D$, 177 (1964), 469-534.

19-3873. Vinci, J_"Las ideas eclécticas sobre la filosoffa del amor y de la hermosura. (A propósito de La conversión de la Magdalena de Malón de Chaide)".- $-R, C, 8$ (1963), 539-562.

19-3874. Vinc1, J.-“The neoplatonic influence of Marsilio Ficino on fray $\mathrm{Pe}$. 
dro Malón de Chaide" (N. 17-3060). $L R, 19$ (1965), 145 (Groult); BICC, 19 (1964), 378-380 (Valderrama Andrade) .

19.3875. CarozzA, D. - "Another Italian source for La Magdalena of Ma]ón de Chaide".-It, 41 (1964), 9]-98. [Pico della Mirandola].

19-3876. Isabel de los Ângeles__Cartas de la Madre..., O.C.D. (1565-1664)._El Monte Carmelo, Burgos, 1963. $330 \mathrm{pp}$. (Biblioteca mistica carmelitana).

19-3877. Villasante, L.- "Ante el tercer centenario de la venerable madre Āgreda"._ $V y V, 22$ (1964), 683-701.

19-3878. Martínez, A.--"La Ininaculada Concepción en la Mistica ciudad de Dios de la madre Agreda".- $V y V, 22$ (1964), 645-665.

19-3879. Schaffer, T. E.-"Miguel de la Fuente: un intento de evaluación del misticismo español del siglo xvil".CuH, 58 (1964), 511-528.

V. también nums. 168, 1705, 2276.

\section{AUTORES Y OBRAS DE GENEROS DIVERSOS}

19-3880. PabóN NúÑez, L.-_"Tres meditaciones sobre fray Luis de León".-BICC, $20 \quad(1965), 241-296$.

19-3881. DurAn, M. - "Américo Castro, Luis de León, and the inner tensions of Spain's Golden Age".- $H A C, 83-90$.

19-3882. LEón, FRAY LuIS DE-Poesie originali. Introd., testo criticamente riveduto, trad. metrica, note e bibliografia di Oreste Macrl. Nuova ed._. Vallecchi, Firenze, 1963. 359 pp. (Coll. La Cederna).-V. núm, 6-6987. || BHi, 67 (1965), 202 (Ricard) .

19-3883. LEÓN, FRAY LUIS DE-Poesias. El Cantar de los Cantares. La perfecta casada._Edaf, Madrid, 1964. 485 pp.

19-3884. StaGc, G.- "Tmesis in the verse of Fray Luis de León and others: A western Romance mannerism".-FHH, 385-392.

19-3885. Doddis, A__ "Fray Luis de León y su Vida retirada".-EFil, 1964, nủm. 1 , 99-107.

19-3886. DAvies, G. A.- "Luis de León and a passage from Seneca's Hippoly. tus".-BHS, 41 (1964), 10-27. \|LR, 19 (1965), 144 (Gottigny).

V. también núm. 3853.

19-3887. LANUZA, J. L-“Las máscaras de don Francisco de Quevedo"._Lyra, 1964, núms. 192/4.
19-3888. RocAmora, P.-“"Quevedo o la aventura de la libertad". - Arb, 57 (1964), 137-154. || LR, 20 (1966), 384 (De Poortere) .

19-3889. Iventosch, H. - "Quevedo and the defense of the slandered" (N. 17 . 6814). I BICC, 19 (1964), 602-606 (Valderrama Andrade); CdS, 1966, núm. 5, 107-108 (Zamudio de Predan).

19-3890. Quevedo, Francisco de-Obras completas. T. 2: Obras en verso. Ed. de Felicidad Bucndía, 5: ed._-Aguilar, Madrid, 1964. 1488 pp. (Obras eternas).- $Y$. núm. 16-49863.

19-3891. QUEVEDO, FRANCISCO DE-Oheren Sonetien. Vert. van D. Verspoor.--Van Gennepp, Amsterdam, 1964. 32 pp. II FM, 1965, núms. 17/18, 118.119 (Daal).

19-3892. Maurer, K.-"Ronsard und die dunklen Dichter".- $F H F, 165-191$. [Hay una comparación con Quevedo].

19-3893. Quevedo, Francisco dE-Poemas satiricos.-Marte, Barcelona, 1964. xiv + 226 pp., ilustr. (Pliegos de cordel de oro).

19-3894. Quevedo, Francisco DE-Poema heroico de las necedades y locuras de Orlando el Enamorado. Introd., texto crítico y notas por M. E. Malfatti.Barcelona, 1964. 141 pp. || BHS, 43 (1966), 62-64 (Pierce); RLit, 27 (1965), 231 (Rodríguez Cepeda).

19-3895. ScilaLk, F._.'Uber Quevedo und El Buscón" (N. 17-6825) . \|RFE, 48 (1965), 437-438 (Llorente).

19-3896. Levisi, MarGarita MAría A. R.Los "Sueños" de Quevedo. El estilo, el humor, el arte.-[Tesis, Ohio State Univ.; resumen en $D A, 25$ (1964-65), 6629].

V. también núms. 2293, 3212, 3279, 3281-2.

19-3897. RICARD, R."Jovellanos y la nobleza"._All, 3 (1965), 456-472.

19-3898. BaLil, A.-"Los manuscritos epigráficos de Jovellanos". - Zeph, 14 (1963) , 101-102.

V. también núms. 275, 2399, 2608.

19-3899. Di Stefano, G.-“"Per una introduzione all' opera letteraria di Martinez de la Rosa".-MSI, 1964, núm. 8, 38-60.

19-3900. Martínez de la Rosa, Franctsco_Obras dramáticas. - Espasa-Calpe, Madrid, 1964. 348 pp. (Clás, cast., 107).V. núm. 10-23734.

19-3901. AслмPo, V._"En el día de Unamuno".-_Sur, 1965, núm. 292, 1-3.

19-3902. Unamuno. - Departamento de Extensión Universitaria, Santiago de 
Chile, 1964. 173 pp. || RHM, 32 (1966), 116-117 (Basdekis).

19-3903. Laín Entralco, P.-"Respuesia académica a don Miguel de Unamuno".-BRAE, 45 (I965), 29-40.

19-3904. FonTAN, A.- "Unamuno".- $T R$, 1965, núm. 207, 33-45.

19-3905. Castañeyra Schrmann, R.-“A la memoria de don Miguel de Unamuno en el centenario de su nacimiento".MCan, 26 (1965), 209-212.

19-3906. Fontín, A.-_En el centenario del nacimiento de Unamuno".- $C d S, 2$ (1965), 181-189.

19-3907. Montes, E.- "En el centenario de Unamuno"._- $S J$, 1965, nứm. 57, $37-$ 47.

19-3908. Serrano Castilla, FranctscoDos palabras ocasionales sobre el cen. tenario de Unamuno.-Autor, La Coruก̃a, 1964. 7 pp. $\| E M, 21$ (1965), 489 (Ortúzar).

19-3909. Ortiz Armengol, P._."A propos d'un centenaire: Stendhal et Unamu. no". - Stendhal Club, Lausanne, 7 (1965) , 234-238.

19-3910. García Blanco, M. - “Crónica unamunialla (I962-1963)". $-C M d U, 13$ (1963), 95-110.-V. núm. 18-7955.

19-3911. GUY, ALAIN-Unamuno-Seghers, Paris, 1964. 224 pp. $\| C D, 177$ (1964), 595 (Alvarez Turienzo); BHi, 67 (1965). 205-206 (Laffranquc); Revue Thomiste, Paris, 65 (1965), 656 (Llinarés); $C I, \quad 1$ (1965), 138-141 (Maiorana); Asom, 1964, núm, 4, 62-64 (Otero Scco) : Pens, 21 (1965), 209-210 (Roldån) .

19-3912. Ponce Ribadeneira, GonzaloEl ingenoso hidalgo Miguel de Unamuno.-Instituto Ecuatoriano de Cultura Hispánica, Quito, 1965. 16 pp.

19-3913. Salcedo, Emillo-Vida de don Miguel de Unamuno en su tiempo, en su España, en su Salamanca. Un hombre en lucha con su leyenda. Pról. de P. Laín Entralgo._Anaya, Salamanca, 1964. 437 pp., láms. || PSA, 36 (1965), $126-128$ (A. F. M.); RPFB, 6 (1960), I96 (Araujo); CuH, 6I (1965), 633659 (Bravo-Villasante); REP, 1965, núms. 141/2, 269-271 (Día); Ins, 1964, núins. 216/7 (Marra-Lópcz); $E L$, 1964, núm. 304 (Rincón) ; $L T, 1966$, nún. 54, 197-200 (Zavala).

19-3914. Gullón, Ricardo-Autobiografias de Unamuno._Gredos, Madrid, 1964. 390 pp. (BRH). || PSA, 35 (1964), 333-337 (Albornoz); fns, 1964, núms.
$216 / 7$ (Cano); LFr, Is (1965), 89.90 (García) ; CL, 17 (I965), 263-265 (Gicovate); $E L, 1964$, núms. $300 / 1$ (Ponce de León); Sur, 1965, núm. 269, 85. 87 (Torre); $R L M O, 1967$, núm. 6, 128129 (Zuleta).

19-3915. FAGoAGA, Isidoro DE-Unamuno $a$ orillas del Bidasoa y otros ensayos.Auñamendi, San Sebastiản, 1964. 194 pp. (Col. Auñamendi, 39). $\| B S V, 21$ (1965), 113-114 (Arocena).

19-3916. Vaisman, Gladys O.-Un ensayo sobre Miguel de Unamuno.-Castellvi, Santa Fe, Argentina, 1965. 59 pp.

19-3917. Unamuno, Miguel DE-Pensamiento politico. Sel. de textos y est. prel. sobre El pensaniento politico de Unamuno, por Elfas Díaz.-Tecnos, Madrid, 1965. (Res Publica. Bibl. del perisamiento politico y social). \| $H f$, 1968, núm. 32, 62 (Bosch); CuH, 68 (1966), 487.492 (Romero Márquez); $H, 50$ (1967) , 607-608 (Valdés); REP, 1966, núm. 149, 175-179 (Vega).

19-3918. BÉCARUD, JEAN-Miguel de Unamuno y la Segunda República espanola. Versión española de $F$. Trape. ro._Taurus, Madrid, 1965. $65 \mathrm{pP}$. (Cuadernos Taurus). II REP, 1965. núms. 141/2, 274-277 (Diaz) ; RLit, 27 (1965) , 264 (Rozas); PSA, 38 (1965), 94-95 (Viñuelas).

19-3919. Nozick, M._. "Unamuno and the Second Spanish Republic".-HMU, 379 . 393.

19-3920. Blanco Aguinaga, C._"El socialisino de Unamuno (1894-1897)"...ROcc, I4 (1966), 166-184.

19-3921. Tudela, J. -. "Unamuno agrario".-RHM, 31 (1965), 425-430.

19-3922. Aguilera, C._-"Pensamiento edu. cacional de don Miguel de Unamuno".Rev. Calasancia, 1965, núm. 44; 116 pp.; IIsCo, 45 (1966), 291 (Alejandro); $R y C, 1$ I (1966), 427 (Castellanos); Helm, 17 (1966), 162 (Oroz); EM, 22 (1966), 363-364 (Vázquez).

19-3923. Conde Gargollo, Enrique-Unamuno viajero-Madrid, 1964. [Separata del Bol. del Consejo General de Colegios Médicos].

19-3924. García Branco, Manuel-En torno a Unamuno. (Personalia, España, Europa)__.Taurus, Madrid, 1965. 625 pp. (Col. Persiles). || HR, 35 (1967), \$81.383 (Valdés) .

19-3925. LEón, M. T.__"El buho de papel de Miguel de Unamuno",-_L.os Sesenta, Mí́xico, 1965, 11úm. 2. 
19-3926. Gascó Contell, E._-"Notas sobre don Miguel de Unamuno"_LLLibros Selectos, México, 1965, núm. 24.

19-3927. García, E.- "Don Miguel de Unamuno y don Américo Castro".Map, 1965, núm. 1, 144-150.

19-3928. Helwis, W.-"Unamuno wieder in Sicht?"-Merkur, 19 (1965), 1093 1095.

19.3929. MADARIAGA, S. DE-_Unamuno herlezen".-De Vlaamse Gids, 49 (1965), 217-227.

19-3930. ORTega y Gasset, J-_"En defensa de Unamuno]"-_CMdU, 14-15 (1964-65) , 5-10.

19-3931. Serrano Poncela, S. - "Apología de Unamuno". $-R N C, 1964$, núm. $166,80-97$; CuA, 1965, núm. 2, 284299.

19-3932. MIRo, E.- "Unamuno con nosotros"_-CuD, 1965, núm. 20.

19-3933. Maragall, J.—“Unamuno: diálogo interior"._CuD, 1965, núm. 20.

19-3934. PACHeco, L.- "Miguel de Unamuno y la agonía".-CuA, 1967, núnı. $5, \quad 120-140$.

19-3935. CAstelli, F._-“Miguel de Unamuno profeta della speranza disperata"-Letture, 20 (1965), 171-193.

19-3936. ZAVALA, IRIS M-La angustia $y$ la buisqueda del hombre en la literatura. I. La anguslia y el hombre. II. Descle Unamuno a Unamuno. Seis ensayos de interpretación.-Universidad Veracruzana, Jalapa, $1965 . \| P H, 10$ (1966), 530-534 (Sigüenza); BHi, 69 (1967), 302-304 (Trigueros).

19-3937. Sell, Havs J.-Das Drama Unamunos. Ein Vortrag zum 100. Wieder. kehr des Geburtstages des spanischen Dichters und Philosophen Miguel de Unamuno._Ellermann, München, 1965. $41 \mathrm{pp}$.

19-3938. Gómez MorinNA, A.-"Über den Sinn von congoja bei Unamuno". $Z P F$, 19 (1965), 3-31.

19-3939. Gómez MORIANA, ANTONIO-Uber den Sinn yon acongojas bei Unamuno. -- Anton Hain, Meisenheim am Glann, 1965. $90 \mathrm{pp}$.

19-3940. Díez, G.-“La cruz de Unamuno".-Ciervo, 1965, núm. 132.

19-3941. Devaux, A.-A.-_"Unamuno et le sens tragique de la vie"._Synth, 1965, núms. 230/1, 193-202.

19-3942. GonzÁlez RodríGuez, A. -- “El pensamiento filosófico religioso de Unamuno: un caso de catolicismo ateo". Map, 1965, núm. 1, 169-189.
19-3943. MendzÁBAL, C. M.—“El problema de Dios en Unamuno"._R Jav, 63 (1965), núm. 317.

19-3944. SÁNchez BARbudo, A.- "The faith of Unamuno: his unpublished Diary".TQ 8 (1965), núm. 1, 46-66.

19-3945. Balbontín, J. A.- "Sobre el sentimiento trágico de la muerte en Unamuno".-IAL, 1965, núm. 195.

19-3946. VALDÉS, MARIO J.-Death in the literature of Unamuno._Univ. of Illi. nois Press, Urbana, 1964. 173 pp. (Studies in language and literature, 54)._V. núm. 18-4051. || RHM, 32 (1966), 9091 (Basdekis); $H f, 1967$, núm. 30, 6869 (Bosch); RJ, 18 (1967), 384-386 (Caravaca); $A D, 14$ (1964), 296-300 (E. G. D.) ; $R F, 78$ (1966), 499-501 (Feldmann) ; $C M d U, 13$ (1963), 100 101 (García Blanco); Ins, 1964, nums. 216/7 (Gullón); $B A b r, 39$ (1965), 348 (Klibbe) ; $M L J, 50$ (1966), 167-168 (Nozick) ; S, 20 (1966), 283-285 (Palley); H, 48 (1965), 939 (Predmore); $B H S, 45$ (1968) , 68-69 (Ribbans); $F H$, 3 (1965), 945 (Ruiz-Fornells) .

19-3947. ZaragüeTA, J._-"Ciencia y creencia en Unamuno"._RevFil, 24 (1965), 5-21.

19-3948. Schürr, F,-Miguel de Unamuno, der Dichterphilosoph... (N. 18-4054). || $R R, 55$ (1964), 150-151 (Charney); $E L$, 1965, núm. 309 (Iglesias Lagu. na); $B H S, 41$ (1964), 121 (Ribbans); $R F, 77$ (1965) , 208-209 (Sobejano).

19-3949. SÁnchez Ruiz, José Marí_-Razón, mito y tragedia. Ensayo sobre la filosofia de D. Miguel de Unamuno.Pont. Athenaeum Salesianum, Zürich, 1964. xvi + $322 \mathrm{pp}$.

19-3950. Young, C._-'La presencia de William James en el pensamiento de $\mathbf{M}$. de Unamuno".- $R F C R, \&$ (1964-65), 329-338.

19-3951. Earle, P. G.-"El evolucionismo en el pensamiento de Unamuno".$C M d U, 14-15$ (1964-65), 19-28.

19-3952. Garagorri, P._."Unamuno y la filosofía"_Map, 1965, núm. 1, 114120.

19-3953. JUÁREZ PAz, R._-“Unamuno: su concepción filosófica del mundo".RFCR, 4 (1964-65), 323-327.

19-3954, TORre, J, DE LA_-"Unamuno o la filosofía de un caballero"....PN, 1965. núm. 11.

19-3955. Condus, C.-"La contradicción en Nietzsche y en Unamuno".-Map, 1965, núm. 1, 128-143. 
19-3950. Quentin-Mauroy, D._-Une rencontre manquée: Unamuno et Maurice Blondel".__Carav, 1965, núm. 4, 135177.

19-3957. Iriarte, J-“Los tres grandes de la filosofía".-RyF, 171 (1965), 589-598. [Santayana, Unamuno, Ortega y Gasset].

19-3958. Anido-Meulener, G._"La polémica Unamuno-Ortega y Gasset".DHR, 4 (1965), 91-99.

19-3959. RosA, M. DE LA-“La discrepancia en concordia: Unamuno-Ortega", Azor, 1965̆, núm. 21.

19-3960. ABeldáN, J. L.-“Aportaciones de Unamuno y Ortega para una filo. sofía española".-CMdU, 14-15 (196465) , $11-18$

19-3961. PiñeRA, HumberTo-Unamuno $y$ Ortega y Gasset. (Contraste de dos pensadores)._-Centro de Estudios Humanisticos de la Universidad de Nuevo León, Monterrey, 1965. 454 pp.

19-3962. Scuderi, M.-“Unamuno y Ortega. ¿Aquende o allende los Pirineos?"-CuA, 1965, núm. 5, 129-146.

19-3963. Garagorri, P__."Unamuno y Ortega, frente a frente". $-C u H, 64$ (1965), 15-32.

19-3964. Sandoval, C.-..'Unamuno y Ortega"._Cults, 1965, núm. 35, 95-97.

19-3965. Cudeiro, V._."El método irracionalista de M. de Unamuno".-EstF, 13 (1964), 547-585; 14 (1965), 55-102, $255 \cdot 282$.

19-3966. SÁnctiez Astudillo, M. "El ser de Unamuno".-Abs, 29 (1965), 179194.

19-3967. Schnemer Graziosi, RaffaeleUmanesimo ed esistenzialismo di Miguel de Unamuno.-Gastaldi, Milano, 1965. 99 pp.

19-3968. SchürR, F._"EI amor, problema existencial en la obra de Unamuno".CI, 1965, núm. 1, 63-93. || ZRPh, 82 (1966), 650-652 (Rüegg).

19-3969. Trabazo, L-_Unamuno y la ciencia".-IAL, 1964, núm. 191.

19-3970. Viera Altamirano, N._"Unamuno y su desdén por los cientificistas".-CCL, 1965, núm. 99, 88-90.

19.3971. LEGAZ LAcAMBRA, L_-_Unamuno y el derecho".-REP, 1965, núms. 141/ 2, 5-32.

19-3972. Conrad, G._-'La contribución de Unamuno a un renacimiento espiritual de Europa"._[En] Estudios sobre historia de España (1965), 427-443.V. núnı. 18-4062.
19-3973. Sopeña, Federico_-Música y antimúsica en Unamuno. - Taurus, Madrid, 1965. 48 pp. (Cuadernos Taurus). || PEsp, 1966, núm. 165 (Murciano). 19-3974. Basdekis, Demetrios - Unamuno and Spanish literature.-[Tesis, Columbia Univ.; resumen en $D A, 26$ (1965), 3324-3325].

19-3975. Nuez Caballero, S. DE LA_"Unamuno y sus amigos canarios".-MCan, 26 (1965), 214-230.

19-3976. Meregalli, F. — "Da Clarfn a Unamuno". - Annali di Ca' Foscari, 1965.

19-3977. García Blanco, M. "La pa. sión de Unamuno en su obra multiforme".-LEsp, 8 (I965) , 55-73.

19-3978. LucrezI, B.—“Introduzione a Miguel de Unamuno. (Saggezza e follia)". - Quaderni degli amici della Spagna, Napoli, 1965, núm. 1.

19-3979. Monón, G._"Por leer de nue. vo a Unamuno".-CCL, 1965, núm. 95, 59-67; BANHV, 47 (1964), 507 524.

19-3980. Guereña, I. L.-“Con prosa vieja de Unamuno".-PSA, 38 (1965), 9-28.

19-3981. Carramolino, R.-_Don Miguel - la encarnación de un paisaje".$E C A, 19$ (1964), 237-240.

19-3982. UnAmuno, Miguel DE-Obras selectas. Pról. de Julián Marfas. 5! ed.Plenitud, Madrid, 1965. 1120 pp.V. núm. 17-3128.

19-3983. Unamuno, Miguel DE-Poesias escogidas_Losada, Buenos Aires, 1965. 185 pp. (Bibl. contemporánea, 185). || $C U$, 1965, núm. 89, 243-245 (Aristeguieta)

19-3984. Difco, G._-“Unamuno, poeta".$B R A E, 45$ (1965), 7-17.

19-3985. YRACHE, L.— “Una nota al estilo poético de Unamuno".-PSA, 36 (1965), 239-240.

19-3986. García Morejón, J.-“Génesis y elaboración de un soneto unamuniano". $\subseteq C M d U, 14-15(1964-65), 49-62$._ V. núm. 18-8090.

19-3987. Marichal, J.- "Aldebarán y sus poctas: Hugo, Flammarion y Unamu. 110".-UMx, 19 (1964-65), núm. 9; PSA, 37 (1965), 9-22.

19-3988. Ferrada Partarrieu, G.-“Unamuno y el Cristo de Velázquez".—Map, 1965, núm. I, 151-166.

19-3989. Combarros, M._-"El mejor Cristo de Unamuno". $-P N, 1965$, núm. 11. 19-3990. Gutiérrez Macías, V._Cáceres 
en la poesía de Unamuno".-Alcántara, Cáceres, 1965, núm. 145.

19-3991. Torre, G. DE- "Unamuno y sll teatro".-EFil, 1964, núm. 1, 219-235; PSA, 36 (1965), 13-44.

19-3992. Tornos, A. M.-_Temas y problemas del teatro de Unamuno".--Res, 2 (1965), 65.70.

19-3993. Unamuno, Miguel DE-El otro. Misterio en tres jornadas y un epílogo.-Aymá, Barcelona, 1964. 137 pp. (Col. Voz imagen, Serie Teatro, 3) .

19-3994. J, C. A.- "El otro, de Unamuno".-PA, 1965, núm. 63, 56-57. [Representado en Barcelona].

19-3995. Gullón, R.-“Imágenes de $E l$ olro".-HAU, 257-269; RHM, 31 (1965), 210-221. [Kierkegaard, Dostoyevsky, Unamuno].

19-3996. LIJERón, Hugo-El existencialismo en las obras de ficción de Miguel de Unamuno.-[Tesis, Univ. de Madrid, 1965; resumen en $R U M, 14$ (1965), 216-217].

19-3997. BARRENECHEA, A. M.-_'Unamuno en el movimiento de renovación de la novela europea".- $H A C, 39.47$.

19-3998. AGACIR-"Releyendo a Unamuno. El fratricidio de Monegro".-CMdU, $14-15$ (1964-65) , 69-72.

19-3999. UnAMuno, Miguel DE-El espejo de la muerte y otros relatos novelescos.-Juventud, Barcelona, 1965. 400 pp. (Novelas modernas). \| BHS, 45 (1968), 69.70 (Ribbans).

19.4000. Unamuno, Miguel DE - Nebel. Aus dem Spanischen von $O$. Bueck, neu durchgesehen von D. Deinhard.Kiepenheuer \& Witsch, Köln-Berlin, 1965. $320 \mathrm{pp}$.

19-4001. FeHLeisen de IBÁNEz, ElSA EliDA-Dos ensayos: Garcilaso. Unamuno.-Ed. de la Mesopotamia, Paraná, 1965. [Sobre el Inca Garcilaso y sobre Niebla de Unamuno].

19-4002. RibBans, G.-"Estructura y significado de Niebla"._-RUM, 13 (1964), 211-240.

19-4003. VENTo, A. C._-"Una interpretación onfrico-estructural de Niebla".$C M d U, \quad 14-15 \quad(1964-65)$.

19-4004. Unamuno, Miguel DE-Contes. Trad. Raymond Lantier. - Gallimard, Paris, 1965. 336 pp. I| NRF, 13 (1965), 731.732 (Spens); Etudes, nov. 1965, 596 (Tilliette).

19-4005. PAucker, Eleanor Krane-Los crientos de Unamuno: clave de su obra_-Minotauro, Madrid, 1965. 230 pp. || $B A b r, 40$ (1966), 316 (Browne); $L N L, 1966$, núm. 1, 118-120 (Chicharro de León); H, 50 (1967), 388 (Metzidakis); $R R, 58$ (1967), 154-157 (Nozick) ; $B H S, 45$ (1968) , 69-70 (Ribbans); RHM , 32 (1966) , 115 (Roberts); $M L N$, 83 (1968), 341-344 (Zavala).

19-4006. NuEz, S. DE LA_-“Novela y drama de Tulio Montalbán. Comentarios a una creación de Unamuno".-Ocid, 68 (1965), 109-136.

19-4007. Abrams, F._."Dante, Unamuno and the symbolic treatment of death in La sima del secreto".-It, 42 (1965), 175-183.

19-4008. MEjÍA SÁnchez, E.-"Ecos mexicanos del centenario de Unamuno: un cuento desconocido". - $A L M, 5$ (1965) , 203-211.

19-4009. Unamuno, Micuel De-Del senlimiento trágico de la vida, en los hombres y en los pueblos._Las Américas, New York; Plenitud, Madrid, 1965. 236 pp.

19-4010. Vivanco, L. F.“"La semilla que muere. Releyendo Del sentimiento trigico de la vida"._CuD, 1964, núm. 12.

19.4011. UnAMUNo, MICUEL DE-Paisajes del alma._2: ed.-Revista de Occidente, Madrid, 1965. 196 pp. (Col. Se lecta).

19-4012. Unamuno, Miguel DE-Por tierras de Portugal $y$ de España. Ed. de Manuel Garcia Blanco.-Anaya, Salamanca-Madrid, 1964. 152 pp. (Bibl. Anaya, 40). II PSA, 36 (1965), 230 233 (A. de V.).

19-4013. UNAMUNo, Miguel DE-Textos inéditos. Ed. Ch. Moeller. Trad. A. Colao._-Athenas, Cartagena, 1965. 91 pp. (Lectio philosophica).

19-4014. PREDMORE, R. L,-"Tres cartas inćditas de Unamuno".-CMdU, 14 15 (1964-65), 63-67.

19-4015. Unamuno, Miguel DE - Cartas inéditas. Recopilación, pról. y notas de Sergio Fernández Larrain,-Zig-Zag, Santiago de Chile, 1965. (Historia y documentos). || Map, 1966, núm. 4, 355357 (Fernández de la Mora); ibid. núms. 2/3, 304-306 (García) ; Fin, 1966. núm. 54, p. 53 (Ruiz-Tagle).

19-4016. Garcia Alvarez, C. - "Cartas inéditas de Miguel de Unamuno".$R y C, 11$ (1966), 273-277.

19-4017. Nuez, S. DE LA_ "Cartas de Miguel de Unamuno a Galdós"._PSA, 37 (1965), 145.178.

19-4018. García Blanco, M._-"Unas car- 
tas de Unamuno y de Pérez de Ayala".PSA, 38 (1965), 237-254.

19-4019. F[errada] P[Artarkieu], G. "Unamuno a Baldomero Lillo: una carta inédita".-Map, 1965,, núm. 1, 167-168.

19-4020. Martel, E-"Lecturas francesas de Unamuno: Senancour".-CMdU, $14 / 15$ (1964-65), 85-96.

19.4021. FAGOAGA, I. DE-“El diálogo imposible".-BSV, 2I (1965), 157-163. [Unamuno y Francis Jammes].

19-4022. Gallant, C. J-“"Miguel de Unamuno y François Mauriac".-CMdU, $14-15 \quad(1964-65), 77-84$.

19-4023. BARDI, U.-_"Fortuna di don Miguel de Unamuno in Italia"-CMdU, 14-15 (1964-65), 97-102,_V. núm. 176936.

19-4024. Carelli, L.-"Tre personaggi e due scrittori: Unamuno e Pirandel10".-Quaderni degli Amici della Spa. gna, Napoli, 1965, núm. 2.

19-4025. KouRím, Z.-."Unamuno y Checoslovaquia".-CMdU, 14/15 (1964-65). 73-76.

19-4026. Pieczara, S.- "La difusión de la obra de Unamuno en Polonia" $C M d U, 14 / 15$ (1964-65), 103-118.

19.4027. Otero, C. P.-"Unamuno y Cavafy: Il gran rifiuto"._-PSA, 36 (1965), 253-294.

19-4028. García Morfjón, Julio — Unamuno y Portugal. Cultura Hispánica, Madrid, 1964. 514 pp.-V. núm. 16 49996. || REP, 1965, núms. 141/2, 278 279 (Diaz); CuH, 60 (1964), 365.368 (Echánove); fns, 1964, núms. 216/7, (Gullón); Yermo, 3 (1965), 43-44. (I. M. G.) ; $E L, 1964$, núm. 304 (Iglesias Laguna) ; EstF, 14 (1965), 400-401 (Mon(uII) ; IAL, I964, núm. 192 (R. G.) ; RHM, 30 (1964), 315-316 (Ruiz-Fornells).

19-4029. Chaves, Juiro César-Unamuno y América. Pról. de Joaquín Ruiz Giménez. - Cultura Hispánica, Madrid, 1964. 559 pp., ilustr. $\| A W$, 1966, núm. 1 (Appleyard) ; H, 49 (1966), 162-169 (Basdekis); RIM, 26 (1966), 166-168 (Carreras); $R E P, 1965$, núms. 141/2, 278 (Díaz); CuH, 60 (1964), 562-565 (Echánove); Yermo, 3 (1965), 43-44 (I. M. G.); RHM, 30 (1964), 315 (Iduarte) ; $E L, 1964$, núm. 304 (Iglesias Laguna); EstF, I4 (1965), 401 (Montull) ; EG, 1966, núm. 15, 79-81 (Zavala); RIB, 16 (1966), 420-422 (Zavala) .
19-4030. Garcia Blanco, Manutl-América y Unamuno. - Gredos, Madrid, 1964. 4.34 pp. (BRH). \|NT, 23 (1965), 272-273 (A. del T.) ; BHS, 42 (1965), 264-265 (Alberich); BAbr, 39 (1965). 439 (Angeles); Reulb, 31 (1965), 123126 (Ashhurst) ; $A E A, 21$ (1964), 812813 (Collantes de Terán); Ins, 1964, núms. 212/3 (Marra-López); EL, 1964, núms. 300/01 (Ponce de León); TR, 1965, núm. 208, 159-160 (Toro) .

19-4031. Barahona Jiménez, L.-“Unamuno e Hispanoamérica". - $R F C R$, 1965, núm. I7, 53-61.

19-4032. Zavala, I. M.-"Hacia una teorfa de «Españoamérica: Hispanoamérica en Unamuno. ¿Realidad o ficcion".-RIB, 15 (1965), 347-354.

19-4033. Ruiz-Fornells, E.-“América en el primer centenario del nacimiento de $M$. de Unamuno".-FH, 3 (1965), 357-360.

19-4034. Mejía SÁNCHEZ, E.-“De Unamuno y Nervo".-ALM, 4 (1964), 203295.

19-4035. Unamuno en Colombia.-Instituto Colombiano de Cultura Hispánica, Bogotí, 1965.

19-4036. Rosenblat, A. - "Sarmiento y Unamuno ante los problemas de la lengua".-[ [En su libro] La primera vision de América (Caracas, 1965), 167-183.

19-4037. Chaves, J. C.-“'Zorrilla de San Martín y Unamuno". - $R N a, 1965$, nưms. 223/4, 5-12.

19-4038. Malorana, M. T.- "La obra de un pensador español vista en Francia".-Cl, I (1965), 138-141.

19-4039. García Bianco, M. (ed.)-Corona poética dedicada a Miguel de Unamuno (1864.1964). - Centro de Estudios Salmantinos, Salamanca, 1964. 206 pp. $\|$ PSA, 37 (1965), 10I-102 (A. dc V.); $E L, 1965$, núm. 315 (Jiménez Martos) .

V. también nưms. 1574, I690, 2293, 2313$5,2361,3403,3582,3651$.

19-4040. Perez Rioja, J. A. - "Azorín. Perfil humano y literario".-LEsp, 8 (1965), 169-193.

19-4041. Olsen, M.-"Hacia el siglo de Azorfn"-Cults, 1965, núm. 35, 39-42.

19-4042. Tiramo Fuentes, René - Reencuentro con Azortn.-Finisterre, Mexico, 1965.

19-4049. Serna, José S.-Vida y fantasía de Azorin.-Albacete, 1965. 166 pp. 19-4044. Martínez B., M. G.-“Azorin, re- 
valorizador de lo español".--HUNL, 6 (1965), 189-200.

19-4045. Ferrero, R.--"Castilla y Azorín".-[En] Temas vallisoletanos (Valladolid, 1965), 139-150.

19-4046. Martin, Charles EDWard_Ideas in the works of Azorin.-[Tesis, Tulane Univ.; resumen en $D A, 26$ (196566) , 2219-2220].

19-4047. Azorín_El caballero inaclual.Espasa-Calpe, Madrid, 1965. 154 pp. (Austral, 830).

19-4048. Azorín_ $\mathrm{Ni}$ si ni no.-Destino, Barcelona, 1965. 229 pp. (Ancora y delfin, 269) . I RLit, 28 (1965), 304 (Morales); $E L, 1966$, núm. 346 (Ponce).

19-4049. Fox, E. 1.- "Una bibliografía anotada del periodismo de José Martinez Ruiz (Azorín), 1894-1904",-RLit, 28 (1965), 231-244.

19-4050. PorTillo, A-"Ambrogi y Azorín".-CultS, 1965, núm. 35, 35-38.

19-4051. APONTE, B. B._"El diálogo entre Azorin y Alfonso Reyes"...Ins, 1965, núm. 219.

19-4052. U'rRuLlo, M. - "Luisa sin Ramón".-EL, ]965, núm. 311 [Gómez de la Serna].

19-4053. Espina, A.-."Ramón y los ismos".-[En su libro] El genio cómico y otros ensayos (Madrid, 1965).

19-4054. Jackson, R. L.-_" A new literary genre: the gregueria”.-BAbr, 39 (1965), 415-417.

19-4055. Jackson, R. L.-"An aspect of the metaphysical technique in the gregueria"..-RNo, 7 (1965), 9-11.

19-4056. JAckson, R. L.-“"Sobre la definición de la greguería de Ramón Gómez de la Serna".-DHR, 4 (1965), 163-165.

19-4057. Jackson, R. I._-"Toward a clussification of the gregueria"._- $H, 48$ (1965), 826-832.

19-4058. Jackson, R. L.-"La presencia de la greguería en la obra de Garcia Lorca".-Hf, 1965, núm. 25, 51.55.

\section{FOLKLORE}

19.4059. WILDHABER, ROBFRT - Biblingraphie internationale des arts et trnditions poptlaires, 1959-1960. Mit Nachträgen für die vorausgehenden Jahre.-Habelt, Bonn, 1964. xix +725 pp.

19-4060. Simmons, M. F. (cul.)-"Folklote bibliography for 1964"-SFQ, 29 (1965), 1-125.-V. núm. 18-4143.

19-4061. Ricimono, It . Enson (comp) -
"Annual bibliography, 1964".-Abstracts of Folklore Studies, 3 (1965), 109-193.Y. núm. 18-4144.

19-4062. Cortazar, Alcusto Raúl - Es quema del folklore. Conceptos y métodos. 2: ed.-Columba, Buenos Aires, 1965. 66 pp. (Col. Esquemas, 41).--Y'. nún. 14-41734.

19-4063. Flury, LAzARo-Perspecliva del folklore.-Santa Fe, Arg., 1965, 37 pp. 19-4064. Dundes, ALAN (ed.) - The siudy of folklore.-Prentice-Hall, Englewood Cliffs, 1965. xi +481 pp.

19-4065. Girse, W._-"Los estudios de folclor románico en Alemania"...BICC, 20 (1965) , 370-375.

19-4066. THOMPSON, 5.-"The challenge of folklore".-PMLA, 79 (1964), 357.365.

19-4067. KRAPPE, AleXander Haggerty The science of folklore.-Norton, New York, 1964. xxi + 344 pp. (Norton $l i$ brary, N282) ...V. núm. 18-4147.

19-4068. DI LULJ.o, O.-“Folklore comparado" (N. 16-48567). $\|$ BHI, 66 (1964), 170-171 (Devoto).

19-4069. KARLINGER, F.- "Volkskunde als neuphilologische Hilfswissenschaft". NS, 14 (1965) , 232-236.

19.4070. Dundes, A.-."The study of folklore in literature and culture. lclentiffcation and interpretation".-J $J F, 78$ (1965), 136-142.

19.4071. Carvalfo Neto, P. DE-Folklote y educación (N. 17-6993). \| Anthropos, 58 (1963), 307 (J.V.C.).

19-4072. Caro Baroja, J._."Del folklore religioso europeo como disciplina histórica".-RDTP, 21 (1965) , 370-379.

19-4073. Dindes, A.-"Texture, text, and context". - SFQ, 28 (1964), $251-265$.

19-4074. PRopP, V. J.-["Principios de clasificación de los géneros folklóricos"].Sov. Etnografija, 1964, num. 4, 147-154.

19-4075. CocchiarA, G...'Dal preromanticismo al romanticismo: la scoperta della poesia popolare"._Cultura e Scuola, 3 (1964), núın. 12, 13-19.

19-4076. "Folksong and folksong scholarship. Changing approaches and attitudes".-[En el volumen colectivo] $A$ good lale and a bonny tume (Dallas, 1964), 199-268. [Siete contribuciones].

19-4077. Krüss, James (ed., trad.) _Lie Hirlenflöle. Europäische Volkslieder.Biederstein, München, 1965.

19-4078. Gil., Bonifacio-Cancionero infantil universal.-Aguilar, Madricl, 1964. 216 pp. || CuH, 58 (1964), 233-234 (G.) ; RDTP, 22 (1966), $229-230$ (Iarrea). 
19-4079. TAỵlor, A.- "The parallels between ballads and tales"'.-Festschrift Erich Seemann (Berlin, 1964), 104-I15.

19.4080. RANKE, K._-"Beiträge zum internationalen Typenindex"._Fabula, 6 (1963), 73-74, 177-179, 259-261; 7 (1964), 76-78._V. nún. I1-27832.

19-4081. AARne, A., \& S. Thompson-The types of the folktale (N. 17-6995). I SFQ, 27 (1963), 17I-173 (Frautschi): Fabula, Berlin, 6 (1963), 182-194 (Schwarzbaum) .

19-4082. ANDERson, W._-'Zu Aarne-Thompson The types of the folklale". $-Z V$, 59 (1963), 89-98.

19-4083. Legros, E.-“Un examen de la classification internationale des contes dans sa seconde revision".-Les Dialectes Belgo-Romans, 19 (1962), 77. 115. $\| L R, 19$ (1965), 76 (Goosse).

19-4084. Sugiyama, Y.-“Time and folk literature: a comparative study". East-West Rev., Kyoto, 1 (1964), 1337, $145-166$.

19-4085. PINON, ROGER El cucnto folklórico. Trad. de Susana Chertudi._Eı* deba, Buenos Aires, 1965.

19-4086. Jolzes, ANDRÉ_Einfache Formen: Legende, Sage, Mythe, Rätsel, Spruch, Kasus, Memorabile, Märchen, Witz. 3. Aufl,_Max Niemeyer. Tübingen, 1965. 272 pp._. V. núm. 14-38689.

19.4087. Fischer, J. L.-“'The sociopsychological analysis of folktales"._-Current Anthropology, 4 (1963), 235-273.

19-4088. SCHMIDT, LEOPOLD_Die Volkserzählung. Märchen, Sage, Legende, Schwanh._E. Schmidt, Berlin, 1963. 448 pp. || Era, 16 (1964), 506-507 (Dörrer).

19.4089. HüLLEN, GEORG (ed.)-Märchen der europäischen Völher: Unveröffentlichte Quellen.-Aschendorff, Münster, 1965.

19-4090. BöDKER, LAuRits, et al. (eds.) -European folk tales. - Rosenkilde \& Bagger, Köbenhavn, 1963.

19-4091. Burde-SChNeIdewind, G. - "Zur Katalogisierung historischer Volkssagen".-Acta Ethnographica Academiae Scienliarum Hung., 13 (1964), 27-41.

19-4092. TAyLor, A._- "The study of proverbs"__Proverbium, 1965, núm. 1, 1-10.

19.4093. PEUCKERT, WILL-ERICH - Eutopäische Sagen._Schmidt, Berlin, 1965. 19.4094. Cocchiara, Giuserpe_Il mondo alla rovescia.-P. Boringhieri, Torino, 1963. 320 pp. $\| M L J, 48$ (1964), 535. 536 (Fucilla); RDTP, 20 (1964), 247248 (Hoyos).
19-4095. Pires de Lima, F. de C.-_"A sereia na Idade Média". — BAu, 16-17 (1964), 208-222. [Folklore y literatura de España y Portugal].-V. núm. 810941.

19-4096. Pires DE LimA, F. DE C.-“Da sereia homérica à sereia dos descobrimentos"._ACE, 5, 251-275; REt, 3 (1964), 255-290.

19-4097. Pires de Lim A, F. DE C. $-A$ mulher vestida de homem (N. 1645755). ||$R E t, 4$ (1965), 225-228 (Anderson) .

19-4098. VIANA, H._.A mulher vestida de homem".- $R B F, 3$ (1966), 177-193.

\section{Españ}

19-4099. Giese, W._.'Spanien und Portugal'.-Sonderdruck aus der Iro-Volkskunde (Iro-Verlag, München, 1964), pp. 141-156, láms.

19-4100. Brotherston, J. G. - "Antonio Machado y Alvarez and positivism".BHS, 41 (1964), 223-229.

19-4101. BASÁÑEZ, JESÚS - El humorismo vasco a través de la historia-Edit. Gómez, Pamplona, 1965. 325 pp. (Col. Ipar).

19-4102. Manrique, G._-EI casticismo de Castilla en el folklore"._-RDTP, I9 (1963), 55-77. || BICC, 19 (1964), 594595 (Suárez Pineda).

19-4103. FERRER GINARD, ANDRis-Folklore balear._Cort, Palma de Mallorca, 1965. 87 pp. || RDTP, 22 (1966), 433-434 (Pérez Vidal).

19-4I04. López dE. Guereñu, G.—“'Iolklore de la montaña alavesa".-Anuario de Eusho-Folklore, 20 (1963-64), 25-77.

I9-4105. IRIBARREN, José MARÍA-Ramillete español. Zarandajas, ensayos y recuerdos_Aramburu, Pamplona, 1965. 276 pp.

19-4106. Ronricuez-Moñino, A.- "Diccionario geográfico popular de Extremadura".-REE, I8 (1962), 319-380, 585632; 19 (1963), I5I-2I4, 403-435, 657 . $689 ; 20$ (1964), 169-173, 549-569_. . núm. I7-7044.

19-4I07. Gutiérrez Macias, V._"Estudio etnológico de Torrcjoncillo (Cáceres)".-RDTP, 21 (I965), I82-193.

19-4I08. Caro Baroja, J.- "Folklore experimental: el Carnaval de Lanz (1964) ". - PV, 26 (I965), 5-22.

19-4I09. Llompart, G. _- "San Cristóbal, como abogado popular de la peregrinación medieval".-RDTP, 21 (1965), 293.313. 
19-4110. Garcia-Lomas, G. Adriano-Mitologia y supersticiones de Cantabria. (Materiales y tanteos para su esludio).Dip. Provincial, Santander, 1964. 375 pp., ilustr.

19-4111. Peña Santiago, Luts Pedro La "Argizaiola" vasca. Creencias, rilos $y$ costumbres relacionados con la misma.Auñamendi, San Scbastián, 1964. 197 pp., ilustr. (Auñamendi, 18). $\| B S V$, 21 (1965), 258-259 (Alvarez Osés).

19-4112. CAstillo DE LuCAS, A.- "Folklore médico del agua".-Cuadernos del Instituto Nacional de Antropologia, Buenos Aires, 1963, núm. 4, 73-79.

19-4113. Carré, L.—“As feiras na Galiza".-REt, 2 (1964), 97-124.

19-4114. LlomparT, G. - "Dos notas de folklore religioso levantino: Evangelios de bautizo y Peregrinos de representación".-RDTP, 22 (1966), 7-25.

19-4115. BOUza-BREy TRILHo, L..."O forrobodo. Un rito y un vocablo gallego del Bajo Miño"__CIEL(5), 3, 277-282.

19-4116. Caro Baroja, J.-“El ritual de la danza en el País Vasco". - RDTP, 20 (1964), 40-76.

19-4117. BARANDIARÁN, GAIZKA DE - Danzas de Euzkalerri. T. 2.-Auñamendi, San Sebastián, 1963. 177 pp., grabs.

19-4118. ARMStronc, L., \& V. ALFORD"The sword dance of Puebla de Guzman".-Journal of the English Folk Dance and Song Society, 9 (1964), 274 278; 360 Congreso de Americanistas (Sevilla, 1966), 2, 46I-467.

19-4119. Moral Moral, M._-"Matzas de Fontioso" (N. 18-4182). \| BICC, 19 (1964), 590-592 (Suárez Pineda).

19-4120. MuÑoz Renedo, C._-_Las auroras de María (Almerfa)" (N. 17-7055). || BICC, 19 (1964), 593 (Suárez Pineda).

19-4121. Ebersole, A. V.-“Los Sanfermines de Paniplona en 1628", - $H, 46$ (1963) , 77-80.

19-4122. Bouza BREY, F._"Xogos iniciáticos infantiles da Galiza". — REt, 1 (1963), 181-188.

19-4123. DUNy PÉTRÉ, P. - "Formulettes enfantines, rengaines traditionnelles et proverbes basques".-Actas del 111 Congreso Inlemacional de Estudios Pirenaicos, t. 6 (Gerona, 1963) , 33-43. I! $A F A, 14 / 15$ (1963-64), 380 (Mondéjar).

19-4124. PEREZ V1DAL, J._.'Pico, pico, melorico: un juego infantil en Canarias". AEAtl, 8 (1962). 20 pp.

19-4125. PÉREZ VIDAL, J.- ¿Dónde esiá el agua?... ¿Dónde está el buey?... (Un dialoguillo infantil encadenado)".RDTP, 19 (1963), 28-44.

19-4126. Amades, J. - "Etnología nusical".-RDTP, 20 (1964), 113-200, 289 . $332,480-526$.

19-4127. SubirÁ, J.-_"En torno al folk]ore musical español".-Estudios Turísticos, Madrid, 1965, núm. 7, 5-30.

19-4128. ANGLEs, H._- Relations of Spanisl folk song to the Gregorian chant".JIFM, 16 (1964), 54-56.

19-4129. Kirsch, HIANS-Christian (ed., trad.) - Coplas. Spanische Gedichte. Lieder und Romanzen.-Beclitle Verlag, München, 1963.

19-4130. Gil, Bonifacio (ed.) -Muertes de toreros, según el romancero popular__Taurus, Madrid, 1964. 141 pp.

19-4131. PAz, EinNa (ed.)-Favorite Span. ish folksongs: traditional songs from Spain and Latin America.-Oak Publications, New York, 1965. 96 pp., ilustr. 19-4132. TомÁs, J._-"Canciones popula. res de trabajo"._AnM, 19 (1964), 225 239.

19-4133. Gil, Bonifacio_Cancionero taurino (popular y profesional).-Libr. para Bibliófilos, Madrid, 1964-65. 3 ts. 19-4134. Gil, Bonifacio (ed.) -Cancionero popular taurino. (Antologia).-Tau. rus, Madrid, 1963. $187 \mathrm{pp}$. (Temas de España).

19-4135. García Matos, M.-“Pervivencia en la tradición actual de canciones populares recogidas en el siglo xvI por Salinas en su tratado De música libri seplem":-AnM, 18 (1963), 67-84.

19-4136. Herrera y SÁnchez, F._."Características de la filosofía barroca calderoniana en los cantos del pueblo". $-K F L Q$ 11 (1964), 200-208.

19-4137. Gella lturriaga, J.-“Cancionero de la Independencia".-II Congreso Hist. Intern. de la Guerra de la Independencia y su Epoca (Zaragoza, 1965), t. 2, 373-403.

19-4138. GArcía DE Diego, P.-“Canciones de Navidad".-RDTP, 20 (1964), 532 544. $\| B I C C, 21$ (1966), 233-234 (Suárez Pineda).

19-4139. Fraguas y Fraguas, A. - "La Virgen en el cancionero popular gallego"._Museo de Pontevedra, 14 (1960), 67-88.

19-4140. L1s Quibén, V.-_Cancionero médico de Galicia".-RDTP, 20 (1964), 203-227, 333-388. || BICC, 21 (1966), 231-233 (Suárez Pineda). 
I9-4141.Fernández García, José-Recopilación de canciones asturianas.Madrid, 1960. $89 \mathrm{pp}$.

19-4142. Llompart, G.-“'Los gozos populares de San Cayctano en el Levantc español".- $R D T P, 20$ (1964) , 461-479.

19-4143. Veny I Clar, J.-_Cançons populars mallorquines". $\ldots E R, 11$ (1962), $305 \cdot 325$.

19-4144. Gil Garcia, B.-_Panorama de la canción popular burgalesa".- $A n M$, 18 (1963), 85-102.

19-4145. Marazuela Albornoz, AgapttaCancionero segoviano.-Instituto Diego Colmenares, Segovia, 1964. $421 \mathrm{pp}$.

19-4146. García Matos, M.-Cancionero popular de la provincia de Madrid (N. 10-21763) . || Rev. Musicale, 49 (1963), $221-222$ (Devoto).

19-4147. GiL, B.-Cancionero popular de Extremadura (N. 17-7042). $\| R E E, 20$ (1964), 573-576 (Armstrong).

19-4148. LARrEA, A. DE-“La canción andaluza"._Arb, 57 (1964), 593-595.-.V. núm. 17-7057.

19-4149. Luna, José Carlos de, y Pedro EchevarRía Bravo-La canción andaluza.-Centro de Estudios Históricos Jerezanos, Jerez de la Frontera, 1962-63. 3 ts. + fndices: $71,100,49,80$ pp. $\|$ RDTP, 18 (1962), 563-564 (Larrea). 19-4150. CAFFARENA, ĀNGEL_Cantes anda. luces (La saeta, La petenera)._-Málaga, 1964. || CuH, 6I (I965), 465-466 (Crande) .

19-415I. Molina, Ricardo, y Antonio Marrena-Mundo y formas del cante flamenco.-Rev, de Occidente, Madrid, 1963. 326 pp. I| ROcc, 8 (1965), 120 . 123 (Quiñones).

19-4152. MANFredi Cano, Domingo-Geografia del cante jondo.-Bullón. Madrid, 1963. 219 pp. (Generaciones jun. tas).-V. núm. 10-19676.

19-4153. Caballero Bonald, J. M.Diccionario del cante jondo.-Artes Gráficas, Madrid, s. a. $39 \mathrm{pp}$.

19-4154. Quiñones, Fernando-De Cidiz $y$ sus cantes.-Seix Barral, Barcelona, 1964. (Col. Ateneo). \| CuH, 64 (1965), 607-610 (Molina).

19-4155. ButLER, AugusTo_ferez en la canción popular andaluza. - Ayunta. miento, Jerez de la Frontera, 1962. 82 pp.

19-4156. Luque Navajas, José - Málaga en el cante.-El Guadalhorce, Málaga, 1965, 95 pp. || RLit, 28 (1965), 258 . 259 (Morales).
19-4157. Caffarena Such, Ángel-Málaga cantaora._El Guadalhorce, Málaga, 1962. 32 pp., ilustr.

19-4158. Guttŕrrez Macias. V..“Apuntes de etnología cacereña. Jaraiz de la Ve. ra"_-RDTP, 20 (1964), 228-240. [Canciones].

19-4159. Siemens Hernández, L._-“La folía histórica y la folía popular canaria'.-MCan, 26 (1965), 19-46.

19-4160. LECuONA, MANuEL DE-Literatura oral vasca.-Auñamendi, San Sebastián, 1965. 244 pp. || RLit, 28 (1965), 258 (Morales).

19-4161. HARItschelHAR, J._-"Textes folkloriques de la vallée de Baigorry".Actas del III Congreso Internacional de Esiudios Pirenaicos, t. 6 (Gerona, 1963). 51-73. II $A F A, 14 / 15$ (1963-64), 38I-383 (Mondéjar).

19-4I62. Pires de lma, F. DE C.-“O mito da sereia segundo Alonso de $\mathrm{Ma}$ drigal"._REt, 4 (1965), 389-409.

19-4I63. AMADES, J._"Temas americanos en la literatura de cafia y cordel".Rev. del Centro de Lectura, Reus, 1965. núm. 158.

19-4164. "Coloquio sobre poesía popular"._Verbo, Alicante, 1963, núm. 32.

19-4165. Glendinning, N.-“Nuevos datos sobre las fuentes del Capricho $58 \mathrm{dc}$ Goya"._PSA, 3 I (1963), 13-29. [Coplas del siglo XviII].

19-4166. MicheL, F., y A. Irigaray-Poesias populares de los vascos (N. 177005). $\| B S V^{\prime}, 19$ (1963), 288-289 (Arocena) .

19-4167. González Climent, AnselmoAntologia de poesia flamenca-Madrid, 1961. 383 pP. || RDTP, 18 (1962), 276277 (Pérez Vidal) .

19-4168. FERrer I SOLER, Albert, \& ANTONI ANGUERA I LLAURADO_Llibte dels gegants $i$ demes entremesos populars de Vilanova $i$ La Geltru._-Edit. J. Rius i Vila, Vilanova-La Gelirú, 1964. xviii +167 pp., ilustr.

19-4169. Aranda Muñoz, E.-Teatro me. dieval en un pueblo murciano ("Rejes" en Churra) (N. 17-7049). I| Seg, I (1965), 141-142 (Esquer Torres).

19-4170. Brugarola, M.-“Función de rey'es y pastores por la huerta de Murcia". - RDTP, 20 (1964), 527-531. ॥ $B I C C, 21$ (1966), 233 (Suárez Pincda) .

19-4171. Carrasco Lrgotti, M. S.-“Aspectos folcloricos y literarios de la fiesta de moros y cristianos en España".- 
PMLA, 78 (1963), 476-491. I| RDTP, 20 (1964), 547-548 (Perez Vidal).

19-4172. Caro Baroja, J. - "Mascaradas de invierno en España y en otras partes".-RDTP, 19 (1963), 139-296.

19-4173. Caro Baroja, J.-"A caza de botargas". $-R D T P, 21$ (1965), 273-292.

19-4174. Brugarola, M.-." Las comparsas de Villena en la fiesta de Nuestra Señora de las Virtudes". _ RDTP, 21 (1965), 165-181,

19-4175. Espinosa, Aurelio M.-Cuentos populares de España. 3: cd.-EspasaCalpe, Madrid, 196ว. 214 pp. (Austral, 585) ._-V. núm, 4-4285.

19-4176. Bouza Brey, F._."E] tema romancesco del ciervo del pie blanco en la novelística popular gallega"._C CuEG, $18 \cdot(1963), 148-166$.

19-4137. Cuentos populares de la prorincia de lugo._Galaxia, Vigo, 1963. 380 pp. || RDTP, 19 (1963), 443-444 (Ramón y Fernández O.); $R J, 15$ (1964), 361-362 (Giese).

19-4178. LARREA PALACIN, A.-Cuentos gaditanos (N. 16.45720.) || RLit, 20 (1961), 447-448 (Pinedo) -_V. núm. 17-7061.

19-4179. Satrústecul, J. M.-"Versión popular vasca de un cuento de Grimm".$B S Y, 21$ (1065), 283-291.

19-4180. AmADES, J.-'Zoología fabulosa portuguesa en la literatura dc cordel catalana"._BBPM, 1962, núm. 9, 111131.

19-4181. Llompart, G._"Jna leyenda medieval mallorquina".-RDTP, 20 (1964), 90-97. II BICC, 21 (1966), 229-230 (Suárez Pineda) .

10-4182. Martinez, E. "Leyendas del Nalón". _ RDTP, 20 (1964), 98-108. II $B I C C, 21$ (1966), 230-231 (Suárez).

19.4183. AMAdES, J_-"Atala en la literatura de cordel".-SJ, 1963, núm. 51.

19-4184. Soberanas Lleó, A. J._Leyendas historicas de Tarragona.-Inst. de Estudios Tarraconenses "Ramón Berenguer 1V", Tarragona, 1965. 137 pp.

19-4185. Ruiz DE MATEO, A.-Leyendas alicantinas. - Artes Gráficas, Alicante, 1965. $129 \mathrm{pp}$.

19.4186. AzzolA, M. T.-“Una clasificación de las adivinanzas en lengua española"._CCL, 1963, núm. 76, 49-54.

19.4187. EspinosA, A. M._'Algunas adivinanzas españolas" (N. 9-18129). BICC, 17 (1962), 469-471 (Suárez Pineda) .

I. también núms. 613, 897, 1276, 1767, 1811.
Portugal

19.4188. LOPEs DIAS, JAIME - Etnografia da Beira. 2: ed. Ts. 2, 5, 9.-Ferin, Lisboa, 1963-66. xiii + 201,312, 263 pp.V. núm. 11.29196. || $R D T P, 19$ (1963), $439.440 ; 20$ (1964)，548-549 (Castillo de Lucas).

19-4189. Pires Gonçalves, ]-_Monsataz e seu termo" (N. 18.4648). "| Bro, 77 (1963) , 246-247 (Maurício).

19-4190. Pestana, Eduardo Antonino Ilha da Madeira. T. 1: Folclore madeirense. - Câmara Municipal, Funchal, 1965. 224 pp.

19-4191. Carreiro dA Costa, F.-“Religiosidade do provo açoriano através do seu folclore".-Livro da I Semana de Es. tudos dos Accores (1964), 71-95.

19-4192. FERnandes Mascarenhas, J-As festas do Natal, Ano Bom e Reis no Algarve. Subsidios de Etnografia e Folclore, Tavira, 1965. $32 \mathrm{pp}$.

19-4193. Veiga dE Oliveira, E.-"O S. João em Portugal".-REt, 5 (1965), 56-112.

19-4194. Veríssimo DE MELO_-"Folguedos natalinos"._ $R E t, 5$ (1965), 163-170.

19-4195. Lopes CARdoso, C.-“'A fuga para o Egipto na tradição oral portuguesa".Pan, 1964, núm. 12.

19-4196. RIBERro, MARCARIDA_Estudos sobre a Aldeia da Gloria. V. Crenças $e$ superstições. - Ocidente, Lisboa, 1964. 34 pp.-V. núm. 19-812.

19-4197. VAlle, Carlos-Tradições do casamento $e$ superstições do povo_-Porto, 1963. $48 \mathrm{pp}$.

19-4198. Felguerras, G.-“As reses galliudas no folclore. O corno na superstição, na alegoria escarninha e nas aplicações utilitárias. S. Comélio e outros santos na crença popular".-Ethnos, 4 (1965), 177-195.

19-4199. Ferreira dE Almeida, C. A."Ementação das almas. Rezas da ceia".REt, 1964, núm. 1, 41-68.

19-4200. Costa GARCEZ - "Duas procis. sões tradicionais em Lisboa". - Rev. Municipal, Lisboa, 1963, núm. 1.

19-4201. CostA, MARIo-Danças $e$ dançarinos em lisboa_CA Lisboa, 1962. 346 pp. || Ocid, 65 (1963), 142 (F. S.).

19-4202. Costa RANGel, A. M. DA_."Dança dos bugios e mourisqueiros. Auto popular típico da freguesia de Sobrado de Valongo, talvez o único no género"._Praça Nova, 1963, núm. 13. 19.4203. MACHADO DRUMOND, L. F._."Es- 
tudo de folclore terceirense. Jogos populares".-Bol. do Instituto Hislórico da Ilha Terceira, 18 (1960), 129-224.

19-4204. GoMEs, P._-"Introdução a uma etnografia infantil". $-R P, 29$ (1964), 596-606.

19-4205. Santos Neves, G.-."As doze palavras ditas e retornadas". - $R E t$, I (1963), 327-347.

19-4206. Sampaio Ribeiro, M. DE - "Velhos pregões musicados de Lisboa. Achegas para seu estudo e sua inventariação"$R E t, 4$ (1965) , 69-123.

19-4207. REBELO BONITO - "Pregões do Porto".--BCP, 26 (1963), I17-149.

19-4208. Lopes GraçA, F.-."Algumas considerações sobre a música folclórica portuguesa".-Co, 1963, núm. 24.

19-4209. REBElO Bontro, P. A.-"Reminiscências da poética medieval no cancioneiro popular".-BAu, I4/15 (I963), 108-116.

19-4210. Chaves, L,-“A colheita folclórica [de quadras populares] efectuada pelas Casas do Povo". - CP, 1965-1966, núms. 223, 225-231, 239, 236, 237.

19-4211. Cardoso, N. C.-“'Os cancioneiros populares portugueses". $-B C L, 1965$, 185-207.

19-42:12. Pires de Lima, Fernando de C. (ed.) _Cancioneiro._Gabinete de Etnografia, Lisboa, 1962. $173 \mathrm{pp} . \|$ RDTP, 18 (1962), 545 (Pérez Vidal).

19-4213. Silva paiva, Marta adelame DA_Cancioneiro do Alto Douro. Barqueiros. - Junta Distrital, Vila Real, 1962. $84 \mathrm{pp}$.

19-4214. Pinharanda Gomes-"o cancioneilo de Quadrazais".-_RP, 29 (1964), 369-378.

19-4215. PereIRA, V. - Cancioneiro de Arouca (N. 17-7090) . II RDTP, 19 (1963), 440 (Castillo de Lucas).

19-4216. Lopes Cardoso, C._-“Cancioneiro popular de Cete" (N. 12-32957). II Schweiz. Archiv für Volkskunde, 60 (1964), 105-106 (Wildhaber).

19-4217. ANDRADE, I. - "Cancioneiro da ilha do Faial".-Boletim do Núcleo Cultural da Horta, 8 (1964), 415-452.

19-4218. AZINHAL ABEIRo-Cancioneito do Nalal portugués. Antologia. - Lisboa, 1964. 152 pp. (Col. antologica BestSellers).

19-4219. FARIA, M.-“O mistério do Natal na canção popular portuguesa".$B B P M$, 1969, nưm. 10, 107-115.

19-4220. Crespo, Firmino (ed.) -Senhora de Almortăo. Cancioneiro. - Lisboa,
[963. 53 pp. || Ocid, 66 (1964), 280 (A.C.) .

19-4221. Ribeiro dA Cunita, A- - "Braga na poesia popular".- $D B, 2$ (1964) , 197-210.

19-4222. Paço, Alfonso do-A vida militar no cancioneiro popular portugues.Porto, 1964. 88 pp. [Sep. da REt, 1 (1963) , 395-414; 3 (1964), 191-238, 409428]. || RDTP, 21 (1965), 197-198 (Pérez Vidal) .

19-4223. BRAN'Āo, T. -- "Novíssimos ro. mances do gado".-REt, 1 (1963), 349 363.

19-4224. Rebelo, J. M. - "Achega para o estudo do romanceiro de Trás-os-Montes e Alto Douro".-REt, 9 (1964), 115-197.

19-4225. FraGA, J. L. DE_-"Cantares açorianos. Apontamentos". - Atlântida, 5 (1961) , 92-47, 61-83, 125-128; 6 (I962), 98-112.-V. nưm. 17-7106.

19-4226, Bogcs, R. S.-"A Nau Catrineta".-RAMSP, 169 (1962).

19-4227. Morais Da Silva, H._-"Autos do Natal em casas de Monforte".-Estudos Flavienses, 1963, núm. 1, 8-26.

19-4228. Caratäo Soromenho, P. - introdução dos "Contos populares e lendas" coligidos por J. Leite de Vasconcelos._Lisboa, 1963. $28 \mathrm{pp}$.

19-4229. Leitre de VAsconcelos, J. (cd.) Contos populares e lendas. Coordinação de A. da Silva Soromenho e P. Caratāo Soromenho-Universidade, Coimbra, 1964. xxix + 702 pp. $\| R P, 29$ (1964), 482-491 (Machado).

19-4230. Silva leal, Maria J. S. L. G. DaContos populares. 2n ed.-.Direcção Geral do Ensino Primário, Lisboa, 1963. V. núm. 11-25750.

19-4231. BRANQuinho DA FonseCA-Contos tradicionais portugueses _Portugália, Lisboa, I963. 226 pp. [2" ed., 1964; 3? ed., 1968].

19-4232. Castro Osório, ANa DE-Contos, fábulas, facécias $e$ exemplos da tradição popular portuguesa-Soc. de Expansão Cultural, Lisboa, 1962-63. 4 ts.: 124, 106, 126, I24 pp.

19-4233. REIs, FERNANDo-Soiá. Literatura oral de São Tomé Braga.-Pax. Braga, 1965. 132 pp. (Col. Metropole e Ultramar, 9) .

19-4234. ChMara Cascudo, L.-"Temas do Mireio no folclore de Portugal e Bra. sil"'-Ocid, 63 (1963), 31-43.

V. tambiéır núms. 685, 1767, 1877, I879, 2071.2. 